\title{
BANKRUPTCY PREDICTION OF \\ COMPANIES IN THE RETAIL-APPAREL INDUSTRY USING DATA ENVELOPMENT ANALYSIS
}

by

Angela Tsui-Yin Tran Kingyens

A thesis submitted in conformity with the requirements

for the degree of Doctor of Philosophy

Graduate Department of Chemical Engineering and Applied Chemistry

University of Toronto

(C) Copyright by Angela Tsui-Yin Tran Kingyens 2012 


\title{
BANKRUPTCY PREDICTION OF COMPANIES IN THE RETAIL-APPAREL INDUSTRY USING DATA ENVELOPMENT ANALYSIS
}

\author{
Angela Tsui-Yin Tran Kingyens \\ Degree of Doctor of Philosophy \\ Graduate Department of Chemical Engineering and Applied Chemistry \\ University of Toronto
}

2012

\begin{abstract}
Since 2008, the world has been in recession. As daily news outlets report, this crisis has prompted many small businesses and large corporations to file for bankruptcy, which has grave global social implications. Despite government intervention and incentives to stimulate the economy that have put nations in hundreds of billions of dollars of debt, and have reduced the prime rates to almost zero, efforts to combat the increase in unemployment rate as well as the decrease in discretionary income have been troublesome. It is a vicious cycle: consumers are apprehensive of spending due to the instability of their jobs and ensuing personal financial problems; businesses are weary from the lack of revenue and are forced to tighten their operations which likely translates to layoffs; and so on. Cautious movement of cash flows are rooted in and influenced by the psychology of the players (stakeholders) of the game (society). Understandably, the complexity of this economic fallout is the subject of much attention. And while the markets have recovered much of the lost ground as of late, there is still great opportunity to learn about all the possible factors of this recession, in anticipation of and bracing for one more downturn before we emerge from this crisis. In fact, there is no time like today more appropriate for research in bankruptcy prediction because of its relevance, and in an age where documentation is highly encouraged and often mandated by law, the amount and accessibility of data is paramount - an academic's paradise!
\end{abstract}


The main objective of this thesis was to develop a model supported by Data Envelopment Analysis (DEA) to predict the likelihood of failure of US companies in the retail-apparel industry based on information available from annual reports - specifically from financial statements and their corresponding Notes, Management's Discussion and Analysis, and Auditor's Report. It was hypothesized that the inclusion of variables which reflect managerial decision-making and economic factors would enhance the predictive power of current mathematical models that consider financial data exclusively. With a unique and comprehensive dataset of 85 companies, new metrics based on different aspects of the annual reports were created then combined with a slacks-based measure of efficiency DEA model and modified layering classification technique to capture the multidimensional complexity of bankruptcy. This approach proved to be an effective prediction tool, separating companies with a high risk of bankruptcy from those that were healthy, with a reliable accuracy of $80 \%$ - an improvement over the widely-used Altman bankruptcy model having $70 \%, 58 \%$ and $50 \%$ accuracy when predicting cases today, from one year back and from two years back, respectively. It also provides a probability of bankruptcy based on a second order polynomial function in addition to targets for improvement, and was designed to be easily adapted for analysis of other industries. Finally, the contributions of this thesis benefit creditors with better risk assessment, owners with time to improve current operations as to avoid failure altogether, as well as investors with information on which healthy companies to invest in and which unhealthy companies to short. 


\section{Acknowledgements}

The greatest compliment I have ever received is that I am a reflection of my wonderful family, friends and mentors. This $\mathrm{PhD}$ has been an incredible journey - one that I am extremely grateful for because I had the privilege of learning from the wisest, working with the most brilliant, sharing with the most generous, and laughing with the funniest individuals along the way.

First, I wish to express my deepest appreciation to my advisor, Professor Joseph C. Paradi, for his support and guidance, and more importantly, for his offerings of ever-colourful lessons on life. Being his student has been a gift: I am extremely grateful for his kindness, his understanding of my need to follow my heart to California, and his belief in my ability to do great things.

I would like to thank Professors Yuri Lawryshyn and Bradley Saville for always finding the time to offer valuable feedback, as well as Professors Mark Kortschot, Roy Kwon and Victor Podinovski for serving on my defense committee. I would also like to acknowledge the Department of Chemical Engineering and Applied Chemistry, the Faculty of Applied Science and Engineering, and the Leaders of Tomorrow Office for their continued support in my personal and professional development. I would also like to thank my friends at the University of Toronto and the Centre for Management of Technology and Entrepreneurship, present and alumni.

I wish to extend a personal thanks to my family. In particular, I am indebted to my incredible parents: my father, my hero, who inspires me through his hard work and accomplishments, and my mother, my rock, who encourages me through her beauty and compassion. Thank you both for your unconditional love, and putting my happiness first. I am so lucky. Also, I would like to thank my brother, Chris, for just always being there for me without question.

And last, but never least, I thank my wonderful husband Jeff, for all that he has been for me, for all that he is to me, and all that he will be. I am truly blessed.

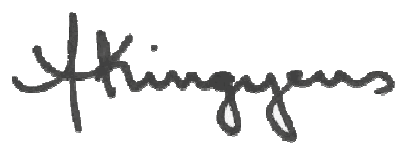

Angela Tran Kingyens

May 2012 
Table of Contents

ABSTRACT

ACKNOWLEDGEMENTS IV

TABLE OF CONTENTS $\quad$ V

LIST OF TABLES $\quad X$

LIST OF FIGURES $\quad$ XIII

LIST OF ABBREVIATIONS $\quad$ XVIII

LIST OF SYMBOLS $\quad$ XIX

1 INTRODUCTION 1

$\underline{2}$ BACKGROUND I: ACCOUNTING AND FINANCIAL STATEMENT ANALYSIS

2.1 The ANNUAL RePORT 3

2.1.1 Balance SHEET 3

2.1.2 INCOME STATEMENT

2.1.3 CASH FLOW STATEMENT

2.1.4 NOTES TO THE FinANCIAL STATEMENTS 6

2.1.5 MANAGEMENT'S DISCUSSION AND ANALYSIS (MD\&A) 8

2.1.6 AUDITOR'S REPORT

2.2 FinanCial Statement ANAlysis: Ratios 9

2.2.1 INDUSTRY ANALYSIS 9

2.2.2 PROFITABILITY ANALYSIS $\quad 10$

2.2.3 SHORT-TERM LIQUIDITY AND LONG-TERM SOLVENCY 11

2.3 BANKRUPTCY 12

2.3.1 ALTMAN'S BANKRUPTCY MODEL

2.3.2 OHLSON'S BANKRUPTCY MODEL 15

2.4 FRAUD 17

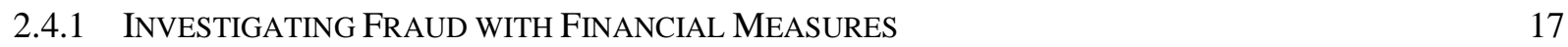

2.4.2 INVESTIGATING FRAUD WITH NON-FINANCIAL DATA 20

2.4.3 CRITICAL RED FLAGS 21

2.4.4 SUMMARY OF FRAUD LITERATURE 24

2.5 MARKET BETA EQUITY RISK AND OTHER FACTORS 25 
$\begin{array}{rrr}3.1 & \text { OVERVIEW } & 28\end{array}$

$\begin{array}{lll}3.2 & \text { SWOT ANALYSIS } & 30\end{array}$

$\begin{array}{lll}3.2 .1 & \text { STRENGTHS } & 30\end{array}$

$\begin{array}{lll}3.2 .2 & \text { OPPORTUNITIES } & 31\end{array}$

3.2.3 WEAKNESSES AND THREATS

3.3 FUTURE OUTLOOK

$\underline{4}$ DATA ENVELOPMENT ANALYSIS

$\begin{array}{lll}4.1 & \text { INTRODUCTION } & 36\end{array}$

$\begin{array}{ll}\text { 4.2 CCR MODEL } & 38\end{array}$

$\begin{array}{lll}\text { 4.2.1 INPUT ORIENTATION } & 38\end{array}$

$\begin{array}{lll}4.2 .2 & \text { OUTPUT ORIENTATION }\end{array}$

4.3 BCC MODEL $\lcm{42}$

4.3.1 INPUT ORIENTATION

$\begin{array}{lll}4.3 .2 & \text { OUTPUT ORIENTATION } & 44\end{array}$

4.4 ADDITIVE MODEL

4.5 Slacks-BaSed Measure OF EFficienCy ModeL 46

4.6 SENSITIVITY ANALYSIS

4.7 SUMMARY OF THE BASIC DEA MODELS

4.8 DEA CHARACTERISTICS

$\begin{array}{lll}\text { 4.8.1 STRENGTHS } & 48\end{array}$

$\begin{array}{ll}4.8 .2 & 50\end{array}$

4.9 DEA STUDIES IN BANKRUPTCY

$\underline{5}$ OBJECTIVES $\quad 55$

6 DATA COLLECTION, PREPARATION AND EXPLORATION

6.1 List OF RETAIL-APPAREL COMPANIES

6.2 Definition OF StUdy Period, COMParable Units ANd COMPANy STATE 57

6.3 FinANCIAL DATA

6.3.1 LIST OF FinANCIAL VARIABLES

6.3.2 COLLECTION AND ORGANIZATION OF FINANCIAL VARIABLES $\quad 60$

6.3.3 DisTRIBUTIONS OF FINANCIAL VARIABLES 64

6.3.4 CORRELATIONS OF FiNANCIAL VARIABLES 67

6.3.5 PROFITABILITY ANALYSIS 69

6.3.6 SHORT-TERM LIQUIDITY AND LONG-TERM SOLVENCY 72

6.3.7 EARNINGS MANIPULATION RISK

6.3.8 QUALITY OF INCOME

6.4 MANAGERIAL DECISION-MAKING DATA 
$\begin{array}{lll}\text { 6.5 OUTLIERS AND MiSSING DATA } & 77\end{array}$

$\begin{array}{lll}\text { 6.6 ECONOMIC DATA } & 78\end{array}$

6.7 MARKeT AND STOCK PERFORMANCE 8

6.8 CROSS-DATA EXPLORATION $\mathbf{8 3}$

6.8.1 CORRELATION BETWEEN FINANCIAL AND MANAGERIAL DECISION-MAKING DATA 83

6.8.2 CORRELATION BETWEEN FINANCIAL AND ECONOMIC DATA 85

6.8.3 CORRELATION BETWEEN MANAGERIAL DECISION-MAKING AND ECONOMIC DATA 86

6.8.4 CORRELATION TO MARKET AND STOCK PERFORMANCE DATA 87

6.9 SUMMARY OF DATA EXPLORATION 8

\begin{tabular}{llr}
7 & BENCHMARKS & 91 \\
\hline
\end{tabular}

7.1 DEFINITION OF TYPE I AND TYPE II ERRORS

7.2 ALTMAN'S Z-SCORE
92

$\begin{array}{lll}7.3 & \text { Credit Rating AgenCIeS } & 93\end{array}$

$\begin{array}{ll}8 \text { METHODOLOGY } & 94\end{array}$

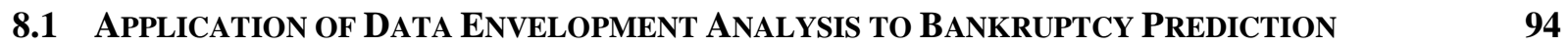

8.1.1 FRONTIERS, INPUTS AND OUTPUTS 94

8.1.2 A NEW ClassifiCATION APPROACH: A MODIFIED LAYERING TECHNIQUE 95

8.2 OVERVIEW: METRICS AND THE SECOND STAGE MODEL 96

8.3 VARIABLE SELECTION AND METRICS TESTED 97

8.4 SlaCKS-BASEd MEASURE OF EFFICIENCY (SBM) MODEL 99

8.5 ClaSSIFICATION BY ZONES AND LAYERING

9 PRELIMINARY MODELS: RESULTS AND DISCUSSION 102

9.1 Principal Component ANAlysis AND Logistic REgReSSion Metrics 102

$\begin{array}{lll}\text { 9.2 Profitability Metrics } & 106\end{array}$

9.3 COMBINING NORMAL AND INVERSE SCORES $\quad 110$

$\begin{array}{lll}9.4 & \text { INSOLVENCY METRICS } & 113\end{array}$

9.5 Summary OF Preliminary MOdels 115

10 FINANCIAL STATEMENT AND MANAGERIAL DECISION-MAKING MODELS: RESULTS AND DISCUSSION

10.1 INCOME STATEMENT METRIC 116

$\begin{array}{llr}10.2 & \text { BalanCE SHEET METRICS } & 117\end{array}$

$\begin{array}{lll}10.3 & \text { CASH Flow Statement METRIC } & 120\end{array}$

10.4 MANAGERIAL DECISION-MAKING METRIC 120

$\begin{array}{llr}10.5 & \text { Trade Data Metric } & 121\end{array}$ 
10.6 CORRELATION BETWEEN METRICS 122

10.7 THE EFFECT OF INFLATION 122

11 MARKET AND ECONOMIC FACTORS: RESULTS AND DISCUSSION 125

$\begin{array}{lll}11.1 & \text { GENERAL ECONOMIC INDICATOR } & 125\end{array}$

$\begin{array}{llr}11.2 & \text { APPAREL INDUSTRY INDICATOR } & 126\end{array}$

$\begin{array}{llr}11.3 & \text { HOUSING MARKET INDICATOR } & 127\end{array}$

$\begin{array}{llr}11.4 & \text { PRICES INDICATOR } & 128\end{array}$

11.5 GENERAL MARKET PERFORMANCE INDICATOR 129

11.6 ALL-ENCOMPASSING MARKET AND ECONOMIC (ME) INDICATOR 129

11.7 COMBINING MARKET AND ECONOMIC FACTORS WITH FINANCIAL AND MANAGERIAL

DECISION-MAKING DATA

12 SECOND STAGE DEA MODELS: RESULTS AND DISCUSSION 132

12.1 MOTIVATION 132

12.2 LaYered SCORES ANd SECONd Stage MOdEl SPECIFICATIONS 134

12.3 Classification bY ZONES

12.4 ClasSification BY LAYERING 136

12.4.1 SECOND STAGE MODEL WITH IS, BSA, BSL AND MDM 137

12.4.2 SECOND STAGE MODEL WITH IS, BSA, BSL AND MDM WITH CFO 140

12.5 TYPE I AND TYPE II ERROR TRADE-OFF 140

12.6 COMPARING THE LAYERING AND NON-LAYERING APPROACHES 142

12.7 COMPARISON TO ALL-ENCOMPASSING MARKET AND ECONOMIC INDICATOR 143

12.8 Improving Prediction by Changing SAMPle Size 145

12.9 TRANSLATING DEA RESUltS INTO TARGETS OF IMPROVEMENT 146

13 PREDICTION AND VALIDATION OF THE SECOND STAGE DEA MODEL 158

13.1 Estimating The Probability OF Bankruptcy 158

13.2 RELIABILITY AND VALIDITY OF THE SECOND STAGE MODEL 160

13.2.1 PREDICTION OF HEALTH AFTER 2009 BASED ON DATA FROM 1996 TO 2009

13.2.2 PREDICTION OF HEALTH AFTER 2008 BASED ON 1996-2008 DATA 162

13.2.3 PREDICTION OF HEALTH AFTER 2007 BASED ON 1996-2007 DATA 163

13.2.4 PREDICTION OF HEALTH AFTER 2006 BASED ON 1996-2006 DATA 163

13.2.5 PREDICTION OF HEALTH AFTER 2005 BASED ON 1996-2005 DATA 163

13.2.6 PREDICTION OF HEALTH AFTER 2004 BASED ON 1996-2004 DATA 164

$\underline{14}$ CONCLUSIONS 165

$\begin{array}{lll}\text { 14.1 SUMMARY OF MAJOR CONTRIBUTIONS } & 165\end{array}$ 
A.1 StOChaStic Frontier ANALYSIS (SFA) $\quad 175$

A.2 THICK FrONTIER APPROACH (TFA) $\quad 175$

A.3 Distribution-FrEe APPROACH (DFA) 176

APPENDIX B EXAMPLES OF DATA ENVELOPMENT ANALYSIS $\quad 177$

B.1 ONE INPUT, ONE OUTPUT 177

B.2 Minimize Two InPUTS, UNITIZED OUTPUT $\quad 178$

B.3 MAXIMIZE Two OUTPUTS, UnITIZED INPUT 180

APPENDIX C REASONS FOR BANKRUPTCY AS CITED BY PRESS RELEASES 182

APPENDIX D SUPPLEMENTARY BACKGROUND

$\begin{array}{lll}\text { D.1 Credit Rating AgenCies } & 185\end{array}$

$\underline{\text { APPENDIX E }}$ LIST OF METRICS

APPENDIX F MODELLING RESULTS $\quad 189$

F.1 LOGISTIC REgRESSION (LR) METRIC

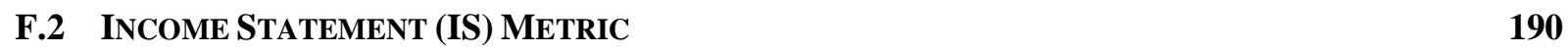

F.3 BaLANCE SHEET ASSETS (BSA) METRIC 191

F.4 BalanCE SheEt Liabilities (BSL) MEtric 192

F.5 MaNagerial DeCision-MaKing (MDM) METRIC 193

F.6 SECOND Stage MODElS $\quad 194$

F.7 ProJeCtIONS FOR ACTIVE COMPANIES

F.8 SECOND Stage Model Results With DifFerent Time Windows 202

F.9 Probability FunCTIONS FOR DIFFERENT TIME Windows 204 


\section{List of Tables}

TABLE 2.1: COMMON ENTRIES IN A BALANCE SHEET (GILL, 1994) 3

TABLE 2.2: COMMON ENTRIES IN AN INCOME STATEMENT (GILL, 1994) 4

TABLE 2.3: FINANCIAL ACTIVITIES REPORTED IN A CASH FLOW STATEMENT

TABLE 2.4: INDUSTRY ANALYSIS (STICKNEY ET AL., 2007) 10

TABLE 2.5: COMMON LIQUIDITY AND SOLVENCY RATIOS 12

TABLE 2.6: Z-SCORES BY FIRM TYPE AND ZONES OF DISCRIMINATION (ALTMAN, 1968; HANSON, 2003)

TABLE 2.7: ERROR CLASSIFICATION FOR ALTMAN'S ORIGINAL MODEL 14

TABLE 2.8: ERROR CLASSIFICATION FOR OHLSON'S MODEL 16

TABLE 2.9: SAS NO. 82 (APOSTOLOU, 2001) 20

TABLE 2.10: DEFINITION OF B OF SECURITY OR COMPANY 26

TABLE 2.11: MARKET RATIOS

TABLE 3.1: RETAIL INDUSTRY SEGMENTATION (US CENSUS, 2002) 28

TABLE 3.2: VALUE-ADDED BY INDUSTRY, 2005-2010, IN BILLIONS OF DOLLARS (BEA) 29

TABLE 3.3: MANUFACTURING AND TRADE (BEA) 29

TABLE 3.4: TOTAL SALES OF APPAREL INDUSTRY FROM 2001-2009 (US DEPARTMENT OF
COMMERCE)

TABLE 3.5: US POPULATION PROJECTIONS (US DEPARTMENT OF COMMERCE) 32

TABLE 3.6: BANKRUPTCY CASES COMMENCED, TERMINATED AND PENDING DURING TWELVE MONTH PERIODS ENDING DECEMBER 31

TABLE 4.1: SUMMARY OF MODEL CHARACTERISTICS (COOPER ET AL., 2007) 48

TABLE 6.1: LIST OF COMPANIES BY TICKER CODE IN RETAIL-APPAREL INDUSTRY

TABLE 6.2: REASONS FOR CHAPTER 11 FILINGS CITED IN PRESS RELEASES

TABLE 6.3: POSSIBLE DMU STATES

TABLE 6.4: FINANCIAL ITEMS

TABLE 6.5: HIGHLY CORRELATED FINANCIAL ACCOUNTS ON THE BALANCE SHEET 68

TABLE 6.6: HIGHLY CORRELATED FINANCIAL ACCOUNTS ON THE INCOME STATEMENT 68

TABLE 6.7: HIGHLY CORRELATED FINANCIAL ACCOUNTS ACROSS STATEMENTS 69

TABLE 6.8: AVERAGE MEDIAN ROAS, PMS, TATS BY STATE 70

TABLE 6.9: AVERAGES OF RATIOS IN PROFIT MARGIN BREAKDOWN 71

TABLE 6.10: AVERAGES OF RATIOS IN ASSETS TURNOVER (TO) BREAKDOWN 71

TABLE 6.11: AVERAGE OF MEDIAN ROCE

TABLE 6.12: COMPANY LEVERAGE POSITION

TABLE 6.13: AVERAGE LIQUIDITY RATIOS

TABLE 6.14: AVERAGE LIQUIDITY RATIOS

TABLE 6.15: AVERAGE SOLVENCY RATIOS

TABLE 6.16: AVERAGE BENEISH INDEX

TABLE 6.17: BANKRUPT COMPANIES AND EARNINGS MANIPULATION RISK 74

TABLE 6.18: QUALITY OF INCOME

TABLE 6.19: MANAGERIAL DECISION-MAKING VARIABLES 76

TABLE 6.20: CHI-SQUARE TEST RESULTS OF MANAGERIAL DECISION-MAKING DATA AND STATE

TABLE 6.21: LIKELIHOOD OF MANAGEMENT TURNOVER

TABLE 6.22: PROBABILITY OF AUDITOR CHANGE BY STATE 77

TABLE 6.23: PERCENTAGE OF DMUS WITH NON-SERIOUS AND SERIOUS LEGAL PROCEEDINGS BY STATE $\quad 77$

TABLE 6.24: ECONOMIC FACTORS IN THIS THESIS $\quad 79$ 
TABLE 6.25: SPEARMAN CORRELATION COEFFICIENTS OF ECONOMIC FACTORS 80

TABLE 6.26: CORRELATION BETWEEN COMPOSITE INDICES

TABLE 6.27: AVERAGE ANNUAL RETURN, VOLATILITY AND BETA 82

TABLE 6.28: CORRELATION BETWEEN COMPOSITE INDICES AND STOCK PERFORMANCE 83

TABLE 6.29: CORRELATION BETWEEN FINANCIAL AND ECONOMIC VARIABLES 86

TABLE 6.30: CORRELATION BETWEEN MANAGERIAL-DECISION MAKING AND ECONOMIC VARIABLES

TABLE 6.31: CORRELATION BETWEEN MARKET AND STOCK PERFORMANCE AND FINANCIAL DATA

TABLE 6.32: CORRELATION BETWEEN MARKET AND STOCK PERFORMANCE AND ECONOMIC FACTORS

TABLE 6.33: CORRELATION BETWEEN MARKET AND STOCK PERFORMANCE AND MANAGERIAL DECISION-MAKING DATA

TABLE 7.1: CONFUSION MATRIX

TABLE 7.2: AVERAGE BANKRUPTCY SCORES OF RETAIL-APPAREL COMPANIES BY STATE

TABLE 7.3: TYPE II ERROR

TABLE 7.4: CUMULATIVE HISTORIC CORPORATE DEFAULT RATES (U.S. MUNICIPAL BOND FAIRNESS ACT, 2008)

TABLE 8.1: COMMON VARIABLES MEASURING GOOD PERFORMANCE OR SUCCESS

TABLE 8.2: COMMON VARIABLES MEASURING POOR PERFORMANCE OR FAILURE

TABLE 8.3: ABBREVIATED LIST OF METRICS TESTED

TABLE 9.1: NORMAL SCORES CALCULATED WITH VARIABLES DERIVED FROM PCA BY STATE 102

TABLE 9.2: CONFUSION MATRIX FOR PCA NORMAL MODEL

TABLE 9.3: INVERSE SCORES CALCULATED WITH VARIABLES DERIVED FROM PCA BY STATE 104

TABLE 9.4: CONFUSION MATRIX FOR PCA INVERSE MODEL

TABLE 9.5: SUMMARY OF RESULTS FOR MODELS WITH VARIABLES SELECTED BY PCA AND LR 106

TABLE 9.6: CORRELATION BETWEEN PCA AND LR SCORES

TABLE 9.7: CORRELATION BETWEEN NORMAL AND INVERSE PROFITABILITY MODELS 108

TABLE 9.8: EXAMPLE OF INCONSISTENT NORMAL AND INVERSE MODELS OF A TWO INPUTS TWO OUTPUTS SYSTEM

TABLE 9.9: PARALLEL CLASSIFICATION OF MODELS "A" AND "B"

TABLE 9.10: SERIAL CLASSIFICATION OF MODELS "A" AND "B" (NORMAL THEN INVERSE DEA) 112

TABLE 9.11: SERIAL CLASSIFICATION OF MODELS “A” AND "B” (INVERSE THE NORMAL DEA) 113

TABLE 9.12: PARALLEL CLASSIFICATION OF NORMAL AND WORST-PRACTICE MODELS $\quad 114$

TABLE 9.13: SERIAL CLASSIFICATION OF NORMAL THEN WORST-PRACTICE MODELS $\quad 114$

TABLE 9.14: SERIAL CLASSIFICATION OF WORST-PRACTICE THEN NORMAL MODELS $\quad 114$

TABLE 10.1: CORRELATION BETWEEN METRICS AFTER FIRST RUN 122

TABLE 11.1: CORRELATIONS TO AGGREGATE GENERAL ECONOMIC INDICATOR 126

TABLE 11.2: CORRELATIONS TO AGGREGATE APPAREL INDUSTRY INDICATOR 127

TABLE 11.3: CORRELATIONS TO AGGREGATE HOUSING PERFORMANCE INDICATOR 128

TABLE 11.4: CORRELATIONS TO AGGREGATE PRICES INDICATOR

TABLE 12.1: INPUT-ORIENTED MODELS: SPECIFICATIONS AND RESULTS WITH INPUT VALUE RANGE BETWEEN 1 AND 3

TABLE 12.2: INPUT-ORIENTED MODELS: SPECIFICATIONS AND RESULTS WITH INPUT VALUE RANGE BETWEEN 1 AND 100

TABLE 12.3: CORRELATION OF LAYERED SCORES

TABLE 12.4: SECOND STAGE MODEL PREDICTION WITH CLASSIFICATION BY ZONES

TABLE 12.5: ACCURACY OF CLASSIFICATION BY LAYERING OF SECOND STAGE MODEL AND INDIVIDUAL METRICS 
TABLE 12.6: SECOND STAGE MODEL WITH AND WITHOUT CFO METRIC 140

TABLE 12.7: SPECIFICITY AND SENSITIVITY TRADE-OFF $\quad 142$

TABLE 12.8: PERFORMANCE OF NON-LAYERING AND LAYERING TECHNIQUES 143

TABLE 12.9: TESTS OF SIMILARITY BETWEEN SECOND STAGE SCORES AND ME INDICATOR 144

TABLE 12.10: DIRECTION OF CHANGE FROM YEAR TO YEAR 145

TABLE 13.1: PROBABILITIES OF BANKRUPTCY (B) AND NON-BANKRUPTCY (NB) 159

TABLE 13.2: ACCURACY OF CLASSIFICATION BY LAYERING OF SECOND STAGE MODEL FROM

ONE YEAR BACK

TABLE 13.3: SECOND ORDER POLYNOMIAL FUNCTIONS ESTIMATING THE PROBABILITY OF BANKRUPTCY

TABLE B.1: TWO INPUTS AND ONE OUTPUT CASE $\quad 178$

TABLE B.2: ONE INPUT AND TWO OUTPUTS CASE $\quad 180$

TABLE D.1: BROAD CATEGORIES FOR ECONOMIC INDICATORS

TABLE D.2: RATING CODES FOR EACH CREDIT RATING AGENCIES 185

TABLE E.1: VARIABLES FROM PRINCIPAL COMPONENT ANALYSIS AND LOGISTIC REGRESSION 186

TABLE E.2: PROFITABILITY AND SUCCESS METRICS (NORMAL DEA FRONTIER) 186

TABLE E.3: PROFITABILITY AND SUCCESS METRICS (INVERSE DEA FRONTIER) 186

TABLE E.4: BANKRUPTCY AND FAILURE METRICS (WORST-PRACTICE DEA FRONTIER) 187

TABLE E.5: BANKRUPTCY AND FAILURE METRICS (BAD OUTPUTS MODEL) 187

TABLE E.6: BALANCE SHEET METRICS (NORMAL DEA FRONTIER) 187

TABLE E.7: INCOME STATEMENT METRICS (NORMAL DEA FRONTIER) 187

TABLE E.8: QUALITATIVE METRICS (NORMAL DEA FRONTIER) 187

TABLE E.9: VARIABLES FOR "MEGA" MODEL 188

TABLE F.1: NORMAL SCORES CALCULATED WITH VARIABLES DERIVED FROM LR BY STATE 189

TABLE F.2: CONFUSION MATRIX FOR LR NORMAL MODEL 189

TABLE F.3: INVERSE SCORES CALCULATED WITH VARIABLES DERIVED FROM LR BY STATE 189

TABLE F.4: CONFUSION MATRIX FOR LR INVERSE MODEL 190 


\section{List of Figures}

FIGURE 2.1: RELATIONSHIP BETWEEN THE BALANCE SHEET AND CASH FLOWS 4

FIGURE 2.2: CAPITAL ASSET PRICING MODEL (CAPM) 26

FIGURE 2.3: CAPM SECURITY MARKET LINE

FIGURE 3.1: US IMPORTS AND EXPORTS BY YEAR (IN BILLIONS OF DOLLARS) (US DEPARTMENT OF COMMERCE) $\quad 30$

FIGURE 3.2: CONSUMER CONFIDENCE INDEX BY YEAR (1985 = 100) (THE CONFERENCE BOARD) 33 FIGURE 3.3: APPAREL'S SHARE OF TOTAL PERSONAL CONSUMPTION EXPENDITURES BY YEAR (IN \%) (US DEPARTMENT OF COMMERCE)

FIGURE 3.4: CONSUMER PRICE INDICES (1982-84 = 100) (BUREAU OF LABOUR STATISTICS) 34

FIGURE 3.5: US APPAREL INDUSTRY EMPLOYMENT BY YEAR (PRODUCTION WORKERS, IN MILLIONS) (BUREAU OF LABOUR STATISTICS)

FIGURE 4.1: DATA ENVELOPMENT ANALYSIS VERSUS REGRESSION ANALYSIS 37

FIGURE 4.2: INEFFICIENCIES AND PROJECTIONS IN CCR AND BCC MODELS WITH ONE INPUT AND $\begin{array}{ll}\text { ONE OUTPUT } & 38\end{array}$

FIGURE 4.3: DEA SYSTEM WITH MULTIPLE INPUTS AND MULTIPLE OUTPUTS 38

FIGURE 4.4: INPUT MINIMIZATION, OUTPUT MAXIMIZATION AND SLACKS 40

FIGURE 4.5: CONSTANT VERSUS VARIABLE RETURNS-TO-SCALE (RTS) 43

FIGURE 4.6: ADDITIVE MODEL

FIGURE 4.7: TRANSLATION INVARIANCE IN THE ADDITIVE MODEL 46

FIGURE 4.8: TRUE (THEORETICAL) FRONTIER VERSUS DEA (EMPIRICAL) FRONTIER 49

FIGURE 4.9: ONE INPUT, TWO OUTPUT EXAMPLE FOR USE OF RATIOS IN DEA

FIGURE 5.1: CURRENT LIMITATIONS

FIGURE 6.1: TIME FRAME OF AVAILABLE DATA FOR COMPANIES AENA-JWN 58

FIGURE 6.2: TIME FRAME OF AVAILABLE DATA FOR COMPANIES KDRH-ZUMZ 59

FIGURE 6.3: CREATION OF TEMPLATE FINANCIAL STATEMENTS 61

FIGURE 6.4: EXAMPLE OF TEMPLATE INCOME STATEMENT (IN \$M) 62

FIGURE 6.5: EXAMPLE OF TEMPLATE BALANCE SHEET (IN \$M) 62

FIGURE 6.6: EXAMPLE OF TEMPLATE CASH FLOW STATEMENT (IN \$M) 63

FIGURE 6.7: COMBINING ALL DATA INTO ONE WORKSHEET (IN \$M) 64

FIGURE 6.8: HISTOGRAM FOR AVERAGE ANNUAL CASH 64

FIGURE 6.9: HISTOGRAM FOR AVERAGE ANNUAL AR 64

FIGURE 6.10: HISTOGRAM FOR AVERAGE ANNUAL INV

FIGURE 6.11: HISTOGRAM FOR AVERAGE ANNUAL CA 65

FIGURE 6.12: HISTOGRAM FOR AVERAGE ANNUAL PPE 65

FIGURE 6.13: HISTOGRAM FOR AVERAGE ANNUAL AD 65

FIGURE 6.14: HISTOGRAM FOR AVERAGE ANNUAL TA 65

FIGURE 6.15: HISTOGRAM FOR AVERAGE ANNUAL AP 65

FIGURE 6.16: HISTOGRAM FOR AVERAGE ANNUAL CM 65

FIGURE 6.17: HISTOGRAM FOR AVERAGE ANNUAL CL 65

FIGURE 6.18: HISTOGRAM FOR AVERAGE ANNUAL LTD 66

FIGURE 6.19: HISTOGRAM FOR AVERAGE ANNUAL TL 66

FIGURE 6.20: HISTOGRAM FOR AVERAGE ANNUAL RE 66

FIGURE 6.21: HISTOGRAM FOR AVERAGE ANNUAL SE 66

FIGURE 6.22: HISTOGRAM FOR AVERAGE ANNUAL REV 66

FIGURE 6.23: HISTOGRAM FOR AVERAGE ANNUAL COGS 66

FIGURE 6.24: HISTOGRAM FOR AVERAGE ANNUAL SGA 66

FIGURE 6.25: HISTOGRAM FOR AVERAGE ANNUAL II 66 
FIGURE 6.26: HISTOGRAM FOR AVERAGE ANNUAL IE 67

FIGURE 6.27: HISTOGRAM FOR AVERAGE ANNUAL NI 67

FIGURE 6.28: HISTOGRAM FOR AVERAGE ANNUAL CFO 67

FIGURE 6.29: HISTOGRAM FOR AVERAGE ANNUAL CFF 67

FIGURE 6.30: HISTOGRAM FOR AVERAGE CFF 67

FIGURE 6.31: HISTOGRAM FOR AVERAGE ANNUAL CC 67

FIGURE 6.32: MEDIAN EFFICIENCY AND PROFITABILITY CHART FOR ALL COMPANIES 70

FIGURE 6.33: STRATEGY FOR DERIVING A THRESHOLD FOR EVALUATING RATIOS 73

FIGURE 6.34: EXAMPLE OF ORGANIZATION OF QUALITATIVE INFORMATION EXTRACTED FROM ANNUAL REPORTS

FIGURE 6.35: EXAMPLE OF ORGANIZATION OF ECONOMIC DATA

FIGURE 6.36: COUNT AND PERCENTAGE OF COMPANIES TRADED ON SPECIFIC EXCHANGES 81

FIGURE 6.37: AVERAGE YEARLY RETURNS OF COMPOSITE INDICES 81

FIGURE 6.38: AVERAGE RETURN

FIGURE 6.39: AVERAGE VOLATILITY $\quad 82$

FIGURE 6.40: AVERAGE BETA 83

FIGURE 6.41: RELATIONSHIP BETWEEN RELATED PARTY TRANSACTIONS AND AVERAGE REVENUE

FIGURE 6.42: RELATIONSHIP BETWEEN LEGAL PROCEEDINGS AND AVERAGE REVENUE 85

FIGURE 6.43: RELATIONSHIP BETWEEN AUDITOR'S OPINION AND AVERAGE REVENUE 85

FIGURE 6.44: RELATIONSHIP BETWEEN RETIREMENT PLAN AND AVERAGE REVENUE 85

FIGURE 6.45: RELATIONSHIP BETWEEN AUDITOR CHANGE AND AVERAGE CHANGE IN REVENUE

FIGURE 6.46: RELATIONSHIP BETWEEN TURNOVER OF MANAGEMENT AND AVERAGE CHANGE IN REVENUE

FIGURE 7.1: TYPE I ERROR BY YEARS PRIOR TO BANKRUPTCY 92

FIGURE 8.1: DEA FRONTIER OF BEST PERFORMERS 95

FIGURE 8.2: DEA FRONTIER OF WORST PERFORMERS 95

FIGURE 8.3: LAYERING TECHNIQUE FOR NORMAL DEA 96

FIGURE 8.4: EXAMPLE OF METRICS AND SECOND STAGE ANALYSIS 96

FIGURE 8.5: EXAMPLE OF HANDLING NEGATIVE DATA 99

FIGURE 8.6: CLASSIFICATION WITH ONE CUT-OFF VALUE $(X) \quad 100$

FIGURE 8.7: CLASSIFICATION WITH TWO CUT-OFF VALUES ( $X$ AND $Y$ ) 101

FIGURE 9.1: DISTRIBUTION OF SCORES GENERATED FROM PCA NORMAL MODEL 102

FIGURE 9.2: DISTRIBUTION OF SCORES GENERATED FROM PCA INVERSE MODEL 104

FIGURE 9.3: DISTRIBUTION OF SCORES GENERATED FROM LR NORMAL MODEL 105

FIGURE 9.4: SUMMARY OF NORMAL PROFITABILITY MODEL “A” 107

FIGURE 9.5: SUMMARY OF NORMAL PROFITABILITY MODEL “B” 107

FIGURE 9.6: SUMMARY OF INVERSE PROFITABILITY MODEL “A” 108

FIGURE 9.7: SUMMARY OF INVERSE PROFITABILITY MODEL "B” 108

FIGURE 9.8: EXAMPLE OF CONSISTENT NORMAL AND INVERSE MODELS 109

FIGURE 9.9: EXAMPLE OF INCONSISTENT NORMAL AND INVERSE MODELS 110

FIGURE 9.10: PARALLEL CLASSIFICATION 111

FIGURE 9.11: SERIAL CLASSIFICATION (NORMAL THEN INVERSE DEA) 112

FIGURE 9.12: SERIAL CLASSIFICATION (INVERSE THEN NORMAL DEA) 113

FIGURE 9.13: SUMMARY OF SOLVENCY WORST-PRACTICE MODEL “C”

FIGURE 10.1: SUMMARY OF INCOME STATEMENT (IS) METRIC 116

FIGURE 10.2: PREDICTION BY IS METRIC FROM ONE YEAR BACK 117

FIGURE 10.3: SUMMARY OF BALANCE SHEET ASSETS (BSA) METRIC 
FIGURE 10.4: PREDICTION BY BSA METRIC FROM ONE YEAR BACK 118

FIGURE 10.5: SUMMARY OF BALANCE SHEET LIABILITIES (BSL) METRIC 119

FIGURE 10.6: PREDICTION BY BSL METRIC FROM ONE YEAR BACK 119

FIGURE 10.7: CASH FLOWS IN PRODUCT LIFE CYCLE (STICKNEY ET AL., 2007) 120

FIGURE 10.8: SUMMARY OF MANAGERIAL DECISION-MAKING (MDM) METRIC 121

FIGURE 10.9: PREDICTION BY MDM METRIC FROM ONE YEAR BACK 121

FIGURE 10.10: THE EFFECT OF INFLATION ON IS SCORES 123

FIGURE 10.11: THE EFFECT OF INFLATION ON BSA SCORES 123

FIGURE 10.12: THE EFFECT OF INFLATION ON BSL SCORES 123

FIGURE 10.13 PREDICTION BY IS METRIC FROM ONE YEAR BACK AND BASED ON REAL DOLLARS

FIGURE 11.1: GENERAL ECONOMIC PERFORMANCE BY YEAR - I

FIGURE 11.2: GENERAL ECONOMIC PERFORMANCE BY YEAR - II 126

FIGURE 11.3: APPAREL INDUSTRY PERFORMANCE BY YEAR 127

FIGURE 11.4: HOUSING MARKET PERFORMANCE AND MONTHS FOR A SALE BY YEAR 128

FIGURE 11.5: HOUSING MARKET PERFORMANCE AND CONSTRUCTION BY YEAR 128

FIGURE 11.6: PRICES BY YEAR $\quad 129$

FIGURE 11.7: GENERAL MARKET PERFORMANCE BY YEAR 129

FIGURE 11.8: ALL-ENCOMPASSING MARKET AND ECONOMIC INDICATOR BY YEAR 130

FIGURE 11.9: POSSIBILITIES OF ADDING MARKET AND ECONOMIC FACTORS INTO DEA MODELS

FIGURE 12.1: SECOND STAGE RESULTS WITH IS, BSA AND BSL 136

FIGURE 12.2: SECOND STAGE RESULTS WITH IS, BSA, BSL AND CFO 136

FIGURE 12.3: SECOND STAGE RESULTS WITH IS, BSA BSL AND MDM 136

FIGURE 12.4: SECOND STAGE RESULTS WITH IS, BSA, BSL, CFO AND MDM 136

FIGURE 12.5: CLASSIFICATION BY LAYER IN ABSOLUTE NUMBERS FROM ONE YEAR BACK 137

FIGURE 12.6: CLASSIFICATION BY LAYER IN PERCENTAGES FROM ONE YEAR BACK 138

FIGURE 12.7: PREDICTION BY SECOND STAGE MODEL FROM ONE YEAR BACK 138

FIGURE 12.8: ROC CURVES FOR ONE YEAR BACK $\quad 139$

FIGURE 12.9: ROC CURVES FOR ONE YEAR BACK WITH CFO 140

FIGURE 12.10: TYPE I AND II ERRORS TRADE-OFF

FIGURE 12.11: CORRELATION BETWEEN LAYERING AND NON-LAYERING TECHNIQUES 143

FIGURE 12.12: AVERAGE SCORES BY YEAR $\quad 144$

FIGURE 12.13: ALL COMPANIES (3.4-TO-1 RATIO) 146

FIGURE 12.14: 3-TO-1 RATIO $\quad 146$

FIGURE 12.15: 2-TO-1 RATIO $\quad 146$

FIGURE 12.16: 1-TO-1 RATIO 146

FIGURE 12.17: PROJECTIONS FOR METRICS IN THE SECOND STAGE FOR SELECTED DMUS 147

FIGURE 12.18: PROJECTIONS FOR IS METRIC VARIABLES FOR SELECTED DMUS 148

FIGURE 12.19: IS PROJECTIONS FOR COGS 149

FIGURE 12.20: IS PROJECTIONS FOR SGA 149

FIGURE 12.21: IS PROJECTIONS FOR NET INTEREST EXPENSE 149

FIGURE 12.22: IS PROJECTIONS FOR INCOME TAX EXPENSE 149

FIGURE 12.23: IS PROJECTIONS FOR REVENUE $\quad 150$

FIGURE 12.24: IS PROJECTIONS FOR NET INCOME $\quad 150$

FIGURE 12.25: BSA PROJECTIONS FOR MARKETABLE SECURITIES $\quad 150$

FIGURE 12.26: BSA PROJECTIONS FOR ACCOUNTS RECEIVABLE $\quad 150$

FIGURE 12.27: BSA PROJECTIONS FOR INVENTORIES 151

FIGURE 12.28: BSA PROJECTIONS FOR CURRENT ASSETS 151 
FIGURE 12.29: BSA PROJECTIONS FOR LONG-TERM INVESTMENT IN SECURITIES 151

FIGURE 12.30: BSA PROJECTIONS FOR NET PPE

FIGURE 12.31: BSA PROJECTIONS FOR GOODWILL $\quad 152$

FIGURE 12.32: BSA PROJECTIONS FOR TOTAL ASSETS 152

FIGURE 12.33: BSA PROJECTIONS FOR CASH 152

FIGURE 12.34: BSA PROJECTIONS FOR RETAINED EARNINGS 152

FIGURE 12.35: BSA PROJECTIONS FOR SHAREHOLDERS' EQUITY 153

FIGURE 12.36: BSL PROJECTIONS FOR ACCOUNTS PAYABLE 153

FIGURE 12.37: BSL PROJECTIONS FOR NOTES PAYABLE AND SHORT-TERM DEBT 153

FIGURE 12.38: BSL PROJECTIONS FOR CURRENT MATURITIES OF LONG-TERM DEBT 154

FIGURE 12.39: BSL PROJECTIONS FOR CURRENT LIABILITIES 154

FIGURE 12.40: BSL PROJECTIONS FOR LONG-TERM DEBT 154

FIGURE 12.41: BSL PROJECTIONS FOR TOTAL LIABILITIES $\quad 154$

FIGURE 12.42: BSL PROJECTIONS FOR RETAINED EARNINGS 155

FIGURE 12.43: BSL PROJECTIONS FOR SHAREHOLDERS' EQUITY 155

FIGURE 12.44: MDM PROJECTIONS FOR RELATED PARTY TRANSACTIONS

FIGURE 12.45: MDM PROJECTIONS FOR AUDITOR'S OPINION

FIGURE 12.46: MDM PROJECTIONS FOR CHANGE OF AUDITOR 156

FIGURE 12.47: MDM PROJECTIONS FOR MANAGEMENT TURNOVER 156

FIGURE 12.48: MDM PROJECTIONS FOR LEGAL PROCEEDINGS 156

FIGURE 12.49: MDM PROJECTIONS FOR RETIREMENT PLAN 156

FIGURE 12.50: SECOND STAGE PROJECTIONS FOR IS METRIC 157

FIGURE 12.51: SECOND STAGE PROJECTIONS FOR BSA METRIC 157

FIGURE 12.52: SECOND STAGE PROJECTIONS FOR BSL METRIC 157

FIGURE 12.53: SECOND STAGE PROJECTIONS FOR MDM METRIC 157

FIGURE 13.1: DISTRIBUTION OF SECOND STAGE LAYERED SCORES $\quad 158$

FIGURE 13.2: PROBABILITY OF BANKRUPTCY 160

FIGURE 13.3: TIME WINDOWS FOR MODEL TESTING 161

FIGURE 14.1: SUMMARY OF METHODOLOGY AS APPLICABLE TO ALL INDUSTRIES 167

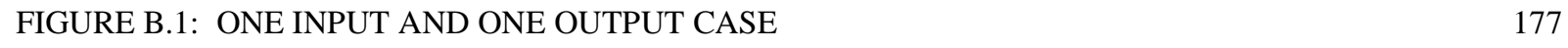

FIGURE B.2: TWO INPUTS AND ONE OUTPUT CASE $\quad 178$

FIGURE B.3: ONE INPUT AND TWO OUTPUTS CASE $\quad 180$

FIGURE F.1: DISTRIBUTION OF SCORES GENERATED FROM LR INVERSE DEA MODEL 189

FIGURE F.2: PREDICTION BY IS METRIC FROM TWO YEARS BACK 190

FIGURE F.3: PREDICTION BY IS METRIC FROM THREE YEARS BACK 190

FIGURE F.4: PREDICTION BY BSA METRIC FROM TWO YEARS BACK 191

FIGURE F.5: PREDICTION BY BSA METRIC FROM THREE YEARS BACK 191

FIGURE F.6: PREDICTION BY BSL METRIC FROM TWO YEARS BACK 192

FIGURE F.7: PREDICTION BY BSL METRIC FROM THREE YEARS BACK 192

FIGURE F.8: PREDICTION BY MDM METRIC FROM TWO YEARS BACK 193

FIGURE F.9: PREDICTION BY MDM METRIC FROM THREE YEARS BACK 193

FIGURE F.10: CLASSIFICATION BY LAYER IN ABSOLUTE NUMBERS FROM TWO YEARS BACK 194

FIGURE F.11: CLASSIFICATION BY LAYER IN PERCENTAGES FROM TWO YEARS BACK 194

FIGURE F.12: PREDICTION BY SECOND STAGE MODEL FROM TWO YEARS BACK 194

FIGURE F.13: CLASSIFICATION BY LAYER IN ABSOLUTE NUMBERS THREE YEARS BACK 195

FIGURE F.14: CLASSIFICATION BY LAYER IN PERCENTAGES FROM THREE YEARS BACK 195

FIGURE F.15: PREDICTION BY SECOND STAGE MODEL FROM THREE YEARS BACK 195

FIGURE F.16: IS PROJECTIONS FOR COGS

FIGURE F.17: IS PROJECTIONS FOR SGA 196 
FIGURE F.18: IS PROJECTIONS FOR NET INTEREST EXPENSE

FIGURE F.19: IS PROJECTIONS FOR INCOME TAX EXPENSE

FIGURE F.20: IS PROJECTIONS FOR REVENUE

FIGURE F.21: IS PROJECTIONS FOR NET INCOME

FIGURE F.22: BSA PROJECTIONS FOR MARKETABLE SECURITIES 197

FIGURE F.23: BSA PROJECTIONS FOR ACCOUNTS RECEIVABLE 197

FIGURE F.24: BSA PROJECTIONS FOR INVENTORIES 197

FIGURE F.25: BSA PROJECTIONS FOR CURRENT ASSETS 197

FIGURE F.26: BSA PROJECTIONS FOR LONG-TERM INVESTMENTS IN SECURITIES 197

FIGURE F.27: BSA PROJECTIONS FOR NET PPE 197

FIGURE F.28: BSA PROJECTIONS FOR GOODWILL 198

FIGURE F.29: BSA PROJECTIONS FOR TOTAL ASSETS 198

FIGURE F.30: BSA PROJECTIONS FOR CASH $\quad 198$

FIGURE F.31: BSA PROJECTIONS FOR RETAINED EARNINGS 198

FIGURE F.32: BSA PROJECTIONS FOR SHAREHOLDERS' EQUITY 198

FIGURE F.33: BSL PROJECTIONS FOR ACCOUNTS PAYABLE 198

FIGURE F.34: BSL PROJECTIONS FOR NOTES PAYABLE AND SHORT-TERM DEBT 199

FIGURE F.35: BSL PROJECTIONS FOR CURRENT MATURITIES OF LONG-TERM DEBT 199

FIGURE F.36: BSL PROJECTIONS FOR CURRENT LIABILITIES 199

FIGURE F.37: BSL PROJECTIONS FOR LONG-TERM DEBT 199

FIGURE F.38: BSL PROJECTIONS FOR TOTAL LIABILITIES 199

FIGURE F.39: BSL PROJECTIONS FOR RETAINED EARNINGS 199

FIGURE F.40: BSL PROJECTIONS FOR SHAREHOLDERS' EQUITY 200

FIGURE F.41: MDM PROJECTIONS FOR RELATED PARTY TRANSLATIONS 200

FIGURE F.42: MDM PROJECTIONS FOR AUDITOR'S OPINION 200

FIGURE F.43: MDM PROJECTIONS FOR CHANGE IN AUDITORS 200

FIGURE F.44: MDM PROJECTIONS FOR MANAGEMENT TURNOVER 200

FIGURE F.45: MDM PROJECTIONS FOR LEGAL PROCEEDINGS 200

FIGURE F.46: MDM PROJECTIONS FOR RETIREMENT PLANS 201

FIGURE F.47: SECOND STAGE PROJECTIONS FOR IS METRIC 201

FIGURE F.48: SECOND STAGE PROJECTIONS FOR BSA METRIC 201

FIGURE F.49: SECOND STAGE PROJECTIONS FOR BSL METRIC 201

FIGURE F.50: SECOND STAGE PROJECTIONS FOR MDM METRIC 201

FIGURE F.51: PREDICTION BY SECOND STAGE MODEL FROM ONE YEAR BACK, 1996-2008 202

FIGURE F.52: PREDICTION BY SECOND STAGE MODEL FROM ONE YEAR BACK, 1996-2007 202

FIGURE F.53: PREDICTION BY SECOND STAGE MODEL FROM ONE YEAR BACK, 1996-2006 202

FIGURE F.54: PREDICTION BY SECOND STAGE MODEL FROM ONE YEAR BACK, 1996-2005 203

FIGURE F.55: PREDICTION BY SECOND STAGE MODEL FROM ONE YEAR BACK, 1996-2004 203

FIGURE F.56: PROBABILITY OF BANKRUPTCY FROM ONE YEAR BACK, 1996-2009 204

FIGURE F.57: PROBABILITY OF BANKRUPTCY FROM ONE YEAR BACK, 1996-2008 204

FIGURE F.58: PROBABILITY OF BANKRUPTCY FROM ONE YEAR BACK, 1996-2007 205

FIGURE F.59: PROBABILITY OF BANKRUPTCY FROM ONE YEAR BACK, 1996-2006 205

FIGURE F.60: PROBABILITY OF BANKRUPTCY FROM ONE YEAR BACK, 1996-2005 205

FIGURE F.61: PROBABILITY OF BANKRUPTCY FROM ONE YEAR BACK, 1996-2004 206 


\section{List of Abbreviations}

\begin{tabular}{|c|c|c|c|}
\hline Acronym & Definition & Acronym & Definition \\
\hline $\mathrm{AD}$ & Accumulated Depreciation & MD\&A & Management's Discussion and Analysis \\
\hline ADD & Additive Model & MDA & Multiple Discriminant Analysis \\
\hline $\mathrm{AR}$ & Accounts Receivable & $\mathrm{ME}$ & Market and Economic \\
\hline AP & Accounts Payable & MS & Marketable Securities \\
\hline $\mathrm{BCC}$ & Banker-Charnes-Cooper Model & Net IE & Net Interest Expense \\
\hline $\mathrm{CA}$ & Current Assets & Net PPE & Net Property, Plant and Equipment \\
\hline $\mathrm{CC}$ & Change in Cash & NI & Net Income \\
\hline CCR & Charnes-Cooper-Rhodes Model & Notes & Notes to the Financial Statement \\
\hline CFF & Cash Flow From Financing Activities & NPSTD & Notes Payable and Short-Term Debt \\
\hline CFI & Cash Flow From Investing Activities & OTC & Over-the-Counter \\
\hline $\mathrm{CFO}$ & Cash Flow From Operating Activities & Other CA & Other Current Assets \\
\hline COGS & Cost of Goods Sold & Other NonCA & Other Non-Current Assets \\
\hline $\mathrm{CL}$ & Current Liabilities & PCA & Principal Component Analysis \\
\hline $\mathrm{CM}$ & Current Maturities of Long-Term Debt & PM & Profit Margin \\
\hline DEA & Data Envelopment Analysis & PPE & Property, Plant and Equipment \\
\hline DMU & Decision Making Unit & RE & Retained Earnings \\
\hline EBIT & Earnings Before Interest and Taxes & Rev & Revenue \\
\hline FASB & Financial Accounting Standards Board & ROA & Return on Assets \\
\hline Goodwill & Goodwill & ROCE & Return on Common Equity \\
\hline IE & Interest Expense & RTS & Returns-to-Scale \\
\hline IFRS & International Financial Reporting Standards & SBM & Slacks-based Measure of Efficiency Models \\
\hline II & Interest Income & SE & Shareholders' Equity \\
\hline Inv & Inventories & SEC & Securities and Exchange Commission \\
\hline ITE & Income Tax Expense & SGA & Selling, General and Administrative Expenses \\
\hline Lev & Leverage & TA & Total Assets \\
\hline LR & Logistic Regression & TAT & Total Assets Turnover \\
\hline LTD & Long-Term Debt & TL & Total Liabilities \\
\hline LTIS & Long-Term Investment in Securities & WC & Working Capital \\
\hline
\end{tabular}




\section{List of Symbols}

\begin{tabular}{|c|c|}
\hline Symbol & Definition \\
\hline $\mathrm{A}$ & Active, Non-bankrupt State \\
\hline $\mathrm{B}$ & Bankrupt State \\
\hline B-1 & One Year Prior to Bankruptcy State \\
\hline B-2 & Two Years Prior to Bankruptcy State \\
\hline B-3 & Three Years Prior to Bankruptcy State \\
\hline$\beta, \beta_{i}$ & Beta, Beta of Firm \\
\hline $\mathrm{E}\left(\mathrm{R}_{\mathrm{i}}\right)$ & Expected Return of Firm \\
\hline $\mathrm{E}\left(\mathrm{R}_{\mathrm{m}}\right)$ & Expected Return of Market \\
\hline $\mathrm{R}_{\mathrm{i}}$ & Return of Firm \\
\hline $\mathrm{R}_{\mathrm{f}}$ & Risk-Free Rate of Interest \\
\hline $\mathrm{R}_{\mathrm{m}}$ & Return of Market \\
\hline$\lambda$ & Set of Non-Negative Intensity Variables \\
\hline$m$ & Total Number of Inputs \\
\hline$\eta$ & Efficiency (Output Oriented Model) \\
\hline$\eta^{*}$ & Optimal Efficiency (Output Oriented Model) \\
\hline$\eta_{B C C}$ & BCC Efficiency (Output Oriented Model) \\
\hline$N$ & Total Number of Inputs and Outputs \\
\hline$\rho$ & SBM Efficiency or Spearman's Rank Correlation Coefficient \\
\hline$\rho^{*}$ & SBM Optimal Efficiency \\
\hline$\sigma$ & Standard Deviation \\
\hline$s$ & Total Number of Outputs \\
\hline$s_{i}^{-}, t_{i}^{-}$ & Input Slack for $i^{\text {th }}$ Input (Input and Output Oriented, respectively) \\
\hline$s_{r}^{+}, t_{r}^{+}$ & Output Slack for $r^{\text {th }}$ Output (Input and Output Oriented, respectively) \\
\hline$\theta$ & Efficiency (Input Oriented Model) \\
\hline$\theta^{*}$ & Optimal Efficiency \\
\hline$\theta_{B C C}$ & BCC Efficiency (Input Oriented Model) \\
\hline$u^{*}$ & Best Set of Output Weights \\
\hline$u_{o}$ & Unrestricted Dual Variable \\
\hline$u_{r}$ & Output Weight Given to $r^{\text {th }}$ Input \\
\hline$v$ & Value Function \\
\hline$v^{*}$ & Best Set of Input Weights \\
\hline$v_{o}$ & Unrestricted Dual Variable \\
\hline$v_{i}$ & Input Weight Given to $i^{\text {th }}$ Input \\
\hline$x$ & Input \\
\hline$x_{i j}$ & Amount of $i^{\text {th }}$ Input to DMU $j$ \\
\hline$\left(\hat{x}_{o}, \hat{y}_{o}\right)$ & Coordinates of Virtual Linear Composite, Target \\
\hline$y$ & Output \\
\hline$y_{i j}$ & Amount of $r^{\text {th }}$ Output to DMU $j$ \\
\hline$Z$ & Altman's Z-Score \\
\hline$\zeta$ & DMU DEA Score \\
\hline
\end{tabular}




\section{Introduction}

Bankruptcy is a legally declared financial inability of an individual or organization to meet their debt obligations. In the U.S., nearly 1.59 million filings for bankruptcy protection were made in 2010, an increase of 8\% from 2009 and 43\% from 2008 (U.S. Courts, 2011). The effect of bankruptcy is two-fold. Creditors (financial institutions, government financing programs) lose interest payments and their principal investment while business owners are subject to unpleasant legal, financial and personal consequences. For example, a trustee may be assigned to the bankrupt business and force a sale of its property to pay back creditors without the consent of the owner. This inevitably harms the owner's reputation, discouraging potential associates, damaging existing relationships and making it difficult to obtain credit in the future.

Clearly, there are economic and social incentives for both parties to have the capacity to predict the probability of bankruptcy. For creditors, accurate prediction would translate to better assessment or pricing of interest payments with respect to risk. Essentially, financial institutions and government financing programs could avoid making wrong credit decisions by distinguishing companies in or heading for trouble (as to mitigate potential loss) from those in "good" health (as to not refuse potential profits). For owners, prediction would translate to prevention, buying time for them to secure more financing and avoid potential demise.

Current mathematical models predict bankruptcy with common financial ratios as inputs, disregarding market and economic factors. Also, while existing techniques make dichotomous predictions (i.e. fail or survive) on the state of firms, they do not provide strategies for owners to improve their operations when bankruptcy is imminent and finding external sources of cash unlikely. Therefore, the objective of this research is to develop a Data Envelopment Analysis (DEA) based model that assesses the likelihood of failure of American retail-apparel companies and suggests preventative measures based on data available from financial statements and their accompanying Notes (which provide hints on managerial decision-making) as well as market and economic influences. It is hypothesized that the inclusion of variables that reflect managerial decision-making, and market and economic factors, enhance the predictive power of mathematical models that consider 
financial data exclusively. Also, because this work is specific to retail-apparel, it is critical to develop of a methodology that can be easily adapted for another industry.

This thesis is structured as follows:

- Chapter 2 provides the basics on accounting and financial statement analysis, as well as a brief literature survey on bankruptcy prediction and fraud.

- Chapter 3 profiles the U.S. retail-apparel industry.

- Chapter 4 offers a full background on Data Envelopment Analysis, its different models and their mathematical formulations, with examples provided in the Appendix.

- Chapter 5 outlines the objectives of this research as motivated by the limitations of the current techniques discussed in Chapters 2, 3 and 4.

- Chapter 6 summarizes the collection, preparation and exploration of financial, managerial decision-making, and market and economic data.

- Chapter 7 describes the benchmarks of this work.

- Chapter 8 outlines the methodology.

- Chapters 9, 10, 11, 12, and 13 present and discuss the results.

- Chapter 14 summarizes the major contributions of this thesis and lists recommendations for future work. 


\section{Background I: Accounting and Financial Statement Analysis}

\subsection{The Annual Report}

The U.S. Financial Accounting Standards Board (FASB) issues a common set of authoritative rules, guides, conventions and procedures that all companies must adhere to in recording their transactions and preparing their annual reports. Here, the most important parts of the annual report - the financial statements and its accompanying Notes, the Management's Discussion and Analysis (MD\&A) and the Auditor's Report - are described.

\subsubsection{Balance Sheet}

A balance sheet provides a snapshot of a company's financial resources and obligations at a point in time. It indicates how money is distributed among generally recognized areas of a business, namely, assets, liabilities and shareholders' equity (Table 2.1).

Table 2.1: Common Entries in a Balance Sheet (Gill, 1994)

\begin{tabular}{|c|c|}
\hline \multicolumn{2}{|c|}{$\begin{array}{l}\text { Assets: Anything that a company owns with monetary value. There are two types - current assets and non-current } \\
\text { assets - which are listed on a balance sheet in decreasing order of liquidity. }\end{array}$} \\
\hline $\begin{array}{r}\text { Current } \\
\text { Assets }\end{array}$ & $\begin{array}{l}\text { All items that can be converted into cash quickly, in less than a year. e.g. cash and cash } \\
\text { equivalents, marketable securities, accounts receivable, inventories, prepaid expenses }\end{array}$ \\
\hline $\begin{array}{r}\text {-Current } \\
\text { Assets }\end{array}$ & $\begin{array}{l}\text { Items that cannot be converted into cash quickly. e.g. property, plant and equ } \\
\text { accumulated depreciation, long-term investments in securities, amortizable in } \\
\text { patents, trademarks, copyrights), goodwill and non-amortizable intangibles }\end{array}$ \\
\hline \multicolumn{2}{|c|}{ Liabilities: Everything that a company owes. There are two types: current liabilities and non-current liabilities. } \\
\hline $\begin{array}{r}\text { Current } \\
\text { Liabilities }\end{array}$ & $\begin{array}{l}\text { The sum of monies owed that must be paid within } 12 \text { months. e.g. accounts payable, notes and } \\
\text { loans payable, short-term provisions, current maturities or interest on long-term debt, accruals (i.e. } \\
\text { taxes or salaries accumulated against current profits but not yet due to be paid) }\end{array}$ \\
\hline $\begin{array}{r}\text { Non-Current } \\
\text { Liabilities }\end{array}$ & $\begin{array}{l}\text { Loans with obligations due more than one year fr } \\
\text { mortgage), deferred taxes, bonds payable }\end{array}$ \\
\hline \multicolumn{2}{|c|}{$\begin{array}{l}\text { Shareholders' Equity or Net Worth or Share Capital: The difference between total assets and total liabilities, } \\
\text { which encompasses minority interest in subsidiaries, treasury stock, preferred stock, common stock and dividends } \\
\text { paid, and retained earnings. }\end{array}$} \\
\hline
\end{tabular}

\subsubsection{Income Statement}

An income statement indicates how transactions (revenues and expenses, Table 2.2) are transformed into net income or loss, over a period of time, measured either in months or a year. The balance sheet and income statement are linked by Equation 2.1. Companies are also required to disclose their earnings per share which reveals how much money shareholders would receive for each share of stock they own if a firm distributed all of its net income for the period (Equation 2.2). 
Retained Earnings $_{\text {year } t}=$ Retained Earnings $_{\text {year } t-1}-$ Dividends Paid $_{\text {year } t}+$ Net Income $_{\text {year }} \mathrm{t}$

$$
\text { Earnings Per Share }=\frac{\text { Net Income }- \text { Preferred Stock Dividends }}{\text { Weighted Average Common Stock Shares Outstanding }}
$$

Table 2.2: Common Entries in an Income Statement (Gill, 1994)

\begin{tabular}{|c|c|}
\hline \multicolumn{2}{|l|}{ Operating Revenues } \\
\hline Revenues & $\begin{array}{l}\text { Money made from goods/services sold. The total dollar volume of all sales } \\
\text { minus returns, allowances, discounts and rebates. }\end{array}$ \\
\hline \multicolumn{2}{|l|}{ Operating Expenses } \\
\hline Cost of Goods Sold & $\begin{array}{l}\text { Money spent to have goods/services ready which includes raw materials, direct } \\
\text { labour, delivery and overhead (spread over cost of units). }\end{array}$ \\
\hline $\begin{array}{r}\text { Selling, General \& } \\
\text { Administrative Expenses }\end{array}$ & $\begin{array}{l}\text { Non-production costs such as salaries, legal and professional fees, utilities, } \\
\text { insurance, rents, commissions and travel expenses, advertising, etc. }\end{array}$ \\
\hline Depreciation and Amortization & Decrease in value of assets purchased over time, reflecting "wear and tear". \\
\hline Other Operating Expenses & Expenses or losses related to primary business operations (e.g. R\&D). \\
\hline \multicolumn{2}{|c|}{ Operating Income $=$ Operating Revenue - Operating Expenses } \\
\hline Non-Operating Gains & $\begin{array}{l}\text { Income generated from non-primary business activities (e.g. rent, patents) or } \\
\text { unusual or infrequent transactions (e.g. sale of securities or fixed assets) }\end{array}$ \\
\hline Non-Operating Losses & $\begin{array}{l}\text { Expenses unrelated to primary operations (e.g. loss on sales of securities or fixed } \\
\text { assets, strikes). }\end{array}$ \\
\hline \multicolumn{2}{|c|}{ Non-Operating Income $=$ Non-Operating Revenue - Non-Operating Expenses } \\
\hline \multicolumn{2}{|c|}{ Earnings Before Interest and Income Taxes $($ EBIT) $=$ Operating Income + Non-Operating Income } \\
\hline Interest Income & $\begin{array}{l}\text { Money received from external investments either as dividends from another } \\
\text { company's earnings or interest made from lending money to others. }\end{array}$ \\
\hline Interest Expense & Expense of borrowing money. \\
\hline \multicolumn{2}{|c|}{ Net Interest Expense $=$ Interest Expense - Interest Income } \\
\hline \multicolumn{2}{|c|}{ Earnings Before Income Taxes = EBIT - Net Interest Expense } \\
\hline $\begin{array}{l}\text { Earnings (Losses) from } \\
\text { Discontinued Operations }\end{array}$ & $\begin{array}{l}\text { Excludes shifting business location, stopping production temporarily or changes } \\
\text { due to technological improvement. }\end{array}$ \\
\hline Extraordinary Gains (Losses) & $\begin{array}{l}\text { Items that are both abnormal and infrequent (e.g. natural disasters, expropriation, } \\
\text { prohibitions under new regulations). }\end{array}$ \\
\hline Changes in Accounting & $\begin{array}{l}\text { An example: deciding to depreciate an investment property that has not } \\
\text { previously been depreciated. Changes in estimates (i.e. useful life of fixed } \\
\text { assets) do not qualify. }\end{array}$ \\
\hline Income Taxes & Amount of taxes paid according to income. \\
\hline \multicolumn{2}{|c|}{$\begin{array}{l}\text { Net Income }=\text { EBIT }- \text { Net Interest Expense } \pm \text { Earnings or Losses from Discontinued Operations, Extraordinary } \\
\text { Events, Changes in Accounting }- \text { Income Taxes }\end{array}$} \\
\hline
\end{tabular}

\subsubsection{Cash Flow Statement}

The cash flow statement summarizes inflows and outflows of cash and cash equivalents of a company during a specified period of time, and ties into the balance sheet (Figure 2.1).

\begin{tabular}{|c|c|c|c|}
\hline \multirow{3}{*}{$\begin{array}{c}\text { Operating Cash Flows } \rightarrow \\
\text { Investing Cash Flows } \rightarrow\end{array}$} & Current Assets & Current Liabilities & \multirow{3}{*}{$\begin{array}{l}\leftarrow \text { Operating Cash Flows } \\
\} \text { Financing Cash Flows }\end{array}$} \\
\hline & Capital (Fixed) & Non-Current Liabilities & \\
\hline & Assets & Shareholders' Equity & \\
\hline
\end{tabular}

Figure 2.1: Relationship between the Balance Sheet and Cash Flows 
It is a cash-basis ${ }^{1}$ report on three activities: operating, investing and financing (Table 2.3).

Table 2.3: Financial Activities Reported in a Cash Flow Statement

\begin{tabular}{|c|c|}
\hline \multicolumn{2}{|c|}{ Operating Activities are related to the principle line of business. } \\
\hline Cash Inflows (Receipts) & Cash Outflows (Payments) \\
\hline $\begin{array}{l}\text { - } \quad \text { Sales to or collection from customers } \\
\text { - } \quad \text { Receipts of interest and dividends from } \\
\text { investments }\end{array}$ & $\begin{array}{l}\text { - Payment to suppliers and contractors in purchase } \\
\text { - } \quad \text { Payment to employees (salaries and wages) } \\
\text { - } \quad \text { Payment of income tax } \\
\text { - } \quad \text { Payment of interest on liabilities } \\
\text { - } \quad \text { Payment of rent and utilities }\end{array}$ \\
\hline \multicolumn{2}{|c|}{ Investing Activities include capital expenditures and investments unrelated to the normal line of business. } \\
\hline Cash Inflows (Receipts) & Cash Outflows (Payments) \\
\hline $\begin{array}{l}\text { - Sale or disposal of capital assets (PPE) } \\
\text { - } \quad \text { Sale or maturity of investments that are not } \\
\text { cash equivalents } \\
\text { - } \quad \text { Collection of long-term loans receivables }\end{array}$ & $\begin{array}{l}\text { - } \text { Acquisition or purchase of capital assets (PPE) } \\
\text { - Purchase of investments that are not cash } \\
\text { equivalents } \\
\text { - Issuing long-term loans to others }\end{array}$ \\
\hline \multicolumn{2}{|c|}{ Financing Activities reveal the company’s debt or equity financing. } \\
\hline Cash Inflows (Receipts) & Cash Outflows (Payments) \\
\hline $\begin{array}{l}\text { - Borrowing money on notes, mortgages, bonds, } \\
\text { etc. from creditors } \\
\text { - Issuing equity securities (stock, shares) to } \\
\text { owners }\end{array}$ & $\begin{array}{l}\text { - Repay principal amount of debts to creditors } \\
\text { (excluding interest) } \\
\text { - } \quad \text { Repurchase of equity securities from owners } \\
\text { - Payment of dividends to owners }\end{array}$ \\
\hline
\end{tabular}

There are two methods for preparing the cash flow statement - direct and indirect both yielding the same result. While the direct method is more easily understood, the indirect method is almost universally used (Epstein, 2007). The direct method reports major classes of receipts and payments, and then arrives at the net cash effect. For example, operating activities prepared under the direct method may resemble the following:

Cash Receipts from Customers

$=$ Net Sales per Income Statement + Beginning Balance in Accounts Receivable -

Ending Balance in Accounts Receivable

+ Cash Payments for Inventory

$=$ Beginning Inventory - Ending Inventory + Beginning Balance in Accounts

Payable - Ending Balance in Accounts Payable

+ Cash Paid to Employees

$=$ Salaries and Wages per Income statement + Beginning Balance in Salaries and

Wages Payable - Ending Balance in Salaries and Wages Payable

+ Cash Paid for Operating Expenses

$=$ Operating Expenses per Income Statement - Depreciation Expenses \pm Increase or Decrease in Prepaid Expenses \pm Decrease or Increase in Accrued Expenses

+ Taxes paid

$=$ Tax Expense per Income Statement + Beginning Balance in Taxes Payable Ending Balance in Taxes Payable

+ Interest paid

$=$ Interest Expense per Income Statement + Beginning Balance in Interest Payable

- Ending Balance in Interest Payable

= Net Cash Provided By (Used In) Operating Activities

\footnotetext{
${ }^{1}$ In cash-basis accounting, revenues/expenses are recognized when cash is received/paid. In accrual-basis accounting, revenue is recorded when it is earned and realized regardless of when monies are received while expenses match with revenues, regardless of when they are actually paid.
} 
Similar calculations can be made from the balance sheet to determine the cash flows to be reported in the investing and financing activities sections of the cash flow statement.

Under the indirect method, net cash is derived from net income less the change in working capital accounts and with adjustments in non-working capital accounts. Working capital accounts include current assets and current liabilities, while non-working capital accounts are those that are non-cash entries such as depreciation, deferred income taxes, stock option expense and gain/loss on the disposition of property, plant and equipment (PPE). The presentation of operating activities may resemble:

Net Income per Income Statement

- entries to income accounts that do not represent cash flows

+ entries to expense accounts that do not represent cash flows

$=$ Cash Flows Before Movements in Working Capital

\pm the change in working capital

- Increase in current assets would be negative because cash was spent or converted into other current assets, thereby reducing the cash balance.

- Decrease in current assets would be positive because they were converted into cash.

- Increase in current liabilities would be positive since more liabilities imply less cash was spent.

- Decrease in current liabilities would be negative because cash was spent to reduce liabilities

$=$ Net Cash Provided By (Used In) Operating Activities

The cash flows from investing and financing activities would be presented as under the direct method (Epstein, 2007).

\subsubsection{Notes to the Financial Statements}

Notes to the Financial Statements (herein referred to as "Notes") provide supplementary information to the financial statements. They are not presented in any specific format but generally explain the accounting method and assumptions used to prepare the statements, the computation of items in the financial statements, and the valuations for how particular accounts are represented. Furthermore, they offer a comprehensive assessment of a company's financial situation, particularly on outstanding debt, going concern, contingent liabilities or context (lawsuits, mergers and acquisitions), which clarify the financial numbers. Some significant accounting policies in the Notes are:

- Asset Types and Method of Valuation, Depreciation and Amortization: A company must describe how assets are valued and used because the selection of both valuation and depreciation methods may greatly impact net income. For example, a slower depreciation rate translates to less expenses and higher net income. 
- Recognition of Revenues and Expenses: The timing of revenue and expense recognition affects the profit reported. Revenue recognition depends on the certainty of collectability, which relies on the business environment, customer's financial condition, historical collection experience, and the aging of accounts receivable. Expense recognition may depend on whether product development is in-house or outsourced, and/or when advertising expenses are written-off (at the time of print or air versus over a period of time as with catalogue sales).

- Commitments: A company's debt structure is divided into short-term and long-term borrowings, and income tax obligations. Of particular interest are leases. A capital lease provides ownership at no cost or at a low residual value at the end of the lease; it appears as a long-term obligation on the balance sheet since the lessee bears the risk. An operating lease offers no ownership; it is mentioned in the Notes but excluded from the balance sheet since the lessor bears the risk. In some cases, the capitalization of operating leases is necessary to reflect the firm's debt structure more accurately. A lease is a capital lease if it meets any of one four conditions (FASB, 1976):

1. If it extends for at least $75 \%$ of the asset's total expected useful life (i.e. the lessee uses the asset for most of its life).

2. If it transfers ownership to the lessee at the end of the lease term.

3. If it seems likely that the lessor will transfer ownership to the lessee because of a "bargain purchase" option that gives the lessee the right to purchase the asset for a price less than the expected fair market value of the asset when the lessee exercises its option.

4. The present value of the contractual minimum lease payments equals or exceeds $90 \%$ of the fair market value of the asset at the time of signing.

- Pensions: For companies that offer pension benefits to their current and future retirees, this obligation may be greater than that to creditors and shareholders. A company with a defined benefit plan promises retirement benefits to each employee whereas one with a defined contribution plan requires both employer and employee to make contributions until retirement. 
- Stock-Based Compensation: If relevant, a company will describe its employee incentive plans which may involve stock ownership.

- Significant Relationships and Events: Significant relationships and events that may impact financial positions include related-party transactions, legal proceedings, restructuring, discontinued operations and contingencies. A company should discuss the impact of a relevant relationship or event on the current year as well as on expected future performance.

\subsubsection{Management's Discussion and Analysis (MD\&A)}

Valuable information may be found in the Management's Discussion and Analysis (MD\&A) which provides an overview of a corporation noting any special or unusual circumstances that may have affected the financial results over the past year. In the U.S., the MD\&A is monitored by the Securities and Exchange Commission (SEC) to ensure a company presents all critical information about current operations, capital and liquidity. With respect to operations, the MD\&A should focus on: revenue and expense recognition; key profit results and their consistency with previous year's projections; its outlook on future financials based on historical sales, product performance and improvements, research and development, and economic or market conditions. With respect to capital, the MD\&A should cover key points affecting cash flow: any merger, acquisition or expansion that translates to major expenses in the past year or carry over to future years; and current plans for new debt. With respect to liquidity, the MD\&A should discuss the firm's cash position and ability to pay its creditors. And finally, if applicable, the MD\&A should touch upon issues such as restructuring charges, impairments to assets, environmental and product liabilities, and allowance for doubtful accounts.

\subsubsection{Auditor's Report}

For credibility, a company must hire an independent accounting firm to audit their internal controls and financial statements. Auditors raise any red flags about its financial results but do not provide $100 \%$ assurance nor endorse the company's financial position. Their report consists of three paragraphs: 
1. Introduction - outlines the time period that the audit covers and who is responsible for the statement (to alleviate the auditors of their responsibility for possible inaccuracies).

2. Scope - describes how the audit is carried out and any material misstatements (or errors) that significantly impact company's financial position.

3. Opinion - states whether the financials are prepared in conformity with the FASB.

A standard report is an unqualified opinion. A nonstandard report requires auditors to explain their qualified opinion, which typically arises when there is a change in accounting policies, debt-agreement violations, lawsuits, loss of major customers or market share, and going-concern problems.

\subsection{Financial Statement Analysis: Ratios}

The analysis of a company's financial statements to determine corporate health is heavily based on ratios. Financial ratios quantify specific aspects of a business, and enable comparisons of strengths and weaknesses between firms within a given industry, against the average and across different time periods. However, ratios of firms in different industries facing different risks, capital requirements and competition, are not comparable and are onedimensional (Gill, 1994).

The following sections elaborate on common financial statement analyses.

\subsubsection{Industry Analysis}

Industry analysis examines the degree of competition and the degree of capital investment in terms of return on assets (ROA), profit margin (PM) and total assets turnover (TAT) (Table 2.4). A company that requires a high capital investment is likely in an industry that is monopolistic by nature (Type A). Consequently, ROA depends on high profit margin as opposed to high assets turnover. In contrast, a company in an industry without high barriers to entry faces competition. In this case, ROA is driven by efficiency (high asset turnover) as opposed to high profit margin (Type C). It is noted that there is no one better way for a company to operate: industries are simply different and as such, companies can only be compared if they operate under the same conditions; thus, Type A firms are not comparable 
to Type $\mathrm{C}$ firms. Also, in plotting these variables of a company over time, one can observe whether its strategic focus is consistent.

Table 2.4: Industry Analysis (Stickney et al., 2007)

\begin{tabular}{|c|c|c|c|c|c|}
\hline Type & $\begin{array}{c}\text { Competition } \\
\text { Level }\end{array}$ & $\begin{array}{c}\text { Capital } \\
\text { Investment }\end{array}$ & $\begin{array}{c}\text { Profit } \\
\text { Margin }\end{array}$ & $\begin{array}{c}\text { Assets } \\
\text { Turnover }\end{array}$ & $\begin{array}{c}\text { Strategic Focus } \\
\text { for ROA }\end{array}$ \\
\hline A & Low & High & Large & Low & Profit Margin \\
\hline B & Medium & Medium & Medium & Medium & Profit Margin and/or Assets Turnover \\
\hline C & High & Low & Small & High & Assets Turnover \\
\hline
\end{tabular}

\subsubsection{Profitability Analysis}

Mathematically, ROA is a product of profitability and efficiency, and can be broken down into 3 levels.

Level I - Return on Assets (ROA) is calculated by:

$$
\mathrm{ROA}=\frac{\text { Net Income }+ \text { Interest } \times(1-\text { tax rate })+\text { Minority Interest in Net Income }}{\text { Average Total Assets }}
$$

ROA can be expressed as function of profit margin and total assets turnover, introducing a second level:

$$
\text { ROA = Profit Margin for ROA } \times \text { Total Assets Turnover }
$$

Level II - Profitability and Efficiency are defined as:

Profit Margin

$$
=\frac{\text { Net Income }+ \text { Interest } \times(1-\text { tax rate })+\text { Minority Interest in Net Income }}{\text { Sales }}
$$

Total Assets Turnover $=\frac{\text { Sales }}{\text { Average Total Assets }}$

Both these measures can be examined more specifically, presenting a third level of analysis.

Level IIIa - Profit Margin can be related to different items on the income statement, as a percentage of revenues, for example:

Cost of Goods Sold $\%=\frac{\text { Cost of Goods Sold }}{\text { Sales }}$
Selling, General and Administrative Expenses $\%$
\[ =\frac{\text { Selling, General and Administrative Expenses }}{\text { Sales }} \]
Income Tax Expense $\%=\frac{\text { Income Tax Expense }+ \text { Tax Rate } \times \text { Interest Expense }}{\text { Sales }}$ 
Level IIIb - Total Assets Turnover can be studied in terms of accounts receivable, inventory and fixed assets:

$$
\begin{aligned}
& \text { Accounts Receivable Turnover }=\frac{\text { Sales }}{\text { Average Accounts Receivable }} \\
& \text { Inventory Turnover }=\frac{\text { Cost of Goods Sold }}{\text { Average Inventory }} \\
& \text { Fixed Assets Turnover }=\frac{\text { Sales }}{\text { Average Fixed Assets }}
\end{aligned}
$$

In addition to ROA, a company's Return on Common Equity (ROCE, Equation 2.13) reveals information about its capital structure leverage. If ROCE is greater than ROA, then the company is positively leveraged; that is, it manages its debt well. If ROCE is equal to ROA, then it is neutrally leveraged. If ROCE is less than ROA, then it is negatively leveraged - a signal for concern.

$$
\begin{aligned}
& \text { ROCE }=\frac{\text { Net Income }}{\text { Average Shareholders' Equity }} \\
& =\frac{\text { Net Income }+ \text { Interest } \times(1-\text { tax rate })+\text { Minority Interest in Net Income }}{\text { Sales }} \times \frac{\text { Average Total Assets }}{\text { Average Shareholders' Equity }} \\
& \text { Another common measure of profitability is return on sales: } \\
& \text { Return on Sales }=\text { Operating Margin }=\frac{\text { Operating Income }}{\text { Revenue }}
\end{aligned}
$$

\subsubsection{Short-Term Liquidity and Long-Term Solvency}

Liquidity refers to the ability of a firm to quickly and easily convert non-cash assets into cash without incurring a significant loss. Common tests of liquidity focus on the relationship between current assets and current liabilities, measuring the availability of cash to pay debt (Table 2.5). Solvency refers to the ability to meet maturing obligations as they come due. Common tests of solvency measure a company's capacity to repay long-term debt or financial leverage (Table 2.5). 
Table 2.5: Common Liquidity and Solvency Ratios

\begin{tabular}{|c|c|}
\hline \multicolumn{2}{|c|}{ Short-Term Liquidity Ratios } \\
\hline \multirow{2}{*}{ Current Ratio } & Current Assets \\
\hline & $\overline{\text { Current Liabilities }}$ \\
\hline \multirow{2}{*}{ Quick Ratio } & Quick Assets $^{2}$ \\
\hline & $\overline{\text { Current Liabilities }}$ \\
\hline \multirow{2}{*}{ Operating Cash Flow to Current Liabilities Ratio } & Cash Flow from Operations \\
\hline & $\overline{\text { Average Current Liabilities }}$ \\
\hline \multirow{2}{*}{ Days Receivable Outstanding (Average Collection Period) } & 365 \\
\hline & $\overline{\text { Accounts Receivable Turnover }}$ \\
\hline \multirow{2}{*}{ Days Inventory Outstanding (Average Inventory Period) } & 365 \\
\hline & $\overline{\text { Inventory Turnover }}$ \\
\hline \multirow{2}{*}{ Accounts Payable Turnover } & Purchases \\
\hline & $\overline{\text { Average Accounts Payable }}$ \\
\hline \multirow{2}{*}{ Days Payable Outstanding (Average Payment Period) } & 365 \\
\hline & $\overline{\text { Accounts Payable Turnover }}$ \\
\hline \multirow{2}{*}{ Revenues to Cash Ratio } & Revenues \\
\hline & $\overline{\text { Average Cash Balance }}$ \\
\hline \multirow{2}{*}{ Days Revenues in Cash } & 365 \\
\hline & $\overline{\text { Revenues to Cash Ratio }}$ \\
\hline \multicolumn{2}{|c|}{ Long-Term Solvency Ratios } \\
\hline \multirow{2}{*}{ Times Interest Earned (Interest Coverage) Ratio } & Earnings Before Interest and Tax \\
\hline & Interest Expense \\
\hline \multirow{2}{*}{ Cash Coverage Ratio } & Operating Cash Flow Before Interest Tax \\
\hline & Interest Paid \\
\hline \multirow{2}{*}{ Liabilities to Assets Ratio } & Total Liabilities \\
\hline & Total Assets \\
\hline \multirow{2}{*}{ Liabilities to Shareholders' Equity (Debt to Equity) Ratio } & Total Liabilities \\
\hline & $\overline{\text { Total Shareholders' Equity }}$ \\
\hline \multirow{2}{*}{ Long-Term Debt to Long-Term Capital Ratio } & Long-Term Debt \\
\hline & $\overline{\text { Long-Term Debt+ Total Shareholders' Equity }}$ \\
\hline \multirow{2}{*}{ Long-Term Debt to Shareholders' Equity Ratio } & Long-Term Debt \\
\hline & $\overline{\text { Total Shareholders' Equity }}$ \\
\hline
\end{tabular}

\subsection{Bankruptcy}

Bankruptcy is a legally declared financial inability of an organization to meet its debt obligations. Causes of bankruptcy include: financial mismanagement, poor location, competition, difficulties with cash flow, loss of capitalization, high debt, lack of planning, tax burdens and regulations, loss of a key person, lack of technology, poor record keeping, personal issues, and natural disaster or accident leading to high insurance (Bradley et al., 2004).

\footnotetext{
${ }^{2}$ Quick Assets $=$ cash + accounts receivable + notes receivable + short term investments + marketable securities
} 
Bankruptcy is often incorrectly used as a synonym for insolvency: insolvency refers to a financial state whereas bankruptcy is a matter of law. Insolvency occurs when either:

- a company's liabilities exceed their assets (known as balance-sheet insolvency); or

- a company cannot meet its debt obligations as they become due (known as cash flow insolvency).

On the other hand, bankruptcy is a successful legal procedure that results from:

- an application to the relevant court by a company in order to have itself declared bankrupt; or

- an application to the relevant court by a creditor of a company in order to have the company declared bankrupt.

A state of insolvency can lead to bankruptcy but the condition may also be temporary and fixable without legal protection from creditors. In other words, insolvency does not necessarily lead to bankruptcy, but all bankrupt firms are considered insolvent.

Researchers have worked diligently to identify keys to business survival by applying various factors - from financial ratios derived from financial statements, to geographic location, type of industry and competition, size and age - to different mathematical techniques. To date, there are over 200 journal articles reporting on bankruptcy prediction using common financial ratios alone. In 2006, Ravi Kumar et al. conducted an extensive review of nearly 120 papers, grouping them by methodology: 1. statistical techniques, 2 . neural networks, 3. case-based reasoning, 4. decision trees, 5. operational research, 6. evolutionary approaches, 7 . rough set based techniques, 8 . other techniques subsuming fuzzy logic, support vector machine and isotonic separation and 9. soft computing subsuming seamless hybridization of all the above-mentioned techniques. A brief review will be provided on two categories, relevant to this study:

1. Statistical techniques (Sections 2.3 .1 and 2.3.2): traditionally used and serve as benchmarks for this thesis; and,

2. Operations research (Section 4.9): the foundation of the approach taken in this work.

\subsubsection{Altman's Bankruptcy Model}

In 1968, Edward Altman developed the Z-Score bankruptcy predictor to gauge a firm's financial health (Table 2.6). Applying common financial ratios to multiple discriminant 
analysis (MDA), the original Z-Score forecasts the probability of a manufacturing company entering bankruptcy within a two-year period. There are 3 zones of discrimination: the safe zone $(Z \geq 3)$, grey zone $(1.8<Z<3)$ and distress zone $(Z \leq 1.8)$ (Altman, 1968). From a dataset of 33 bankrupt and 33 non-bankrupt firms, the reliability of Altman's model is 72$80 \%$ with Type I and II errors ${ }^{3}$ presented in Table 2.7 ). Table 2.6 also provides the $Z$-Scores for private and non-manufacturing firms which differ from the original by coefficients.

Table 2.6: Z-Scores by Firm Type and Zones of Discrimination (Altman, 1968; Hanson, 2003)

\section{Original Z-Score for Public Manufacturing Firms}

$$
\begin{aligned}
Z & =1.2 \times \frac{\text { Working Capital }}{\text { Total Assets }}+1.4 \times \frac{\text { Retained Earnings }}{\text { Total Assets }}+3.3 \times \frac{\text { Earnings Before Interest and Taxes }}{\text { Total Assets }} \\
& +0.6 \times \frac{\text { Market Value of Equity }}{\text { Book Value of Total Debt }}+0.99 \times \frac{\text { Sales }}{\text { Total Assets }}
\end{aligned}
$$

Zones of Discrimination: $Z \geq 3$ : Safe Zone; $1.8<Z<3$ : Grey Zone; $Z \leq 1.8$ : Distress Zone

\section{Z'-Score for Private Firms}

$$
\begin{aligned}
Z^{\prime} & =0.717 \times \frac{\text { Working Capital }}{\text { Total Assets }}+0.847 \times \frac{\text { Retained Earnings }}{\text { Total Assets }}+3.107 \times \frac{\text { Earnings Before Interest and Taxes }}{\text { Total Assets }} \\
& +0.420 \times \frac{\text { Market Value of Equity }}{\text { Market Value of Total Liabilities }}+0.998 \times \frac{\text { Sales }}{\text { Total Assets }}
\end{aligned}
$$

Zones of Discrimination: $Z^{\prime} \geq 2.9$ : Safe Zone; $1.23<Z^{\prime}<2$. 9: Grey Zone; $Z^{\prime} \leq 1.23$ : Distress Zone

\section{Z'-Score for Public Non-Manufacturing Firms}

$$
\begin{aligned}
Z^{\prime} & =6.56 \times \frac{\text { Working Capital }}{\text { Total Assets }}+3.26 \times \frac{\text { Retained Earnings }}{\text { Total Assets }}+6.72 \times \frac{\text { Earnings Before Interest and Taxes }}{\text { Total Assets }} \\
& +1.05 \times \frac{\text { Market Value of Equity }}{\text { Market Value of Total Liabilities }}
\end{aligned}
$$

Zones of Discrimination: $Z^{\prime} \geq 2.6$ : Safe Zone; $1.1<Z^{\prime}<2$. 6: Grey Zone; $Z^{\prime} \leq 1.1$ : Distress Zone

Table 2.7: Error Classification for Altman's Original Model

\begin{tabular}{|l|c|c|}
\cline { 2 - 3 } \multicolumn{1}{c|}{} & Year 1 & Year 2 \\
\hline Type I & $6 \%$ & $28 \%$ \\
\hline Type II & $3 \%$ & $6 \%$ \\
\hline Total & $5 \%$ & $17 \%$ \\
\hline
\end{tabular}

The strengths of MDA are that it incorporates multiple financial ratios simultaneously; it provides coefficients for the combined independent variables; and it is simple to apply once the formula is derived. However, MDA can only select from ratios provided to it which may not necessarily have the strongest explanatory power. Also, the value of the "cut-off" score(s) that best distinguishes bankrupt from non-bankrupt firms is

\footnotetext{
${ }^{3}$ A Type I Error misclassifies bankrupt firms whereas a Type II Error misclassifies non-bankrupt firms. Hence, a Type I Error is more costly than a Type II Error.
} 
subjective. Other limitations include the assumption of normal distribution of financial ratios and the requirement that the covariance matrix of the explanatory variables be the same for bankrupt and non-bankrupt firms.

\subsubsection{Ohlson's Bankruptcy Model}

In 1980, James Ohlson used maximum likelihood estimation of the so-called conditional logit model to predict bankruptcy. The population boundaries of his dataset were restricted by:

1. the period from 1970 to 1976 ;

2. the equity of each company having had to be traded on some stock exchange; and,

3. the classification of each company being industrial (no small or private corporations, utilities, transport and financial services).

From a sample of 105 bankrupt and 2068 non-bankrupt firms, Ohlson derived the probability of bankruptcy to be $1 /\left(1+\mathrm{e}^{-\mathrm{y}}\right)$, where

$$
\begin{aligned}
& \mathrm{y}=-1.32-0.407 \times \text { SIZE }+6.03 \times \text { TLTA }-1.43 \times \text { WCTA }+0.0757 \times \text { CLCA }-2.37 \times \\
& \text { NITA }-1.83 \times \text { FUTL }+0.285 \times \text { INTWO }-1.72 \text { ONNEG }-0.521 \times \text { CHIN } \\
& \text { and SIZE }=\ln \left(\frac{\text { Absolute Total Assets }}{\text { GNP Implicit Price Deflator }}\right) \\
& \text { TLTA }=\frac{\text { Total Liabilities }}{\text { Total Assets }} \\
& \text { WCTA }=\frac{\text { Net Working Capital }}{\text { Total Assets }} \\
& \text { CLCA }=\frac{\text { Current Liabilities }}{\text { Current Assets }} \\
& \text { NITA }=\frac{\text { Net Income }}{\text { Total Assets }} \\
& \text { FUTL }=\frac{\text { Operating Working Capital }}{\text { Total Liabilities }}
\end{aligned}
$$

INTWO = one if net income was negative for the last two years; zero otherwise

OENEG = one if total liabilities exceeds total assets; zero otherwise

$$
\text { CHIN }=\frac{\text { Net Income }_{t}-\text { Net Income }_{\mathrm{t}-1}}{\mid \text { Net Income }_{\mathrm{t}}|+| \text { Net Income }_{\mathrm{t}-1} \mid}
$$

A probability greater than $4 \%$ is concerning. Compared to Altman, Ohlson has greater accuracy (Table 2.8). However, there is an important difference between the models 
in that the magnitude of total assets relative to other variables is significant to bankruptcy risk: Altman predicted that bankruptcy is imminent when the firms' use of assets is inefficient whereas Ohlson predicted that bankruptcy is unlikely due to the underlying assumption that their absolute assets (large size) could be sold.

Table 2.8: Error Classification for Ohlson's Model

\begin{tabular}{|l|c|c|c|}
\cline { 2 - 4 } \multicolumn{1}{c|}{} & Year 1 & Year 2 & Year 3 \\
\hline Type I & $12 \%$ & $20 \%$ & $24 \%$ \\
\hline Type II & $7 \%$ & $18 \%$ & $20 \%$ \\
\hline Total & $10 \%$ & $19 \%$ & $22 \%$ \\
\hline
\end{tabular}

These studies and those by pioneers Beaver (1966), Wilcox (1971), Deakin (1972), Edmister (1972), Blum (1974), Libby (1975) and Moyer (1977) who used various statistical methods (e.g. linear discriminant analysis, MDA, quadratic discriminant analysis, logistic regression, factor analysis, maximum likelihood estimation) paved the way for others to consider mathematical alternatives to bankruptcy prediction (refer to Ravi Kumar et al. (2006)). These works also share some key methodological issues in bankruptcy prediction research.

1. Sample sizes of bankrupt and non-bankrupt firms: The proportion of bankrupt firms in the economy is substantially smaller than that of non-bankrupt firms. It is inadvisable to make the groups equal (as Altman did) because this results in overfitting models towards the characteristic of bankrupt firms. Thus, the challenge is to find a proportion of non-bankrupt firms that more closely reflects the populations of firms but does not inherently bias the model.

2. Difference in company size and industry characteristics: Companies in different industries have different structures and environments. Also, small firms may experience greater difficulty obtaining funds than larger firms. Thus, models should be developed for a specific industry and normalized for size.

3. Stability in bankruptcy prediction models over time. Bankruptcy laws and their judicial interpretations, and frequency of filings due to economic change, evolve over time. Hence, models should be periodically updated to reflect new financing vehicles that emerge that help finance firms that were not originally available.

4. External influences. Companies are subject to market and economic risk factors. 


\subsection{Fraud}

Financial statement fraud is usually committed to meet financial performance goals, analysts' forecasts, and stakeholders' expectations, or to mask volatility and financial distress (Ramamoorti, 2007). In a study of 204 organizations, Albrecht (2008) found that some common characteristics include:

- the CEO being the primary perpetrator (in $72 \%$ of fraud cases);

- the last audit opinion prior to fraud containing going concerns, litigation and uncertainties (24\%);

- the average financial statement fraud lasting 23.7 months;

- the mean cumulative financial statement misstatement being $\$ 25 \mathrm{M}$;

- $78 \%$ of fraudulent firms being listed on NASDAQ or OTC markets, 15\% on NYSE, and $7 \%$ on American Stock Exchange;

- the industries with the most frauds being hardware/software (12\%), financial services providers $(11 \%)$, health care providers $(9 \%)$ and retailers/wholesalers $(7 \%)$;

- family relationships between directors and officers being fairly common (40\%); and,

- many experiencing net losses or being close to break-even positions in periods prior to fraud.

Clearly, there is value in studying the characteristics of fraudulent reporting as a precursor to bankruptcy. In general, there are two fraud detection methods based on: 1. financial measures (quantitative data extracted from financial statements) and 2. non-financial measures (either qualitative or quantitative data derived from other sections of the annual report).

\subsubsection{Investigating Fraud with Financial Measures}

Earnings manipulation is defined as an instance in which a company's management intentionally represents its financial performance more favourably than it really is. In 1999, Beneish developed a model to distinguish manipulated from non-manipulated reporting by using financial statement data to construct variables that would capture the effects of manipulation and preconditions that might prompt companies to engage in such activity. His sample consisted of 74 firms: $45 \%$ were in the manufacturing or services industries while 
only 4 companies were in software, 3 companies were in computers, and 3 companies were in audiovisual retail stores.

His probability of manipulation was given by the value of the probability density function or the cumulative distribution function for the normal distribution with a given mean and standard deviation at $\mathrm{Y}$, where

$$
\begin{aligned}
& \mathrm{Y}=-4.840+0.92 \times \mathrm{DSRI}+0.528 \times \mathrm{GMI}+0.404 \times \mathrm{AQI}+0.892 \times \mathrm{SGI}+0.115 \times \\
& \text { DEPI }-0.172 \times \text { SGAI }-0.327 \times \text { LVGI }+4.679 \times \text { TATA } \\
& \text { and } \quad \text { DSRI }=\frac{\text { Accounts Receivables }_{t} / \text { Sales }_{t}}{\text { Accounts Receivables }_{t-1} / \text { Sales }_{t-1}} \\
& \mathrm{GMI}=\frac{\text { Gross Margin }_{\mathrm{t}-1}}{{\text { Gross } \text { Margin }_{\mathrm{t}}}}
\end{aligned}
$$

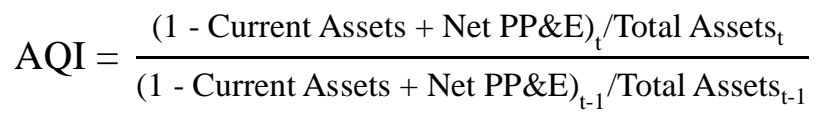

$$
\begin{aligned}
& \mathrm{SGI}=\frac{\text { Sales }_{\mathrm{t}}}{\text { Sales }_{\mathrm{t}-1}}
\end{aligned}
$$

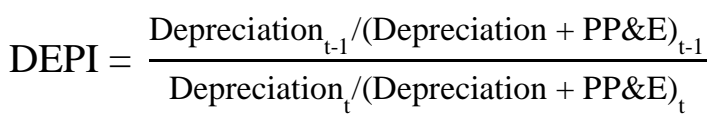

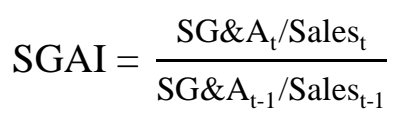

$$
\begin{aligned}
& \text { LVGI }=\frac{(\text { Long Term Debt }+ \text { Current Liabilities })_{t} / \text { Total Assets }_{t}}{(\text { Long Term Debt }+ \text { Current Liabilities })_{t-1} / \text { Total Assets }_{t-1}} \\
& \text { TATA }=\frac{\text { Net Income from Continuing Operations } s_{t}-\text { Cash Flow from Operations } s_{t}}{\text { Total Assets }_{t}}
\end{aligned}
$$

Probabilities greater than 3\% raised suspicion for earnings manipulation - at which point, any of the above ratios with a value greater than 1 should be analyzed.

Beneish's model was modified by others like Weidman (1999) as follows:

Manipulation Index $=-2.224+0.221 \times$ DSRI $+0.102 \times$ GMI $+0.007 \times$ AQI + $0.062 \times$ DEPI $+0.198 \times$ SGAI $-0.684 \times$ Abnormal Index $+0.001 \times$ Time Listed + $0.587 \times$ LVGI $+0.421 \times$ Positive Accruals Dummy $-0.431 \times$ Declining Cash Sales Dummy

where 
Abnormal Index is computed by subtracting the difference in average holding period (buy-and-hold) returns of issuing and non-issuing size-matched valueweighted firms from the company's buy-and-hold return;

Time Listed is the number of months between the fiscal year end and the date that the company was first listed on either the NYSE or NASDAQ;

Positive Accruals Dummy is equal to 1 if total accurals are positive in the current and prior year, and 0 otherwise; and,

Declining Cash Sales Dummy is equal to 1 if cash sales in the current year are lower than in the previous year, and 0 otherwise (n.b. Cash Sales ${ }_{t}=$ Sales $_{t}-$ $\Delta$ Receivables).

Here, a probability greater than $11.72 \%$ indicated a "very significant danger of manipulation"; between $5.99 \%$ and $11.72 \%$ indicated a "serious risk of manipulation"; between $2.94 \%$ and $5.99 \%$ indicated a "grey zone"; and less than $2.94 \%$ indicated no evidence of manipulation.

In another example, Kaminski et al. (2004) examined 21 financial ratios on 79 matched pairs of firms, spanning a time period of three years prior to and post the fraud year. Five ratios were found to be significant prior to the fraud year ( $\frac{\text { Accounts Receivables }}{\text { Total Assets }}$, $\frac{\text { Cost of Goods Sold }}{\text { Sales }}, \frac{\text { Fixed Assets }}{\text { Total Assets }}, \frac{\text { Interest Expense }}{\text { Total Liabilities }}$ and $\left.\frac{\text { Sales }}{\text { Average Total Assets }}\right)$ and when coupled with quadratic discriminant analysis, 24-59\% of fraudulent firms were correctly classified while the accuracy of classifying non-fraudulent firms was $98 \%$.

In addition to quadratic discriminant analysis, other data mining techniques have been applied. For instance, Kirkos et al. (2007) studied 76 Greek manufacturing firms (half fraud, half non-fraud) and tested 10 financial ratios ${ }^{4}$ as variables in decision trees, Bayesian belief networks and neural networks. The results were consistent: for the decision tree, Altman's Z-Score was the first node, followed by NPTA, EBIT, COSAL and DEBTQ; for the Bayesian belief, the significant ratios were Z-Score, NPTA, DEBTEQ, SALTA and WCTA; and for the neural network, classification was claimed to be $100 \%$ correct when all ratios were considered.

\footnotetext{
${ }^{4}$ DEBTEQ $=$ debt to equity ratio; SALTA = sales to total assets ratio; $\mathrm{COSAL}=$ sales minus gross margin; EBIT = earnings before interest and taxes; WCAP $=$ working capital; $Z$-Score $=$ Altman's Z-Score; TDTA = total debt to total assets ratio; NPTA $=$ net profit to total assets ratio; WCTA $=$ working capital to total assets ratio; GPTA $=$ gross profit to total assets ratio
} 


\subsubsection{Investigating Fraud with Non-Financial Data}

Detecting fraud with non-financial data is common practice among professional auditors and accountants. The American Institute of Certified Public Accountants (AICPA) has audit and attest standards for conducting, planning and reporting such as the Statements on Auditing Standards (SASs). In 1988, the Auditing Standards Board (ASB) of AICPA issued SAS No. 52 The Auditor's Responsibility to Detect and Report Errors and Irregularities which was later replaced by SAS No. 82 Consideration of Fraud in a Financial Statement Audit. SAS No. 82 identifies 25 fraud risk factors in 3 categories: 1. management characteristics and influence over control environment; 2. industry conditions; and, 3. operating and financial stability characteristics (Table 2.9). It has served as guidelines for researchers aiming to determine the probability of fraudulent reporting.

Table 2.9: SAS No. 82 (Apostolou, 2001)

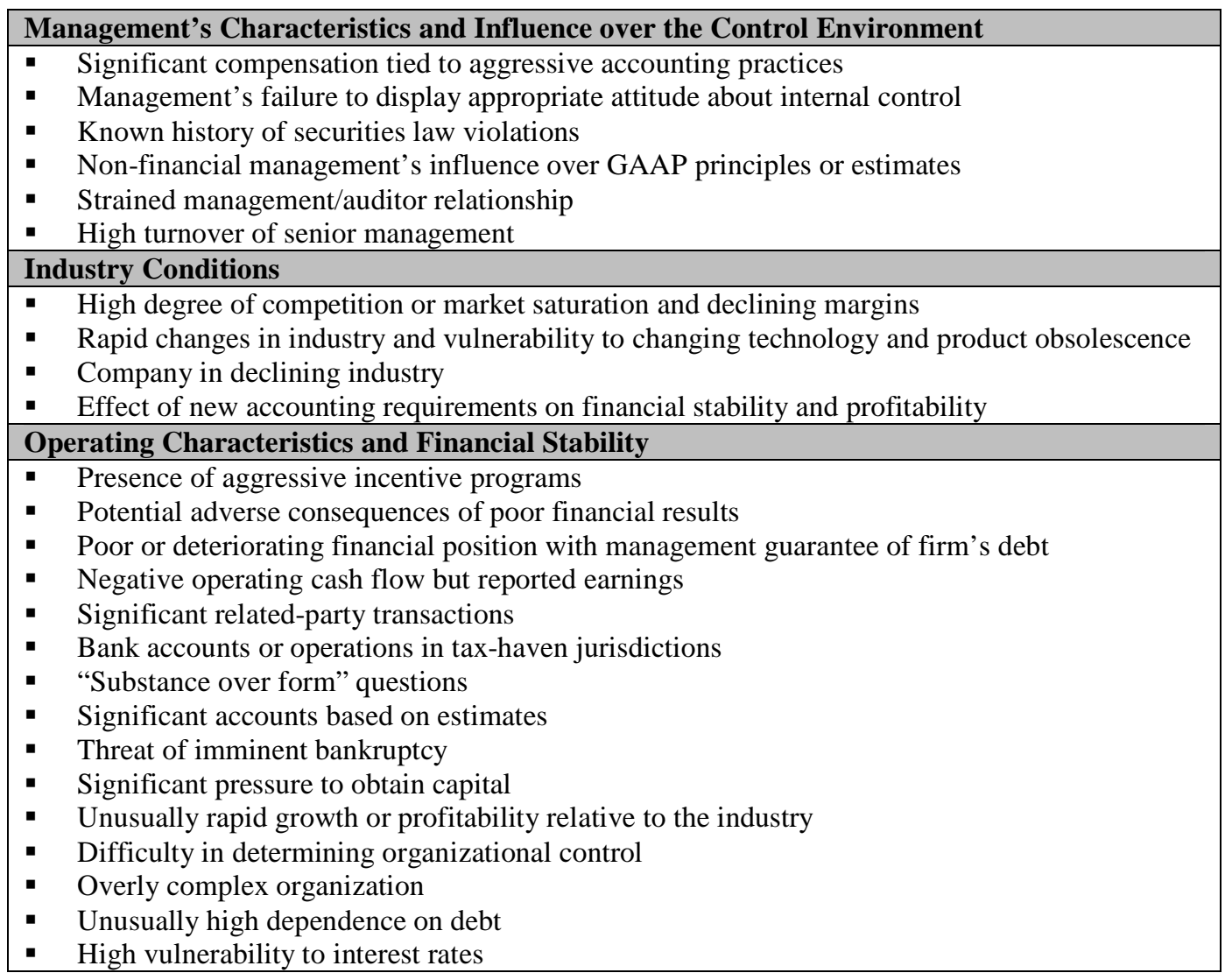

In 2001, Apostolou et al. evaluated the relative importance of the SAS No. 82 risk factors using Analytic Hierarchy Process: experts were first asked to indicate which category was most important, then to score each risk factor within each category on a nine-point scale. 
Management's characteristics were rated most important (58.5\%), followed by operating and financial stability $(27.0 \%)$ and industry conditions (14.5\%). The two most important individual factors were "significant compensation tied to aggressive accounting practices" (18.0\%) and "management's failure to display an appropriate attitude about internal controls" (16.5\%). While Apostolou's methodology was quite subjective, it provided insight into what the average expert valued.

In a similar work, Bell et al. (2000) studied 77 fraud and 305 non-fraud engagements based on 46 risk factors, 21 of which were derived from SAS No. 53. Auditors were asked ("yes" or "no") whether they believed a given risk factor was a reliable fraudulent reporting predictor. Although many of the 25 non-SAS No. 53 risk factors lacked any relationship to fraud (likely because of their infrequency), several SAS No. 53 factors did significantly correlate with fraud:

- management lied to the auditor or was overly evasive when responding to audit inquiries (0.48)

- weak internal control environment (0.46)

- management's attitude unduly aggressive (0.42)

- management places undue emphasis on meeting earnings projections $(0.41)$

- significant difficult-to-audit transactions or balances are present (0.40)

Like Apostolou et al., Bell et al. found that factors related to management's characteristics and influence over control environment were stronger indicators for fraud compared to those related to industry conditions and operating characteristics and financial stability. This was consistent with most studies like Smith et al. (2005) who also concluded that "management's failure to display an appropriate attitude about internal control" was most important.

\subsubsection{Critical Red Flags}

Unlike the models in Section 2.4.1, which provided clear tangible measures of manipulation, how does one determine if "management has failed to display an appropriate attitude about internal control" or assess other SAS No. 82 risk factors that were vaguely described? Most studies discussed in Section 2.4.2 were ambiguous with respect to data collection and specification. Here, some strategies in financial reporting that management employ to 
mislead stakeholders are listed, and techniques that bring these manipulations to light are offered (Albrecht, 2008; Elitzur, 2009; Seow, 2009).

- Manipulation of Earnings: There are three common approaches:

- Income-increasing - to appear more profitable for greater bonuses to be paid to executives;

○ Income-decreasing - to thwart industry-specific or antitrust actions against the firm; and,

- Income smoothing - to reflect economic results as management wishes them to look, through redistribution of income statement credits and charges among periods.

- Improper or Premature Revenue Recognition: This strategy maximizes revenues to influence market valuation even if it does not affect net income. A firm can recognize revenues by either the percent completion method (PCM) which spreads recognition over the entire contract period, or the completed contract method (CCM).

- Quality of Income: High-quality earnings have a high correlation with cash flows, which are more difficult to manipulate than reported income. Hence, comparing cash flows with net income using Equation 2.15 or a plot of these variables over time should reveal the level of accounting accruals used.

$$
\text { Quality of Income }=\frac{\text { Operating Cash Flow }}{\text { Net Income }}
$$

A ratio of over 1 (i.e. operating cash flow greater than net income) suggests high quality of income whereas a ratio of less than 1 is problematic. Moreover, if operating cash flow is negative and net income is positive, the ratio serves as a red flag, indicating a poor earnings quality.

It may also be worthwhile to run a regression (Equation 2.16) between the two variables to observe the lag in converting net income (NI) into cash (CFO).

$$
\mathrm{CFO}_{\mathrm{t}+1}=\alpha+\beta \mathrm{NI}_{\mathrm{t}}
$$

From the regression, a positive $\beta$, a high value for the adjusted $\mathrm{R}^{2}$ (reflecting variability of net income) and a p-value tending to zero indicate high quality of numbers. Furthermore, the Durbin-Watson statistic reveals whether the regression 
must be adjusted to account for seasonality. If such is the case, dummy variables are added to Equation 2.16.

- Off-Balance Sheet Liabilities: A root cause of many manipulation cases, offbalance sheet liabilities improve the reported capital structure of the company by not reporting some debt on the balance sheet. Liabilities may be disguised with the noncapitalization of operating leases or the creation of special purpose entities (SPEs). Notes pertaining to long-term debt and pensions should also be analyzed for whether cash is available to pay these obligations.

- Valuation of Assets and Liabilities: Because of its potential for accounting creativity, the valuation of assets and liabilities must be justified. Overvaluing assets may suggest that a firm believes to own more than it does, or the recording of fictitious assets or the improper asset depreciation or amortization. Undervaluing liabilities may indicate that a company owes less than it does. It may create excess reserves by initially over-accruing a liability in one accounting period, and then reducing the excess reserves to operating income in later accounting period.

- Changes in Accounting Policies: It is important to understand the motivation behind any changes and the impact on the financial numbers, especially when comparing year-to-year results.

- Change of Auditors: This change may signal disagreements on the accounting rules between the management of the company and its auditors.

- Auditor's Opinion and Reputation: A nonstandard (qualified) opinion is a disclaimer on accounting irregularities and encourages additional research through the Notes and MD\&A.

- Management Turnover: When executive managers (especially key accounting and financial personnel) leave the firm, it may be the result of an accounting problem in the company.

- Financial Distress: If liquidity, solvency and/or bankruptcy analysis reveal difficulties for a firm's ability to pay debt, management may be tempted to manipulate their financial statements. 
- Growth of Receivables vs. Sales Growth: When a company's receivables percentage growth exceeds sales growth, this may suggest sales are increased through fictitious receivables, or that the firm prematurely recognizes revenues.

- Executive Compensation: Studying the firm's executive compensation plans may reveal any incentive to manipulate earnings (i.e. if bonuses are a percentage of profit).

- Trading by Insiders: Stock transactions by insiders could indicate a future trend in earnings. For example, if many insiders sell their shares, it may be in anticipation of earning problems.

- Related-Party or Enormous Transactions with a Small Number of Customers: Transactions between the firm and its related parties (i.e. officers, directors, employees, affiliates, subsidiaries and SPEs) are often at the heart of accounting irregularities. Also, a drastic increase in sales due to a small number of transactions with customers may be an issue in revenue recognition.

- Labelling: Companies may label unusual accounts in their financial statements differently to manipulate their earnings.

- Opportunistic Use of Exogenous Events: Some companies may emphasize the effect of events that are anticipated beyond their control (i.e. the effect of fuel prices or recession) to justify their numbers for an uncertain period of time.

- Other Significant Events: A firm that has undergone "restructuring" or report "discontinued operations" may have continuing expenses for a number of years. Also, the impact of lawsuits potentially resulting in significant settlements should be considered. This may not necessarily be of great concern given that many corporations face lawsuits annually.

\subsubsection{Summary of Fraud Literature}

To date, past works have used either financial data or qualitative data to detect fraudulent reporting. However, considering financial data only is risky as management can make fictitious entries to make its firm look favourable. Meanwhile, auditors who only use fraud "checklists" tend to overweight cues indicative of management's characteristics when they are not fully reliable because important factors vary by industry (Wilks et al., 2004). 
Therefore, combining both financial and qualitative data would be a valuable contribution to this field.

\subsection{Market Beta Equity Risk and Other Factors}

In addition to short-term liquidity, long-term solvency, bankruptcy and manipulation risks, companies face risks like recessions, inflation, changes in interest rates, rising unemployment and similar market and economic factors that affect all firms but to varying degrees, depending on the nature of their operations (Luenberger, 1998). From the Capital Asset Pricing Model (Figure 2.2), the reward-to-risk ratio for any security, portfolio or firm in relation to that of the overall market is given by:

$$
E\left(R_{i}\right)=R_{f}+\beta_{i}\left(E\left(R_{m}\right)-R_{f}\right)
$$

where $E\left(R_{i}\right)$ is the expected return of the firm, $R_{f}$ is the risk-free rate of interest and $E\left(R_{m}\right)$ is the expected return of the market. $E\left(R_{m}\right)-R_{f}$ is often referred to as the market premium. $\beta_{i}$ measures the sensitivity or covariability of a firm's returns to the returns of diversified

portfolio of all the shares traded on the market; that is, $\beta_{\mathrm{i}}=\frac{\operatorname{Cov}\left(\mathrm{R}_{\mathrm{i}}, \mathrm{R}_{\mathrm{m}}\right)}{\operatorname{Var}\left(\mathrm{R}_{\mathrm{m}}\right)}$. It represents systematic or nondiversifiable risk of the firm which depends on its degree of operating leverage, degree of financial leverage, and variability of sales. Since $\beta_{\mathrm{i}}$ of the market portfolio is equal to 1 (Figure 2.3 ), a security with a $\beta_{\mathrm{i}}$ less than 1 is less volatile than the market, while a $\beta_{\mathrm{i}}$ greater than 1 is more volatile. For example, a stock with $\beta_{i}=1.2$ is theoretically $20 \%$ more volatile than the market. In addition, a positive $\beta$ implies that the firm's returns follow the market's returns whereas a negative $\beta_{\mathrm{i}}$ implies that the firm's returns move opposite to that of the market. Finally, when $\beta_{i}=0$, the firm's returns change independent of the market's returns (Table 2.10).

CAPM makes several assumptions:

- Trades may occur without transaction or taxation costs.

- There is perfect competition (i.e. participants cannot influence prices).

- Investors are rational, risk-averse and make decisions based solely on the expected return and variance of portfolio returns.

- All information is available to all investors at the same time.

- Unlimited lending and borrowing is permitted at the risk-free interest rate. 
- All assets, including human capital, are marketable and infinitely divisible.

- Firm returns are normally distributed random variables and investors employ a quadratic utility.

- The variance of returns is an adequate measurement for risk.

- Given a certain expected return, investors will prefer lower risk to higher risk, and conversely, given a certain level of risk, they will prefer higher returns to lower ones.

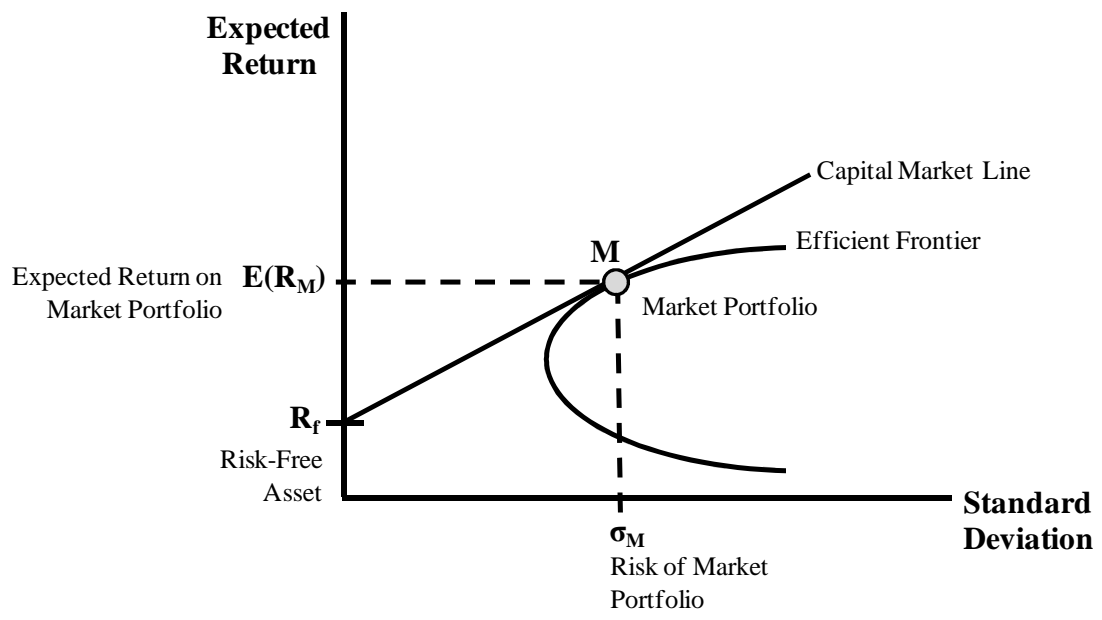

Figure 2.2: Capital Asset Pricing Model (CAPM)

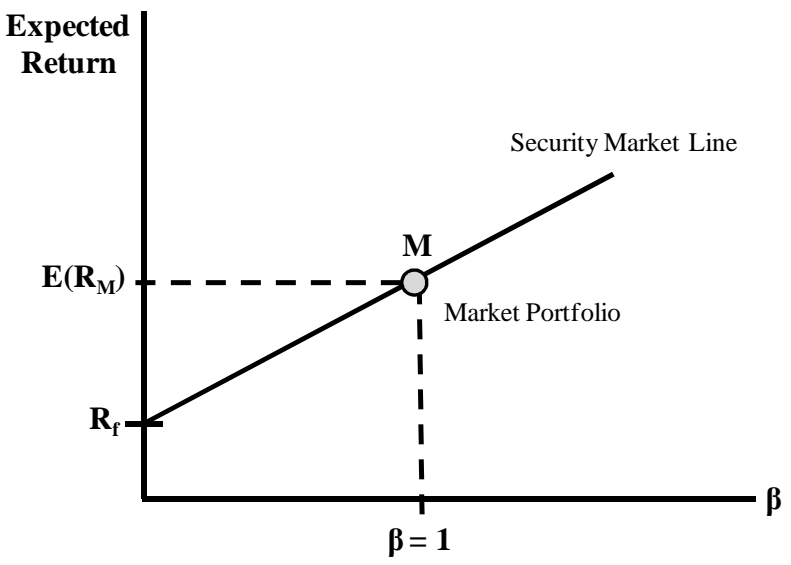

Figure 2.3: CAPM Security Market Line

Table 2.10: Definition of $\beta$ of Security or Company

\begin{tabular}{|c|c|c|c|c|}
\hline$\beta<0$ & $\beta=0$ & $0<\beta<1$ & $\beta=1$ & $\beta>1$ \\
\hline $\begin{array}{l}\text { Returns move } \\
\text { opposite of market } \\
\text { returns and are less } \\
\text { volatile }\end{array}$ & $\begin{array}{l}\text { Returns change } \\
\text { independent of } \\
\text { market returns and } \\
\text { are less volatile }\end{array}$ & $\begin{array}{l}\text { Returns follow } \\
\text { market returns } \\
\text { and are less } \\
\text { volatile }\end{array}$ & $\begin{array}{l}\text { Market } \\
\text { return }\end{array}$ & $\begin{array}{l}\text { Returns follow } \\
\text { market returns } \\
\text { and are more } \\
\text { volatile }\end{array}$ \\
\hline
\end{tabular}


Other market ratios which measure investor response to owning a company's stock and also the cost of issuing stock include the payout ratio; P/E ratio and dividend yield (Table 2.11).

Table 2.11: Market Ratios

\begin{tabular}{|l|c|}
\hline Payout Ratio & $\frac{\text { Dividend per Share }}{\text { Earnings per Share }}$ \\
\hline P/E Ratio & $\frac{\text { Market Price of Common Stock per Share }}{\text { Earnings per Share }}$ \\
\hline Dividend Yield & $\frac{\text { Dividend per Share }}{\text { Market Price of Common Stock per Share }}$ \\
\hline
\end{tabular}




\section{Background II: Profile of the Retail-Apparel Industry}

\subsection{Overview}

Any business that sells finished merchandise to an end user is in the retail industry. According to the U.S. Census Bureau, retail is the second largest industry (only to health care) in the country. It can be divided into many sectors (Table 3.1) with an average gross margin of $28 \%$. Annual total sales were estimated at $\$ 4.45$ trillion, $\$ 4.40$ trillion and $\$ 4.09$ trillion in 2007, 2008 and 2009, respectively - accounting for $12 \%$ of the total trade volume of all U.S. based businesses. According to the U.S. Department of Labour, the retail industry employed nearly 15.5 million people in 2007, providing more than $11 \%$ of the total employment in the country. However, by the end of 2008, 500,000 jobs were eliminated - a notable $30 \%$ of the 2.6 million layoffs that occurred overall. The recent decline is the effect of the recession.

Table 3.1: Retail Industry Segmentation (US Census, 2002)

\begin{tabular}{|l|r|r|r|r|}
\cline { 2 - 5 } \multicolumn{1}{c|}{} & Establishments & Sales (in \$M) & $\begin{array}{c}\text { Annual Payroll } \\
\text { (in \$M) }\end{array}$ & $\begin{array}{c}\text { Paid } \\
\text { Employees }\end{array}$ \\
\hline Retail Trade & $1,114,637$ & $\$ 3,056,422$ & $\$ 302,114$ & $14,647,675$ \\
\hline Motor vehicle \& parts dealers & 125,139 & $\$ 801,7402$ & $\$ 64,549$ & $1,845,496$ \\
\hline $\begin{array}{l}\text { Furniture \& home furnishings } \\
\text { stores }\end{array}$ & 65,204 & $\$ 91,814$ & $\$ 12,843$ & 535,029 \\
\hline Electronics \& appliance stores & 46,779 & $\$ 82,228$ & $\$ 9,330$ & 391,015 \\
\hline $\begin{array}{l}\text { Building material \& garden } \\
\text { equipment \& supplies dealers }\end{array}$ & 88,314 & $\$ 246,561$ & $\$ 30,067$ & $1,160,016$ \\
\hline Food \& beverage stores & 148,804 & $\$ 456,942$ & $\$ 48,686$ & $2,838,653$ \\
\hline Health \& personal care stores & 81,797 & $\$ 177,947$ & $\$ 20,266$ & $1,024,429$ \\
\hline Gasoline stations & 121,446 & $\$ 249,141$ & $\$ 13,701$ & 926,792 \\
\hline $\begin{array}{l}\text { Clothing \& clothing } \\
\text { accessories stores }\end{array}$ & 149,810 & $\$ 167,934$ & $\$ 21,391$ & $1,426,573$ \\
\hline $\begin{array}{l}\text { Sporting goods, hobby, book, } \\
\text { \& music stores }\end{array}$ & 62,236 & $\$ 73,212$ & $\$ 8,703$ & 611,144 \\
\hline General merchandise stores & 40,723 & $\$ 445,225$ & $\$ 42,647$ & $2,524,729$ \\
\hline Miscellaneous store retailers & 129,464 & $\$ 90,812$ & $\$ 12,835$ & 792,361 \\
\hline Non-store retailers & 54,921 & $\$ 172,865$ & $\$ 17,094$ & 571,438 \\
\hline
\end{tabular}

Ninety percent of retail stores are single-store businesses which make up for less than half of total sales. The majority of revenue is generated by companies that run retail chains such as Wal-Mart. In fact, 35 "big box" retailers generate approximately $\$ 335$ billion each year. These retailers also have large payrolls: Wal-Mart alone employs 1 million people in the US.

The Bureau of Economic Analysis (BEA) provides statistics on GDP by industry (Table 3.2). Historically, the retail industry's contribution to the GDP has increased at a compounded annual rate of $4 \%$ from 1997 to 2008. However, in 2009, the value-added fell 
for the first time since 1991, coinciding with a $4 \%$ decrease in personal consumption expenditures. The BEA also reports on sales and inventories (Table 3.3) which have remained fairly constant for this industry.

Table 3.2: Value-Added by Industry, 2005-2010, in Billions of Dollars (BEA)

\begin{tabular}{|l|r|r|r|r|r|r|}
\cline { 2 - 7 } \multicolumn{1}{c|}{} & \multicolumn{1}{c|}{$\mathbf{2 0 0 5}$} & \multicolumn{1}{c|}{$\mathbf{2 0 0 6}$} & \multicolumn{1}{c|}{$\mathbf{2 0 0 7}$} & \multicolumn{1}{c|}{$\mathbf{2 0 0 8}$} & \multicolumn{1}{c|}{$\mathbf{2 0 0 9}$} & \multicolumn{1}{c|}{$\mathbf{2 0 1 0}$} \\
\hline Total GDP & $12,421.9$ & $13,178.4$ & $14,061.8$ & $14,369.1$ & $14,119.0$ & $14,660.4$ \\
\hline Retail Trade GDP & 824.7 & 866.5 & 886.1 & 840.2 & 819.6 & 862.8 \\
\hline
\end{tabular}

Table 3.3: Manufacturing and Trade (BEA)

\begin{tabular}{|c|c|c|c|c|c|c|}
\hline & \multicolumn{5}{|c|}{2009} & \multirow{2}{*}{\begin{tabular}{|c|}
2010 \\
January
\end{tabular}} \\
\hline & August & September & October & November & December & \\
\hline & \multicolumn{6}{|c|}{ Sales (\$B) } \\
\hline Retail Trade & 316.6 & 309.1 & 312.8 & 318.5 & 317.4 & 316.3 \\
\hline \multirow[t]{2}{*}{ Clothing and accessing stores } & 18.2 & 18.3 & 18.3 & 18.2 & 18.0 & 18.4 \\
\hline & \multicolumn{6}{|c|}{ Inventory (\$B) } \\
\hline Retail Trade & 441.2 & 445.7 & 447.4 & 446.6 & 449.0 & 448.0 \\
\hline \multirow[t]{2}{*}{ Clothing and accessing stores } & 36.8 & 36.2 & 36.0 & 35.8 & 35.8 & 35.6 \\
\hline & \multicolumn{6}{|c|}{ Inventory-Sales Ratio (\$B) } \\
\hline Retail Trade & 1.39 & 1.44 & 1.43 & 1.40 & 1.42 & 1.42 \\
\hline Clothing and accessing stores & 2.03 & 1.98 & 1.97 & 1.97 & 1.98 & 1.94 \\
\hline
\end{tabular}

The segment of the retail industry of focus in this thesis is apparel. The apparel industry supplies consumers with affordable utilitarian attire and innovative styles for those fashion-forward. It is diverse, with hundreds of product lines varying in style, price and demographic. The US apparel industry is large, mature, and highly fragmented, with total sales decreasing since the onset of recession (Table 3.4). Despite over 150,000 establishments, the largest companies (which are studied in this thesis) account for $65 \%$ of the revenue. In fact, most businesses operate one store with average annual sales of $\$ 1$ million and 10 employees, and compete by targeting their specialties at different customers.

Table 3.4: Total Sales of Apparel Industry from 2001-2009 (US Department of Commerce)

\begin{tabular}{|c|c|c|c|c|c|c|c|c|c|}
\hline & 2001 & 2002 & 2003 & 2004 & 2005 & 2006 & 2007 & 2008 & 2009 \\
\hline Sales (\$B) & 168 & 173 & 179 & 191 & 201 & 213 & 221 & 216 & 204 \\
\hline
\end{tabular}

Apparel is made domestically and internationally with imports and exports shown in Figure 3.1. 


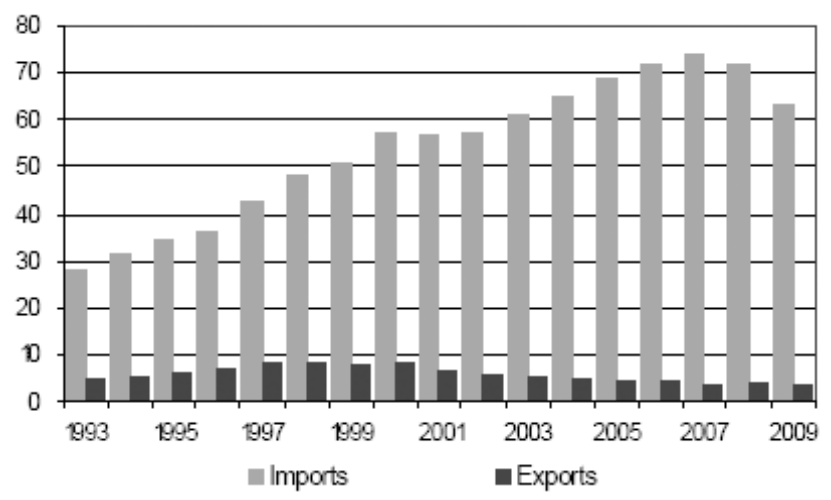

Figure 3.1: US Imports and Exports by Year (in Billions of Dollars) (US Department of Commerce)

\subsection{SWOT Analysis}

For a greater understanding of the retail-apparel industry, a survey of SWOT analysis reports prepared by Business Source Primer on companies studied in this thesis was conducted. SWOT analysis identifies and categorizes internal (strengths and weaknesses) and external factors (opportunities and threats) that are favourable and unfavourable to achieving an objective. In this context, a strength gives a firm an advantage over others (leading to stronger financials) whereas a weakness places it at a disadvantage (leading to a decline in revenue or profit, increase in bad debts or weakened debt service capability). An opportunity is an external chance to make greater sales profits whereas a threat is an external factor that could cause trouble for the business.

This section presents the strengths, weaknesses, opportunities and threats that apparel companies generally share. Note that this list is not comprehensive and excludes financialrelated characteristics.

\subsubsection{Strengths}

\section{Brand Portfolio Management and Customer Loyalty}

Brands are increasingly significant to apparel as consumers are spending their disposable income more carefully. Firms need strategies (advertising campaigns, focus groups, licensing, loyalty programs, etc.) to create value for the consumer and brand equity for themselves. To be competitive and to ensure that pricing is not the sole driver of purchases, companies must incorporate tangible product features, such as quality and appearance, with 
intangibles, such as a personal level of communication and innovation, an emotional connection or inspirational value.

\section{Multi-Sales Channels}

Most companies distribute their products through a variety of channels: wholesale, catalogue, and Internet sales, and their own retail stores. Of particular importance, consumers are increasingly shopping on the Internet: U.S. e-commerce sales reached $\$ 36.6$ billion or $4.1 \%$ of total sales in 2010 (US Department of Commerce). Online sales of apparel accounted for about $\$ 23.6$ billion of sales or $17 \%$ of total US online sales in 2008 (Forrester Research, 2011). Thus, companies must establish a strong online presence through a user-friendly and convenient website to take advantage of this trend.

\subsubsection{Opportunities}

Retailers can look to U.S. population projections (Table 3.5) for growth opportunities (National Retail Federation, NRF, 2010):

- Teenagers: Youth aged 15 to 19 represents $7.1 \%$ of the US population and will soon have more income as they enter adulthood.

- Generation Y: 71 million Americans born between 1977 and 1994 have or are entering the workforce and have more to spend on apparel, especially to expand their wardrobes to include professional attire.

- Children: As Generation Y grows older, they are starting to have children, benefiting retailers that target infants and youth.

- Women: Ladies born between 1946 and 1964 make up the largest segment of the apparel market.

Other rising trends that businesses should note include:

- Apparel for sports and activities-based entertainment: People are increasingly interested in maintaining an active and healthy lifestyle. Athletic apparel has advanced with the creation of materials that insulate from the cold while repelling sweat from the body, and devices that can be synched with computers to measure performance. 
- Green initiatives and goods: Some companies have marketed themselves as socially responsible, appealing to consumers who favour "conscious spending." Despite the faltering economy, $61 \%$ of consumers bought a green product in 2008 (NRF, 2010).

Table 3.5: US Population Projections (US Department of Commerce)

\begin{tabular}{|l|r|r|r|r|r|r|}
\cline { 2 - 7 } \multicolumn{1}{c|}{} & \multicolumn{2}{c|}{$\mathbf{2 0 0 0}$} & \multicolumn{2}{c|}{$\mathbf{2 0 1 5}$} & \multicolumn{2}{c|}{$\mathbf{2 0 3 0}$} \\
\hline Age Group & $\begin{array}{c}\text { Number } \\
(\mathbf{1 0 0 0 s})\end{array}$ & $\begin{array}{c}\text { \% of } \\
\text { Total }\end{array}$ & $\begin{array}{c}\text { Number } \\
(\mathbf{1 0 0 0 s})\end{array}$ & $\begin{array}{c}\text { \% of } \\
\text { Total }\end{array}$ & $\begin{array}{c}\text { Number } \\
(\mathbf{1 0 0 0 s})\end{array}$ & $\begin{array}{c}\text { \% of } \\
\text { Total }\end{array}$ \\
\hline Under 5yrs & 21,100 & 6.8 & 22,076 & 6.8 & 23,484 & 6.6 \\
\hline 5 to 14 yrs & 41,281 & 13.3 & 43,365 & 13.3 & 47,225 & 13.2 \\
\hline 15 to 19 yrs & 21,770 & 7.0 & 21,209 & 6.5 & 23,545 & 6.6 \\
\hline 20 to 24 yrs & 21,779 & 7.0 & 22,342 & 6.9 & 23,168 & 6.5 \\
\hline 25 to 29 yrs & 21,418 & 6.9 & 22,400 & 6.9 & 22,417 & 6.3 \\
\hline 30 to 34 yrs & 29,400 & 6.9 & 22,099 & 6.8 & 23,699 & 6.6 \\
\hline 35 to 39 yrs & 20,267 & 6.5 & 20,841 & 6.4 & 23,645 & 6.6 \\
\hline 40 to 44yrs & 21,010 & 6.8 & 20,460 & 6.3 & 22,851 & 6.4 \\
\hline 45 to 49 yrs & 22,595 & 7.3 & 21,001 & 6.5 & 21,154 & 6.9 \\
\hline 50 to 54 yrs & 22,109 & 7.1 & 22,367 & 6.9 & 20,404 & 5.7 \\
\hline 55 to 64 yrs & 36,275 & 11.7 & 40,544 & 12.5 & 41,952 & 11.7 \\
\hline 65 yrs and over & 40,229 & 13.0 & 46,837 & 14.4 & 63,907 & 17.9 \\
\hline All ages & 310,233 & 100.0 & 325,540 & 100.0 & 357,452 & 100.0 \\
\hline
\end{tabular}

\subsubsection{Weaknesses and Threats}

\section{Intense Competition}

The apparel industry is highly competitive due to the power that consumers have to readily switch brands and the relatively low barriers of entry. However, while it may be easy to start a business, it is difficult to sustain as start-ups are typically undercapitalized and lack marketing resources to build brand loyalty as well as the technological infrastructure that major retailers now demand.

Rising Unemployment Rate, Declining Consumer Confidence and Decreasing Discretionary Spending

A high unemployment rate, at over 10\% (Bureau of Labor Statistics, 2010) because of the recession, has decreased total disposable personal income. As a result, consumer confidence ${ }^{5}$ (Figure 3.2) has weakened, dampening spending on apparel (Figure 3.3). In 2009, consumers spent about $\$ 322$ billion on clothing and footwear down 3.6\% from 2008, when they spent \$334 billion (BEA, 2010).

\footnotetext{
${ }^{5}$ The index represents a relative measure of how consumers feel about the strength of the economy, business trends, their job security or employment prospects, and their future earnings prospects.
} 


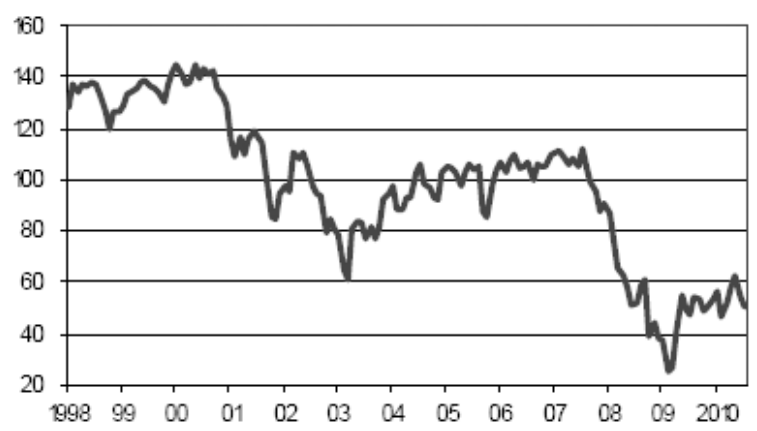

Figure 3.2: Consumer Confidence Index by Year $(1985=100)$ (The Conference Board)

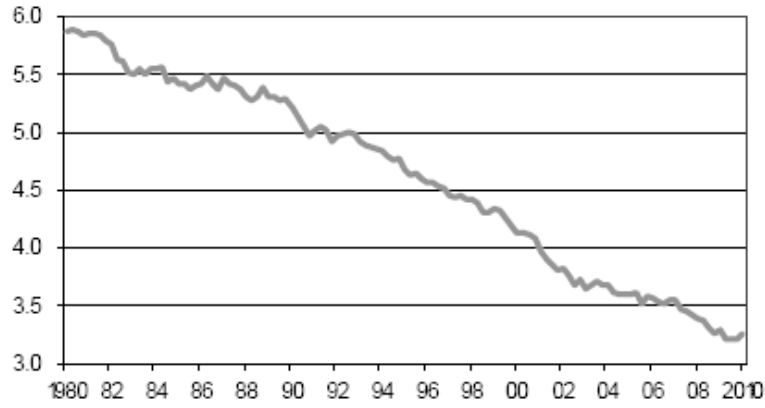

Figure 3.3: Apparel's Share of Total Personal Consumption Expenditures by Year (in \%) (US Department of Commerce)

\section{Interest Rates and Inflation}

Interest rates affect consumer purchasing decisions as higher levels can curb spending as people prioritize paying off credit card debts and reining in expenses. To a business, the cost of borrowing influences management decisions regarding acquisitions, new product introductions, capital expenditures, dividends and stock repurchases.

Inflation affects pricing decisions of apparel companies and their suppliers who likely pass on cost increases to the consumer. However, while prices for many products and services tend to rise over time, apparel prices have fallen each year from 1998 through 2005 (Figure 3.4). 


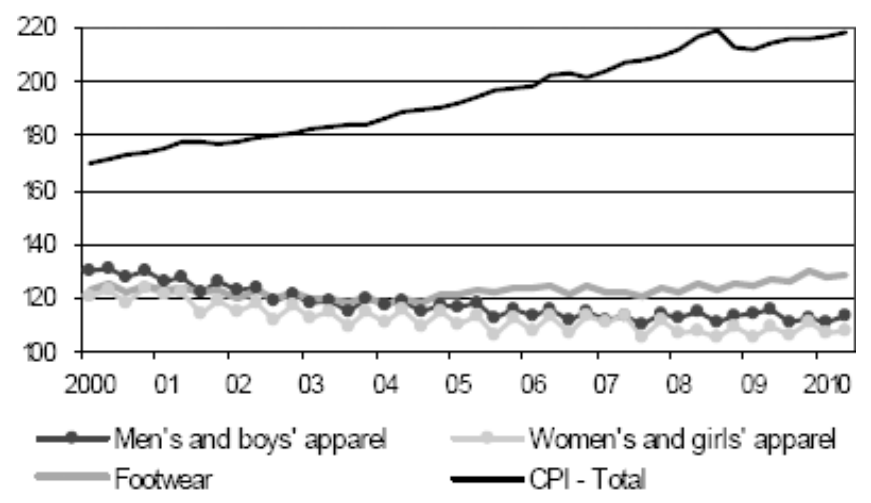

Figure 3.4: Consumer Price Indices (1982-84 = 100) (Bureau of Labour Statistics)

\section{Rising Costs and Reliance on Foreign Production}

As raw material, freight and labour costs continue to rise, retailers outsource manufacturing jobs to Asia, Latin America and the Caribbean, especially with increased quotas, reduced tariffs and free-trade and preferential-trade agreements. According to the US Department of Labour, domestic employment in apparel manufacturing peaked in 1973 at 14.5 million and has since decreased drastically (Figure 3.5).

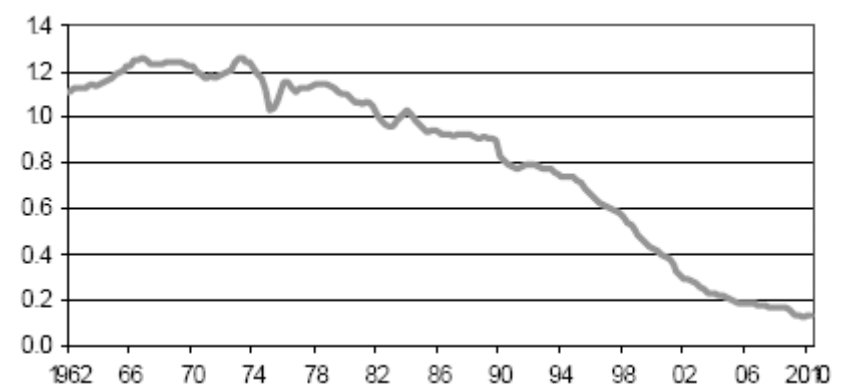

Figure 3.5: US Apparel Industry Employment by Year (Production workers, in millions) (Bureau of Labour Statistics)

China accounted for $37.2 \%$ of all apparel imported into the US in 2009 , rising from $32.0 \%$ in 2008 (US Department of Commerce). At the same time, more manufacturing plants are surfacing in Mexico and the Caribbean, providing a quicker turnaround time just based on proximity. Although foreign production drives apparel prices down for consumers, there are risks associated with heavy reliance when the yuan appreciates and production costs increase in China, as well as when there is political strife in Mexico. 


\subsection{Future Outlook}

The recession has led to many personal and business bankruptcy filings. The Administrative Office of the U.S. Courts compiles statistics on bankruptcy filings each year (Table 3.6). As shown, the number of corporate filing has increased with the onset of recent recession.

Table 3.6: Bankruptcy Cases Commenced, Terminated and Pending During Twelve Month Periods Ending December 31

\begin{tabular}{|l|r|r|r|}
\hline Year & \multicolumn{1}{|c|}{ Filings } & \multicolumn{1}{c|}{ Terminations } & Pending \\
\hline 2000 & $1,253,444$ & $1,238,805$ & $1,401,552$ \\
\hline 2001 & $1,492,129$ & $1,357,252$ & $1,536,429$ \\
\hline 2002 & $1,577,651$ & $1,475,810$ & $1,637,418$ \\
\hline 2003 & $1,660,245$ & $1,589,383$ & $1,708,606$ \\
\hline 2004 & $1,597,462$ & $1,661,919$ & $1,644,149$ \\
\hline 2005 & $2,078,415$ & $1,576,555$ & $2,148,845$ \\
\hline 2006 & 617,660 & $1,435,482$ & $1,331,023$ \\
\hline 2007 & 850,912 & 891,784 & $1,280,137$ \\
\hline 2008 & $1,117,771$ & $1,019,426$ & $1,378,482$ \\
\hline 2009 & $1,473,675$ & $1,284,714$ & $1,575,624$ \\
\hline 2010 & $1,593,081$ & $1,512,408$ & $1,656,340$ \\
\hline
\end{tabular}

While this Office does not provide a breakdown of bankruptcy cases by industry, the International Council of Shopping Centres (ICSC) reports that more than 150,000 retail stores closed in 2008, an increase from the 135,000 that went out of business in 2007. Furthermore, bankruptcy is not limited to small stores. For a complete listing of large companies that have filed for bankruptcy, please visit http://retailindustry.about.com/.

The apparel industry is starting to look promising again. In fact, from its low in March 2009 to its recent high in February 2012, the S\&P Apparel Retail Index has risen 136\%. Despite a decline in sales, there are other positives: 1 . most cost-cutting that could be done has been done; 2. inventories are no longer declining sharply and are now aligned with consumer demand so businesses need fewer markdowns to sell excess goods which translates into gross margins recovering and revenue stability; and 3. retailers that closed stores and exited marginal locations have effectively reduced fixed costs and support improved margins.

In the longer term, however, apparel sales may continue to be weak as baby boomers prioritize funding retirement, children's tuition and healthcare costs, over clothing. In order to improve profitability, companies will have to operate leaner (less inventory and lower payroll), improve customer experience and loyalty, use multichannel shopping, and/or create private label brands (Deloitte, 2008). 


\section{Data Envelopment Analysis}

In industry, measuring the performance or efficiency of a production or decision making unit (DMU) can be a complicated proposition. Over the past thirty years, two classes of frontier methodologies have been developed to measure DMU efficiency relative to an empirically defined best-practice standard: the non-parametric linear programming approach and the parametric econometric approach. These approaches differ in the assumptions made about the shape of the efficient frontier, the treatment of random error, and the distributional assumptions regarding inefficiency and random error. Specifically, nonparametric approaches measure technical efficiency, focusing on levels of input relative to levels of output. For a DMU to be technically efficient, it must either minimize its inputs given outputs and/or maximize its outputs given inputs. On the other hand, parametric approaches measure economic efficiency, choosing optimal levels of inputs and/or outputs based on reactions to market prices. For a DMU to be economically efficient, its inputs and/or outputs must be at levels that achieve cost minimization or profit maximization (Bauer et al., 1998).

Generally, the major advantages of frontier methodologies are that they can identify and assess areas of best performance within complex operational settings, and they provide a single aggregate measure of performance (or efficiency score) for each DMU in and relative to the sample. Moreover, nonparametric approaches can simultaneously handle multiple inputs and multiple outputs. However, they are often deterministic and cannot account for any potential errors in the data, treating deviations from the efficient frontier as inefficiencies (Cummins and Zi, 1996).

In this chapter, a thorough description of a nonparametric linear programming approach called Data Envelopment Analysis is provided. For a brief overview of parametric econometric approaches, please refer to Appendix A.

\subsection{Introduction}

Data Envelopment Analysis (DEA) is a nonparametric fractional linear programming technique that can be used to rank and compare the relative performance of DMUs operating under comparable conditions. It is particularly effective in handling complex processes where DMUs use multiple inputs to produce multiple outputs. Unlike parametric methodologies which assume that the same average equation applies to all observations or 
DMUs, DEA “optimizes" each DMU, arriving at an efficiency score for every DMU relative to the entire sample (Figure 4.1) (Cooper et al., 2007).

DMUs identified as empirically efficient define the efficient frontier: an $N$ dimensional surface (where $N$ is the total number of inputs and outputs) that "envelops" the inefficient DMUs in the sample. The efficient frontier provides a benchmark for the changes in inputs and outputs necessary to render inefficient DMUs efficient; that is, inefficient DMUs can be projected to a specific achievable target on the efficient frontier.

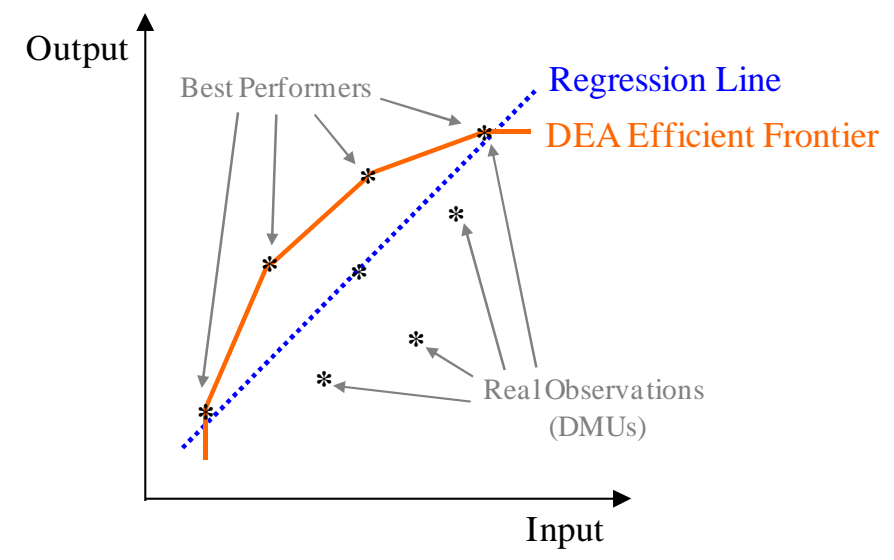

Figure 4.1: Data Envelopment Analysis Versus Regression Analysis

There are two main models in DEA: Charnes-Cooper-Rhodes (CCR), which is a constant returns-to-scale model, and Banker-Charnes-Cooper (BCC), which is a variable returns-to-scale model. Both models generate a piecewise-linear envelopment surface and are either input- or output-oriented, depending on whether the objective is to maximize input contraction or output expansion, with output production or input consumption, respectively, kept constant. Both orientations yield identical envelopment (convex) surfaces but differ in the manner in which inefficient DMUs are projected onto the efficient frontier (Figure 4.2) (Cooper et al., 2007). Examples are provided in Appendix B. 


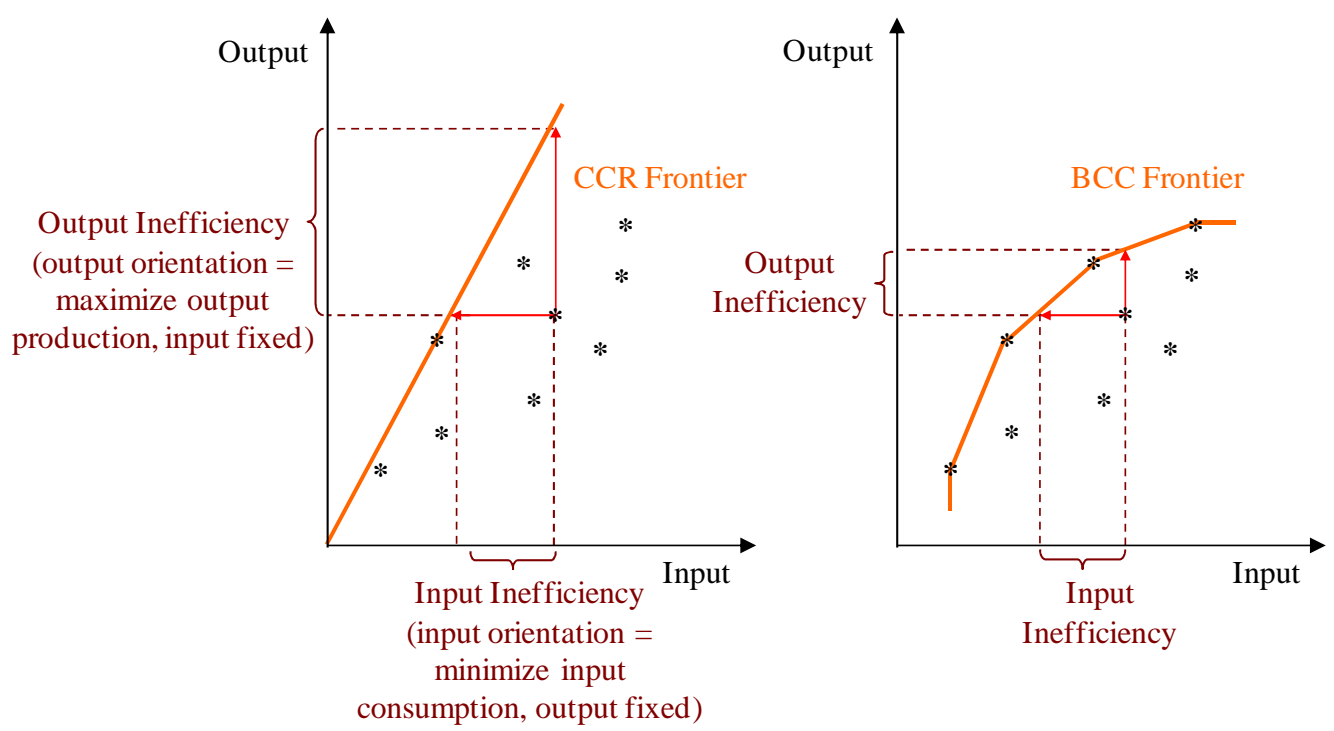

Figure 4.2: Inefficiencies and Projections in CCR and BCC Models with One Input and One Output

\subsection{CCR Model}

\subsubsection{Input Orientation}

The Farrell measure for efficiency $\theta$ of a production unit (or DMU) in the case of a single virtual input producing a single virtual output is (Farrell, 1957):

$$
\theta=\frac{\text { Virtual Output }}{\text { Virtual Input }}
$$

In 1978, Charnes, Cooper, and Rhodes developed DEA as an extension of Farrell's approach to evaluating empirical efficiency for the case of multiple inputs and multiple outputs (Figure 4.3).

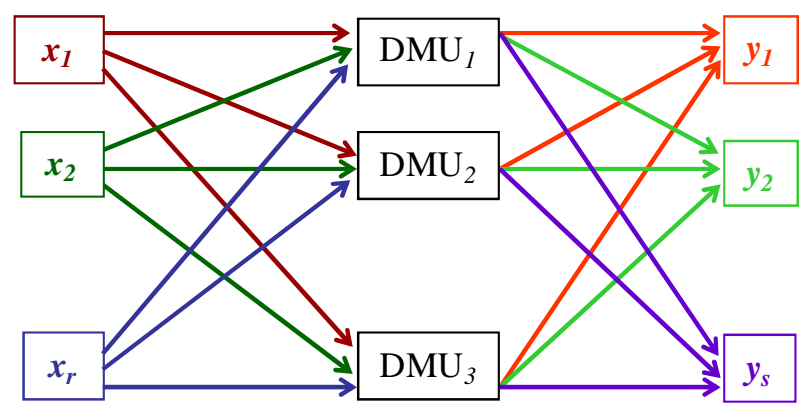

Figure 4.3: DEA System with Multiple Inputs and Multiple Outputs

Known as the CCR model, a given $\mathrm{DMU}_{o}$ has a relative efficiency $\theta_{o}$ defined as the ratio of the sum $s$ of weighted outputs $\left(y_{r}\right.$ for $\left.r=1, \ldots, s\right)$ and the sum of $m$ weighted inputs $\left(x_{i}\right.$ for $i=$ $1, \ldots, m)$ : 


$$
\theta_{o}=\frac{u_{1} y_{1 o}+u_{2} y_{2 o}+\ldots+u_{s} y_{s o}}{v_{1} x_{1 o}+v_{2} x_{2 o}+\ldots+v_{m} x_{m o}}
$$

Input weights $v_{i}(i=1, \ldots, m)$ and output weights $u_{r}(r=1, \ldots, s)$ are not fixed in advance but derived from the data such that each DMU appears as "favourable" as possible. An efficiency score and weights for $\mathrm{DMU}_{o}$ can be obtained by solving the following optimization (Formulation 4.1). From a sample of $n$ DMUs, each with $m$ inputs and $s$ outputs, the objective of this input-oriented CCR model is to obtain the best set of weights $\left(v^{*}, u^{*}\right)$ that maximizes the ratio $\theta^{*}$ of each $\operatorname{DMU}_{o}(o=1, \ldots, n)$, by minimizing observed inputs equiproportionally while output levels remain fixed with the constraint that the optimal efficiency for each DMU is at most $1\left(\theta^{*} \leq 1\right)$. A DMU ${ }_{o}$ is CCR-efficient only if $\theta^{*}=$ 1 and there exists at least one optimal $\left(v^{*}, \boldsymbol{u}^{*}\right)$ with $\boldsymbol{v}^{*}>\mathbf{0}$ and $\boldsymbol{u}^{*}>\mathbf{0}$.

$$
\begin{array}{ll}
\text { Maximize } & \theta_{o}=\frac{\sum_{r=1}^{s} u_{r} y_{r o}}{\sum_{i=1}^{m} u_{i} y_{i o}}=\frac{u_{1} y_{1 o}+u_{2} y_{2 o}+\ldots+u_{s} y_{s o}}{v_{1} x_{1 o}+v_{2} x_{2 o}+\ldots+v_{m} x_{m o}} \\
\text { Subject to } & \frac{\sum_{r=1}^{s} u_{r} y_{r j}}{\sum_{i=1}^{m} v_{i} x_{i j}}=\frac{u_{1} y_{1 j}+\ldots+u_{s} y_{s j}}{v_{1} x_{1 j}+\ldots+v_{m} x_{m j}} \leq 1 \quad(j=1, \ldots, n) \\
& v_{1}, v_{2}, \ldots, v_{m} \geq 0 \\
& u_{1}, u_{2}, \ldots, u_{s} \geq 0 \\
& y_{r j} \text { is the amount of the } r^{\text {th }} \text { output from DMU } j \\
& x_{i j} \text { is the amount of the } i^{\text {th }} \text { input to DMU } j \\
& u_{r} \text { is the output multiplier given to the } r^{\text {th }} \text { output } \\
& v_{i} \text { is the input multiplier given to the } i^{\text {th }} \text { input }
\end{array}
$$

The CCR model can be presented in a less computationally intensive linear programming (LP) form: both primal and dual formulations (Formulations 4.2 and 4.3) yield the same optimal solution. The dual formulation of the input-oriented CCR model is expressed with a set of non-negative intensity variables $\lambda=\left(\lambda_{1}, \lambda_{2}, \ldots, \lambda_{n}\right)^{T}$, representing the weight of each of the $n$ DMUs. 


$$
\begin{array}{ll}
\text { Maximize } & \sum_{r=1}^{s} u_{r} y_{r o} \\
\text { Subject to } & \sum_{i=1}^{m} v_{i} x_{i o}=1 \\
& \sum_{r=1}^{s} u_{r} y_{r j}-\sum_{i=1}^{m} v_{i} x_{i j} \leq 0 \quad(j=1, \ldots, n) \\
& v_{1}, v_{2}, \ldots, v_{m} \geq 0 \\
& u_{1}, u_{2}, \ldots, u_{s} \geq 0
\end{array}
$$

Minimize $\theta$

Subject to

$$
\begin{aligned}
\theta x_{i o} & \geq \sum_{j=1}^{n} x_{i j} \lambda_{j} \quad(i=1, \ldots, m) \\
y_{r o} & \leq \sum_{j=1}^{n} y_{r j} \lambda_{j} \quad(r=1, \ldots, s) \\
\lambda_{j} & \geq 0
\end{aligned}
$$

The optimization is performed once for each DMU in the sample with the objective of reducing all inputs equiproportionally; that is, optimality is achieved by minimizing inputs by a factor of $\theta$. Consequently, CCR models are radial models as their goal is to adjust inputs or outputs (in the case of output orientation) radially from the origin. However, further input decreases or output increases may still be possible after radial optimization has been achieved (Figure 4.4).

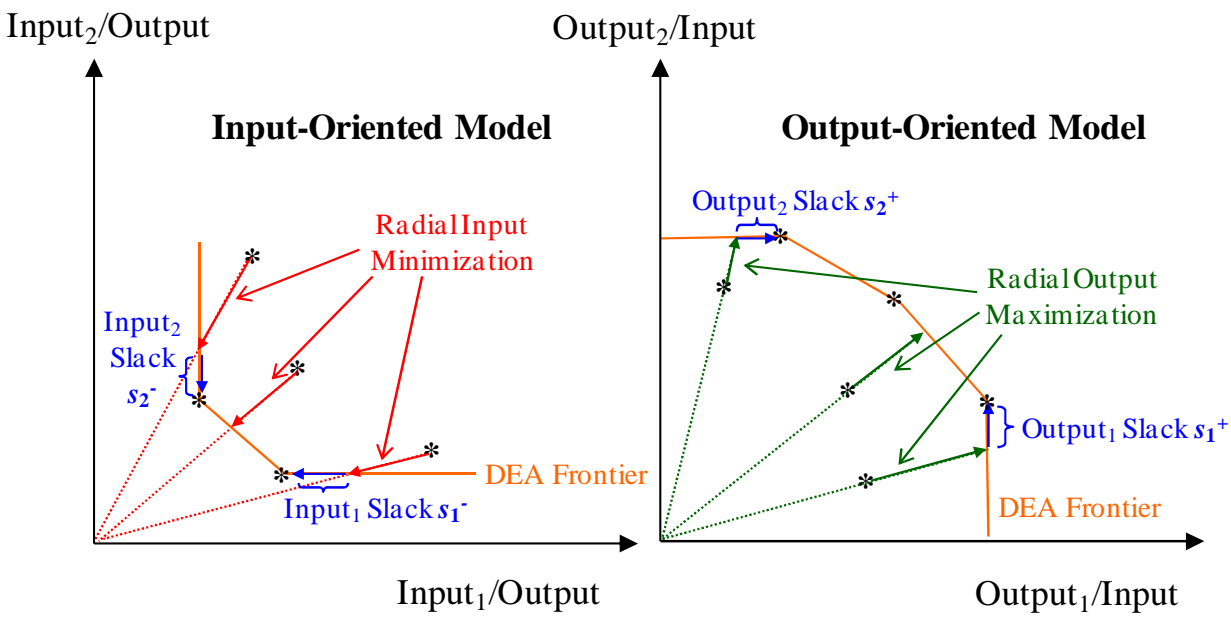

Figure 4.4: Input Minimization, Output Maximization and Slacks

Input excesses $s^{-}$and output shortfalls $s^{+}$are known as input and output slack variables, respectively, and are optimized in a second phase: 


$$
\begin{aligned}
\text { Maximize } \quad w & =\sum_{i=1}^{m} s_{i}^{-}+\sum_{r=1}^{s} s_{r}^{+} \\
\text {Subject to } \quad s_{i}^{-} & =\theta^{*} x_{i o}-\sum_{i=1}^{m} x_{i j} \lambda_{j} \quad(i=1, \ldots, m) \\
s_{r}^{+} & =\sum_{r=1}^{s} y_{r j} \lambda_{j}-y_{r o} \quad(r=1, \ldots, s) \\
\lambda_{j} & \geq 0 \quad(j=1, \ldots, n) \\
s_{i}^{-} & \geq 0 \quad(i=1, \ldots, m) \\
s_{r}^{+} & \geq 0 \quad(r=1, \ldots, s)
\end{aligned}
$$

where $\theta^{*}$ is the optimal radial contraction computed from the first phase (Formulation 4.3).

Thus, a DMU is defined as fully efficient if and only if $\theta^{*}=1$ (radial or technical efficiency) and $\boldsymbol{s}^{+*}=\boldsymbol{s}^{-*}=0$ (zero slacks). It is considered Pareto-Koopman efficient if and only if it is not possible to improve any input or output without worsening some other input or output (Charnes et al., 1978). If only $\theta^{*}=1$ is satisfied, then the DMU is "weakly efficient", with the "mix inefficiencies" associated with nonzero slacks. Note that fully and weakly efficient units are radially efficient regardless of slacks.

An inefficient DMU can be "improved" by referring its inefficient behaviour to the efficient frontier formed by $E_{o}$, the reference set of $\mathrm{DMU}_{o}$ composed of efficient DMUs. This improvement is a projection to the point $\left(\widehat{\boldsymbol{x}}_{\boldsymbol{o}}, \widehat{\boldsymbol{y}}_{\boldsymbol{o}}\right)$ on the frontier where:

$$
\begin{aligned}
& \hat{x}_{i o}=\theta^{*} x_{i o}-s_{i}^{-*}=\sum_{j \in E_{o}} x_{i j} \lambda_{j}^{*} \leq x_{i o} \quad(i=1, \ldots, m) \\
& \hat{y}_{r o}=y_{r o}+s_{r}^{+*}=\sum_{j \in E_{o}} y_{r j} \lambda_{j}^{*} \geq y_{r o} \quad(r=1, \ldots, s)
\end{aligned}
$$

$\left(\widehat{\boldsymbol{x}}_{\boldsymbol{o}}, \widehat{\boldsymbol{y}}_{\boldsymbol{o}}\right)$ are the coordinates of a virtual linear composite DMU (i.e. $\sum D M U_{i} \lambda_{i}$ where $D M U_{i}$ 's are efficient and $\lambda_{i}$ are proportionality weights for $D M U_{i}$ ) used to evaluate the performance of $\mathrm{DMU}_{o}$. It represents the target for efficient production that $\mathrm{DMU}_{o}$ strives for (Cooper et al., 2005).

\subsubsection{Output Orientation}

The output-oriented CCR model aims to maximize outputs without any addition to the observed input values. The primal and dual formulations are: 


$$
\begin{array}{ll}
\text { Minimize } & \sum_{r=1}^{m} p_{i} x_{i o} \\
\text { Subject to } & \sum_{r=1}^{s} q_{r} y_{r o}=1 \\
& \sum_{r=1}^{s} q_{r} y_{r j}-\sum_{i=1}^{m} p_{i} x_{i j} \leq 0 \quad(j=1, \ldots, n) \\
& p_{1}, p_{2}, \ldots, p_{m} \geq 0 \\
& q_{1}, q_{2}, \ldots, q_{s} \geq 0
\end{array}
$$

Maximize $\eta$

Subject to $\quad x_{i o} \geq \sum_{j=1}^{n} x_{i j} \mu_{j} \quad(i=1, \ldots, m)$

$\eta y_{r o} \leq \sum_{j=1}^{n} y_{r j} \mu_{j} \quad(r=1, \ldots, s)$

$\mu_{j} \geq 0$

In relation to the input-oriented model, $\boldsymbol{p}^{*}=\frac{v^{*}}{\theta^{*}}, \boldsymbol{q}^{*}=\frac{u^{*}}{\theta^{*}}, \boldsymbol{\mu}^{*}=\frac{\lambda^{*}}{\theta^{*}}$ and $\eta^{*}=\frac{1}{\theta^{*}}$. Consequently, $\eta^{*} \geq 1$ (i.e. the inverse of $\theta^{*} \leq 1$ ). The input $t^{-}$and output $\boldsymbol{t}^{+}$slacks (Equation 4.8) of the outputoriented model are also introduced in a second phase (Formulation 4.4):

$$
\begin{aligned}
& t_{i}^{-}=x_{i o}-\sum_{i=1}^{m} x_{i j} \mu_{j} \quad(i=1, \ldots, m) \\
& t_{r}^{+}=\sum_{r=1}^{s} y_{r j} \mu_{j}-\eta^{*} y_{r o} \quad(r=1, \ldots, s)
\end{aligned}
$$

where $\eta^{*}$ is the optimal expansion from the first phase (Formulation 4.7) and $t^{* *}=\frac{s^{-*}}{\theta^{*}}$ and $\boldsymbol{t}^{+*}=\frac{s^{+*}}{\theta^{*}}$.

A DMU is fully efficient if and only if $\eta^{*}=1$ and all optimal slacks are zero. For inefficient DMUs, the CCR projection $\left(\widehat{\boldsymbol{x}}_{\boldsymbol{o}}, \widehat{\boldsymbol{y}}_{\boldsymbol{o}}\right)$ is:

$$
\begin{aligned}
& \hat{x}_{i o}=x_{i o}-t_{i}^{-*} \quad(i=1, \ldots, m) \\
& \hat{y}_{r o}=\eta^{*} y_{r o}+t_{r}^{+*} \quad(r=1, \ldots, s)
\end{aligned}
$$

Finally, the CCR model assumes that the production process is governed by constant returns-to-scale (CRS) which states that if $\left(\boldsymbol{x}_{\boldsymbol{o}}, \boldsymbol{y}_{\boldsymbol{o}}\right)$ is a possible combination of input and output activity, then $\left(k_{\boldsymbol{o}}, k \boldsymbol{y}_{\boldsymbol{o}}\right)$ is also feasible for every positive scalar $k$ (Charnes et al., 1978). A CRS efficient frontier is one hyperplane, such that for every increase in inputs, there is a proportionate increase in outputs.

\subsection{BCC Model}

Banker, Charnes and Cooper modified the CCR model for variable returns-to-scale (VRS). The frontier of this BCC model is comprised of piecewise linear and concave segments which exhibit increasing returns-to-scale, followed by constant returns-to-scale, then 
decreasing returns-to-scale (Figure 4.5). The BCC model also has two "skirts" (shown as dotted lines) that run parallel to the input and output axes. These are virtual segments that allow for calculations of input excesses $s^{-}$and output shortfalls $s^{+}$. Like the CCR model, the BCC model is radial and either input- or output-oriented (Banker et al., 1984).

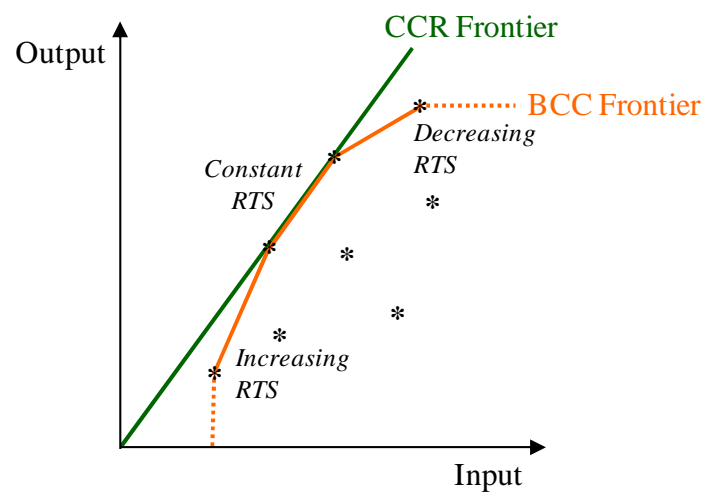

Figure 4.5: Constant versus Variable Returns-to-Scale (RTS)

\subsubsection{Input Orientation}

The primal and dual formulations for the BCC input-oriented model are: BCC Primal (4.10)

$$
\begin{aligned}
& \text { Maximize } z=\sum_{r=1}^{s} u_{r} y_{r j}-u_{o} \\
& \text { Minimize } \theta_{B C C} \\
& \text { Subject to } \sum_{i=1}^{m} v_{i} x_{i o}=1 \\
& \text { Subject to } \theta_{B C C} x_{i o} \geq \sum_{j=1}^{n} x_{i j} \lambda_{j} \quad(i=1, \ldots, m) \\
& \sum_{r=1}^{s} u_{r} y_{r j}-\sum_{i=1}^{m} v_{i} x_{i j}-u_{o} \leq 0 \quad(j=1, \ldots, n) \\
& y_{r o} \leq \sum_{j=1}^{n} y_{r j} \lambda_{j} \quad(r=1, \ldots, s) \\
& v_{1}, v_{2}, \ldots, v_{m} \geq 0 \\
& u_{1}, u_{2}, \ldots, u_{s} \geq 0 \\
& u_{o} \text { free in sign }
\end{aligned}
$$

BCC Dual (4.11)

$\theta_{B C C}$ is the proportional reduction that can be applied to all inputs to improve BCC efficiency. As previously, slacks (Equation 4.12) can be incorporated in a second phase (Formulation 4.4):

$$
\begin{aligned}
& s_{i}^{-}=\theta_{B C C}{ }^{*} x_{i o}-\sum_{i=1}^{m} x_{i j} \lambda_{j} \quad(i=1, \ldots, m) \\
& s_{r}^{+}=\sum_{r=1}^{s} y_{r j} \lambda_{j}-y_{r o} \quad(r=1, \ldots, s)
\end{aligned}
$$

A DMU is BCC-efficient if and only if $\theta_{B C C}^{*}=1$ and has zero slacks $\left(\boldsymbol{s}^{+*}=\boldsymbol{s}^{-*}=0\right)$. CCR efficiency can never exceed BCC efficiency; a DMU found to be efficient in CRS will 
also be efficient in VRS, but the converse is not necessary true. The BCC input-oriented projection $\left(\widehat{\boldsymbol{x}}_{\boldsymbol{o}}, \widehat{\boldsymbol{y}}_{\boldsymbol{o}}\right)$ is:

$$
\begin{aligned}
& \hat{x}_{i o}=\theta_{B C C}^{*} x_{i o}-s_{i}^{-*} \quad(i=1, \ldots, m) \\
& \hat{y}_{r o}=y_{r o}+s_{r}^{+^{*}} \quad(r=1, \ldots, s)
\end{aligned}
$$

As can be seen, the BCC model is identical to the CCR model except for the addition of the convexity constraint, $\sum_{j=1}^{n} \lambda_{j}=1$ or the variable $u_{o}$, which is the unrestricted dual variable in the primal formulation. This constraint reduces the feasible region for the LP from a convex cone defined by the DMUs to the convex hull covering all the DMUs, thereby increasing the number of efficient DMUs (Charnes et al., 1994).

\subsubsection{Output Orientation}

The primal and dual formulations of the output-oriented BCC model are presented in Formulations 4.14 and 4.15, respectively (Charnes et al., 1994). $\eta_{\mathrm{BCC}}$ is the proportional augmentation in all of the outputs that represents technical, radial efficiency, while $v_{o}$ is the dual variable associated with the convexity constraint in the primal problem.

BCC Primal (4.14)

$$
\begin{aligned}
\text { Minimize } & z=\sum_{r=1}^{m} v_{i} x_{i o}-v_{o} \\
\text { Subject to } & \sum_{r=1}^{s} u_{r} y_{r o}=1 \\
& \sum_{i=1}^{m} v_{i} x_{i j}-\sum_{r=1}^{s} u_{r} y_{r j}-v_{o} \geq 0 \quad(j=1, \ldots, n) \\
& p_{1}, p_{2}, \ldots, p_{m} \geq 0 \\
& q_{1}, q_{2}, \ldots, q_{s} \geq 0 \\
& v_{o} \text { free in sign }
\end{aligned}
$$

$$
\begin{array}{ll}
\text { Maximize } & \eta_{B C C} \\
\text { Subject to } & x_{i o} \geq \sum_{j=1}^{n} x_{i j} \lambda_{j} \quad(i=1, \ldots, m) \\
& \eta_{B C C} y_{r o} \leq \sum_{j=1}^{n} y_{r j} \lambda_{j} \quad(r=1, \ldots, s) \\
& \sum_{j=1}^{n} \lambda_{j}=1 \\
& \lambda_{j} \geq 0
\end{array}
$$

Slacks (Equation 4.16) are accounted for in a second phase (Formulation 4.4) after maximal augmentation $\eta_{\mathrm{BCC}}$ (Formulation 4.15).

$$
\begin{aligned}
& t_{i}^{-}=x_{i o}-\sum_{i=1}^{m} x_{i j} \lambda_{j} \quad(i=1, \ldots, m) \\
& t_{r}^{+}=\sum_{r=1}^{s} y_{r j} \lambda_{j}-\eta_{B C C}^{*} y_{r o} \quad(r=1, \ldots, s)
\end{aligned}
$$

A DMU is BCC-efficient if and only if $\eta^{*}$ BCC and $\boldsymbol{t}^{\boldsymbol{t}^{*}}=\boldsymbol{t}^{*}=0$, while an inefficient DMU can be improved with the projection: 


$$
\begin{aligned}
& \hat{x}_{i o}=x_{i o}-t_{i}^{-*} \quad(i=1, \ldots, m) \\
& \hat{y}_{r o}=\eta_{B C C}^{*} y_{r o}+t_{r}^{+*} \quad(r=1, \ldots, s)
\end{aligned}
$$

\subsection{Additive Model}

Both the CCR and BCC models require a distinction between input and output orientation. However, the additive (ADD) model combines both orientations (Figure 4.6) with Formulations 4.18 and 4.19.

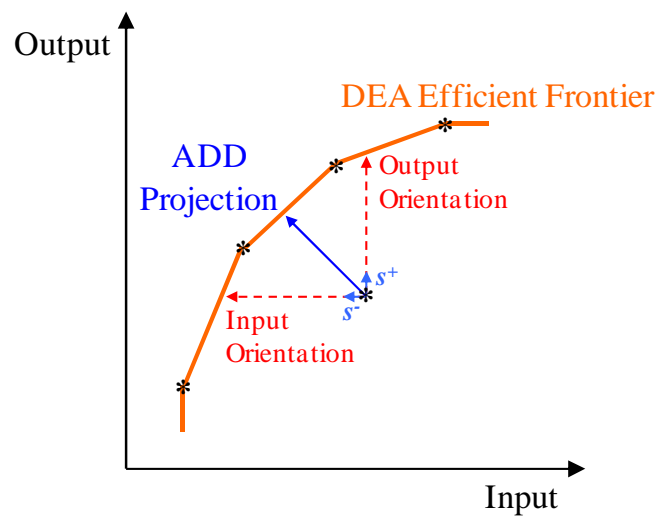

Figure 4.6: Additive Model

ADD Primal (4.18)

Maximize $\quad w=\sum_{i=1}^{m} v_{i} x_{i o}-\sum_{r=1}^{s} u_{j} y_{j o}+u_{o}$

Subject to $\sum_{i=1}^{m} v_{i} x_{i j}-\sum_{r=1}^{s} u_{j} y_{i j}+u_{o} \geq 0 \quad(j=1, \ldots, n)$

$v_{1}, v_{2}, \ldots, v_{m} \geq 1$

$u_{1}, u_{2}, \ldots, u_{s} \geq 1$

$u_{o}$ free in sign
ADD Dual (4.19)

Maximize $\quad z=\sum_{i=1}^{m} s_{i}^{-}+\sum_{r=1}^{s} s_{r}^{+}$

Subject to $\quad \sum_{j=1}^{n} x_{i j} \lambda_{j}+s_{i}^{-}=x_{i o} \quad(i=1, \ldots, m)$

$\sum_{j=1}^{n} y_{r j} \lambda_{j}-s_{r}^{+}=y_{r o} \quad(r=1, \ldots, s)$

$\sum_{j=1}^{n} \lambda_{j}=1$

$\lambda_{j} \geq 0 \quad(j=1, \ldots, n)$

$s_{i}^{-} \geq 0 \quad(i=1, \ldots, m)$

$s_{r}^{+} \geq 0 \quad(r=1, \ldots, s)$

$z$ and $w$ reflect all inefficiencies in both inputs and outputs, with the efficiency score measured implicitly in the slacks. A DMU is ADD-efficient if and only if the DMU has zero slacks $\left(s^{t^{*}}=s^{-*}=0\right)$; there are no restrictions for $z$ and $w$. Inefficient DMUs can be improved by ADD projection $\left(\widehat{\boldsymbol{x}}_{\boldsymbol{o}}, \widehat{\boldsymbol{y}}_{\boldsymbol{o}}\right)$ : 


$$
\begin{aligned}
& \hat{x}_{i o}=x_{i o}-s_{i}^{-*} \quad(i=1, \ldots, m) \\
& \hat{y}_{r o}=y_{r o}+s_{r}^{+^{*}} \quad(r=1, \ldots, s)
\end{aligned}
$$

The ADD model is particularly useful for applications that have negative data in the inputs and outputs because it is translation invariant: a DEA model is translation invariant if translating the original input and/or output values results in a new problem that has the same optimal solution as the original (Figure 4.7). In other words, efficiency evaluation is independent of the origin of the coordinate system, and with respect to the unit of measurement of each input and output. ADD is translation invariant in both inputs and outputs when the convexity constraint is added, as opposed to input-oriented models which are translation invariant with respect to outputs only, and output-oriented models which are invariant under the translation of inputs.

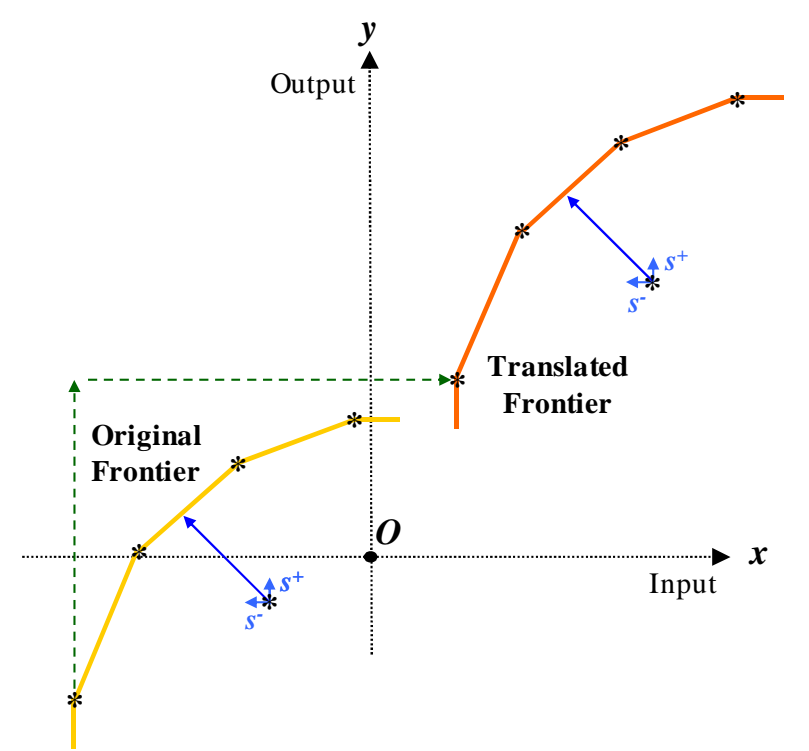

Figure 4.7: Translation Invariance in the Additive Model

\subsection{Slacks-Based Measure of Efficiency Model}

An extension of the additive model is the slacks-based measure of efficiency (SBM) model (Formulation 4.21). The main difference between the ADD and SBM models is that the former is an absolute measure (a summation of slacks) while the latter computes an efficiency score $\rho \in[0,1]$ as a ratio of average relative input consumption to average relative 
output production. Consequently, SBM models are units invariant ${ }^{6}$ (unlike ADD models), but not translation invariant (Tone, 2001).

$$
\begin{array}{ll}
\text { Minimize } & \rho=\frac{1-\frac{1}{m} \sum_{i=1}^{m} s_{i}^{-} / x_{i o}}{1+\frac{1}{s} \sum_{i=1}^{s} s_{r}^{+} / y_{r o}} \\
\text { Subject to } \quad \sum_{j=1}^{n} x_{i j} \lambda_{j}+s_{i}^{-}=x_{i o} \quad(i=1, \ldots, m) \\
\sum_{j=1}^{n} y_{r j} \lambda_{j}-s_{r}^{+}=y_{r o} \quad(r=1, \ldots, s) \\
\lambda_{j} \geq 0 \quad(j=1, \ldots, n) \\
\quad s_{i}^{-} \geq 0 \quad(i=1, \ldots, m) \\
\text { Where } \quad s_{r}^{+} \geq 0 \quad(r=1, \ldots, s) \\
0 \leq \rho \leq 1
\end{array}
$$

A DMU is SBM-efficient when $\rho^{*}=1$ (zero slacks). Inefficient DMUs can be improved with the same projection as ADD (Equation 4.20). To solve the SBM model, a positive scalar variable $t$ must be introduced (Formulation 4.22) then linearized (Formulation 4.23) such that $S^{-}=t s^{-}, S^{+}=t s^{+}$and $\Lambda=t \lambda$ :

$$
\begin{aligned}
& \text { Minimize } \tau=t-\frac{1}{m} \sum_{i=1}^{m} t s_{i}^{-} / x_{i o} \\
& \text { Minimize } \tau=t-\frac{1}{m} \sum_{i=1}^{m} S_{i}^{-} / x_{i o} \\
& \text { Subject to } \quad 1=t+\frac{1}{s} \sum_{i=1}^{s} t s_{r}^{+} / y_{r o} \\
& \text { Subject to } \quad 1=t+\frac{1}{s} \sum_{i=1}^{s} S_{r}^{+} / y_{r o} \\
& \sum_{j=1}^{n} x_{i j} \lambda_{j}+s_{i}^{-}=x_{i o} \quad(i=1, \ldots, m) \\
& \sum_{j=1}^{n} x_{i j} \Lambda_{j}+s_{i}^{-}=t x_{i o} \quad(i=1, \ldots, m) \\
& \sum_{j=1}^{n} y_{r j} \lambda_{j}-s_{r}^{+}=y_{r o} \quad(r=1, \ldots, s) \\
& \sum_{j=1}^{n} y_{r j} \Lambda_{j}-s_{r}^{+}=t y_{r o} \quad(r=1, \ldots, s) \\
& \lambda_{j} \geq 0 \quad(j=1, \ldots, n) \\
& \Lambda_{j} \geq 0 \quad(j=1, \ldots, n) \\
& s_{i}^{-} \geq 0 \quad(i=1, \ldots, m) \\
& S_{i}^{-} \geq 0 \quad(i=1, \ldots, m) \\
& s_{r}^{+} \geq 0 \quad(r=1, \ldots, s) \\
& S_{r}^{+} \geq 0 \quad(r=1, \ldots, s) \\
& t>0 \\
& t>0
\end{aligned}
$$

The optimal solution is defined by $\rho^{*}=\tau^{*}, \lambda^{*}=\Lambda^{*} / t^{*}, s^{-*}=S^{*} / t^{*}, s^{+^{*}}=S^{+^{*}} / t^{*}$.

\footnotetext{
${ }^{6}$ A DEA model is considered units invariant if the efficiency scores are independent of the units in which the inputs and outputs are measured provided these units are the same for every DMU.
} 


\subsection{Sensitivity Analysis}

There are three approaches to sensitivity analysis in DEA.

1. Varying the values of inputs and outputs: test the robustness of the model by changing the extreme values (minimums and maximums) of inputs and outputs.

2. Adding and removing variables: include or exclude an input or output variable, one at a time, to observe the effect on the scores.

3. Searching for outliers and super-efficiencies: remove DMUs that are highly referenced as they may be super-efficient outliers that skew the frontier.

\subsection{Summary of the Basic DEA Models}

Table 4.1 summarizes some important topics to consider when choosing between basic DEA models (Cooper et al, 2007). In this table, "Semi-Pos" is notation for semi-positive or nonnegative with at least one positive element in the data for each DMU, whereas "Free" allows negative, zero or positive data. $\theta^{*}$ is the efficiency score of input-oriented models while its reciprocal $\left(\eta^{*} \geq 1\right)$ is for output-oriented models. "Technical and Mix Efficiency" indicates whether a model measures technical efficiency or mix efficiency. "CRS" and "VRS" denote constant and variable returns to scale, respectively; for ADD and SBM models, this depends on the addition of the convexity constraint (i.e. $\sum \lambda_{i}=1$ ).

Table 4.1: Summary of Model Characteristics (Cooper et al., 2007)

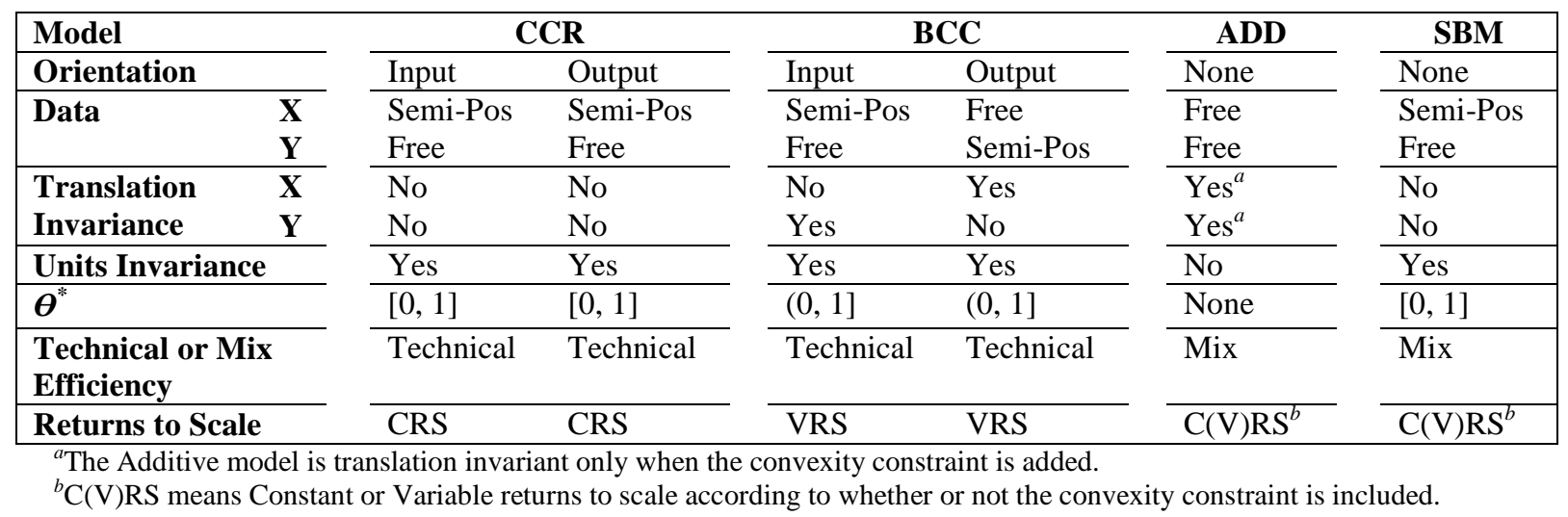

\subsection{DEA Characteristics}

\subsubsection{Strengths}

DEA has several strengths over other frontier methodologies and techniques used in performance measurement, such as regression analysis. First, regression analysis describes 
the average behaviour of all units (DMUs) or maximal variance within the dataset. DEA identifies best practice units (based on inputs consumed/outputs produced) as benchmarks and potential improvements that are real and feasible for inefficient units to target. Furthermore, because DEA measures empirical efficiency based on observations, no assumptions are made as to what productions are theoretically possible (Figure 4.8). However, in the past decade, researchers have developed approaches, such as Hall and Simar (2002) who proposed a technique for estimating boundary points in the presence of noise, to predict the form of a theoretical frontier.

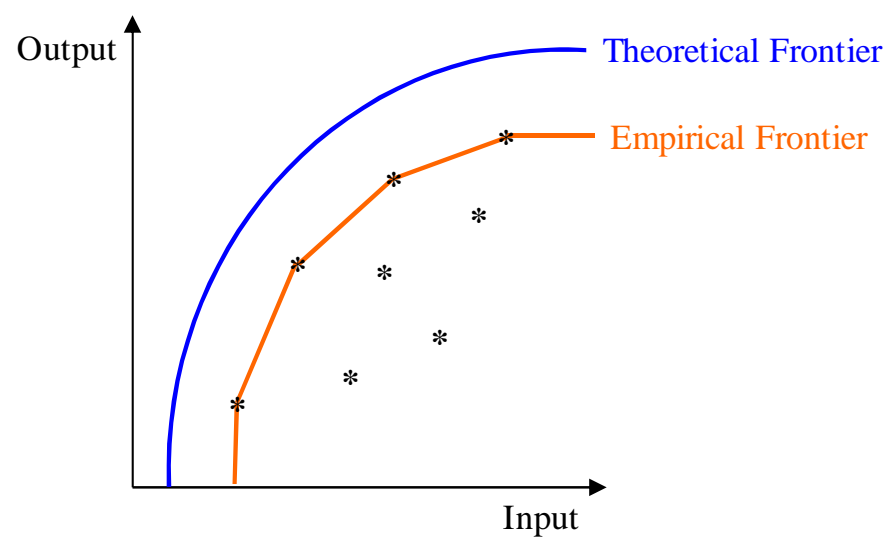

Figure 4.8: True (Theoretical) Frontier versus DEA (Empirical) Frontier

Second, DEA is nonparametric. Unlike regression, it can simultaneously handle multiple inputs and outputs which can be non-discretionary or exogenous (those over which DMUs have no control) (Charnes et al., 1994). Also, it does not require the specification of weights a priori, but calculates the optimal weightings for each DMU in order to maximize its efficiency score, provided that all other DMUs satisfy feasibility $\left(\theta^{*} \leq 1, \eta^{*} \geq 1\right)$.

Third, DEA can handle different types of units for the variables in the same model. In fact, because the first phase of both the BCC and CCR models are units invariant, variables with different units can be considered at the same time. The second stage, however, is not units invariant but can be rendered so by modifying slacks in the objective function by weights $1 / w_{i}^{+}$or $1 / w_{i}^{-}$, where $w_{i}^{+(-)}$is the amount of output ${ }_{i}\left(\mathrm{input}_{i}\right.$ ) for $\mathrm{DMU}_{o}$, or the inter-percentile range, average, or standard deviation of the amount of output ${ }_{i}\left(\right.$ input $\left._{i}\right)$ employed by all DMUs.

Finally, DEA produces a single all-encompassing efficiency score that characterizes a unit's production of all relevant outputs. This facilitates the ranking and comparison of 
DMUs in multiple output frameworks, as opposed to having a separate ratio measure for each output.

\subsubsection{Limitations}

First, standard DEA models do not account for random error; the assumption is that deviations from the frontier are due to inefficiency only and makes no allowances for measurement error or other noise. The fact that random errors may alter the shape of the frontier, resulting in inaccurate scores, has led to the development of several stochastic DEA models. For example, Land, Lovell and Thore (1993) accommodated uncertainty by introducing a set of chance constraints stating that observed outputs must not exceed best practice outputs more than $5 \%$ of the time (when inputs are predetermined). However, their model also requires information on the joint probability distribution of variables.

Second, DEA is unable to accurately model small sample sizes because analyses containing less than the recommended number of DMUs yield higher efficiency scores with many DMUs appearing on the frontier. The rough rule of thumb is $n \geq \max \{m \times s, 3(m+s)\}$ where $n, m$ and $s$ are the number of DMUs, inputs and outputs, respectively (Banker et al., 1986).

Third, DEA provides only a relative efficiency score based on the set of DMUs studied. If certain key DMUs (which are highly efficient) are excluded, then the scores provided will not be as accurate. Because an empirical efficient frontier represents the best practices observed within the sample, DEA provides little insight into the location of the theoretical frontier (best performance actually possible). Thus, standard DEA models do not identify possible improvements and targets for those DMUs found to be efficient.

Fourth, standard DEA models have complete freedom to assign the relative weights for inputs and outputs. Consequently, DEA can assign zero or near-zero weights to some inputs and outputs in order to maximize the efficiency of individual DMUs, especially to outliers that consume a very small amount of one particular input, or those that produce a very large amount of one particular output. Realistically, however, it is possible to impose constraints on the relative magnitude of the weights via the Assurance Region method or cone ratio methods. As an example, the ratio of weights for Input 1 and Input 2 may be restricted as $L_{1,2} \leq \frac{v_{2}}{v_{1}} \leq U_{1,2}$ where $L_{1,2}$ and $U_{1,2}$ are lower and upper bounds. Generally, Assurance 
Region efficiency scores are worsened by the addition of constraints; a DMU otherwise characterized as efficient may be found to be inefficient (Thompson et al., 1986).

Weight restrictions have also been used to capture the time lag between the consumption of inputs and the production of outputs (Özpeynirci and Köksalan, 2007). Standard DEA may sometimes be incorrect in scenarios where producing outputs in a given period is possible by consuming inputs during several time periods. Moreover, this "production lead time" may be unknown, deterministic or controllable. This led to the introduction of "dynamic DEA" where Sengupta (1996) measured the efficiency of systems by analyzing two aspects of changes over time: incremental capital inputs or investments associated new technology, and adjustments costs, when firms tend to adapt their short-run behaviour to the long-run optimal goals. Dynamic or time-varying efficiency scores may assist in planning and decision-making as to when to start production, how long to produce, which storable inputs to store, and which intermediate outputs to produce them.

Similarly, "network DEA" was introduced to combat the "black box" effect of DEA; that is, inputs "enter" and outputs "exit" a DMU with no consideration of the intervening steps that may be sources of inefficiency within it. Lewis and Sexton's model (2004) handled DMUs that consisted of a network of sub-DMUs, some consuming resources produced by other sub-DMUs and some producing resources consumed by other sub-DMUs. Perhaps of greatest significance, the network DEA Model allowed individual DMU managers to focus efficiency-enhancing strategies on the individual stages of the production process (Lewis and Sexton, 2004).

Finally, the use of DEA is problematic when one or more of the input or output variables are in a ratio form (Hollingsworth et al., 2003). For example, consider a system where single input $x$ produces two outputs $y_{1}$ and $y_{2}$ and 4 DMUs form the efficient frontier: $\mathrm{A}, \mathrm{B}, \mathrm{C}$ and D (Figure 4.9). DMU $\mathrm{E}$ is inefficient and according to the convexity axiom of DEA, the convex combination of $\mathrm{A}$ and $\mathrm{E}$, a DMU AE, should lie in the production possibility set. However, if either output is in ratio form, the actual convex combination of the A and E should be calculated as a weighted combination of two DMUs, which may fall outside the feasible region (as illustrated by DMU AE'). Therefore, the convexity assumption may fail, leading to incorrect efficiency scores and distorted projections 
(Emrouznejad and Amin, 2007). The best way to rectify this problem is to use absolute values if both the numerator and the dominator of the ratio variables are known.

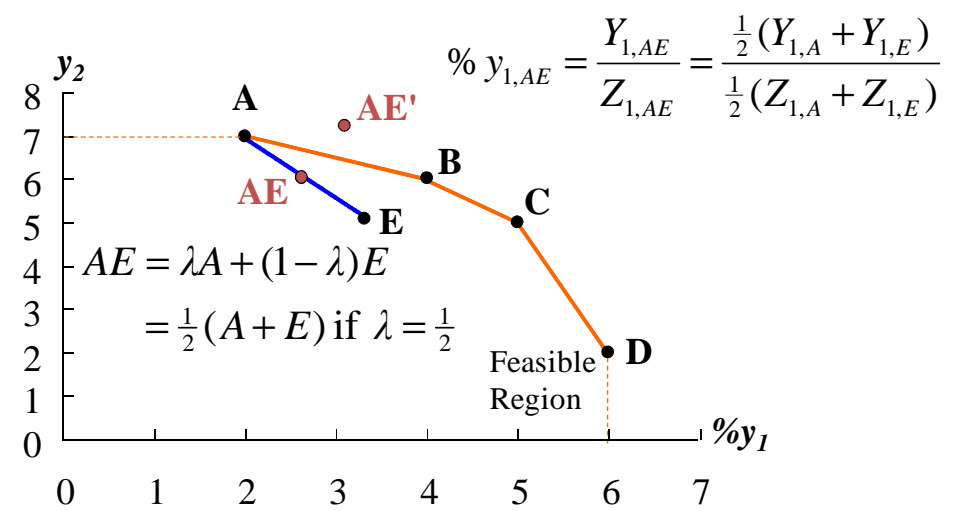

Figure 4.9: One Input, Two Output Example for Use of Ratios in DEA

\subsection{DEA Studies in Bankruptcy}

The advantages of DEA and the intuitive relationship between inefficiency and failure have inspired many studies on DEA and failure, mainly with banks - only a few of which will be discussed here ${ }^{7}$.

Barr et al. (1993, 1994) incorporated the international bank-rating system CAMELS

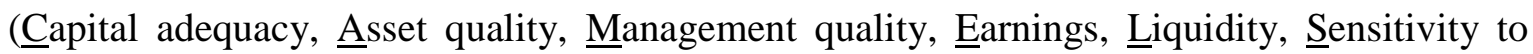
market risk) with DEA to predict bank failure, relating it to inefficiency. The analysis of these 6 factors for 930 banks over 5 years validated the use of DEA as surviving institutions scored significantly different than those that failed. However, the results were specific only to banks and not general corporations.

In another study, Kao et al. (2004) applied DEA to predict bankruptcy of 24 Taiwanese commercial banks based on 3 inputs (total deposits, interest expenses, noninterest expenses) and 3 outputs (total loans, interest income, non-interest income). They administered a questionnaire to general managers asking for their forecasts of financial data for the following year. A DEA model using interval data to account for pessimistic and optimistic views, generated efficiency scores for each bank based on these managerial predictions. These scores were then compared to the true efficiency scores calculated from data available in financial statements a year later, and were within the ranges of predicted

\footnotetext{
${ }^{7}$ Please refer to the paper by Ravi Kumar et al. (2006) for a comprehensive survey of past studies.
} 
scores from financial forecasts. Nonetheless, despite the value of human judgment and hypothesis, this type of prediction was still subjective.

Extending beyond banks to general companies, Pušnik et al. (2008) investigated whether technical and cost efficiency as measured by DEA can predict small business failures in Slovenia. However, little information was provided on the methodology, particularly with respect to how data for all years and companies from different industries were accounted for. Also, the choice, definition and orientation of variables were not explicit beyond the use of financial ratios - a practical problem as companies may perform differently and a mathematical limitation of DEA. Consequently, results seemed counterintuitive: there was no difference in the rate of return on sales between surviving and failed firms; the average value of the rate of return on equity increased for bankrupt firms; and the absolute values of liquidity ratios were not critical even for failed firms, suggesting that a firm with high liquidity could go bankrupt. Similarly, Cielen et al. (2004) applied 11 financial ratios to DEA to predict bankruptcy between 1994 and 1996 with Type I and II errors of $24 \%$ and $21 \%$, respectively. However, the number of companies, and the industries and countries under study were not mentioned - only that 276 non-bankrupt and 90 bankrupt annual reports were examined. Also, Premachandra et al. (2011) investigated over 1000 US companies from a spectrum of industries between 1991 and 2004. Seven ratios were applied to an additive model with the generated DEA scores classified as bankrupt or non-bankrupt based on a single cut-off value. This model was relatively weak in predicting corporate failures compared to healthy firms, highlighting a common problem among bankruptcy prediction using cut-off values: the trade-off between Type I and II errors.

DEA has also been used in conjunction with other techniques to predict bankruptcy. For instance, Xu et al. (2009) studied corporations listed on the Shanghai Stock Exchange and proposed a financial failure prediction model using efficiency as a predictor variable. Specifically, the score generated by DEA (with total assets, total liabilities and cost of sales as inputs, and income of sales as the output) was a proxy for the relative efficiency of business operations. It was combined with 7 ratios and then applied to support vector machines, logistic regression, multiple discriminant analysis. Results showed that using DEA efficiency as a predictor improves prediction accuracy. However, these were limited by an unrepresentative sample of firms: half of the 120 firms had filed for bankruptcy 
between 1999 and 2005. Furthermore, the selection of the 7 ratios as variables was based on the results of the $t$-test only, which assumed that the ratios were normally distributed.

While literature in bankruptcy has been enriched by work with DEA, prediction has also offered opportunities to develop new DEA models. For example, in a study of manufacturing companies, Paradi et al. (2004) analyzed a series of financial variables with their novel "worst practice" DEA model ${ }^{8}$. A small and equal number of good and bad performing firms showed very encouraging results. However, after more extensive analysis with a larger dataset to reflect real proportions, the model did not work as well. Following a similar philosophy, Shetty et al. (2012) assessed bankruptcy of IT companies operating in India by creating an inefficient frontier based on 10 financial ratios. Although the authors stated that their bankruptcy scores were consistent with poor performing firms, there was no discussion of the reliability or validity of their model (i.e. no reports of misclassification or success rates).

And in a final example, Sueyoshi et al. $(1998,2009)$ developed and applied DEA-DA to assess bankruptcy. DEA-DA was derived from the DEA-Additive model and incorporated the unique features of DEA into the framework of discriminant analysis (DA). It was designed to find an overlap between two groups in a first stage, then in a second stage, determine a piecewise linear classification function to further separate the groups. Sueyoshi et al. (2009) compared DEA and DEA-DA with a dataset of 609 firms (951 non-bankrupt and 50 bankrupt). Although the input and output variables were ratios, they made a valuable finding: DEA models misclassified all bankrupt firms because of the data imbalance; however, DEA-DA can potentially deal with this imbalance by "controlling the importance" of the two groups, as determined by size.

\footnotetext{
${ }^{8}$ Where normal DEA selects potentially distressed firms by measuring how inefficient they are at being good, worst practice DEA picks out distressed firms based on how efficient they are at being bad. This approach is particularly fitting for credit risk evaluation where the worst companies need to be clearly identified (Section 8.1.1).
} 


\section{Objectives}

The objective of this research is to develop a Data Envelopment Analysis (DEA)-based model which predicts the likelihood of failure of American retail-apparel companies and suggests preventative measures based on data available from financial statements and their accompanying Notes (which provide hints on managerial decision-making) as well as market and economic influences. It is hypothesized that the inclusion of variables that reflect managerial decision-making, and market and economic factors, enhance the predictive power of mathematical models that consider financial data exclusively. For example, the industrystandard Altman model has an accuracy of only $70 \%, 58 \%$ and $50 \%$ when predicting cases today, from one year back and two years back, respectively. This work is an opportunity for cross-disciplinary contributions to the fields of finance, accounting, and operations research as novel metrics are created and the shortcomings of current approaches are addressed (Figure 5.1). Also, although analysis in this thesis is specific to retail-apparel, the development of a methodology to predict bankruptcy which can then be adapted for another industry is of great value.

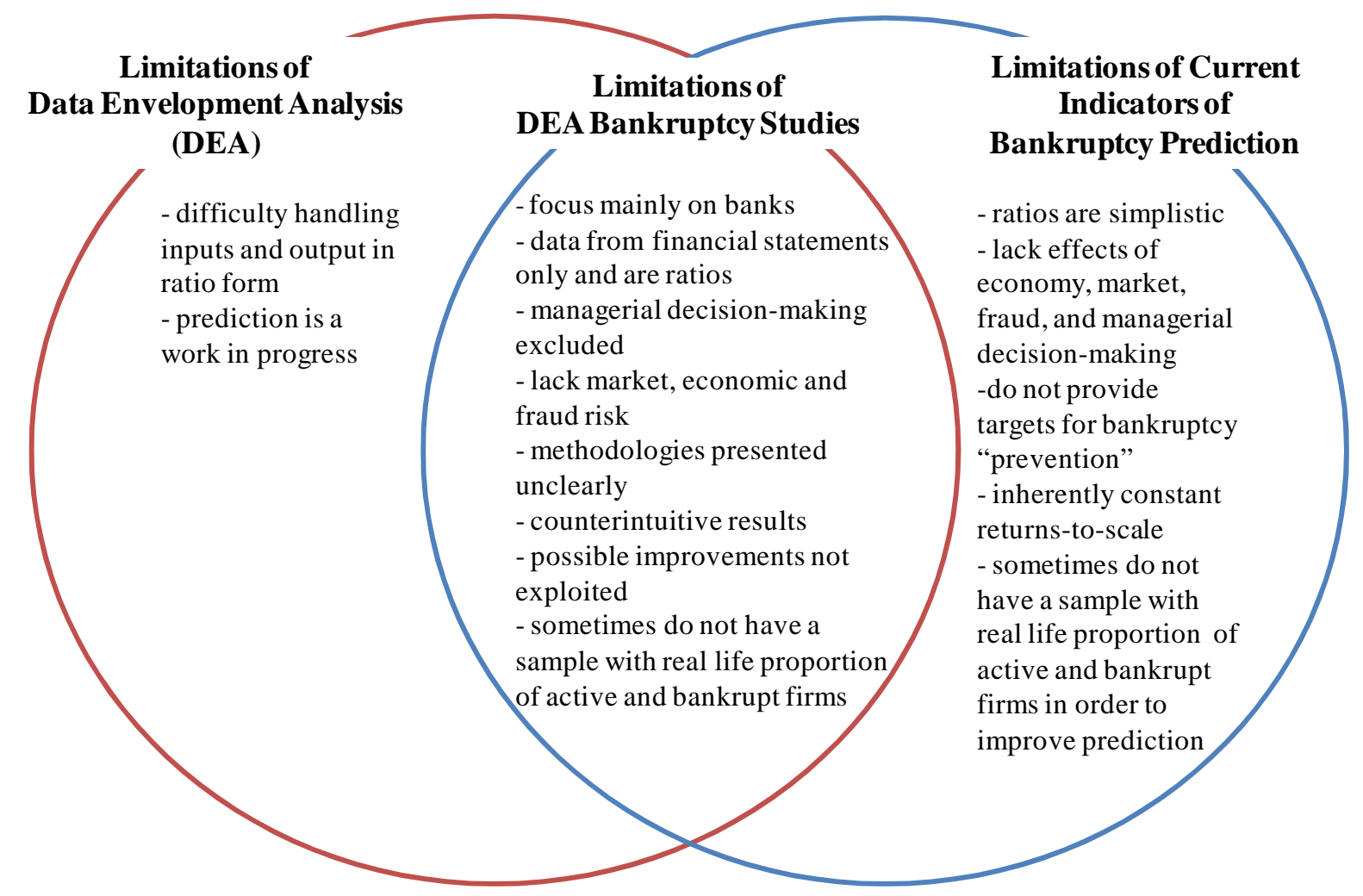

Figure 5.1: Current Limitations 


\section{Data Collection, Preparation and Exploration}

\subsection{List of Retail-Apparel Companies}

The US retail-apparel industry ${ }^{9}$ was selected because 1 . it contains a large sample of public companies of roughly the same size or market capitalization operating in the same country; 2 . there is competition such that turnover of companies is not uncommon; 3. while firms within it may not sell the same products, they employ similar business models; and 4. the industry's working environment has remained relatively consistent over the time of study to avoid modeling the effect of external factors (i.e. the significant influence of advancing technology) other than inflation or recession.

Originally, 85 companies in the retail-apparel industry that are actively or have been publicly traded at some time since 1988 were considered (Table 6.1).

Table 6.1: List of Companies by Ticker Code in Retail-Apparel Industry

\begin{tabular}{|c|c|c|c|c|c|}
\hline Company & State & Company & State & Company & State \\
\hline AENA & Active & DSW & Active & LOEHQ & Bankrupt (1999) \\
\hline $\mathrm{AEO}$ & Active & DUSS & Active & LTD & Active \\
\hline ANF & Active & EBHI & Bankrupt (2009) & LULU & Active \\
\hline ANN & Active & EDBRW & Bankrupt (1996) & MGR & Bankrupt (1994) \\
\hline ARO & Active & EXLA & Active & MW & Active \\
\hline BEBE & Active & FEETQ & Bankrupt (2000) & NWY & Active \\
\hline BKE & Active & FINL & Active & ONPRQ & Bankrupt (2004) \\
\hline BKRS & Active & FL & Active & PHRS & Bankrupt (2000) \\
\hline BSMT & Bankrupt (1999) & $\mathrm{FOH}$ & Bankrupt (2003) & PLCE & Active \\
\hline BSST & Active (1997) & FTAR & Bankrupt (2002) & PRVU & Active \\
\hline $\mathrm{CACH}$ & Active & FTUS & Bankrupt (2004) & PSS & Active \\
\hline CATH & Active (2000) & GADZQ & Bankrupt (2005) & PSUN & Active \\
\hline CBK & Bankrupt (1996) & GCO & Active & ROST & Active \\
\hline $\mathrm{CHIC}$ & Active & GDYS & Active (2005) & SCVL & Active \\
\hline CHRS & Active & GPS & Active & SHOE & Bankrupt (2008) \\
\hline $\mathrm{CHS}$ & Active & GYMB & Active & SJKI & Active \\
\hline CMALQ & Bankrupt (2001) & HOTT & Active & SKFB & Active \\
\hline CML & Bankrupt (1998) & HRLS & Bankrupt (2008) & SMRT & Active \\
\hline CMRG & Active & IBI & Active (2002) & SSI & Active \\
\hline CSS & Bankrupt (1997) & JAYJ & Bankrupt (1994) & SYMS & Active \\
\hline CTMEQ & Bankrupt (1996) & JCG & Active & TJX & Active \\
\hline CTR & Active & JOSB & Active & TLB & Active \\
\hline CTRN & Active & JWN & Active & TMAN & Bankrupt $(1996,2002)$ \\
\hline CWTR & Active & KDRH & Bankrupt (1993) & URBN & Active \\
\hline DABR & Active (2000) & KGM & Active (1999) & URGI & Active (2007) \\
\hline DBRN & Active & KNWN & Bankrupt (1994) & WALK & Active \\
\hline DEBS & Active (2007) & KUHM & Active & WTSL & Active \\
\hline DEST & Active & LAM & Bankrupt (1995) & ZUMZ & Active \\
\hline DLIA & Active & & & & \\
\hline
\end{tabular}

\footnotetext{
${ }^{9}$ SIC Division G (Retail Trade), Major Group 56 (Apparel and Accessory Stores)
} 
The 61 firms that never declared bankruptcy between 1988 and 2009 were categorized as "active" while the 24 firms that declared bankruptcy at least once (in the year(s) in parentheses) were categorized as "bankrupt". Common reasons for filing Chapter 11 included a heavy debt burden, change in management, fraud and recession (Table 6.2, Appendix C). Firms that merged with or were acquired by another (in italics in Table 6.1) were re-classified as either active or bankrupt depending on their state at the year of transition (in parentheses).

Table 6.2: Reasons for Chapter 11 Filings Cited in Press Releases

\begin{tabular}{|l|c|}
\hline \multicolumn{1}{|c|}{ Reason } & Companies Citing Given Reason \\
\hline Illiquidity and/or insolvency & 16 \\
\hline Unprofitability, net/operating losses, negative cash flows & 14 \\
\hline Competition & 9 \\
\hline Declining sales & 8 \\
\hline Recession & 8 \\
\hline Vendors refusing to deliver merchandise resulting in low inventory & 5 \\
\hline Management changes & 3 \\
\hline Excess inventory & 2 \\
\hline Accounting fraud or discrepancies & 2 \\
\hline
\end{tabular}

With a list of companies, the search for data followed through federal agencies and the University of Toronto Libraries. EDGAR is the most popular database of online corporate information. The Electronic Data-Gathering, Analysis and Retrieval system performs automated collection, validation, indexing, acceptance and forwarding submissions by companies who are required by law to file forms with SEC. While it is free for public use, EDGAR has several limitations. First, not all SEC filings before May 6, 1996 are available although as of this date, all public companies must file on EDGAR. Second, actual annual reports to shareholders need not be submitted on EDGAR. However, Form 10-K or 10-KSB, which contains much of the same information as the annual report, is required. Third, the presentation of the filings (often .pdf) is not in a manageable format (such as in Microsoft Excel spreadsheets) ideal for mathematical analysis.

\subsection{Definition of Study Period, Comparable Units and Company State}

A challenge in bankruptcy research is that the data from companies do not all overlap entirely over the same time period; that is, the "start" and "end" dates vary by company (Figure 6.1 and Figure 6.2). All studies circumvent this by working with a smaller time frame where there are data for each company for each year but this reduces the sample size 
considerably. Because creating a technique that calibrates for time is beyond the scope of this thesis, to consistently compare companies in the same environment, the period between 1996 and 2009 was studied. At best, the effect of inflation was considered but appeared to be insignificant to the results (Section 10.7)

\begin{tabular}{|c|c|c|c|c|c|c|c|c|c|c|c|c|c|c|c|c|c|c|c|c|c|c|}
\hline Company & 1988 & 1989 & 1990 & 1991 & 1992 & 1993 & 1994 & 1995 & 1996 & 1997 & 1998 & 1999 & 2000 & 2001 & 2002 & 2003 & 2004 & 2005 & 2006 & 2007 & 2008 & 2009 \\
\hline AENA & & & & & & & & & & & & & & & & & & 0 & 0 & 1 & 0 & \\
\hline AEO & & & & & & 0 & 0 & 0 & 0 & 1 & 1 & 1 & 1 & 1 & 1 & 1 & 1 & 1 & 1 & 1 & 1 & 1 \\
\hline ANF & & & & & & & 0 & 0 & 0 & 1 & 1 & 1 & 1 & 1 & 1 & 1 & 1 & 1 & 1 & 1 & 1 & 1 \\
\hline ANN & & & & & 0 & 0 & 1 & 1 & 1 & 1 & 1 & 1 & 1 & 1 & 1 & 1 & 1 & 1 & 1 & 1 & 1 & 1 \\
\hline ARO & & & & & & & & & & & & 0 & 0 & 0 & 1 & 1 & 1 & 1 & 1 & 1 & 1 & 1 \\
\hline BEBE & & & & & & & & 0 & 0 & 0 & 1 & 1 & 1 & 1 & 1 & 1 & 1 & 1 & 1 & 1 & 1 & \\
\hline BKE & & & & & & 0 & 0 & 0 & 1 & 1 & 1 & 1 & 1 & 1 & 1 & 1 & 1 & 1 & 1 & 1 & 1 & 1 \\
\hline BKRS & & & & & & & & & & & & & 0 & 0 & 0 & 0 & 1 & 1 & 1 & 1 & 1 & \\
\hline BSMT & & & & & & & & 0 & 0 & 1 & 1 & 1 & 0 & & & & & & & & & \\
\hline BSST & & & & & & 0 & 0 & 0 & 1 & $\mathrm{~A}$ & & & & & & & & & & & & \\
\hline $\mathrm{CACH}$ & & & & & 0 & 0 & 0 & 1 & 1 & 1 & 1 & 1 & 1 & 1 & 1 & 1 & 1 & 1 & 1 & 1 & 1 & \\
\hline CATH & & & & & & & 0 & 0 & 0 & 1 & 1 & 1 & $\mathrm{~A}$ & & & & & & & & & \\
\hline CBK & & & & & & 0 & 0 & 0 & B & 1 & 1 & 1 & 1 & 1 & 1 & 1 & 1 & 1 & 1 & 1 & 1 & 1 \\
\hline CHIC & & & & & & & & & 0 & 0 & 0 & 1 & 1 & 1 & 1 & 1 & 1 & 1 & 1 & 1 & 1 & \\
\hline CHRS & & & & 0 & 0 & 0 & 1 & 1 & 1 & 1 & 1 & 1 & 1 & 1 & 1 & 1 & 1 & 1 & 1 & 1 & 1 & 1 \\
\hline CHS & & & & 0 & 0 & 0 & 0 & 0 & 0 & 1 & 1 & 1 & 1 & 1 & 1 & 1 & 1 & 1 & 1 & 1 & 1 & 1 \\
\hline CMAL Q & & & & & 0 & 0 & 1 & 1 & 1 & 1 & 1 & 1 & 1 & 1 & 0 & & & & & & & \\
\hline CML & & & & & 0 & 0 & 1 & 1 & 1 & 1 & 1 & & & & & & & & & & & \\
\hline CMRG & & & & & & 0 & 0 & 1 & 1 & 1 & 1 & 1 & 1 & 1 & 1 & 1 & 1 & 1 & 1 & 1 & 1 & 1 \\
\hline CSS & & & & & & & & 0 & 0 & B & 0 & & & & & & & & & & & \\
\hline CTME Q & & & & & & & 0 & 0 & 1 & 1 & & & & & & & & & & & & \\
\hline CTR & & & & & & & & & & & & & & & & 1 & 1 & 1 & 1 & 1 & 1 & 1 \\
\hline CTRN & & & & 0 & 0 & 0 & 0 & 0 & 0 & 0 & 0 & 0 & 0 & 0 & 0 & 0 & 0 & 1 & 1 & 1 & 1 & 1 \\
\hline CWTR & & & & & & & 0 & 0 & 0 & 0 & 1 & 1 & 1 & 1 & 1 & 1 & 1 & 1 & 1 & 1 & 1 & 1 \\
\hline DABR & & & & & & & & & & 0 & 0 & 0 & 1 & & & & & & & & & \\
\hline DBRN & & & 0 & 0 & 0 & 0 & 1 & 1 & 1 & 1 & 1 & 1 & 1 & 1 & 1 & 1 & 1 & 1 & 1 & 1 & 1 & \\
\hline DEBS & & 0 & 0 & 0 & 0 & 0 & 0 & 1 & 1 & 1 & 1 & 1 & 1 & 1 & 1 & 1 & 1 & 1 & 1 & 1 & & \\
\hline DEST & & & & & & & & & & & & & & & & 1 & 1 & 1 & 1 & 1 & 1 & \\
\hline DLIA & & & & & & & & & & & & & & & & & 0 & 0 & 1 & 1 & 1 & 1 \\
\hline DSW & & & & & & & & & & & & & & & 0 & 0 & 0 & 0 & 1 & 1 & 1 & 1 \\
\hline DUSS & & & & & & & & & & & & & & & & & & & 0 & 1 & 1 & 1 \\
\hline EBHI & & & & & & & & & & & & & & & & & 0 & 0 & 1 & 1 & 0 & 1 \\
\hline EDBR W & & & & & 0 & 0 & 1 & 1 & 1 & 1 & 1 & & & & & & & & & & & \\
\hline EXLA & & & & & & & & & & & & & & & & & & & 1 & 1 & 1 & \\
\hline FEET Q & & & & & & & & 0 & 0 & 1 & 1 & 1 & B & & & & & & & & & \\
\hline FINL & & & & & & 0 & 0 & 0 & 0 & 1 & 1 & 1 & 1 & 1 & 1 & 1 & 1 & 1 & 1 & 1 & 1 & 1 \\
\hline FL & & & & & & 0 & 0 & 1 & 1 & 1 & 1 & 1 & 1 & 1 & 1 & 1 & 1 & 1 & 1 & 1 & 1 & 1 \\
\hline $\mathrm{FOH}$ & & & & & & 0 & 0 & 1 & 1 & & & & & & & & & & & 1 & 1 & \\
\hline FTAR & & & & & & & 0 & 0 & 1 & 1 & 1 & 1 & 1 & 1 & 1 & 1 & 1 & 1 & 1 & 1 & 1 & \\
\hline FTUS & & & & & & 0 & 0 & 0 & 1 & 1 & 1 & 1 & 1 & 1 & 1 & 1 & 1 & & & & & \\
\hline GADZ Q & & & & & & & & 0 & 0 & 1 & 1 & 1 & 1 & 1 & 1 & 1 & 1 & B & & & & \\
\hline GCO & 0 & 0 & 0 & 0 & 0 & 0 & 1 & 1 & 1 & 1 & 1 & 1 & 1 & 1 & 1 & 1 & 1 & 1 & 1 & 1 & 1 & 1 \\
\hline GDYS & & & 0 & 0 & 0 & 0 & 0 & 0 & 0 & 1 & 1 & 1 & 1 & 1 & 1 & 1 & 1 & 1 & & & B & \\
\hline GPS & & & 0 & 0 & 0 & 0 & 0 & 0 & 1 & 1 & 1 & 1 & 1 & 1 & 1 & 1 & 1 & 1 & 1 & 1 & 1 & \\
\hline GYMB & & & & & & & & & & & & & & & & & 1 & 1 & 1 & 1 & 1 & 1 \\
\hline HOTT & & & & & & & & & & & & & & & & & 1 & 1 & 1 & 1 & 1 & 1 \\
\hline HRLS & & & & & & 0 & 0 & 0 & 1 & 1 & 1 & 1 & 1 & 1 & 1 & 1 & 1 & 1 & 1 & 1 & 1 & \\
\hline IBI & & & & & & & & 1 & 1 & 1 & 1 & 1 & 1 & 1 & A & & & & & & & \\
\hline JAYJ & & & & & & & B & 0 & 0 & 0 & 1 & 0 & & & & & & & & & & \\
\hline JCG & & & & & & & & & & & & & & & & & 1 & 1 & 1 & 1 & 1 & 1 \\
\hline JOSB & & & & & & & & 0 & 0 & 1 & 1 & 1 & 1 & 1 & 1 & 1 & 1 & 1 & 1 & 1 & 1 & 1 \\
\hline JWN & & & & & 0 & 0 & 1 & 1 & 1 & 1 & 1 & 1 & 1 & 1 & 1 & 1 & 1 & 1 & 1 & 1 & 1 & 1 \\
\hline
\end{tabular}

Figure 6.1: Time Frame of Available Data for Companies AENA-JWN

Highlighted Box Colour: Green $=$ Active; Pink $= \pm 3$ years prior/post bankruptcy

Bolded Font Colour: Red = Year of bankruptcy; Blue = Year merged/acquired

Numbers: "1" = Managerial decision-making data available; "0" = Managerial decisionmaking data unavailable

Letters: "A" = Year merged/acquired, now active without managerial decision-making data; "B" = Year of bankruptcy without managerial decision-making data; 


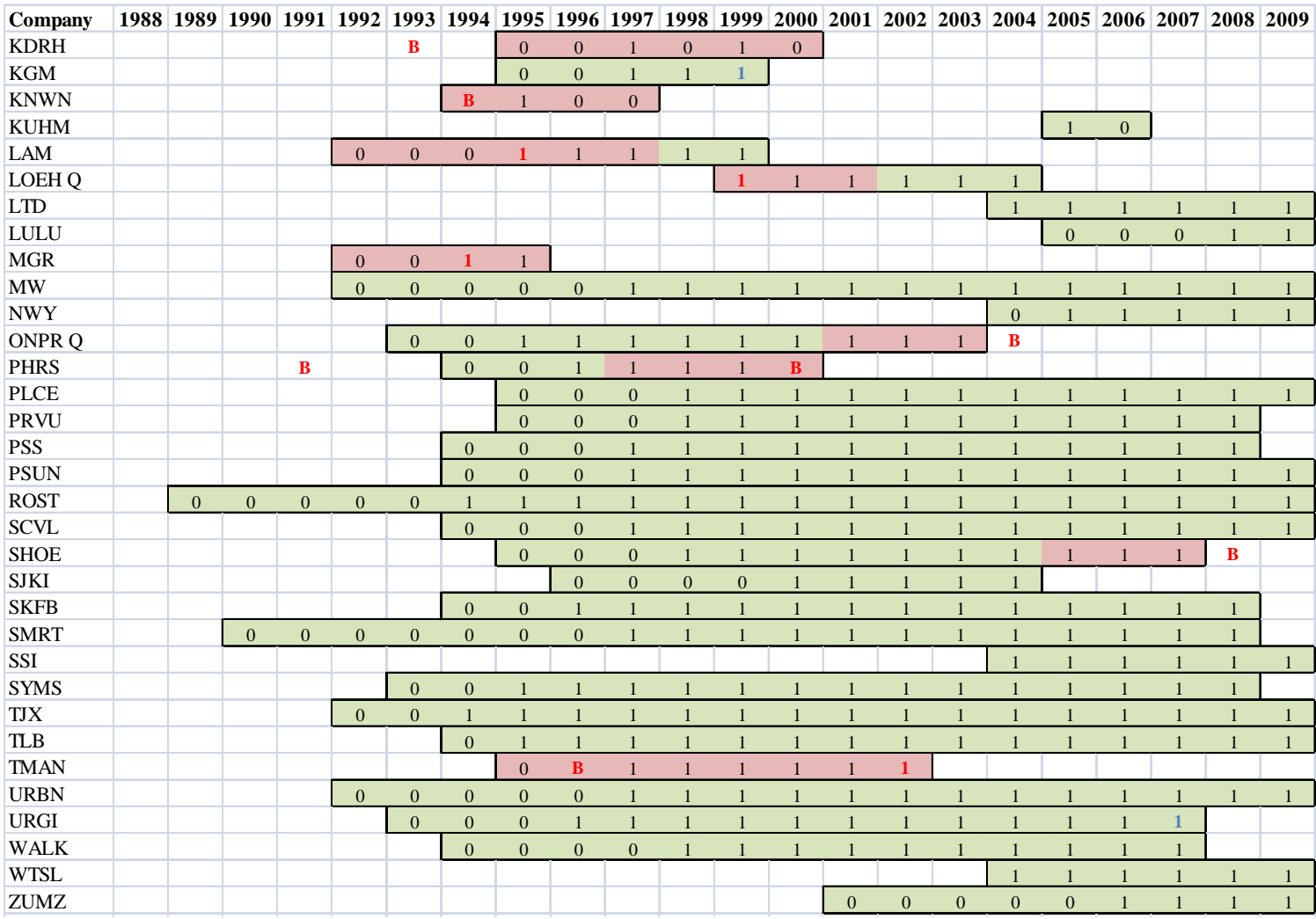

Figure 6.2: Time Frame of Available Data for Companies KDRH-ZUMZ

Highlighted Box Colour: Green $=$ Active; Pink $= \pm 3$ years prior/post bankruptcy

Bolded Font Colour: Red = Year of bankruptcy; Blue = Year merged/acquired

Numbers: "1" = Managerial decision-making data available; "0" = Managerial decisionmaking data unavailable

Letters: "A" = Year merged/acquired, now active without managerial decision-making data;

"B" = Year of bankruptcy without managerial decision-making data;

Here, a DMU ("Decision Making Unit" or Unit of Comparison) was associated with both a company and a year. Each DMU had a corresponding state (Table 6.3). The reason for predicting up to 3 years back was to be consistent with other past studies. In some analyses, a DMU was assigned a less specific state of bankruptcy: if it was 3 years or less from bankruptcy, then it was simply classified as bankrupt (i.e. instead of "B- $x$ " where $x=1,2$ or 3 , it was just "B").

Table 6.3: Possible DMU States

\begin{tabular}{|l|l|c|}
\hline Notation & \multicolumn{1}{|c|}{ Definition } & Colour in Figure 6.1 and Figure 6.2 \\
\hline A & Active, non-bankrupt year & Green \\
\hline B-3 & Three years prior to bankruptcy & Pink \\
\hline B-2 & Two years prior to bankruptcy & Pink \\
\hline B-1 & One year prior to bankruptcy & Pink \\
\hline B & Bankruptcy Year & Pink \\
\hline
\end{tabular}




\subsection{Financial Data}

\subsubsection{List of Financial Variables}

The balance sheet, income statement and cash flow statement for each company were obtained for every year historical values were available. All entries recorded from these financial statements are listed in Table 6.4, though not all were used in analysis. Financial data are reported in millions of dollars.

Table 6.4: Financial Items

\begin{tabular}{|c|c|c|}
\hline \multicolumn{3}{|c|}{ Balance Sheet } \\
\hline $\begin{array}{l}\text { - Cash } \\
\text { - Marketable Securities } \\
\text { - Accounts Receivables } \\
\text { - Inventories } \\
\text { - Other Current Assets } \\
\text { - Current Assets } \\
\text { - Long-Term Investments in } \\
\text { - Securities } \\
\text { - Property, Plant and Equipment } \\
\text { - Accumulated Depreciation } \\
\text { - Amortizable Intangible Assets } \\
\text { - Goodwill and Non- } \\
\text { Amortizable Intangibles }\end{array}$ & $\begin{array}{l}\text { - Other Non-Current Assets } \\
\text { - Total Assets } \\
\text { - Accounts Payable } \\
\text { - Notes Payable and Short-Term } \\
\text { Debt } \\
\text { - Current Maturities of Long- } \\
\text { Term Debt } \\
\text { - Other Current Liabilities } \\
\text { - Current Liabilities } \\
\text { - Long-Term Debt } \\
\text { - Deferred Taxes } \\
\text { - Other Non-Current Liabilities } \\
\text { - Total Liabilities }\end{array}$ & $\begin{array}{l}\text { - Minority Interest in } \\
\text { Subsidiaries } \\
\text { - Preferred Stock } \\
\text { - Common Stock } \\
\text { - Retained Earnings } \\
\text { - Accumulated Other } \\
\text { Comprehensive Income } \\
\text { - Treasury Stock } \\
\text { - Shareholders' Equity } \\
\text { - Total Liabilities and } \\
\text { Equities }\end{array}$ \\
\hline \multicolumn{2}{|c|}{ Income Statement } & Cash Flow Statement \\
\hline $\begin{array}{l}\text { - Revenue } \\
\text { - Cost of Goods Sold } \\
\text { - Gross Profit } \\
\text { - Selling, General and } \\
\text { Administrative Expenses } \\
\text { - Other Operating Expenses } \\
\text { (Income) } \\
\text { - Operating Profit } \\
\text { - Interest Income } \\
\text { - Interest Expense }\end{array}$ & $\begin{array}{l}\text { - Other Expenses (Income) } \\
\text { - Income Before Tax } \\
\text { - Income Tax Expense } \\
\text { - Income from Discontinued } \\
\text { Operations } \\
\text { - Extraordinary Gains (Losses) } \\
\text { - Changes in Accounting } \\
\text { Principles } \\
\text { - Net Income }\end{array}$ & $\begin{array}{l}\text { - Cash Flow from } \\
\text { Operating Activities } \\
\text { - Cash Flow from } \\
\text { Investing Activities } \\
\text { - Cash Flow from } \\
\text { Financing Activities } \\
\text { - Change in Cash }\end{array}$ \\
\hline
\end{tabular}

\subsubsection{Collection and Organization of Financial Variables}

Because EDGAR does not provide its data in a manageable format, all financial data dating back to 1988 (if available) were downloaded from the Capital IQ database accessible at the Rotman School of Management. The Capital IQ database stores an assortment of data ${ }^{10}$ for each company in its own .xls (MS Excel) file. In this work, the most relevant information was contained in the "Balance Sheet", "Income Statement" and "Cash Flow Statement" spreadsheets.

\footnotetext{
${ }^{10}$ Capital IQ spreadsheets include: Key Stats, Income Statement, Balance Sheet, Cash Flow, Multiples, Historical Capitalization, Capital Structure Summary, Capital Structure Details, Ratios, Supplemental, Industry Specific, Pension OPEB, Segments
} 
Companies within the same industry often label items in their financial statements identically. However, in the instances where this was not the case, differences were resolved in order for the comparison among companies to be legitimate. This required that financial statements be "converted" into template statements (Figure 6.3). Templates were taken from the Financial Statement Analysis Package (FSAP), Version 6.0, provided by Stickney et al. (2007) (Figure 6.4- Figure 6.6). They are in .xls format and include the most important items as well as unspecified fields (with the preceding label called "Other") for the user to fit his/her choice of data.

Creating template financial statements for all companies was time consuming yet imperative. The conversion steps taken for one company typically involved:

1. creating a new company file where template statements were stored;

2. scouring through a company's original spreadsheets (in its Capital IQ file) and extracting appropriate financial data to fill into the new template file; and,

3. validating the new template statements.

Macros coded in Visual Basic (VB) were written to automate the most tedious part of the process (Step 2). After the templates were generated, they were manually inspected to verify the numbers. For example, checkpoints were placed in the template statements to ensure that the balance sheet, indeed, balanced and the computed net income was identical to that stated in the income statement. If these checkpoints were violated, template data were carefully reviewed and problems were manually fixed.

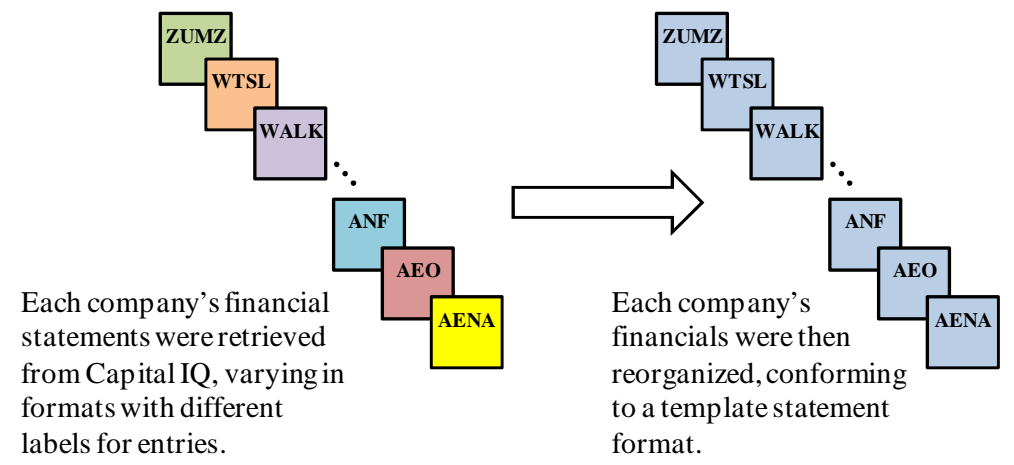

Figure 6.3: Creation of Template Financial Statements 


\begin{tabular}{|c|c|c|c|c|c|c|c|c|c|c|c|}
\hline Year & 1999 & 2000 & 2001 & 2002 & 2003 & 2004 & 2005 & 2006 & 2007 & 2008 & 2009 \\
\hline Revenues & 587.6 & 832.1 & $1,093.5$ & $1,371.9$ & $1,382.9$ & $1,435.4$ & $1,889.6$ & $2,322.0$ & $2,794.4$ & $3,055.4$ & $2,988.9$ \\
\hline Cost of Goods Sold & -293.4 & -398.4 & -657.3 & -824.5 & -842.0 & -885.9 & -865.9 & $-1,244.2$ & $-1,454.0$ & $-1,632.3$ & $-1,814.8$ \\
\hline Gross Profit & 294.2 & 433.7 & 436.2 & 547.4 & 541.0 & 549.5 & $1,023.7$ & $1,077.7$ & $1,340.4$ & $1,423.1$ & $1,174.1$ \\
\hline Selling, General and Admin. Expense & -198.5 & -272.0 & -266.5 & -339.0 & -328.2 & -354.9 & -591.9 & -538.5 & -665.6 & -714.6 & -734.0 \\
\hline Other Operating Expenses & -8.6 & -12.2 & -23.2 & -41.9 & -53.4 & -60.0 & -68.2 & -74.6 & -81.9 & -102.5 & -126.3 \\
\hline Other Operating Income & 0.0 & 0.0 & 0.0 & 0.0 & 0.0 & 0.0 & 0.0 & 0.0 & 0.0 & 0.0 & 0.0 \\
\hline Non-Recurring Operating Gains & 0.0 & 0.0 & 0.0 & 0.0 & 0.0 & 0.0 & 0.0 & 0.0 & 0.0 & 0.0 & 0.0 \\
\hline Non-Recurring Operating Losses & 0.0 & 0.0 & 0.0 & 0.0 & 0.0 & 0.0 & 0.0 & 0.0 & 0.0 & 0.0 & 0.0 \\
\hline Operating Profit & 87.1 & 149.5 & 146.6 & 166.5 & 159.4 & 134.7 & 363.6 & 464.6 & 592.9 & 606.0 & 313.8 \\
\hline Interest Income & 2.4 & 0.0 & 0.0 & 0.0 & 0.0 & 2.0 & 0.0 & 0.0 & 0.0 & 39.3 & 18.9 \\
\hline Interest Expense & 0.0 & 0.0 & 0.0 & 0.0 & 0.0 & 0.0 & 0.0 & 0.0 & 0.0 & 0.0 & 0.0 \\
\hline Other Income or Gains & 0.0 & 4.4 & 6.2 & 2.8 & 2.4 & 0.0 & 5.9 & 18.5 & 39.4 & -1.3 & 0.0 \\
\hline Unusual Income or Gains & 0.0 & 0.0 & 0.0 & 0.0 & 0.0 & 0.0 & 0.0 & 0.0 & 0.0 & 0.0 & 0.0 \\
\hline Other Expenses or Losses & 0.0 & -4.6 & 0.0 & 0.0 & -0.5 & -1.4 & -2.6 & -6.1 & -3.2 & -7.7 & -35.6 \\
\hline Unusual Expenses or Losses & 0.0 & 0.0 & 0.0 & 0.0 & 0.0 & 0.0 & 0.0 & 0.0 & 0.0 & 0.0 & 0.0 \\
\hline \begin{tabular}{|l|} 
Income before Tax \\
\end{tabular} & 89.5 & 149.4 & 152.8 & 169.2 & 161.3 & 135.3 & 366.8 & 477.0 & 629.1 & 636.4 & 297.0 \\
\hline Income Tax Expense & -35.4 & -58.7 & -59.0 & -63.8 & -61.6 & -52.2 & -142.6 & -183.3 & -241.7 & -236.4 & -118.0 \\
\hline Minority Interest in Earnings & 0.0 & 0.0 & 0.0 & 0.0 & 0.0 & 0.0 & 0.0 & 0.0 & 0.0 & 0.0 & 0.0 \\
\hline Income from Discontinued Ops. & 0.0 & 0.0 & 0.0 & 0.0 & -11.5 & -23.5 & -10.9 & 0.4 & 0.0 & 0.0 & 0.0 \\
\hline Extraordinary Gains (Losses) & 0.0 & 0.0 & 0.0 & 0.0 & 0.0 & 0.0 & 0.0 & 0.0 & 0.0 & 0.0 & 0.0 \\
\hline Changes in Acctg. Principles & 0.0 & 0.0 & 0.0 & 0.0 & 0.0 & 0.0 & 0.0 & 0.0 & 0.0 & 0.0 & 0.0 \\
\hline \begin{tabular}{|l} 
NET INCOME \\
\end{tabular} & 54.1 & 90.7 & 93.8 & 105.5 & 88.1 & 59.6 & 213.3 & 294.2 & 387.4 & 400.0 & 179.1 \\
\hline
\end{tabular}

Figure 6.4: Example of Template Income Statement (in \$M)

\begin{tabular}{|c|c|c|c|c|c|c|c|c|c|c|c|}
\hline Year & 1999 & 2000 & 2001 & 2002 & 2003 & 2004 & 2005 & 2006 & 2007 & 2008 & 2009 \\
\hline Cash & 71.9 & 76.6 & 133.4 & 180.4 & 194.5 & 137.1 & 219.4 & 130.5 & 59.7 & 116.1 & 473.3 \\
\hline Marketable Securities & 13.4 & 91.9 & 27.9 & 45.1 & 47.0 & 200.7 & 370.2 & 621.0 & 754.1 & 503.9 & 10.5 \\
\hline Accounts Receivable & 8.6 & 13.5 & 29.5 & 17.6 & 13.6 & 24.1 & 26.4 & 29.1 & 26.0 & 31.9 & 41.5 \\
\hline Inventories & 49.7 & 60.4 & 84.1 & 91.1 & 124.7 & 120.6 & 170.6 & 210.7 & 263.6 & 286.5 & 294.9 \\
\hline Other Current Assets & 11.0 & 20.2 & 43.8 & 42.5 & 46.8 & 48.2 & 78.8 & 85.4 & 85.6 & 82.5 & 105.1 \\
\hline CURRENT ASSETS & 143.5 & 242.3 & 274.9 & 334.2 & 379.9 & 482.5 & 786.6 & 991.4 & $1,103.5$ & 938.3 & 820.3 \\
\hline Long Term Investments in Securities & 0.0 & 0.0 & 0.0 & 0.0 & 0.0 & 24.4 & 84.4 & 145.8 & 264.9 & 165.8 & 251.0 \\
\hline Property, Plant \& Equipment - at cost & 83.3 & 122.7 & 240.2 & 345.9 & 403.8 & 566.8 & 603.5 & 667.0 & 857.7 & $1,091.3$ & $1,298.6$ \\
\hline Accumulated Depreciation & -29.9 & -37.8 & -56.9 & -88.2 & -136.3 & -225.8 & -263.6 & -321.5 & -376.0 & -465.7 & -558.4 \\
\hline Amortizable Intangible Assets & 0.0 & 0.0 & 0.0 & 0.0 & 0.0 & 0.0 & 0.0 & 0.0 & 0.0 & 0.0 & 0.0 \\
\hline Goodwill and Nonamort. Intangibles & 0.0 & 0.0 & 26.6 & 24.0 & 23.6 & 10.1 & 10.0 & 10.0 & 10.0 & 11.5 & 10.7 \\
\hline Other Non-Current Assets & 3.1 & 7.1 & 14.4 & 15.5 & 23.5 & 26.3 & 29.4 & 27.6 & 33.9 & 44.0 & 36.4 \\
\hline TOTAL ASSETS & 196.9 & 327.3 & 484.9 & 615.9 & 671.0 & 858.0 & $1,220.8$ & $1,492.6$ & $1,860.0$ & $1,741.2$ & $1,822.2$ \\
\hline Accounts Payable - Trade & 18.6 & 30.7 & 42.0 & 39.1 & 50.6 & 71.3 & 108.9 & 139.2 & 171.2 & 157.9 & 152.1 \\
\hline Notes Payable and Short Term Debt & 0.0 & 0.0 & 0.0 & 0.0 & 0.0 & 0.0 & 0.0 & 0.0 & 0.0 & 0.0 & 75.0 \\
\hline Current Maturities of Long Term Debt & 30.8 & 39.1 & 52.4 & 61.4 & 45.7 & 59.9 & 81.1 & 100.6 & 115.9 & 111.7 & 94.1 \\
\hline Other Current Liabilities & 10.4 & 18.7 & 54.7 & 50.7 & 45.3 & 77.7 & 92.6 & 111.7 & 177.6 & 106.6 & 80.6 \\
\hline CURRENT LIABILITIES & 59.8 & 88.4 & 149.1 & 151.1 & 141.6 & 209.0 & 282.6 & 351.5 & 464.6 & 376.2 & 401.8 \\
\hline Long Term Debt & 0.0 & 0.0 & 24.9 & 19.4 & 16.4 & 13.9 & 0.0 & 0.0 & 0.0 & 0.0 & 0.0 \\
\hline Deferred Taxes & 0.0 & 0.0 & 0.0 & 0.0 & 0.0 & 0.0 & 0.0 & 0.0 & 0.0 & 0.0 & 0.0 \\
\hline Other Non-Current Liabilities & 0.0 & 1.7 & 1.3 & 1.4 & 5.9 & 72.2 & 82.8 & 98.6 & 97.6 & 151.0 & 152.9 \\
\hline TOTAL LIABILITIES & 59.8 & 90.1 & 175.4 & 171.8 & 163.9 & 295.0 & 365.4 & 450.1 & 562.2 & 527.2 & 554.6 \\
\hline Minority Interest in Subsidiaries & 0.0 & 0.0 & 0.0 & 0.0 & 0.0 & 0.0 & 0.0 & 0.0 & 0.0 & 0.0 & 0.0 \\
\hline Preferred Stock & 0.0 & 0.0 & 0.0 & 0.0 & 0.0 & 0.0 & 0.0 & 0.0 & 0.0 & 0.0 & 0.0 \\
\hline Common Stock + Paid in Capital & 65.0 & 89.7 & 119.4 & 152.0 & 155.6 & 157.5 & 269.8 & 372.2 & 455.9 & 495.9 & 516.1 \\
\hline Retained Earnings & 89.9 & 180.5 & 274.3 & 379.8 & 468.5 & 522.3 & 726.8 & 978.9 & $1,302.3$ & $1,601.8$ & $1,694.2$ \\
\hline Accum. Other Comprehensive Income & -2.4 & -5.7 & -3.7 & -4.8 & -2.3 & 2.6 & 11.9 & 21.0 & 21.7 & 35.5 & -14.4 \\
\hline Treasury Stock & -1.3 & 0.0 & -22.3 & -24.9 & -44.3 & -45.0 & -45.0 & -216.5 & -362.6 & -792.7 & -786.8 \\
\hline SHAREHOLDERS' EQUITY & 151.2 & 264.5 & 367.7 & 502.1 & 577.5 & 637.4 & 963.5 & $1,155.6$ & $1,417.3$ & $1,340.5$ & $1,409.0$ \\
\hline \begin{tabular}{|l|} 
TOTAL LIABILITIES AND EQUITIES \\
\end{tabular} & 210.9 & 354.6 & 543.0 & 673.9 & 741.3 & 932.4 & $1,328.9$ & $1,605.6$ & $1,979.6$ & $1,867.7$ & $1,963.7$ \\
\hline
\end{tabular}

Figure 6.5: Example of Template Balance Sheet (in \$M) 


\begin{tabular}{|c|c|c|c|c|c|c|c|c|c|c|c|}
\hline Year & 1999 & 2000 & 2001 & 2002 & 2003 & 2004 & 2005 & 2006 & 2007 & 2008 & 2009 \\
\hline NET INCOME & 54.1 & 90.7 & 93.8 & 105.5 & 88.1 & 59.6 & 213.3 & 294.2 & 387.4 & 400.0 & 179.1 \\
\hline Add back Depreciation and Amortization Exps. & 8.6 & 12.2 & 23.2 & 41.9 & 53.4 & 60.0 & 68.2 & 74.6 & 83.6 & 104.1 & 128.2 \\
\hline Other Addbacks to Net Income & 2.8 & 5.8 & 7.0 & 3.1 & -10.9 & \begin{tabular}{l|l}
-9.3 \\
\end{tabular} & 59.9 & 45.1 & 48.6 & 42.1 & 55.2 \\
\hline Other Subtractions from Net Income & 0.0 & 0.0 & 0.0 & 0.0 & 0.0 & 0.0 & 0.0 & 0.0 & 0.0 & 0.0 & 0.0 \\
\hline (Incr.) Decrease in Accts. Receivable - Trade & -0.9 & -4.9 & -13.4 & 8.7 & 4.9 & -9.3 & 3.9 & 10.5 & 7.4 & -5.7 & -10.1 \\
\hline (Incr.) Decrease in Inventories & -13.4 & -10.7 & -5.6 & -7.7 & -34.5 & 14.5 & -44.5 & -39.1 & -53.5 & -19.1 & -13.7 \\
\hline (Incr.) Decr. in Other Curr. Ass sets & 1.7 & 4.3 & 5.4 & 4.5 & 15.2 & 2.7 & 7.4 & 10.1 & 11.6 & -0.7 & -11.4 \\
\hline Incr. (Decr.) in Acct. Payable - Trade & -5.4 & 12.1 & 12.2 & -2.1 & 12.8 & 13.4 & 23.2 & 29.4 & 32.3 & -15.6 & -3.1 \\
\hline Incr. (Decr.) in Other Current Liabilities & 0.0 & 0.0 & 0.0 & 0.0 & 0.0 & 0.0 & 0.0 & 8.6 & 43.5 & -31.4 & -20.7 \\
\hline Incr. (Decr.) in Other Non-Current Liabs. & 0.0 & 0.0 & 0.0 & 0.0 & 0.0 & 0.0 & 0.0 & 0.0 & 0.0 & 0.0 & 0.0 \\
\hline Other Operating Cash Flows & 12.3 & 23.4 & 28.1 & 21.1 & -6.8 & 72.6 & 40.7 & 31.9 & 188.4 & -9.5 & -1.4 \\
\hline NET CF FROM OPERATIONS & 59.8 & 132.9 & 150.6 & 174.9 & 122.1 & 204.0 & 372.0 & 465.2 & 749.3 & 464.3 & 302.2 \\
\hline Property, Plant, and Equipment Sold & 0.0 & 0.0 & 0.0 & 0.0 & 0.0 & 0.0 & 0.0 & 0.0 & 12.3 & 0.0 & 0.0 \\
\hline Property, Plant, and Equipment Acquired & -24.9 & -45.6 & -87.8 & -119.3 & -78.8 & -77.5 & -97.3 & -81.5 & -225.9 & -250.4 & -265.3 \\
\hline (Increase) Decrease in Marketable Securities & -13.4 & -85.4 & 66.5 & -17.2 & -30.3 & -151.9 & -178.4 & -311.4 & -437.4 & 354.2 & 344.9 \\
\hline Investments Sold & 0.0 & 0.0 & 0.0 & 0.0 & 0.0 & 0.0 & 0.0 & 0.0 & 0.0 & 0.0 & 0.0 \\
\hline Investments Acquired & 0.0 & 0.0 & 0.0 & 0.0 & 0.0 & 0.0 & 0.0 & 0.0 & 0.0 & 0.0 & 0.0 \\
\hline Other Investment Transactions & 0.0 & 0.0 & -88.1 & 2.0 & -5.1 & -2.9 & 5.4 & -0.1 & -0.1 & -1.2 & -1.2 \\
\hline \begin{tabular}{|l} 
NET CF FROM INVES TING ACTIVITIES \\
\end{tabular} & -38.3 & -130.9 & -109.4 & -134.5 & -114.2 & -232.3 & -270.3 & -393.1 & -651.1 & 102.7 & 78.4 \\
\hline Increase in ST Borrowing & 0.0 & 0.0 & 0.0 & 0.0 & 4.8 & 0.0 & 0.0 & 0.0 & 2.0 & 0.0 & 75.0 \\
\hline Decrease in ST Borrowing & 0.0 & 0.0 & 0.0 & 0.0 & 0.0 & 0.0 & 0.0 & 0.0 & 0.0 & 0.0 & 0.0 \\
\hline Increase in LT Borrowing & 0.0 & 0.0 & 29.1 & 0.0 & 0.0 & 0.0 & 0.0 & 0.0 & 0.0 & 0.0 & 0.0 \\
\hline Decrease in LT Borrowing & 0.0 & 0.0 & -1.7 & -5.7 & -9.6 & -5.4 & -19.6 & -0.7 & -3.0 & -1.9 & -2.2 \\
\hline Is sue of Capital Stock & 2.0 & 2.7 & 10.2 & 15.8 & 1.8 & 1.1 & 57.5 & 48.2 & 28.4 & 13.2 & 3.8 \\
\hline Share repurchases - Treasury Stock & 0.0 & 0.0 & -22.3 & -2.5 & -19.5 & -0.7 & 0.0 & -171.5 & -154.2 & -450.6 & -3.4 \\
\hline Dividend Payments & 0.0 & 0.0 & 0.0 & 0.0 & 0.0 & 0.0 & -8.8 & -42.1 & -61.5 & -80.8 & -82.4 \\
\hline Other Financing Transactions & 0.0 & 0.0 & 0.0 & 0.0 & 0.0 & 0.0 & 0.0 & 0.0 & 19.5 & 6.2 & 0.7 \\
\hline NET CF FROM FINANCING ACTIVITIES & 2.0 & 2.7 & 15.3 & 7.6 & -22.4 & -5.0 & 29.1 & -166.1 & -168.8 & -514.0 & -8.5 \\
\hline Effects of exchange rate changes on cash & 0.0 & 0.0 & 0.4 & -1.0 & 0.3 & 2.0 & 2.7 & 5.1 & -0.2 & 3.4 & -14.8 \\
\hline NET CHANGE IN CASH & 23.6 & 4.6 & 56.9 & 47.0 & -14.2 & -31.3 & 133.5 & -88.8 & -70.8 & 56.3 & 357.3 \\
\hline
\end{tabular}

Figure 6.6: Example of Template Cash Flow Statement (in \$M)

Since the data for each company were stored in a separate .xls file, retrieving a common financial entry (e.g. cash) in a given year for all firms required traversing through 85 files. Because opening all files to extract specific data would be time consuming and require substantial CPU power and memory, special VB macros were created with the ability to:

1. retrieve data when the file was closed;

2. use query and store the data when the file was closed; and,

3. identify and manipulate the retrieved data into one open file.

Ultimately, these macros combined the balance sheet, income statement, and cash flow statement of all 85 companies found across 85 files into one workable spreadsheet (Figure 6.7). Each row represented a company and a year while each column of the spreadsheet stored the values of a particular financial entry. There was a total of 994 DMUs between 1988 and 2009; though only 701 DMUs were used between 1996 and 2009. 


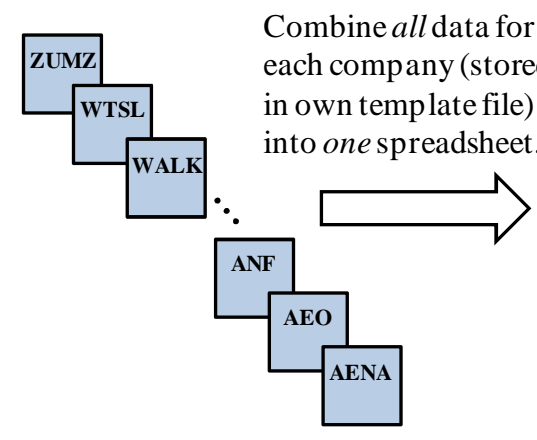

\begin{tabular}{|r|r|r|r|r|r|r|r|r|}
\hline \multicolumn{8}{|c|}{ Dalance Sheet Entries } \\
\hline
\end{tabular}

Figure 6.7: Combining All Data into One Worksheet (in \$M)

\subsubsection{Distributions of Financial Variables}

Figure 6.8 to Figure 6.31 present the distributions of selected variables with each count being the average annual value for a given company (see List of Abbreviations for definitions of variable acronyms). The mean, median and range are also provided. It is noted that a DMU was predicted bankrupt up to 3 years prior to filing Chapter 11 .

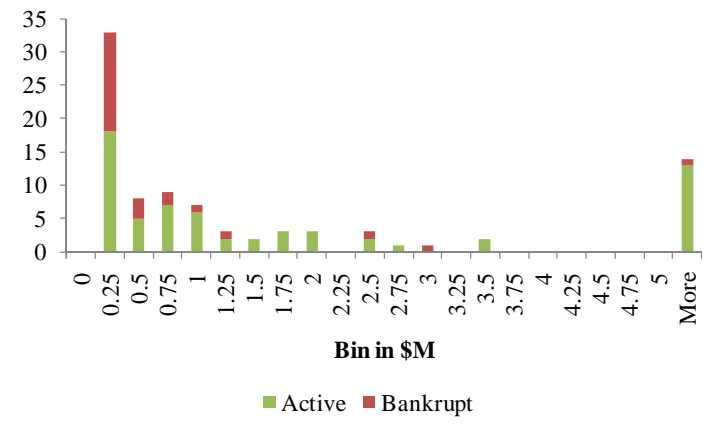

Figure 6.8: Histogram for Average Annual Cash Mean $=4.7 ;$ Median $=0.5 ;$ Minimum $=0 ;$ Maximum $=98$

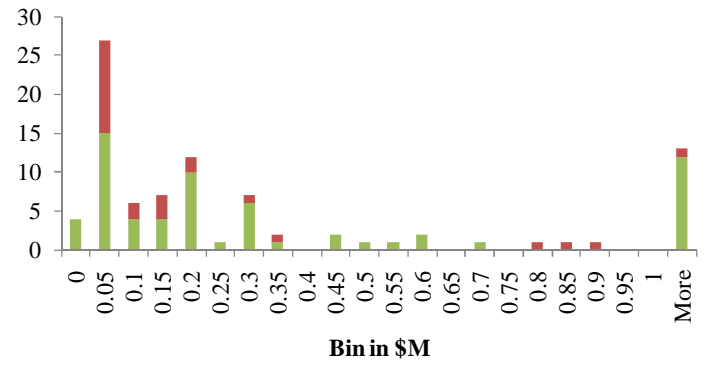

Active $\square$ Bankrupt

Figure 6.9: Histogram for Average Annual AR Mean $=1.3 ;$ Median $=0.2 ;$ Minimum $=0 ;$ Maximum $=24$ 


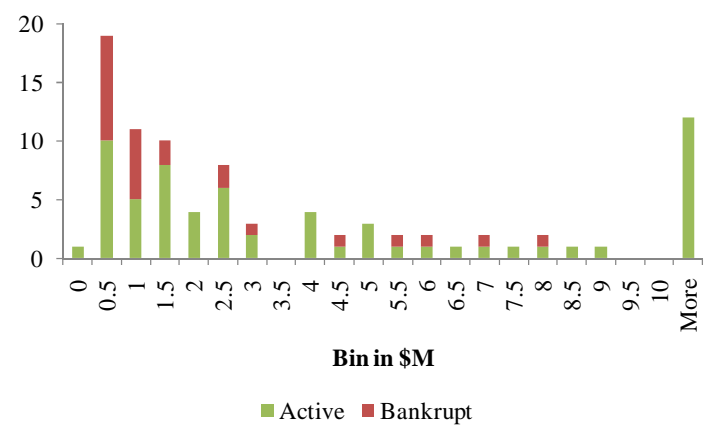

Figure 6.10: Histogram for Average Annual Inv Mean $=9.2 ;$ Median $=1.6 ;$ Minimum $=0 ;$ Maximum $=217$

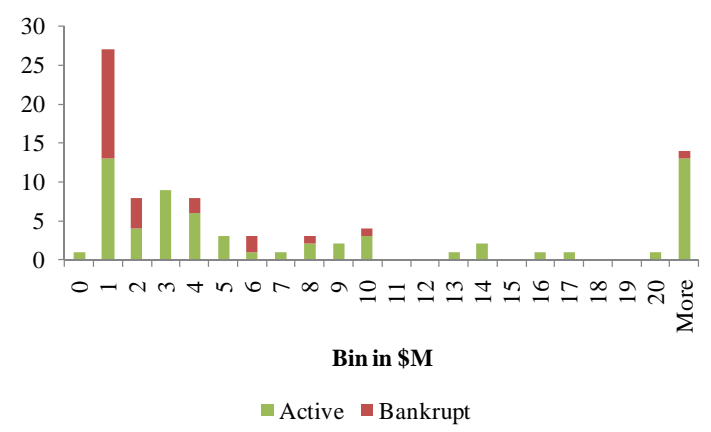

Figure 6.12: Histogram for Average Annual PPE Mean $=23 ;$ Median $=2.9 ;$ Minimum $=0 ;$ Maximum $=480$

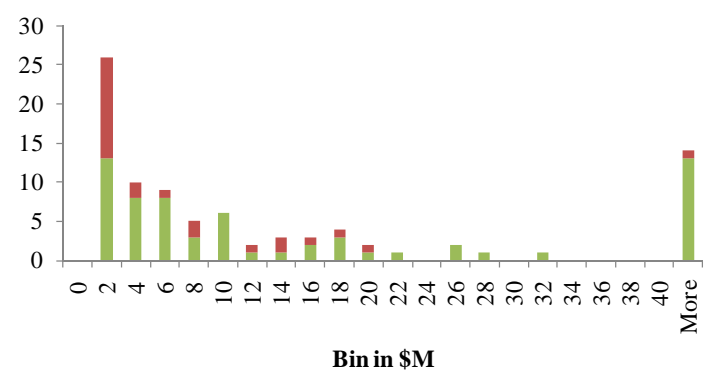

Active $\square$ Bankrupt

Figure 6.14: Histogram for Average Annual TA Mean $=41 ;$ Median $=5.1 ;$ Minimum $=0 ;$ Maximum $=830$

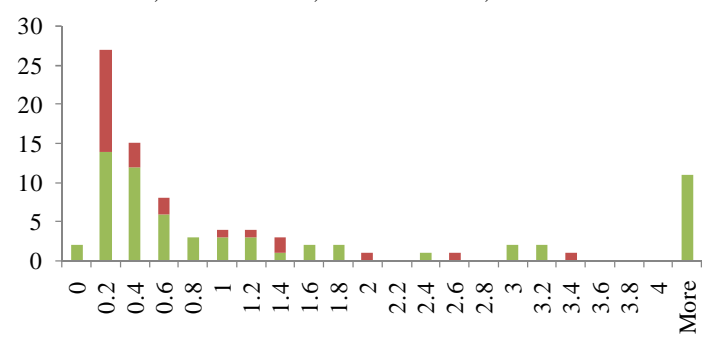

Bin in \$M

$$
\text { active } \square \text { Bankrupt }
$$

Figure 6.16: Histogram for Average Annual CM Mean $=3.2 ;$ Median $=0.4 ;$ Minimum $=0 ;$ Maximum $=48$

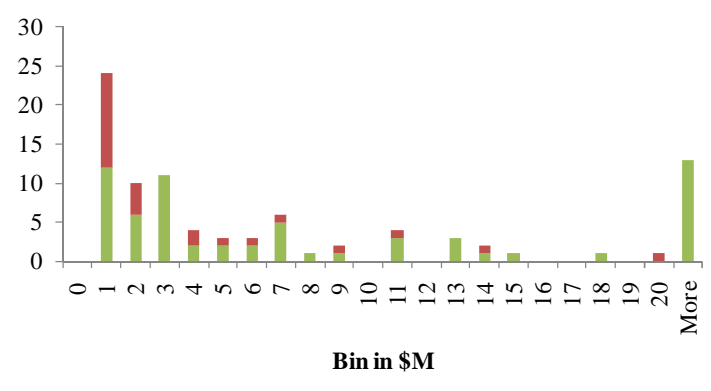

- Active $\square$ Bankrupt

Figure 6.11: Histogram for Average Annual CA Mean $=22 ;$ Median $=2.9 ;$ Minimum $=0 ;$ Maximum $=510$

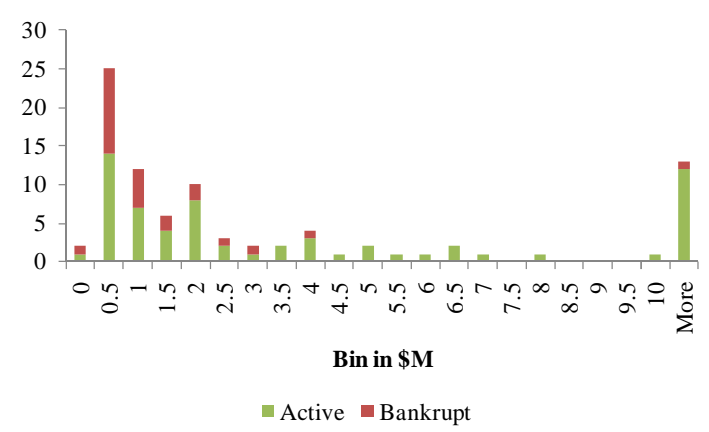

Figure 6.13: Histogram for Average Annual AD Mean $=10 ;$ Median $=1.5 ;$ Minimum $=0 ;$ Maximum $=210$

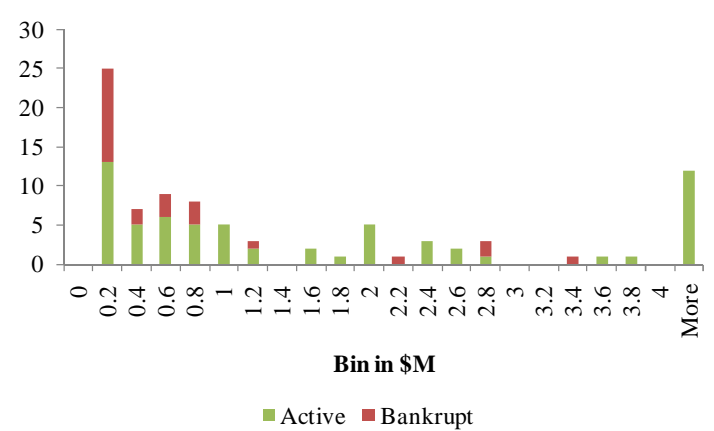

Figure 6.15: Histogram for Average Annual AP Mean $=4.0 ;$ Median $=0.7 ;$ Minimum $=0 ;$ Maximum $=99$

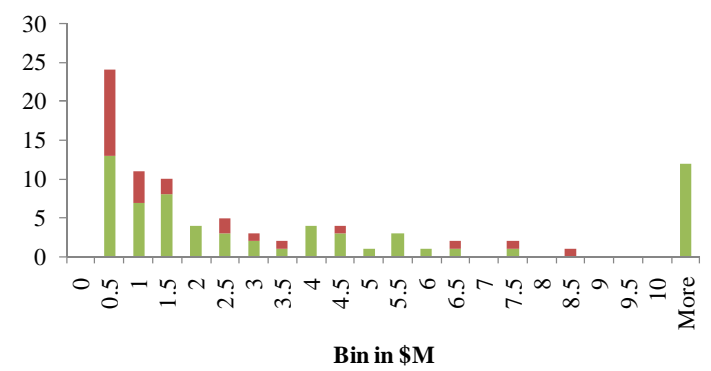

Active Bankrupt

Figure 6.17: Histogram for Average Annual CL Mean =9.8; Median $=1.4 ;$ Minimum $=0 ;$ Maximum $=200$ 


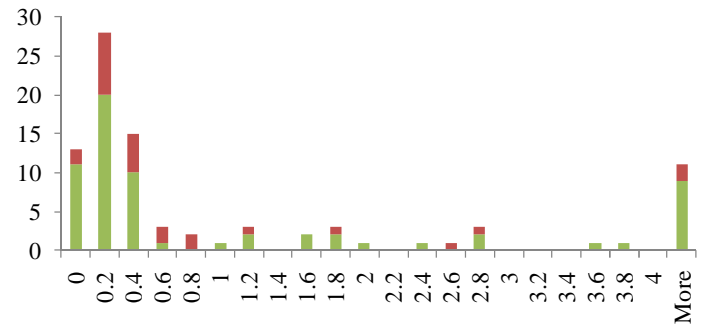

Bin in \$M

- Active $\square$ Bankrupt

Figure 6.18: Histogram for Average Annual LTD Mean $=2.6 ;$ Median $=0.2 ;$ Minimum $=0 ;$ Maximum $=51$

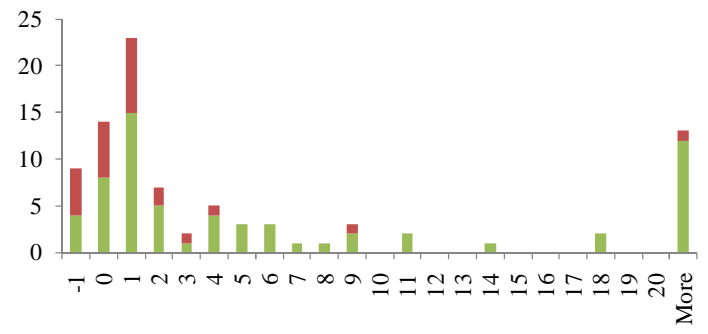

Bin in \$M

Active $\square$ Bankrupt

Figure 6.20: Histogram for Average Annual RE Mean = 19; Median = 1.0; Minimum = -7.7; Maximum $=390$

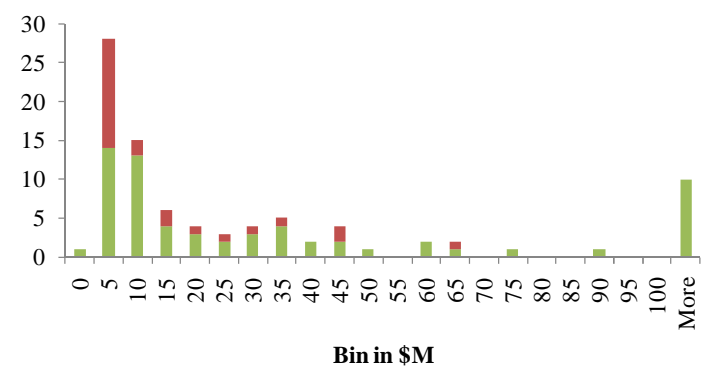

- Active $\square$ Bankrupt

Figure 6.22: Histogram for Average Annual Rev Mean $=75 ;$ Median $=11 ;$ Minimum $=0 ;$ Maximum $=1800$

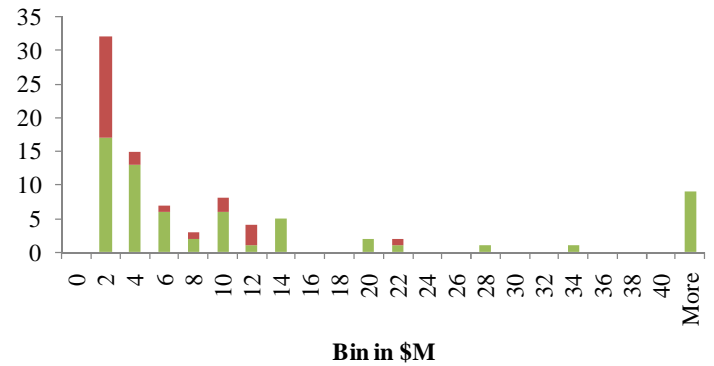

Active $\quad$ Bankrupt

Figure 6.24: Histogram for Average Annual SGA Mean $=22 ;$ Median $=3.7 ;$ Minimum $=0 ;$ Maximum $=470$

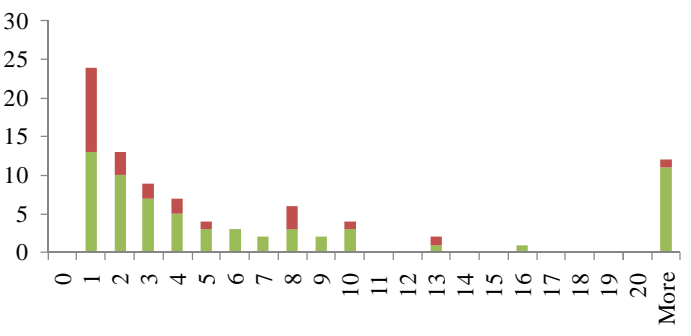

Bin in \$M

- Active $\square$ Bankrupt

Figure 6.19: Histogram for Average Annual TL Mean $=16 ;$ Median $=2.4 ;$ Minimum $=0 ;$ Maximum $=270$

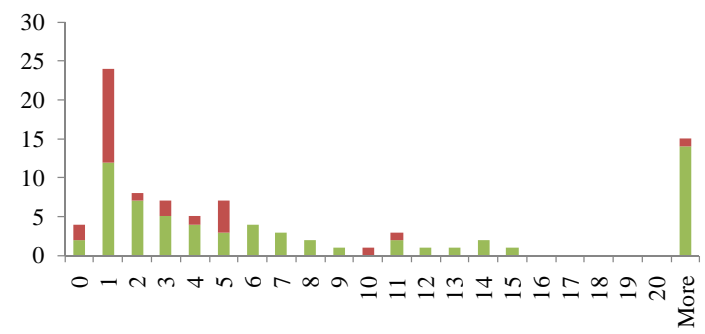

Bin in \$M

Active $\square$ Bankrupt

Figure 6.21: Histogram for Average Annual SE Mean = 25; Median = 3.3; Minimum = -0.4; Maximum $=560$

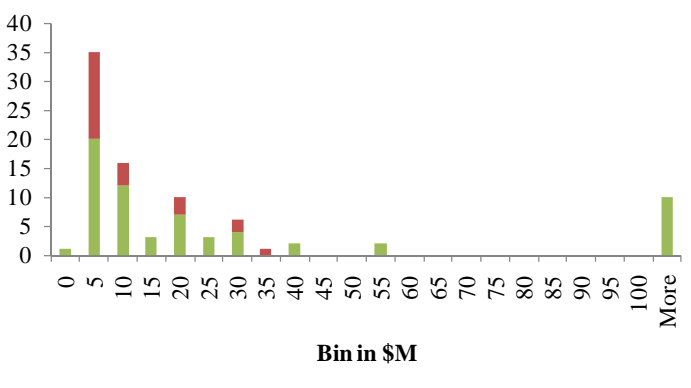

Figure 6.23: Histogram for Average Annual COGS

Mean $=45 ;$ Median $=6.6 ;$ Minimum $=0 ;$ Maximum $=1200$

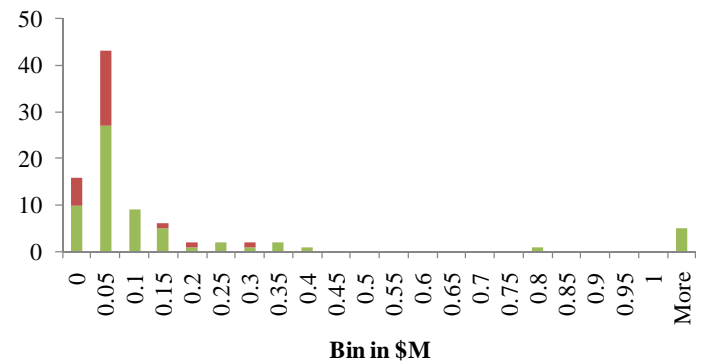

Active Bankrupt

Figure 6.25: Histogram for Average Annual II Mean $=0.2 ;$ Median $=0 ;$ Minimum $=0 ;$ Maximum $=5.6$ 


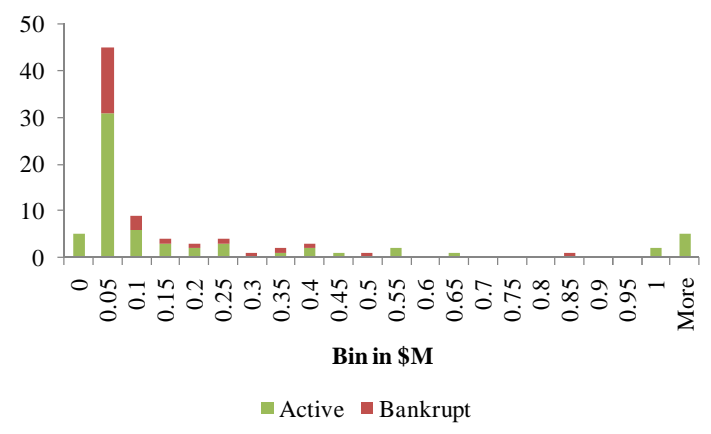

Figure 6.26: Histogram for Average Annual IE Mean $=0.2 ;$ Median $=0 ;$ Minimum $=0 ;$ Maximum $=5.6$

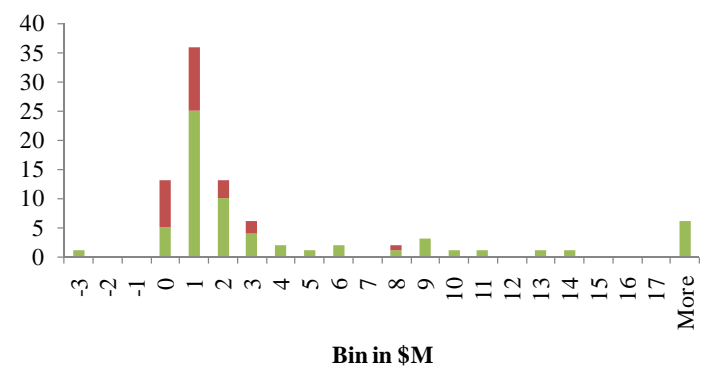

- Active $\square$ Bankrupt

Figure 6.28: Histogram for Average Annual CFO Mean $=7.3 ;$ Median $=0.6 ;$ Minimum $=-3.2 ;$ Maximum $=150$

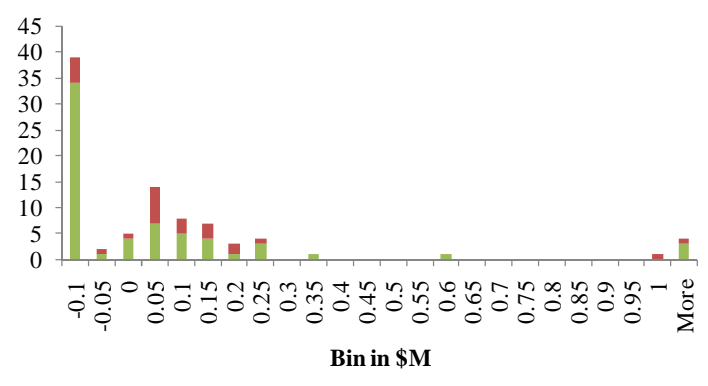

Active Bankrupt

Figure 6.30: Histogram for Average CFF Mean $=-1.1 ;$ Median $=0 ;$ Minimum $=-38 ;$ Maximum $=28$

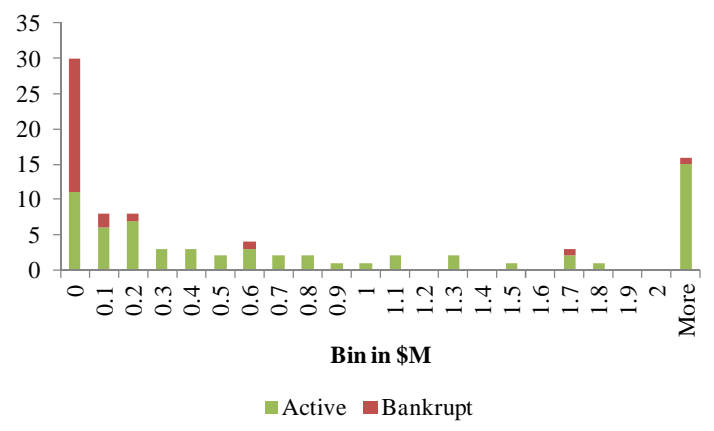

Figure 6.27: Histogram for Average Annual NI Mean 4.2; Median $=0.2 ;$ Minimum $=-4.7 ;$ Maximum $=98$

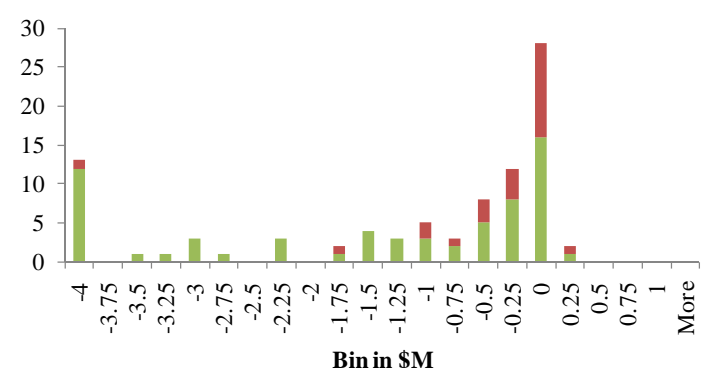

$\square$ Active $\square$ Bankrupt

Figure 6.29: Histogram for Average Annual CFF Mean $=-6.1 ;$ Median $=-0.5 ;$ Minimum $=-200 ;$ Maximum $=0.2$

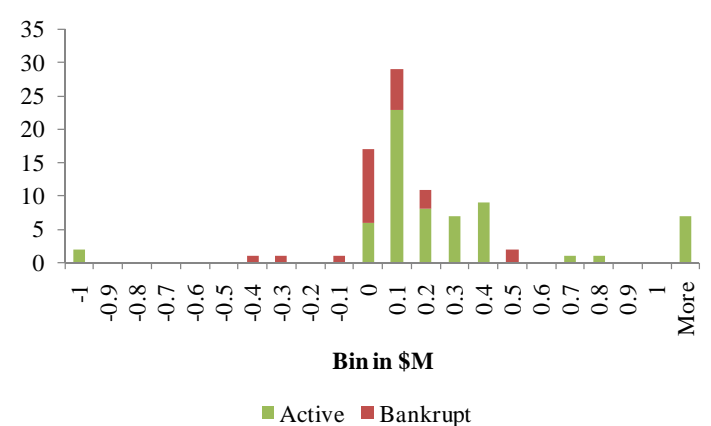

Figure 6.31: Histogram for Average Annual CC Mean $=0.1 ;$ Median $=0 ;$ Minimum $=-50 ;$ Maximum $=24$

\subsubsection{Correlations of Financial Variables}

Correlations between the values of all financial accounts in the balance sheet, income statement and cash flow statements were found. Table 6.5 to Table 6.7 present those correlations greater than 0.85 and significant at the 0.01 level. 
Table 6.5: Highly Correlated Financial Accounts on the Balance Sheet Refer to List of Abbreviations for definitions of variable acronyms.

\begin{tabular}{|l|c|l|c|}
\hline \multicolumn{1}{|c|}{ Accounts } & Correlation & \multicolumn{1}{c|}{ Accounts } & Correlation \\
\hline Inv, CA & 0.95 & PPE, CM & 0.87 \\
\hline Inv, PPE & 0.87 & PPE, CL & 0.89 \\
\hline Inv, Other NonCA & 0.91 & PPE, TL & 0.88 \\
\hline Inv, TA* & 0.94 & PPE, SE & 0.88 \\
\hline Inv, AP & 0.94 & AD, Other NonCA & 0.93 \\
\hline Inv, CM & 0.87 & AD, TA* & 0.90 \\
\hline Inv, CL & 0.94 & AD, CM & 0.85 \\
\hline Inv, TL & 0.92 & AD, CL & 0.86 \\
\hline Inv, SE & 0.86 & AD, TL & 0.85 \\
\hline OtherCA, CA & 0.88 & Other NonCA, TA* & 0.96 \\
\hline OtherCA, PPE & 0.85 & Other NonCA, AP & 0.89 \\
\hline OtherCA, Other NonCA & 0.89 & Other NonCA, CM & 0.88 \\
\hline OtherCA, TA* & 0.90 & Other NonCA, CL & 0.92 \\
\hline OtherCA, CL & 0.86 & Other NonCA, TL & 0.91 \\
\hline OtherCA, TL & 0.87 & Other NonCA, SE & 0.91 \\
\hline CA, PPE & 0.91 & TA*, AP & 0.92 \\
\hline CA, AD & 0.89 & TA*, CM & 0.91 \\
\hline CA, Other NonCA & 0.93 & TA*, CL & 0.95 \\
\hline CA, TA* & 0.98 & TA*, TL & 0.95 \\
\hline CA, AP & 0.93 & TA*, SE & 0.94 \\
\hline CA, CM & 0.90 & AP, CM & 0.87 \\
\hline CA, CL & 0.95 & AP, CL & 0.96 \\
\hline CA, TL & 0.93 & AP, TL & 0.91 \\
\hline CA, SE & 0.93 & CM, CL & 0.94 \\
\hline PPE, AD & 0.98 & CM, TL & 0.93 \\
\hline PPE, Other NonCA & 0.97 & CL, TL & 0.97 \\
\hline PPE, TA* & 0.93 & CL, SE & 0.86 \\
\hline PPE, AP & 0.87 & RE, SE & \\
\hline & & & \\
\hline & & & \\
\hline
\end{tabular}

*Total Assets $=$ Total Liabilities and Shareholders' Equity

Table 6.6: Highly Correlated Financial Accounts on the Income Statement

\begin{tabular}{|l|c|}
\hline \multicolumn{1}{|c|}{ Accounts } & Correlation \\
\hline Revenue, CoGS & 0.99 \\
\hline Revenue, Gross Profit & 0.98 \\
\hline Revenue, SG\&A & 0.98 \\
\hline CoGS, Gross Profit & 0.94 \\
\hline CoGS, SG\&A & 0.95 \\
\hline Gross Profit, SG\&A & 0.99 \\
\hline Operating Profit, Income before Tax & 0.94 \\
\hline Operating Profit, Income Tax Expense & 0.91 \\
\hline Operating Profit, Net Income & 0.89 \\
\hline Income before Tax, Income Tax Expense & 0.94 \\
\hline Income before Tax, Net Income & 0.95 \\
\hline Income Tax Expense, Net Income & 0.87 \\
\hline
\end{tabular}

On the Balance Sheet (Table 6.5), the strongest correlations were between "larger" accounts such as total current assets, total assets, total current liabilities and total liabilities, etc., which are sums of other entries. Smaller accounts such as cash, marketable securities, 
accounts receivable, long-term investments in securities, amortizable intangible assets, goodwill assets that cannot be amortized, notes payable and short-term debt, deferred taxes, minority interest in subsidiaries, preferred stock, common stock, treasury stock and retained earnings, were weakly correlated with other financial accounts. The strongest correlations in the Income Statement (Table 6.6) were also between its larger accounts. And in the Cash Flow Statement, only weak correlations existed between the cash flows (operating, investing and financing) and the overall change in cash.

As for correlations across the financial statements (Table 6.7), there were many highly correlated accounts between the Balance Sheet and Income Statement. This is attributed to the redundancy of revenue, CoGS, Gross Profit and SG\&A (as they were highly correlated among themselves), and their inherent connection to assets and liabilities. When correlating the Balance Sheet and Income Statement with the Cash Flow Statement, only two strong relationships emerged: Gross Profit and Operating Cash Flow, and Operating Profit and Operating Cash Flow.

Generally, a weak correlation implies that variables are independent while a strong correlation suggests that trimming the dataset is desirable.

Table 6.7: Highly Correlated Financial Accounts across Statements

\begin{tabular}{|l|c|l|c|}
\hline \multicolumn{1}{|c|}{ Accounts } & Correlation & \multicolumn{1}{c|}{ Accounts } & Correlation \\
\hline Inventories, Revenue & 0.86 & Total Assets*, Gross Profit & 0.89 \\
\hline Inventories, CoGS & 0.86 & Total Assets*, SG\&A & 0.89 \\
\hline Inventories, Gross Profit & 0.84 & Accounts Payable, Revenue & 0.86 \\
\hline Inventories, SG\&A & 0.85 & Accounts Payable, CoGS & 0.86 \\
\hline Current Assets, Revenue & 0.89 & Accounts Payable, Gross Profit & 0.84 \\
\hline Current Assets, CoGS & 0.87 & Current Liabilities, Revenue & 0.89 \\
\hline Current Assets, Gross Profit & 0.89 & Current Liabilities, CoGS & 0.88 \\
\hline Current Assets, SG\&A & 0.88 & Current Liabilities, Gross Profit & 0.87 \\
\hline PPE, Gross Profit & 0.85 & Current Liabilities, SG\&A & 0.88 \\
\hline PPE, SG\&A & 0.85 & Total Liabilities, Revenue & 0.87 \\
\hline Other Non-Current Assets, Revenue & 0.88 & Total Liabilities, CoGS & 0.85 \\
\hline Other Non-Current Assets, CoGS & 0.85 & Total Liabilities, Gross Profit & 0.86 \\
\hline Other Non-Current Assets, Gross Profit & 0.88 & Total Liabilities, SG\&A & 0.87 \\
\hline Other Non-Current Assets, SG\&A & 0.87 & Gross Profit, Operating Cash Flow & 0.85 \\
\hline Total Assets*, Revenue & 0.89 & Operating Profit, Operating Cash Flow & 0.85 \\
\hline Total Assets*, CoGS & 0.87 & &
\end{tabular}

*Total Assets = Total Liabilities and Shareholders' Equity

\subsubsection{Profitability Analysis}

Profitability ratios - return on assets (ROA), profit margin (PM) and total assets turnover (TAT) - were calculated for each company for each year with available data. Median ROA, 
PM and TAT for each company (across all years) were then computed and correlated with its state. The median was taken to eliminate outliers and because the distributions of these ratios were not normally distributed. As expected, ROA of active companies was higher than bankrupt firms (Table 6.8). Similar trends can be observed for PM and TAT. With these data, industry analysis was conducted by plotting median TAT and median PM for all companies (Figure 6.32).

Table 6.8: Average Median ROAs, PMs, TATs by State

A company was classified as active if it never filed Chapter 11 and as bankrupt if it filed at least once.

\begin{tabular}{|l|c|c|c|c|}
\hline Ratio & Industry Average & Active & Bankrupt & All \\
\hline TAT & 2.1 & $2.4 \pm 0.9$ & $2.7 \pm 0.9$ & $2.4 \pm 0.9$ \\
\hline PM & $3.0 \%$ & $4.2 \% \pm 3.0 \%$ & $-3.1 \% \pm 6.0 \%$ & $2.1 \% \pm 5.5 \%$ \\
\hline ROA & $12 \%$ & $10.6 \% \pm 6.0 \%$ & $-3.3 \% \pm 14.7 \%$ & $6.9 \% \pm 10.9 \%$ \\
\hline
\end{tabular}

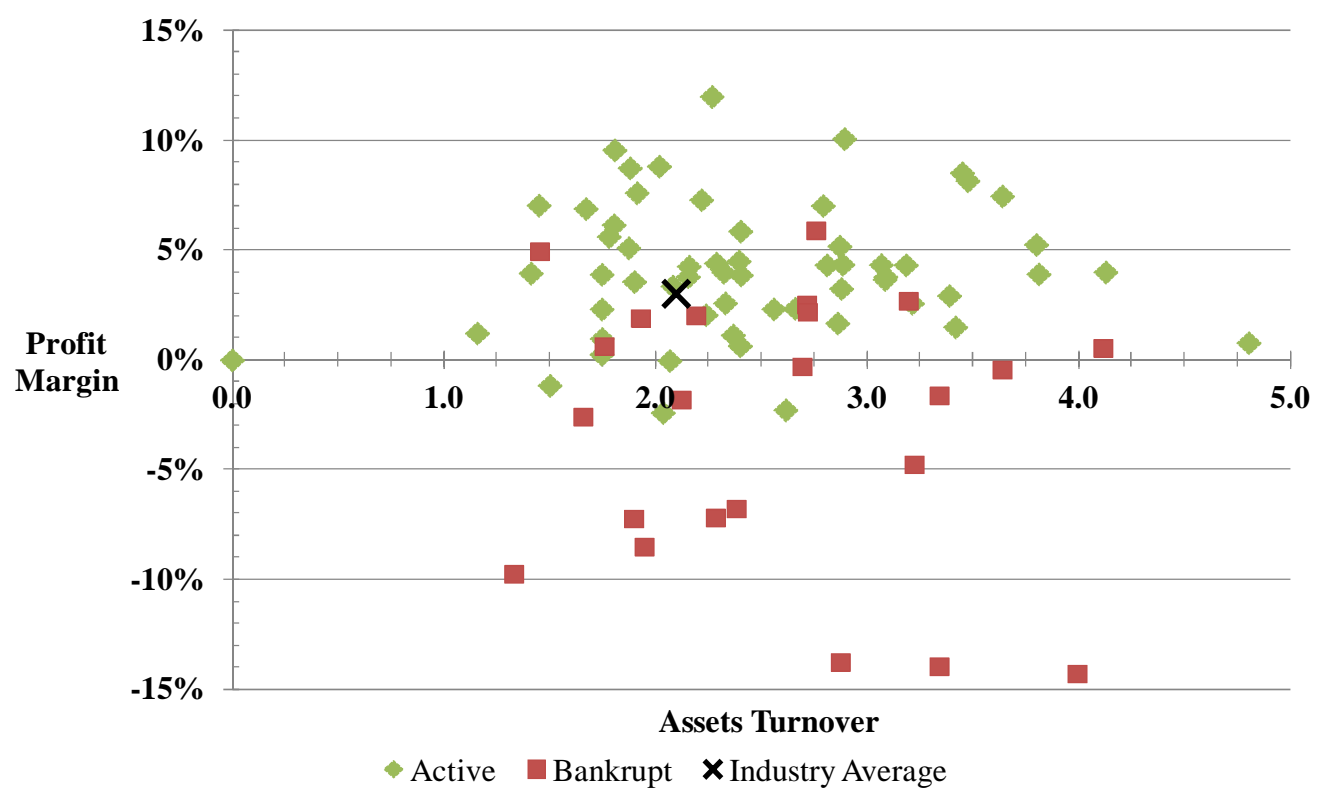

Figure 6.32: Median Efficiency and Profitability Chart for All Companies A company was classified as active if it never filed Chapter 11 and as bankrupt if it filed at least once.

Recall that in Table 2.4, companies in the retail apparel industry should be classified as "Type C" because they operate in a highly competitive environment. The strategic focus for ROA for Type $\mathrm{C}$ companies should thus be on increasing assets turnover. However, in this sample (Figure 6.32), firms were more clearly distinguishable by profit margin: those active had higher profit margins compared to those that filed for bankruptcy. Hence, while these ratios provided hints of a company's health, they alone were unreliable for use as benchmarks or measures of financial health as seen by the scatter (variance) in the data, which can be attributed to taking the median between all years (and thereby ignoring possible 
market and economic influences that produce "outliers"). It is also noted that in Table 6.8, the product of PM and TAT do not necessarily match up with ROA because in some instances, the denominator of a ratio was zero.

To further decipher profit margin and total asset turnover, several ratios were calculated for each company for each year: Cost of Goods Sold (COGS) \%, Selling, General and Administrative Expenses (SGA) \% and Income Tax Expense \% as well as average accounts receivable turnover, average inventory turnover and average fixed assets turnover. The averages of these ratios were then correlated to company state (Table 6.9 and Table 6.10). As expected, CoGS\% and SG\&A\% were lower for active firms because they likely learned to be more operationally efficient. With respect to turnover (TO), the accounts receivable and inventory TOs averages were higher for active companies while fixed assets TO was the same across both states.

Table 6.9: Averages of Ratios in Profit Margin Breakdown

A DMU was classified bankrupt up to 3 years prior to filing Chapter 11.

\begin{tabular}{|l|c|c|c|}
\hline \multicolumn{1}{|c|}{ State } & COGS \% & SGA \% & Income Tax Expense \% \\
\hline Active & $62 \% \pm 10 \%$ & $31 \% \pm 18 \%$ & $3 \% \pm 2 \%$ \\
\hline Bankrupt & $66 \% \pm 9 \%$ & $32 \% \pm 11 \%$ & $2 \% \pm 4 \%$ \\
\hline All & $63 \% \pm 10 \%$ & $31 \% \pm 17 \%$ & $3 \% \pm 3 \%$ \\
\hline
\end{tabular}

Table 6.10: Averages of Ratios in Assets Turnover (TO) Breakdown A DMU was classified bankrupt up to 3 years prior to filing Chapter 11.

\begin{tabular}{|l|c|c|c|}
\hline \multicolumn{1}{|c|}{ State } & Accounts Receivable TO & Inventory TO & Fixed Assets TO \\
\hline Active & $150 \pm 220$ & $100 \pm 290$ & $4 \pm 3$ \\
\hline Bankrupt & $96 \pm 95$ & $15 \pm 20$ & $4 \pm 2$ \\
\hline All & $147 \pm 210$ & $94 \pm 280$ & $4 \pm 3$ \\
\hline
\end{tabular}

Return on Common Equity (ROCE) was also investigated (Table 6.11). As expected, the ROCE of active companies was greater than that of bankrupt firms.

Table 6.11: Average of Median ROCE

A company was classified as active if it never filed Chapter 11 and as bankrupt if it has filed at least once.

\begin{tabular}{|l|c|}
\hline \multicolumn{1}{|c|}{ State } & Average Median ROCE \\
\hline Active & $15.9 \% \pm 13.7 \%$ \\
\hline Bankrupt & $-7.3 \% \pm 20.9 \%$ \\
\hline All & $9.4 \% \pm 19.1 \%$ \\
\hline
\end{tabular}

Moreover, the ROCE of each company was compared to its ROA to determine leverage (Table 6.12) with those missing ROA or ROCE values removed from the dataset. Active firms were more likely positively leveraged, while approximately half the bankrupt firms were positively leveraged, making this an unreliable index for determining bankruptcy. 
Table 6.12: Company Leverage Position

A company was classified as active if it never filed Chapter 11 and as bankrupt if it filed at least once.

\begin{tabular}{|l|c|c|c|}
\hline \multicolumn{1}{|c|}{ State } & Total & Negatively Leveraged & Positively Leveraged \\
\hline Active & 55 & $4(7 \%)$ & $51(93 \%)$ \\
\hline Bankrupt & 19 & $10(53 \%)$ & $9(47 \%)$ \\
\hline
\end{tabular}

\subsubsection{Short-Term Liquidity and Long-Term Solvency}

Ratios for liquidity and solvency (defined in Table 2.5) were computed for each company for every year and then correlated to its state. As expected, current ratio, quick ratio and operating cash flow to current liabilities ratio were higher for active firms than those bankrupt (Table 6.13). The days outstanding for receivables and inventory were lower for active companies; though, for days revenue in cash, the ratio was higher (perhaps because bankrupt firms need cash immediately to pay bills) (Table 6.14). As for solvency, the interest coverage ratio was highest for active companies (i.e. they have sufficient income to pay interest) who also had lower liabilities/long-term debt ratios (Table 6.15).

Table 6.13: Average Liquidity Ratios

A DMU was classified bankrupt up to 3 years prior to filing Chapter 11.

\begin{tabular}{|l|c|c|c|}
\hline \multicolumn{1}{|c|}{ State } & Current Ratio & Quick Ratio & CFO to CL \\
\hline Active & $2.5 \pm 1.1$ & $1.1 \pm 1.0$ & $0.6 \pm 0.6$ \\
\hline Bankrupt & $1.8 \pm 1.0$ & $0.6 \pm 0.6$ & $0.2 \pm 0.5$ \\
\hline All & $2.4 \pm 1.1$ & $1.1 \pm 0.9$ & $0.6 \pm 0.6$ \\
\hline
\end{tabular}

Table 6.14: Average Liquidity Ratios

A DMU was classified bankrupt up to 3 years prior to filing Chapter 11.

\begin{tabular}{|l|c|c|c|}
\hline \multicolumn{1}{|c|}{ State } & Average Collection Period & Average Inventory Period & Days Revenue in Cash \\
\hline Active & $9 \pm 16$ & $58 \pm 56$ & $35 \pm 66$ \\
\hline Bankrupt & $10 \pm 10$ & $80 \pm 71$ & $12 \pm 15$ \\
\hline All & $9 \pm 15$ & $60 \pm 58$ & $33 \pm 64$ \\
\hline
\end{tabular}

Table 6.15: Average Solvency Ratios

A DMU was classified bankrupt up to 3 years prior to filing Chapter 11.

\begin{tabular}{|l|c|c|c|c|c|}
\hline \multicolumn{1}{|c|}{ State } & $\begin{array}{c}\text { Interest } \\
\text { Coverage }\end{array}$ & $\begin{array}{c}\text { Liabilities } \\
\text { to Assets }\end{array}$ & $\begin{array}{c}\text { Liabilities to } \\
\text { Shareholders' Equity }\end{array}$ & $\begin{array}{c}\text { Long-Term Debt } \\
\text { to Capital }\end{array}$ & $\begin{array}{c}\text { Long-Term Debt to } \\
\text { Shareholders' Equity }\end{array}$ \\
\hline Active & $41.7 \pm 79.1$ & $0.4 \pm 0.2$ & $0.9 \pm 1.2$ & $0.2 \pm 0.3$ & $0.2 \pm 0.5$ \\
\hline Bankrupt & $9.1 \pm 45.4$ & $0.7 \pm 0.3$ & $1.3 \pm 3.0$ & $0.2 \pm 0.4$ & $0.3 \pm 1.3$ \\
\hline All & $38.6 \pm 77.1$ & $0.5 \pm 0.2$ & $0.9 \pm 1.4$ & $0.2 \pm 0.3$ & $0.2 \pm 0.6$ \\
\hline
\end{tabular}

While there were clear trends between liquidity and solvency ratios, and state, no information on industry averages was readily available for these ratios; thus, the relevance of these ratios (determined by percentage of error) as proxies for company health was qualified by creating a set of "bankruptcy" thresholds and/or boundaries based on the dataset. In other words, to determine how well a given ratio $R$ predicted bankruptcy, a value $x$ was found such that when $x>R$, a company was classified as active and when $x<R$ a firm was classified as 
bankrupt (Figure 6.33). Another objective of $x$ was to classify as many companies correctly. With this $x$, counts for true positive, true negative, false positive and false negative were computed to determine if the given ratio was a good indicator of health.

Interestingly, with this dataset, the optimal $x$ (i.e. with minimum Type I and II Errors) for all ratios was always equal to the minimum value of $R$; there was no such $x$ better than always "predicting" active. This is likely due to the large percentage of active companies in the dataset. Thus, with such a primitive predictive approach, liquidity and solvency ratios and company were unreliable measures of company state. Perhaps instead at the intersection of error, there may be an $x$ such that when $x<R$, a company could be classified as bankrupt; and a $y$ such that when $y>R$, a company could be classified as active; while the range $x-y$ could be indeterminate like Altman's Z-Score (Section 2.3.1).

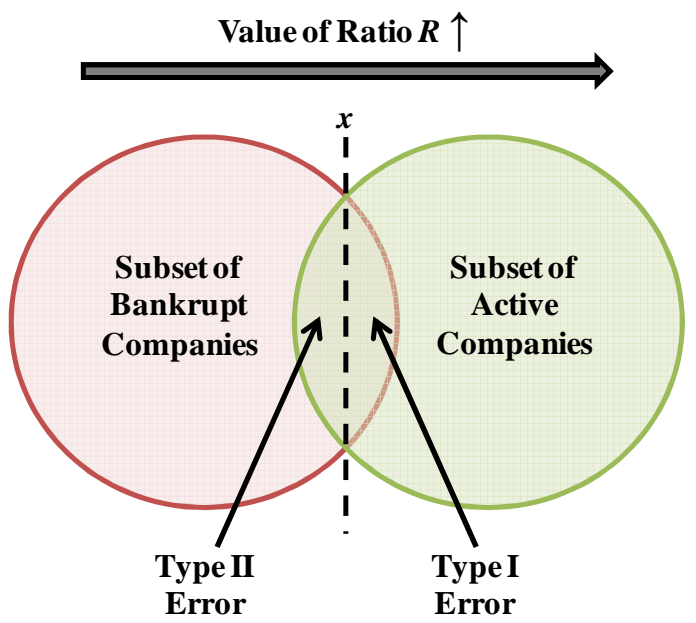

Figure 6.33: Strategy for Deriving a Threshold for Evaluating Ratios

\subsubsection{Earnings Manipulation Risk}

The Beneish Index (Section 2.4.1) was calculated for all companies with a particular focus on bankrupt firms. Table 6.16 presents average scores by company state. Surprisingly, bankrupt companies were no more likely to engage in manipulation - despite what one's intuition would suspect (

Table 6.17). This is likely because Beneish based his model on manufacturing firms. 
Table 6.16: Average Beneish Index

A DMU was classified bankrupt up to 3 years prior to filing Chapter 11.

\begin{tabular}{|l|c|}
\hline \multicolumn{1}{|c|}{ State } & Beneish \\
\hline Active & $0.05 \pm 0.17$ \\
\hline Bankrupt & $0.02 \pm 0.30$ \\
\hline All & $0.05 \pm 0.19$ \\
\hline
\end{tabular}

Table 6.17: Bankrupt Companies and Earnings Manipulation Risk

A DMU was classified bankrupt up to 3 years prior to filing Chapter 11.

\begin{tabular}{|l|c|c|c|c|}
\cline { 2 - 5 } \multicolumn{1}{c|}{} & Year 0 & Year 1 & Year 2 & Year 3 \\
\hline Classified Suspicious & $2(17 \%)$ & $2(17 \%)$ & $2(17 \%)$ & $3(25 \%)$ \\
\hline Classified Non-Suspicious & $10(83 \%)$ & $10(83 \%)$ & $10(83 \%)$ & $9(75 \%)$ \\
\hline
\end{tabular}

\subsubsection{Quality of Income}

High-quality earnings have a high correlation with cash flows, which are more difficult to manipulate than reported income. Table 6.18 shows the average values of Quality of Income by state. As expected, the average of active companies was higher than 1 (implying high earnings quality) whereas for bankrupt companies, it was below 1 (implying a red flag). The quality of income measure was also evaluated as a determinant of bankrupt. While it yielded a true positive rate of $96 \%$, it produced a false positive rate of $83 \%$, making it an inadequate proxy.

Table 6.18: Quality of Income

A DMU was classified bankrupt up to 3 years prior to filing Chapter 11.

\begin{tabular}{|l|c|}
\hline \multicolumn{1}{|c|}{ State } & Quality of Income \\
\hline Active & $1.3 \pm 3.6$ \\
\hline Bankrupt & $0.4 \pm 2.7$ \\
\hline All & $1.2 \pm 3.5$ \\
\hline
\end{tabular}

\subsection{Managerial Decision-Making Data}

Of the 85 firms studied, annual reports for all but two companies (BSST and CSS) were available from EDGAR, SEC and/or company websites. Because of the abundance of information in the Notes, MD\&A, and Auditor's Report, a comprehensive review of fraud literature and the retail-apparel industry was conducted to determine what was worth collecting. A particular variable was chosen only if: 1. it was relevant to the retail-apparel industry; 2. it was a commonly reported item across all companies; 3. it was easily extracted from the annual report; and 4. it could be translated into a useful scale (i.e. binary). Eight types of information were extracted from each annual report for each year for each company: 
1. Significant Related-Party Transactions, in the form of leases or loans to the executive, etc.;

2. Auditor's Opinion, either unqualified or qualified;

3. Independent Auditing Company, typically either Arthur Andersen LLP, Deloitte \& Touche LLP, Ernst \& Young LLP, KPMG Peat Marwick LLP or PricewaterhouseCoopers LLP;

4. Legal proceedings, such as those arising in the normal course of business that do not have a material adverse effect on the company, litigations that lead to significant payouts and filing of Chapter 11 bankruptcy;

5. Name of Chairman;

6. Name of Chief Executive Officer;

7. Name of Chief Financial Officer; and,

8. Retirement plans, where if applicable, employees are eligible to participate in the company's 401(k) plan or there is a specific company-sponsored pension program.

Because each annual report is presented as a .pdf and/or .doc file, data collection required manual key word searches (e.g. "related party transactions"). Relevant information was recorded as categorical variables in an .xls file in the same format as financial data (Figure 6.34). This was an extremely tedious process as approximately 1000 annual reports were read. It is also noted that annual reports prior to 1994 (before EDGAR's mandatory filing) could not be found and not all were available post-1996. The categorical variables were then translated to have numerical values associated with their possible outcomes (Table 6.19). All variables except for "Legal Proceedings" were binary and assigned a value of 0 or 1 . For "Legal Proceedings", the outcomes "None", "Insignificant", "Significant", "Going Concern" and "Bankruptcy" translated to 0,2,10, 20 and 25, respectively, based on the frequency of their occurrence among all DMUs. 


\begin{tabular}{|c|c|c|c|c|c|c|c|c|}
\hline Company & Year & \begin{tabular}{|c|} 
Related \\
Parties \\
\end{tabular} & $\begin{array}{c}\text { Legal } \\
\text { Proceedings }\end{array}$ & Auditor & Opinion & $\begin{array}{c}\text { Chairman of the } \\
\text { Board }\end{array}$ & $\begin{array}{c}\text { Chief Executive } \\
\text { Officer }\end{array}$ & $\begin{array}{c}\text { Chief Financal } \\
\text { Officer }\end{array}$ \\
\hline AENA & 2005 & & & & & & & \\
\hline AENA & 2006 & & & & & & & \\
\hline AENA & 2007 & Yes & Insignificant & Goldstein Schechter Koch & Unqualified & Ilia Lekach & Ilia Lekach & Jeffrey Geller \\
\hline AENA & 2008 & & & & & & & \\
\hline AEO & 1993 & & & & & & & \\
\hline AEO & 1994 & & & & & & & \\
\hline AEO & 1995 & & & & & & & \\
\hline AEO & 1996 & & & & & & & \\
\hline $\mathrm{AEO}$ & 1997 & Yes & None & Ernst \& Young LLP & Unqualified & Jay Schottenstein & Jay Schottenstein & Laura Weil \\
\hline $\mathrm{AEO}$ & 1998 & Yes & None & Ernst \& Young LLP & Unqualified & Jay Schottenstein & Jay Schottenstein & Laura Weil \\
\hline AEO & 1999 & Yes & None & Ernst \& Young LLP & Unqualified & Jay Schottenstein & Jay Schottenstein & Laura Weil \\
\hline $\mathrm{AEO}$ & 2000 & Yes & None & Ernst \& Young LLP & Unqualified & Jay Schottenstein & Jay Schottenstein & Laura Weil \\
\hline AEO & 2001 & Yes & None & Ernst \& Young LLP & Unqualified & Jay Schottenstein & Jay Schottenstein & Laura Weil \\
\hline $\mathrm{AEO}$ & 2002 & Yes & None & Ernst \& Young LLP & Unqualified & Jay Schottenstein & Jay Schottenstein & Laura Weil \\
\hline AEO & 2003 & Yes & Insignificant & Ernst \& Young LLP & Unqualified & Jay Schottenstein & James O'Donell & Laura Weil \\
\hline AEO & 2004 & Yes & Insignificant & Ernst \& Young LLP & Unqualified & Jay Schottenstein & James O'Donell & Laura Weil \\
\hline AEO & 2005 & Yes & Insignificant & Ernst \& Young LLP & Unqualified & Jay Schottenstein & James O'Donell & Laura Weil \\
\hline AEO & 2006 & Yes & Insignificant & Ernst \& Young LLP & Unqualified & Jay Schottenstein & James O'Donell & Joan Holstein Hilson \\
\hline $\mathrm{AEO}$ & 2007 & Yes & Insignificant & Ernst \& Young LLP & Unqualified & Jay Schottenstein & James O'Donell & Joan Holstein Hilson \\
\hline AEO & 2008 & Yes & Insignificant & Ernst \& Young LLP & Unqualified & Jay Schottenstein & James O'Donell & Joan Holstein Hilson \\
\hline AEO & 2009 & Yes & Insignificant & Ernst \& Young LLP & Unqualified & Jay Schottenstein & James O'Donell & Joan Holstein Hilson \\
\hline$\ldots$ & $\ldots$ & $\ldots$ & $\ldots$ & $\ldots$ & $\ldots$ & $\ldots$ & $\ldots$ & $\ldots$ \\
\hline$\ldots$ & $\ldots$ & $\ldots$ & $\ldots$ & $\ldots$ & $\ldots$ & $\ldots$ & $\ldots$ & $\ldots$ \\
\hline ZUMZ & 2006 & Yes & None & PricewaterhouseCoopers LLP & Unqualified & Tom Campion & Rick Brooks & Brenda Morris \\
\hline ZUMZ & 2007 & Yes & None & Pricewaterhouse Coopers LLP & Unqualified & Tom Campion & Rick Brooks & Brenda Morris \\
\hline ZUMZ & 2008 & Yes & None & Moss Adams LLP & Unqualified & Tom Campion & Rick Brooks & Trevor Lang \\
\hline ZUMZ & 2009 & Yes & None & Moss Adams LLP & Unqualified & Tom Campion & Rick Brooks & Trevor Lang \\
\hline
\end{tabular}

Figure 6.34: Example of Organization of Qualitative Information Extracted from Annual Reports

Table 6.19: Managerial Decision-Making Variables

\begin{tabular}{|c|c|c|}
\hline Variable & Outcome & Value Assigned \\
\hline \multirow{2}{*}{ Significant Related Party Transactions } & None & 0 \\
\hline & Yes & 1 \\
\hline \multirow{2}{*}{ Auditor's Opinion } & Unqualified & 0 \\
\hline & Qualified & 1 \\
\hline \multirow{5}{*}{ Legal Proceedings } & None & 0 \\
\hline & Insignificant & 2 \\
\hline & Significant & 10 \\
\hline & Going Concern & 20 \\
\hline & Bankruptcy Filing & 25 \\
\hline \multirow{2}{*}{ Retirement Plan } & None & 0 \\
\hline & Yes & 1 \\
\hline \multirow{2}{*}{$\begin{array}{l}\text { Auditor Change } \\
\text { (Change in auditor company) }\end{array}$} & None & 0 \\
\hline & Yes & 1 \\
\hline \multirow{2}{*}{$\begin{array}{l}\text { Turnover of Management } \\
\text { (Change in either Chairman, Chief Executive Officer } \\
\text { or Chief Financial Officer) }\end{array}$} & None & 0 \\
\hline & Yes & $\begin{array}{c}1,2 \text { or } 3 \text { (depending on how many } \\
\text { changed in that year) }\end{array}$ \\
\hline
\end{tabular}

As shown in Table 6.20, legal proceedings, auditor change and management turnover had a statistically significant relationship to a company's state. Specifically, an unhealthy firm was more likely to make changes to their management (Table 6.21) and auditors (Table 6.22), and be involved in more serious legal proceedings (Table 6.23). 
Table 6.20: Chi-Square Test Results of Managerial Decision-Making Data and State

\begin{tabular}{|l|r|c|c|}
\hline \multicolumn{1}{|c|}{ Variable $\times$ State } & \multicolumn{1}{c|}{$\boldsymbol{\chi}^{\mathbf{2}}$} & $\boldsymbol{d} \boldsymbol{f}$ & $\boldsymbol{p}$ \\
\hline Related Party Transactions & 8.8 & 4 & 0.067 \\
\hline Auditor's Opinion & 0.5 & 4 & 0.969 \\
\hline Legal Proceedings & 226.1 & 16 & 0.000 \\
\hline Retirement Plan & 3.7 & 8 & 0.884 \\
\hline Auditor Change & 20.3 & 4 & 0.000 \\
\hline Management Turnover & 14.7 & 4 & 0.005 \\
\hline
\end{tabular}

Table 6.21: Likelihood of Management Turnover

A DMU was classified bankrupt up to 3 years prior to filing Chapter 11 .

\begin{tabular}{|l|c|c|}
\hline \multicolumn{1}{|c|}{ State } & Average Number of Management Changes & Times Over Average \\
\hline Active & 0.4 & 0.9 \\
\hline Bankrupt & 0.8 & 1.9 \\
\hline All & 0.4 & - \\
\hline
\end{tabular}

Table 6.22: Probability of Auditor Change by State

A DMU was classified bankrupt up to 3 years prior to filing Chapter 11.

\begin{tabular}{|l|c|}
\hline \multicolumn{1}{|c|}{ State } & Probability of Auditor Change \\
\hline Active & 0.05 \\
\hline Bankrupt & 0.10 \\
\hline All & 0.05 \\
\hline
\end{tabular}

Table 6.23: Percentage of DMUs with Non-Serious and Serious Legal Proceedings by State A DMU was classified bankrupt up to 3 years prior to filing Chapter 11.

\begin{tabular}{|c|l|c|c|}
\hline State & Legal Proceedings* & Count & Percentage \\
\hline \multirow{2}{*}{ Active } & Non-serious & 606 & $93.1 \%$ \\
\cline { 2 - 4 } & Serious & 45 & $6.9 \%$ \\
\hline \multirow{2}{*}{ Bankrupt } & Non-serious & 33 & $66.0 \%$ \\
\cline { 2 - 4 } & Serious & 17 & $34.0 \%$ \\
\hline
\end{tabular}

*Non-serious legal proceedings include the categories: "None" and "Insignificant";

Serious legal proceedings include the categories: "Significant", "Going Concern" and "Bankruptcy"

\subsection{Outliers and Missing Data}

Because numerical data were collected directly from financial statements prepared by companies and approved by independent auditors, measurement error was assumed to be negligible as one cannot be concerned about "observations" that are not in one's "control". However, this did not rule out the outliers which appear with the conversion of values from absolute to relative terms. In some instances, there were some extreme percentage changes from year-to-year. These occurred when there was a dramatic increase or decrease of a

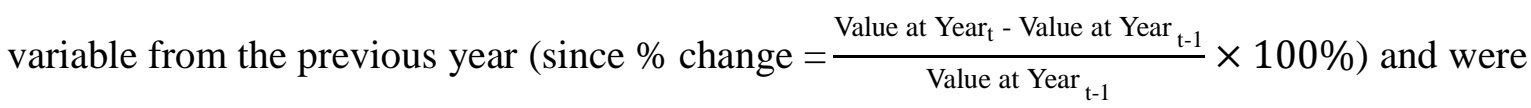
addressed by rounding down or up to a reasonable level (like one magnitude above or below the average). For example, if a company with minimal to no long-term debt (i.e. $\$ 100,000$ ) suddenly took a large loan (i.e. $\$ 10,000,000$ ), the change in total liabilities from the previous 
year would be $9900 \%$. In this case, the change was scaled to $300 \%$ (20 times over the average). Dealing with data in this manner recognized the value of and reflected upon the extreme change relative to other DMUs (without removing it completely) and did not skew the rest of the data.

Because annual reports are professionally audited, there were no missing financial data entries with any of them. However, in cases where an annual report could not be found for a given company for a given year (and thus, no data on managerial decision-making data could be collected), the corresponding DMU was removed entirely.

\subsection{Economic Data}

The historical values for over 100 economic factors were collected from federal agencies with statistical programs such as the Bureau of Economic Analysis (Department of Commerce), the Bureau of Labour Statistics (Department of Labour), the Census Bureau (Department of Commerce), National Agricultural Statistics Service (Department of Agriculture) and the National Retail Federation. These factors fall into seven broad categories (Table D.1) - each having one of two relationships to the economy - either:

- Procyclic, if it moves in the same direction as the economy; or,

- Countercyclic, if it moves in the opposite direction as the economy.

Each factor can also be classified by time, either:

- Leading, if it changes before economy changes;

- Lagging, if it does not change direction until a few quarters after the economy does; or,

- Coincident, if it moves with the economy.

As the majority of the factors were strongly correlated with one another (i.e. greater than 0.9), this prompted a reduction to a manageable set. Ultimately, 17 economic factors having a direct effect on the apparel industry were considered (Table 6.24) with information stored in .xls format (Figure 6.35). For the most part, these factors were weakly correlated (< |0.4|) with one another (Table 6.25). 
Table 6.24: Economic Factors in this Thesis

\begin{tabular}{|c|c|c|c|c|}
\hline \multicolumn{2}{|r|}{ Factor } & $\begin{array}{l}\text { Measured } \\
\text { in }\end{array}$ & $\begin{array}{l}\text { Analysis } \\
\text { in }\end{array}$ & $\begin{array}{l}\text { Timing and Relation to } \\
\text { Business Cycle }\end{array}$ \\
\hline \multicolumn{5}{|c|}{ General Economic Factors } \\
\hline E1 & GDP Rate & $\$ B$ & $\%$ & Coincident, Procyclical \\
\hline E2 & Debt as $\%$ of GDP & $\%$ & Same & Coincident, Countercyclical \\
\hline E3 & Inflation & $\%$ & Same & Coincident, Procyclical \\
\hline E4 & Interest rate & $\%$ & Same & Coincident, Procyclical \\
\hline E5 & Unemployment Rate & $\%$ & Same & Lagged, Countercyclical \\
\hline \multicolumn{5}{|c|}{ Apparel Factors } \\
\hline E6 & $\begin{array}{l}\text { Personal Consumption Expenditures: Clothing } \\
\text { \& Footwear }\end{array}$ & $\$ B$ & $\%$ & Coincident, Procyclical \\
\hline E7 & GDP: Clothing \& Footwear & $\$ B$ & $\%$ & Coincident, Procyclical \\
\hline E8 & CPI: Apparel & $\begin{array}{l}\text { Index } \\
(1982)\end{array}$ & $\%$ & Coincident, Procyclical \\
\hline E9 & Industrial Production: Clothing & $\begin{array}{l}\text { Index } \\
(2007)\end{array}$ & $\%$ & Coincident, Procyclical \\
\hline E10 & $\begin{array}{l}\text { Apparel Unit Labor Cost = (total labour } \\
\text { compensation / hours) / productivity }\end{array}$ & $\%$ & Same & Coincident, Procyclical \\
\hline E11 & Apparel Labor Productivity $=$ output/hours & $\%$ & Same & Coincident, Procyclical \\
\hline E12 & Apparel Imports & $\$$ & $\%$ & Coincident, Procyclical \\
\hline E13 & Apparel Exports & $\$$ & $\%$ & Coincident, Countercyclical \\
\hline \multicolumn{5}{|c|}{ Other Factors } \\
\hline E14 & New Privately Owned Housing Units Started & $1000 \mathrm{~s}$ & Same & Leading, Procyclical \\
\hline E15 & Median Number of Months for a Sale & Months & Same & Leading, Countercyclical \\
\hline E16 & Oil price & $\$ / \mathrm{bbl}$ & Same & Coincident, Countercyclical \\
\hline E17 & Cotton price & cent/lb & Same & Coincident, Countercyclical \\
\hline
\end{tabular}

\begin{tabular}{|c|c|c|c|c|c|}
\hline Year & GDP Growth Rate (\%) & Debt as \% of GDP & Inflation (\%) & Interest Rate (\%) & Unemployment Rate (\%) \\
\hline 1988 & 7.69 & 51.02 & 4.08 & 7.57 & 5.5 \\
\hline 1989 & 7.48 & 52.12 & 4.84 & 9.21 & 5.3 \\
\hline 1990 & 5.81 & 55.74 & 5.39 & 8.10 & 5.6 \\
$\ldots \ldots$ & $\ldots$ & $\ldots$ & $\ldots$ & $\ldots$ & $\ldots$ \\
$\ldots \ldots$ & $\ldots$ & $\ldots$ & $\ldots$ & $\ldots$ & $\ldots$ \\
\hline 2007 & 5.07 & 63.99 & 2.85 & 5.02 & 4.6 \\
\hline 2008 & 2.58 & 69.15 & 3.85 & 1.92 & 5.8 \\
\hline 2009 & -1.28 & 83.29 & -0.34 & 0.16 & 9.3 \\
\hline
\end{tabular}

Figure 6.35: Example of Organization of Economic Data 
Table 6.25: Spearman Correlation Coefficients of Economic Factors

\begin{tabular}{|l|c|c|c|c|c|c|c|c|c|c|c|c|c|c|c|c|c|}
\hline & E1 & E2 & E3 & E4 & E5 & E6 & E7 & E8 & E9 & E10 & E11 & E12 & E13 & E14 & E15 & E16 & E17 \\
\hline E1 & 1.00 & -0.17 & 0.07 & 0.16 & -0.45 & 0.88 & 0.86 & 0.24 & 0.28 & -0.30 & 0.17 & 0.54 & 0.16 & 0.50 & -0.26 & 0.03 & -0.03 \\
\hline E2 & & 1.00 & 0.30 & 0.26 & 0.28 & -0.22 & -0.09 & 0.69 & 0.30 & 0.06 & -0.05 & 0.01 & 0.60 & -0.57 & 0.71 & 0.20 & 0.61 \\
\hline E3 & & & 1.00 & 0.09 & -0.03 & 0.03 & 0.02 & 0.16 & -0.06 & -0.06 & -0.06 & -0.26 & 0.23 & -0.22 & 0.19 & 0.78 & 0.00 \\
\hline E4 & & & & 1.00 & -0.60 & 0.40 & 0.09 & 0.34 & 0.65 & -0.26 & 0.31 & 0.53 & 0.65 & -0.57 & 0.52 & -0.36 & 0.56 \\
\hline E5 & & & & 1.00 & -0.70 & -0.52 & -0.21 & -0.20 & 0.06 & -0.10 & -0.25 & -0.01 & 0.04 & -0.23 & 0.17 & 0.11 \\
\hline E6 & & & & & 1.00 & 0.86 & 0.19 & 0.42 & -0.46 & 0.34 & 0.57 & 0.24 & 0.35 & -0.06 & -0.17 & 0.06 \\
\hline E7 & & & & & & 1.00 & 0.28 & 0.21 & -0.27 & 0.13 & 0.33 & 0.05 & 0.58 & -0.13 & 0.00 & -0.05 \\
\hline E8 & & & & & & & 1.00 & 0.28 & 0.17 & -0.17 & 0.20 & 0.47 & -0.26 & 0.55 & 0.10 & 0.31 \\
\hline E9 & & & & & & & & 1.00 & -0.74 & 0.80 & 0.69 & 0.85 & -0.25 & 0.19 & -0.55 & 0.66 \\
\hline E10 & & & & & & & & & 1.00 & -0.88 & -0.45 & -0.51 & -0.07 & 0.17 & 0.37 & -0.42 \\
\hline E11 & & & & & & & & & & 1.00 & 0.44 & 0.49 & -0.07 & -0.06 & -0.47 & 0.44 \\
\hline E12 & & & & & & & & & & & 1.00 & 0.58 & 0.09 & -0.13 & -0.45 & 0.58 \\
\hline E13 & & & & & & & & & & & & 1.00 & -0.45 & 0.40 & -0.22 & 0.72 \\
\hline E14 & & & & & & & & & & & & & 1.00 & -0.80 & 0.03 & -0.45 \\
\hline E15 & & & & & & & & & & & & & & & 1.00 & 0.03 & 0.36 \\
\hline E16 & & & & & & & & & & & & & & & & 1.00 & -0.22 \\
\hline E17 & & & & & & & & & & & & & & & & & 1.00 \\
\hline
\end{tabular}

\subsection{Market and Stock Performance}

The 85 public firms in this thesis were either traded on the NASDAQ, NYSE or OTC (Figure 6.36). Therefore, the NASDAQ and NYSE Composite Indices were analyzed as measures that reflect overall stock performance. The NASDAQ Composite is a stock market index of common stocks listed on the NASDAQ stock market with over 3000 components. Similarly, the NYSE Composite is a stock market index of common stocks listed on the New York Stock Exchange with over 2000 components. Moreover, the S\&P Composite was considered as it combines three indices (the S\&P 500, the S\&P MidCap 400 and the S\&P SmallCap 600) that cover approximately $90 \%$ of the U.S. Market Capitalization. It is designed for investors seeking to replicate the performance of the U.S. equity market or benchmark against a representative universe of tradable stocks. Figure 6.37 plots the average yearly returns of these composites, which are leading, procyclical and highly correlated with one another (Table 6.26). 


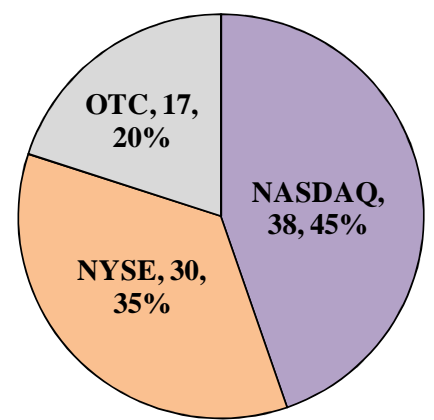

Figure 6.36: Count and Percentage of Companies Traded on Specific Exchanges

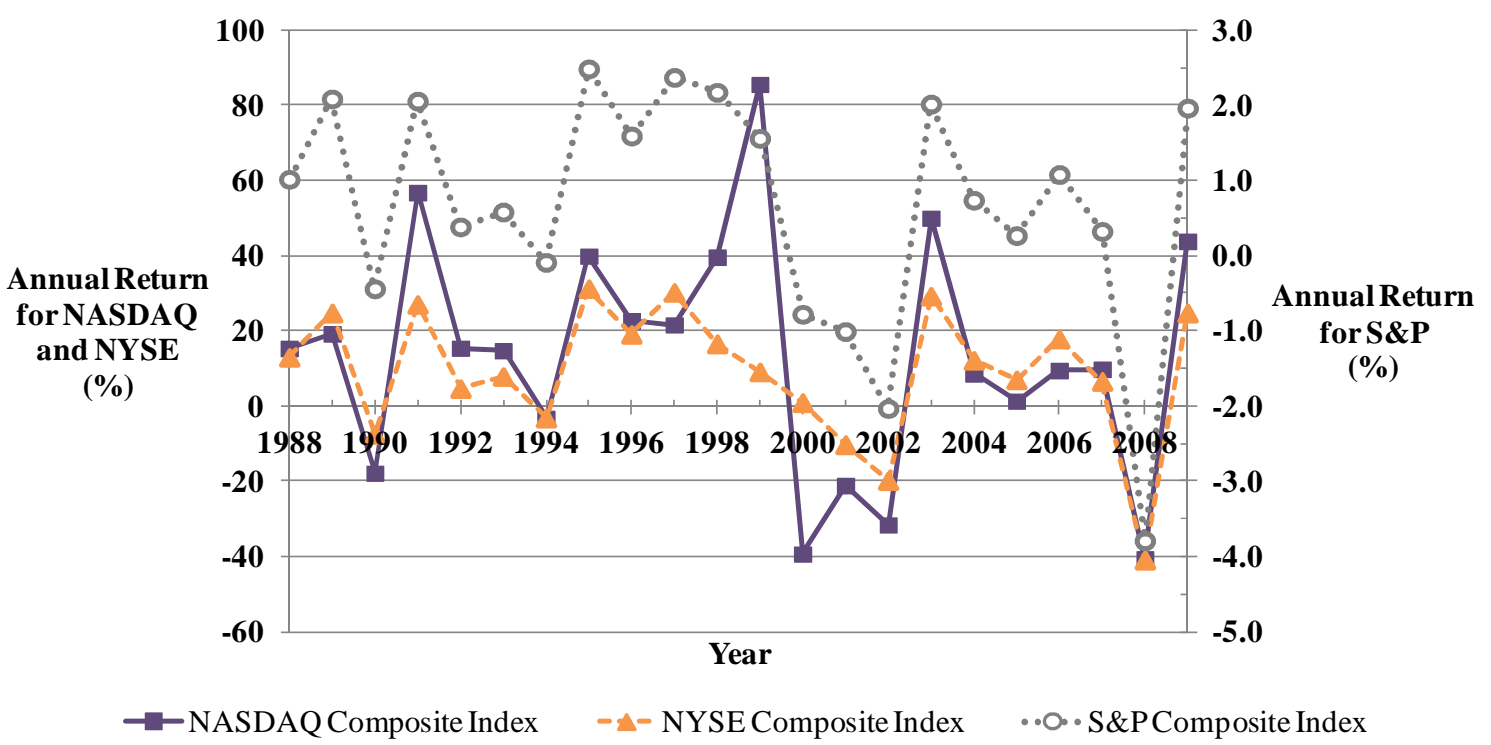

Figure 6.37: Average Yearly Returns of Composite Indices

Table 6.26: Correlation between Composite Indices Significant at the 0.01 level (2-tailed)

\begin{tabular}{|l|c|c|c|}
\cline { 2 - 4 } \multicolumn{1}{c|}{} & NASDAQ & NYSE & S\&P \\
\hline NASDAQ & 1.00 & 0.82 & 0.88 \\
\hline NYSE & & 1.00 & 0.95 \\
\hline S\&P & & & 1.00 \\
\hline
\end{tabular}

In addition to indices reflecting the general market performance, end-of-month stock prices were collected for each company (except CSS, DUSS, EXLA since information was not available) between 1988 and 2009 from the CRSP database as well as Google and Yahoo! Finance websites. The monthly prices were used to calculate monthly returns, from which annual return, annual volatility and annual beta ${ }^{11}$ were computed. Table 6.27 presents the average annual return, volatility and beta by state while Figure 6.38, Figure 6.39 and Figure

\footnotetext{
${ }^{11}$ Volatility is equivalent to standard deviation while beta is covariance of company return and market return, divided by the variance of the market (Section 2.5). It is standard practice to use the S\&P Composite to represent market performance.
} 
6.40 plot these measures by year (from 1994 to 2009). As expected, healthier firms had higher returns, and are less volatile with lower beta.

Table 6.27: Average Annual Return, Volatility and Beta A DMU was classified bankrupt up to 3 years prior to filing Chapter 11.

\begin{tabular}{|l|c|c|c|}
\hline \multicolumn{1}{|c|}{ State } & Return & Volatility & Beta \\
\hline Active & $0.013 \pm 0.055$ & $0.16 \pm 0.08$ & $1.16 \pm 1.45$ \\
\hline Bankrupt & $-0.019 \pm 0.099$ & $0.26 \pm 0.15$ & $1.63 \pm 3.11$ \\
\hline All & $0.011 \pm 0.059$ & $0.17 \pm 0.09$ & $1.19 \pm 1.61$ \\
\hline
\end{tabular}

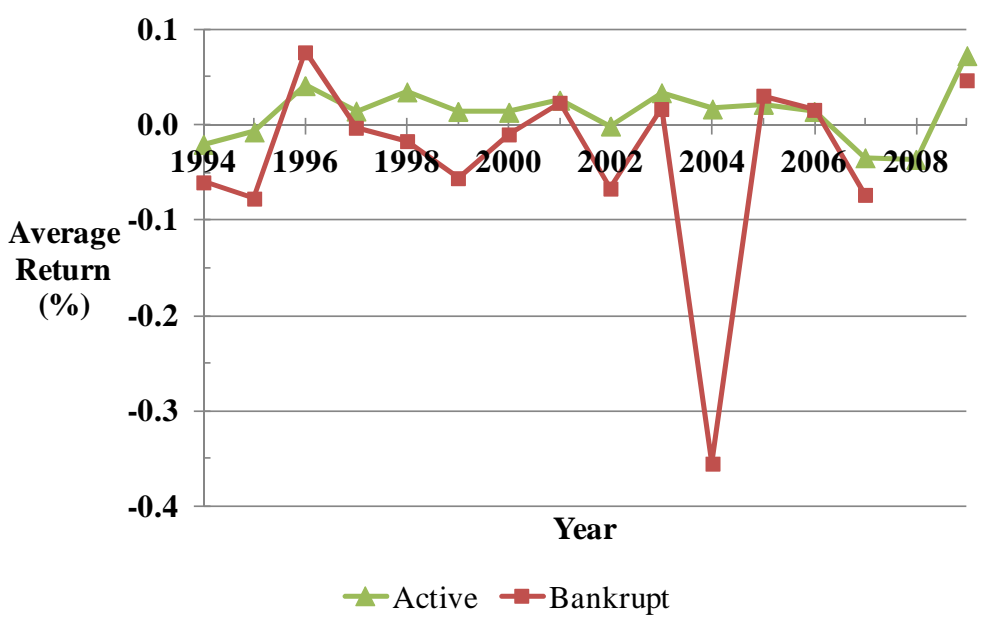

Figure 6.38: Average Return

A DMU was classified bankrupt up to 3 years prior to filing Chapter 11.

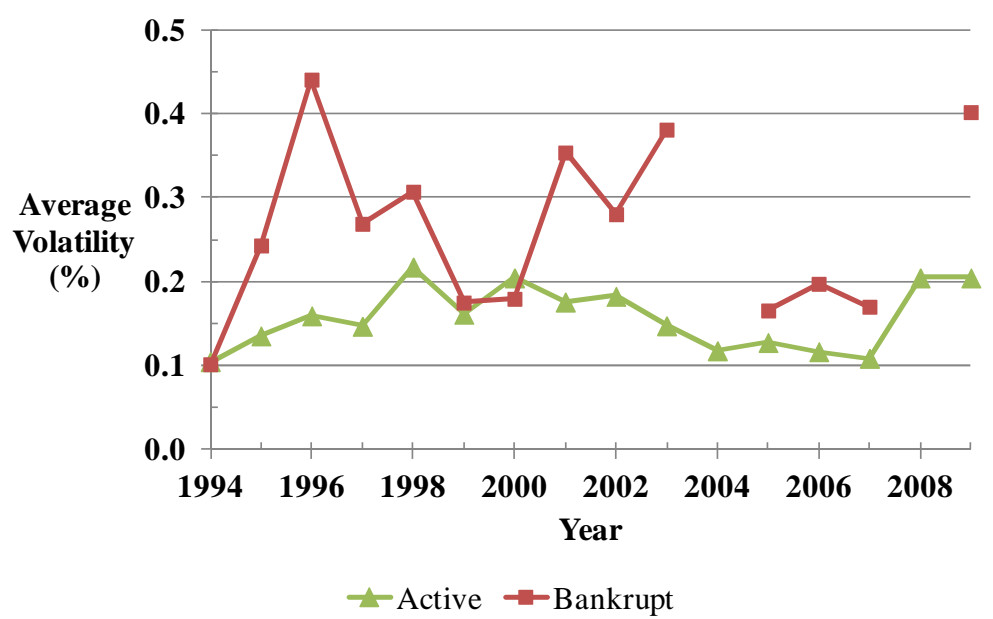

Figure 6.39: Average Volatility

A DMU was classified bankrupt up to 3 years prior to filing Chapter 11. 


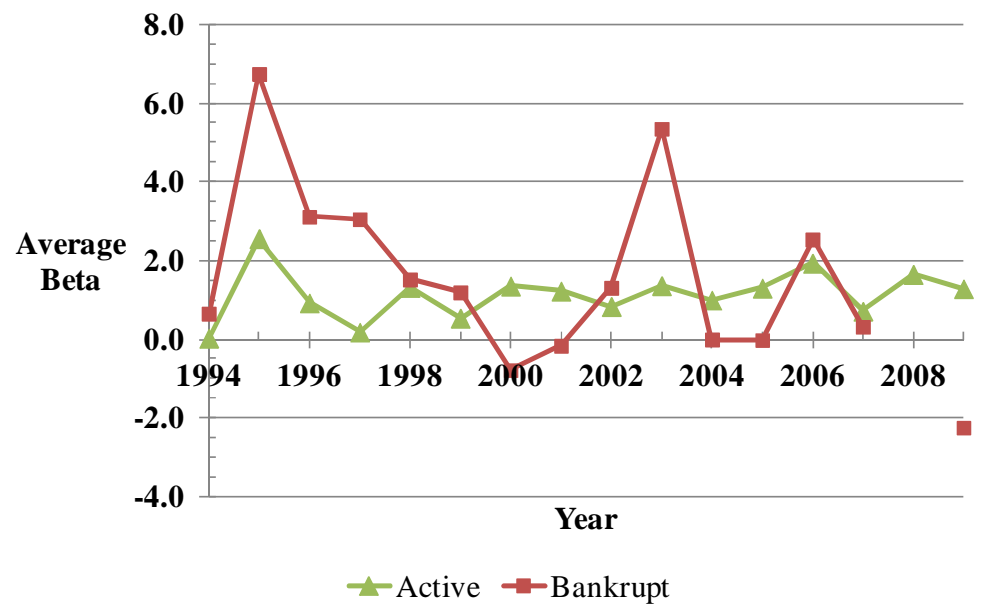

Figure 6.40: Average Beta

A DMU was classified bankrupt up to 3 years prior to filing Chapter 11 .

Finally, the correlations among the composites, return, volatility and beta were generally weak (Table 6.28), suggesting that all these variables should be individually considered in prediction.

Table 6.28: Correlation between Composite Indices and Stock Performance A DMU was classified bankrupt up to 3 years prior to filing Chapter 11.

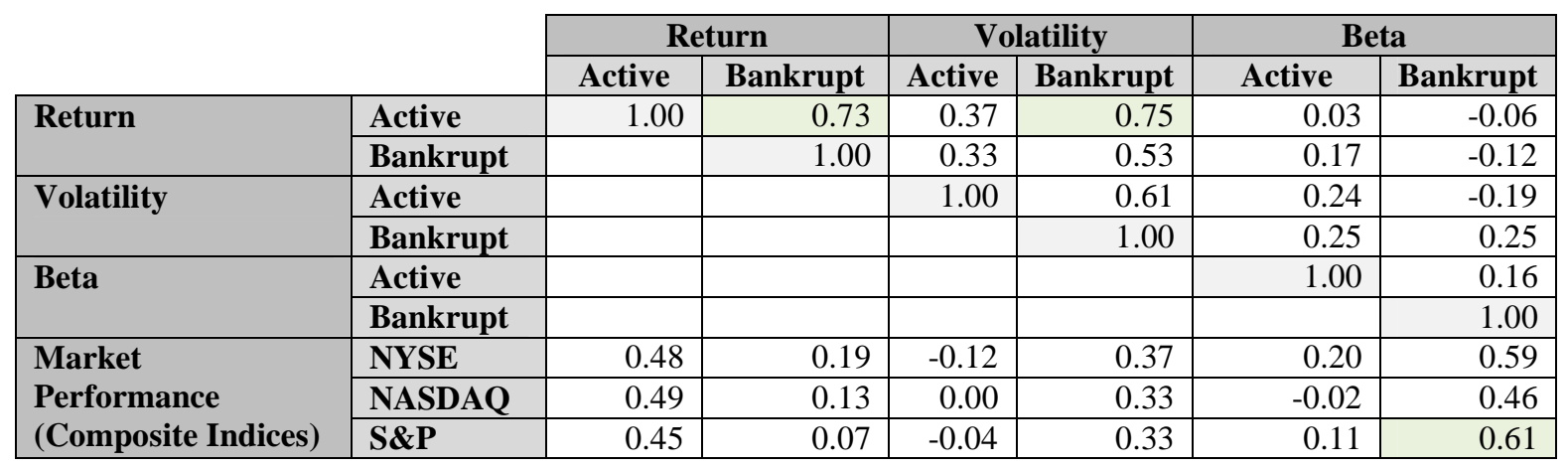

\subsection{Cross-Data Exploration}

\subsubsection{Correlation between Financial and Managerial Decision-Making Data}

The relationship between financial and managerial decision-making data was investigated by creating bar graphs for each managerial decision-making variable and the average value of each financial variable. For example, Figure 6.41 correlates the possible categories of related-party transactions ("None" or "Yes") and average revenue. This relationship is further broken down by state (i.e. active or bankrupt ${ }^{12}$ ). As illustrated, DMUs with relatedparty transactions had greater revenue than those without, regardless of their state.

\footnotetext{
${ }^{12}$ A DMU is classified bankrupt up to 3 years prior to filing Chapter 11.
} 
Over 150 graphs (25 financial $\times 6$ managerial decision-making variables) resembling Figure 6.41 were generated to analyze the relationship between all financial and managerial decision-making variables, and yielded similar conclusions (though some were less statistically significant with high standard deviations). Results include:

- Related-Party Transactions: Most variables ${ }^{13}$ (i.e. COGS, SGA, II, IE, NI, Cash, Inv, AR, CA, PPE, AD, TA, AP, CM, CL, LTD, TL, RE, SE and CFO) were similar to revenue.

- Legal Proceedings: Most variables were similar to revenue (Figure 6.42). Revenue was higher without legal proceedings or with minor litigations compared to those with significant proceedings, going concerns or bankruptcy filings, regardless of state.

- Auditor's Opinion: Most variables were similar to revenue (Figure 6.43). Revenue was higher with unqualified opinions compared to qualified opinions, regardless of state.

- Retirement Plan: Most variables were similar to revenue (Figure 6.44). Revenue was higher for those with either a company-sponsored pension program or 401(k) plan compared to those with none, regardless of state.

- Auditor Change: Because a change of auditors was recorded from one year to the next, the comparison of this managerial decision-making variable to all financial items must be on a percentage change basis. Figure 6.45 correlates auditor change to average percentage change in revenue over one year, and shows an increase in revenue when there is a change. The difference was more pronounced between active and bankrupt DMUs. Again, most variables were similar to revenue.

- Turnover of Management: Figure 6.46 illustrates that those with management turnover had less revenue, regardless of state. Also, most variables were similar to revenue.

${ }^{13}$ See List of Abbreviations for definitions of variable acronyms. 


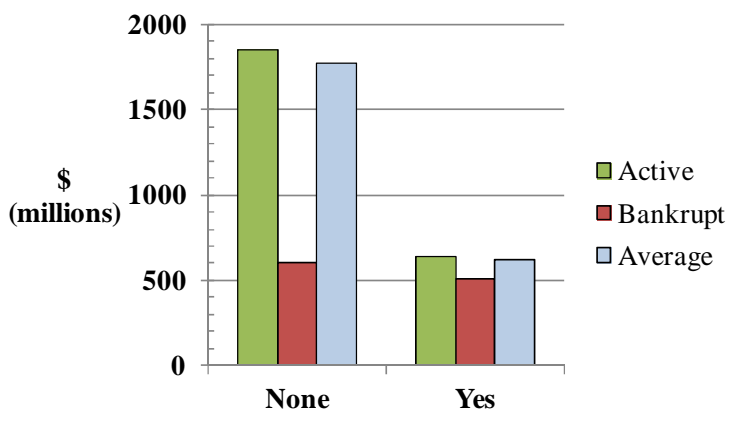

Figure 6.41: Relationship between Related Party Transactions and Average Revenue

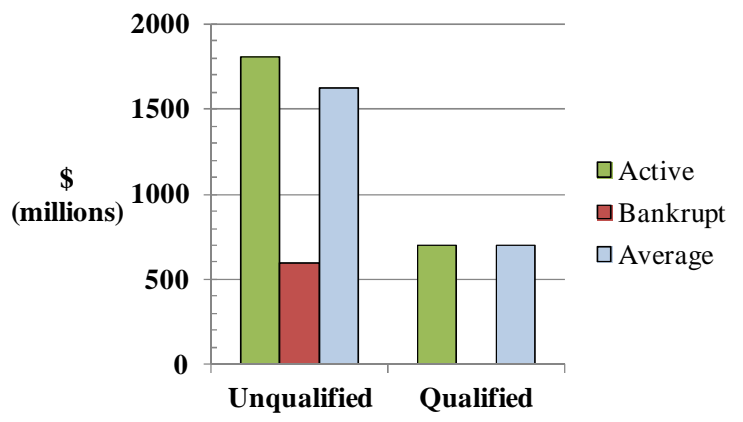

Figure 6.43: Relationship between Auditor's Opinion and Average Revenue

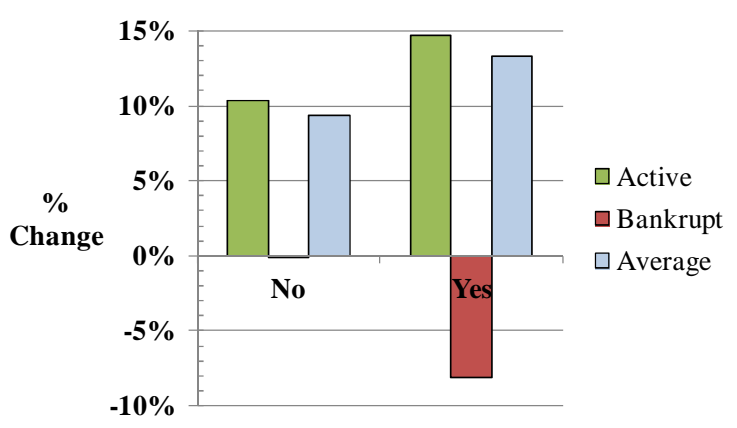

Figure 6.45: Relationship between Auditor Change and Average Change in Revenue

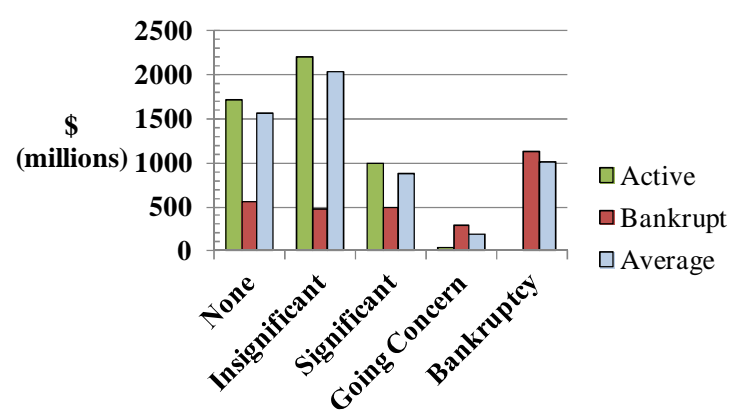

Figure 6.42: Relationship between Legal Proceedings and Average Revenue

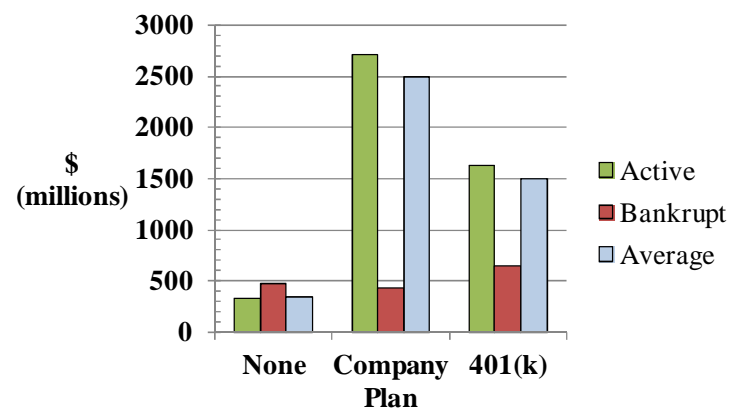

Figure 6.44: Relationship between Retirement Plan and Average Revenue

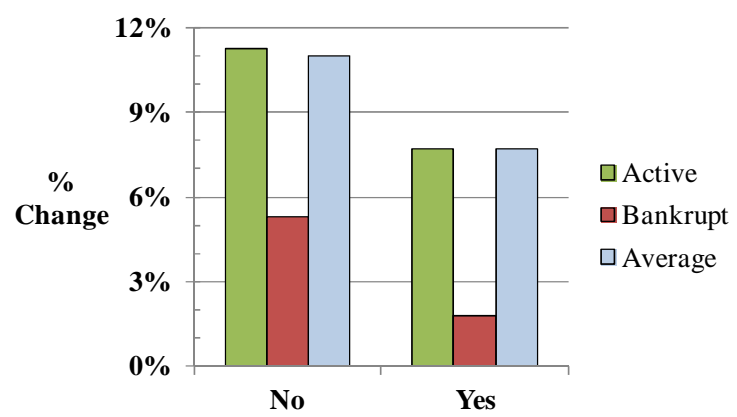

Figure 6.46: Relationship between Turnover of Management and Average Change in Revenue

\subsubsection{Correlation between Financial and Economic Data}

Spearman correlation coefficients were calculated for each economic factor and the average of each variable for a particular year by state (Table 6.29; and for E1-E17 codes, refer to Table 6.24). The correlations for active and bankrupt DMUs were generally weak, with less than $4.7 \%$ and $1.9 \%$ respectively, having coefficients greater than 0.6 (highlighted in shades of green) or less than -0.6 (highlighted in shades of red). 
Table 6.29: Correlation between Financial and Economic Variables

A DMU was classified bankrupt up to 3 years prior to filing Chapter 11.

\begin{tabular}{|c|c|c|c|c|c|c|c|c|c|c|c|c|c|c|c|c|c|}
\hline & E1 & $\mathbf{E 2}$ & E3 & E4 & E5 & E6 & E7 & E8 & E9 & E10 & E11 & E12 & E13 & E14 & E15 & E16 & E17 \\
\hline \multicolumn{18}{|c|}{ Active } \\
\hline Revenue & 0.31 & \begin{tabular}{l|l|}
-0.40 \\
\end{tabular} & -0.14 & 0.39 & -0.71 & 0.52 & 0.40 & 0.01 & 0.29 & \begin{tabular}{|l|}
-0.10 \\
\end{tabular} & 0.17 & 0.36 & 0.01 & 0.21 & -0.06 & -0.42 & \begin{tabular}{|l|}
-0.23 \\
\end{tabular} \\
\hline Cost of Goods Sold & -0.09 & -0.18 & -0.22 & 0.43 & -0.58 & 0.18 & -0.05 & 0.10 & 0.19 & -0.07 & 0.11 & 0.09 & 0.02 & -0.31 & 0.32 & -0.40 & \begin{tabular}{|l|}
-0.11 \\
\end{tabular} \\
\hline Selling, General and Administrative Expenses & 0.51 & -0.59 & 0.11 & 0.05 & -0.65 & 0.57 & 0.64 & -0.16 & 0.00 & -0.03 & 0.06 & 0.19 & -0.33 & 0.63 & -0.44 & 0.02 & -0.42 \\
\hline Interest Income & 0.48 & -0.15 & 0.27 & 0.22 & -0.54 & 0.50 & 0.73 & 0.13 & 0.09 & 0.04 & -0.06 & 0.09 & -0.13 & 0.46 & \begin{tabular}{|c|c|}
-0.19 \\
\end{tabular} & 0.05 & -0.13 \\
\hline Interest Expense & -0.01 & 0.40 & 0.04 & -0.29 & 0.11 & 0.00 & 0.11 & 0.47 & -0.25 & 0.00 & -0.20 & -0.48 & -0.09 & -0.17 & 0.51 & 0.25 & -0.21 \\
\hline Income Tax Expense & 0.03 & -0.38 & -0.36 & -0.40 & -0.02 & 0.03 & 0.05 & -0.16 & -0.27 & 0.00 & 0.05 & -0.09 & -0.40 & 0.34 & -0.27 & 0.05 & -0.31 \\
\hline Net Income & 0.28 & -0.35 & -0.06 & 0.10 & -0.23 & 0.36 & 0.24 & -0.49 & 0.09 & -0.26 & 0.28 & 0.31 & -0.15 & 0.17 & -0.15 & \begin{tabular}{|c|}
-0.18 \\
\end{tabular} & \begin{tabular}{|l|}
-0.04 \\
\end{tabular} \\
\hline Cash & -0.04 & 0.14 & -0.59 & 0.14 & 0.02 & 0.01 & 0.03 & 0.14 & 0.33 & -0.35 & 0.21 & 0.19 & 0.19 & \begin{tabular}{|l|}
-0.10 \\
\end{tabular} & 0.08 & -0.55 & 0.35 \\
\hline Accounts Receivable & 0.16 & -0.03 & 0.18 & -0.07 & 0.04 & 0.20 & 0.16 & 0.11 & 0.00 & -0.04 & \begin{tabular}{|l|}
-0.14 \\
\end{tabular} & 0.08 & 0.23 & 0.22 & -0.11 & \begin{tabular}{|l|}
0.10 \\
\end{tabular} & -0.09 \\
\hline Inventories & 0.49 & -0.59 & 0.17 & 0.53 & -0.85 & 0.69 & 0.53 & -0.32 & 0.29 & -0.15 & 0.28 & 0.44 & -0.07 & 0.30 & -0.25 & -0.28 & -0.20 \\
\hline Current Assets & 0.52 & -0.40 & -0.43 & \begin{tabular}{|l|}
-0.09 \\
\end{tabular} & -0.36 & 0.51 & 0.63 & 0.03 & 0.07 & 0.04 & 0.01 & 0.41 & -0.20 & 0.69 & -0.40 & -0.30 & -0.22 \\
\hline Plant, Property and Equipment & 0.16 & -0.72 & -0.05 & 0.26 & -0.46 & 0.31 & 0.15 & -0.70 & -0.05 & 0.15 & 0.11 & 0.13 & -0.36 & 0.25 & -0.29 & -0.41 & -0.45 \\
\hline Accumulated Depreciation & 0.32 & -0.86 & -0.31 & 0.04 & -0.43 & 0.33 & 0.23 & -0.58 & -0.08 & 0.19 & 0.08 & 0.20 & -0.50 & 0.49 & -0.55 & -0.49 & -0.55 \\
\hline \begin{tabular}{|l|} 
Total Assets \\
\end{tabular} & 0.40 & -0.73 & -0.19 & 0.22 & -0.72 & 0.56 & 0.44 & -0.41 & -0.10 & 0.16 & 0.02 & 0.29 & -0.44 & 0.40 & -0.28 & -0.29 & -0.41 \\
\hline Accounts Payable & 0.54 & -0.44 & -0.01 & 0.08 & -0.41 & 0.49 & 0.49 & -0.12 & 0.26 & \begin{tabular}{|c|}
-0.12 \\
\end{tabular} & 0.24 & 0.54 & -0.09 & 0.52 & -0.47 & -0.22 & -0.17 \\
\hline Current Maturities of Long-Term Debt & 0.31 & -0.20 & -0.19 & 0.18 & -0.41 & 0.40 & 0.40 & 0.11 & 0.48 & -0.34 & 0.57 & 0.39 & 0.09 & 0.26 & -0.18 & -0.29 & 0.21 \\
\hline Current Liabilities & 0.53 & -0.43 & -0.21 & 0.09 & -0.43 & 0.58 & 0.56 & $\begin{array}{l}-0.09 \\
\end{array}$ & 0.41 & -0.38 & 0.49 & 0.58 & 0.00 & 0.53 & -0.42 & -0.35 & 0.00 \\
\hline Long-Term Debt & 0.17 & -0.04 & 0.66 & 0.17 & 0.01 & 0.14 & -0.03 & -0.33 & -0.08 & -0.03 & \begin{tabular}{|l|}
-0.10 \\
\end{tabular} & 0.07 & 0.13 & -0.10 & -0.05 & \begin{tabular}{|l|}
0.40 \\
\end{tabular} & 0.02 \\
\hline Total Liabilities & 0.51 & \begin{tabular}{l|l|}
-0.53 \\
\end{tabular} & -0.17 & -0.10 & -0.16 & 0.47 & 0.31 & -0.32 & 0.12 & -0.33 & \begin{tabular}{|l|}
0.34 \\
\end{tabular} & 0.50 & -0.17 & 0.47 & -0.51 & -0.23 & \begin{tabular}{|l|}
-0.11 \\
\end{tabular} \\
\hline Retained Earnings & -0.56 & -0.01 & -0.75 & -0.34 & 0.40 & -0.53 & -0.44 & -0.15 & -0.15 & 0.11 & 0.00 & -0.11 & -0.29 & -0.05 & -0.01 & \begin{tabular}{|l|}
-0.40 \\
\end{tabular} & 0.11 \\
\hline Shareholders' Equity & 0.45 & -0.53 & -0.01 & 0.16 & -0.76 & 0.58 & 0.64 & -0.07 & -0.12 & 0.21 & \begin{tabular}{|l|}
-0.22 \\
\end{tabular} & 0.16 & -0.34 & 0.51 & -0.23 & \begin{tabular}{|c|}
-0.08 \\
\end{tabular} & -0.50 \\
\hline Cash Flow from Operating Activities & 0.23 & -0.50 & -0.03 & -0.27 & \begin{tabular}{l|l|l}
-0.03 \\
\end{tabular} & 0.13 & 0.30 & -0.44 & -0.08 & -0.13 & 0.17 & -0.18 & -0.38 & 0.58 & -0.61 & -0.08 & -0.38 \\
\hline Cash Flow from Investing Activities & 0.34 & -0.53 & -0.14 & 0.32 & -0.43 & 0.53 & 0.38 & -0.55 & 0.15 & -0.10 & 0.30 & 0.46 & -0.10 & 0.34 & -0.29 & -0.35 & 0.07 \\
\hline Cash Flow from Financing Activities & 0.31 & -0.04 & -0.45 & 0.10 & -0.05 & 0.30 & 0.39 & 0.05 & 0.58 & -0.35 & 0.58 & 0.53 & 0.18 & 0.34 & -0.23 & -0.63 & 0.35 \\
\hline Change in Cash & -0.40 & 0.18 & -0.04 & $\mid-0.10$ & 0.19 & -0.26 & $\mid-0.26$ & 0.14 & 0.09 & 0.00 & 0.13 & -0.10 & 0.13 & $\mid-0.13$ & 0.22 & $\mid-0.11$ & 0.00 \\
\hline \multicolumn{18}{|c|}{ Bankrupt } \\
\hline Revenue & 0.17 & -0.10 & 0.31 & 0.09 & -0.57 & 0.33 & 0.45 & 0.08 & -0.25 & 0.22 & -0.30 & -0.17 & -0.23 & 0.16 & 0.19 & 0.30 & -0.31 \\
\hline Cost of Goods Sold & 0.07 & 0.04 & 0.31 & 0.10 & -0.50 & 0.26 & 0.40 & 0.15 & -0.28 & 0.28 & -0.36 & -0.22 & -0.19 & 0.07 & 0.32 & 0.33 & -0.22 \\
\hline Selling, General and Administrative Expenses & 0.20 & 0.17 & 0.49 & 0.36 & -0.45 & 0.44 & 0.46 & 0.13 & 0.10 & -0.23 & 0.11 & -0.11 & 0.20 & -0.07 & 0.33 & 0.30 & 0.20 \\
\hline Interest Income & -0.06 & 0.00 & 0.38 & 0.02 & -0.17 & -0.15 & -0.01 & 0.13 & -0.27 & 0.21 & -0.23 & -0.28 & -0.28 & -0.02 & -0.11 & 0.47 & 0.01 \\
\hline Interest Expense & 0.47 & -0.18 & -0.16 & \begin{tabular}{|l|l|}
-0.41 \\
\end{tabular} & -0.26 & 0.49 & 0.70 & 0.19 & -0.43 & 0.16 & -0.35 & -0.05 & -0.35 & 0.64 & \begin{tabular}{|l|}
-0.07 \\
\end{tabular} & 0.21 & \begin{tabular}{|l|}
-0.38 \\
\end{tabular} \\
\hline Income Tax Expense & 0.12 & -0.17 & 0.21 & 0.25 & -0.30 & 0.15 & 0.12 & -0.08 & 0.40 & -0.49 & 0.55 & -0.01 & 0.07 & -0.03 & -0.18 & -0.13 & 0.07 \\
\hline Net Income & 0.51 & -0.12 & -0.16 & 0.11 & 0.09 & 0.32 & 0.20 & -0.09 & 0.31 & -0.13 & \begin{tabular}{|l|}
0.09 \\
\end{tabular} & 0.57 & 0.35 & 0.26 & -0.32 & \begin{tabular}{|l|}
-0.23 \\
\end{tabular} & 0.00 \\
\hline Cash & 0.49 & -0.38 & -0.04 & -0.20 & -0.26 & 0.40 & 0.56 & -0.06 & -0.21 & 0.03 & \begin{tabular}{|l|}
-0.09 \\
\end{tabular} & -0.25 & -0.37 & 0.54 & -0.33 & \begin{tabular}{|l|}
0.03 \\
\end{tabular} & \begin{tabular}{|l|}
-0.51 \\
\end{tabular} \\
\hline Accounts Receivable & 0.38 & -0.02 & 0.24 & -0.40 & 0.00 & 0.33 & 0.60 & 0.14 & -0.24 & -0.12 & \begin{tabular}{|c|}
-0.05 \\
\end{tabular} & -0.15 & -0.27 & 0.60 & -0.24 & 0.38 & \begin{tabular}{|l|}
-0.12 \\
\end{tabular} \\
\hline Inventories & 0.43 & -0.32 & 0.08 & 0.17 & -0.70 & 0.53 & 0.58 & 0.22 & 0.04 & -0.01 & -0.10 & 0.08 & -0.09 & 0.36 & -0.13 & \begin{tabular}{|l|}
-0.02 \\
\end{tabular} & -0.37 \\
\hline Current Assets & 0.33 & -0.37 & 0.16 & 0.09 & -0.37 & 0.45 & 0.50 & -0.16 & 0.09 & -0.38 & 0.21 & -0.05 & -0.06 & 0.44 & -0.36 & 0.00 & \begin{tabular}{|l|}
-0.11 \\
\end{tabular} \\
\hline Plant, Property and Equipment & 0.27 & -0.40 & -0.10 & -0.04 & -0.60 & 0.34 & 0.52 & -0.03 & -0.26 & 0.21 & \begin{tabular}{|c|}
-0.27 \\
\end{tabular} & -0.10 & -0.45 & 0.44 & -0.17 & 0.03 & -0.43 \\
\hline Accumulated Depreciation & 0.18 & -0.52 & -0.33 & 0.16 & -0.54 & 0.21 & 0.15 & -0.28 & -0.17 & 0.13 & -0.16 & 0.05 & -0.43 & 0.09 & -0.18 & -0.21 & -0.26 \\
\hline Total Assets & -0.04 & -0.15 & 0.38 & \begin{tabular}{|l|l|}
-0.09 \\
\end{tabular} & -0.31 & 0.10 & 0.13 & 0.03 & -0.20 & 0.10 & -0.20 & -0.25 & -0.07 & 0.11 & 0.05 & 0.34 & \begin{tabular}{|l|}
-0.39 \\
\end{tabular} \\
\hline Accounts Payable & -0.24 & -0.13 & -0.11 & 0.42 & -0.37 & 0.06 & -0.01 & -0.02 & 0.04 & -0.05 & -0.02 & -0.17 & 0.00 & -0.15 & 0.16 & -0.32 & 0.05 \\
\hline Current Maturities of Lo & -0.28 & -0.17 & 0.19 & 0.07 & -0.22 & 0.03 & -0.13 & -0.06 & 0.02 & -0.38 & 0.21 & -0.30 & -0.04 & -0.16 & 0.11 & -0.08 & \begin{tabular}{|l|}
-0.09 \\
\end{tabular} \\
\hline Current Liabilities & -0.16 & -0.05 & 0.26 & 0.32 & -0.34 & 0.14 & 0.08 & 0.10 & 0.02 & -0.12 & -0.02 & -0.20 & 0.11 & -0.07 & 0.15 & 0.00 & 0.03 \\
\hline Long-Term Debt & -0.51 & -0.66 & -0.32 & -0.38 & -0.16 & -0.34 & -0.34 & -0.64 & -0.35 & 0.05 & 0.04 & -0.45 & -0.59 & 0.25 & -0.30 & \begin{tabular}{|l|}
-0.19 \\
\end{tabular} & -0.45 \\
\hline Total Liabilities & -0.07 & -0.22 & 0.46 & -0.21 & -0.22 & 0.00 & 0.05 & -0.14 & -0.42 & 0.25 & -0.35 & -0.41 & -0.24 & 0.13 & -0.01 & 0.52 & -0.52 \\
\hline Retained Earnings & 0.09 & -0.37 & -0.24 & -0.12 & -0.49 & 0.27 & 0.43 & -0.11 & -0.44 & 0.21 & \begin{tabular}{|l|}
-0.29 \\
\end{tabular} & -0.30 & -0.65 & 0.35 & 0.00 & -0.07 & -0.39 \\
\hline Shareholders' Equity & 0.29 & -0.12 & 0.24 & 0.17 & -0.49 & 0.52 & 0.60 & 0.02 & 0.10 & -0.27 & \begin{tabular}{|l|}
0.11 \\
\end{tabular} & -0.02 & 0.08 & 0.28 & 0.02 & \begin{tabular}{|l|}
0.10 \\
\end{tabular} & -0.05 \\
\hline Cash Flow from Operating Activities & 0.67 & -0.06 & 0.13 & 0.15 & -0.31 & 0.45 & 0.49 & 0.35 & 0.07 & 0.09 & -0.17 & 0.24 & 0.12 & 0.30 & -0.24 & 0.22 & -0.07 \\
\hline Cash Flow from Investing Activities & 0.02 & -0.08 & 0.48 & -0.12 & -0.04 & 0.04 & 0.02 & -0.14 & 0.18 & -0.34 & 0.31 & -0.10 & 0.17 & 0.04 & -0.13 & 0.28 & -0.16 \\
\hline Cash Flow from Financing Activities & 0.38 & -0.13 & -0.29 & -0.13 & -0.17 & 0.17 & 0.38 & 0.02 & -0.10 & 0.24 & -0.03 & -0.10 & -0.34 & 0.25 & -0.10 & -0.03 & -0.24 \\
\hline Change in Cash & -0.31 & 0.11 & 0.19 & 0.15 & -0.17 & -0.18 & -0.28 & 0.05 & 0.18 & \begin{tabular}{|l|}
-0.12 \\
\end{tabular} & \begin{tabular}{|l|}
0.18 \\
\end{tabular} & -0.12 & 0.09 & \begin{tabular}{|l|}
-0.44 \\
\end{tabular} & 0.33 & $\mid-0.07$ & -0.05 \\
\hline
\end{tabular}

\subsubsection{Correlation between Managerial Decision-Making and Economic Data}

To determine the relationship between managerial decision-making data and economic factors, the managerial decision-making variables were transformed for comparison. To do so, the number of DMUs with active and bankrupt states for a given year for a given category of a managerial decision-making variable was counted and then taken as a percentage with 
respect of the total number of DMUs across all categories of the variable for the given year. These percentages were then correlated to each economic factor (Table 6.30; and for E1-E17 codes, please to Table 6.24). The correlations between active and bankrupt DMUs were generally weak, with less than $9.4 \%$ and $9.2 \%$ respectively, having coefficients greater than 0.6 (highlighted in shades of green) or less than -0.6 (highlighted in shades of red).

Table 6.30: Correlation between Managerial-Decision Making and Economic Variables A DMU was classified bankrupt up to 3 years prior to filing Chapter 11.

\begin{tabular}{|c|c|c|c|c|c|c|c|c|c|c|c|c|c|c|c|c|c|c|}
\hline & & E1 & E2 & E3 & E4 & E5 & E6 & E7 & E8 & E9 & 10 & E11 & E12 & E13 & E14 & E15 & E16 & E17 \\
\hline \multicolumn{19}{|c|}{ Active } \\
\hline \multirow{2}{*}{\begin{tabular}{|l|}
$\begin{array}{l}\text { Related-Party } \\
\text { Transactions }\end{array}$ \\
\end{tabular}} & one & -0.05 & \begin{tabular}{|l|}
-0.01 \\
\end{tabular} & 0.12 & 0.33 & 0.14 & 0.04 & \begin{tabular}{|l|}
-0.05 \\
\end{tabular} & -0.21 & 0.31 & \begin{tabular}{|l|}
-0.40 \\
\end{tabular} & 0.19 & 0.22 & 0.35 & 0.03 & -0.22 & -0.25 & 0.3 \\
\hline & es & 0.05 & 0.01 & -0.12 & -0.33 & -0.14 & -0.04 & 0.05 & 0.21 & -0.31 & 0.40 & -0.19 & -0.22 & -0.35 & -0.03 & 0.22 & 0.25 & -0.33 \\
\hline \multirow{2}{*}{ Auditor's Opinion } & Unqu & 60 & 0.03 & \begin{tabular}{|l|}
-0.33 \\
\end{tabular} & 0.36 & \begin{tabular}{l|l|}
-0.02 \\
\end{tabular} & -0.35 & \begin{tabular}{|l|}
-0.63 \\
\end{tabular} & -0.20 & 0.22 & .13 & 32 & 0.00 & 0.14 & .68 & 37 & 0.44 & 0.3 \\
\hline & Qualifi & 0.60 & \begin{tabular}{|l|}
-0.03 \\
\end{tabular} & 0.33 & \begin{tabular}{|l|}
-0.36 \\
\end{tabular} & \begin{tabular}{|l|}
0.02 \\
\end{tabular} & 0.35 & \begin{tabular}{|l|}
0.63 \\
\end{tabular} & 0.20 & -0.22 & 0.13 & -0.32 & .00 & .14 & 0.68 & 0.37 & 0.44 & -0.3 \\
\hline \multirow{4}{*}{ Legal Proceedings } & None & 0.19 & -0.50 & \begin{tabular}{|l|}
-0.52 \\
\end{tabular} & \begin{tabular}{|l|}
0.19 \\
\end{tabular} & -0.48 & 0.38 & \begin{tabular}{|l|}
0.13 \\
\end{tabular} & -0.04 & 0.32 & -0.31 & 0.45 & 0.34 & -0.01 & 0.11 & 0.17 & -0.57 & -0.0 \\
\hline & Insigni & -0.02 & \begin{tabular}{|l|}
0.22 \\
\end{tabular} & 0.50 & \begin{tabular}{|l|}
-0.46 \\
\end{tabular} & 0.33 & -0.22 & \begin{tabular}{|l|}
0.13 \\
\end{tabular} & 0.01 & -0.61 & 0.47 & -0.62 & -0.47 & -0.31 & 0.27 & 0.06 & 0.76 & -0.2 \\
\hline & Signi & -0.31 & \begin{tabular}{|l|}
0.46 \\
\end{tabular} & 0.20 & 0.04 & 0.58 & 45 & \begin{tabular}{|c|}
-0.37 \\
\end{tabular} & 0.01 & 0.19 & \begin{tabular}{|c|}
-0.19 \\
\end{tabular} & 0.04 & -0.09 & 0.31 & -0.28 & 0.02 & -0.01 & 0.3 \\
\hline & Going & -0.42 & \begin{tabular}{|l|}
0.47 \\
\end{tabular} & \begin{tabular}{|l|}
0.42 \\
\end{tabular} & \begin{tabular}{|l|}
-0.12 \\
\end{tabular} & 0.13 & -0.42 & \begin{tabular}{|l|}
-0.38 \\
\end{tabular} & 0.21 & -0.44 & 0.44 & -0.44 & -0.52 & -0.12 & -0.56 & 0.61 & 0.61 & -0.01 \\
\hline \multirow{3}{*}{ Retirement Plan } & None & -0.18 & 0.30 & \begin{tabular}{|c|}
-0.26 \\
\end{tabular} & \begin{tabular}{|l|}
0.59 \\
\end{tabular} & -0.24 & 0.12 & \begin{tabular}{|c|}
-0.15 \\
\end{tabular} & 0.22 & 0.62 & \begin{tabular}{|l|}
-0.42 \\
\end{tabular} & 0.55 & 0.18 & 0.51 & -0.64 & 0.62 & -0.61 & 0.45 \\
\hline & Compa & 0.10 & \begin{tabular}{|l|}
-0.86 \\
\end{tabular} & \begin{tabular}{|l|}
-0.19 \\
\end{tabular} & -0.20 & $\mid-0.31$ & 0.20 & \begin{tabular}{|l|}
0.07 \\
\end{tabular} & -0.43 & -0.37 & 0.06 & -0.18 & 0.04 & $\begin{array}{ll}-0.52 \\
\end{array}$ & 0.54 & -0.62 & $\begin{array}{l}-0.09 \\
\end{array}$ & -0 . \\
\hline & 401(1 & 0.02 & \begin{tabular}{|l|}
0.38 \\
\end{tabular} & \begin{tabular}{|l|}
0.52 \\
\end{tabular} & \begin{tabular}{|c|}
-0.23 \\
\end{tabular} & 0.38 & -0.24 & 0.02 & 0.04 & -0.30 & 0.32 & -0.43 & -0.16 & -0.01 & 0.07 & -0.01 & 0.67 & 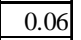 \\
\hline \multirow{2}{*}{ Change of Auditor } & None & \begin{tabular}{|l|}
-0.08 \\
\end{tabular} & \begin{tabular}{|l|}
0.04 \\
\end{tabular} & \begin{tabular}{|l|}
-0.07 \\
\end{tabular} & \begin{tabular}{|l|}
0.57 \\
\end{tabular} & -0.20 & 0.03 & \begin{tabular}{|l|}
-0.17 \\
\end{tabular} & 0.07 & 0.63 & \begin{tabular}{|c|}
-0.34 \\
\end{tabular} & 0.51 & 0.15 & 0.46 & -0.38 & 0.16 & -0.57 & 10 \\
\hline & Yes & 0.08 & \begin{tabular}{|l|}
-0.04 \\
\end{tabular} & \begin{tabular}{|l|l|}
0.07 \\
\end{tabular} & \begin{tabular}{|l|}
-0.57 \\
\end{tabular} & 0.20 & -0.03 & \begin{tabular}{|l|}
0.17 \\
\end{tabular} & -0.07 & -0.63 & 0.34 & -0.51 & -0.15 & -0.46 & 0.38 & -0.16 & 0.57 & -0.1 \\
\hline \multirow{2}{*}{\begin{tabular}{|l|}
$\begin{array}{l}\text { Management } \\
\text { Turnover }\end{array}$ \\
\end{tabular}} & $\mathbf{N}$ & -0.19 & -0.54 & -0.51 & \begin{tabular}{|l|}
0.09 \\
\end{tabular} & -0.11 & 0.04 & \begin{tabular}{|l|}
-0.09 \\
\end{tabular} & -0.69 & 0.01 & -0.14 & 0.17 & 0.10 & -0.23 & 0.15 & -0.22 & -0.61 & -0.1 \\
\hline & & 0.19 & 0.54 & 0.51 & \begin{tabular}{|l|}
-0.09 \\
\end{tabular} & 0.11 & -0.04 & \begin{tabular}{|l|}
0.09 \\
\end{tabular} & 0.69 & -0.01 & 0.14 & -0.17 & -0.10 & 0.23 & -0.15 & 0.22 & 0.61 & 0. \\
\hline \multicolumn{19}{|c|}{ Bankrupt } \\
\hline \multirow{2}{*}{\begin{tabular}{|l}
$\begin{array}{l}\text { Related-Party } \\
\text { Transactions }\end{array}$ \\
\end{tabular}} & & 0.37 & \begin{tabular}{|l|}
-0.08 \\
\end{tabular} & \begin{tabular}{|l|}
-0.34 \\
\end{tabular} & \begin{tabular}{|l|}
0.72 \\
\end{tabular} & -0.70 & 0.57 & 0.31 & 0.26 & 0.48 & \begin{tabular}{|l|l|}
-0.24 \\
\end{tabular} & 0.31 & 0.44 & 0.27 & -0.24 & 0.28 & -0.54 & 0.2 \\
\hline & Nor & \begin{tabular}{|l|}
-0.37 \\
\end{tabular} & \begin{tabular}{|l|}
0.08 \\
\end{tabular} & \begin{tabular}{|l|}
0.34 \\
\end{tabular} & \begin{tabular}{|l|}
-0.72 \\
\end{tabular} & 0.70 & -0.57 & -0.31 & -0.26 & -0.48 & 0.24 & -0.31 & -0.44 & -0.27 & 0.24 & -0.28 & 0.54 & -0.2 \\
\hline \multirow{2}{*}{ Auditor's Opinion } & Unc & & & & & & & & & & & & & & & & & \\
\hline & $\bar{Q} \mathbf{t}$ & & & & & & & & & & & & & & & & & \\
\hline \multirow{5}{*}{ Legal Procee dings } & No & \begin{tabular}{|c|}
-0.18 \\
\end{tabular} & \begin{tabular}{|c|}
-0.06 \\
\end{tabular} & 0.27 & \begin{tabular}{|l|}
0.37 \\
\end{tabular} & -0.42 & 0.02 & $\mid-0.23$ & 0.02 & 0.26 & -0.07 & 0.26 & 0.03 & .25 & -0.43 & 0.32 & -0.04 & -0.1 \\
\hline & Insign & -0.04 & 0.58 & \begin{tabular}{|l|}
-0.22 \\
\end{tabular} & 0.63 & 0.05 & 0.04 & \begin{tabular}{|c|}
-0.07 \\
\end{tabular} & 0.48 & 0.73 & -0.34 & 0.37 & 0.49 & 0.73 & -0.46 & 0.40 & -0.55 & 0.7 \\
\hline & Significant & 0.08 & -0.21 & \begin{tabular}{|l|}
-0.12 \\
\end{tabular} & \begin{tabular}{|c|}
-0.38 \\
\end{tabular} & 0.00 & 0.05 & 0.38 & -0.19 & -0.37 & 0.14 & -0.32 & -0.16 & -0.42 & 0.59 & -0.36 & 0.17 & -0.1 \\
\hline & \begin{tabular}{|l|} 
Going Concern \\
\end{tabular} & 0.23 & -0.20 & \begin{tabular}{|l|}
-0.25 \\
\end{tabular} & \begin{tabular}{|l|}
-0.60 \\
\end{tabular} & 0.44 & -0.03 & 0.07 & -0.18 & -0.27 & 0.13 & -0.03 & 0.14 & -0.31 & 0.51 & -0.47 & 0.16 & -0 . \\
\hline & Bankruptcy & -0.03 & \begin{tabular}{|c|}
-0.09 \\
\end{tabular} & $\mid-0.04$ & \begin{tabular}{|c|}
-0.25 \\
\end{tabular} & 0.17 & -0.16 & $\mid-0.08$ & -0.12 & -0.49 & 0.29 & -0.35 & -0.45 & -0.46 & 0.03 & -0.05 & 0.17 & -0.2 \\
\hline \multirow{3}{*}{ Retirement Plan } & None & \begin{tabular}{|l|}
-0.04 \\
\end{tabular} & \begin{tabular}{|l|}
0.58 \\
\end{tabular} & \begin{tabular}{|l|}
-0.22 \\
\end{tabular} & \begin{tabular}{|l|}
0.63 \\
\end{tabular} & 0.05 & 0.04 & \begin{tabular}{|l|}
-0.07 \\
\end{tabular} & 0.48 & 0.73 & \begin{tabular}{|l|}
-0.34 \\
\end{tabular} & 0.37 & 0.49 & 0.73 & -0.46 & 0.40 & -0.55 & 0.7 \\
\hline & Compan & 0.37 & \begin{tabular}{|l|}
-0.12 \\
\end{tabular} & \begin{tabular}{|l|}
-0.41 \\
\end{tabular} & \begin{tabular}{|l|}
0.54 \\
\end{tabular} & -0.61 & 0.52 & 0.25 & 0.31 & 0.57 & \begin{tabular}{|l|}
-0.28 \\
\end{tabular} & 0.36 & 0.63 & 0.36 & -0.13 & 0.15 & -0.58 & 0. \\
\hline & 401(k) & \begin{tabular}{|l|}
-0.19 \\
\end{tabular} & $\mid-0.31$ & 0.34 & \begin{tabular}{|l|}
-0.77 \\
\end{tabular} & \begin{tabular}{|l|}
0.33 \\
\end{tabular} & -0.38 & -0.12 & -0.42 & -0.85 & \begin{tabular}{l|l|}
0.47 \\
\end{tabular} & -0.54 & -0.66 & \begin{tabular}{|c|}
-0.73 \\
\end{tabular} & 0.41 & \begin{tabular}{|c|}
-0.39 \\
\end{tabular} & 0.72 & -0. \\
\hline \multirow{2}{*}{ Change of Auditor } & None & 0.35 & \begin{tabular}{|l|}
-0.13 \\
\end{tabular} & \begin{tabular}{|l|}
-0.26 \\
\end{tabular} & \begin{tabular}{|l|}
0.59 \\
\end{tabular} & -0.56 & 0.46 & \begin{tabular}{|l|}
0.29 \\
\end{tabular} & 0.24 & 0.45 & \begin{tabular}{|l|}
-0.09 \\
\end{tabular} & 0.28 & 0.37 & 0.24 & -0.07 & 0.13 & -0.54 & 0.0 \\
\hline & Yes & -0.07 & \begin{tabular}{|l|}
-0.20 \\
\end{tabular} & \begin{tabular}{|l|}
-0.04 \\
\end{tabular} & \begin{tabular}{|l|}
-0.50 \\
\end{tabular} & \begin{tabular}{|l|}
0.38 \\
\end{tabular} & -0.19 & \begin{tabular}{|l|}
0.01 \\
\end{tabular} & -0.46 & -0.40 & \begin{tabular}{|l|}
-0.02 \\
\end{tabular} & -0.20 & -0.09 & -0.42 & 0.42 & -0.49 & 0.28 & 0.0 \\
\hline \multirow{2}{*}{\begin{tabular}{|l|} 
Management \\
Turnover
\end{tabular}} & No & 0.26 & \begin{tabular}{|l|}
-0.04 \\
\end{tabular} & -0.68 & 0.08 & 0.00 & 0.25 & 0.26 & 0.13 & 0.45 & \begin{tabular}{|l|}
-0.36 \\
\end{tabular} & 0.26 & $\begin{array}{ll}0.43 \\
\end{array}$ & 0.20 & 0.23 & -0.17 & \begin{tabular}{|c|}
-0.76 \\
\end{tabular} & 0.1 \\
\hline & Yes & \begin{tabular}{|l|} 
\\
\end{tabular} & \begin{tabular}{|l|} 
\\
\end{tabular} & \begin{tabular}{|l|l|} 
& 0.68 \\
\end{tabular} & -0.08 & \begin{tabular}{|l|}
0.00 \\
\end{tabular} & -0.25 & -0.26 & -0.13 & -0.45 & 0.36 & -0.26 & -0.43 & -0.20 & -0.23 & 0.17 & 0.76 & -0. \\
\hline
\end{tabular}

\subsubsection{Correlation to Market and Stock Performance Data}

Spearman correlation coefficients were computed for each financial variable and stock performance measure (return, volatility and beta). In addition, the average of each financial variable for a particular year was correlated to each composite index (NYSE, NASDAQ and $\mathrm{S} \& \mathrm{P})$ by state. Table 6.31 shows that the relationship between market and stock performance and financial data is weak. In fact, the strongest correlations were between total liabilities of bankrupt DMUs and the NYSE and S\&P composite indices, as well as cash flow from financing activities of active DMUs and all three composite indices. 
Table 6.31: Correlation between Market and Stock Performance and Financial Data

A DMU was classified bankrupt up to 3 years prior to filing Chapter 11.

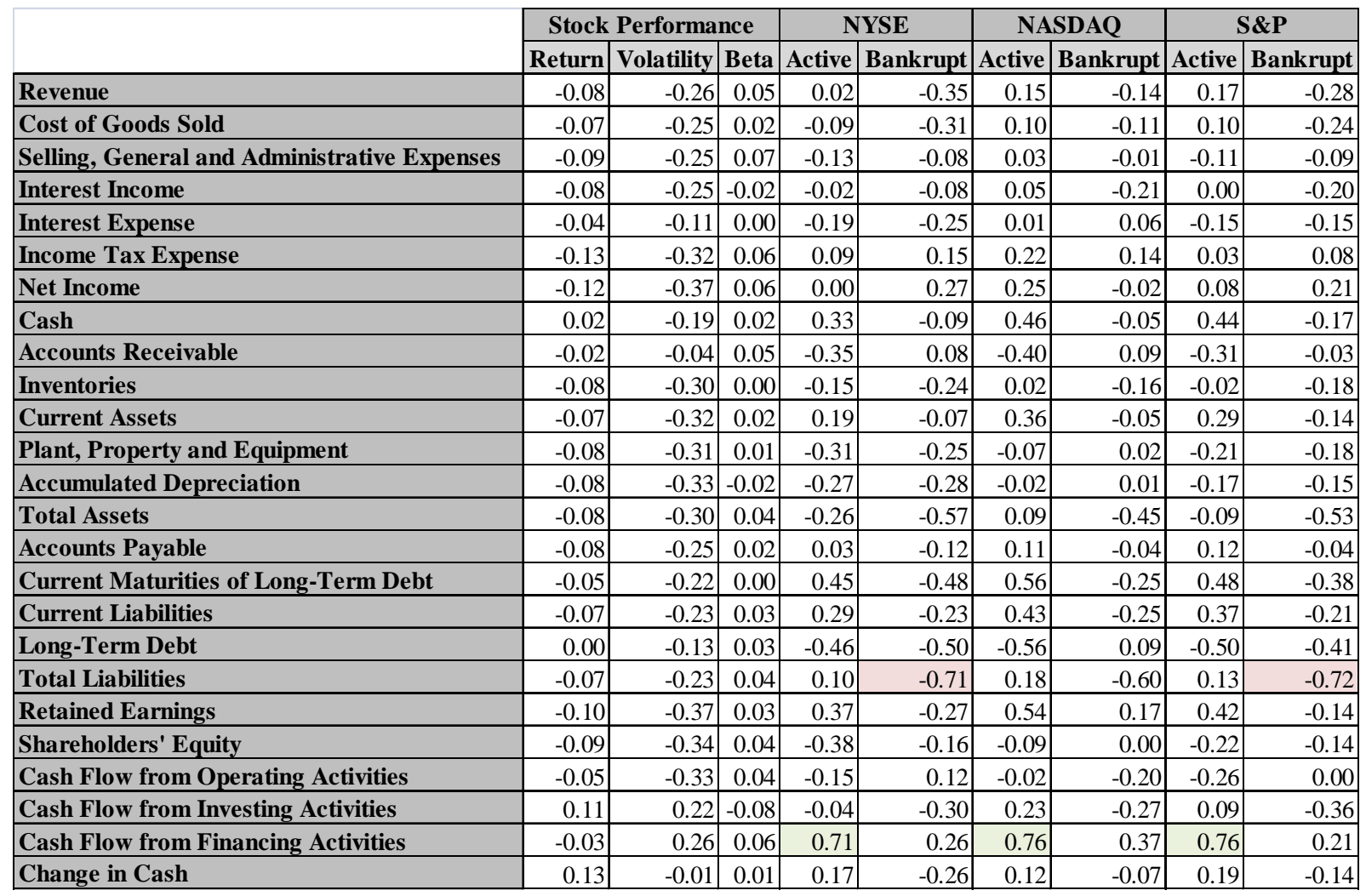

To determine the relationship between managerial decision-making data and market and stock performance, the managerial decision-making variables were first transformed as in Section 6.8.3. Generally, managerial decision-making variables were weakly correlated with market and stock performance, with some exceptions highlighted in shades of red and green (Table 6.33).

Finally, stock performance measures and composite indices were weakly correlated with economic factors (Table 6.32; and for E1-E17 codes, please to Table 6.24), except for volatility of bankrupt DMUs and GDP rate, as well as beta of bankrupt DMUs and cotton price. 
Table 6.32: Correlation between Market and Stock Performance and Economic Factors

A DMU was classified bankrupt up to 3 years prior to filing Chapter 11.

\begin{tabular}{|c|c|c|c|c|c|c|c|c|c|c|c|c|c|c|c|c|c|c|}
\hline & & E1 & E2 & E3 & $\begin{array}{l}\text { E4 } \\
\end{array}$ & \begin{tabular}{l|l} 
E5 \\
\end{tabular} & E6 & E7 & E8 & E9 & \begin{tabular}{|l|} 
E10 \\
\end{tabular} & E11 & \begin{tabular}{|l|} 
E12 \\
\end{tabular} & E13 & E14 & E15 & E16 & E17 \\
\hline \multirow{2}{*}{ Return } & tive & 0.20 & -0.33 & \begin{tabular}{|l|}
-0.28 \\
\end{tabular} & \begin{tabular}{|l|}
-0.04 \\
\end{tabular} & \begin{tabular}{|l|l|}
-0.18 \\
\end{tabular} & \begin{tabular}{|l|}
0.26 \\
\end{tabular} & \begin{tabular}{|l|}
0.28 \\
\end{tabular} & -0.01 & 0.11 & 0.30 & 0.35 & 0.21 & -0.10 & 0.57 & 0.34 & 0.26 & 0 \\
\hline & & -0.02 & -0.10 & \begin{tabular}{|l|}
0.33 \\
\end{tabular} & -0.02 & \begin{tabular}{|l|l|}
-0.13 \\
\end{tabular} & \begin{tabular}{|l|}
0.02 \\
\end{tabular} & \begin{tabular}{|l|}
0.06 \\
\end{tabular} & \begin{tabular}{|l|}
0.05 \\
\end{tabular} & 0.15 & -0.41 & 0 & .06 & 0.07 & 0.27 & .27 & 16 & - \\
\hline \multirow{2}{*}{ olatil } & & 34 & -0 & $\mid-0$ & $\begin{array}{ll}0.15 \\
\end{array}$ & 8 & 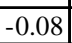 & & & & -0.06 & & & & .04 & 12 & 23 & \\
\hline & & .62 & -0.12 & \begin{tabular}{|l}
-0.33 \\
\end{tabular} & \begin{tabular}{|l|}
-0.04 \\
\end{tabular} & \begin{tabular}{|l|}
0.15 \\
\end{tabular} & -0.51 & -0.53 & -0.15 & -0.13 & 0.14 & 0.17 & 0.16 & -0.08 & \begin{tabular}{|l|}
0.14 \\
\end{tabular} & 0.05 & 0.12 & 0.02 \\
\hline \multirow{2}{*}{ ta } & & .32 & \begin{tabular}{|l|}
0.09 \\
\end{tabular} & \begin{tabular}{|l|}
0.44 \\
\end{tabular} & \begin{tabular}{|l|}
0.0 \\
\end{tabular} & \begin{tabular}{|l|}
0.00 \\
\end{tabular} & -0.19 & 0.18 & -0.06 & -0.13 & 0.21 & -0.02 & 0.09 & 0.11 & \begin{tabular}{|l|}
0.06 \\
\end{tabular} & 0.15 & 0.35 & -0.6 \\
\hline & & -0.37 & 0.58 & \begin{tabular}{|l|}
-0.36 \\
\end{tabular} & \begin{tabular}{|l|}
0.17 \\
\end{tabular} & \begin{tabular}{|l|}
0.38 \\
\end{tabular} & -0.41 & -0.22 & 0.22 & 0.38 & -0.08 & 0.32 & 0.16 & 0.47 & -0.20 & 0.27 & -0.31 & 0.61 \\
\hline \multirow{3}{*}{$\begin{array}{l}\text { Market Performance } \\
\text { (Composite Indices) }\end{array}$} & & 0. & 0.2 & \begin{tabular}{|l}
-0.22 \\
\end{tabular} & 0.26 & \begin{tabular}{|l|}
-0.07 \\
\end{tabular} & -0.07 & 0.18 & 0.12 & 0.29 & -0.28 & 0.33 & 0.39 & 0.24 & 0.1 & 0.01 & -0.24 & 0. \\
\hline & & \begin{tabular}{|l|}
-0.02 \\
\end{tabular} & 0.16 & $|-0.31|$ & 0.19 & 0.05 & 0.00 & 0.26 & 0.15 & 0.4 & -0.34 & & 0.29 & 0.25 & 0.0 & 0.20 & \begin{tabular}{|l} 
\\
\end{tabular} & \\
\hline & $\mathbf{S} \& \mathbf{P}$ & 0.08 & 0.28 & -0.31 & 0.31 & \begin{tabular}{|c|}
-0.06 \\
\end{tabular} & \begin{tabular}{|c|}
-0.00 \\
-0.0
\end{tabular} & 0.22 & \begin{tabular}{|c|}
0.13 \\
0.22
\end{tabular} & \begin{tabular}{|c|}
0.36 \\
0.36
\end{tabular} & \begin{tabular}{|l|}
-0.0 .26 \\
\end{tabular} & \begin{tabular}{|c|}
0.33 \\
0.33
\end{tabular} & 0.43 & 0.30 & 0.02 & 0.13 & \begin{tabular}{|l|}
-0.41 \\
-41 \\
\end{tabular} & 0. \\
\hline
\end{tabular}

Table 6.33: Correlation between Market and Stock Performance and Managerial Decision-Making Data A DMU was classified bankrupt up to 3 years prior to filing Chapter 11.

\begin{tabular}{|c|c|c|c|c|c|c|c|c|c|c|c|}
\hline & & & \multicolumn{3}{|c|}{ Stock Performance } & \multicolumn{2}{|c|}{ NYSE } & \multicolumn{2}{|c|}{ NASDAQ } & \multicolumn{2}{|c|}{ NYSE } \\
\hline & & & Return & \begin{tabular}{|l|} 
Volatility \\
\end{tabular} & Beta & Active & Bankrupt & Active & Bankrupt & Active & Bankrupt \\
\hline \multirow{15}{*}{ Active } & \multirow{2}{*}{\begin{tabular}{|l|} 
Related-Party \\
Transactions
\end{tabular}} & None & 0.21 & -0.08 & 0.13 & 0.25 & 0.32 & 0.09 & 0.21 & 0.28 & 0.16 \\
\hline & & \begin{tabular}{|l|} 
Yes \\
\end{tabular} & -0.21 & 0.08 & \begin{tabular}{|l|}
-0.13 \\
\end{tabular} & -0.25 & -0.32 & -0.09 & -0.21 & -0.28 & -0.16 \\
\hline & \multirow{2}{*}{\begin{tabular}{|l|} 
Auditor's \\
Opinion \\
\end{tabular}} & Unqualified & -0.04 & 0.20 & 0.13 & -0.13 & -0.07 & 0.57 & 0.47 & -0.16 & 0.29 \\
\hline & & \begin{tabular}{|l|} 
Qualified \\
\end{tabular} & 0.04 & -0.20 & -0.13 & 0.13 & 0.07 & -0.57 & -0.47 & 0.16 & -0.29 \\
\hline & \multirow{4}{*}{\begin{tabular}{|l} 
Legal \\
Procee dings
\end{tabular}} & None & 0.03 & 0.26 & 0.18 & 0.45 & 0.15 & 0.60 & 0.24 & -0.37 & -0.13 \\
\hline & & Insignificant & -0.20 & -0.35 & \begin{tabular}{|l|}
-0.38 \\
\end{tabular} & -0.34 & -0.08 & -0.61 & -0.29 & 0.36 & -0.07 \\
\hline & & Significant & 0.22 & -0.06 & 0.11 & 0.01 & 0.22 & -0.24 & 0.20 & -0.01 & 0.39 \\
\hline & & Going Concern & -0.47 & -0.33 & \begin{tabular}{|l|}
-0.42 \\
\end{tabular} & -0.61 & -0.31 & -0.06 & -0.39 & 0.03 & -0.15 \\
\hline & \multirow{3}{*}{$\begin{array}{l}\text { Retirement } \\
\text { Plan }\end{array}$} & None & 0.22 & 0.41 & 0.40 & 0.10 & -0.03 & 0.49 & 0.31 & -0.21 & 0.30 \\
\hline & & \begin{tabular}{|l|} 
Company Plan \\
\end{tabular} & -0.45 & -0.36 & \begin{tabular}{|l|}
-0.41 \\
\end{tabular} & 0.31 & 0.19 & 0.40 & 0.06 & 0.01 & -0.67 \\
\hline & & 401(k) & 0.03 & -0.23 & -0.15 & -0.50 & -0.15 & -0.71 & -0.47 & 0.38 & 0.06 \\
\hline & \multirow{2}{*}{$\begin{array}{l}\text { Change of } \\
\text { Auditor }\end{array}$} & \begin{tabular}{|l|} 
None \\
\end{tabular} & 0.28 & 0.13 & 0.29 & 0.13 & 0.20 & 0.26 & 0.32 & -0.09 & 0.21 \\
\hline & & \begin{tabular}{|l|} 
Yes \\
\end{tabular} & -0.28 & -0.13 & \begin{tabular}{|l|}
-0.29 \\
\end{tabular} & -0.13 & -0.20 & -0.26 & -0.32 & 0.09 & -0.21 \\
\hline & \multirow{2}{*}{\begin{tabular}{|l|} 
Management \\
Turnover
\end{tabular}} & \begin{tabular}{|l} 
None \\
\end{tabular} & -0.06 & 0.24 & \begin{tabular}{|l|}
0.06 \\
\end{tabular} & -0.03 & -0.36 & 0.27 & -0.01 & 0.06 & -0.09 \\
\hline & & Yes & 0.06 & -0.24 & -0.06 & 0.03 & 0.36 & -0.27 & 0.01 & -0.06 & 0.09 \\
\hline \multirow{16}{*}{ Bankrupt } & \multirow{2}{*}{\begin{tabular}{|l|} 
Related-Party \\
Transactions
\end{tabular}} & Yes & 0.25 & 0.34 & 0.40 & 0.22 & -0.09 & 0.22 & 0.04 & -0.52 & -0.02 \\
\hline & & None & -0.25 & -0.34 & \begin{tabular}{|l|}
-0.40 \\
\end{tabular} & -0.22 & 0.09 & -0.22 & -0.04 & 0.52 & 0.02 \\
\hline & \multirow{2}{*}{\begin{tabular}{|l|} 
Auditor's \\
Opinion \\
\end{tabular}} & Unqualified & & & & & & & & & \\
\hline & & Qualified & & & & & & & & & \\
\hline & \multirow{5}{*}{$\begin{array}{l}\text { Legal } \\
\text { Procee dings }\end{array}$} & None & -0.26 & -0.19 & \begin{tabular}{|l|}
-0.17 \\
\end{tabular} & -0.40 & 0.03 & 0.41 & -0.31 & 0.28 & -0.24 \\
\hline & & Insignificant & 0.69 & 0.46 & 0.74 & 0.27 & 0.06 & 0.05 & 0.40 & -0.06 & 0.65 \\
\hline & & Significant & -0.11 & 0.08 & \begin{tabular}{|l|}
-0.13 \\
\end{tabular} & -0.01 & 0.12 & -0.29 & -0.39 & -0.01 & -0.02 \\
\hline & & \begin{tabular}{|l|} 
Going Concern \\
\end{tabular} & 0.24 & 0.18 & 0.14 & 0.29 & -0.21 & -0.27 & 0.39 & 0.08 & 0.08 \\
\hline & & Bankruptcy & -0.20 & -0.16 & \begin{tabular}{|l|}
-0.25 \\
\end{tabular} & 0.15 & -0.13 & -0.24 & 0.31 & -0.45 & -0.19 \\
\hline & \multirow{3}{*}{$\begin{array}{l}\text { Retirement } \\
\text { Plan }\end{array}$} & \begin{tabular}{|l} 
None \\
\end{tabular} & 0.69 & 0.46 & 0.74 & 0.27 & 0.06 & 0.05 & 0.40 & -0.06 & 0.65 \\
\hline & & \begin{tabular}{|l|} 
Company Plan \\
\end{tabular} & 0.19 & 0.29 & 0.38 & 0.14 & -0.08 & 0.41 & -0.11 & -0.38 & -0.04 \\
\hline & & 401(k) & -0.57 & -0.51 & \begin{tabular}{|l|}
-0.71 \\
\end{tabular} & -0.25 & 0.01 & \begin{tabular}{|c|}
-0.29 \\
\end{tabular} & -0.21 & 0.19 & -0.42 \\
\hline & \multirow{2}{*}{\begin{tabular}{|l} 
Change of \\
Auditor \\
\end{tabular}} & None & 0.41 & 0.30 & 0.46 & 0.29 & -0.14 & 0.03 & 0.18 & -0.14 & 0.02 \\
\hline & & Yes & -0.13 & 0.00 & \begin{tabular}{|l|}
-0.19 \\
\end{tabular} & 0.01 & 0.14 & -0.28 & -0.18 & -0.09 & -0.02 \\
\hline & \multirow{2}{*}{\begin{tabular}{|l|} 
Management \\
Turnover
\end{tabular}} & None & 0.35 & 0.45 & 0.47 & 0.40 & -0.08 & 0.16 & 0.12 & $\begin{array}{l}-0.52 \\
\end{array}$ & 0.25 \\
\hline & & Yes & -0.35 & -0.45 & \begin{tabular}{|l|}
-0.47 \\
\end{tabular} & -0.40 & 0.08 & -0.16 & -0.12 & 0.52 & -0.25 \\
\hline
\end{tabular}

\subsection{Summary of Data Exploration}

Results from data exploration showed that financial, managerial decision-making, stock, market and economic data were individually poor predictors of bankruptcy and weakly 
correlated. This reinforced the motivation to combine the different data types as they may add to and reflect different dimensions of company health. 


\section{Benchmarks}

Based on a literature review, the bankruptcy prediction model developed in this thesis must best Altman's model (Section 7.2) and that of the three major credit rating agencies (Section 7.3) because they are commonly used and well-regarded.

\subsection{Definition of Type I and Type II Errors}

To evaluate the effectiveness of a model, a confusion matrix (Table 7.1) can be generated summarizing the count of true positive, true negative, false positive and false negative instances. In this context, true positive was defined as predicting non-bankruptcy (active) and being correct; true negative was defined as predicting bankruptcy and being correct; false positive was defined as predicting non-bankruptcy (active) and being incorrect; and false negative was defined as predicting bankrupt and being incorrect. A Type I Error is equivalent to a false positive instance and a Type II Error is equivalent to a false negative instance. From the confusion matrix, various evaluation measures can be computed (Equations 7.1 to 7.5 ).

Table 7.1: Confusion Matrix

\begin{tabular}{c|c|c|c|}
\multicolumn{1}{c}{} & \multicolumn{3}{c}{ Actual } \\
\cline { 2 - 4 } \multicolumn{1}{c|}{} & + & True Positive (TP) & $\begin{array}{c}\text { False Positive (FP) } \\
\text { Type I Error }\end{array}$ \\
\cline { 2 - 4 } & + & $\begin{array}{c}\text { False Negative (FN) } \\
\text { Type II Error }\end{array}$ & True Negative (TN) \\
\cline { 2 - 4 } & & \multicolumn{2}{c}{ Typeded }
\end{tabular}

$$
\begin{gathered}
\text { True Positive Rate }=\text { Sensitivity }=\frac{\mathrm{TP}}{\mathrm{TP}+\mathrm{FN}} \times 100 \% \\
\text { False Positive Rate }=\text { Specificity }=\frac{\mathrm{FP}}{\mathrm{FP}+\mathrm{TN}} \times 100 \% \\
\text { Success Rate }=\frac{\mathrm{TP}+\mathrm{TN}}{\mathrm{TP}+\mathrm{FP}+\mathrm{TN}+\mathrm{FN}} \times 100 \% \\
\text { Type I Error }=\frac{\mathrm{FP}}{\mathrm{FP}+\mathrm{TN}} \times 100 \% \\
\text { Type II Error }=\frac{\mathrm{FN}}{\mathrm{FN}+\mathrm{TP}} \times 100 \%
\end{gathered}
$$




\subsection{Altman's Z-Score}

Because Altman's bankruptcy model is widely used in industry (Section 2.3.1), it served as a benchmark for this work. A Z-Score for each variation of Altman's model (manufacturing, non-manufacturing, private) was computed for each of the 85 retail-apparel companies for every year that data were available. Table 7.2 presents the average $Z$-Scores for all firms in this sample from 1988 to 2009. While there was a distinction between average scores by health, the high standard deviation indicated poor accuracy.

Table 7.2: Average Bankruptcy Scores of Retail-Apparel Companies by State A DMU was classified bankrupt up to 3 years prior to filing of Chapter 11.

\begin{tabular}{|l|c|c|c|}
\hline \multicolumn{1}{|c|}{ State } & Manufacturing (Original) & Private & Non-Manufacturing \\
\hline Active & $5.8 \pm 3.4$ & $4.5 \pm 2.7$ & $8.7 \pm 7.0$ \\
\hline Bankrupt & $2.7 \pm 2.1$ & $2.8 \pm 1.3$ & $1.6 \pm 4.0$ \\
\hline All & $5.6 \pm 3.4$ & $4.4 \pm 2.7$ & $8.2 \pm 7.0$ \\
\hline
\end{tabular}

Figure 7.1 shows the percentage of Type I errors by years prior to bankruptcy. For this dataset on the retail-apparel industry, Altman's models did not perform well compared to his original data. At its best, the non-manufacturing firms model yielded errors between 29$80 \%$, whereas the private firms and manufacturing firms (original) models, produced errors of $79-100 \%$ and $50-87 \%$, respectively. In addition, the Type II errors were higher (between 12-23\%) than Altman's original study (Table 7.3). The discrepancies may be attributed to Altman's models not being suited for the retail-apparel industry; the closest variation derived for non-manufacturing firms and was not specific enough. Hence, there is a clear goal of improving accuracy rates of $70 \%, 58 \%$ and $50 \%$, when predicting cases today, and from one and two years back, respectively.

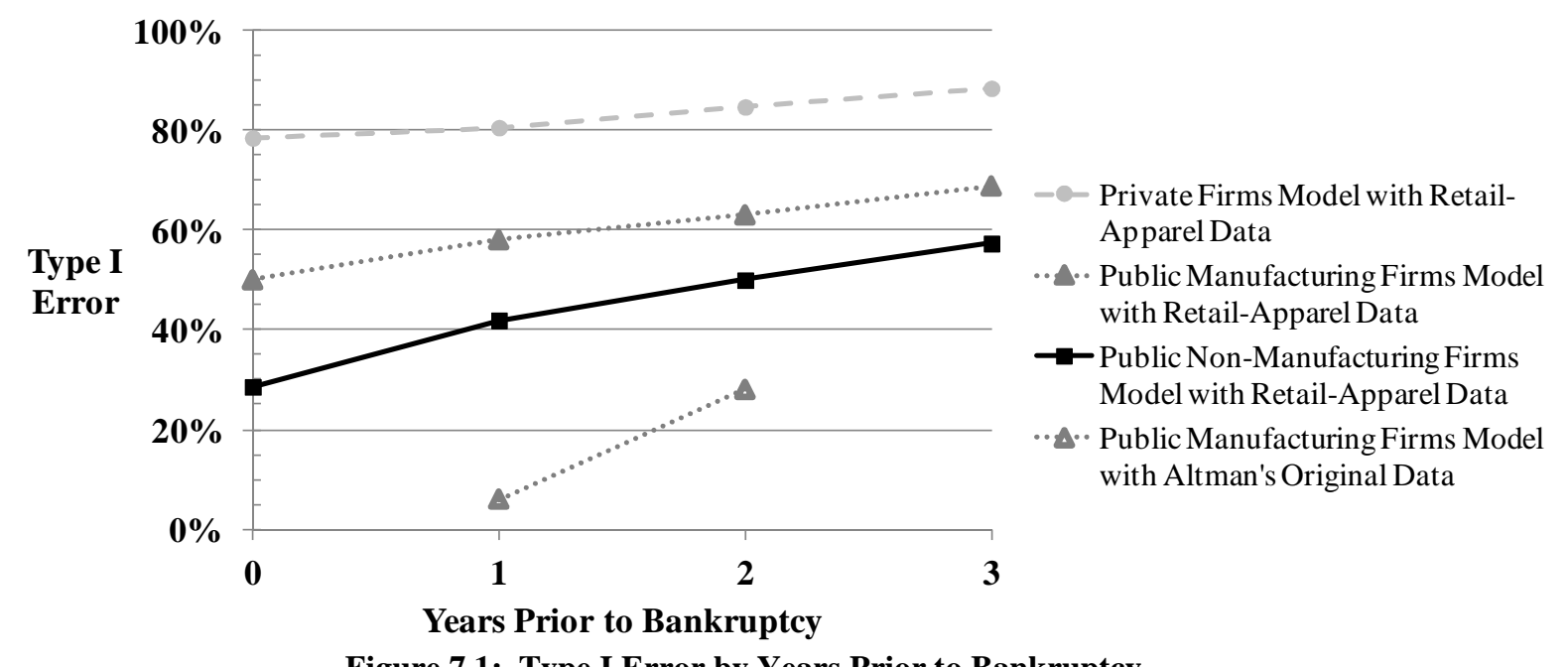

Figure 7.1: Type I Error by Years Prior to Bankruptcy 
Table 7.3: Type II Error

\begin{tabular}{|l|c|}
\hline Model & Type II Error \\
\hline Private Firms with Retail-Apparel Data & $14 \%$ \\
\hline Public Manufacturing Firms with Retail-Apparel Data & $23 \%$ \\
\hline Public Non-Manufacturing Firms with Retail-Apparel Data & $12 \%$ \\
\hline Public Manufacturing Firms with Altman's Original Data & $3-6 \%$ \\
\hline
\end{tabular}

\subsection{Credit Rating Agencies}

Three major credit rating agencies dominate $90-95 \%$ of the world's credit rating market: Moody's, Standard \& Poor's, and Fitch. These agencies issue specific bond credit ratings (in three-letter codes) which assess the credit worthiness of a corporation's or government's debt challenges (Table D.2). A bond can also be broadly classified as either investment or noninvestment grade. The probability of corporate bond defaults is provided in Table 7.4. The default rate of investment grade bonds is $4.1 \%$ and that of non-investment grade bonds is 42.4\%; thus, Type I and II errors are $57.6 \%$ and $4.1 \%$, respectively. These probabilities, however, are based on all industries and not specific to retail-apparel.

Table 7.4: Cumulative Historic Corporate Default Rates (U.S. Municipal Bond Fairness Act, 2008)

\begin{tabular}{|l|l|r|r|}
\hline \multicolumn{1}{|c|}{ Rating Categories } & \multicolumn{1}{|c|}{ Grade } & Moody's (\%) & \multicolumn{1}{c|}{ Standard \& Poor's (\%) } \\
\hline Aaa / AAA & Prime & 0.52 & 0.60 \\
\hline Aa / AA & High & 0.52 & 1.50 \\
\hline A / A & Upper Medium & 1.29 & 2.91 \\
\hline Baa / BBB & Lower Medium & 4.64 & 10.29 \\
\hline Ba / BB & Non-Investment Speculative & 19.12 & 9.93 \\
\hline B / B & Highly Speculative & 43.34 & 53.72 \\
\hline Caa - C / CCC - C & $\begin{array}{l}\text { Substantial Risk, Extremely } \\
\text { Speculative or In Default }\end{array}$ & 69.18 & 69.19 \\
\hline Investment Grade & 2.09 & 4.14 \\
\hline Non-Investment Grade & 31.37 & 42.35 \\
\hline All & 9.70 & 12.98 \\
\hline
\end{tabular}




\section{Methodology}

\subsection{Application of Data Envelopment Analysis to Bankruptcy Prediction}

Although traditionally used to measure productivity and efficiency of healthcare and education systems, banks, manufacturing, benchmarking, franchises, management evaluation, etc., DEA can be used to determine the state of each company in a sample within a specific industry. To clarify DEA terminology in this thesis, a DMU ("Decision Making Unit") is associated with both a company and a year in the retail-apparel industry. Combining a company and year is common DEA practice when analysis is across time periods.

The power of DEA is its ability to act as a multicriteria sorting tool with the objective function serving as a benchmark to organize and classify firms by their level of health. In fact, for each DMU, DEA generates a score that quantifies a particular aspect of a company's health, whether based on its financial operations or managerial performance, relative to that of the sample and lies between 0 and 1. The difference in DEA scores is interpreted as follows: a company $X$ has a higher/lower risk of bankruptcy than company $Y$ based on a given set of criteria. The selection of variables is, therefore, of utmost importance because inputs and outputs, and their definition and orientation, directly affect the frontier (i.e. the benchmark) from which the value and magnitude of each score are determined.

\subsubsection{Frontiers, Inputs and Outputs}

The meaning of a DEA score depends on the composition of the frontier, either of DMUs that are the best or worst performers within the sample.

Traditionally, a frontier comprises DMUs identified by DEA as best performers or having the least risk of bankruptcy relative to the sample, and to these, DEA assigns a score of 1. All other DMUs are scored as a fraction of one, with smaller values (corresponding to farther distances from the frontier) indicative of poorer health and a higher risk of bankruptcy (Figure 8.1). Outputs are defined as variables that improve a company's performance and are maximized in the mathematical optimization, whereas inputs are defined as those that increase its risk of bankruptcy and are minimized. Inputs and outputs are not necessarily related (i.e. a decrease in liabilities does not translate to increase revenue) and generally, these variables reflect on criteria that measure success and profitability. 
Although less common, a frontier can consist of firms that face the greatest risk of bankruptcy. Consequently, these poorest performing companies have a score of 1 while all others are considered healthier and are scored as fractions of the worst companies. Inputs and outputs have the reverse definitions, changing the objective to minimize outputs (now defined as variables that increase the risk of bankruptcy) and maximize inputs (now defined as those that decrease the risk of bankruptcy). There are two philosophies for selecting variables for a worst performance frontier: inverse DEA (Figure 8.2) or worst-practice DEA. Inverse DEA simply swaps the inputs and outputs of a normal DEA model whose variables evaluate success and profitability. In contrast, Worst-Practice DEA, developed by Paradi et al. (2004), selects a different set of variables that focus on measuring failure or insolvency.

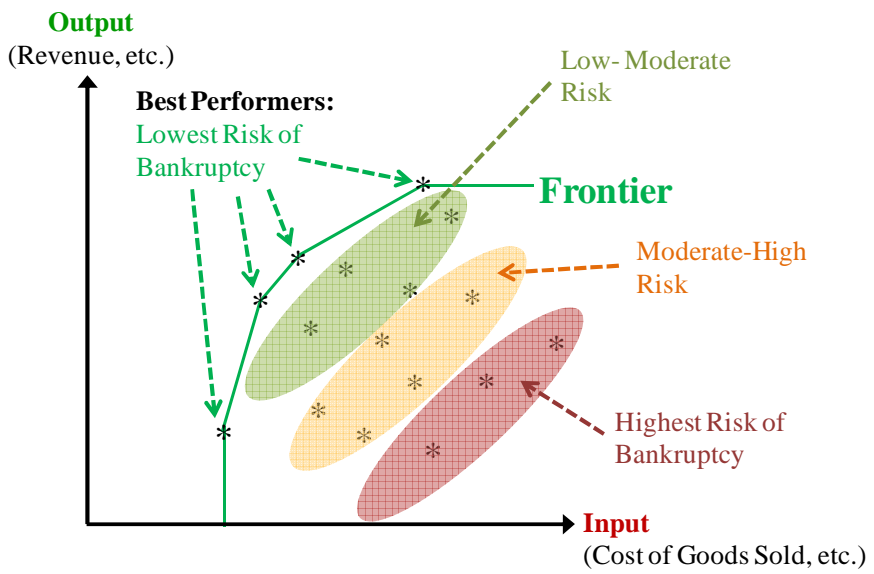

Figure 8.1: DEA Frontier of Best Performers

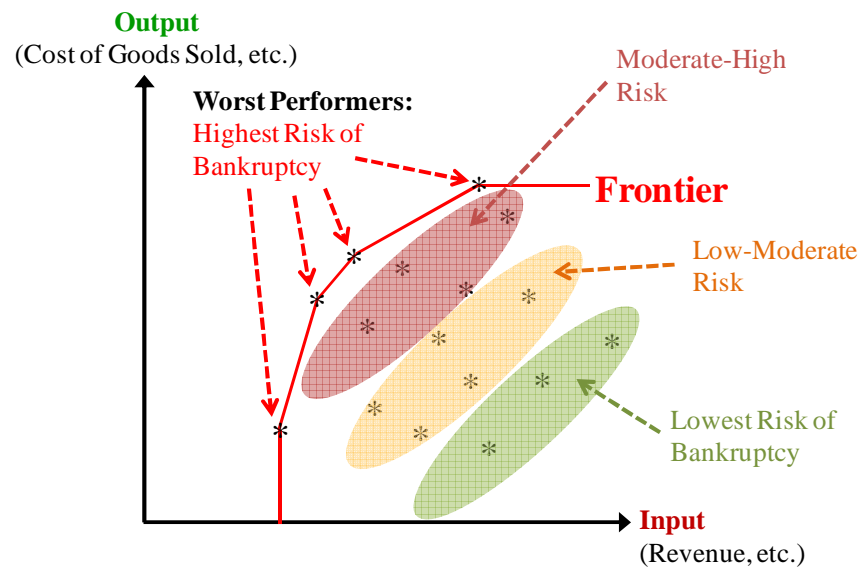

Figure 8.2: DEA Frontier of Worst Performers

\subsubsection{A New Classification Approach: A Modified Layering Technique}

While DEA generates a score between 0 and 1 for every DMU, it is difficult to determine whether there is a significant difference between scores that are relatively close to one another (i.e. 0.80 vs. 0.81). As DMUs on the frontier have the same score of 1, Divine (1986), Thanassoulis (1999) and Paradi et al. (2004) have used a layering technique where these DMUs are removed or "peeled" from the sample and the analysis is re-run (Figure 8.3). In normal DEA, each peel exposes a set of "next best" performing DMUs that form a new frontier. Similarly, in inverse or worst-practice DEA, sequential layers of poor performance are created with decreasing bankruptcy risk. In the three studies mentioned above, only 2-3 peels were made. This thesis was the first to create layers and peel DMUs off the frontier until the following condition was no longer met: $n \geq \max \{m \times s, 3(m+s)\}$ where $n, m$ and $s$ 
are the number of DMUs, inputs and outputs, respectively (Banker et al., 1986). With this process, we could conclude with certainty that one set of DMUs was better or worse than another.

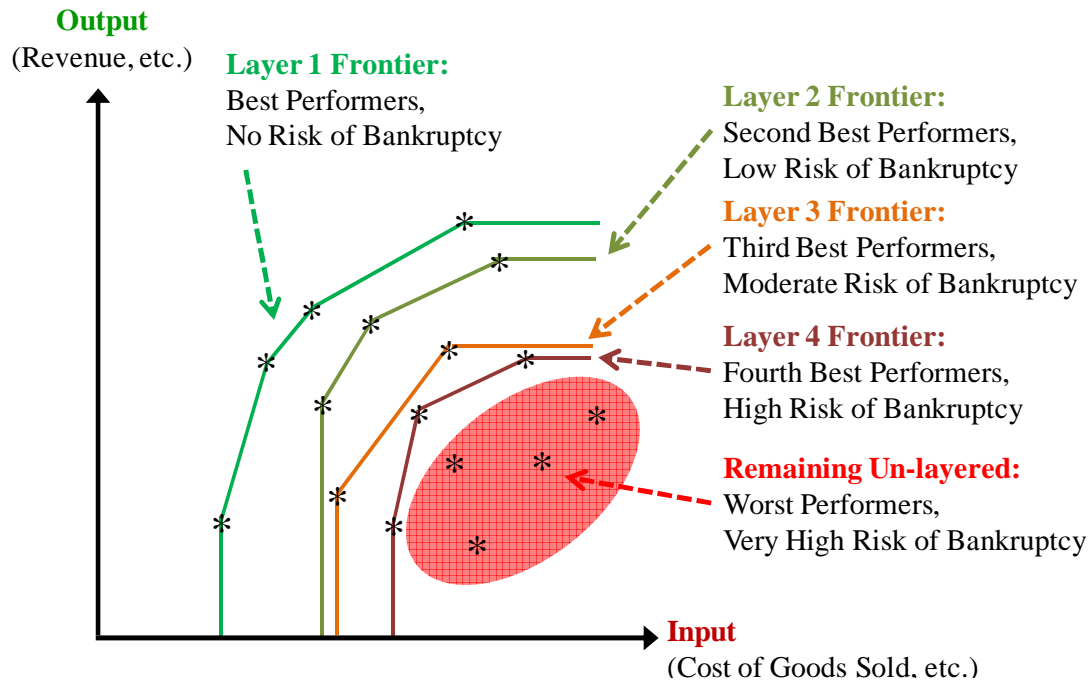

Figure 8.3: Layering Technique for Normal DEA

\subsection{Overview: Metrics and the Second Stage Model}

A metric was defined as a function of inputs and outputs, and was represented in the form of a score generated by DEA. Nearly 60 combinations of inputs and outputs $(V)$ derived from annual reports for each of the 85 companies studied were applied to 60 SBM models which generated 60 scores for each DMU (a firm in a given year) (Figure 8.4).

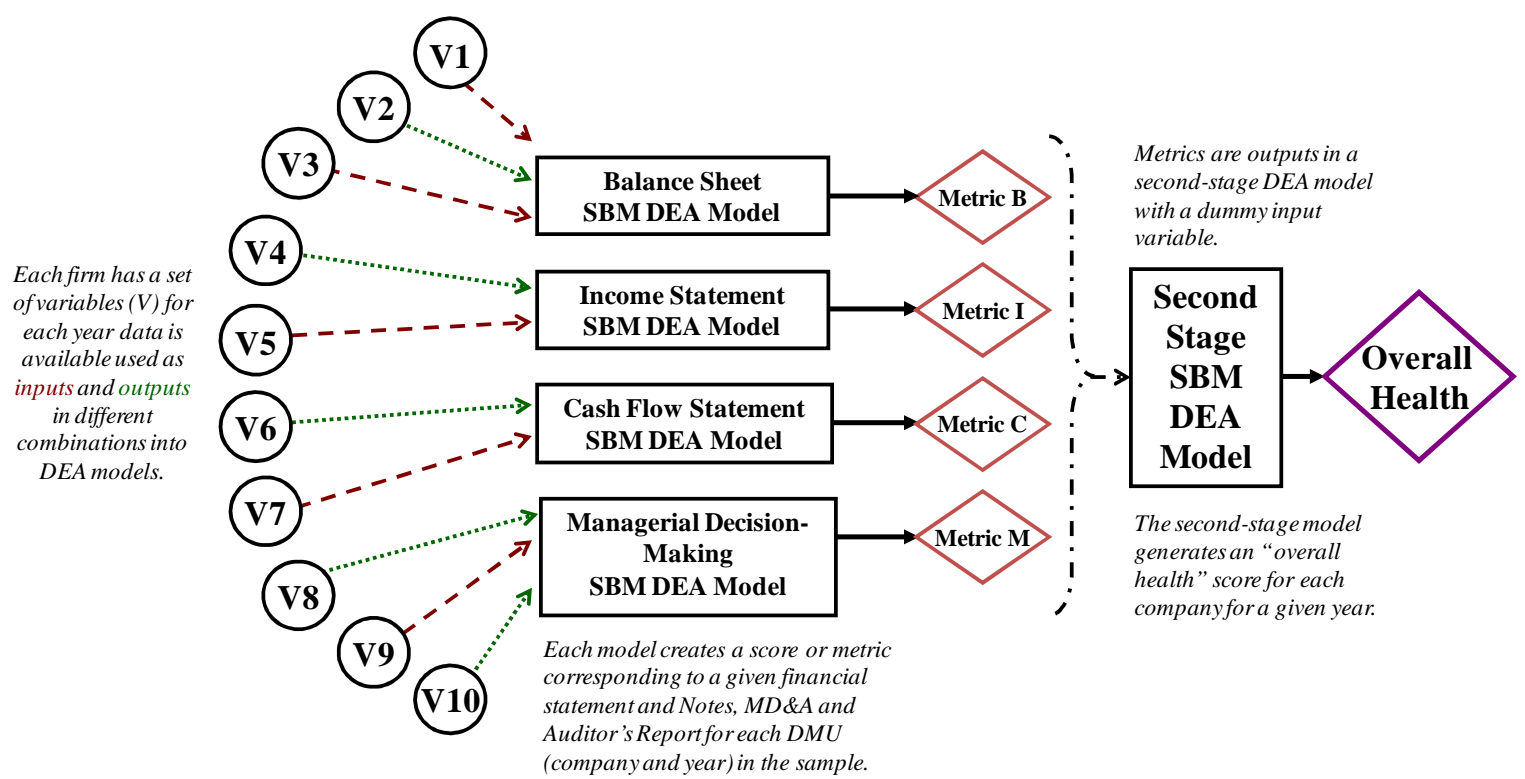

Figure 8.4: Example of Metrics and Second Stage Analysis 
Each score (metric) quantified a particular aspect of a firm's health, relative to that of the sample and was between 0 and 1. As an example, metric B evaluated a company's balance sheet in a given year. Variables included inventories, total assets and total liabilities (as inputs), retained earnings and/or shareholders' equity (as outputs). Similarly, metric M evaluated a firm's managerial decision-making based on management turnover and/or legal proceedings (as inputs).

While each metric can be considered independently, the combination of metrics into one model in a second stage analysis ${ }^{14}$ offered a more holistic view of health. Ultimately, 4 of the 60 metrics were combined by one model to generate an overall health score between 0 and 1 for each company. Specifically, the second stage model treated the 4 metrics as outputs with a dummy input ${ }^{15}$, and created a frontier composed of the healthiest DMUs (Chapters 10 and 12).

\subsection{Variable Selection and Metrics Tested}

The selection of variables is of utmost importance because inputs and outputs, and their definition and orientation, directly affect the frontier from which the value and magnitude of each score are determined. Financial variables considered in this thesis were inspired by past studies that mainly aimed to measure profitability or insolvency as proxies for success or failure, respectively (Table 8.1 and Table 8.2).

Another technique for choosing variables was principal component analysis (PCA) which reduced over 50 financial variables to a set of 13 , contributing to 5 components, explaining $78 \%$ of the total variance (or dataset). The financial dataset was also reduced by starting with all variables and removing one by one those that did not improve prediction using logistic regression (LR). This subset of 14 variables slightly outperformed the PCA group likely because of PCA's assumption of linearity.

\footnotetext{
${ }^{14}$ The concept of a two-stage DEA model was applied by Paradi et al. (2011) for bank branch efficiency. He computed productivity, profitability and intermediation scores of bank branches with 3 separate DEA models, then introduced them to a second DEA calculation which generated an overall performance score that revealed areas for overall performance improvement, and the tradeoffs among the 3 performance measures. A two-stage DEA model has also been used to assess financial risk tolerance to capture its multidimensionality (Tran, 2007). Three elements of risk (attitude, capacity and propensity) were measured independently then combined for overall risk tolerance. This worked well as no knowledge of the relationship between the elements was required nor was there emphasis placed on any particular one.

${ }^{15}$ A dummy variable is one where each DMU is given a value of 1 for that variable.
} 
Table 8.1: Common Variables Measuring Good Performance or Success

\begin{tabular}{|c|c|c|}
\hline \multicolumn{2}{|c|}{ Return on Sales } & $\frac{\text { Operating Income }}{\text { Revenue }}$ \\
\hline \multirow{2}{*}{\multicolumn{2}{|c|}{ Cash Return on Assets }} & Cash Flow from Operations \\
\hline & & Total Assets \\
\hline \multirow{2}{*}{\multicolumn{2}{|c|}{ Cash Flow Margin }} & Cash Flow from Operations \\
\hline & & Net Sales \\
\hline \multirow{2}{*}{\multicolumn{2}{|c|}{ Gross Margin }} & Revenue-Cost of Goods Sold \\
\hline & & Revenue \\
\hline \multirow{2}{*}{\multicolumn{2}{|c|}{ Return on Common Equity }} & Net Income \\
\hline & & $\overline{\text { Average Shareholders' Equity }}$ \\
\hline \multirow{4}{*}{ Profitability } & \multirow{2}{*}{ Return on Assets } & Net Income + Interest $\times(1-$ tax rate $)$ \\
\hline & & Average Total Assets \\
\hline & \multirow{2}{*}{ Profit Margin } & Net Income + Interest $\times(1-$ tax rate $)$ \\
\hline & & Sales \\
\hline \multirow{6}{*}{ Efficiency } & \multirow{2}{*}{ Total Assets Turnover } & Sales \\
\hline & & $\overline{\text { Average Total Assets }}$ \\
\hline & \multirow{2}{*}{ Accounts Receivable Turnover } & Sales \\
\hline & & $\overline{\text { Average Accounts Receivable }}$ \\
\hline & \multirow{2}{*}{ Inventory Turnover } & Cost of Goods Sold \\
\hline & & $\overline{\text { Average Inventory }}$ \\
\hline
\end{tabular}

Table 8.2: Common Variables Measuring Poor Performance or Failure

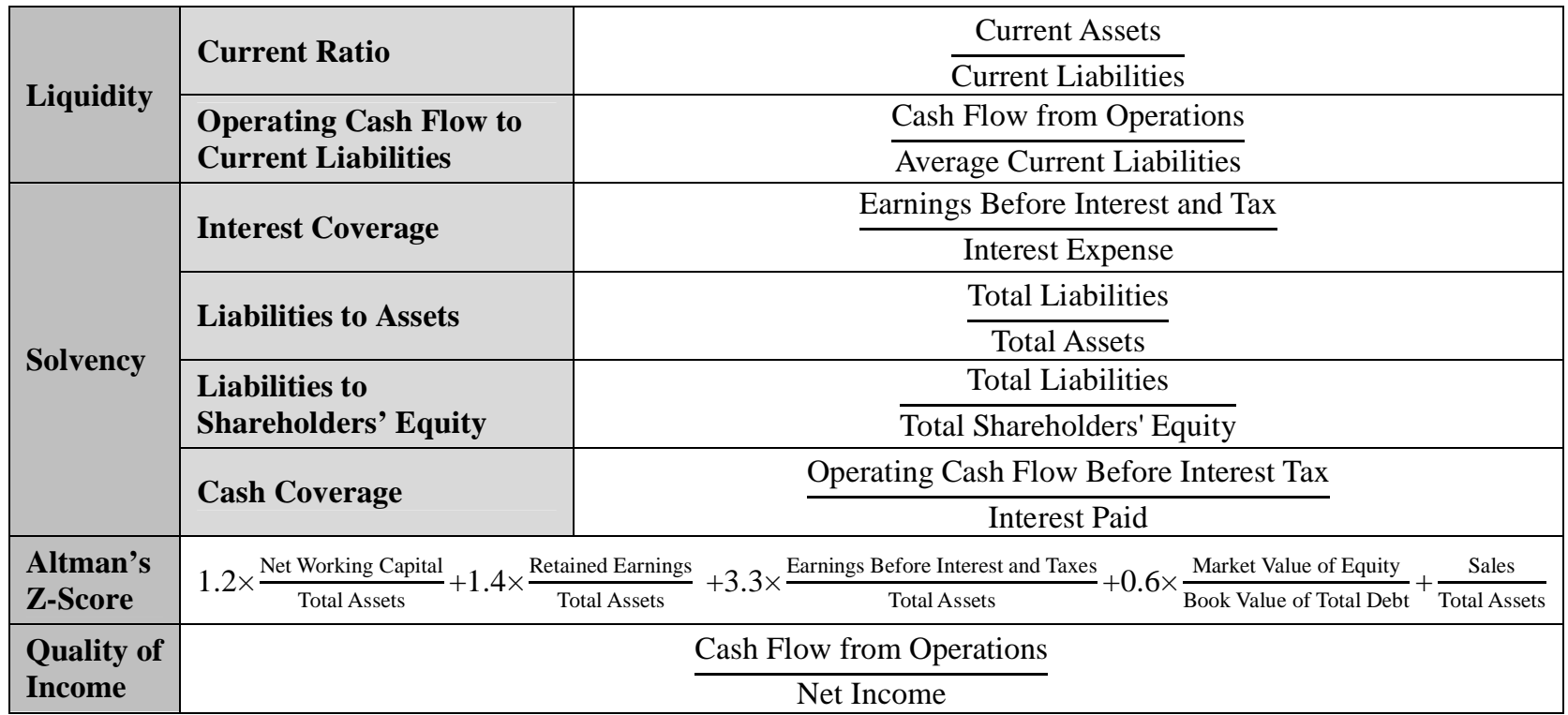

In short, many different sets of variables were applied to SBM models. Those in Table 8.3 are discussed in detail, and characterized by theme and frontier type. For a complete list, see Appendix E. 
Table 8.3: Abbreviated List of Metrics Tested

\begin{tabular}{|c|c|c|c|}
\hline Theme & Frontier & Inputs & Outputs \\
\hline PCA & Normal & $\begin{array}{l}\text { AD, AR,CA, CL, COGS, Inv, } \\
\text { Other NonCA, PPE, SGA, TA, TL, }\end{array}$ & Rev, SE \\
\hline LR & Normal & AP, CM, IE, PPE, SGA, TA, TL & Cash, NI, Rev, SE \\
\hline \multirow{4}{*}{ Profitability or Success } & \multirow{2}{*}{ Normal } & IE, TA & $\mathrm{CFO}, \mathrm{NI}, \mathrm{RE}, \mathrm{Rev}$ \\
\hline & & CFO, NI, RE, Rev & IE, TA \\
\hline & \multirow{2}{*}{ Inverse } & COGS, IE, Inv, PPE, TA & Rev, SE \\
\hline & & Rev, SE & COGS, IE, Inv, PPE,TA \\
\hline Bankruptcy or Failure & Worst-Practice & CFO, EBIT & IE \\
\hline Income Statement & Normal & COGS, ITE, Net IE, SGA & NI, Rev \\
\hline \multirow[t]{2}{*}{ Balance Sheet } & Normal & $\begin{array}{l}\text { AR, CA, Goodwill, Inv, MS, Net } \\
\text { PPE, LTIS, TA }\end{array}$ & Cash, RE, SE \\
\hline & Normal & AP, CL, CM, LTD, NPSTD, TL & RE, SE \\
\hline Cash Flow Statement & Normal & Positive CFO, CFI; Negative CFF & Negative CFO, CFI; Positive CFF \\
\hline $\begin{array}{l}\text { Managerial Decision- } \\
\text { Making }\end{array}$ & Normal & $\begin{array}{l}\text { Auditors' Opinion, Auditor } \\
\text { Turnover, Legal Proceedings, } \\
\text { Management Turnover, Related } \\
\text { Parties, Retirement Plans }\end{array}$ & Dummy $^{16}$ \\
\hline
\end{tabular}

\subsection{Slacks-Based Measure of Efficiency (SBM) Model}

The DEA model used in this work was the non-oriented Slacks-based measure of efficiency (SBM) model with variable returns-to-scale. Unlike radial models, SBM captures the effect of slacks (all inefficiencies) in the scores it produces. Each SBM efficiency score $\rho \in[0,1]$ is a ratio of the average relative input consumption to the average relative output production (Tone, 2001). Because SBM cannot handle zeros, zeros were replaced with a small positive number. Also, variables with negative data (i.e. shareholder's equity, net income) were problematic because SBM is not translation invariant; that is, data cannot be scaled by adding the absolute value of the largest negative number to remove all negatives. In these cases, for any variable with negative data, two new variables (labelled "positive" and "negative" with opposite orientations) were introduced in its place (Figure 8.5).

\begin{tabular}{|c|c|c|c|}
\hline Net Income & & Positive Net Income (Output) & Negative Net Income (Input) \\
\hline$\$ 2,000,000$ & $\rightarrow$ & $\$ 2,000,000$ & $\$ 0$ \\
\hline$-\$ 1,000,000$ & $\rightarrow$ & $\$ 0$ & $\$ 1,000,000$ \\
\hline
\end{tabular}

Figure 8.5: Example of Handling Negative Data

For instance, in normal DEA, a high net income was desirable. If net income was positive, then its value was copied directly to the new variable "positive net income" and treated as an output while the other new variable "negative net income" was assigned a zero and treated as an input. In contrast, if net income was negative, then its absolute value was copied to

\footnotetext{
${ }^{16}$ A dummy variable is one where each DMU is given a value of 1 for that variable.
} 
"negative net income" and treated as an input while "positive net income" was assigned a zero and treated as an output.

\subsection{Classification by Zones and Layering}

The computer software, DEA-Solver-Pro Version 6.0, used to run DEA models was purchased from SAITECH, Inc. It is a Microsoft Excel macro designed on the basis of the textbook "Data Envelopment Analysis - A Comprehensive Text with Models, Applications, References and DEA-Solver Software" written by W.W. Cooper, L.M. Seiford and K. Tone in 2000. Hence, input data files were in .xls form. Results generated by DEA-Solver-Pro were also presented .xls form. "SBM-NonOriented(SBM-V)" was selected for all models. DEA Solver Pro offers a lot of information on results (projections, weights), but this thesis mainly focused on scores which were used to classify DMUs by zones or by layering.

When classifying by zones, DMUs were characterized as active or bankrupt based on where their scores were relative to one or two cut-off values (Figure 8.6 and Figure 8.7, respectively), which were selected to minimize Type I and II errors. The cut-off values create "zones" similar to that of Altman's Z-Score: a DMU in the safe zone has little risk of bankruptcy; a DMU in the danger zone has a high risk of bankruptcy; and a DMU in the grey zone has a moderate risk of bankruptcy. From the cut-off values and zones, the numbers of true positive, true negative, false positive and false negative instances were counted, and TP rate, FP rate, success rate, Type I and II errors were calculated. A histogram of scores was also created, and the averages and variances of all scores were computed by state.

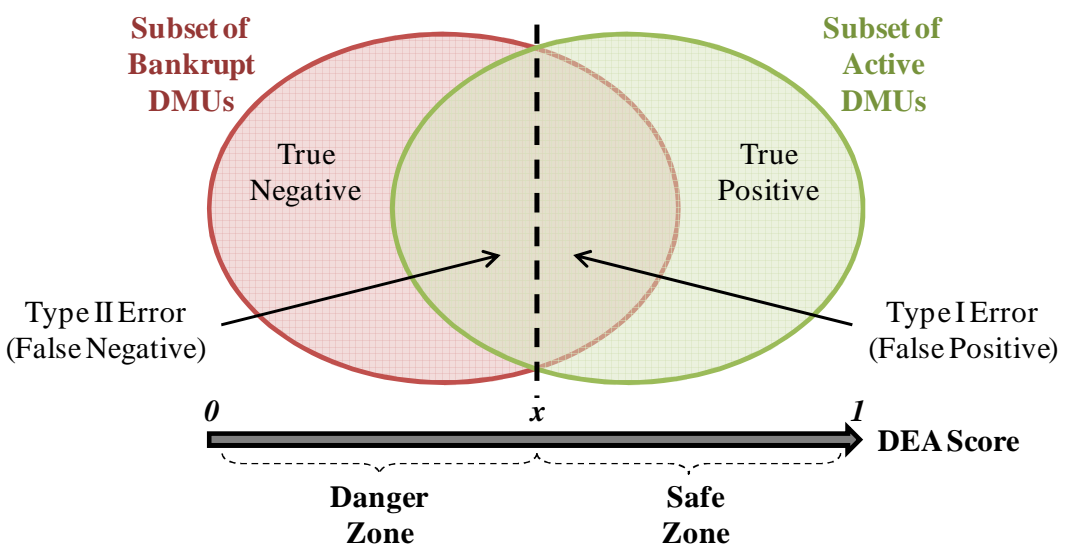

Figure 8.6: Classification with One Cut-Off Value $(x)$ 


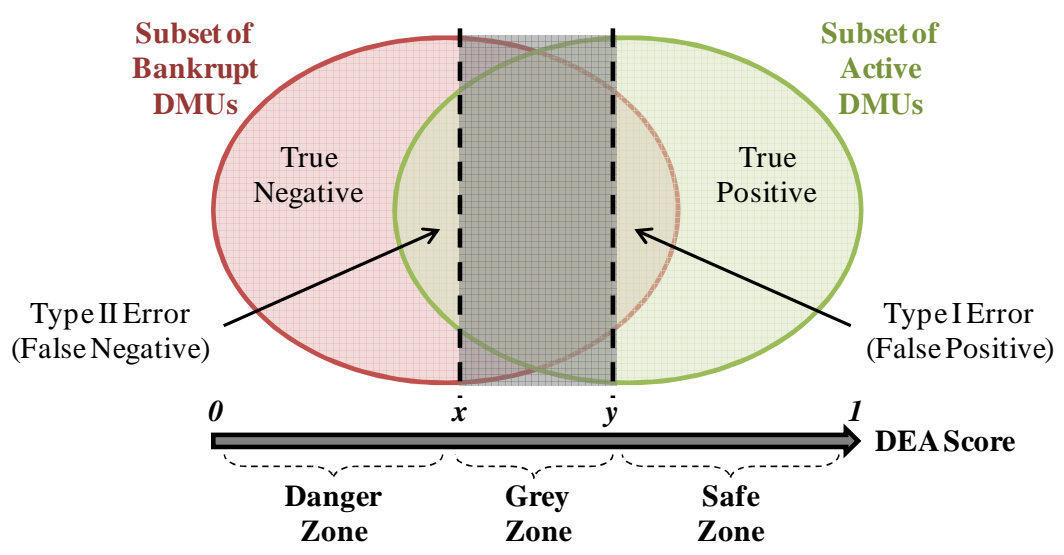

Figure 8.7: Classification with Two Cut-Off Values ( $x$ and $y$ )

When classifying by layering (Section 8.1.2), true positive, true negative, false positive and false negative instances were solely based on whether a DMU was on or away from the frontier. In normal DEA, only a score of 1 represented a prediction of "active"; a DMU with a score less than 1 remained unclassified until the next peel or run. The evaluations (i.e. TP rate, FP rate, Type I and II errors, success rate) for a particular layer were then calculated from the cumulative counts of the above instances, up to and including that layer. For example, first layer evaluations were based only on the instances counted from the first run, whereas second layer evaluations summed the instances counted from the first and second peel. The third layer evaluations added the instances of the first, second and third peel, and so on. 


\section{Preliminary Models: Results and Discussion}

\subsection{Principal Component Analysis and Logistic Regression Metrics}

The first model applied financial variables selected by principal component analysis (PCA) only (Table 8.3). Figure 9.1 presents the distribution of DEA scores based on a normal (bestperforming) frontier. Of the $701 \mathrm{DMUs}^{17}, 180$ (or 26\%) were identified as healthiest relative to the sample and consequently given a score of 1; 4 of these DMUs, however, were actually bankrupt or near failure ${ }^{18}$ (Type I error). Also, the average scores were higher for active DMUs and decreased as bankruptcy was imminent (Table 9.1).

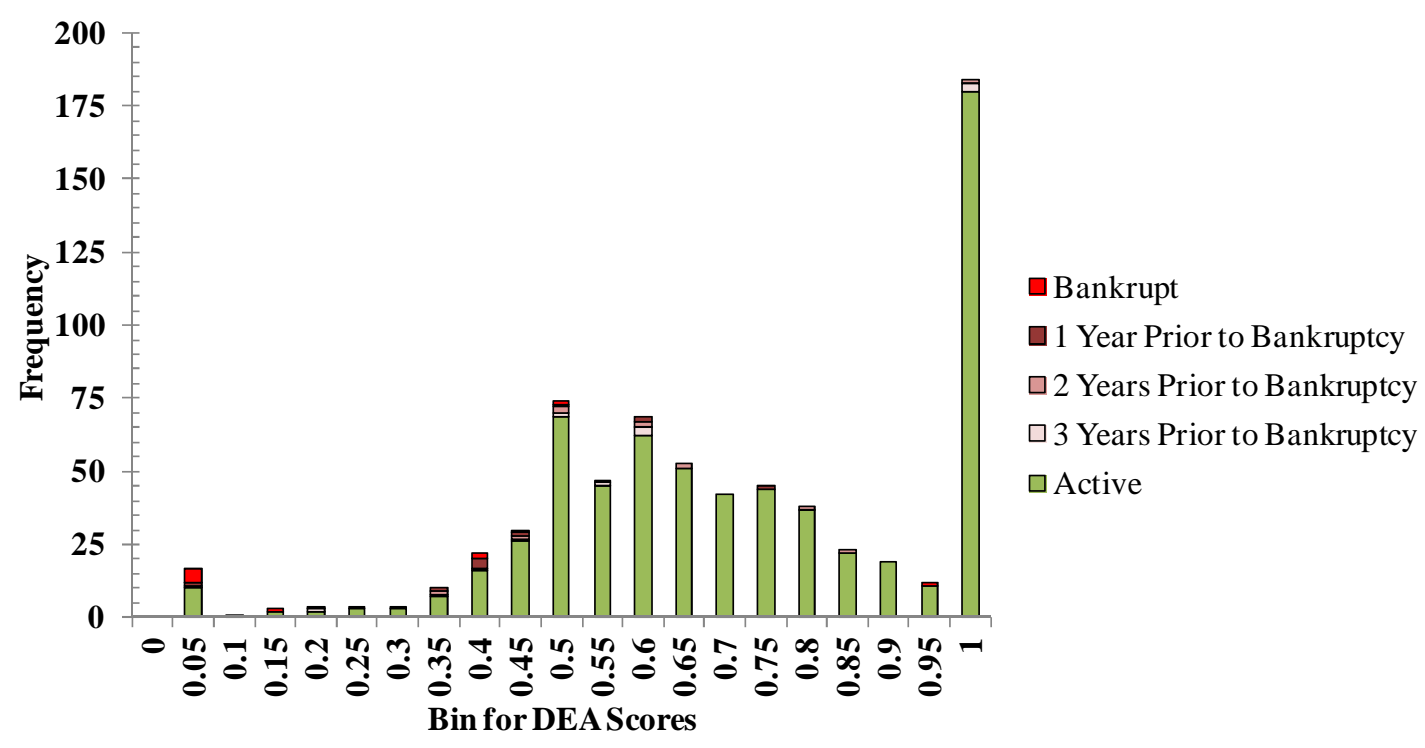

Figure 9.1: Distribution of Scores Generated from PCA Normal Model

Table 9.1: Normal Scores Calculated with Variables Derived from PCA by State

\begin{tabular}{|c|c|c|c|c|c|}
\hline State $^{19}$ & Count & Average & Median & Minimum & Maximum \\
\hline All A & 651 & $0.70 \pm 0.23$ & 0.68 & 0 & 1.00 \\
\hline All B & 50 & $0.44 \pm 0.29$ & 0.44 & 0 & 1.00 \\
\hline B & 13 & $0.26 \pm 0.28$ & 0.19 & 0 & 0.93 \\
\hline B-1 & 12 & $0.38 \pm 0.21$ & 0.37 & 0 & 0.73 \\
\hline B-2 & 13 & $0.54 \pm 0.27$ & 0.56 & 0 & 1.00 \\
\hline B-3 & 12 & $0.59 \pm 0.28$ & 0.56 & 0.17 & 1.00 \\
\hline Total & 701 & $0.69 \pm 0.25$ & 0.67 & 0 & 1.00 \\
\hline
\end{tabular}

With a kurtosis of -0.23 (i.e. a relatively flat distribution) and a skewness of -0.39 (i.e. a distribution with an asymmetric tail extending toward negative values), two cut-off values (or three zones) were used to classify financial health. Here, a DMU with a score $\zeta$ was

\footnotetext{
${ }^{17}$ There are 701 DMUs between 1996-2009 (Section 6.2).

${ }^{18}$ A DMU was predicted bankrupt up to 3 years prior to filing Chapter 11.

${ }^{19}$ Notation for possible DMU states is presented in Table 6.3.
} 
predicted bankrupt if $0 \leq \zeta<0.4$ or active if $0.7 \leq \zeta \leq 1$. If $0.4 \leq \zeta<0.7$, then it was unclassified. Results from prediction by zones are summarized in Table 9.2. Type I and II errors were computed to be $33 \%$ and $7 \%$, respectively. Of the 43 active DMUs that were misclassified as bankrupt, 14 of them represented years of firms that inevitably (after 3 or more years) filed for Chapter 11; thus, the Type II error calculated was conservative. Also, despite a success rate of 91\%, 295 DMUs were unclassified - a number that must be reduced for this model to be effective.

Table 9.2: Confusion Matrix for PCA Normal Model A DMU was predicted bankrupt up to 3 years prior to filing Chapter 11.

\begin{tabular}{|c|c|c|c|}
\hline & \multicolumn{2}{|c|}{ Actual } \\
\hline & & Active & Bankrupt \\
\hline \multirow{2}{*}{ Predicted } & Active & 355 & 8 \\
\hline & Bankrupt & 27 & 16 \\
\hline
\end{tabular}

The PCA inputs and outputs were then swapped and applied to an inverse model for a frontier of worst-performers. One hundred and six DMUs (15\%) were identified as having the highest risk of bankruptcy relative to the sample and were given a score of $1 ; 89$ of these DMUs, however, were actually active (Type II error). The average scores were lower for active DMUs and increased as bankruptcy was imminent (Table 9.3). Unlike the normal model, the distribution was bimodal (Figure 9.2). Hence, only one cut-off value separating two zones was used for characterization: a DMU with a score $\zeta$ was predicted as active if $0 \leq$ $\zeta<0.7$ or bankrupt if $0.7 \leq \zeta \leq 1$. All DMUs were classified (Table 9.4), yielding Type I and II errors of $66 \%$ and $14 \%$, respectively, with a success rate of $82 \%$. 


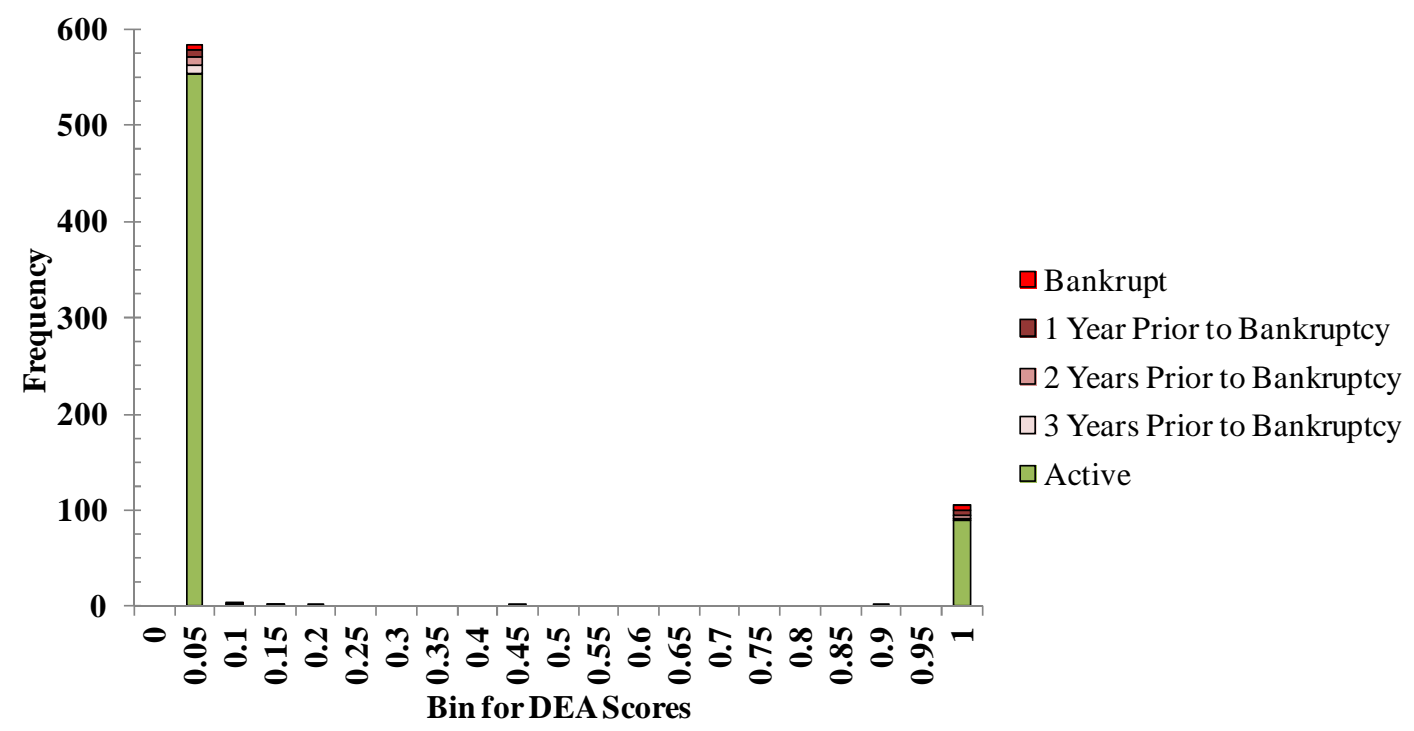

Figure 9.2: Distribution of Scores Generated from PCA Inverse Model

Table 9.3: Inverse Scores Calculated with Variables Derived from PCA by State

\begin{tabular}{|c|c|c|c|c|c|}
\hline State & Count & Average & Median & Minimum & Maximum \\
\hline All A & 650 & $0.14 \pm 0.34$ & 0.002 & 0 & 1 \\
\hline All B & 46 & $0.35 \pm 0.47$ & 0.004 & 0 & 1 \\
\hline B & 13 & $0.47 \pm 0.51$ & 0.087 & 0 & 1 \\
\hline B-1 & 13 & $0.50 \pm 0.52$ & 0.502 & 0 & 1 \\
\hline B-2 & 14 & $0.24 \pm 0.43$ & 0.004 & 0 & 1 \\
\hline B-3 & 12 & $0.17 \pm 0.39$ & 0.004 & 0 & 1 \\
\hline Total & 700 & $0.16 \pm 0.36$ & 0.002 & 0 & 1 \\
\hline
\end{tabular}

Table 9.4: Confusion Matrix for PCA Inverse Model

A DMU was predicted bankrupt up to 3 years prior to filing Chapter 11.

\begin{tabular}{|l|l|c|c|}
\cline { 3 - 4 } \multicolumn{2}{c|}{} & \multicolumn{2}{c|}{ Actual } \\
\cline { 3 - 4 } \multicolumn{2}{c|}{} & Active & Bankrupt \\
\hline \multirow{2}{*}{ Predicted } & Active & 560 & 33 \\
\cline { 2 - 4 } & Bankrupt & 90 & 17 \\
\hline
\end{tabular}

The second model applied variables selected by logistic regression (LR) (Table 8.3). The distribution of DEA scores based on a normal frontier (Figure 9.3) shows that of the 699 DMUs, 133 (or 19\%) were identified as healthiest and given a score of 1; 4 of these DMUs, however, were actually bankrupt or near failure ${ }^{20}$ (Type I error) with 2 being identical to those misclassified by the PCA model. With a kurtosis of -0.84 and skewness of 0.80 , the same two cut-off values ( 0.4 and 0.7$)$ were used for classification, yielding Type I and II errors of $11 \%$ and $71 \%$, respectively.

${ }^{20}$ A DMU was predicted bankrupt up to 3 years prior to filing Chapter 11. 


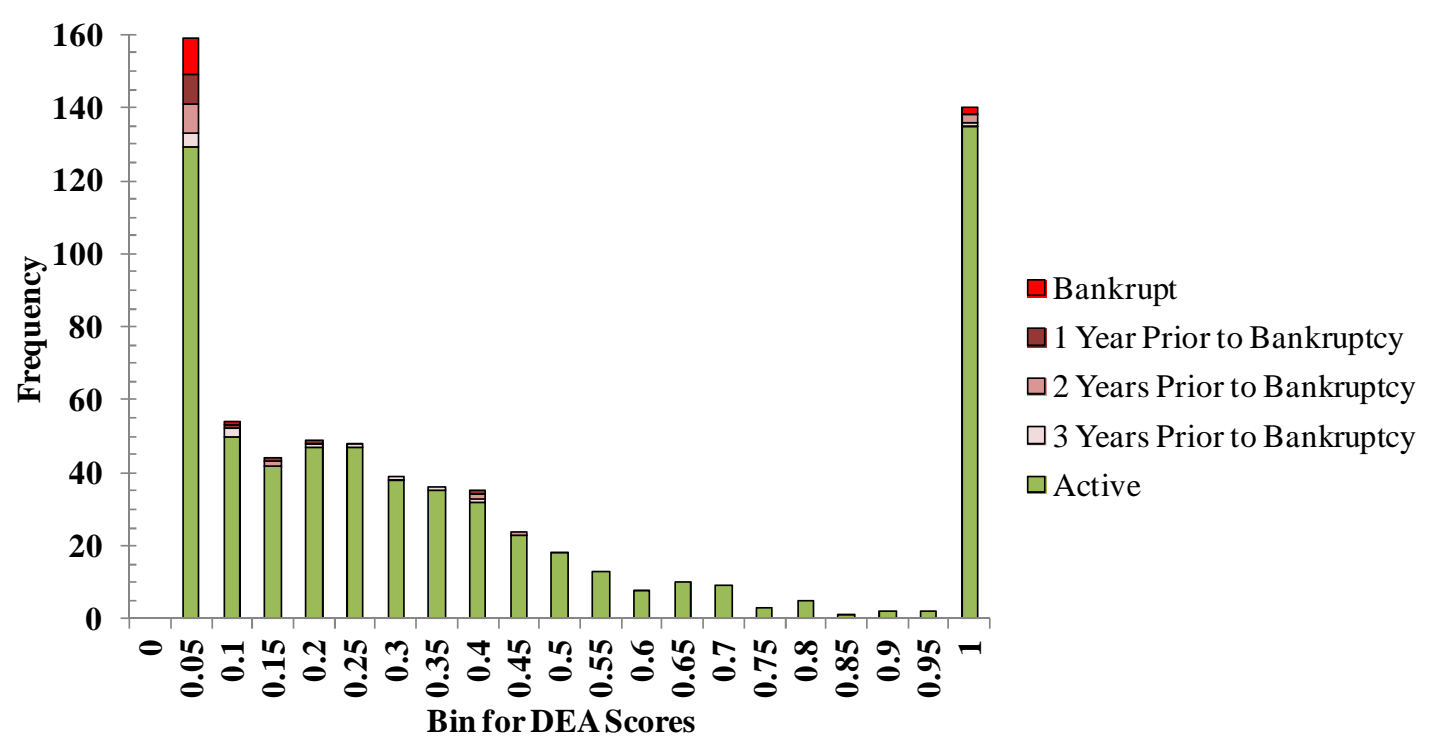

Figure 9.3: Distribution of Scores Generated from LR Normal Model

When LR inputs and outputs were swapped and applied to an inverse model, the results were similar to the PCA inverse model (Appendix F.1). With a bimodal distribution, a cut-off value of 0.7 was used which produced Type I and II errors of 58\% and 16\%, respectively.

Four conclusions came from the PCA and LR models (Table 9.5):

1. Inverse models created bimodal distributions which required only one cut-off value (2 zones) for classification. Normal models required at least 2 cut-off values ( 3 zones) to minimize classification errors but were also conservative, leaving many DMUs unclassified.

2. Type II error was generally lower than Type I error (exception: LR normal model). This must be improved as Type I error is more costly.

3. The overall success rates were high, but this is deceiving because the sample had a higher proportion of active DMUs which drove up the TP rate. In other words, the misclassification of each bankrupt DMU was experienced more strongly.

4. There was nearly no relationship between the normal and inverse scores (Table 9.6) when it was anticipated that the correlation would be -1 . This unexpected result is explained in Section 9.2. 
Table 9.5: Summary of Results for Models with Variables Selected by PCA and LR A DMU was predicted bankrupt up to 3 years prior to filing Chapter 11.

\begin{tabular}{|l|c|c|c|c|}
\hline \multirow{2}{*}{\multicolumn{1}{c|}{ Evaluation }} & \multicolumn{2}{c|}{ PCA } & \multicolumn{2}{c|}{ Logistic Regression } \\
\cline { 2 - 5 } & Normal & Inverse & Normal & Inverse \\
\hline True Positive Rate & $92.9 \%$ & $86.2 \%$ & $28.8 \%$ & $84.2 \%$ \\
\hline False Positive Rate & $33.3 \%$ & $66.0 \%$ & $10.9 \%$ & $58.0 \%$ \\
\hline Type I Error & $33.3 \%$ & $66.0 \%$ & $10.9 \%$ & $58.0 \%$ \\
\hline Type II Error & $7.1 \%$ & $13.8 \%$ & $71.2 \%$ & $15.8 \%$ \\
\hline Success Rate & $91.4 \%$ & $82.4 \%$ & $32.8 \%$ & $81.2 \%$ \\
\hline Unclassified & $42.1 \%$ & $0 \%$ & $15.4 \%$ & $0 \%$ \\
\hline
\end{tabular}

Table 9.6: Correlation between PCA and LR Scores

\begin{tabular}{|c|c|c|c|c|}
\cline { 2 - 5 } \multicolumn{1}{c|}{} & PCA Normal & PCA Inverse & LR Normal & LR Inverse \\
\hline PCA Normal & 1 & -0.15 & 0.66 & -0.15 \\
\hline PCA Inverse & & 1 & -0.18 & 0.72 \\
\hline LR Normal & & & 1 & -0.38 \\
\hline LR Inverse & & & & 1 \\
\hline
\end{tabular}

\subsection{Profitability Metrics}

Over 30 combinations of financial variables were applied to normal and inverse DEA (for a complete list, see Appendix E). Because many varied by one or two variables at a time, only the "best" two models, denoted as "A" and "B", are discussed. Figure 9.4 and Figure 9.5 summarize their results based on a normal frontier reflecting profitability. Again, a DMU with a score $\zeta$ was predicted bankrupt if $0 \leq \zeta<0.4$ or active if $0.7 \leq \zeta \leq 1$. If $0.4 \leq \zeta<0.7$, then it remained unclassified. As expected, results changed with inputs and outputs. For model "A", the inputs were IE and TA, and the outputs were CFO, NI, RE and Rev. It fared well with zero Type I error; however, Type II error was $79 \%$ and the success rate was only 29\%. Also, over a quarter of the DMUs were unclassified. For model "B", the inputs were COGS, IE, Inv, PPE and TA, and the outputs were Rev and SE. It had considerably fewer Type II errors (22\%) and a vastly improved success rate (78\%). However, these improvements came with an increase of Type I error to $20 \%$ and the doubling of unclassified DMUs. The difference between " $\mathrm{A}$ " and " $\mathrm{B}$ " is also rooted in dimensionality: " $\mathrm{A}$ " had 2 inputs and 4 outputs while "B" had 5 inputs and 2 outputs. 


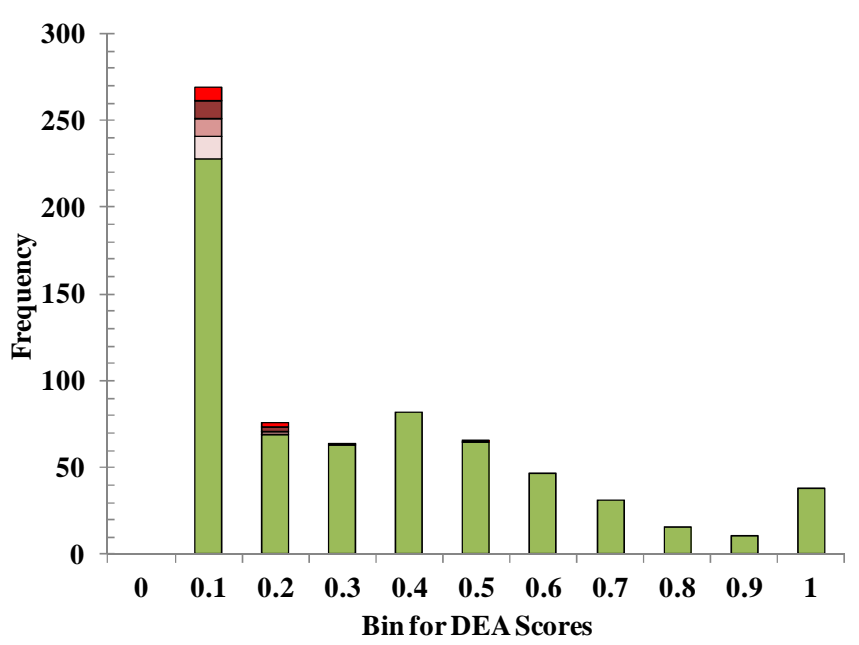

Metric "A" (Normal DEA)

$\square$ Bankrupt

$\square 1$ Year Prior to Bankruptcy

$\square 2$ Years Prior to Bankruptcy

$\square 3$ Years Prior to Bankruptcy

$\square$ Active

Figure 9.4: Summary of Normal Profitability Model "A"

A DMU was predicted bankrupt up to 3 years prior to filing Chapter 11.

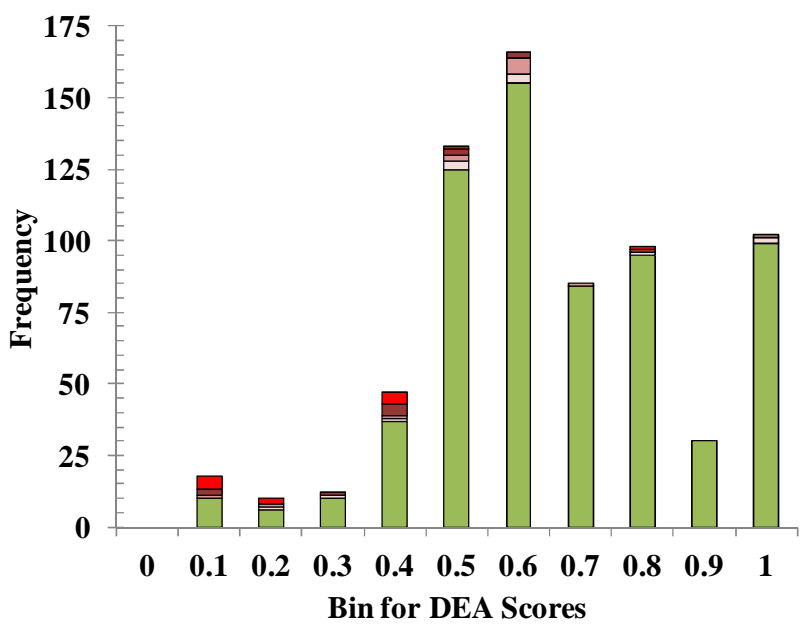

Metric “B” (Normal DEA)

Outputs:

Rev, SE

Inputs:

COGS, IE, Inv, PPE, TA

Kurtosis: 0.15

$\square 1$ Year Prior to Bankruptcy

Skewness: -0.04

$\square 2$ Years Prior to Bankruptcy

$\square 3$ Years Prior to Bankruptcy

$\square$ Active

\begin{tabular}{|l|r|}
\hline \multicolumn{1}{|c|}{ Evaluation } & \multicolumn{1}{c|}{} \\
\hline TP Rate & 78.0 \\
\hline FP Rate & 20.0 \\
\hline Type I Error & 20.0 \\
\hline Type II Error & 22.0 \\
\hline Success Rate & 78.2 \\
\hline Unclassified & 52.2 \\
\hline
\end{tabular}

Figure 9.5: Summary of Normal Profitability Model "B'

A DMU was predicted bankrupt up to 3 years prior to filing Chapter 11.

Figure 9.6 and Figure 9.7 present the results of the inverse models of "A" and "B" having similar classification zones as their normal counterparts; that is, a DMU with a score $\zeta$ was predicted active if $0 \leq \zeta<0.4$ or bankrupt if $0.7 \leq \zeta \leq 1$, or remained unclassified if $0.4 \leq$ $\zeta<0.7$. With bimodal distributions, "A" and "B" had high Type I error ( 74-78\%) and relatively low Type II error $(<10 \%)$. Their success rate was high $(>86 \%)$ but misleading given the higher ratio of active to bankrupt DMUs. Also, over $90 \%$ of DMUs had scores less than 0.1 , driving the mean and median down to 0.08 and 0.0002 , respectively. Overall, inverse models were poor at classification. 


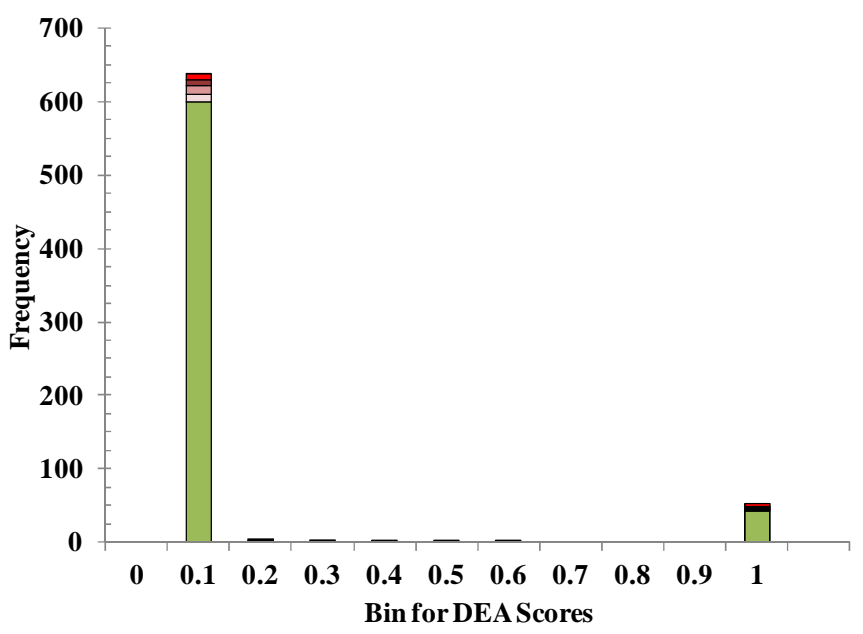

Metric "A" (Inverse DEA)

$\square$ Bankrupt

$\square 1$ Year Prior to Bankruptcy

$\square 2$ Years Prior to Bankruptcy

$\square 3$ Years Prior to Bankruptcy

$\square$ Active

Figure 9.6: Summary of Inverse Profitability Model "A" A DMU was predicted bankrupt up to 3 years prior to filing Chapter 11.

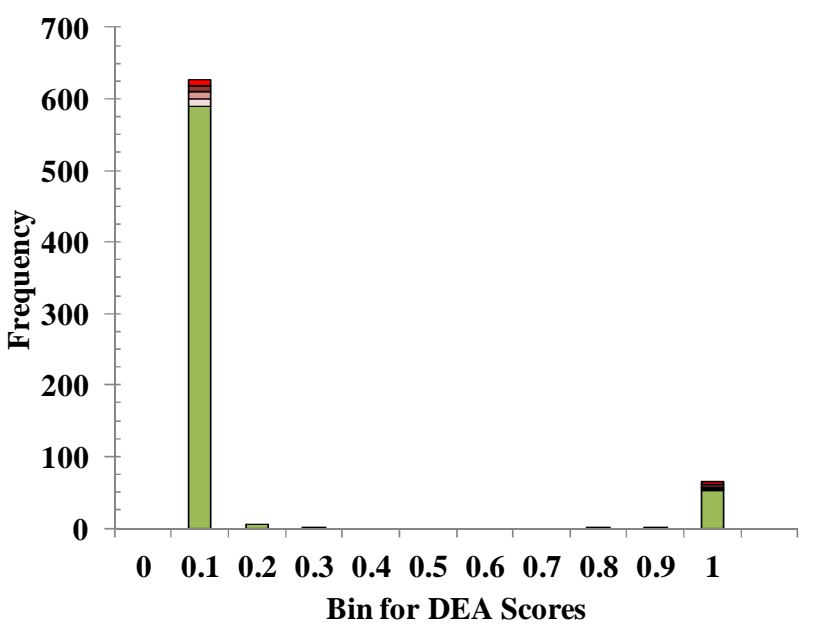

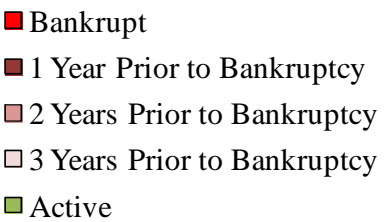

$\square$ Active

Figure 9.7: Summary of Inverse Profitability Model "B"

A DMU was predicted bankrupt up to 3 years prior to filing Chapter 11.

The correlations in Table 9.7 show that normal and inverse models did not have a perfect negative relationship.

Table 9.7: Correlation between Normal and Inverse Profitability Models

\begin{tabular}{|l|c|c|c|c|c|}
\cline { 3 - 6 } \multicolumn{2}{c|}{} & \multicolumn{2}{c|}{ Normal Models } & \multicolumn{2}{c|}{ Inverse Models } \\
\cline { 3 - 6 } \multicolumn{2}{c|}{} & "A" & "B" & "A"A" & “B” \\
\hline Normal & "A" & 1 & 0.69 & -0.66 & -0.47 \\
\cline { 2 - 6 } Models & "B" & & 1 & -0.33 & -0.34 \\
\hline $\begin{array}{l}\text { Inverse } \\
\text { Models }\end{array}$ & "A" & & & 1 & 0.58 \\
\cline { 2 - 6 } & "B" & & & & 1 \\
\hline
\end{tabular}

This inconsistency is attributed to the dimensionality of the DEA programming. To illustrate, consider the following two non-oriented SBM models. In Figure 9.8, both axes represent two output variables normalized by a unit input. A normal frontier (green curve) 
would thus consist of DMUs with the greatest amount of outputs produced given a unit input, so DMUs C, D and E are the best performers while all others are less efficient. When the variables are swapped for a two inputs and a unit output system, the model aims to minimize the output and maximize inputs, yielding an inverse frontier with DMUs F and G. This example illustrates the ideal situation where classification is consistent between normal and inverse models; that is, the best performing DMUs in a normal model are not the worst performing DMUs in its corresponding inverse model.

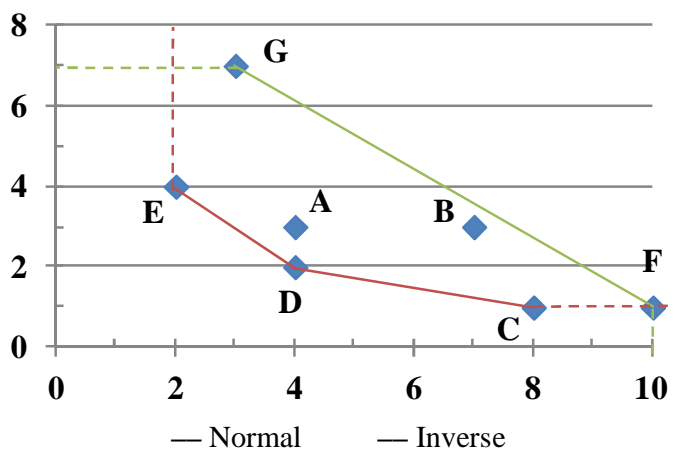

\begin{tabular}{|c|c|c|c|c|c|}
\hline \multirow{2}{*}{ DMU } & \multicolumn{2}{|c|}{ Outputs } & Input & \multicolumn{2}{c|}{ DEA Scores } \\
\cline { 2 - 6 } & Y1 & Y2 & X & $\begin{array}{c}\text { Max Y, } \\
\text { Min X }\end{array}$ & $\begin{array}{c}\text { Max X, } \\
\text { Min Y }\end{array}$ \\
\hline A & 4 & 3 & 1 & 0.83 & 0.66 \\
\hline B & 7 & 3 & 1 & 0.62 & 0.91 \\
\hline C & 8 & 1 & 1 & 1 & 0.54 \\
\hline D & 4 & 2 & 1 & 1 & 0.49 \\
\hline E & 2 & 4 & 1 & 1 & 0.47 \\
\hline F & 10 & 1 & 1 & 0.90 & 1 \\
\hline G & 3 & 7 & 1 & 0.62 & 1 \\
\hline
\end{tabular}

Figure 9.8: Example of Consistent Normal and Inverse Models

However, inconsistent classification between normal and inverse models exists. In Figure 9.9, the normal frontier of the two outputs and a unit input model identifies B, E, F and G as the best DMUs. When the variables are swapped for a two inputs and a unit output model, the inverse model identifies A, D and G as the worst DMUs. Thus, G is present on both best and worst frontiers. This contradiction suggests that a DMU can appear efficient when it produces the greatest amount of outputs $\left(Y_{1}=6, Y_{2}=2\right)$ for one unit of input $(X)$, but at the same time, it can look inefficient when it requires the same unit input $(X=1)$ to produce less outputs compared to another DMU, like B $\left(Y_{1}=2, Y_{2}=7\right)$. This may be due to selfidentification of a unique DMU (one without peers). Also, G appears to be at the ends of each space, serving as a boundary for both normal and inverse frontiers. 


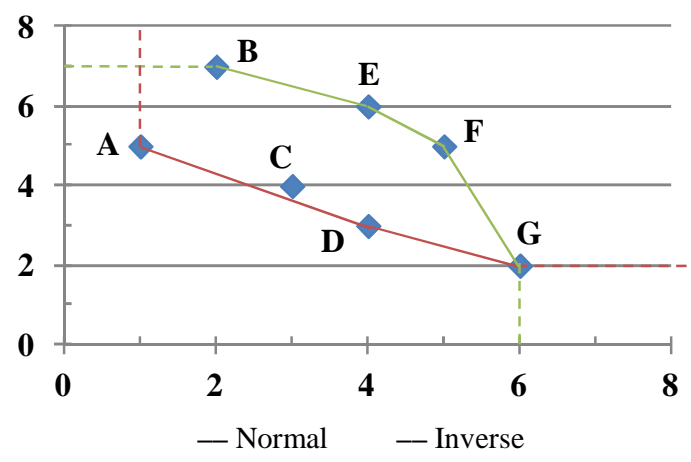

\begin{tabular}{|c|c|c|c|c|c|}
\hline \multirow{2}{*}{ DMU } & \multicolumn{2}{|c|}{ Outputs } & Input & \multicolumn{2}{c|}{ DEA Scores } \\
\cline { 2 - 6 } & Y1 & Y2 & $\mathbf{X}$ & $\begin{array}{c}\text { Max Y, } \\
\text { Min X }\end{array}$ & $\begin{array}{c}\text { Max X, } \\
\text { Min Y }\end{array}$ \\
\hline A & 1 & 5 & 1 & 0.33 & 1 \\
\hline B & 2 & 7 & 1 & 1 & 0.61 \\
\hline C & 3 & 4 & 1 & 0.69 & 0.92 \\
\hline D & 4 & 3 & 1 & 0.67 & 1 \\
\hline E & 4 & 6 & 1 & 1 & 0.54 \\
\hline F & 5 & 5 & 1 & 1 & 0.60 \\
\hline G & 6 & 2 & 1 & 1 & 1 \\
\hline
\end{tabular}

Figure 9.9: Example of Inconsistent Normal and Inverse Models

As the complexity and dimensionality of DEA programming increases with the application of more variables, inconsistency becomes more common and further establishes that normal and inverse models are not opposites. For the 2 inputs and 2 outputs model presented in Table 9.8, the weak relationship between normal and inverse scores is clear as A, B, G, L, N and P are identified as both best and worst performers. Inconsistencies do not necessarily imply that these DMUs are outliers but rather, confirm that the selection of variables and model/frontier greatly influence results and classification.

Table 9.8: Example of Inconsistent Normal and Inverse Models of a Two Inputs - Two Outputs System

\begin{tabular}{|c|c|c|c|c|c|c|}
\hline \multirow{2}{*}{ DMU } & \multicolumn{2}{|c|}{ Inputs } & \multicolumn{2}{c|}{ Outputs } & \multicolumn{2}{c|}{ DEA Scores } \\
\cline { 2 - 7 } & $\mathbf{X 1}$ & $\mathbf{X 2}$ & $\mathbf{Y 1}$ & $\mathbf{Y 2}$ & $\begin{array}{c}\text { Max Y, Min X } \\
\text { (Normal) }\end{array}$ & $\begin{array}{c}\text { Max X, Min Y } \\
\text { (Inverse) }\end{array}$ \\
\hline A & 1 & 4 & 1 & 5 & 1 & 1 \\
\hline B & 2 & 10 & 2 & 7 & 1 & 1 \\
\hline C & 2 & 2 & 3 & 4 & 1 & 0.56 \\
\hline D & 3 & 4 & 4 & 3 & 0.57 & 1 \\
\hline E & 4 & 7 & 4 & 6 & 0.57 & 1 \\
\hline F & 4 & 3 & 5 & 5 & 0.79 & 0.52 \\
\hline G & 4 & 4 & 6 & 2 & 1 & 1 \\
\hline H & 5 & 7 & 7 & 9 & 1 & 0.62 \\
\hline I & 5 & 8 & 7 & 3 & 0.47 & 1 \\
\hline J & 6 & 6 & 8 & 12 & 1 & 0.59 \\
\hline K & 7 & 9 & 9 & 9 & 0.69 & 1 \\
\hline L & 8 & 2 & 9 & 8 & 1 & 1 \\
\hline M & 8 & 7 & 10 & 10 & 0.77 & 1 \\
\hline N & 9 & 1 & 11 & 1 & 1 & 1 \\
\hline O & 9 & 3 & 12 & 6 & 1 & 0.94 \\
\hline P & 10 & 2 & 12 & 9 & 1 & 1 \\
\hline
\end{tabular}

\subsection{Combining Normal and Inverse Scores}

The weak correlation between normal and inverse models alluded to a possible complementary relationship and encouraged the combination of their scores to increase success rate, decrease Type I and II errors, and reduce the number of unclassified DMUs. 
Two novel approaches were created to combine normal and inverse scores generated from "A" and "B" in Section 9.2: parallel classification and serial classification. Parallel classification considered both normal and inverse scores in combination (Figure 9.10). A DMU was predicted active if its normal score was between 0.7 and 1 and its inverse score was between 0 and 0.4. It was predicted bankrupt if its normal score was between 0 and 0.4 and its inverse score was between 0.7 and 1 . If neither of these conditions was satisfied, the DMU was unclassified.

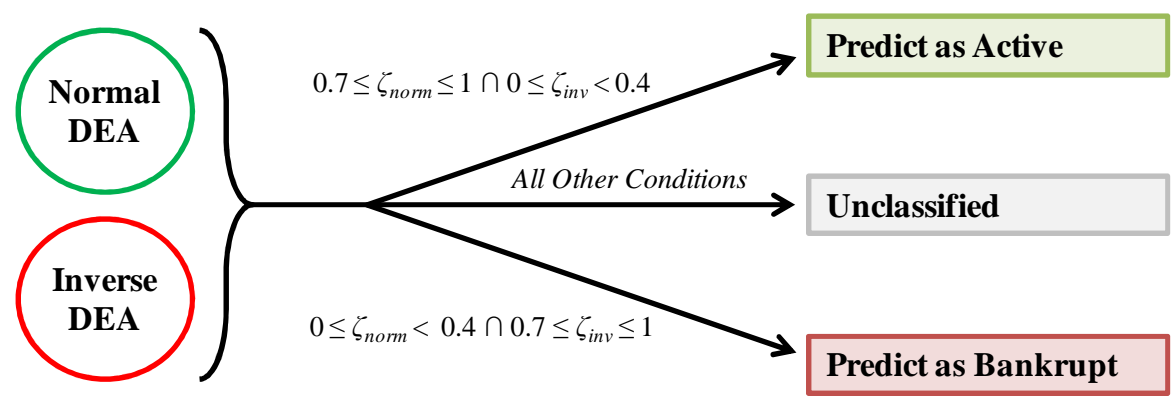

Figure 9.10: Parallel Classification

Table 9.9 summarizes the results of parallel classification of " $\mathrm{A}$ " and "B". The performance of the combination of scores (Normal $\cap$ Inverse) appeared to be an "average" of normal and inverse scores. In fact, the strengths of a normal model (low Type I error, high success rate) were compromised when combined with the inverse model. At the same time, its weaknesses (high Type II error) were reduced. Similarly, the strengths of an inverse model (low Type II error) were reduced when combined with a normal model, while its weaknesses (high Type I error, low success rate) were improved. Furthermore, the percentage of unclassified DMUs increased because of the inconsistency of classification between normal and inverse models on their own.

Table 9.9: Parallel Classification of Models "A" and "B"

A DMU was predicted bankrupt up to 3 years prior to filing Chapter 11.

\begin{tabular}{|l|c|c|c|c|c|c|}
\hline \multirow{2}{*}{$\begin{array}{c}\text { Evaluation } \\
(\%)\end{array}$} & \multicolumn{3}{|c|}{ Model "A" } & \multicolumn{3}{c|}{ Model "B" } \\
\cline { 2 - 7 } & Normal & Inverse & Normal $\cap$ Inverse & Normal & Inverse & Normal $\cap$ Inverse \\
\hline TP Rate & 21.1 & 93.5 & 72.9 & 78.0 & 91.5 & 96.6 \\
\hline FP Rate & 0 & 78.0 & 0 & 20.0 & 74.0 & 45.5 \\
\hline Type I Error & 0 & 78.0 & 0 & 20.0 & 74.0 & 45.5 \\
\hline Type II Error & 78.9 & 6.5 & 27.1 & 22.0 & 8.5 & 3.4 \\
\hline Success Rate & 28.7 & 88.4 & 75.0 & 78.2 & 86.9 & 96.6 \\
\hline Unclassified & 27.9 & 0 & 80.0 & 52.2 & 0 & 56.3 \\
\hline
\end{tabular}

To reduce the occurrence of unclassified DMUs, two serial approaches were tested. The first strategy involved predicting with normal scores as before (active if $0.7 \leq \zeta \leq 1$; 
bankrupt if $0 \leq \zeta<0.4$; and unclassified if $0.4 \leq \zeta<0.7$ ), then sorting any unclassified DMUs by their inverse scores (Figure 9.11). For both "A" and "B", serial classification (Normal $\rightarrow$ Inverse) outperformed normal models in all categories except Type I error (Table 9.10). This is because the subsequent prediction (by inverse scores) of DMUs unclassified (according to normal scores) tended towards active classification (n.b. recall that $90 \%$ of inverse scores were less than 0.1).

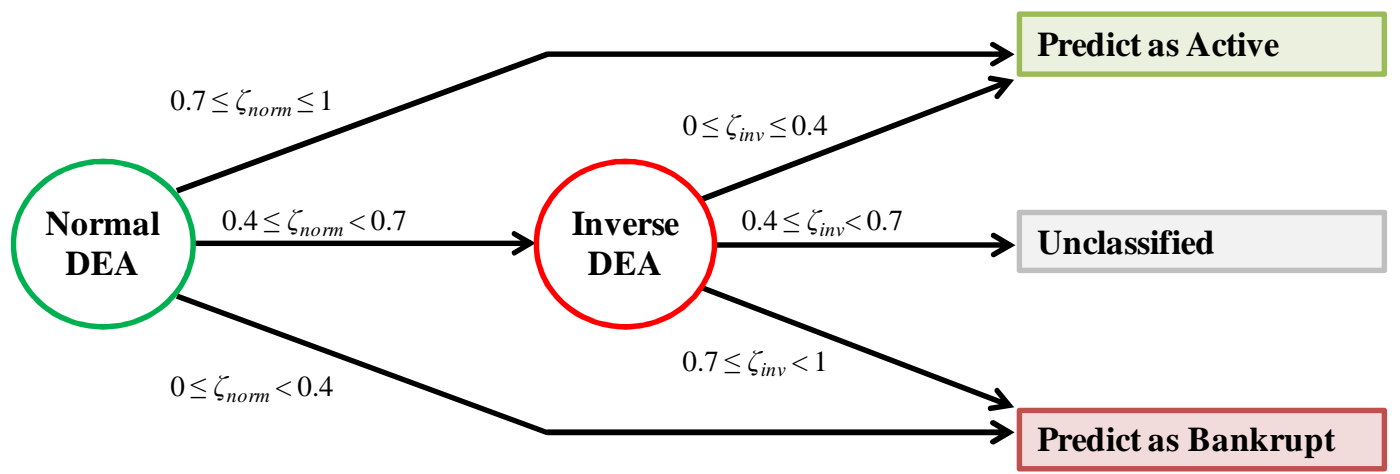

Figure 9.11: Serial Classification (Normal then Inverse DEA)

Table 9.10: Serial Classification of Models " $A$ " and " $B$ " (Normal then Inverse DEA) A DMU was predicted bankrupt up to 3 years prior to filing Chapter 11.

\begin{tabular}{|l|c|c|c|c|}
\hline \multirow{2}{*}{$\begin{array}{c}\text { Evaluation } \\
(\%)\end{array}$} & \multicolumn{2}{|c|}{ Model “A" } & \multicolumn{2}{c|}{ Model "B" } \\
\cline { 2 - 5 } & Normal & Normal $\rightarrow$ Inverse & Normal & Normal $\rightarrow$ Inverse \\
\hline TP Rate & 21.1 & 43.5 & 78.0 & 92.6 \\
\hline FP Rate & 0 & 2.0 & 20.0 & 62.0 \\
\hline Type I Error & 0 & 2.0 & 20.0 & 62.0 \\
\hline Type II Error & 78.9 & 56.2 & 22.0 & 7.4 \\
\hline Success Rate & 28.7 & 47.6 & 78.2 & 88.7 \\
\hline Unclassified & 27.9 & 0 & 52.2 & 0 \\
\hline
\end{tabular}

The second type of serial classification ordered DMUs by their inverse scores first (bankrupt if $0.7 \leq \zeta \leq 1$; active if $0 \leq \zeta<0.4$; and unclassified if $0.4 \leq \zeta<0.7$ ), then sorted those unclassified by their normal scores (Figure 9.12). For both "A" and "B", serial classification (Inverse $\rightarrow$ Normal) performed identically to inverse models alone (Table 9.11). This is because all DMUs were already classified by the inverse model, making subsequent prediction by normal scores obsolete. 


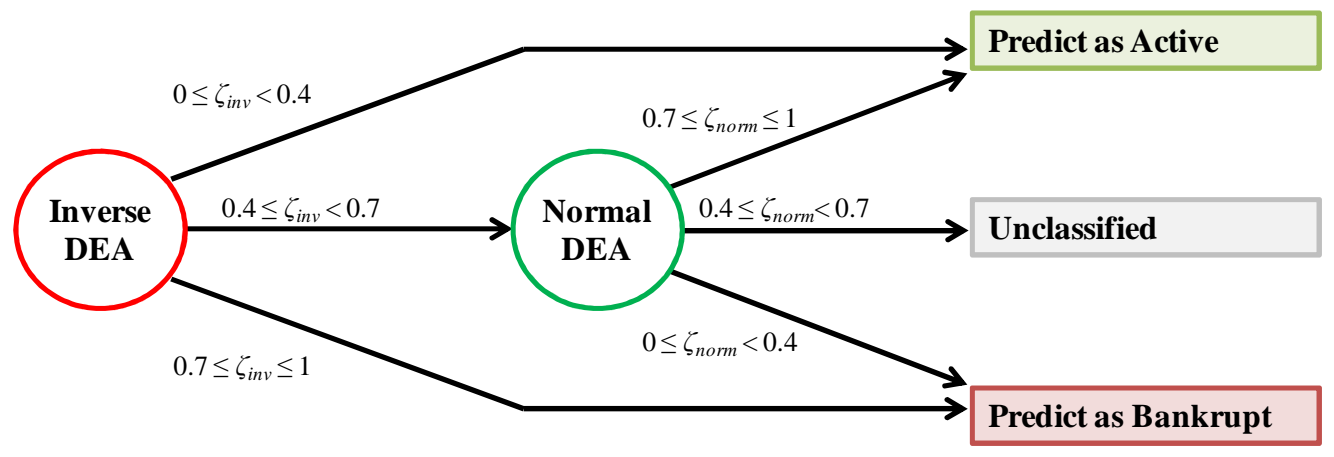

Figure 9.12: Serial Classification (Inverse then Normal DEA)

Table 9.11: Serial Classification of Models " $A$ " and " $B$ " (Inverse the Normal DEA) A DMU was predicted bankrupt up to 3 years prior to filing Chapter 11.

\begin{tabular}{|l|c|c|c|c|}
\hline \multirow{2}{*}{$\begin{array}{c}\text { Evaluation } \\
(\%)\end{array}$} & \multicolumn{2}{|c|}{ Model "A" } & \multicolumn{2}{c|}{ Model "B" } \\
\cline { 2 - 5 } TP Rate & Inverse & Inverse $\rightarrow$ Normal & Inverse & Inverse $\rightarrow$ Normal \\
\hline FP Rate & 93.5 & 93.5 & 91.5 & 91.5 \\
\hline Type I Error & 78.0 & 78.0 & 74.0 & 74.0 \\
\hline Type II Error & 6.5 & 78.0 & 74.0 & 74.0 \\
\hline Success Rate & 88.4 & 6.5 & 8.5 & 8.5 \\
\hline Unclassified & 0 & 88.4 & 86.9 & 86.9 \\
\hline
\end{tabular}

\subsection{Insolvency Metrics}

In addition to creating metrics that reflect profitability, sets of variables commonly used to measure insolvency were also tested. Because of their similarity, the results of one metric only, denoted "C" are discussed (Figure 9.13). This worst-practice model had one output (IE) and two inputs (CFO, EBIT). Like inverse models, a DMU with a score $\zeta$ was predicted active if $0 \leq \zeta<0.4$ or bankrupt if $0.7 \leq \zeta \leq 1$. If $0.4 \leq \zeta<0.7$, then it was unclassified. Generally, worst-practice models were ineffective at prediction because nearly $95 \%$ of DMUs had scores less than 0.1, making the separation of active and bankrupt DMUs difficult. Consequently, Type I error was high. And while the success rate was high, it was misleading given the high ratio of active to bankrupt DMUs.

Moreover, insolvency metric "C" was combined with profitability metrics "A" and "B" using both parallel and serial classification techniques (Table 9.12, Table 9.13 and Table 9.14). Noting that "C" was similar to the inverses of "A" and "B", when it was combined with normal "A" and "B", prediction did not improve. Hence, worst-practice DEA was not applied in this thesis beyond this exercise. 


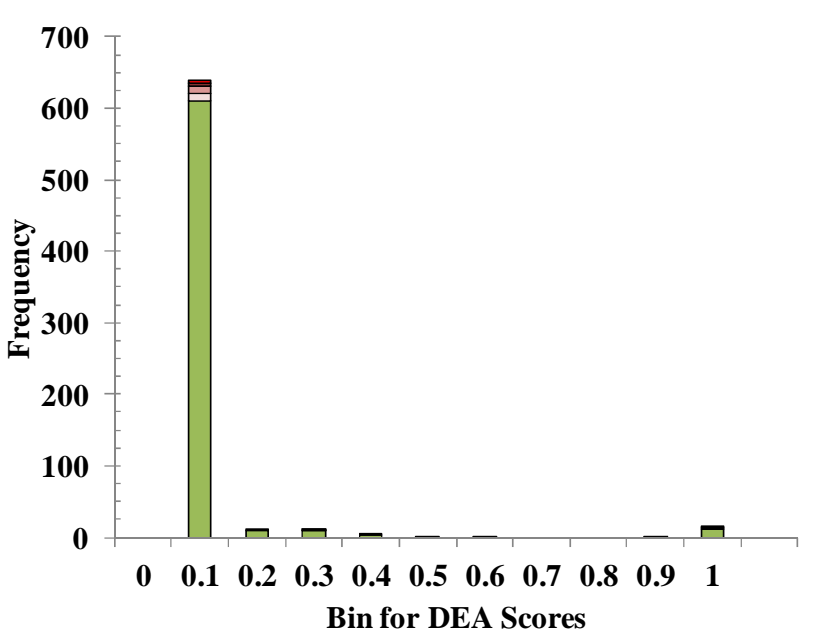

Metric "C" (Worst-

Practice DEA)

$\square$ Bankrupt

$\square 1$ Year Prior to Bankruptcy

$\square 2$ Years Prior to Bankruptcy

$\square 3$ Years Prior to Bankruptcy

$\square$ Active

Figure 9.13: Summary of Solvency Worst-Practice Model "C"

A DMU was predicted bankrupt up to 3 years prior to filing Chapter 11.

Table 9.12: Parallel Classification of Normal and Worst-Practice Models A DMU was predicted bankrupt up to 3 years prior to filing Chapter 11.

\begin{tabular}{|c|c|c|c|c|c|c|}
\hline \multirow{2}{*}{$\begin{array}{c}\text { Evaluation } \\
(\%)\end{array}$} & \multicolumn{3}{|c|}{ Normal "A" $\cap$ Worst-Practice "C" } & \multicolumn{3}{|c|}{ Normal "B" $\cap$ Worst-Practice "C" } \\
\hline & "A" & "C" & "A" $\cap$ "C" & "B" & "C" & "B" $\cap$ "C"' \\
\hline TP Rate & 21.1 & 98.1 & 92.2 & 78.0 & 98.1 & 98.4 \\
\hline FP Rate & 0 & 91.5 & 0 & 20.0 & 91.5 & 75.0 \\
\hline Type I Error & 0 & 91.5 & 0 & 20.0 & 91.5 & 75.0 \\
\hline Type II Error & 78.9 & 1.9 & 7.8 & 22.0 & 1.9 & 1.6 \\
\hline Success Rate & 28.7 & 92.1 & 92.5 & 78.2 & 92.1 & 96.5 \\
\hline Unclassified & 27.9 & 0.9 & 84.7 & 52.2 & 0.9 & 54.6 \\
\hline
\end{tabular}

Table 9.13: Serial Classification of Normal then Worst-Practice Models A DMU was predicted bankrupt up to 3 years prior to filing Chapter 11 .

\begin{tabular}{|c|c|c|c|c|}
\hline \multirow{2}{*}{$\begin{array}{c}\text { Evaluation } \\
(\%)\end{array}$} & \multicolumn{2}{|c|}{ Normal "A" $\rightarrow$ Worst-Practice "C $C$ " } & \multicolumn{2}{|c|}{ Normal "B" $\rightarrow$ Worst-Practice "C" } \\
\hline & "A" & "A'" $\rightarrow$ "CC" & "B" & "B' $\rightarrow$ "CC' \\
\hline TP Rate & 21.1 & 44.1 & 78.0 & 95.4 \\
\hline FP Rate & 0 & 2.0 & 20.0 & 68.1 \\
\hline Type I Error & 0 & 2.0 & 20.0 & 68.1 \\
\hline Type II Error & 78.9 & 55.9 & 22.0 & 4.6 \\
\hline Success Rate & 28.7 & 47.9 & 78.2 & 91.1 \\
\hline Unclassified & 27.9 & 0 & 52.2 & 0.9 \\
\hline
\end{tabular}

Table 9.14: Serial Classification of Worst-Practice then Normal Models A DMU was predicted bankrupt up to 3 years prior to filing Chapter 11 .

\begin{tabular}{|l|c|c|c|c|}
\hline \multirow{2}{*}{$\begin{array}{c}\text { Evaluation } \\
(\%)\end{array}$} & \multicolumn{2}{|c|}{ Worst-Practice "C" $\rightarrow$ Model "A" } & \multicolumn{2}{c|}{ Worst-Practice "C" $\rightarrow$ Model "B" } \\
\cline { 2 - 5 } & "C" & "C" $\rightarrow$ "A" & "C" & "C" $\rightarrow$ "'B" \\
\hline TP Rate & 98.1 & 97.7 & 98.1 & 98.1 \\
\hline FP Rate & 91.5 & 86.0 & 91.5 & 91.5 \\
\hline Type I Error & 91.5 & 86.0 & 91.5 & 91.5 \\
\hline Type II Error & 1.9 & 2.3 & 1.9 & 1.9 \\
\hline Success Rate & 92.1 & 91.7 & 92.1 & 92.1 \\
\hline Unclassified & 0.9 & 0 & 0.9 & 0.9 \\
\hline
\end{tabular}




\subsection{Summary of Preliminary Models}

The preliminary models of Sections 9.1 to 9.4 provided valuable insight that was essentially referenced to develop more comprehensive and complex prediction models in this thesis. The lessons learned were:

- Normal models yielded lower Type I errors and higher overall success rates.

- Inverse models produced lower Type II errors and fewer unclassified DMUs.

- Normal and inverse models were not necessarily consistent.

- When combining normal and inverse scores, the weaknesses of each model were improved but at the expense of reducing their strengths. In other words, parallel and serial classification simply "averaged" the performance of normal and inverse models.

- Worst-practice models were similar in distribution to inverse models, having low Type II errors but high Type I errors.

Ultimately, all modelling (from this point forward) was based on normal DEA only in order to focus on lowering Type I errors, which are more costly than Type II errors. 


\section{Financial Statement and Managerial Decision-Making Models: Results and Discussion}

While most studies focus on measuring profitability and/or insolvency, a different approach was taken in this thesis: creating individual metrics that reflect a particular aspect of an annual report. All DEA models in this and subsequent chapters were SBM and the scores generated were based on a normal frontier.

\subsection{Income Statement Metric}

The metric (IS) based on the income statement included 4 inputs (COGS, ITE, Net IE, SGA) and 2 outputs (NI and Rev). Results from classification by zones ${ }^{21}$ (Figure 10.1) show IS performed similarly to profitability metric "B" because they shared common variables. However, IS may be a better predictor: reducing Type I error (from 23\% to 12\%) and the unclassified rate (from $47 \%$ to $21 \%$ ) while increasing Type II error (from $20 \%$ to $32 \%$ ). Benchmarking against Altman's model, IS lowered Type I error by 85\% but doubled Type II error.

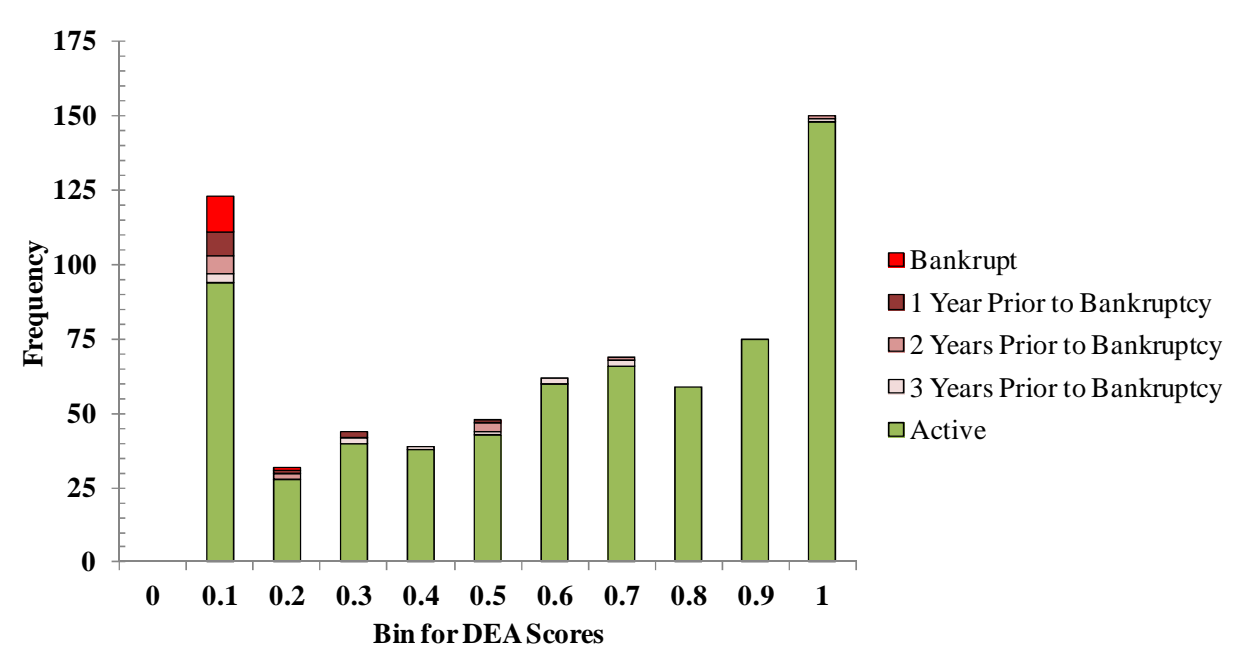

IS Metric (Normal DEA)

Outputs:

NI, Rev

Inputs:

COGS, ITE, Net IE, SGA

Kurtosis: -1.26

Skewness: -0.29

\begin{tabular}{|l|r|}
\hline \multicolumn{1}{|c|}{ Evaluation } & \% \\
\hline TP Rate & 68.2 \\
\hline FP Rate & 11.9 \\
\hline Type I Error & 11.9 \\
\hline Type II Error & 31.8 \\
\hline Success Rate & 69.7 \\
\hline Unclassified & 21.3 \\
\hline
\end{tabular}

Figure 10.1: Summary of Income Statement (IS) Metric A DMU was predicted bankrupt up to 3 years prior to filing Chapter 11.

In addition, classification by layering was applied (Sections 8.1.2). For prediction from one year back, Figure 10.2 shows how Type I and II errors, and active and bankruptcy

\footnotetext{
${ }^{21}$ A DMU with a score $\zeta$ was predicted bankrupt if $0 \leq \zeta<0.4$ or active if $0.7 \leq \zeta \leq 1$, or remained unclassified if $0.4 \leq \zeta<$ 0.7 .
} 
classifications $^{22}$, changed with each subsequent layer. Recall that a goal was to create a metric with a layer where both of its errors (red curves) were less than (below) Altman's model (blue lines). The effectiveness of each model developed in this thesis was determined by this measure.

There were trade-offs between Type I and II errors, and accurate classifications of active and bankrupt DMUs. After the first run, bankruptcy classification and Type II error were at their maximum whereas active classification and Type I error were at their minimum. With each subsequent peel, bankruptcy prediction worsened (Type I error rose) and active prediction improved (Type II error fell). The lines intersected after roughly 3 runs, suggesting that at its best, IS predicted all DMUs 58\% correctly. This error rate was identical to that of Altman's model. Finally, when attempts at classification started from two and three years back (Appendix F.2), the model was less accurate and errors increased.

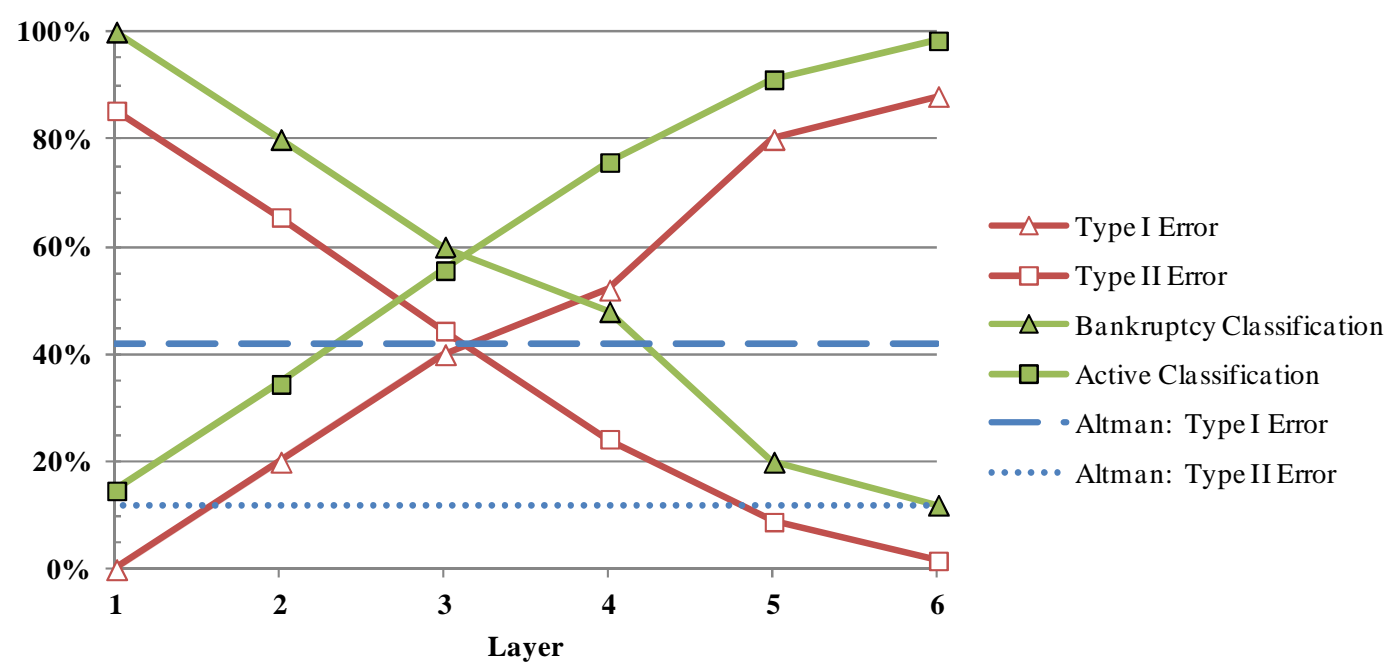

Figure 10.2: Prediction by IS Metric from One Year Back

A DMU was predicted bankrupt up to a year prior to filing Chapter 11.

\subsection{Balance Sheet Metrics}

Because of the abundance of variables on the balance sheet, two metrics were created reflecting assets and liabilities separately.

Figure 10.3 summarizes the results from classification by zones ${ }^{23}$ reflecting assets (BSA) with 8 inputs (AR, CA, Goodwill, Inv, MS, Net PPE, LTIS, TA) and 3 outputs (Cash,

${ }^{22}$ Active classification $=100 \%-$ Type II error; Bankruptcy classification $=100 \%-$ Type I error

${ }^{23}$ A DMU with a score $\zeta$ was predicted bankrupt if $0 \leq \zeta<0.4$ or active if $0.7 \leq \zeta \leq 1$, or remained unclassified if $0.4 \leq \zeta<$ 0.7 . 
RE, SE). BSA performed similarly to profitability metric "A", and compared to Altman's model, it reduced Type I error by three times but with over six times more Type II error. Furthermore, Figure 10.4 shows the effectiveness of the prediction by layering from one year back (see Appendix F.3 for two and three years back). The intersections after 4 peels reveal that BSA correctly classified $78 \%, 72 \%$ and $70 \%$ of all DMUs, when attempting prediction one, two and three year(s) back, respectively - all better than Altman's model.

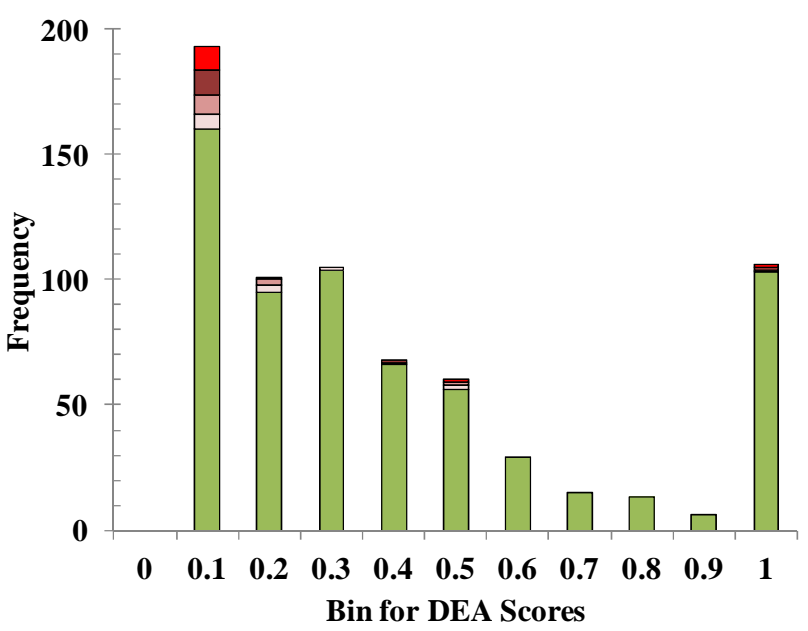

BSA Metric (Normal DEA)

$\square$ Bankrupt

$\checkmark 1$ Year Prior to Bankruptcy

$\square 2$ Years Prior to Bankruptcy

$\square 3$ Years Prior to Bankruptcy

$\square$ Active
Outputs:

Cash, RE, SE

Inputs:

AR, CA, Goodwill, Inv, MS, Net PPE, LTIS, TA

Kurtosis: -0.39

Skewness: 0.93

\begin{tabular}{|l|r|}
\hline \multicolumn{1}{|c|}{ Evaluation } & \multicolumn{1}{|c|}{ \% } \\
\hline TP Rate & 22.3 \\
\hline FP Rate & 6.7 \\
\hline Type I Error & 6.7 \\
\hline Type II Error & 77.7 \\
\hline Success Rate & 27.7 \\
\hline Unclassified & 21.0 \\
\hline
\end{tabular}

Figure 10.3: Summary of Balance Sheet Assets (BSA) Metric A DMU was predicted bankrupt up to 3 years prior to filing Chapter 11 .

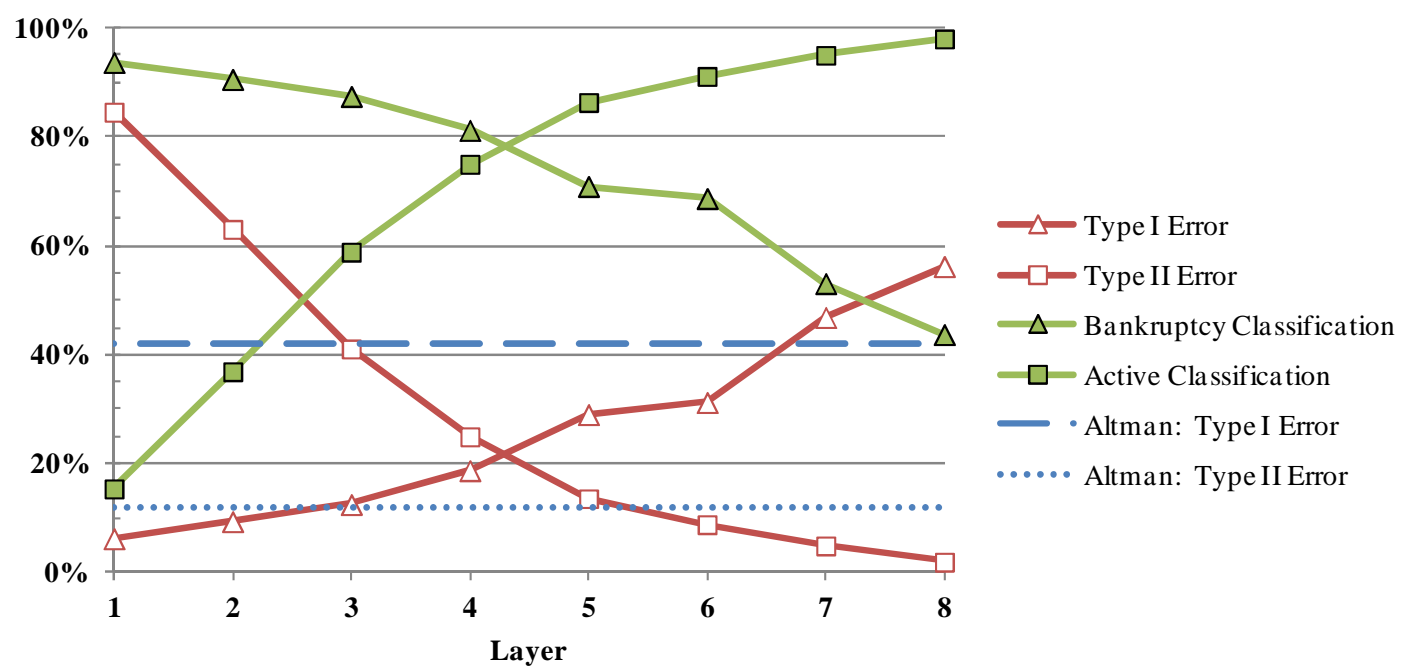

Figure 10.4: Prediction by BSA Metric from One Year Back A DMU was predicted bankrupt up to a year prior to filing Chapter 11. 
Figure 10.5 summarizes the results from classification by zones ${ }^{24}$ reflecting liabilities (BSL) with 6 inputs (AP, CL, CM, LTD, NPSTD, TL) and 2 outputs (RE, SE). BSL performed like profitability metric "A", having zero Type I error. The effectiveness of prediction by layering from one year back is presented in Figure 10.6 (see Appendix F.4 for two and three years back). With 7 peels, BSL correctly classified $78 \%, 72 \%$ and $70 \%$ of all DMUs when attempting prediction one, two and three year(s) back, respectively - an improvement over Altman's model.

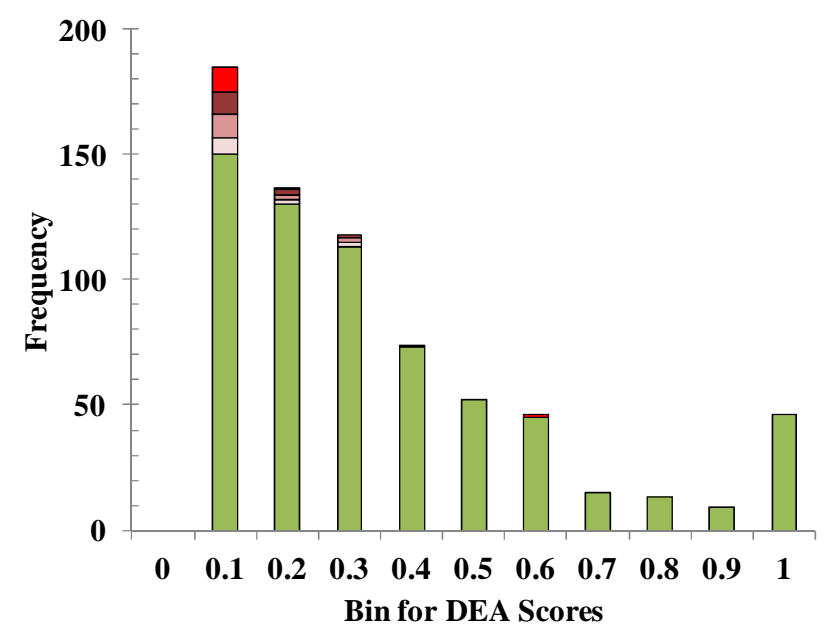

BSL Metric (Normal DEA)

$\square$ Bankrupt

$\square 1$ Year Prior to Bankruptcy

$\square 2$ Years Prior to Bankruptcy

$\square 3$ Years Prior to Bankruptcy

$\square$ Active
Outputs:

RE, SE

Inputs:

AP, CL, CM, LTD,

NPSTD, TL

Kurtosis: 0.83

Skewness: 1.20

\begin{tabular}{|l|r|}
\hline \multicolumn{1}{|c|}{ Evaluation } & \multicolumn{1}{|c|}{$\%$} \\
\hline TP Rate & 12.7 \\
\hline FP Rate & 0 \\
\hline Type I Error & 0 \\
\hline Type II Error & 87.3 \\
\hline Success Rate & 19.9 \\
\hline Unclassified & 22.8 \\
\hline
\end{tabular}

Figure 10.5: Summary of Balance Sheet Liabilities (BSL) Metric A DMU was predicted bankrupt up to 3 years prior to filing Chapter 11.

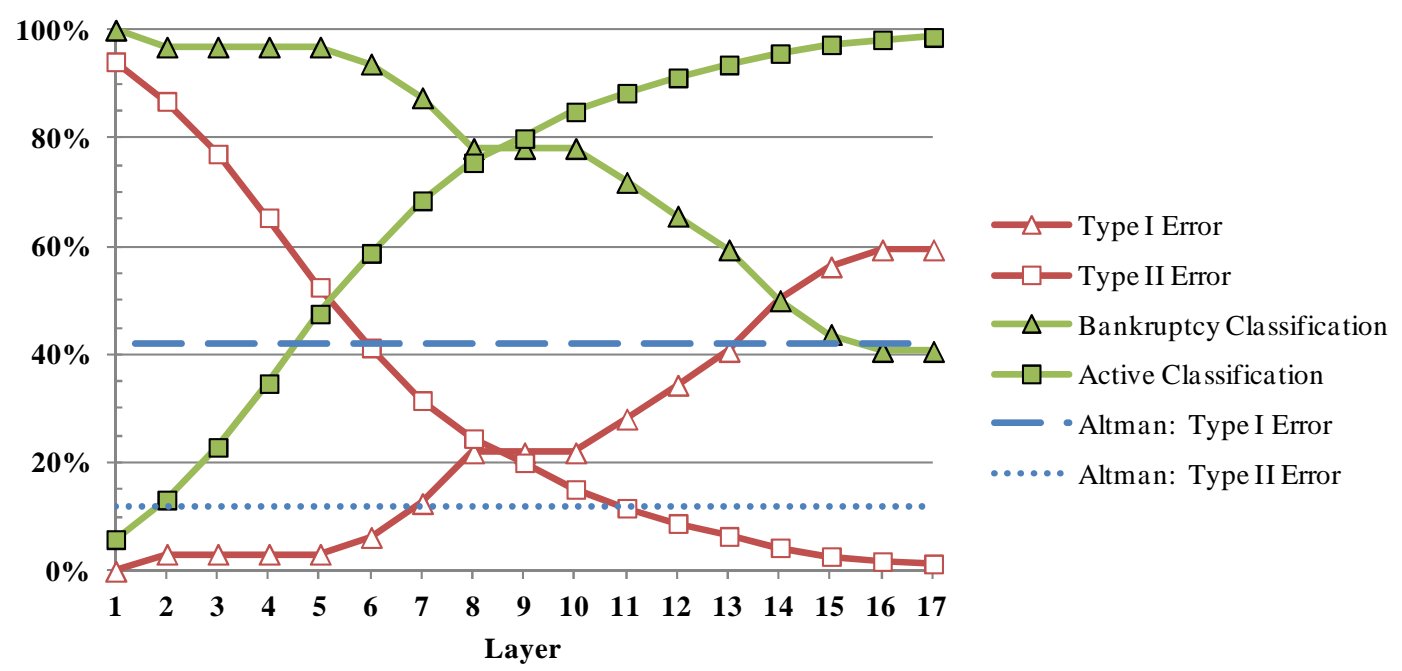

Figure 10.6: Prediction by BSL Metric from One Year Back A DMU was predicted bankrupt up to a year prior to filing Chapter 11.

\footnotetext{
${ }^{24}$ A DMU with a score $\zeta$ was predicted bankrupt if $0 \leq \zeta<0.4$ or active if $0.7 \leq \zeta \leq 1$, or remained unclassified if $0.4 \leq \zeta<$ 0.7
} 


\subsection{Cash Flow Statement Metric}

Three variables from the cash flow statement were considered: cash flow from operating activities (CFO), cash flow from investing activities (CFI), and cash flow from financing activities (CFF). Defining their orientation was a challenge because the sign (positive or negative) of these variables typically indicate different stages of company's life cycle as opposed to good or poor health (Figure 10.7). Since firms in this sample studied were publicly traded, it was assumed that they were more "mature". Thus, good health was associated with positive CFO, positive CFI and negative CFF (and were outputs in DEA) while poor health was linked to negative CFO, negative CFI and positive CFF (inputs). However, after applying this orientation of variables to DEA, no reliable metric was produced from the cash flow statement. In fact, the distribution of scores mimicked that of inverse and worst-practice DEA models (Figure 9.6, Figure 9.7 and Figure 9.13).

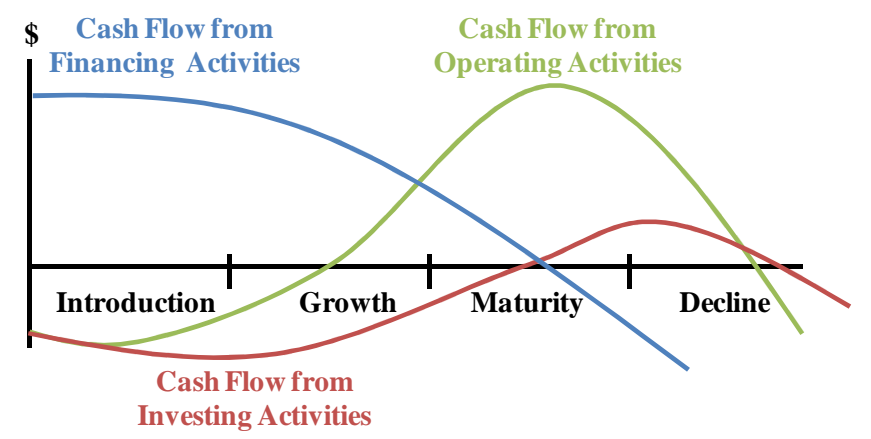

Figure 10.7: Cash Flows in Product Life Cycle (Stickney et al., 2007)

\subsection{Managerial Decision-Making Metric}

Figure 10.8 presents the results from classification by zones ${ }^{25}$ reflecting managerial decisionmaking (MDM) with 6 inputs (auditors' opinion, auditor turnover, legal proceedings, management turnover, related parties and retirement plans, Table 6.19) and a unit output. MDM had the lowest Type II error but a high Type I error. Figure 10.9 plots the results from the prediction by layering from one year back (see Appendix F.5 for two and three years back). With 2 peels, it correctly classified $65 \%, 63 \%$ and $61 \%$ of all DMUs when attempting prediction one, two and three year(s) prior, respectively.

\footnotetext{
${ }^{25}$ A DMU with a score $\zeta$ was predicted bankrupt if $0 \leq \zeta<0.4$ or active if $0.7 \leq \zeta \leq 1$, or remained unclassified if $0.4 \leq \zeta<$ 0.7 .
} 
MDM Metric (Normal DEA)

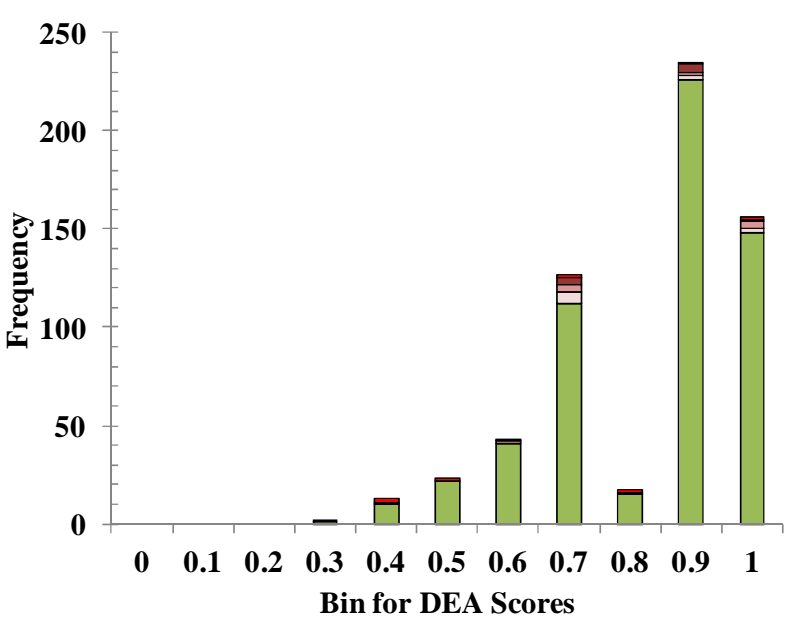

$\square$ Bankrupt

$\square$ Year Prior to Bankruptcy

$\square 2$ Years Prior to Bankruptcy

$\square 3$ Years Prior to Bankruptcy

$\square$ Active
Outputs:

Dummy

Inputs:

Auditors' Opinion, Auditor Turnover, Legal

Proceedings, Management

Turnover, Related Parties,

Retirement Plans

Kurtosis: -0.05

Skewness: -0.58

\begin{tabular}{|l|r|}
\hline \multicolumn{1}{|c|}{ Evaluation } & \multicolumn{1}{c|}{$\%$} \\
\hline TP Rate & 97.3 \\
\hline FP Rate & 82.6 \\
\hline Type I Error & 82.6 \\
\hline Type II Error & 2.8 \\
\hline Success Rate & 92.9 \\
\hline Unclassified & 15.7 \\
\hline
\end{tabular}

Figure 10.8: Summary of Managerial Decision-Making (MDM) Metric A DMU was predicted bankrupt up to 3 years prior to filing Chapter 11.

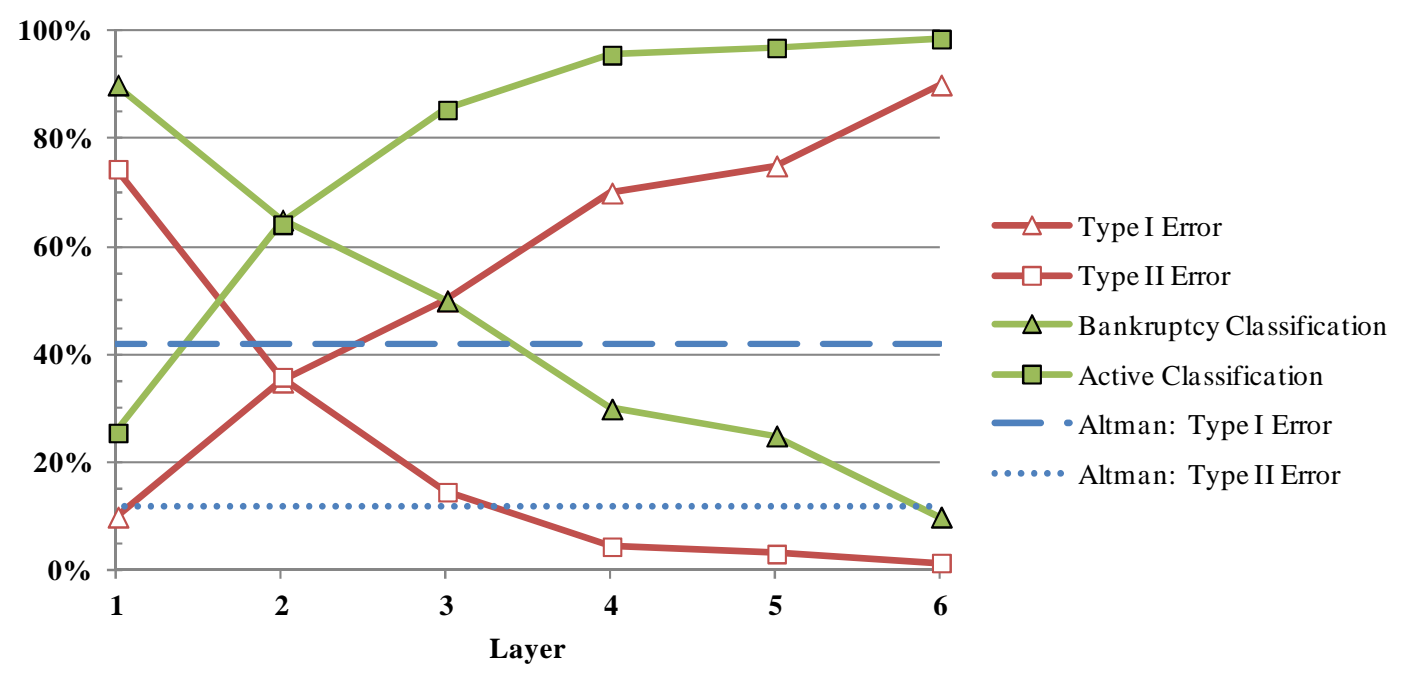

Figure 10.9: Prediction by MDM Metric from One Year Back A DMU was predicted bankrupt up to a year prior to filing Chapter 11.

\subsection{Trade Data Metric}

In addition to creating metrics with information collected from the annual report, stock performance data were considered. Specifically, for each DMU, the annual return was applied as an output while volatility and beta were inputs to DEA. However, no reliable metric could be produced because the distribution of the scores was similar to inverse and 
worst-practice DEA models (Figure 9.6, Figure 9.7 and Figure 9.13); that is, the majority of scores were less than 0.1 and offered little room for discrimination.

\subsection{Correlation between Metrics}

The correlations between scores of metrics IS, BSA, BSL and MDM after the first run were weak (Table 10.1), supporting the hypothesis that they reflect different aspects of company health and should therefore be considered altogether for a holistic view of company health.

Table 10.1: Correlation between Metrics after First Run

All correlations were significant at 0.01 level.

\begin{tabular}{|l|c|c|c|c|}
\cline { 2 - 5 } \multicolumn{1}{c|}{} & $\begin{array}{c}\text { Income } \\
\text { Statement }\end{array}$ & $\begin{array}{c}\text { Balance } \\
\text { Sheet Assets }\end{array}$ & $\begin{array}{c}\text { Balance Sheet } \\
\text { Liabilities }\end{array}$ & $\begin{array}{c}\text { Managerial } \\
\text { Decision-Making }\end{array}$ \\
\hline Income Statement & 1 & 0.49 & 0.47 & 0.14 \\
\hline Balance Sheet Assets & & 1 & 0.71 & 0.08 \\
\hline Balance Sheet Liabilities & & & 1 & 0.15 \\
\hline Managerial Decision-Making & & & & 1 \\
\hline
\end{tabular}

\subsection{The Effect of Inflation}

As mentioned in Section 6.2, all studies in bankruptcy research compare companies across different years without calibrating for the time value of money. Although creating a technique that calibrates for time is beyond the scope of this thesis, the effect of inflation was considered.

Financial statements are typically reported in actual dollars. To convert actual dollars into real dollars relative to a base year, the following formula was applied:

$$
R_{0, N}=\frac{A_{N}}{I_{0, N} / 100}
$$

where $A_{N}$ represents actual dollars in year $N$;

$R_{0, N}$ represents the real dollars equivalent to $A_{N}$ relative to a base year 0 ; and,

$I_{0, N}$ is the value of a global price index at year $N$ relative to a base year 0 .

In this thesis, the Consumer Price Index with a base 1982 of 100 . The values of all the financial variables were transformed accordingly, and the three metrics reflecting the financial statements were re-calculated. Figure 10.10, Figure 10.11 and Figure 10.12 compare IS, BSA and BSL scores based on actual (ignoring inflation) and real (adjusted for inflation) dollars, after the first run. These non-layered results show that the effect of inflation is insignificant as the correlations between results in actual and real dollars are 
strong (0.96 to 1$)$, and the evaluation measures differ by less than 5\%. Furthermore, layering results did not change when adjusted for inflation. For instance, the IS metric maintained a prediction accuracy around 58-60\% (Figure 10.2 without inflation while Figure 10.13 with inflation). The likely reason the time value of money being negligible is likely due to the fact that the objective function in DEA is fractional, thereby "dividing out" the effect of inflation.

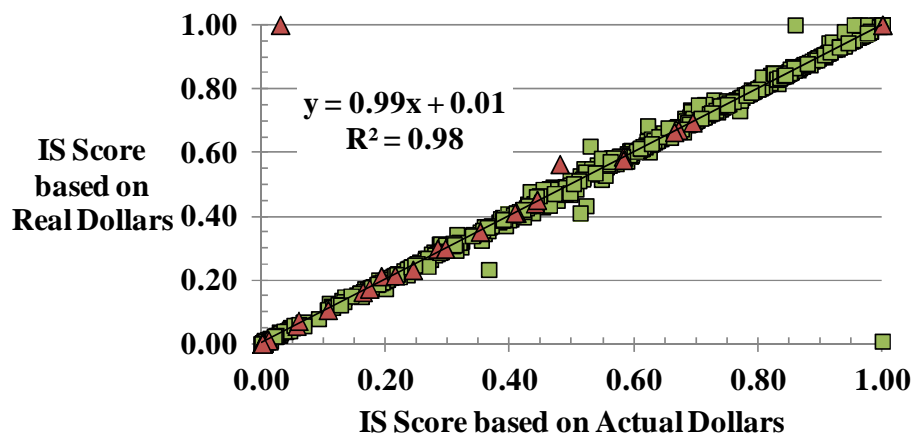

Pearson's Correlation Coefficient $\rho=0.99$ (sig. at the 0.01 level)

\begin{tabular}{|l|r|r|}
\hline \multicolumn{1}{|c|}{ Evaluation } & $\begin{array}{c}\text { Actual } \\
(\mathbf{\%})\end{array}$ & $\begin{array}{c}\text { Real } \\
(\mathbf{\%})\end{array}$ \\
\hline TP Rate & 68.2 & 68.3 \\
\hline FP Rate & 11.9 & 14.3 \\
\hline Type I Error & 11.9 & 14.3 \\
\hline Type II Error & 31.8 & 31.7 \\
\hline Success Rate & 69.7 & 69.7 \\
\hline Unclassified & 21.3 & 20.5 \\
\hline
\end{tabular}

Figure 10.10: The Effect of Inflation on IS Scores

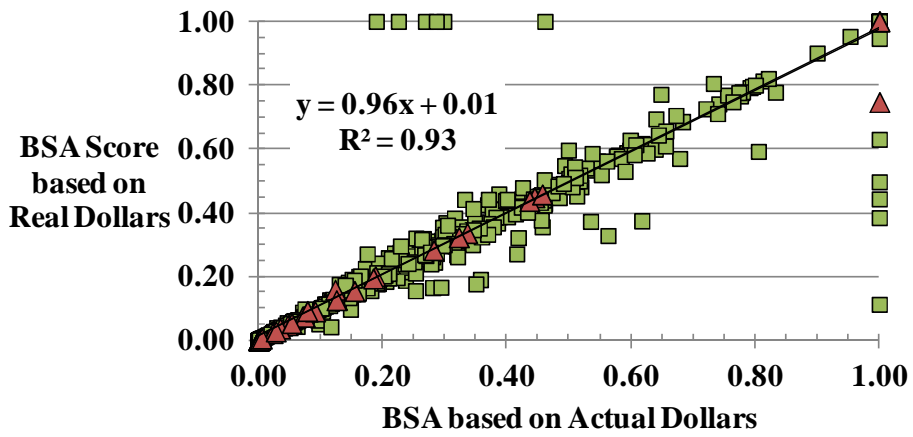

Pearson's Correlation Coefficient $\rho=0.96$ (sig. at the 0.01 level)

\begin{tabular}{|l|r|r|}
\hline \multicolumn{1}{|c|}{ Evaluation } & \multicolumn{1}{c|}{$\begin{array}{c}\text { Actual } \\
(\mathbf{\%})\end{array}$} & $\begin{array}{c}\text { Real } \\
(\mathbf{\%})\end{array}$ \\
\hline TP Rate & 22.3 & 22.6 \\
\hline FP Rate & 6.7 & 6.7 \\
\hline Type I Error & 6.7 & 6.7 \\
\hline Type II Error & 77.7 & 77.4 \\
\hline Success Rate & 27.7 & 28.0 \\
\hline Unclassified & 21.0 & 21.9 \\
\hline
\end{tabular}

Figure 10.11: The Effect of Inflation on BSA Scores

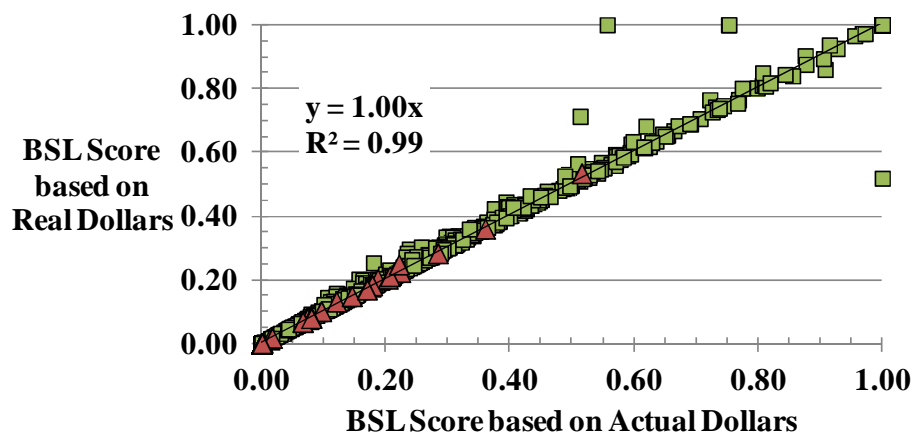

Pearson's Correlation Coefficient $\rho=0.99$ (sig. at the 0.01 level)

\begin{tabular}{|l|r|r|}
\hline \multicolumn{1}{|c|}{ Evaluation } & \multicolumn{1}{c|}{$\begin{array}{c}\text { Actual } \\
(\mathbf{\%})\end{array}$} & $\begin{array}{c}\text { Real } \\
(\mathbf{\%})\end{array}$ \\
\hline TP Rate & 12.7 & 13.2 \\
\hline FP Rate & 0 & 0 \\
\hline Type I Error & 0 & 0 \\
\hline Type II Error & 87.3 & 86.8 \\
\hline Success Rate & 19.9 & 20.5 \\
\hline Unclassified & 22.8 & 24.0 \\
\hline
\end{tabular}

Figure 10.12: The Effect of Inflation on BSL Scores 


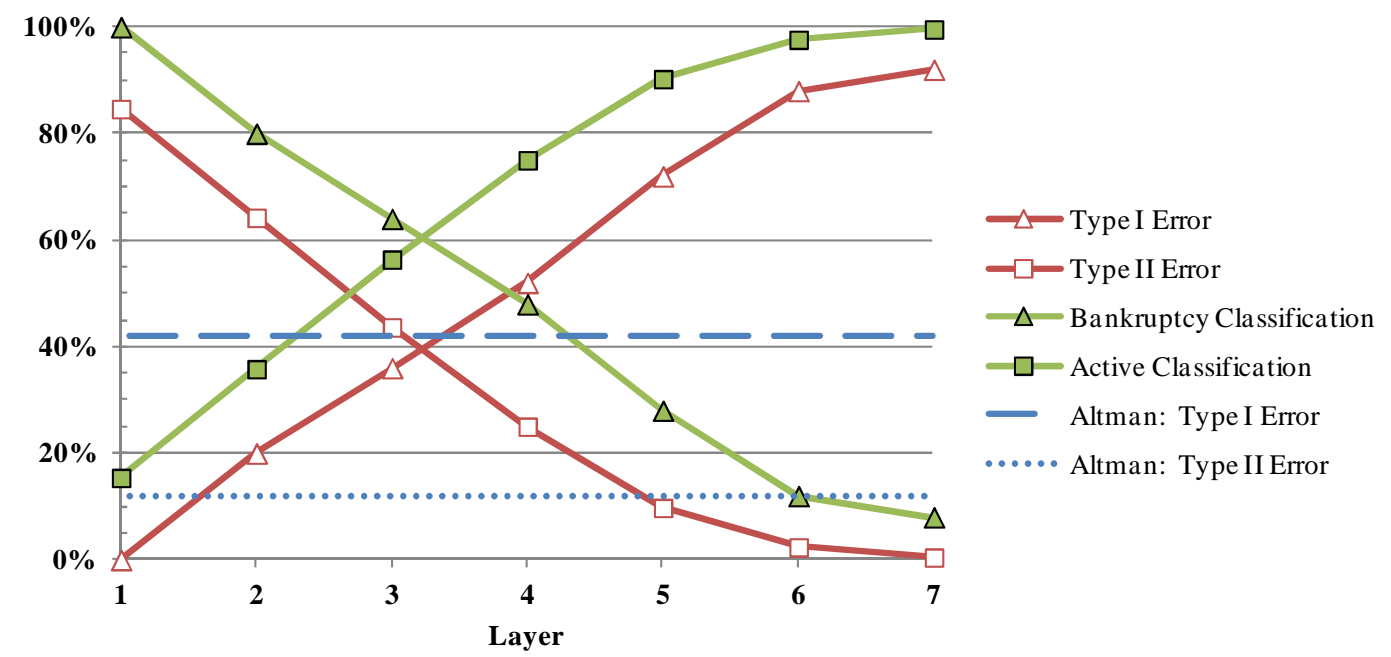

Figure 10.13 Prediction by IS Metric from One Year Back and Based on Real Dollars A DMU was predicted bankrupt up to a year prior to filing Chapter 11. 


\section{Market and Economic Factors: Results and Discussion}

Determining the relationships between financial and managerial decision-making data, and market and economic (ME) data are critical: if ME data is not inherent in financial and managerial decision-making values, then they should be added as separate variables to prediction models. Although $20 \mathrm{ME}$ factors were already selected from the original list of over 100, this set was further reduced because it outnumbered the financial and managerial decision-making variables. Specifically, aggregate indicators were created representing different aspects of the market and economy that could then be regressed with DEA scores from IS, BSA, BSL and MDM models, or used in sensitivity analysis to examine how firms react to non-controllable factors. The most common method to reduce the number of variables is factor analysis; however, the number of DMUs (i.e. years) was insufficient. As a result, a novel DEA approach was developed to create 5 new indicators reflecting the general economy, apparel industry, commodity prices, housing market, and market performance. In other words, 20 individual ME factors were used as inputs and outputs in SBM models with scores generated reflecting 5 broader categories.

\subsection{General Economic Indicator}

To create an aggregate general economic indicator, 2 inputs (unemployment rate, debt as a percentage of GDP) and 3 outputs (GDP growth rate, inflation, prime interest rate) were applied to an SBM model ${ }^{26}$. Figure 11.1 and Figure 11.2 plot the values in percentage or rate of factors on the primary $y$-axis. The factors are separated into two graphs because the range of debt as a percentage of GDP is higher (50-90\%) than that of others $(0-10 \%)$. The score generated for each year is an aggregate measure of economic performance for that given year and is represented by a black line on the secondary $y$-axis.

The strong correlations to this aggregate economic indicator (Table 11.1) proved that the reduction of five variables to one was appropriate.

\footnotetext{
${ }^{26}$ Negative values of the variable were rounded to zero as opposed to separating the variable into its positive and negative components because the latter unnecessarily creates a second variable (a negative component) with most entries equal to zero.
} 


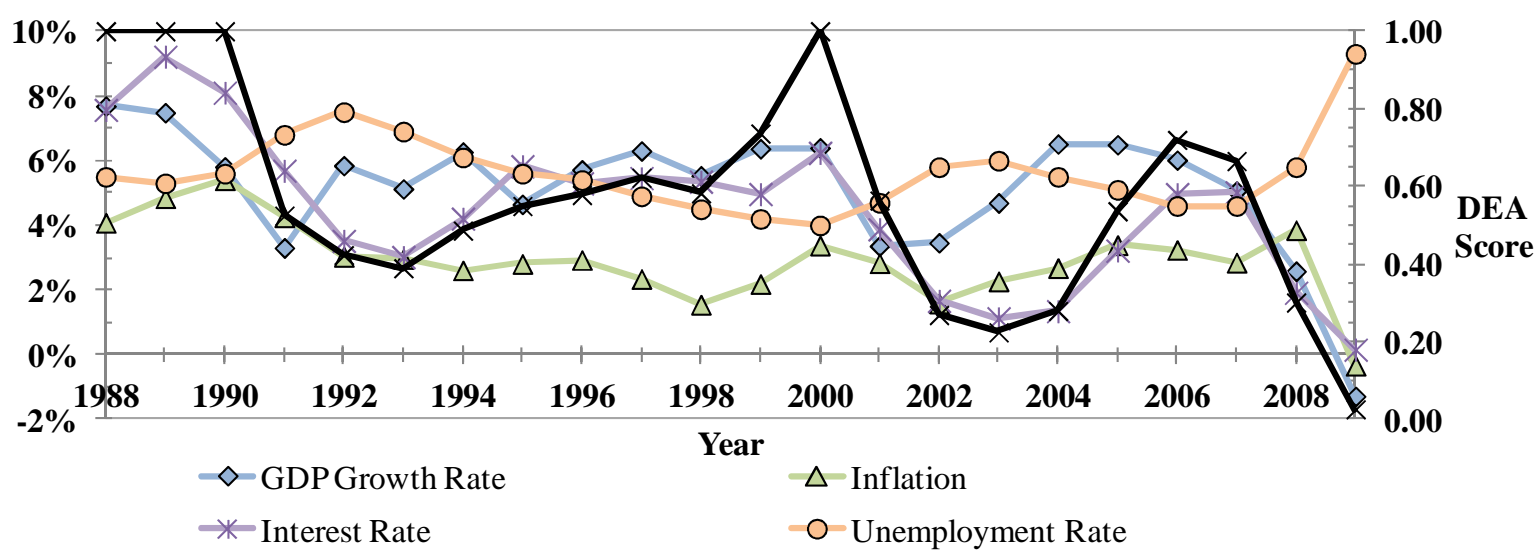

*Aggregate General Economic Indicator

Figure 11.1: General Economic Performance by Year - I

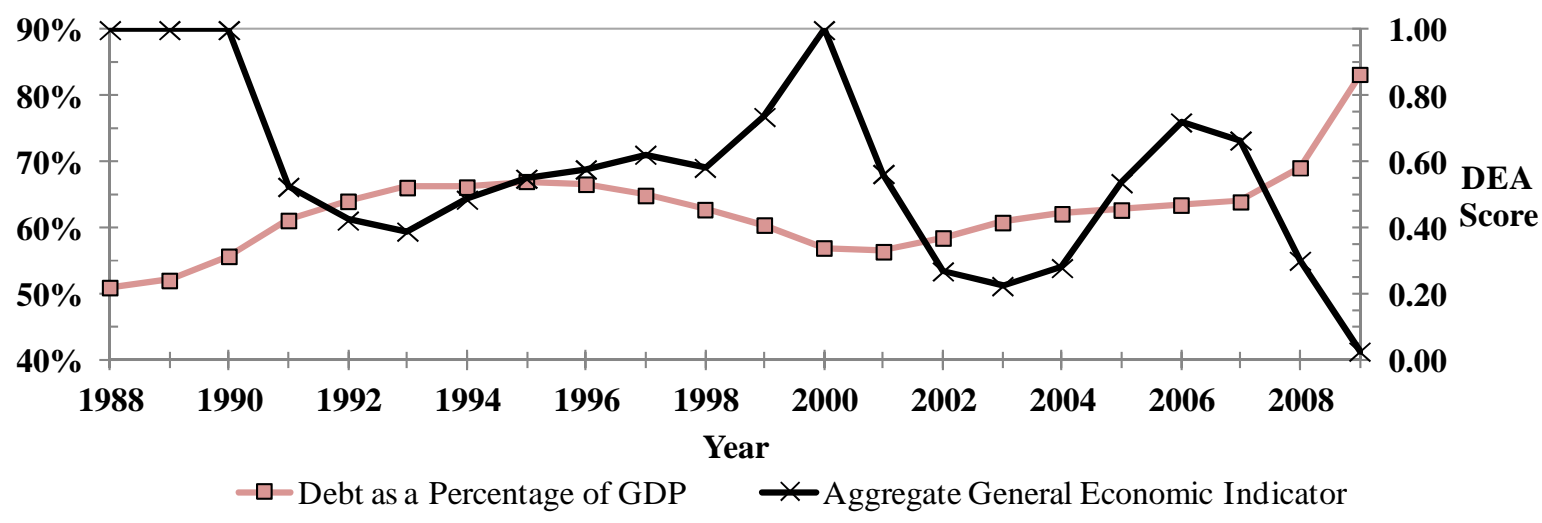

Figure 11.2: General Economic Performance by Year - II

Table 11.1: Correlations to Aggregate General Economic Indicator

\begin{tabular}{|l|c|}
\cline { 2 - 2 } \multicolumn{1}{c|}{} & Aggregate General Economic Indicator \\
\hline GDP Growth Rate & 0.69 \\
\hline Debt as Percentage of GDP & -0.72 \\
\hline Inflation & 0.68 \\
\hline Interest Rate & 0.93 \\
\hline Unemployment Rate & -0.62 \\
\hline
\end{tabular}

\subsection{Apparel Industry Indicator}

To create an aggregate apparel industry indicator, 4 outputs (personal consumption expenditures: clothing, GDP: clothing, apparel labour productivity, apparel imports) were applied with a dummy input to an SBM model (Figure 11.3). Again, the correlation between each factor and the aggregate apparel industry indicator (Table 11.2) showed that the reduction was appropriate. It is noted that not all variables reflecting the apparel industry were included. Those missing were: 
- apparel exports because the volume is much less than and relatively insignificant to imports;

- industrial production index: clothing because it is continuously increasing and thus offers little information;

- apparel unit labour cost because its relationship with the economy is unclear. It is often thought to be a predictor of inflation because it represents two-thirds of the total costs to private US businesses. At the same time, however, rising unit labour costs are associated with economic slowdown (Bureau of Labour Statistics, 2005); and,

- CPI: apparel because this industry experiences deflation, likely due to goods produced becoming increasingly cheaper offshore.

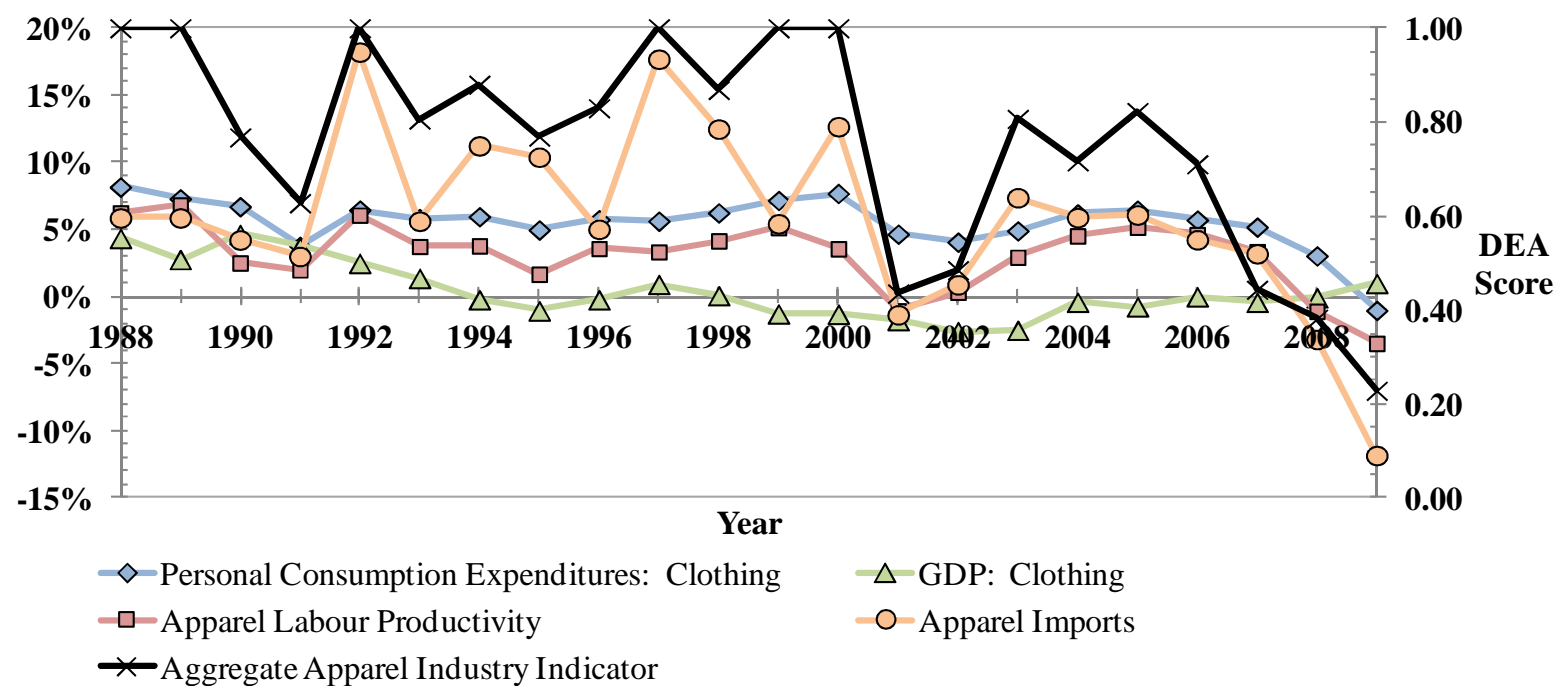

Figure 11.3: Apparel Industry Performance by Year

Table 11.2: Correlations to Aggregate Apparel Industry Indicator

\begin{tabular}{|l|c|}
\cline { 2 - 2 } \multicolumn{1}{c|}{} & Aggregate Apparel Industry Indicator \\
\hline Personal Consumption Expenditures: Clothing & 0.84 \\
\hline GDP: Clothing & 0.85 \\
\hline Apparel Labour Productivity & 0.49 \\
\hline Apparel Imports & 0.83 \\
\hline
\end{tabular}

\subsection{Housing Market Indicator}

To create an aggregate housing market indicator, one input (median months for a sale) and one output (housing units started) were applied to DEA. Figure 11.4 and Figure 11.5 plot the values of these factors which are graphed separately because their units and ranges are 
different. The strong correlations between each factor and the aggregate housing market indicator (Table 11.3) proved that the reduction was acceptable.

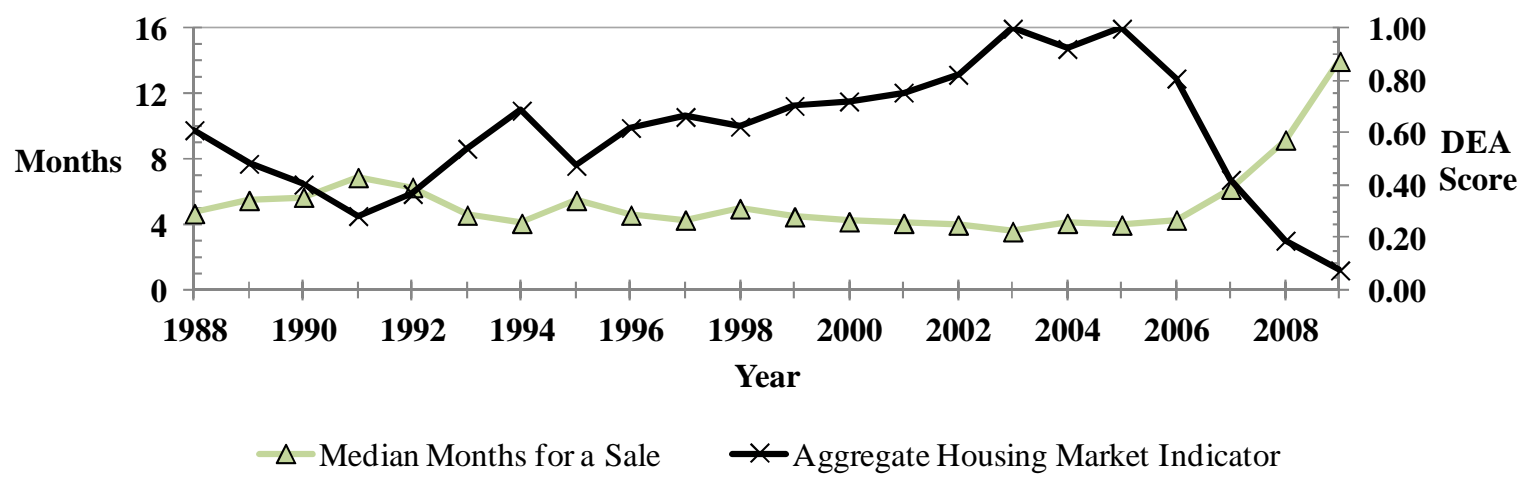

Figure 11.4: Housing Market Performance and Months for a Sale by Year

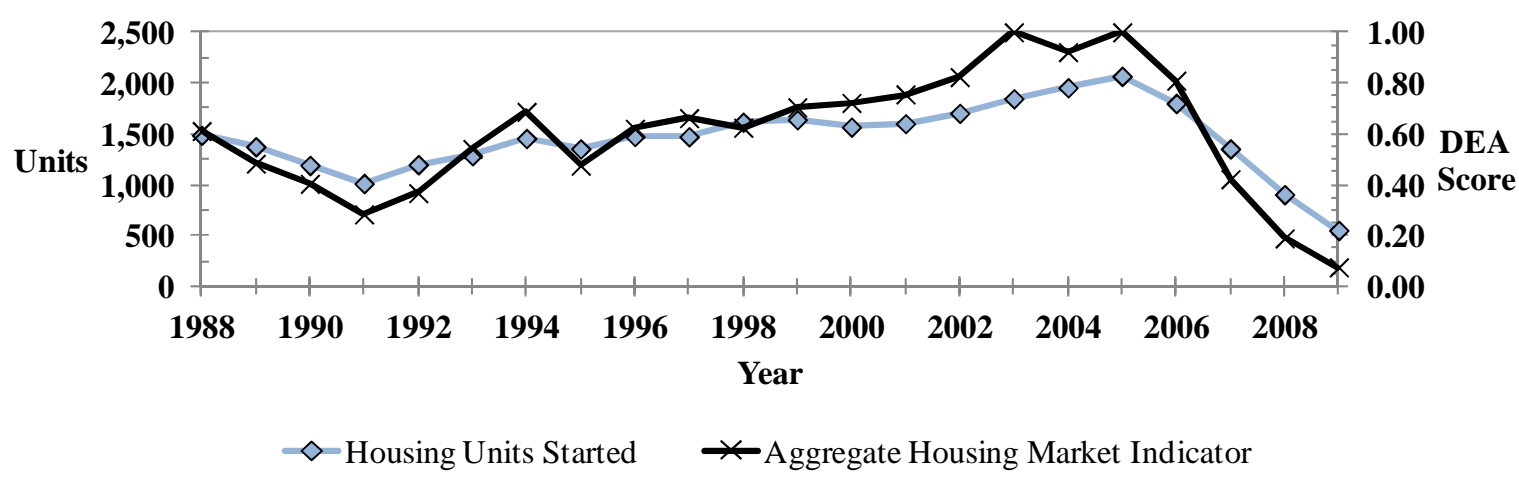

Figure 11.5: Housing Market Performance and Construction by Year

Table 11.3: Correlations to Aggregate Housing Performance Indicator

\begin{tabular}{|l|c|}
\cline { 2 - 2 } \multicolumn{1}{c|}{} & Aggregate Housing Performance Indicator \\
\hline Housing Units Started & 0.97 \\
\hline Median Months for a Sale & -0.83 \\
\hline
\end{tabular}

\subsection{Prices Indicator}

To create an aggregate prices indicator, oil and cotton prices were treated as inputs and combined with a unit output (Figure 11.6). Table 11.4 shows that positive correlations were strong for oil price but weak for cotton price. 


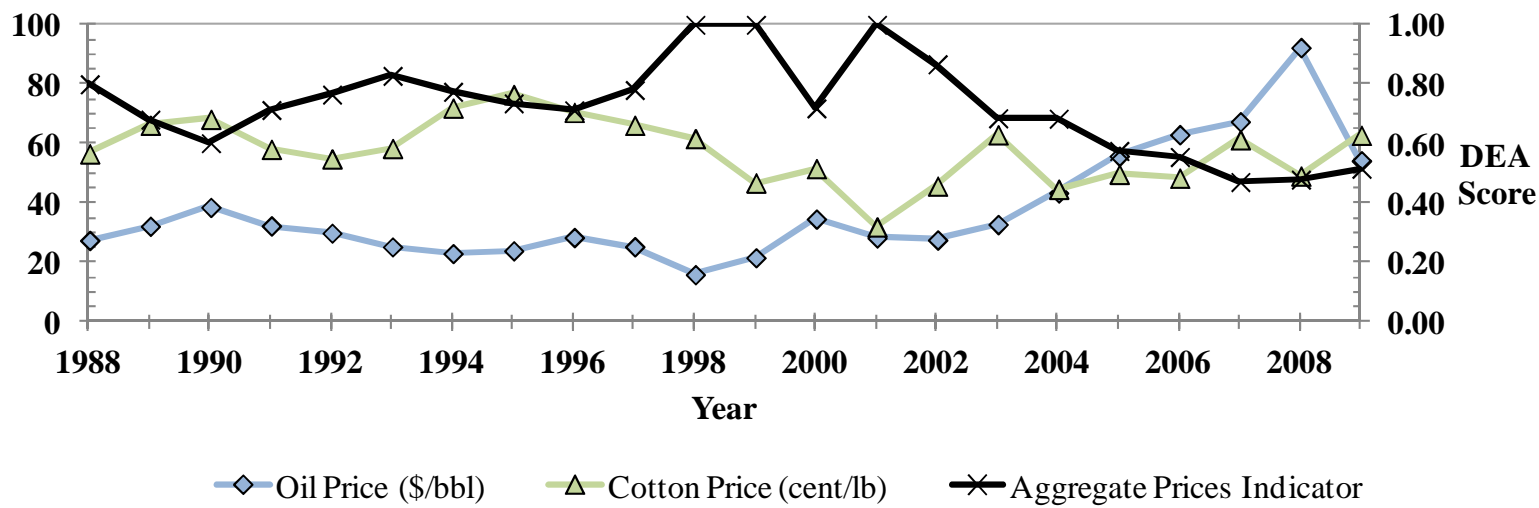

Figure 11.6: Prices by Year

Table 11.4: Correlations to Aggregate Prices Indicator

\begin{tabular}{|l|c|}
\cline { 2 - 2 } \multicolumn{1}{c|}{} & Aggregate Prices Indicator \\
\hline Oil Price $\mathbf{( \$ / b b l )}$ & -0.82 \\
\hline Cotton Price (cent//b) & -0.23 \\
\hline
\end{tabular}

\subsection{General Market Performance Indicator}

Unlike the other categories, a general market indicator was created by taking the weighted average of normalized NASDAQ and NYSE composite indices. The weights $(0.45$ and 0.55 , respectively) were based on the proportion of companies in this thesis traded on these exchanges (Section 6.7).

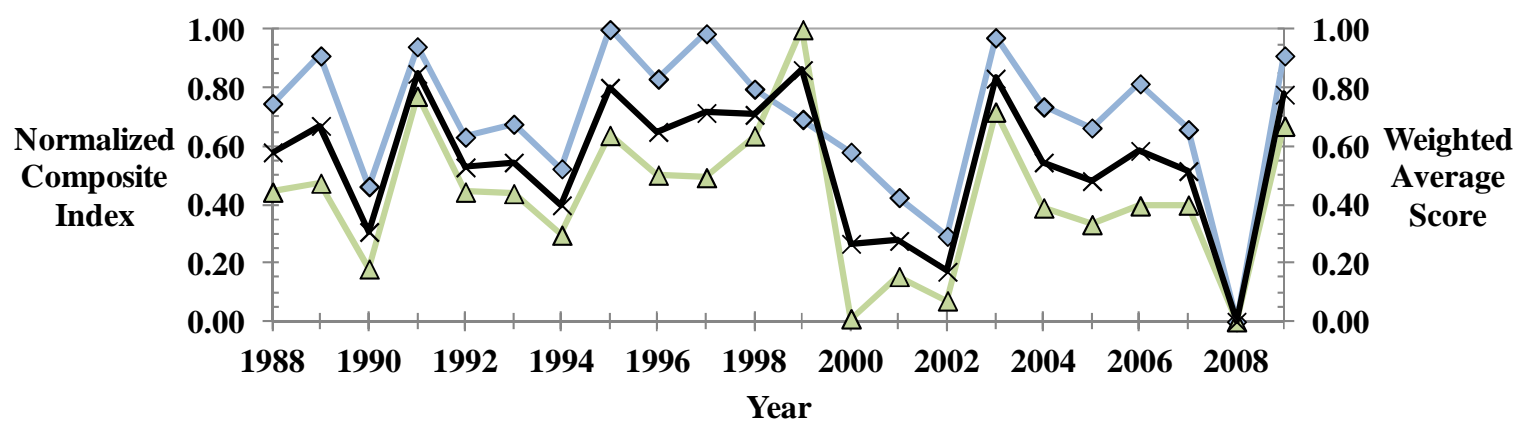

$\diamond$ Normalized NYSE $\triangle$ Normalized NASDAQ $\quad$ Aggregate (Weighted) Market Indicator

Figure 11.7: General Market Performance by Year

\subsection{All-Encompassing Market and Economic (ME) Indicator}

In summary, 20 market and economic (ME) factors were simplified to 5 aggregate indicators reflecting the general economy, apparel industry, commodity prices, housing market, and market performance. The average of these 5 aggregates was then calculated for an allencompassing ME indicator (Figure 11.8). 


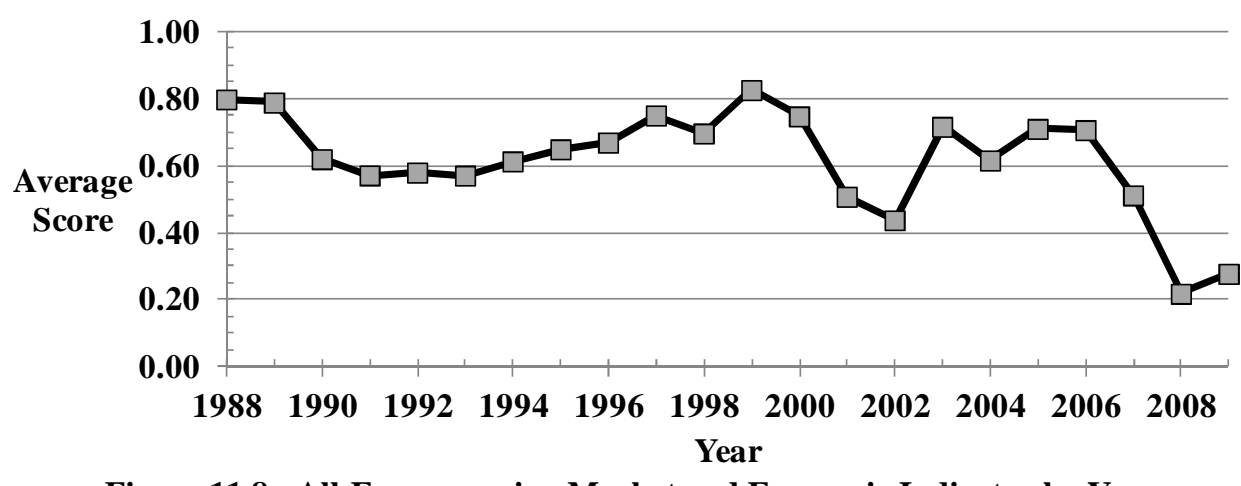

Figure 11.8: All-Encompassing Market and Economic Indicator by Year

To test if this all-encompassing ME indicator was representative of overall market and economic performance, its trend was matched to economic downturns during the time of study. Between 1998 and 2008, there were three recessions:

- 1990-1991: triggered by the saving and loans crisis;

- 2001-2002: triggered by the dot-com bubble collapse and September 11 attacks; and,

- 2007-2009: triggered by the subprime mortgage crisis.

Because the minimums of the all-encompassing ME indicator curve coincided with recessions, it was concluded that 20 factors were successfully reduced to one overall measure of the market and economy consistent with reality.

\subsection{Combining Market and Economic Factors with Financial and Managerial Decision-Making Data}

The hypothesis of this thesis states that the inclusion of managerial decision-making outcomes as well as market and economic (ME) factors will enhance prediction that is based solely on financial data. This inherently assumes that financial and managerial decisionmaking data exclude external risks. If such is the case, there are three possibilities in which ME factors can be integrated: 1 . include them as non-discretionary inputs or outputs in the first stage; 2. consider them with DEA scores or metrics before they are combined in a second stage analysis; or 3. use them to "calibrate" the overall health score at the end. Before exploring these non-trivial options, it must first be proven that the overall health of each company differs from the all-encompassing ME indicator. This requires comparing overall health by year to the all-encompassing ME indicator: if the curves are similar, then 
financial and managerial decision-making data do include ME effects, and thus strategies for integrating them are unnecessary. This comparison is conducted in Section 12.7.

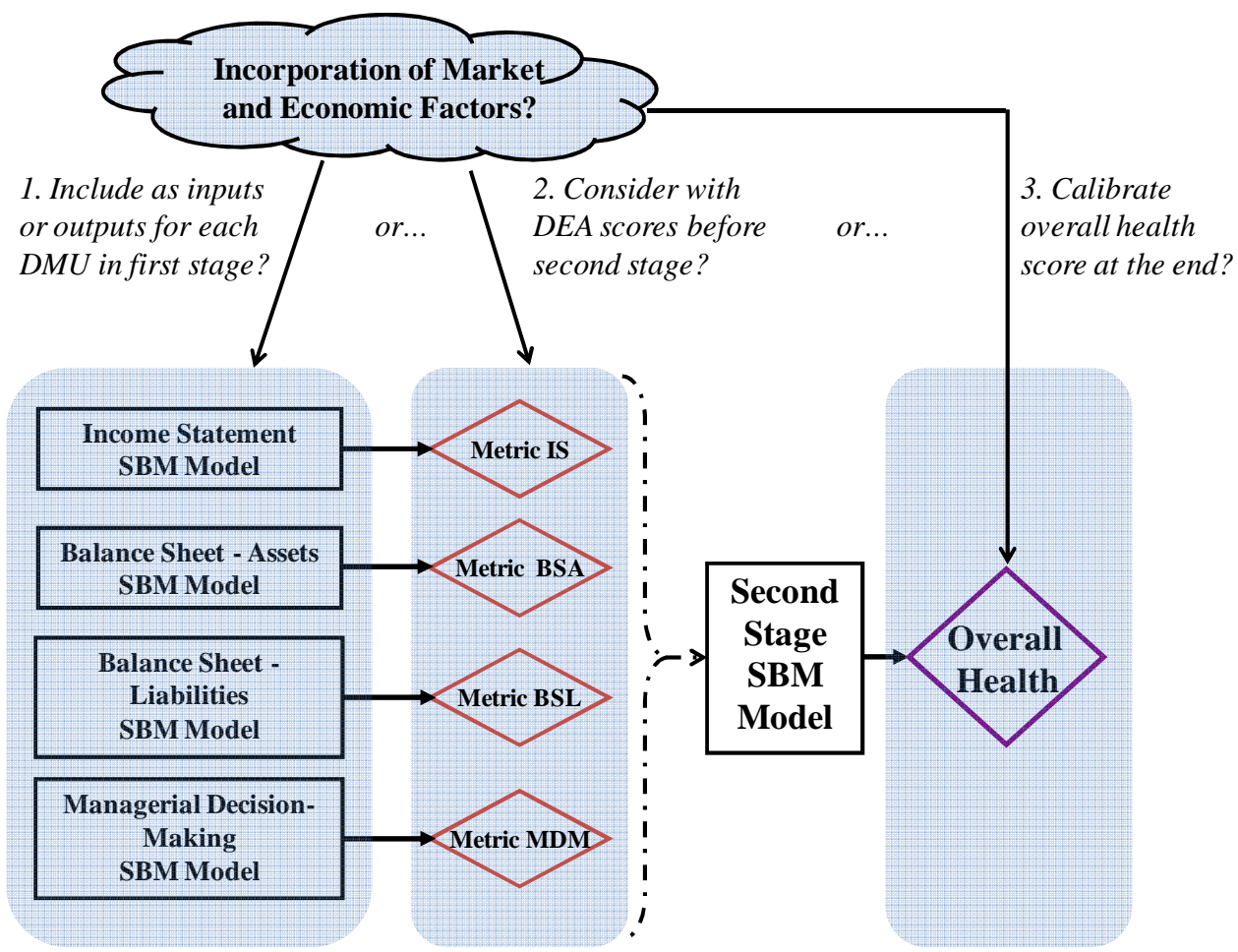

Figure 11.9: Possibilities of Adding Market and Economic Factors into DEA Models 


\section{Second Stage DEA Models: Results and Discussion}

\subsection{Motivation}

Before delving into a second stage of analysis described in Section 8.2, the motivation was reinforced. The alternative to creating metrics and combining them in a second stage was to consider all financial and managerial decision-making variables at once; that is, a large set of inputs and outputs was applied to a "mega" model. Each DMU (i.e. company and year) had a value for each financial and managerial decision-making variable. For market and economic (ME) factors, it was assigned values for each of these non-discretionary variables as they match to its year.

In total, 35 inputs and 20 outputs were applied all at once to a DEA model (Table E.9). Because the presence of non-discretionary variables disallowed the use of SBM for analysis, a non-discretionary input-oriented BCC model was applied. Ninety-nine percent of DMUs were identified as best performers. Even with the substitution of the all-encompassing ME indicator for all the individual ME factors, $98 \%$ of DMUs were identified as healthiest. This may have been due to too little variation in the data and/or building a model with a large number of variables (relative to the number of DMUs) which increases dimensionality of the mathematical program, and thereby landing more DMUs on the frontier. To illustrate, consider the 7 input-oriented BCC models (with a dummy unit output) in Table 12.1.

The first model has one input, the second has two inputs and the third has three inputs, and so on. Keeping the total number of DMUs constant (at 26), the number of DMUs on the frontier increases with the number of inputs. Also, when the input value range is small (i.e. lack of variation in data) - between 1 and 3 - the majority of DMUs appear on the frontier. When the input value range is larger, e.g. 1 to 100 (Table 12.2), the number of DMUs on the frontier decreases. And as before, Table 12.2 shows that the number of variables is proportional to the number of DMUs on the frontier. 
Table 12.1: Input-Oriented Models: Specifications and Results with Input Value Range between 1 and 3

\begin{tabular}{|c|c|c|c|c|c|c|c|c|c|c|c|c|c|c|}
\hline \multirow{2}{*}{ DMU } & \multicolumn{7}{|c|}{ Input Values } & \multicolumn{7}{|c|}{ DMUs on Frontier by Applying Model with: } \\
\hline & Input 1 & Input 2 & Input 3 & Input 4 & Input 5 & Input 6 & Input 7 & Input 1 & Inputs 1-2 & Inputs 1-3 & Inputs 1-4 & Inputs 1-5 & Inputs 1-6 & Inputs 1-7 \\
\hline $\mathbf{A}$ & 3 & 1 & 3 & 3 & 2 & 3 & 2 & Yes & Yes & Yes & Yes & Yes & Yes & Yes \\
\hline B & 1 & 3 & 2 & 1 & 3 & 2 & 1 & Yes & Yes & Yes & Yes & Yes & Yes & Yes \\
\hline $\mathbf{C}$ & 1 & 3 & 2 & 3 & 2 & 3 & 3 & Yes & Yes & Yes & Yes & Yes & Yes & Yes \\
\hline D & 1 & 1 & 2 & 1 & 2 & 1 & 2 & Yes & Yes & Yes & Yes & Yes & Yes & Yes \\
\hline $\mathbf{E}$ & 1 & 3 & 1 & 3 & 2 & 3 & 1 & Yes & Yes & Yes & Yes & Yes & Yes & Yes \\
\hline $\mathbf{F}$ & 3 & 3 & 2 & 3 & 3 & 1 & 2 & & & & & & Yes & Yes \\
\hline G & 3 & 3 & 3 & 3 & 3 & 3 & 2 & & & & & & & \\
\hline $\mathbf{H}$ & 2 & 3 & 1 & 1 & 3 & 2 & 1 & & & Yes & Yes & Yes & Yes & Yes \\
\hline I & 2 & 3 & 1 & 2 & 2 & 2 & 1 & & & Yes & Yes & Yes & Yes & Yes \\
\hline $\mathbf{J}$ & 2 & 1 & 2 & 2 & 3 & 3 & 3 & Yes & Yes & Yes & Yes & Yes & Yes & Yes \\
\hline K & 1 & 3 & 3 & 3 & 3 & 3 & 1 & Yes & Yes & Yes & Yes & Yes & Yes & Yes \\
\hline $\mathbf{L}$ & 1 & 1 & 2 & 2 & 1 & 1 & 3 & Yes & Yes & Yes & Yes & Yes & Yes & Yes \\
\hline $\mathbf{M}$ & 1 & 3 & 2 & 2 & 1 & 3 & 2 & Yes & Yes & Yes & Yes & Yes & Yes & Yes \\
\hline $\mathbf{N}$ & 3 & 3 & 1 & 1 & 1 & 1 & 2 & & & Yes & Yes & Yes & Yes & Yes \\
\hline O & 1 & 2 & 2 & 3 & 2 & 1 & 1 & Yes & Yes & Yes & Yes & Yes & Yes & Yes \\
\hline $\mathbf{P}$ & 3 & 2 & 2 & 3 & 3 & 3 & 3 & & & & & & & \\
\hline $\mathbf{Q}$ & 2 & 3 & 2 & 3 & 3 & 1 & 2 & & & & & & Yes & Yes \\
\hline $\mathbf{R}$ & 1 & 3 & 2 & 2 & 1 & 3 & 1 & Yes & Yes & Yes & Yes & Yes & Yes & Yes \\
\hline $\mathbf{S}$ & 3 & 2 & 2 & 1 & 1 & 3 & 3 & & & & Yes & Yes & Yes & Yes \\
\hline $\mathbf{T}$ & 2 & 1 & 2 & 2 & 1 & 1 & 3 & Yes & Yes & Yes & Yes & Yes & Yes & Yes \\
\hline $\mathbf{U}$ & 2 & 3 & 1 & 1 & 1 & 1 & 1 & & & Yes & Yes & Yes & Yes & Yes \\
\hline $\mathbf{V}$ & 1 & 2 & 2 & 1 & 1 & 3 & 1 & Yes & Yes & Yes & Yes & Yes & Yes & Yes \\
\hline $\mathbf{W}$ & 2 & 3 & 3 & 1 & 3 & 2 & 3 & & & & Yes & Yes & Yes & Yes \\
\hline $\mathbf{X}$ & 1 & 2 & 2 & 3 & 2 & 3 & 1 & Yes & Yes & Yes & Yes & Yes & Yes & Yes \\
\hline $\mathbf{Y}$ & 3 & 2 & 3 & 3 & 2 & 3 & 3 & & & & & & & \\
\hline $\mathbf{Z}$ & 3 & 3 & 1 & 2 & 1 & 3 & 2 & & & Yes & Yes & Yes & Yes & Yes \\
\hline \multicolumn{8}{|c|}{ Total Number of DMUs on Frontier } & 14 & 14 & 19 & 21 & 21 & 23 & 23 \\
\hline
\end{tabular}

Table 12.2: Input-Oriented Models: Specifications and Results with Input Value Range between 1 and 100

\begin{tabular}{|c|c|c|c|c|c|c|c|c|c|c|c|c|c|c|}
\hline \multirow{2}{*}{ DMU } & \multicolumn{7}{|c|}{ Input Values } & \multicolumn{7}{|c|}{ DMUs on Frontier by Applying Model with: } \\
\hline & Input 1 & Input 2 & Input 3 & Input 4 & Input 5 & Input 6 & \begin{tabular}{|l|} 
Input 7 \\
\end{tabular} & Input 1 & Inputs 1-2 & Inputs 1-3 & Inputs 1-4 & Inputs 1-5 & Inputs 1-6 & Inputs 1-7 \\
\hline $\mathbf{A}$ & 97 & 91 & 38 & 37 & 13 & 11 & 9 & & & & & & Yes & Yes \\
\hline $\mathbf{B}$ & 26 & 67 & 87 & 48 & 5 & 31 & 58 & & & & & & & \\
\hline $\mathbf{C}$ & 29 & 51 & 6 & 89 & 36 & 80 & 40 & Yes & Yes & Yes & Yes & Yes & Yes & Yes \\
\hline D & 51 & 67 & 52 & 57 & 13 & 67 & 66 & & & & & & & \\
\hline $\mathbf{E}$ & 25 & 45 & 73 & 85 & 63 & 40 & 51 & & & & & & & \\
\hline $\mathbf{F}$ & 96 & 65 & 80 & 33 & 50 & 81 & 69 & & & & & & & \\
\hline G & 60 & 73 & 12 & 17 & 49 & 95 & 60 & & & & Yes & Yes & Yes & Yes \\
\hline $\mathbf{H}$ & 69 & 12 & 31 & 21 & 77 & 34 & 76 & & & & Yes & Yes & Yes & Yes \\
\hline I & 6 & 42 & 20 & 1 & 3 & 15 & 13 & Yes & Yes & Yes & Yes & Yes & Yes & Yes \\
\hline $\mathbf{J}$ & 23 & 54 & 80 & 51 & 33 & 34 & 42 & & & & & & & \\
\hline $\mathbf{K}$ & 80 & 28 & 36 & 98 & 22 & 41 & 52 & & & & & & & \\
\hline $\mathbf{L}$ & 78 & 67 & 22 & 60 & 43 & 75 & 57 & & & & & & & \\
\hline $\mathbf{M}$ & 9 & 32 & 33 & 22 & 85 & 92 & 57 & & Yes & Yes & Yes & Yes & Yes & Yes \\
\hline $\mathbf{N}$ & 16 & 95 & 5 & 53 & 9 & 11 & 8 & & & Yes & Yes & Yes & Yes & Yes \\
\hline O & 36 & 63 & 5 & 66 & 70 & 37 & 52 & & & Yes & Yes & Yes & Yes & Yes \\
\hline $\mathbf{P}$ & 56 & 40 & 87 & 52 & 4 & 75 & 67 & & & & & Yes & Yes & Yes \\
\hline $\mathbf{Q}$ & 100 & 79 & 71 & 73 & 17 & 75 & 57 & & & & & & & \\
\hline $\mathbf{R}$ & 71 & 77 & 41 & 82 & 87 & 67 & 46 & & & & & & & \\
\hline $\mathbf{S}$ & 26 & 3 & 45 & 78 & 39 & 29 & 39 & & Yes & Yes & Yes & Yes & Yes & Yes \\
\hline$T$ & 11 & 60 & 37 & 51 & 28 & 16 & 45 & Yes & Yes & Yes & Yes & Yes & & \\
\hline $\mathbf{U}$ & 62 & 46 & 80 & 12 & 74 & 60 & 54 & & & & & & Yes & Yes \\
\hline $\mathbf{V}$ & 17 & 72 & 83 & 49 & 79 & 77 & 58 & & & & & & & \\
\hline $\mathbf{W}$ & 31 & 51 & 70 & 90 & 40 & 36 & 21 & & & & & & & \\
\hline $\mathbf{X}$ & 43 & 86 & 66 & 93 & 69 & 97 & 5 & & & & & & & \\
\hline $\mathbf{Y}$ & 71 & 67 & 18 & 9 & 75 & 20 & 22 & & & & & & & \\
\hline $\mathbf{Z}$ & 81 & 2 & 2 & 60 & 65 & 72 & 77 & & Yes & Yes & Yes & Yes & Yes & Yes \\
\hline & & & & Total Nu & Imber of & OMUs or & Frontier & 3 & 6 & 8 & 10 & 11 & 12 & 12 \\
\hline
\end{tabular}




\subsection{Layered Scores and Second Stage Model Specifications}

Because the layering technique provides more discrimination among DMUs and does not require subjective zones, all second stage DEA models used scores derived from layering results as variables. Specifically, the layer $L$ corresponding to when a DMU was efficient (on the frontier) after $L$ peels (or runs) was translated into a novel "layered" score. For a given metric with $N$ layers, the layered score for a DMU was calculated as:

$$
0<\text { Layered Score }=\frac{N+1-L}{N} \leq 1
$$

A DMU with the highest layered score of 1 was the healthiest within the sample; the lower the layered score, the less healthy the DMU. In the instance where the DMU never appeared on a frontier, it was given a layered score of 0. For example, BSL has 17 layers. Suppose a DMU is on the frontier after the first run $(L=1)$. Its layered score would be $\frac{17+1-1}{17}=1$ (the healthiest). Similarly, if a DMU landed on the frontier after 6 peels $(L=6)$, its score would be $\frac{17+1-6}{17}=0.706$. The translation of layered results into layered scores was conducted for each metric, and then correlated (Table 12.3). Consistent with correlations after the first run (Table 10.1), this further supported the need to combine metrics in a second stage analysis.

Table 12.3: Correlation of Layered Scores

\begin{tabular}{|l|c|c|c|c|}
\cline { 2 - 5 } \multicolumn{1}{c|}{} & IS & BSA & BSL & MDM \\
\hline Income Statement (IS) & 1 & 0.23 & 0.14 & 0.06 \\
\hline Balance Sheet Assets (BSA) & & 1 & 0.74 & 0.12 \\
\hline Balance Sheet Liabilities (BSL) & & & 1 & 0.19 \\
\hline Managerial Decision-Making (MDM) & & & & 1 \\
\hline
\end{tabular}

Many different combinations of metrics were applied to a second stage model. Some had:

- Financial data only (IS, BSA, BSL and/or CFO);

- Financial and managerial decision-making data (IS, BSA, BSL and/or CFO, and MDM); or

- Financial and managerial decision-making data, and market and economic factors (IS, BSA, BSL, CFO, MDM and ME).

Also, CFO (cash flow from operating activities) was sometimes added as a proxy because negative values are a red flag of poor health. 
All metrics in each second stage model were treated as outputs combined with a unit input. All models were also non-oriented SBM except when the ME indicator was included, in which case an output-oriented non-discretionary model was used. Finally, the scores generated by second stage models reflected overall health of a DMU.

\subsection{Classification by Zones}

Second stage results based on classification by zones ${ }^{27}$ are presented in Table 12.4. Validating one part of the hypothesis, prediction using models with financial and managerial decision-making improved over those with financial metrics only. It is noted that CFO had a strong effect on prediction: its presence right-skewed the distribution (i.e. more DMUs with lower scores), leading to zero Type I error but higher Type II error (Figure 12.1 versus Figure 12.2, and Figure 12.3 versus Figure 12.4). Furthermore, a model including the allencompassing ME indicator was also tested but produced the highest Type I error.

Table 12.4: Second Stage Model Prediction with Classification by Zones

\begin{tabular}{|l|c|c|c|c|c|}
\hline \multirow{2}{*}{$\%$} & \multicolumn{2}{|c|}{ IS, BSA, BSL } & \multicolumn{2}{c|}{ IS, BSA, BSL, MDM } & \multirow{2}{*}{ IS, BSA, BSL, } \\
\cline { 2 - 5 } & Without CFO & With CFO & Without CFO & With CFO & CFO, MDM, ME \\
\hline TP Rate & 84.0 & 5.5 & 80.7 & 7.8 & 100.0 \\
\hline FP Rate & 32.3 & 0 & 20.7 & 0 & 97.7 \\
\hline Type I Error & 32.3 & 0 & 20.7 & 0 & 97.7 \\
\hline Type II Error & 16.0 & 94.5 & 19.3 & 92.2 & 0 \\
\hline Success Rate & 82.9 & 13.0 & 80.6 & 15.3 & 93.6 \\
\hline Unclassified & 33.1 & 10.0 & 31.5 & 14.4 & 4.0 \\
\hline
\end{tabular}

\footnotetext{
${ }^{27}$ A DMU with a score $\zeta$ was predicted bankrupt if $0 \leq \zeta<0.4$ or active if $0.7 \leq \zeta \leq 1$, or remained unclassified if $0.4 \leq \zeta<$ 0.7 .
} 


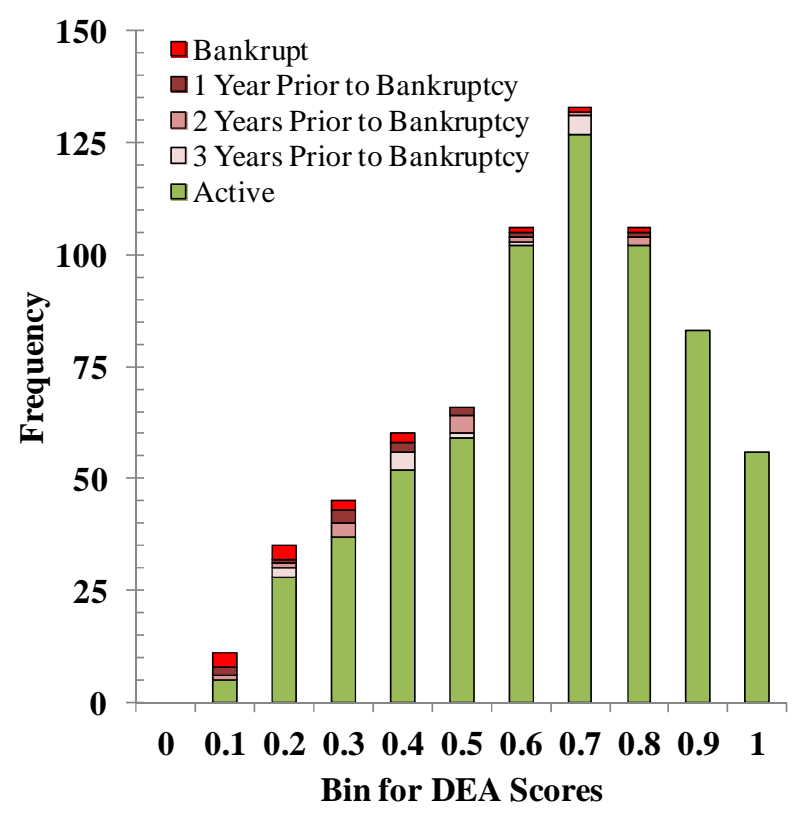

Figure 12.1: Second Stage Results with IS, BSA and BSL

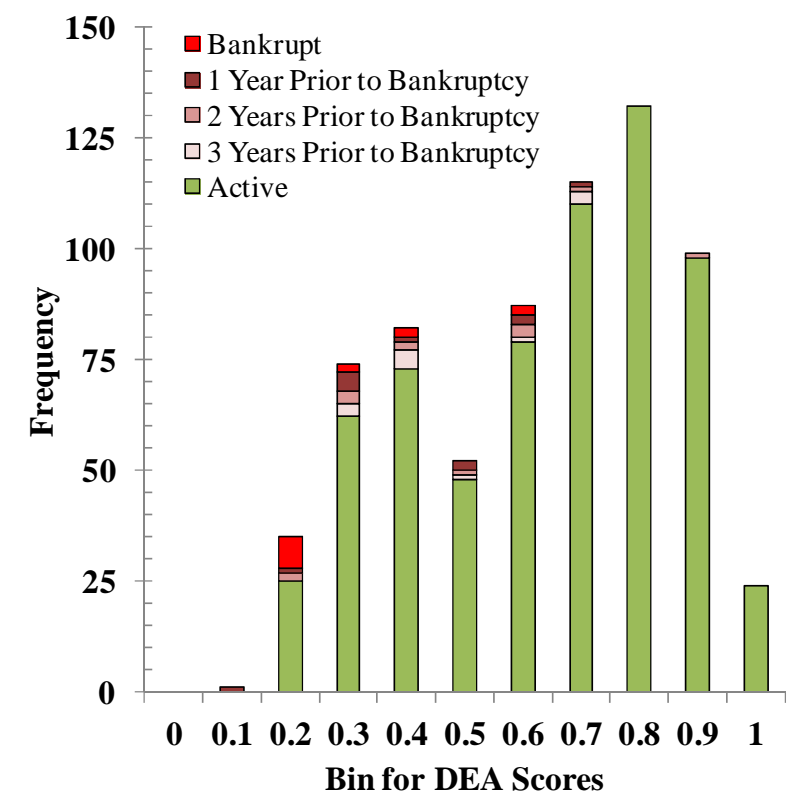

Figure 12.3: Second Stage Results with IS, BSA BSL and MDM

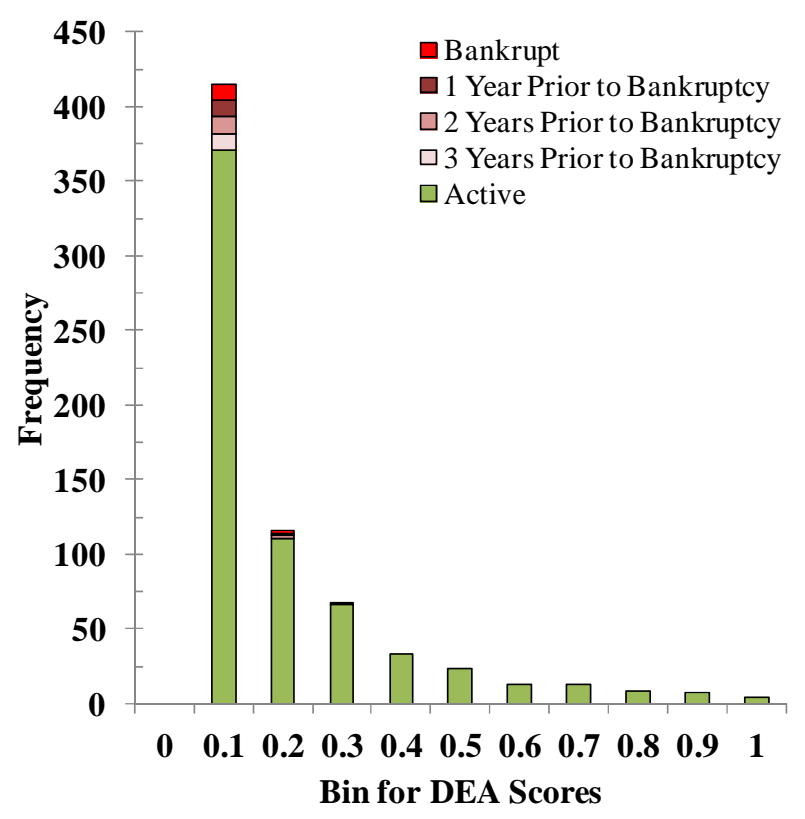

Figure 12.2: Second Stage Results with IS, BSA, BSL and CFO

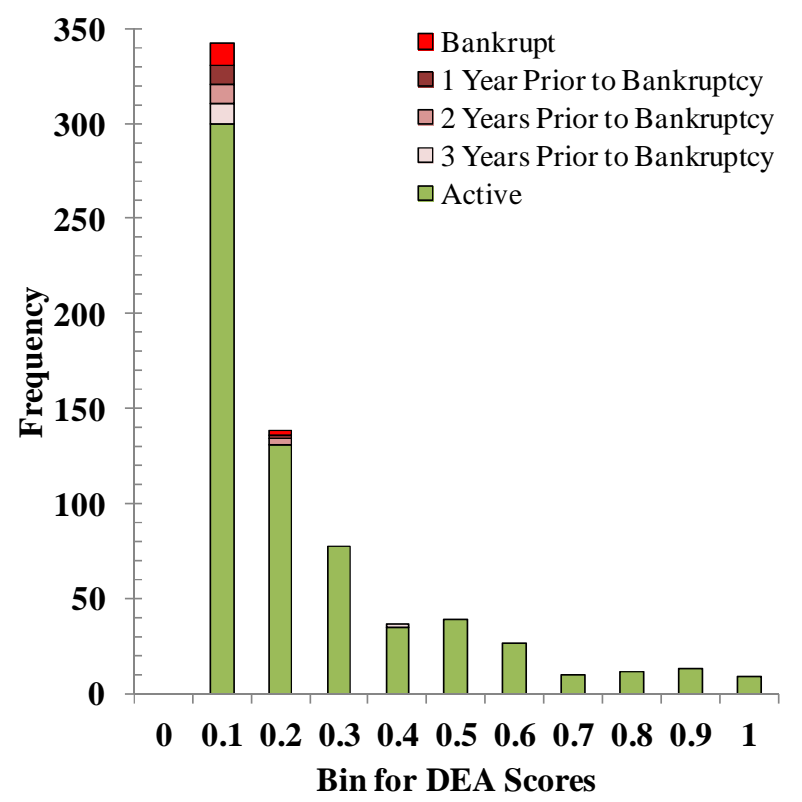

Figure 12.4: Second Stage Results with IS, BSA, BSL, CFO and MDM

\subsection{Classification by Layering}

Based on the second stage analysis of classification by zones (Section 12.3) which showed that prediction was most effective with financial and managerial decision-making data but 
not with market and economic factors, two combinations of metrics were further examined by classification by layering:

1. IS, BSA, BSL and MDM

2. IS, BSA, BSL, and MDM with CFO

\subsubsection{Second Stage Model with IS, BSA, BSL and MDM}

Figure 12.5 graphs the count of actual active and bankrupt DMUs identified on the frontier in each layer when predicting from one year back, on the primary $y$-axis (see Appendix F.6 for two and three years back). The secondary $y$-axis plots the cumulative ratio of active and bankrupt DMUs identified on the frontier to the total active and bankrupt DMUs in the sample. Ideally, the "Cumulative of Total Active DMUs" curve (with green triangular markers) would quickly increase while the "Cumulative of Total Bankrupt DMUs" curve (with red square markers) would remain flat for as many layers as possible. Figure 12.6 is the same as Figure 12.5, except that the primary $y$-axis is the ratio of active to bankrupt DMUs on the frontier. As expected, as more layers were peeled, this ratio decreased.

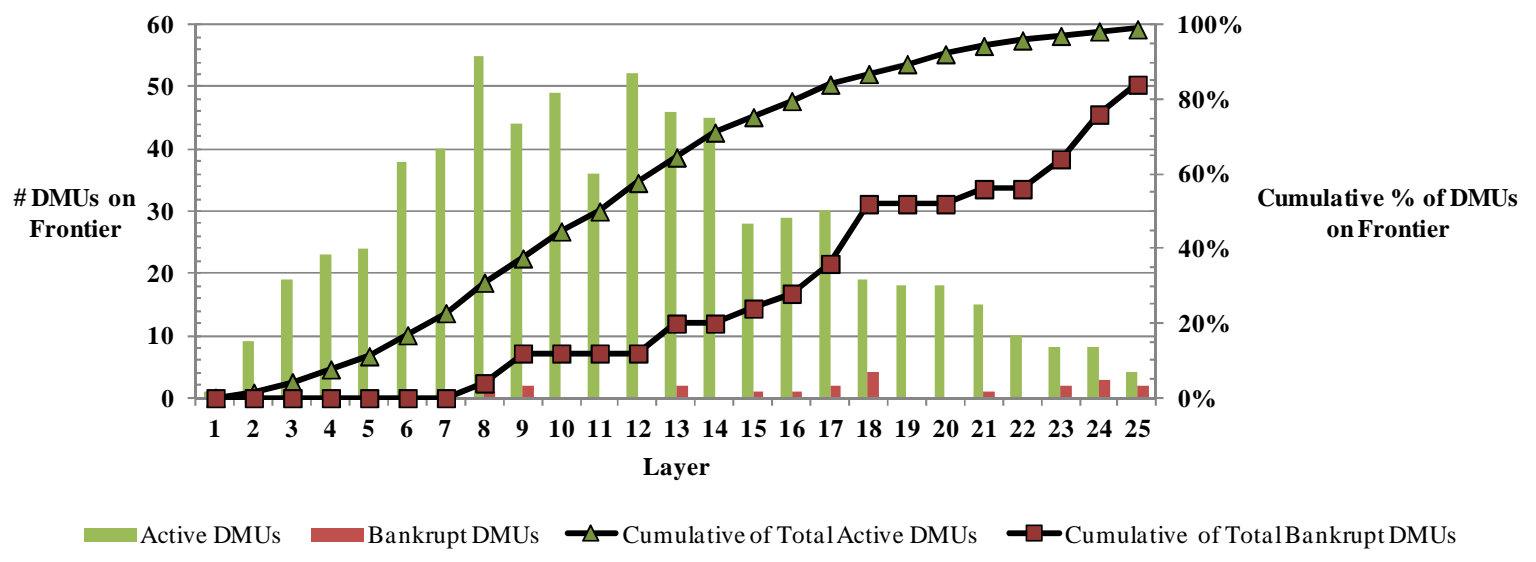

Figure 12.5: Classification by Layer in Absolute Numbers from One Year Back A DMU was predicted bankrupt up to a year prior to filing Chapter 11. 


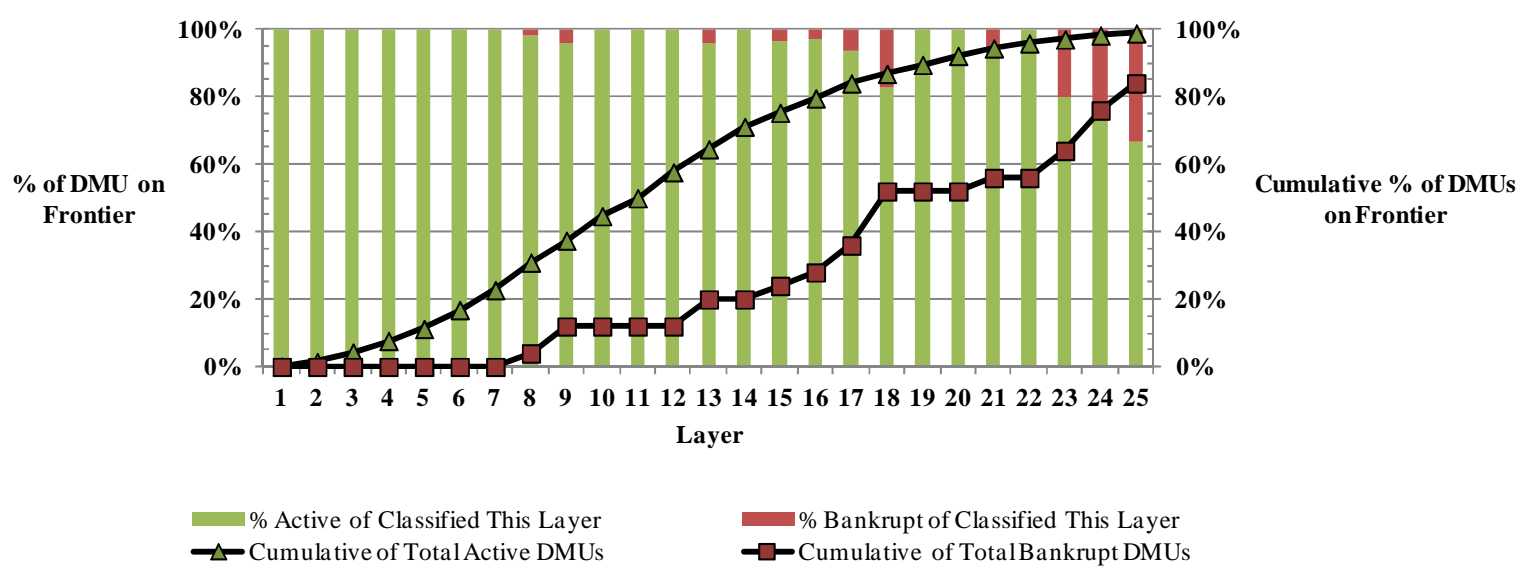

Figure 12.6: Classification by Layer in Percentages from One Year Back A DMU was predicted bankrupt up to a year prior to filing Chapter 11.

Figure 12.7 illustrate the common trade-offs between Type I and II errors, and active and bankruptcy classifications, with each layer when predicting from one year back. Recall that the goal was to create a model with a layer where both of its errors (red curves) are less than (below) Altman's (blue lines). In fact, the point at which the error curves intersect provides a measure of the model's best performance, assuming the costs of Type I and II errors are equal. Thus, a good prediction model would not have a point of intersection that exceeds Altman's errors. Realistically, however, it would be successful provided that its errors lie between Altman's benchmarks since Type I error is more costly than Type II error.

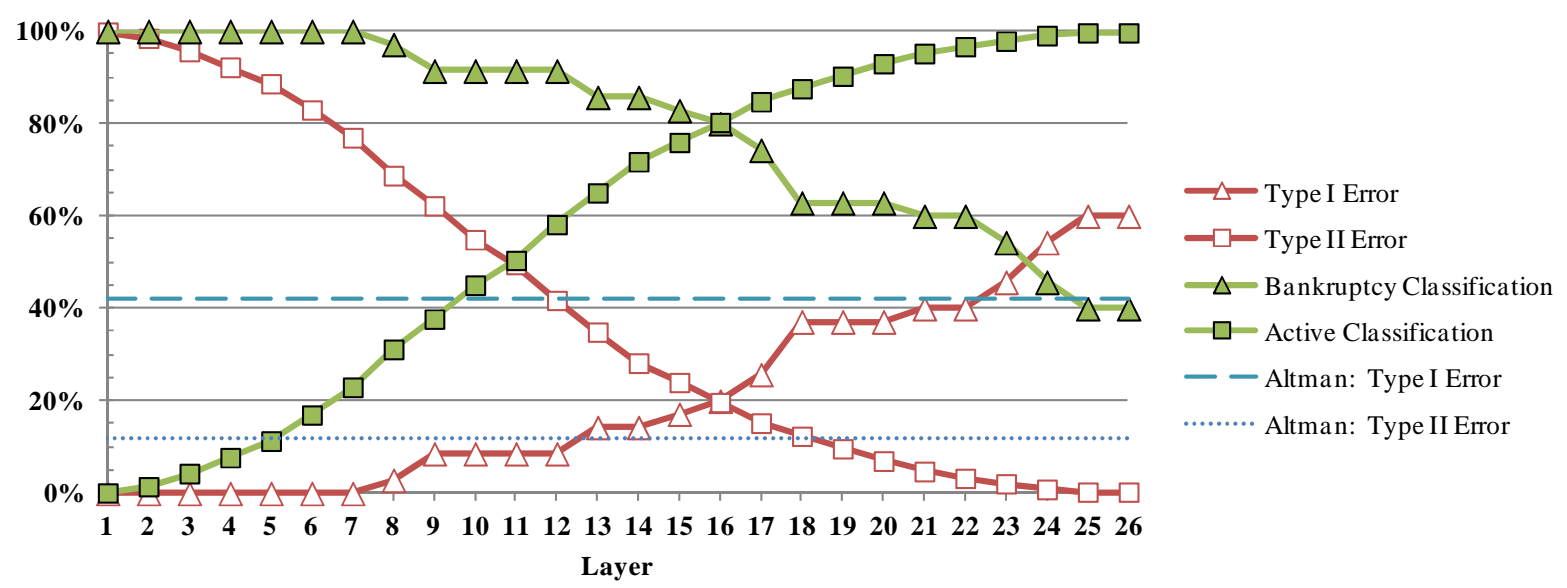

Figure 12.7: Prediction by Second Stage Model from One Year Back

A DMU was predicted bankrupt up to 1 year prior to filing Chapter 11.

Table 12.5 compares the performance, based on the intersections of error curves, between the second stage model and individual metrics. The second stage model correctly classified $80 \%$ of DMUs - an improvement from Altman's Z-Score (58\% accuracy from one year back). 
Generally, it was more accurate than each individual metric; any discrepancy was likely due to the fact that individual metrics were computed from original data from annual reports whereas second stage results were calculated from the layered scores of these metrics.

Table 12.5: Accuracy of Classification by Layering of Second Stage Model and Individual Metrics

\begin{tabular}{|l|c|c|c|c|c|c|c|c|c|}
\cline { 2 - 11 } \multicolumn{1}{c|}{} & \multicolumn{3}{c}{ One Year Back } & \multicolumn{3}{c|}{ Two Years Back } & \multicolumn{3}{c|}{ Three Years Back } \\
\cline { 2 - 12 } \multicolumn{1}{c|}{} & Accuracy & Error & Layer & Accuracy & Error & Layer & Accuracy & Error & Layer \\
\hline Second Stage & $80 \%$ & $20 \%$ & 16 & $73 \%$ & $27 \%$ & 14 & $69 \%$ & $31 \%$ & 13,14 \\
\hline IS & $58 \%$ & $42 \%$ & 3 & $55 \%$ & $45 \%$ & 3 & $55 \%$ & $45 \%$ & 3 \\
\hline BSA & $78 \%$ & $22 \%$ & 4,5 & $72 \%$ & $28 \%$ & 4 & $70 \%$ & $30 \%$ & 3,4 \\
\hline BSL & $78 \%$ & $22 \%$ & 4 & $72 \%$ & $28 \%$ & 7,8 & $70 \%$ & $30 \%$ & 7 \\
\hline MDM & $65 \%$ & $35 \%$ & 2 & $60 \%$ & $40 \%$ & 2 & $61 \%$ & $39 \%$ & 2 \\
\hline
\end{tabular}

To further compare the second stage model with the individual metrics, their Receiver Operating Characteristic $^{28}$ (ROC) curves were plotted (Figure 12.8). All metrics and the second stage model outperformed random guessing; however, the top two among them (i.e. the second stage and BSL) appeared to "leap-frog" each other. To determine which was better (since accuracies differed by only $2 \%$ ), the area under each curve was calculated. Because the area under the second stage model was identical to that of BSL (0.88), ROC could not be used to choose the stronger performer. Thus, the evaluation of the models was based on the accuracy of classification by layering, making the second stage model the best predictor.

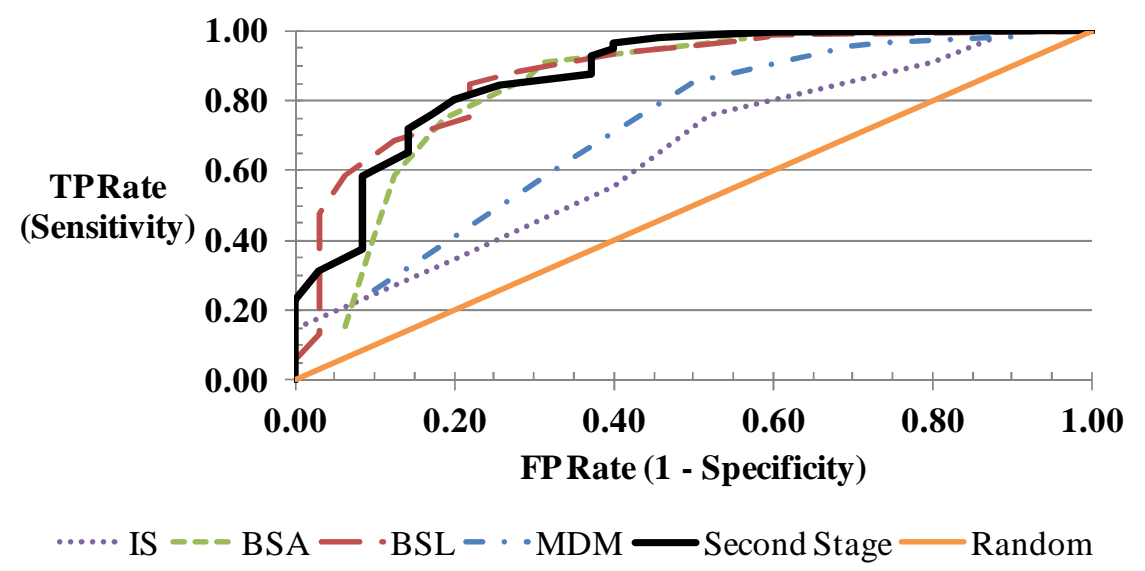

Figure 12.8: ROC Curves for One Year Back

\footnotetext{
${ }^{28}$ An ROC curve is a graphical plot of sensitivity (or true positive rate) versus false positive rate (or 1 - specificity or 1 true negative rate) for a binary classification system as its discrimination threshold is varied. It depicts the relative trade-offs between true positive (benefits) and false positive (costs). Each prediction result represents one point in the ROC space. The perfect prediction method would yield a point in the upper left corner $(0,1)$, representing $100 \%$ sensitivity (no false negatives) and $100 \%$ specificity (no false positives). A completely random guess would give a point along the "nodiscrimination" diagonal (orange) line. Points above and below this diagonal represent good and poor classification, respectively.
} 


\subsubsection{Second Stage Model with IS, BSA, BSL and MDM with CFO}

The inclusion of CFO as a metric to the previous model with IS, BSA, BSL and MDM yielded 13 layers of analysis and did not perform as well as the second stage without CFO (Table 12.6 and Figure 12.9).

Table 12.6: Second Stage Model with and without CFO Metric

\begin{tabular}{|l|c|c|c|c|c|c|c|c|c|}
\cline { 2 - 11 } \multicolumn{1}{c|}{} & \multicolumn{4}{c|}{ One Year Back } & \multicolumn{3}{c|}{ Two Years Back } & \multicolumn{3}{c|}{ Three Years Back } \\
\cline { 2 - 12 } \multicolumn{1}{c|}{} & Accuracy & Error & Layer & Accuracy & Error & Layer & Accuracy & Error & Layer \\
\hline Without CFO & $80 \%$ & $20 \%$ & 16 & $73 \%$ & $27 \%$ & 14 & $69 \%$ & $31 \%$ & 13,14 \\
\hline With CFO & $77 \%$ & $23 \%$ & 17 & $69 \%$ & $31 \%$ & 7 & $67 \%$ & $33 \%$ & 15 \\
\hline
\end{tabular}

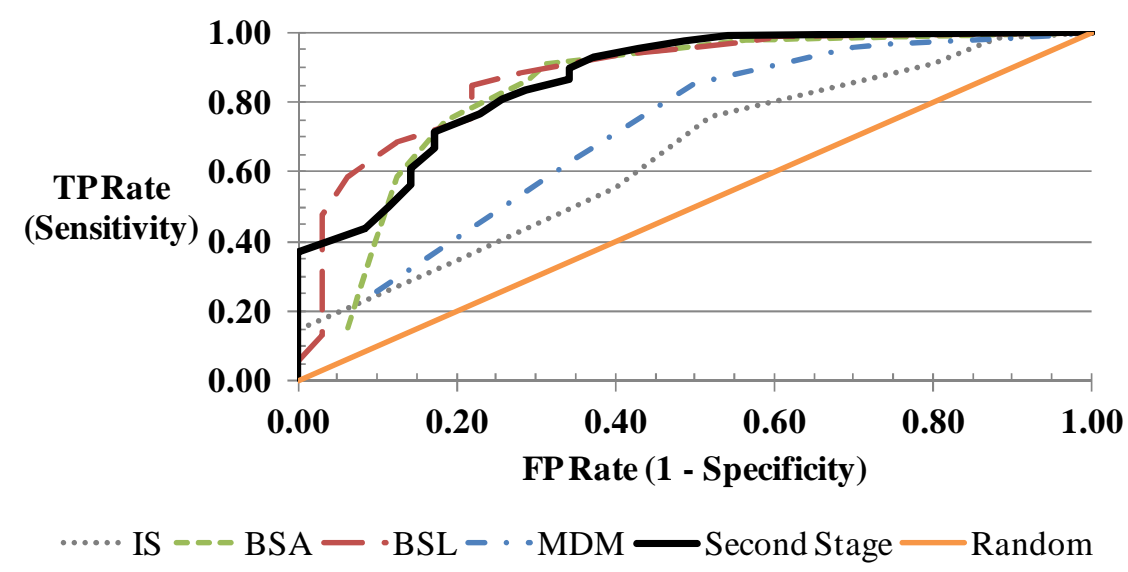

Figure 12.9: ROC Curves for One Year Back with CFO

\subsection{Type I and Type II Error Trade-Off}

As the ROC curves prove, all individual metrics and the second stage model were better than random guessing but were not perfect. Because ROC curves do not reveal any information on true negative or false negative (Type II error) instances, a comparative analysis of models based on Type II errors was conducted. Figure 12.10 shows the trade-off between Type I and II errors. If the objective is to minimize both simultaneously, then the second stage model performed best since the intersection of its curve (coloured black) and the orange diagonal is the lowest $(0.2,0.2)$ among the other metrics. 


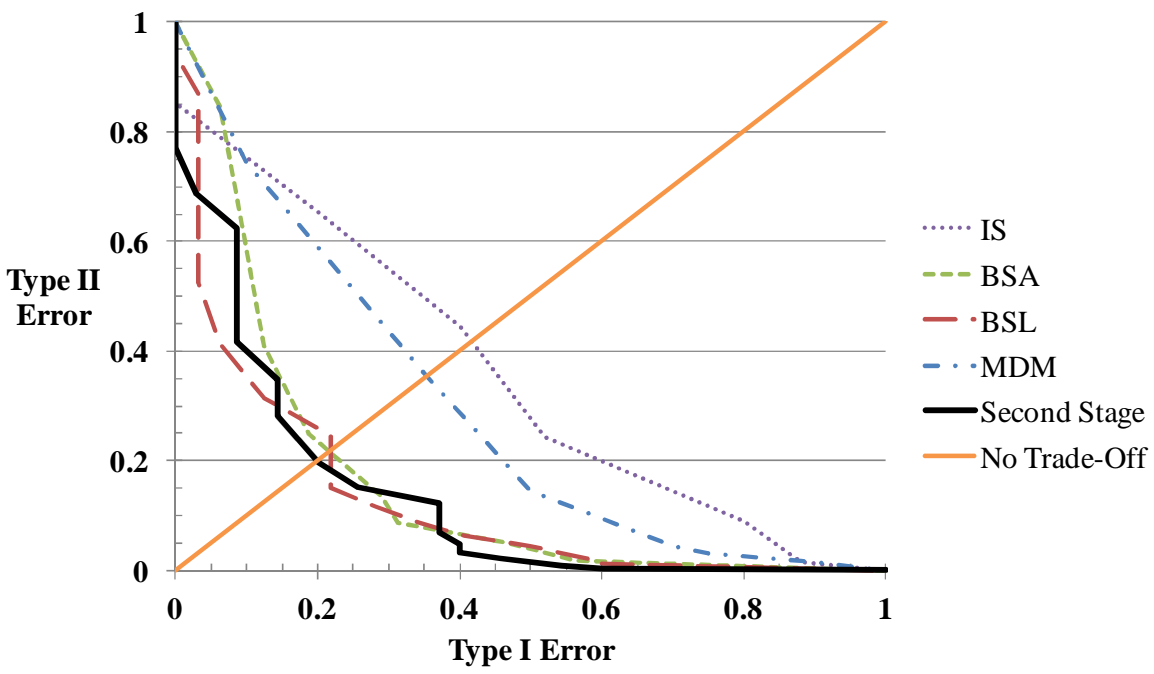

Figure 12.10: Type I and II Errors Trade-Off

Further analysis of the Type I and II errors of the second stage model revealed that the $20 \%$ error rate was a conservative estimate. In fact, for prediction one year back, the 6 bankrupt DMUs that were misclassified as active (Type I error) did not appear on the frontier until the $8^{\text {th }}$ peel and were clearly less healthy than DMUs that were classified as active within the first few layers. Also, over a third of the active DMUs that were misclassified as bankrupt (Type II) were companies that eventually filed for Chapter 11 (i.e. these DMUs were out more than 3 years prior to bankruptcy).

Because attempts at improving a correct classification of $80 \%$ with data-mining techniques (such as clustering) proved unsuccessful, literature was reviewed to see if other studies have overcome the error trade-off problem. In short, varying the cut-off value can increase specificity or sensitivity (Table 12.7): a more specific model (with a higher cut-off value) has an increased risk of accepting false negatives (Type II error) while a more sensitive model (with a lower cut-off value) has an increased risk of accepting false positives (Type I error). In other words, there is no cut-off value with high sensitivity and high specificity, but rather a continuum of risk at all values. Hence, the only options for improving on errors are to introduce new variables that have not been considered in the analysis, or to change the sample size (explored in Section 12.8). 
Table 12.7: Specificity and Sensitivity Trade-Off

\begin{tabular}{|l|c|c|}
\cline { 2 - 3 } \multicolumn{1}{c|}{} & Increasing Cut-Off Value & Decreasing Cut-Off Value \\
\hline Specificity & $\uparrow$ & $\downarrow$ \\
\hline Sensitivity & $\downarrow$ & $\uparrow$ \\
\hline $\begin{array}{l}\text { True Positive } \\
\text { (Correctly predicting non-bankruptcy) }\end{array}$ & $\downarrow$ & $\downarrow$ \\
\hline $\begin{array}{l}\text { True Negative } \\
\text { (Correctly predicting bankruptcy) }\end{array}$ & $\uparrow$ & $\downarrow$ \\
\hline $\begin{array}{l}\text { False positive } \\
\text { (Incorrectly predicting non-bankruptcy) }\end{array}$ & $\downarrow$ & $\downarrow$ \\
\hline $\begin{array}{l}\text { False negative } \\
\text { (Incorrectly predicting bankruptcy) }\end{array}$ & $\uparrow$ & $\checkmark$ \\
\hline
\end{tabular}

\subsection{Comparing the Layering and Non-Layering Approaches}

Figure 12.11 presents the relationship between layering and non-layering (i.e. zoning) techniques for the second stage model composed of metrics IS, BSA, BSL and MDM by actual company state. The second stage layered $\operatorname{scores}^{29}$ (y-axis) were calculated from results after 25 peels whereas the non-layered scores ( $x$-axis) were simply those generated by the first DEA run. Each $(x, y)$ pair is associated with one DMU. The dotted diagonal represents a perfect correlation $(y=x)$. The correlation between techniques was 0.82 and stronger when the scores were higher; that is, there was less scatter when classification tended towards "active" and greater variation in the "bankrupt" zone.

Figure 12.11 is also partitioned into 6 areas. The non-layered $x$-axis is separated into 3 zones: as a DMU with a non-layered score $x$ was predicted bankrupt if $0 \leq x \leq 0.4$ or active if $0.7 \leq x \leq 1$, or remained unclassified if $0.4 \leq x<0.7$. Along the layered $y$-axis, there is a single cut-off value that is determined by the optimal number of peels (i.e. when the second stage model performed best), which in this case, was 16 for prediction one year back (Figure 12.7 and Table 12.6). Because the $16^{\text {th }}$ layer corresponds to a layered score of 0.4 , a DMU with a layered score $y$ was predicted bankrupt if $y \leq 0.4$ or active if $y>0.4$. It is noted that a layered score is inversely related to the number of runs required for a given DMU to arrive at the frontier. With these partitions, it was concluded that there was more variation in the number of peels it took for DMUs to appear on the frontier when their non-layered scores were low. Conversely, the higher the original non-layered score, the more reliable the

\footnotetext{
${ }^{29}$ The second stage layered score for a DMU was calculated as $y=\frac{25+1-L}{25}$ where $L$ is the layer corresponding to when a DMU arrived on the frontier after $L$ peels or runs.
} 
measure and classification of "Active" was; in other words, one can be confident in a healthy firm.

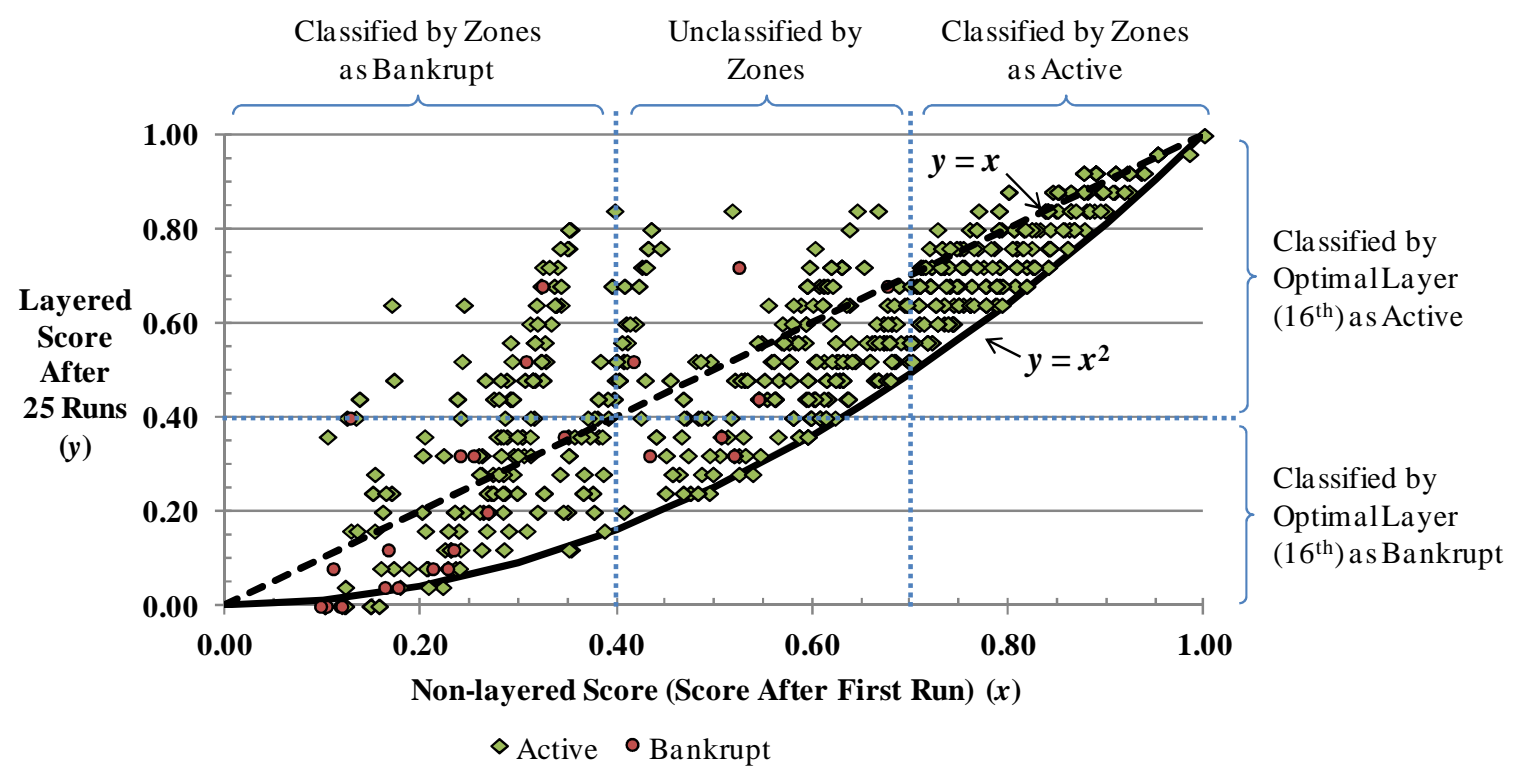

Figure 12.11: Correlation between Layering and Non-Layering Techniques A DMU was predicted bankrupt up to 1 year prior to filing Chapter 11.

The strong correlation between non-layered and layered scores was also apparent in prediction (Table 12.8). The evaluation results were nearly identical, but because of the inability of the non-layering method to classify all DMUs, the layering technique was more effective.

Table 12.8: Performance of Non-Layering and Layering Techniques

\begin{tabular}{|l|c|c|c|c|c|}
\hline $\begin{array}{c}\text { Evaluation } \\
(\boldsymbol{\%})\end{array}$ & Layering & $\begin{array}{c}\text { Non-Layering: } \\
\text { Two Zones }\end{array}$ & $\begin{array}{c}\text { Non-Layering: } \\
\text { Cut-Off of 0.8 }\end{array}$ & $\begin{array}{c}\text { Non-Layering: } \\
\text { Cut-Off of 0.7 }\end{array}$ & $\begin{array}{c}\text { Non-Layering: } \\
\text { Cut-Off of } \mathbf{0 . 6}\end{array}$ \\
\hline TP Rate & 80.3 & 80.7 & 37.7 & 54.6 & 66.9 \\
\hline FP Rate & 20.0 & 20.7 & 0 & 4.0 & 20.0 \\
\hline Type I Error & 20.0 & 20.7 & 0 & 4.0 & 20.0 \\
\hline Type II Error & 19.7 & 19.3 & 62.3 & 45.4 & 33.1 \\
\hline Success Rate & 80.3 & 80.6 & 39.9 & 56.1 & 67.3 \\
\hline Unclassified & 0 & 31.5 & 0 & 0 & 0 \\
\hline
\end{tabular}

Another interesting result was the existence of a lower boundary on the relationship between layered $(y)$ and non-layered scores $(x)$ (Figure 12.11) which can be expressed as $y \geq$ $x^{2}$; this may imply that layered scores were more conservative estimates of health.

\subsection{Comparison to All-Encompassing Market and Economic Indicator}

Because the inclusion of the all-encompassing market and economic (ME) indicator produced poor prediction results (Table 12.4), ME factors were excluded from second stage 
models with the hypothesis that they are inherent in financial and managerial decisionmaking data. To prove this, the second stage layered scores were averaged by year and compared to the all-encompassing ME indicator (Figure 12.12).

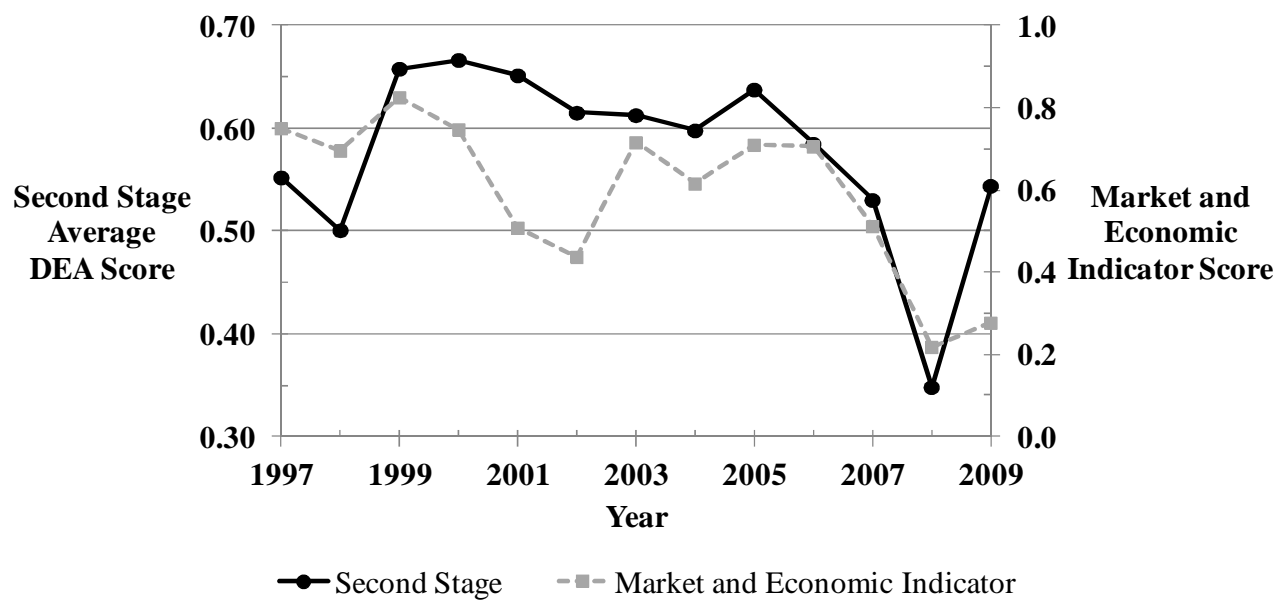

Figure 12.12: Average Scores by Year

Assuming that the null hypothesis is that there is no significant difference between the two, the similarity of their relationship was examined with T- and Mann Whitney U- tests, Pearson and Spearman correlations, ANOVA, area under the curves, and Coefficients of Divergence. These evaluations (Table 12.9) validated the hypothesis that there was no significant difference between the means of the average second stage scores and the ME indicator.

Table 12.9: Tests of Similarity between Second Stage Scores and ME Indicator

\begin{tabular}{|c|c|c|}
\hline Evaluation & & Conclusion \\
\hline \multicolumn{3}{|c|}{ Significance in Difference of Means } \\
\hline Mann-Whitney U Test & 0.29 & \multirow{3}{*}{$\begin{array}{l}\text { No significant difference } \\
\text { between means of scores }\end{array}$} \\
\hline T-Test & 0.77 & \\
\hline ANOVA & 0.77 & \\
\hline \multicolumn{3}{|l|}{ Correlation } \\
\hline Pearson & 0.62 & \multirow{2}{*}{$\begin{array}{l}\text { Weak correlation } \\
\text { between scores }\end{array}$} \\
\hline Spearman & 0.50 & \\
\hline \multicolumn{3}{|l|}{ Difference in Area } \\
\hline Area under the Curves & $3.6 \%$ & No significant difference \\
\hline \multicolumn{3}{|c|}{ Coefficient of Divergence (Wongphatarakul et al., 1998) } \\
\hline Coefficient of Divergence & 0.15 & Similarity \\
\hline
\end{tabular}

While their correlation was weak, it was the matching of the direction of change from year to year that was more important than the magnitude of change itself. In fact, the average second stage score and ME indicator were in agreement 10 out of 12 years (Table 12.10). Thus, it was concluded that financial and managerial data have ME factors inherent in their values. 
Table 12.10: Direction of Change from Year to Year

\begin{tabular}{|c|c|c|}
\hline Year & Second Stage & Market and Economic Indicator \\
\hline $\mathbf{1 9 9 7 - 1 9 9 8}$ & Down & Down \\
\hline $\mathbf{1 9 9 8 - 1 9 9 9}$ & Up & Up \\
\hline $\mathbf{1 9 9 9 - 2 0 0 0}$ & Up & Down \\
\hline $\mathbf{2 0 0 0 - 2 0 0 1}$ & Down & Down \\
\hline $\mathbf{2 0 0 1 - 2 0 0 2}$ & Down & Down \\
\hline $\mathbf{2 0 0 2 - 2 0 0 3}$ & Down & Up \\
\hline $\mathbf{2 0 0 3 - 2 0 0 4}$ & Down & Up \\
\hline $\mathbf{2 0 0 4 - 2 0 0 5}$ & Up & Down \\
\hline $\mathbf{2 0 0 5 - 2 0 0 6}$ & Down & Down \\
\hline $\mathbf{2 0 0 6 - 2 0 0 7}$ & Down & Down \\
\hline $\mathbf{2 0 0 7 - 2 0 0 8}$ & Down & Up \\
\hline $\mathbf{2 0 0 8 - 2 0 0 9}$ & Up & \\
\hline
\end{tabular}

\subsection{Improving Prediction by Changing Sample Size}

As discussed in Section 12.5, the only options for improving Type I and II errors are to introduce new variables or change the sample size. Because trade data and CFO were collected but unused in the formation of second stage results, they were later combined with second stage scores and applied as variables to other data mining techniques in an attempt to improve prediction. However, these efforts were futile.

Until this point, with all companies studied between 1996 to 2009, the ratio of active to bankrupt companies was 61 to 18 (3.4 to 1), and the ratio of active to bankrupt DMUs (company and year) was 651 to 50 (13 to 1$)$. What happens when this ratio is reduced? Figure 12.13, Figure 12.14, Figure 12.15 and Figure 12.16 plot the sensitivity, specificity, and Type I and Type II errors of the second stage model as a function of cut-off value, while decreasing the ratio of active to bankrupt firms from 3.4:1 to $3: 1,2: 1$ and $1: 1$, respectively. Here, each DMU represented a company only with a score averaged of all years in which data were available for the company. The companies selected for each subset were not random but the best and worst firms as determined by their average layered scores. This practice was justified as in theory, it is important to build a database of the best and worst companies such that new data (a new company) can be judged against these benchmarks.

As the ratio of active to bankrupt firms dropped, the sensitivity and specificity increased while the Type I and II errors decreased. In fact, when the ratio was either 2:1 or $1: 1$ with a cut-off value of 0.6 , and between 0.60 and 0.70 , respectively, there was perfect classification. This result was consistent with the common practice taken by Altman and other studies that model with an equal number of active and bankrupt companies (known to 
improve prediction results) despite not being representative of reality where the ratio of active to bankrupt firms is much higher. In other words, the second stage model developed in this thesis was a less biased approach given that it maintained a more natural ratio of active to bankrupt companies.
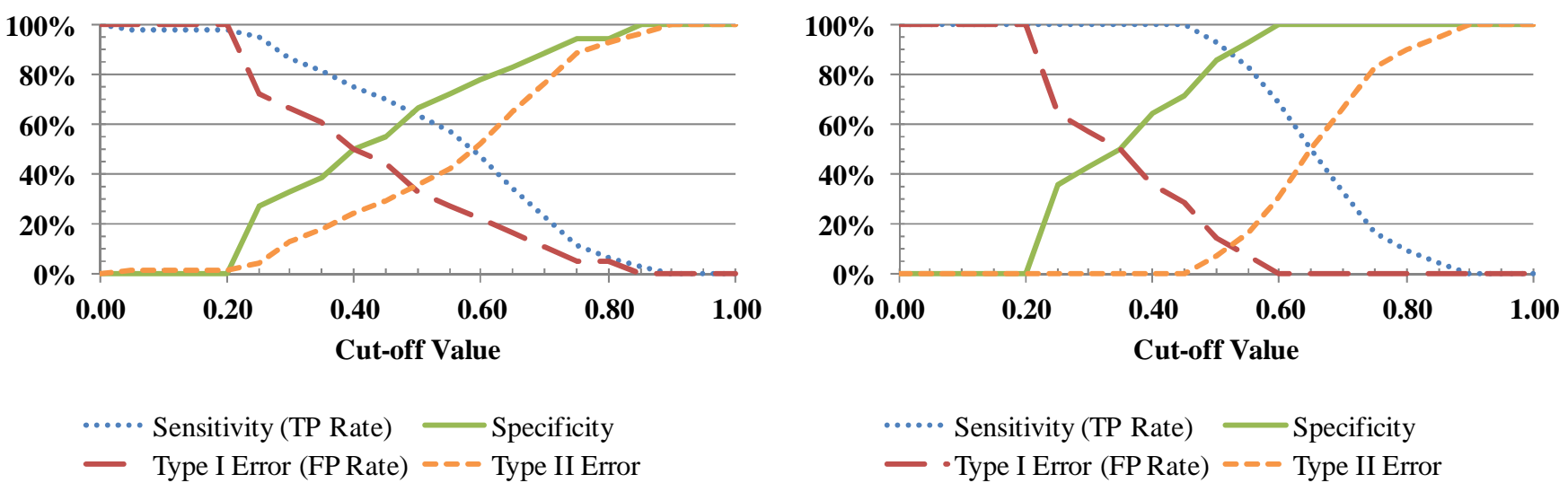

Figure 12.13: All Companies (3.4-to-1 Ratio)
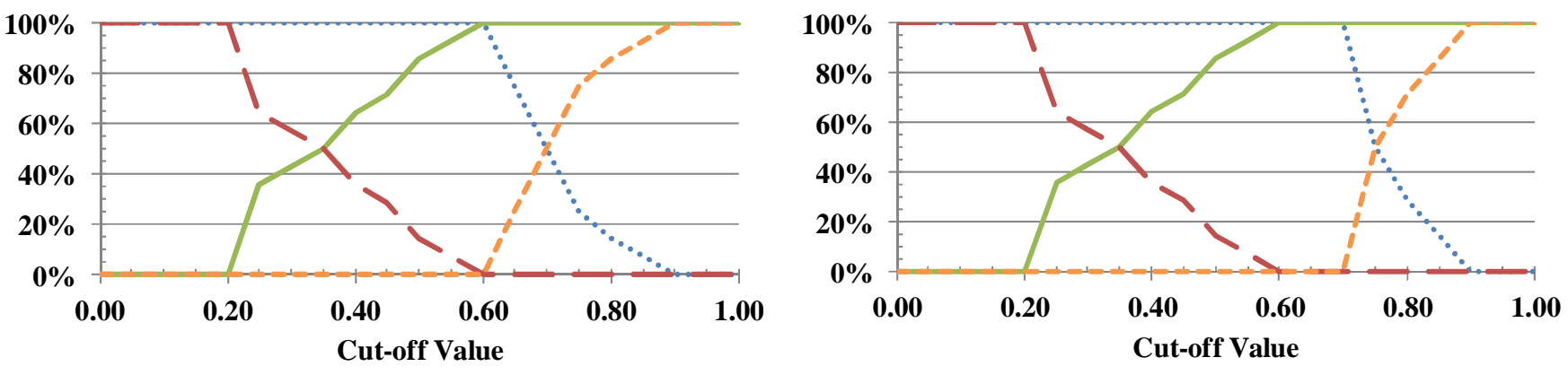

… Sensitivity (TP Rate) $\quad$ Specificity
— Type I Error (FP Rate)
$-\infty-$ Type II Error

Figure 12.15: 2-to-1 Ratio

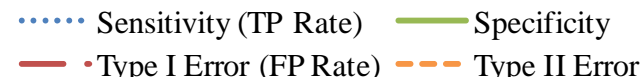

Figure 12.14: 3-to-1 Ratio

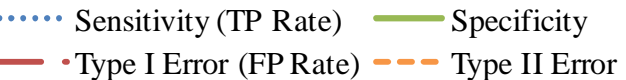

Figure 12.16: 1-to-1 Ratio

\subsection{Translating DEA Results into Targets of Improvement}

A major advantage of DEA technology is that it provides tangible targets for improvement. Recall that an inefficient DMU can be "improved" by referring its inefficient behaviour to the efficient frontier formed by $E_{o}$, the reference set of $\mathrm{DMU}_{o}$ composed of efficient DMUs. This improvement is an SBM projection to the point $\left(\widehat{\boldsymbol{x}}_{\boldsymbol{o}}, \widehat{\boldsymbol{y}}_{\boldsymbol{o}}\right)$ on the frontier where:

$$
\begin{array}{ll}
\hat{x}_{i o}=x_{i o}-s_{i}^{-*} & (i=1, \ldots, m) \\
\hat{y}_{r o}=y_{r o}+s_{r}^{+^{*}} & (r=1, \ldots, s)
\end{array}
$$


$\left(\widehat{\boldsymbol{x}}_{\boldsymbol{o}}, \widehat{\boldsymbol{y}}_{\boldsymbol{o}}\right)$ are the coordinates of a virtual linear composite DMU (i.e. $\sum D M U_{i} \lambda_{i}$ where $D M U_{i}$ 's are efficient and $\lambda_{i}$ are proportionality weights for $D M U_{i}$ ) used to evaluate the performance of $\mathrm{DMU}_{o}$. It represents the target for efficient production that $\mathrm{DMU}_{o}$ strives for (Cooper et al., 2007). $s^{+*}$ are output shortfalls while $s^{-*}$ are inputs which must be reduced and augmented, respectively, to improve efficiency.

As an example, Figure 12.17 presents the second stage projections of an active firm (AEO) and bankrupt firm (FTUS) based on non-layered results (i.e. after one run). These DMUs, which were not on the frontier because their second stage scores were less than 1, show that the lower the score, the greater the possibilities for expansion of outputs for improvement. In fact, the second stage projections are a guide for which aspects of the company, as represented by individual metrics, should be targeted.

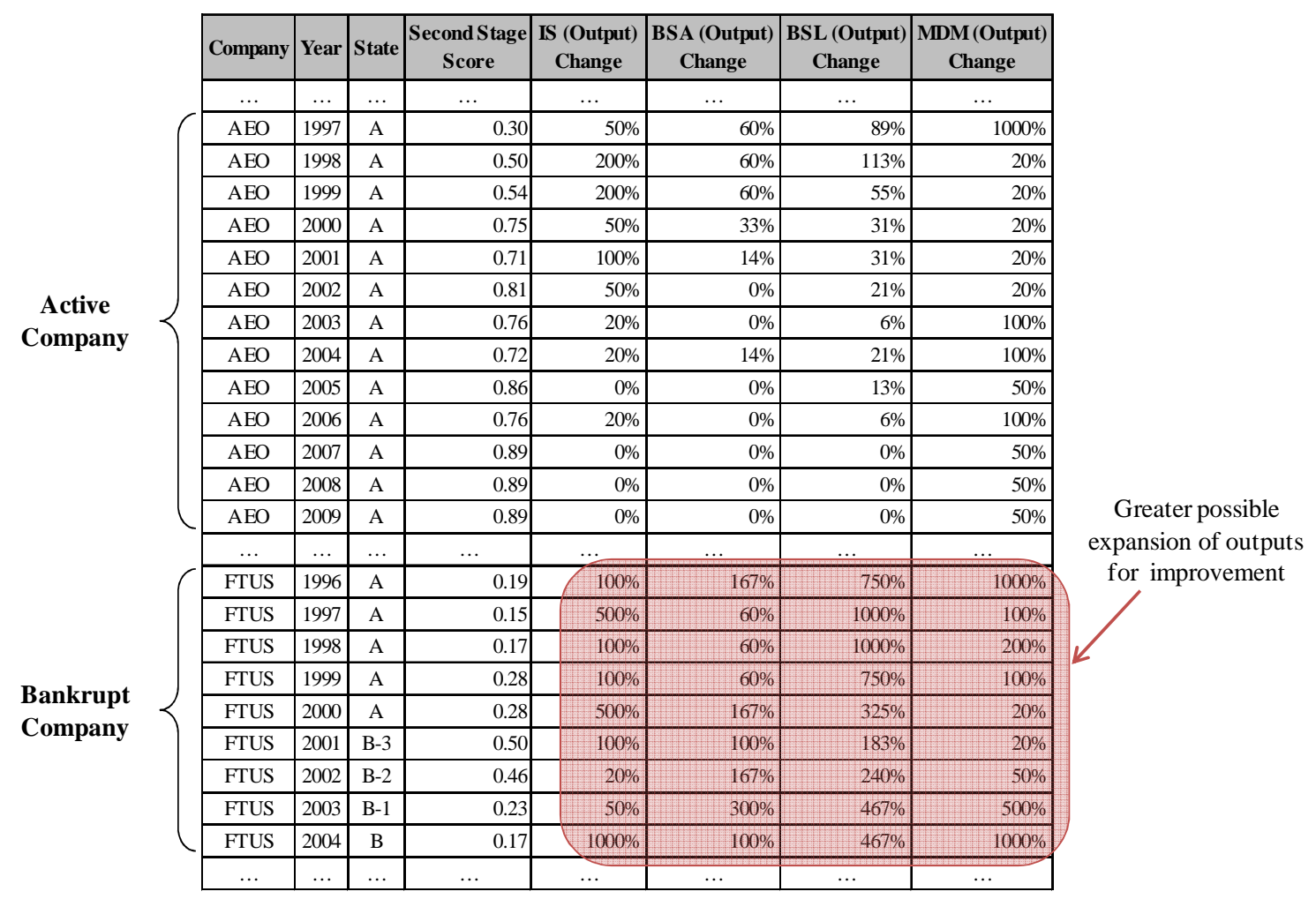

Figure 12.17: Projections for Metrics in the Second Stage for Selected DMUs

For instance, Figure 12.18 presents the projections for the income statement (IS) metric. As seen, in the years prior to bankruptcy, the COGS and SGA of FTUS could be reduced by as much as $20 \%$. In addition, FTUS's net income was significantly less than the healthiest companies. This exercise can be applied to each metric to learn which specific variables can be improved upon. There is also room for improvement for active DMUs that are not among 
the healthiest group. These projections not only provide valuable bankruptcy preventative measures, but also profitability strategies.

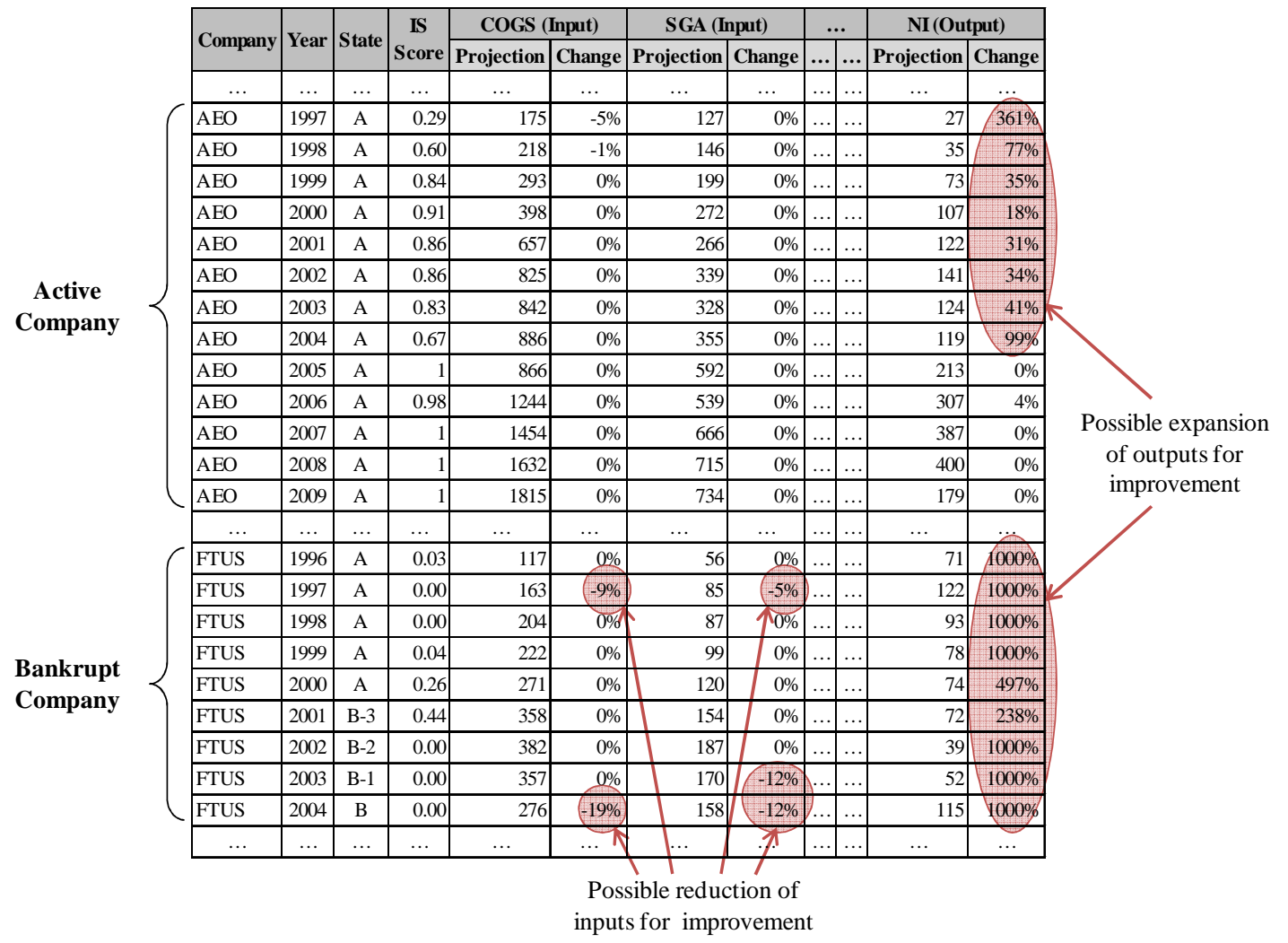

Figure 12.18: Projections for IS Metric Variables for Selected DMUs

Figure 12.19 - Figure 12.53 present the recommended percent changes for all variables of each metric: for inputs, these projections were reductions while for outputs, they were expansions. These histograms focus primarily on bankrupt DMUs. For the results of active companies, please refer to Appendix F.7.

On average, the greatest opportunities for improvement on the income statement for bankrupt DMUs were to reduce net interest expense and income tax expense, as well as to increase net income (Figure 12.19 - Figure 12.24). 


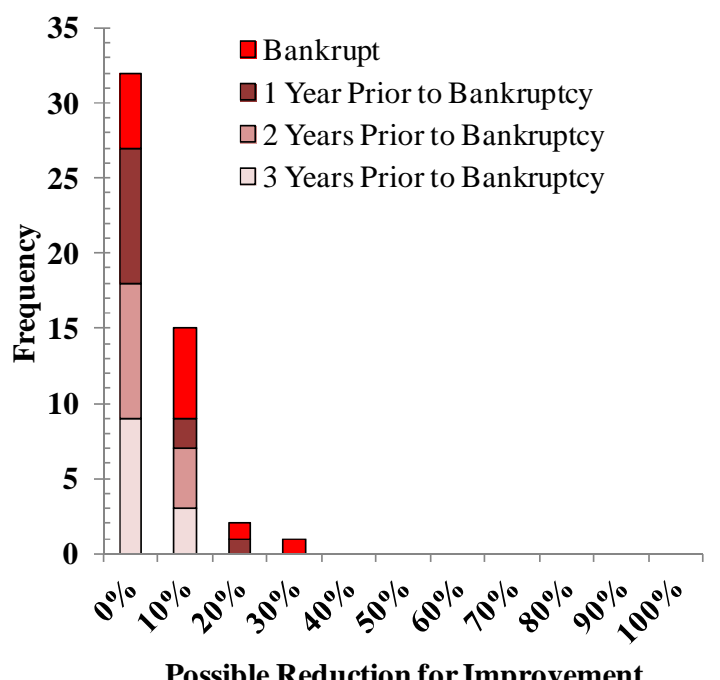

Possible Reduction for Improvement

Figure 12.19: IS Projections for COGS Mean $=2.2 \% \pm 4.9 \% ;$ Median $=0 \%$

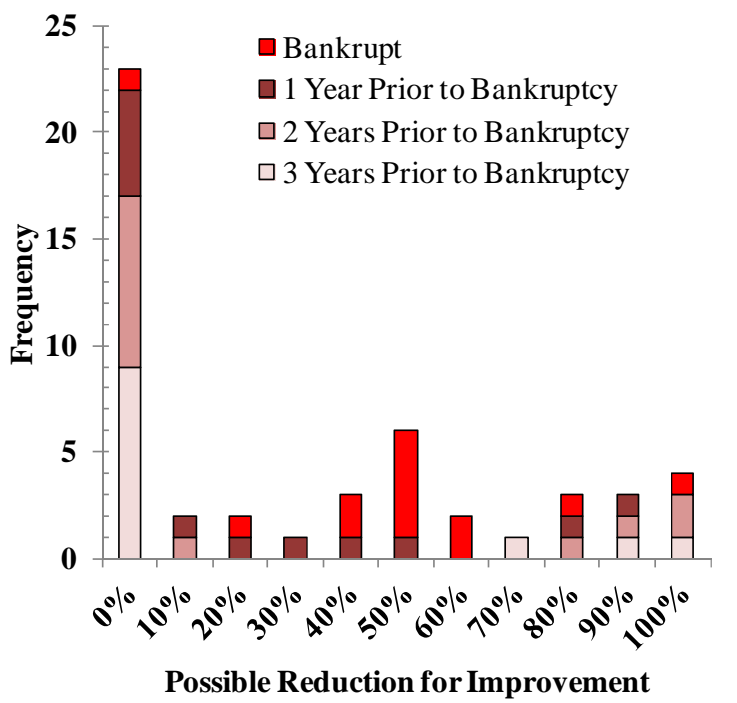

Figure 12.21: IS Projections for Net Interest Expense

Mean $=30 \% \pm 35 \% ;$ Median $=10 \%$;

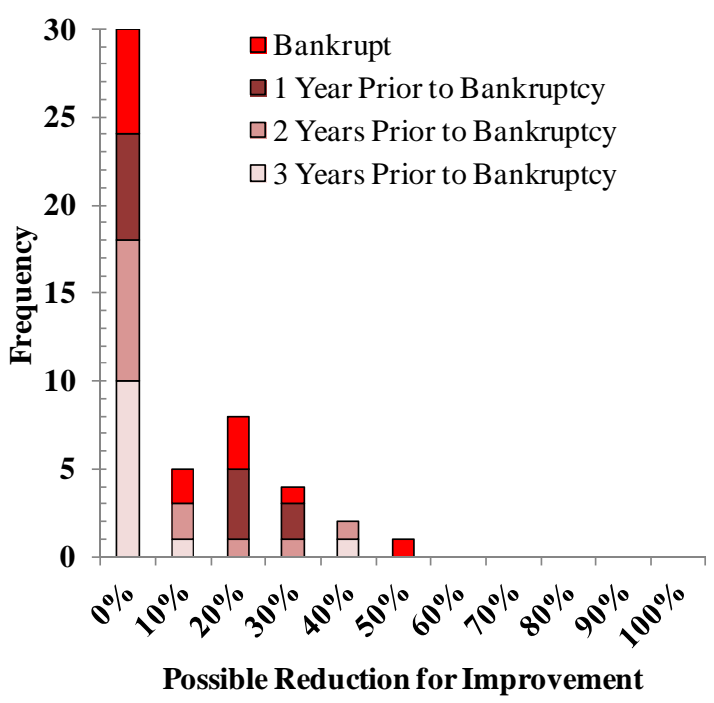

Figure 12.20: IS Projections for SGA Mean $=7 \% \pm 11 \% ;$ Median $=0 \%$

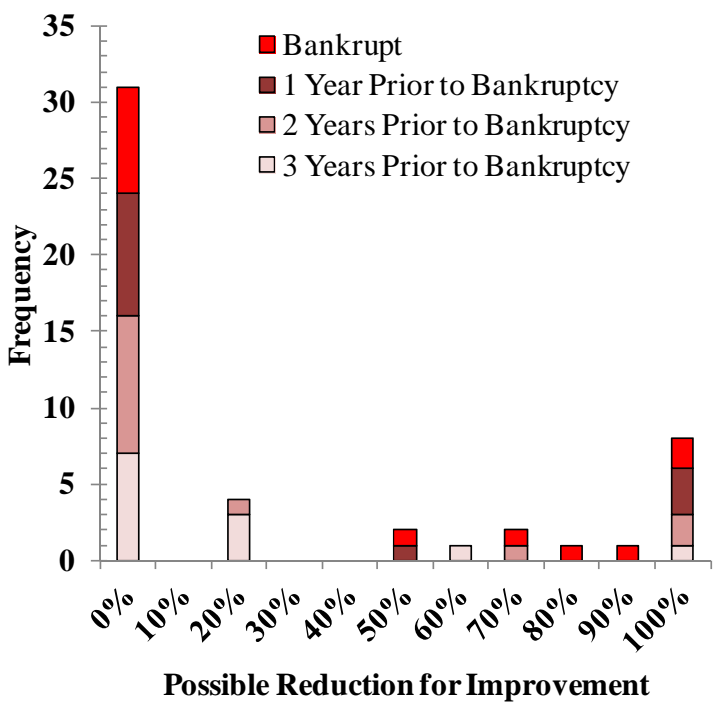

Figure 12.22: IS Projections for Income Tax Expense

Mean $=25 \% \pm 38 \% ;$ Median $=0 \%$ 


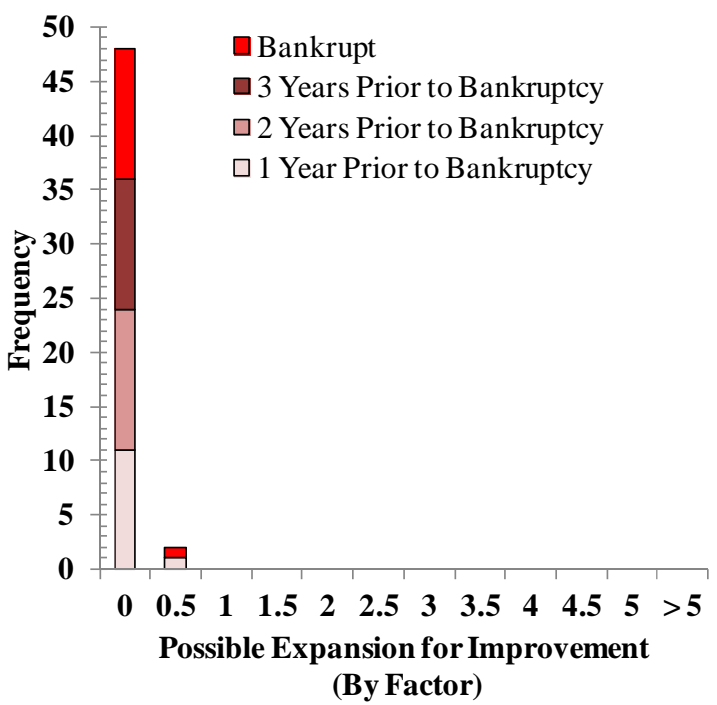

Figure 12.23: IS Projections for Revenue Mean $=0.1 \% \pm 0.4 \% ;$ Median $=0 \%$

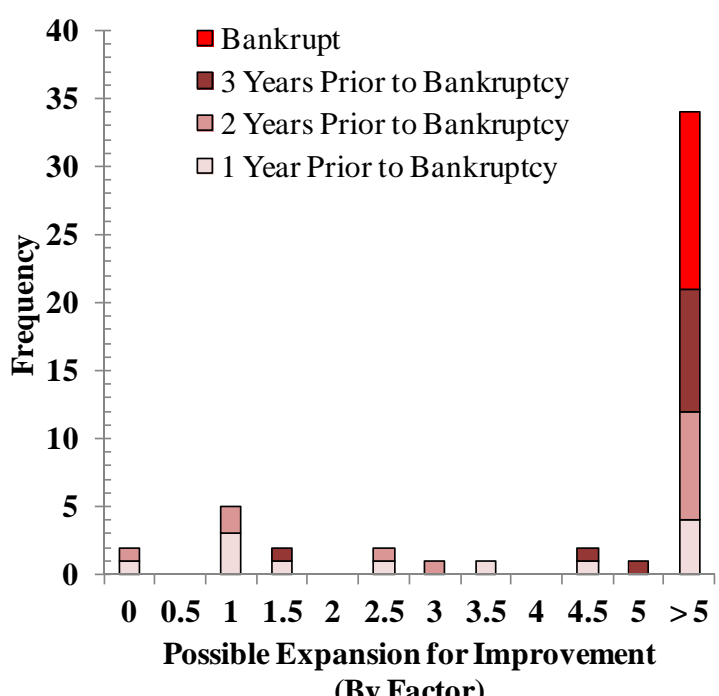

(By Factor)

Figure 12.24: IS Projections for Net Income Mean $=710 \% \pm 390 \%$; Median $=999 \%$

Within asset categories on the balance sheet, the average bankrupt DMUs could have reduced accounts receivable, inventories, goodwill, PPE and total assets, and increased cash, retained earnings and shareholders' equity (Figure 12.25 - Figure 12.35).

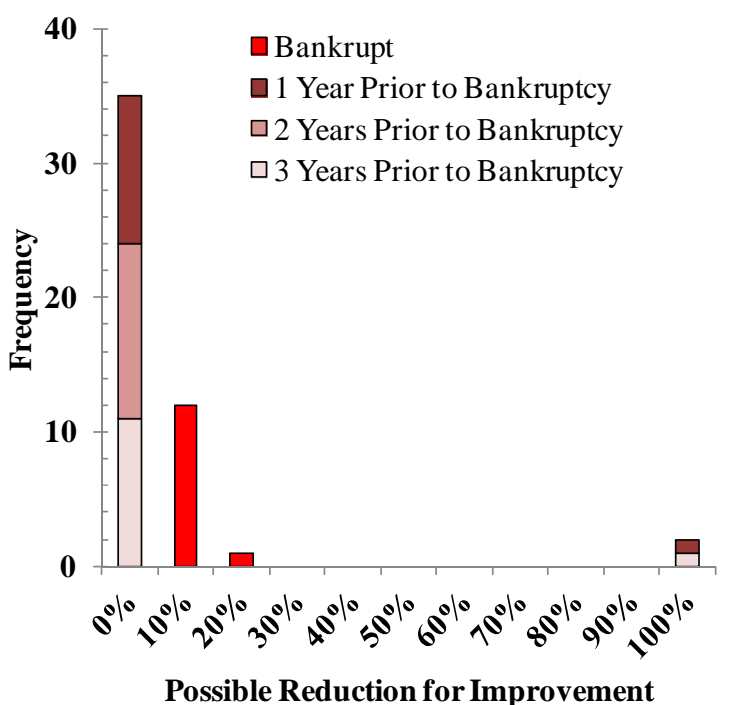

Figure 12.25: BSA Projections for Marketable Securities

Mean $=4 \% \pm 20 \% ;$ Median $=0 \%$

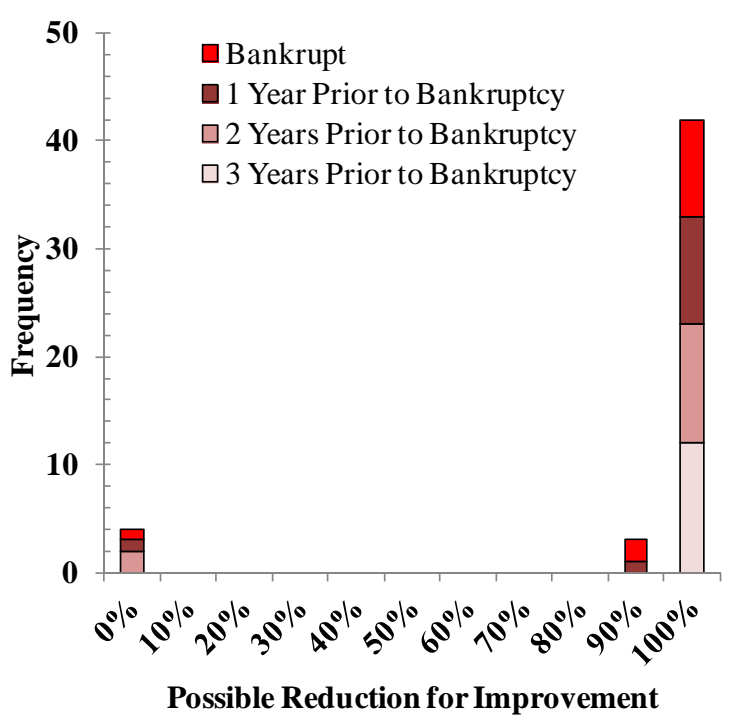

Figure 12.26: BSA Projections for Accounts Receivable

Mean $=90 \% \pm 28 \% ;$ Median $=100 \%$ 


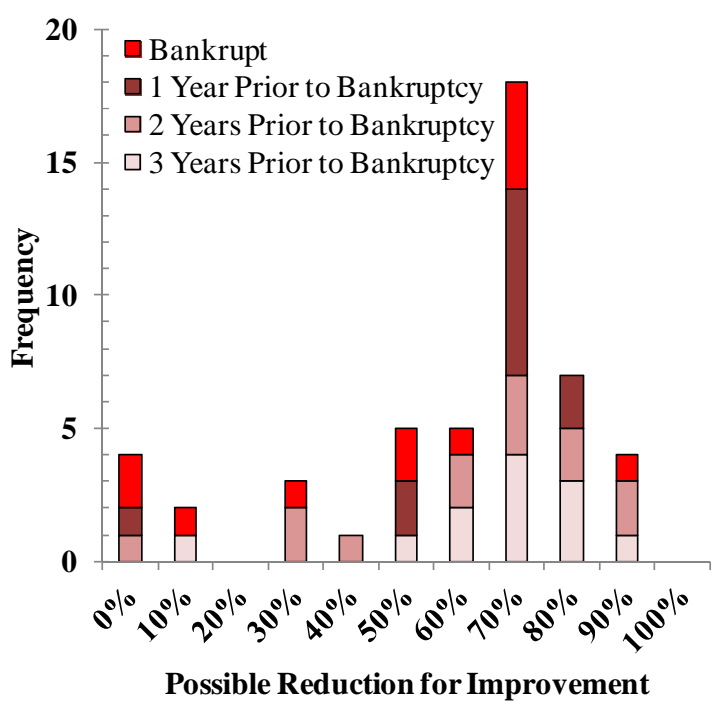

Figure 12.27: BSA Projections for Inventories Mean $=54 \% \pm 24 \%$; Median $=62 \%$

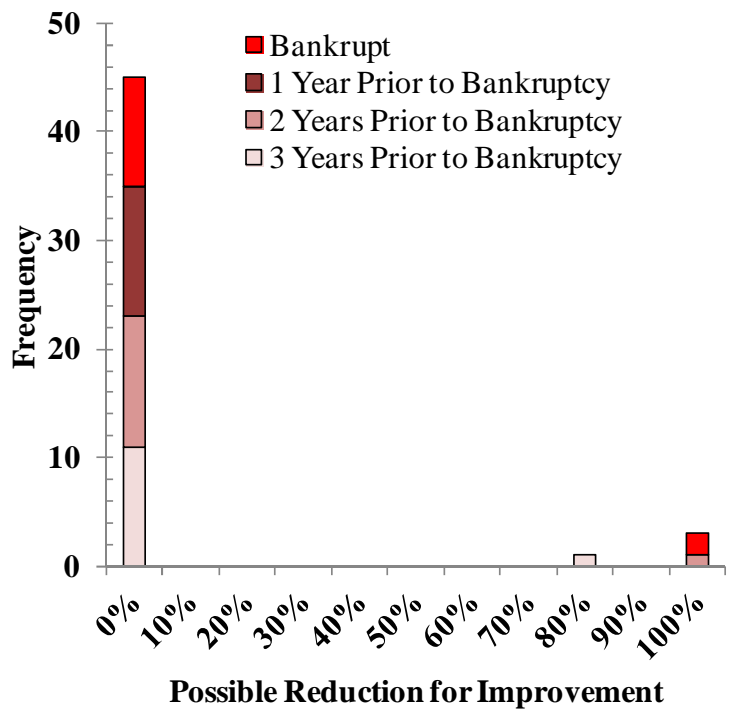

Figure 12.29: BSA Projections for Long-Term Investment in Securities Mean $=8 \% \pm 25 \% ;$ Median $=0 \%$

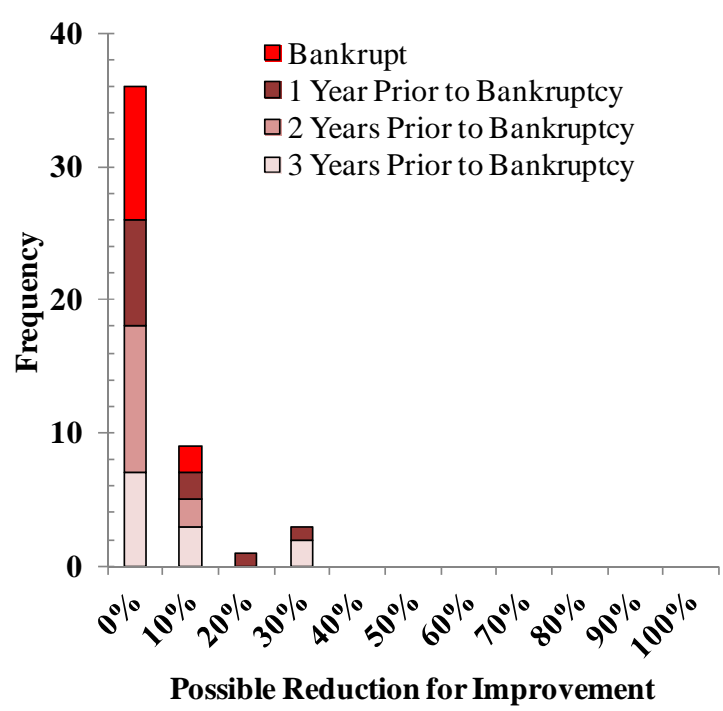

Figure 12.28: BSA Projections for Current Assets Mean $=2.5 \% \pm 6.3 \% ;$ Median $=0 \%$

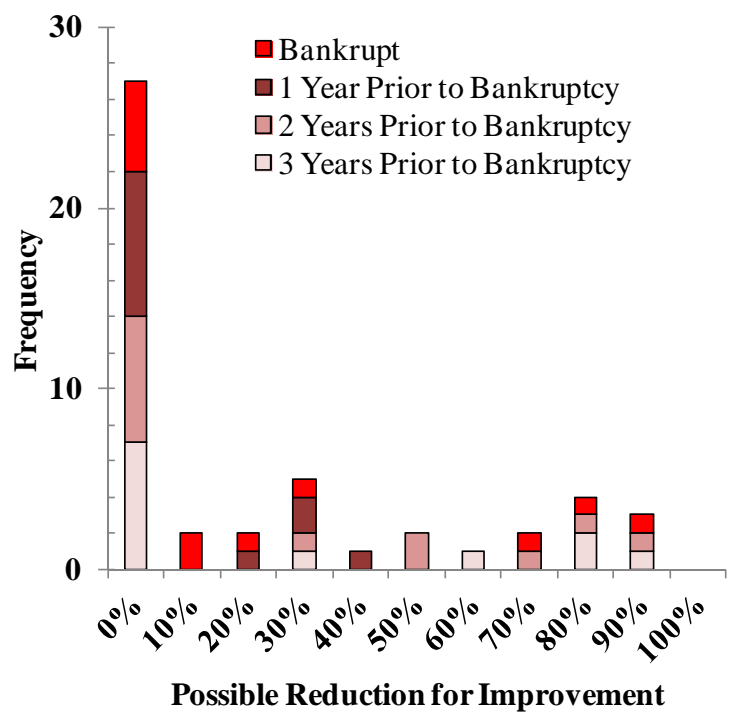

Figure 12.30: BSA Projections for Net PPE Mean $=21 \% \pm 30 \% ;$ Median $=0 \%$ 


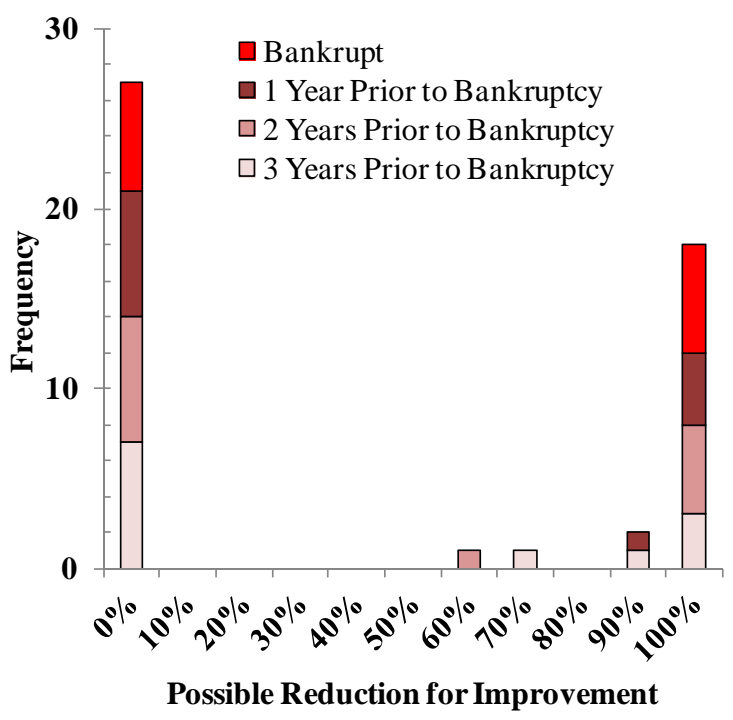

Figure 12.31: BSA Projections for Goodwill Mean $=42 \% \pm 48 \% ;$ Median $=0 \%$

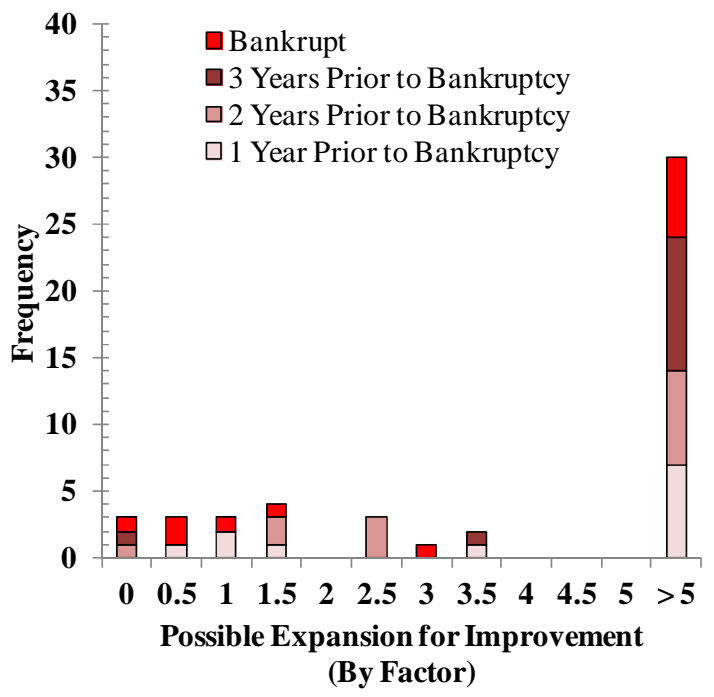

Figure 12.33: BSA Projections for Cash Mean $=620 \% \pm 420 \%$; Median $=990 \%$

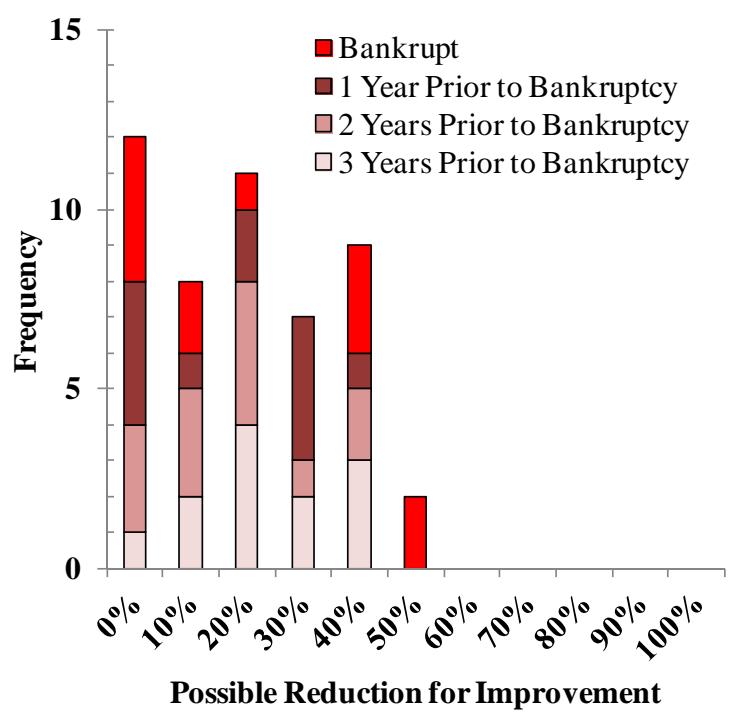

Figure 12.32: BSA Projections for Total Assets Mean $=16 \% \pm 13 \% ;$ Median $=18 \%$

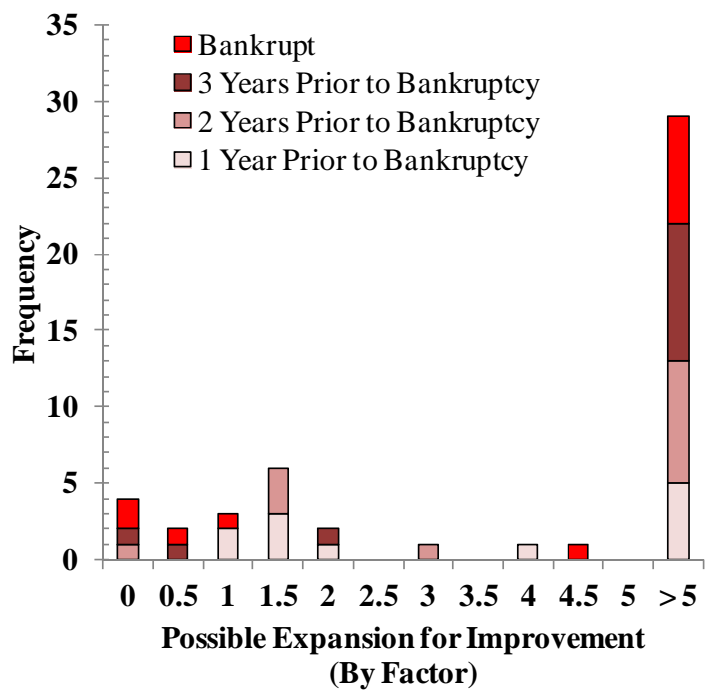

Figure 12.34: BSA Projections for Retained Earnings

Mean $=610 \% \pm 430 \% ;$ Median $=890 \%$ 


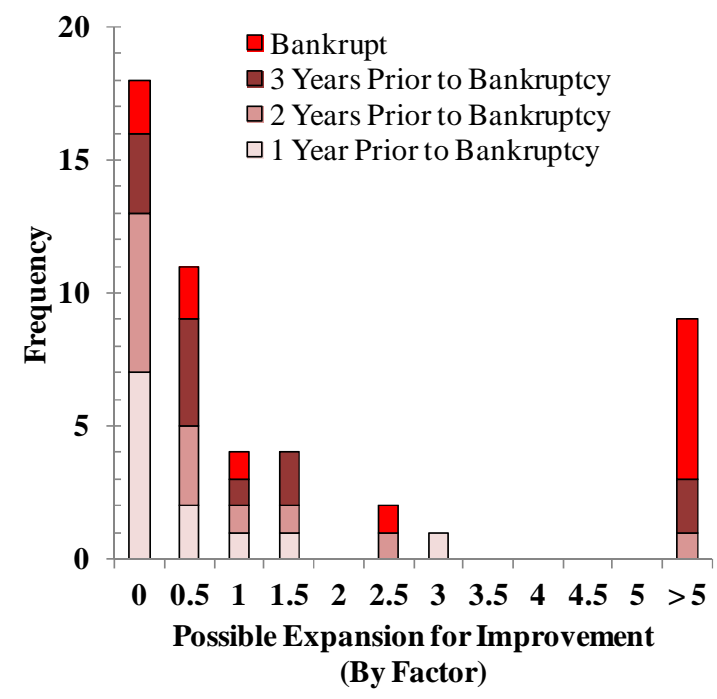

Figure 12.35: BSA Projections for Shareholders' Equity Mean $=210 \% \pm 360 \% ;$ Median $=24 \%$

With respect to liabilities on the balance sheet, the average bankrupt DMU could have reduced notes payable and short-term debt, long-term debt, accounts payable, current maturities, current liabilities, total liabilities, and increased retained earnings and shareholders' equity (Figure 12.36 - Figure 12.43).

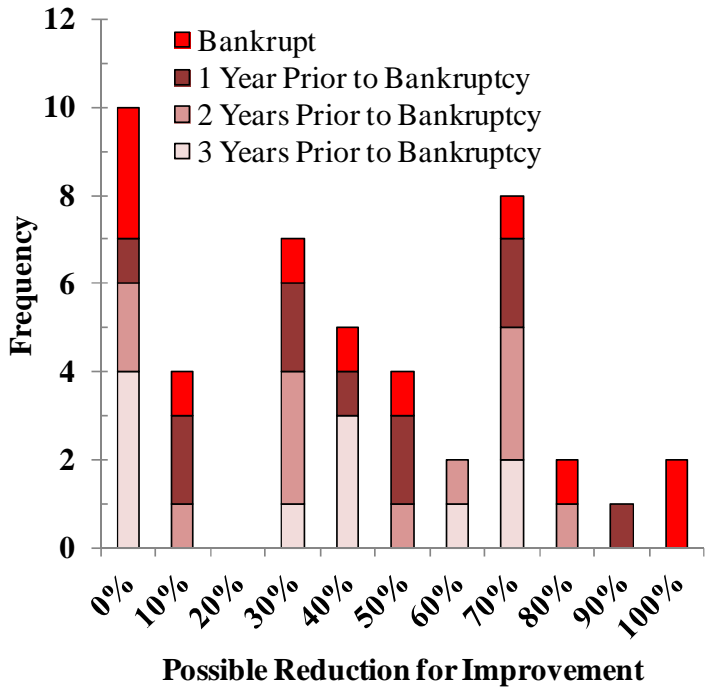

Figure 12.36: BSL Projections for Accounts Payable

Mean $=36 \% \pm 29 \% ;$ Median $=37 \%$

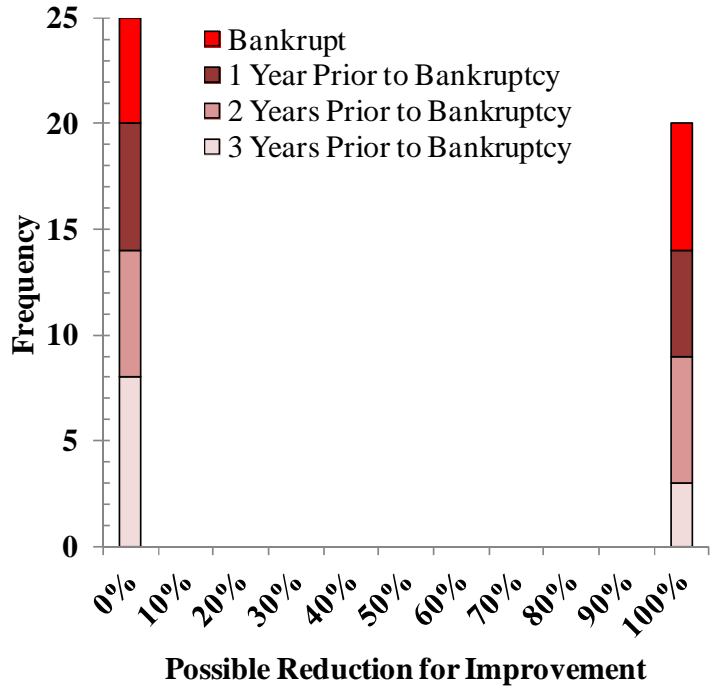

Figure 12.37: BSL Projections for Notes Payable and Short-Term Debt Mean $=44 \% \pm 50 \% ;$ Median $=0 \%$ 


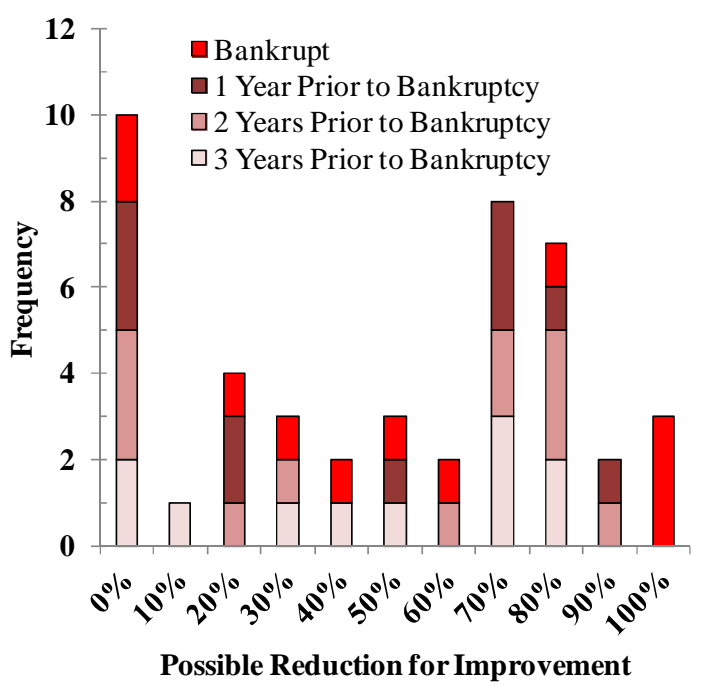

Figure 12.38: BSL Projections for Current

Maturities of Long-Term Debt

Mean $=44 \% \pm 33 \% ;$ Median $=46 \%$

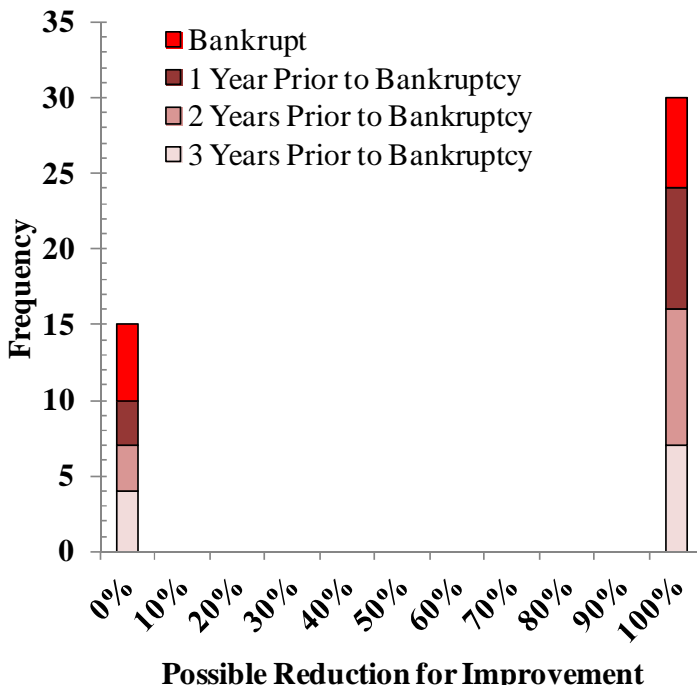

Figure 12.40: BSL Projections for Long-Term Debt

Mean $=67 \% \pm 48 \% ;$ Median $=100 \%$

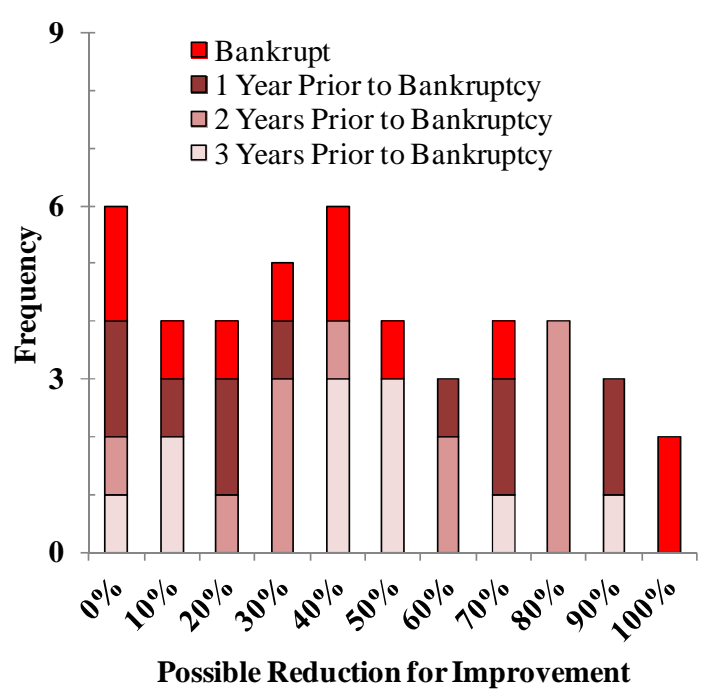

Figure 12.39: BSL Projections for Current Liabilities

Mean $=40 \% \pm 30 \% ;$ Median $=36 \%$

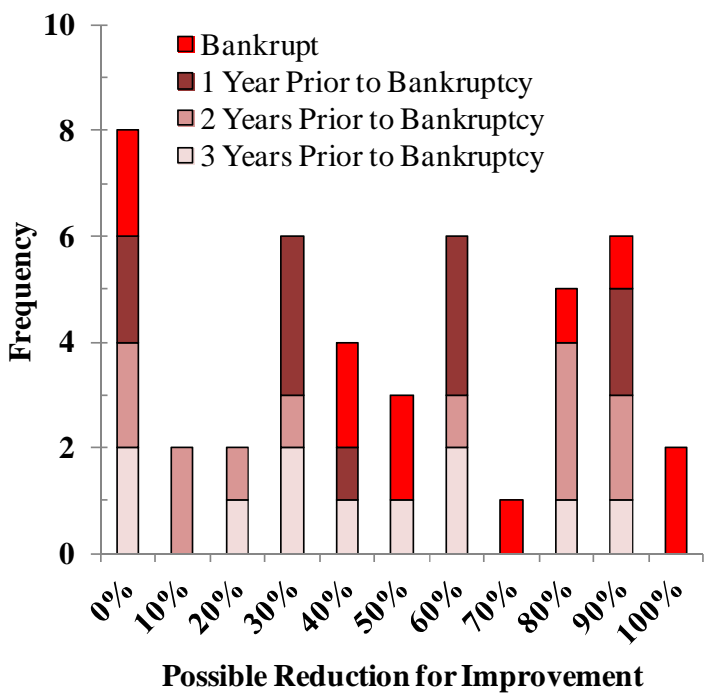

Figure 12.41: BSL Projections for Total Liabilities Mean $=43 \% \pm 32 \% ;$ Median $=43 \%$ 


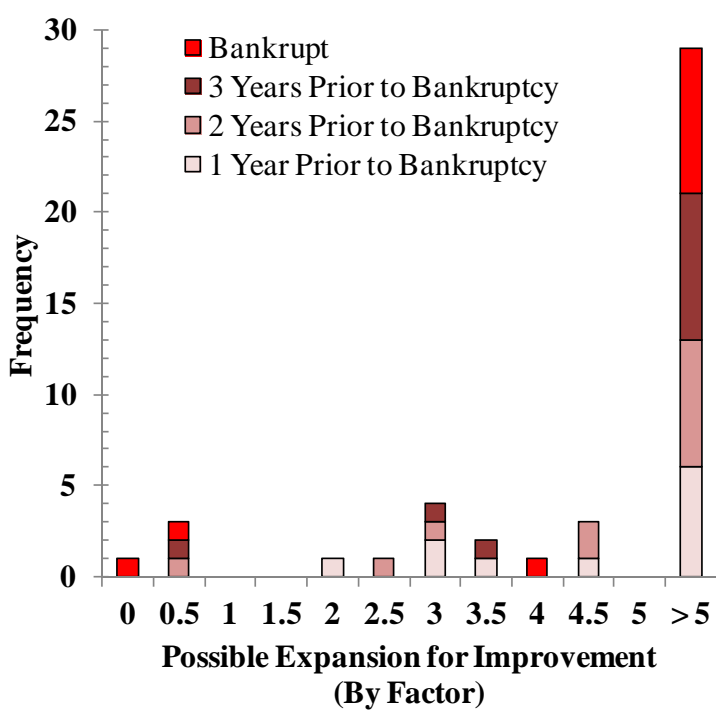

Figure 12.42: BSL Projections for Retained Earnings

Mean $=710 \% \pm 380 \% ;$ Median $=1000 \%$

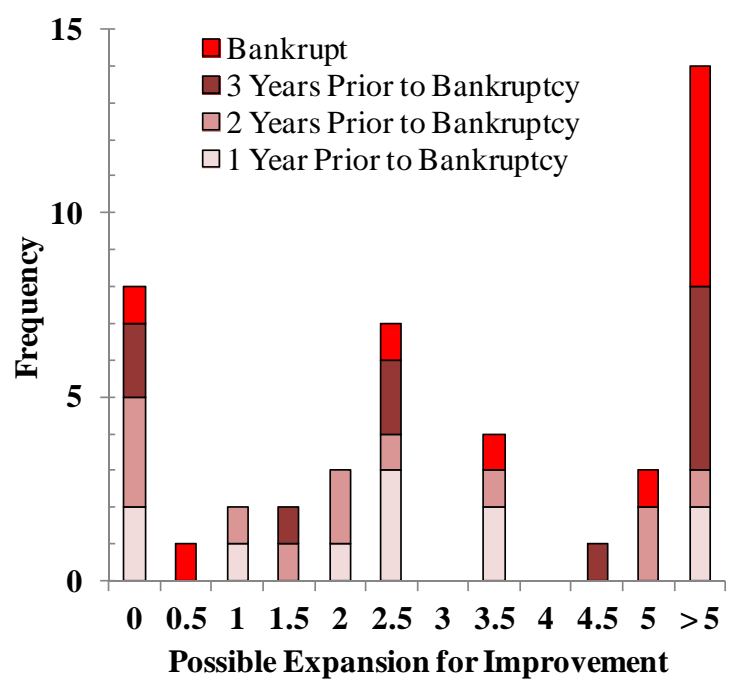

(By Factor)

Figure 12.43: BSL Projections for Shareholders' Equity

Mean $=380 \% \pm 350 \% ;$ Median $=250 \%$

Opportunities for improvement with respect to managerial decision-making for bankrupt DMUs were to reduce management turnover, legal proceedings, related party transactions and retirement plans (Figure 12.44 - Figure 12.49).

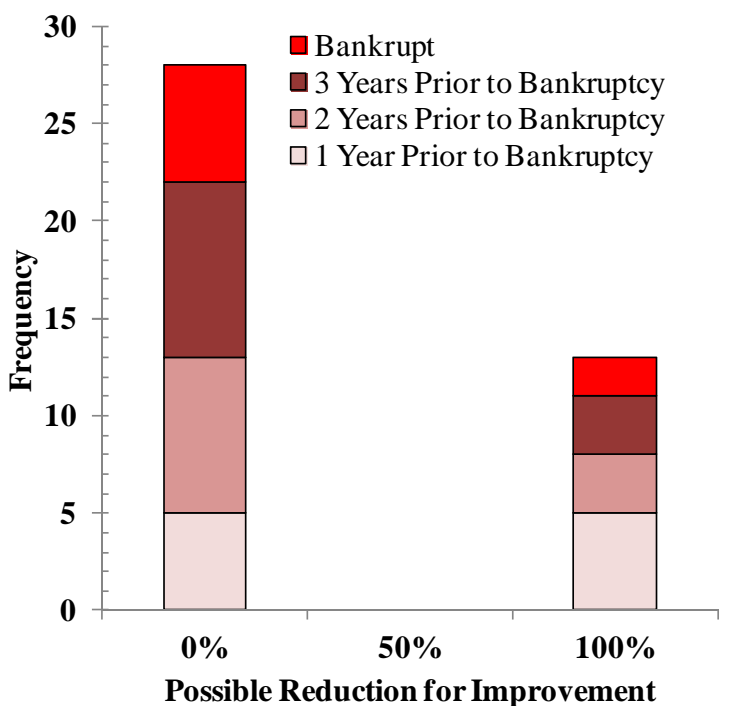

Figure 12.44: MDM Projections for Related Party Transactions

Mean $=32 \% \pm 47 \% ;$ Median $=0 \%$

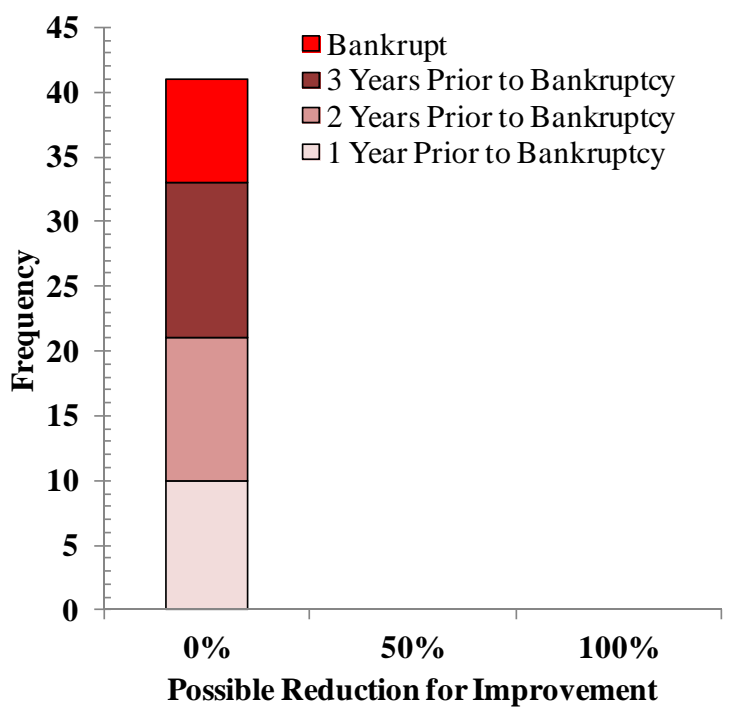

Figure 12.45: MDM Projections for Auditor's Opinion Mean $=0 \% \pm 0 \% ;$ Median $=0 \%$ 


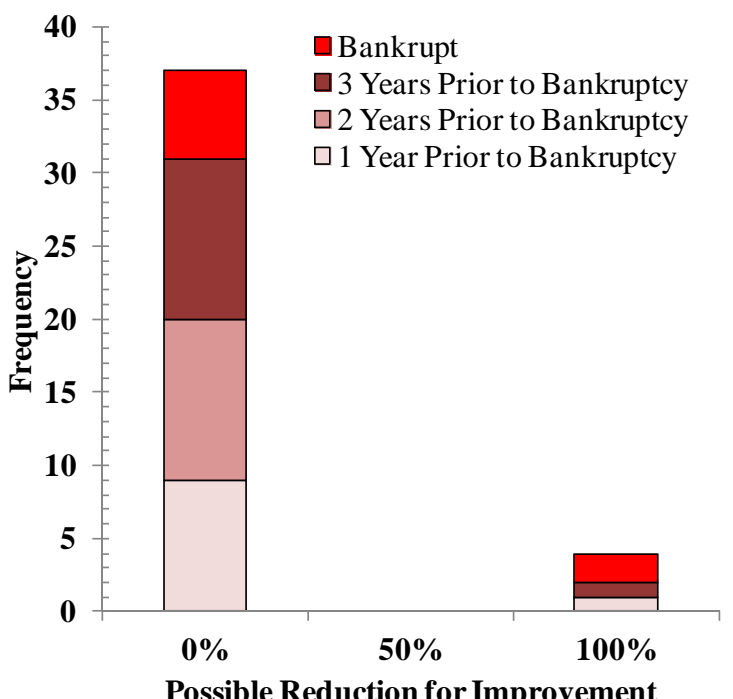

Figure 12.46: MDM Projections for Change of Auditor

Mean $=10 \% \pm 30 \% ;$ Median $=0 \%$

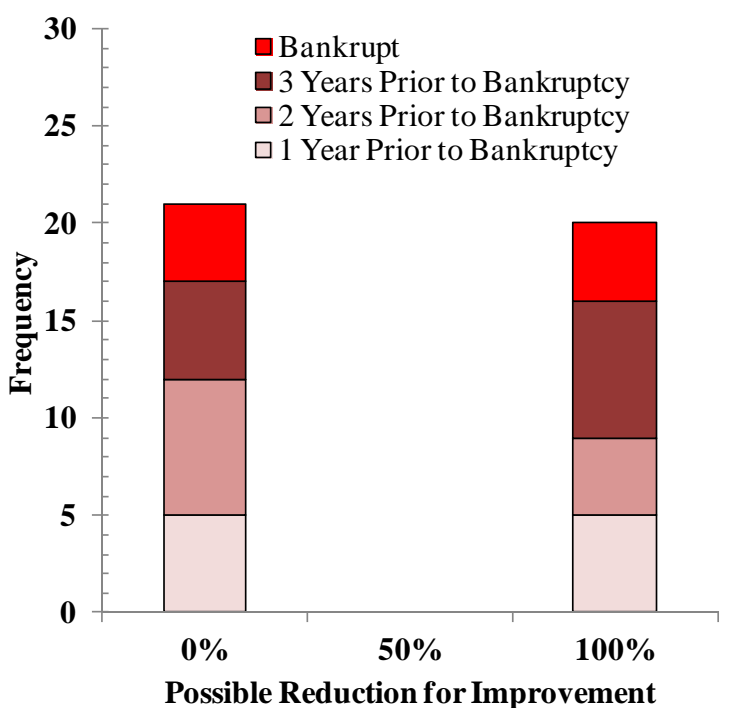

Figure 12.48: MDM Projections for Legal Proceedings

Mean $=45 \% \pm 47 \%$; Median $=0 \%$

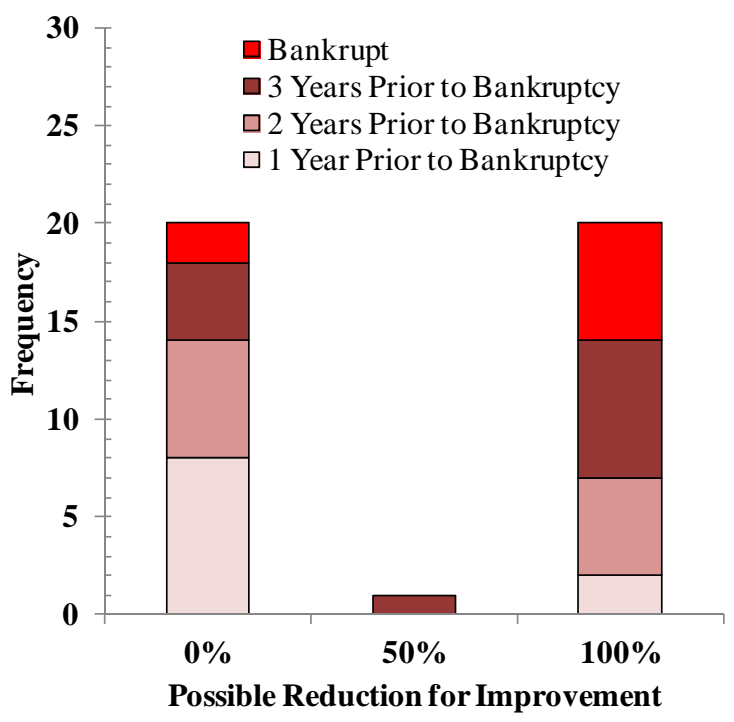

Figure 12.47: MDM Projections for Management Turnover

Mean $=48 \% \pm 49 \% ;$ Median $=50 \%$

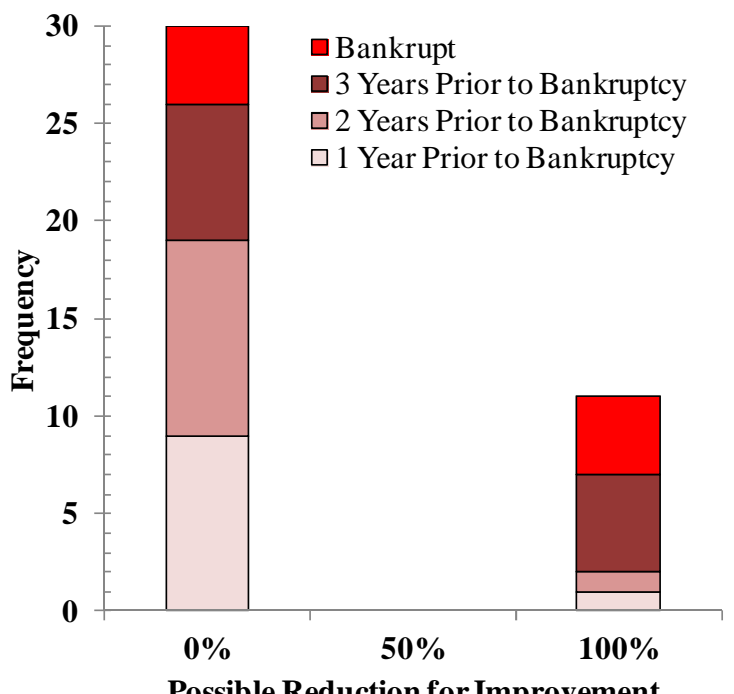

Possible Reduction for Improvement

Figure 12.49: MDM Projections for Retirement Plan

Mean $=27 \% \pm 45 \% ;$ Median $=0 \%$

Finally, in terms of overall health (second stage) of bankrupt DMUS, all metrics could have been improved upon (Figure 12.50 - Figure 12.53). 


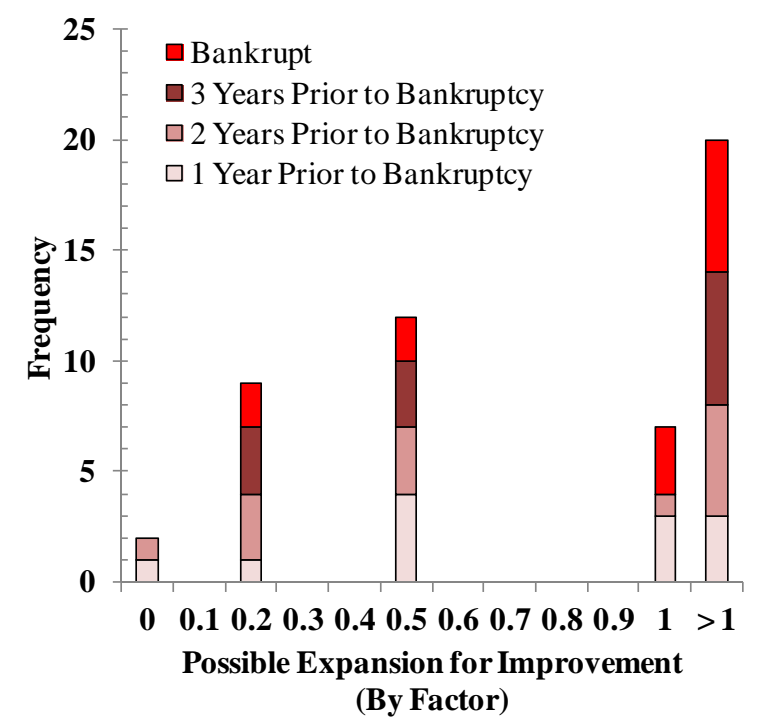

Figure 12.50: Second Stage Projections for IS Metric

Mean $=220 \% \pm 280 \% ;$ Median $=100 \%$

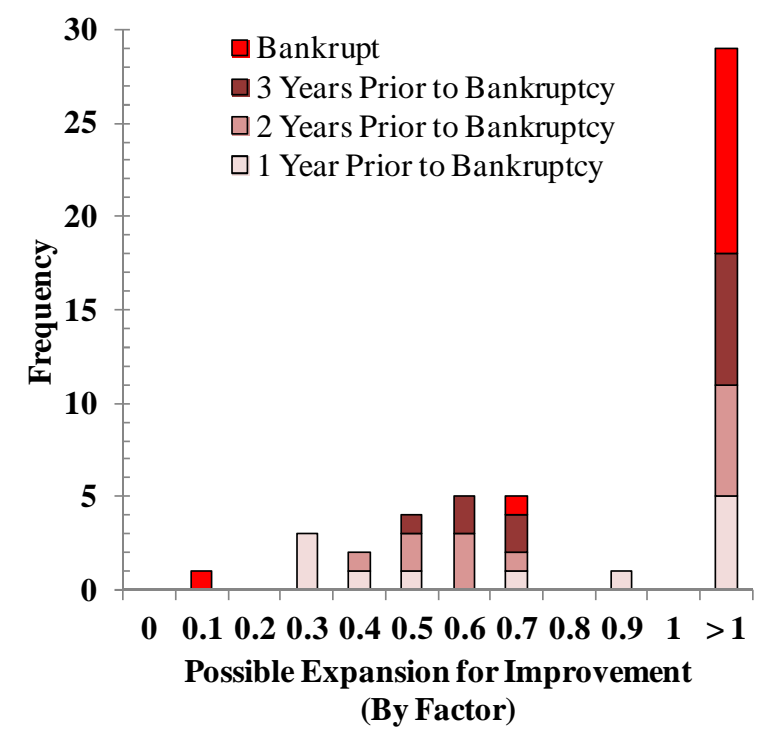

Figure 12.52: Second Stage Projections for BSL Metric

Mean $=280 \% \pm 330 \% ;$ Median $=160 \%$

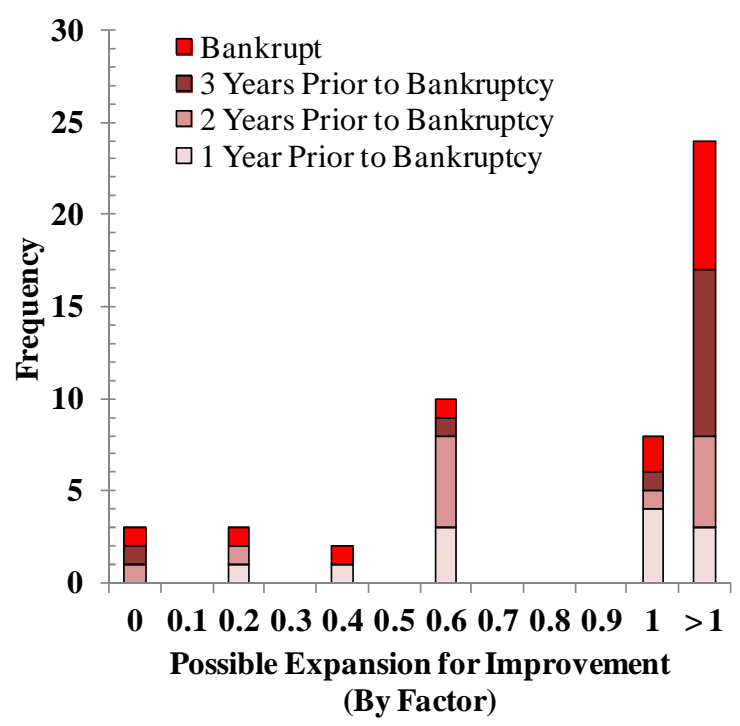

Figure 12.51: Second Stage Projections for BSA Metric

Mean $=360 \% \pm 400 \% ;$ Median $=100 \%$

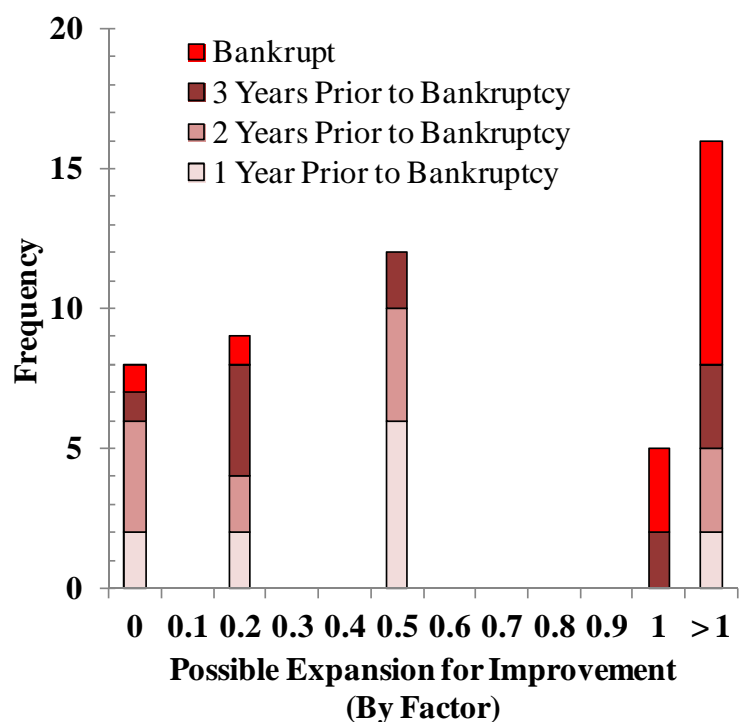

Figure 12.53: Second Stage Projections for MDM Metric

Mean $=300 \% \pm 410 \% ;$ Median $=50 \%$ 


\section{Prediction and Validation of the Second Stage DEA Model}

\subsection{Estimating the Probability of Bankruptcy}

Like Altman's Z-Score and most studies, results from the layering technique provide dichotomous predictions of bankruptcy (i.e. "yes" or "no") but not probabilities. Knowing the chance of failure is valuable because it associates a level of confidence or warning to each DMU; that is, one can answer the question: what is the probability of a DMU going bankrupt given a particular second stage layered score?

A histogram of the second stage layered scores shows that as the scores increased, fewer bankrupt DMUs appeared on the frontier (Figure 13.1). The cumulative number of active and bankrupt DMUs on the frontier, starting from the last layer (i.e. when the score is zero), were counted, from which the actual probabilities of bankruptcy and non-bankruptcy were then computed (Table 13.1). As expected, the higher the score (which is inversely related to the layer that a DMU appears on the frontier), the less probability of bankruptcy. With actual discrete probabilities for comparison, the scores were translated into continuous probabilities with the cumulative distribution function (CDF) of the standard normal distribution and a second order polynomial.

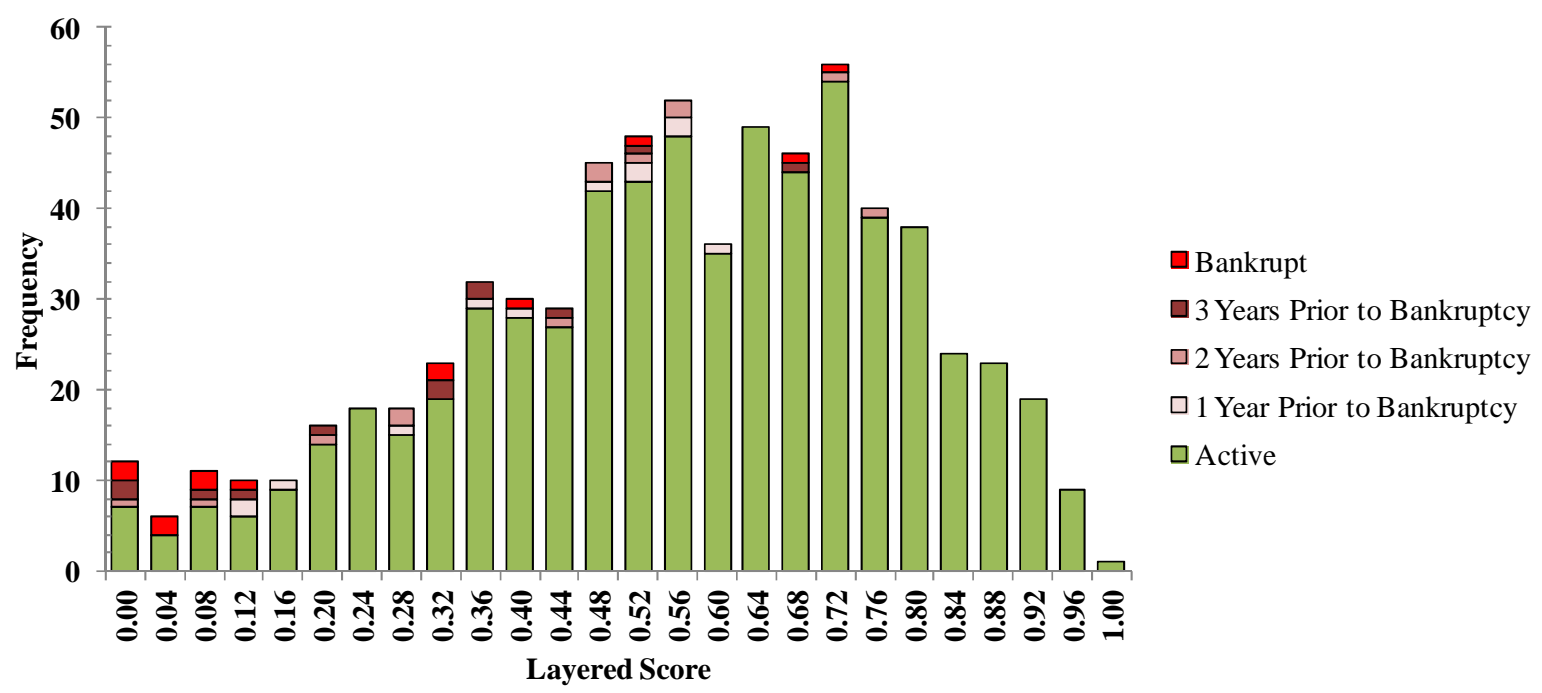

Figure 13.1: Distribution of Second Stage Layered Scores Mean $=0.55 \pm 0.23 ;$ Median $=0.56 ;$ Kurtosis $=-0.39 ;$ Skewness $=0.56$ 
Table 13.1: Probabilities of Bankruptcy (B) and Non-Bankruptcy (NB)

A DMU is classified bankrupt up to 3 years prior to filing Chapter 11.

\begin{tabular}{|c|c|c|c|c|c|c|c|c|c|c|c|c|c|}
\hline \multirow{3}{*}{ Layer } & \multirow{3}{*}{ Score } & \multicolumn{8}{|c|}{ Actual } & \multicolumn{4}{|c|}{ Estimates } \\
\hline & & \multicolumn{3}{|c|}{$\begin{array}{l}\text { Count of } \\
\text { DMUs on } \\
\text { Frontier }\end{array}$} & \multicolumn{3}{|c|}{$\begin{array}{l}\text { Cumulative Count of } \\
\text { DMUs on Frontier }\end{array}$} & \multirow[t]{2}{*}{$\mathbf{P}(\mathrm{NB})$} & \multirow[t]{2}{*}{$\mathbf{P}(\mathbf{B})$} & \multicolumn{2}{|c|}{$\begin{array}{c}\text { Cumulative } \\
\text { Distribution } \\
\text { Function } \\
\end{array}$} & \multicolumn{2}{|c|}{$\begin{array}{c}\text { Second order } \\
\text { Polynomial } \\
\text { Function }\end{array}$} \\
\hline & & Total & NB & B & Total & NB & B & & & $\mathbf{P}(\mathrm{NB})$ & $\mathbf{P}(\mathbf{B})$ & $\mathbf{P}(\mathrm{NB})$ & $\mathbf{P}(\mathbf{B})$ \\
\hline 26 & 0.00 & - & - & - & - & - & - & - & - & $5.1 \%$ & $94.9 \%$ & $60.8 \%$ & $39.2 \%$ \\
\hline 25 & 0.04 & 6 & 4 & 2 & 6 & 4 & 2 & $66.7 \%$ & $33.3 \%$ & $6.6 \%$ & $93.4 \%$ & $63.9 \%$ & $36.1 \%$ \\
\hline 24 & 0.08 & 11 & 7 & 4 & 17 & 11 & 6 & $64.7 \%$ & $35.3 \%$ & $8.5 \%$ & $91.5 \%$ & $66.8 \%$ & $33.2 \%$ \\
\hline 23 & 0.12 & 10 & 6 & 4 & 27 & 17 & 10 & $63.0 \%$ & $37.0 \%$ & $10.7 \%$ & $89.3 \%$ & $69.5 \%$ & $30.5 \%$ \\
\hline 22 & 0.16 & 10 & 9 & 1 & 37 & 26 & 11 & $70.3 \%$ & $29.7 \%$ & $13.3 \%$ & $86.7 \%$ & $72.1 \%$ & $27.9 \%$ \\
\hline 21 & 0.20 & 16 & 14 & 2 & 53 & 40 & 13 & $75.5 \%$ & $24.5 \%$ & $16.3 \%$ & $83.7 \%$ & $74.6 \%$ & $25.4 \%$ \\
\hline 20 & 0.24 & 18 & 18 & 0 & 71 & 58 & 13 & $81.7 \%$ & $18.3 \%$ & $19.8 \%$ & $80.2 \%$ & $76.9 \%$ & $23.1 \%$ \\
\hline 19 & 0.28 & 18 & 15 & 3 & 89 & 73 & 16 & $82.0 \%$ & $18.0 \%$ & $23.6 \%$ & $76.4 \%$ & $79.0 \%$ & $21.0 \%$ \\
\hline 18 & 0.32 & 23 & 19 & 4 & 112 & 92 & 20 & $82.1 \%$ & $17.9 \%$ & $27.8 \%$ & $72.2 \%$ & $81.0 \%$ & $19.0 \%$ \\
\hline 17 & 0.36 & 32 & 29 & 3 & 144 & 121 & 23 & $84.0 \%$ & $16.0 \%$ & $32.4 \%$ & $67.6 \%$ & $82.9 \%$ & $17.1 \%$ \\
\hline 16 & 0.40 & 30 & 28 & 2 & 174 & 149 & 25 & $85.6 \%$ & $14.4 \%$ & $37.2 \%$ & $62.8 \%$ & $84.6 \%$ & $15.4 \%$ \\
\hline 15 & 0.44 & 29 & 27 & 2 & 203 & 176 & 27 & $86.7 \%$ & $13.3 \%$ & $42.2 \%$ & $57.8 \%$ & $86.1 \%$ & $13.9 \%$ \\
\hline 14 & 0.48 & 45 & 42 & 3 & 248 & 218 & 30 & $87.9 \%$ & $12.1 \%$ & $47.4 \%$ & $52.6 \%$ & $87.5 \%$ & $12.5 \%$ \\
\hline 13 & 0.52 & 48 & 43 & 5 & 296 & 261 & 35 & $88.2 \%$ & $11.8 \%$ & $52.6 \%$ & $47.4 \%$ & $88.8 \%$ & $11.2 \%$ \\
\hline 12 & 0.56 & 52 & 48 & 4 & 348 & 309 & 39 & $88.8 \%$ & $11.2 \%$ & $57.8 \%$ & $42.2 \%$ & $89.9 \%$ & $10.1 \%$ \\
\hline 11 & 0.60 & 36 & 35 & 1 & 384 & 344 & 40 & $89.6 \%$ & $10.4 \%$ & $62.8 \%$ & $37.2 \%$ & $90.8 \%$ & $9.2 \%$ \\
\hline 10 & 0.64 & 49 & 49 & 0 & 433 & 393 & 40 & $90.8 \%$ & $9.2 \%$ & $67.6 \%$ & $32.4 \%$ & $91.7 \%$ & $8.3 \%$ \\
\hline 9 & 0.68 & 46 & 44 & 2 & 479 & 437 & 42 & $91.2 \%$ & $8.8 \%$ & $72.2 \%$ & $27.8 \%$ & $92.3 \%$ & $7.7 \%$ \\
\hline 8 & 0.72 & 56 & 54 & 2 & 535 & 491 & 44 & $91.8 \%$ & $8.2 \%$ & $76.4 \%$ & $23.6 \%$ & $92.8 \%$ & $7.2 \%$ \\
\hline 7 & 0.76 & 39 & 39 & 0 & 574 & 530 & 44 & $92.3 \%$ & $7.7 \%$ & $80.2 \%$ & $19.8 \%$ & $93.2 \%$ & $6.8 \%$ \\
\hline 6 & 0.80 & 38 & 38 & 0 & 612 & 568 & 44 & $92.8 \%$ & $7.2 \%$ & $83.7 \%$ & $16.3 \%$ & $93.4 \%$ & $6.6 \%$ \\
\hline 5 & 0.84 & 24 & 24 & 0 & 636 & 592 & 44 & $93.1 \%$ & $6.9 \%$ & $86.7 \%$ & $13.3 \%$ & $93.5 \%$ & $6.5 \%$ \\
\hline 4 & 0.88 & 23 & 23 & 0 & 659 & 615 & 44 & $93.3 \%$ & $6.7 \%$ & $89.3 \%$ & $10.7 \%$ & $93.4 \%$ & $6.6 \%$ \\
\hline 3 & 0.92 & 19 & 19 & 0 & 678 & 634 & 44 & $93.5 \%$ & $6.5 \%$ & $91.5 \%$ & $8.5 \%$ & $93.1 \%$ & $6.9 \%$ \\
\hline 2 & 0.96 & 9 & 9 & 0 & 687 & 643 & 44 & $93.6 \%$ & $6.4 \%$ & $93.4 \%$ & $6.6 \%$ & $92.7 \%$ & $7.3 \%$ \\
\hline 1 & 1.00 & 1 & 1 & 0 & 688 & 644 & 44 & $93.6 \%$ & $6.4 \%$ & $94.9 \%$ & $5.1 \%$ & $92.2 \%$ & $7.8 \%$ \\
\hline
\end{tabular}

Recall that the probability density function (PDF) of a random variable describes the relative frequencies of different values for that random variable. The PDF for the normal distribution is:

$$
f\left(x ; \mu, \sigma^{2}\right)=\frac{1}{\sqrt{2 \pi \sigma^{2}}} \mathrm{e}^{-(x-\mu)^{2} /\left(2 \sigma^{2}\right)}
$$

where $\mu$ and $\sigma^{2}$ are the mean and variance of the distribution, respectively. The CDF of the standard normal distribution, which describes the probability of a random variable falling in the interval $(-\infty, x]$ is:

$$
\Phi(x)=\frac{1}{\sqrt{2 \pi}} \int_{-\infty}^{\mathrm{X}} \mathrm{e}^{-t^{2} / 2} d t
$$


Assuming that the second stage layered scores were normally distributed, each layered score was first transformed to a standard normal score ${ }^{30}$, and then applied to the CDF. As presented in Table 13.1, the estimated probabilities were consistent with the actual probabilities in terms of direction, but had a greater range (5-95\% and 6-33\%, respectively).

A second order polynomial function was also used to predict the probability of bankruptcy by fitting the second set of layered scores to:

$$
y=0.47 x^{2}-0.78 x+0.39
$$

where $y$ is the probability of bankruptcy and $x$ is second stage layered score. This function produced estimated probabilities that matched closer to actual probabilities. The information in Table 13.1 is also represented graphically in Figure 13.2, which plots the relationship between second stage layered score and the probability of bankruptcy, from three years back.

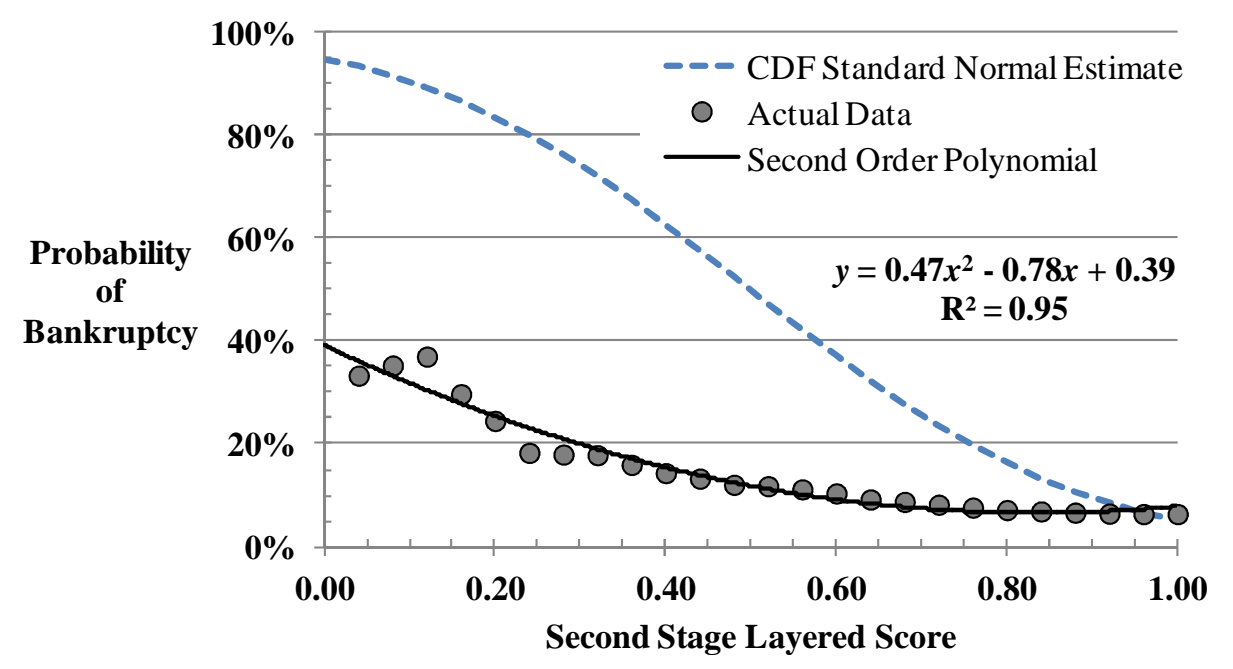

Figure 13.2: Probability of Bankruptcy

A DMU was classified bankrupt up to 3 years prior to filing Chapter 11 .

\subsection{Reliability and Validity of the Second Stage Model}

Because all previous results considered data from 1996 to 2009, in order to test the reliability of the two-stage layered DEA model, the entire process of creating metrics (with the same variables outlined in Sections 10.1, 10.2 and 10.4) and combining them in a second step was repeated 5 additional times with smaller datasets spanning 1996 to year $Y$, where $Y$ ranged from 2004 to 2008 (Figure 13.3).

\footnotetext{
${ }^{30}$ If $X$ is normal with mean $\mu$ and standard deviation $\sigma$, then $\frac{X-\mu}{\sigma}$ has the standard normal distribution.
} 


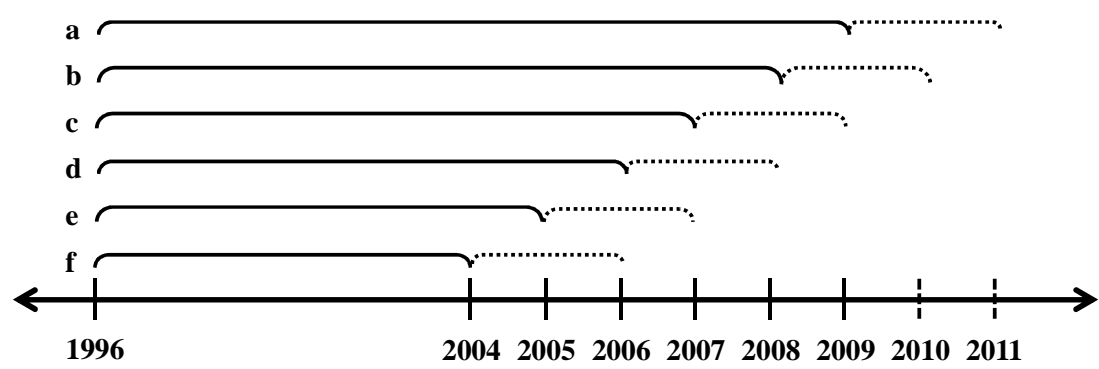

Figure 13.3: Time Windows for Model Testing a: Use data from 1996 to 2009 to predict health in 2010 and 2011 b: Use data from 1996 to 2008 to predict health in 2009 and 2010 c: Use data from 1996 to 2007 to predict health in 2008 and 2009 d: Use data from 1996 to 2006 to predict health in 2007 and 2008 e: Use data from 1996 to 2005 to predict health in 2006 and 2007 f: Use data from 1996 to 2004 to predict health in 2005 and 2006

The results from classification by layering from one year back are summarized in Table 13.2, based on plots presented in Appendix F.8. The accuracy of the second stage model slightly decreased as the time window shortened. This was expected as DEA performs better with more DMUs. Nonetheless, because the model was able to predict all DMUS with an accuracy between $75-80 \%$, this suggests that the second stage model was reliable, and thereby implies that the selection of variables for the metrics was robust.

Table 13.2: Accuracy of Classification by Layering of Second Stage Model from One Year Back

\begin{tabular}{|c|c|c|c|c|c|}
\hline Time Window & Total Number of DMUs & Total Number of Peels & Accuracy & Error & Layer \\
\hline $1996-2009$ & 701 (651 Active, 50 Bankrupt) & 26 & $80 \%$ & $20 \%$ & 16 \\
\hline $1996-2008$ & 584 (543 Active, 41 Bankrupt) & 23 & $76 \%$ & $24 \%$ & 14 \\
\hline $1996-2007$ & $532(492$ Active, 40 Bankrupt) & 22 & $76 \%$ & $24 \%$ & 13,14 \\
\hline $1996-2006$ & $476(439$ Active, 37 Bankrupt) & 21 & $76 \%$ & $24 \%$ & 13 \\
\hline $1996-2005$ & $409(379$ Active, 30 Bankrupt ) & 19 & $75 \%$ & $25 \%$ & 11,12 \\
\hline $1996-2004$ & 357 (331 Active, 26 Bankrupt) & 18 & $77 \%$ & $23 \%$ & 11,12 \\
\hline
\end{tabular}

As in the previous section (13.1), the probability of bankruptcy was estimated by fitting the second set of layered scores to a second order polynomial function. The functions based on the datasets with different time windows are presented in Table 13.3. The graphs comparing the actual probabilities of bankruptcy to the estimate are presented in Appendix F.9.

Table 13.3: Second Order Polynomial Functions Estimating the Probability of Bankruptcy A DMU was classified bankrupt up to a year prior to filing Chapter 11.

\begin{tabular}{|c|c|c|}
\hline Time Window & Equation & Probability of Bankruptcy $(\boldsymbol{y})$ from Second Stage Layered Score $(\boldsymbol{x})$ \\
\hline $1996-2009$ & $\mathrm{a}$ & $y=0.54 x^{2}-0.81 x+0.32$ \\
\hline $1996-2008$ & $\mathrm{~b}$ & $y=0.63 x^{2}-0.91 x+0.34$ \\
\hline $1996-2007$ & $\mathrm{c}$ & $y=0.24 x^{2}-0.41 x+0.20$ \\
\hline $1996-2006$ & $\mathrm{~d}$ & $y=0.16 x^{2}-0.31 x+0.17$ \\
\hline $1996-2005$ & $\mathrm{e}$ & $y=0.05 x^{2}-0.12 x+0.10$ \\
\hline $1996-2004$ & $\mathrm{f}$ & $y=-0.24 x^{2}+0.24 x$ \\
\hline
\end{tabular}

These datasets were then used to predict health over the next two years (i.e. years $Y+$ 1 and $Y+2)$. The effectiveness of the prediction models are discussed in the following 
sections. In general, the reliability of the models decreased as the time frame was shortened because of the reduction of DMUs resulting in lower accuracy.

\subsubsection{Prediction of Health after 2009 based on Data from 1996 to 2009}

Data for 39 companies (all active) were available in 2009, lending to 39 second stage layered scores and corresponding probabilities for 2009 based on a second order polynomial function (Equation "a" in Table 13.3). In this year, 23 of these firms had scores greater than 0.6 or probability of bankruptcy at less than $5 \%$. This low chance was consistent with the fact that all these companies remained active through 2010 and 2011. In contrast, there were 3 companies with scores less than 0.3 or an $11 \%$ chance of bankruptcy. In 2010 and 2011, one of these 3 companies declared bankruptcy; another entered a transitional period; and one remained active. In 2009, 13 companies had scores between 0.3 and 0.6 , or a chance of bankruptcy between 5\% and 11\%. In 2010 and 2011, most of these companies reached new credit agreements, closed stores, merged with other companies and/or went private - showing that they were in a less stable state with a higher risk of bankruptcy compared to those with higher scores.

\subsubsection{Prediction of Health after 2008 based on 1996-2008 Data}

Data for 52 companies were available in 2008 , lending to 52 second stage layered scores and corresponding probabilities for 2008 based on a second order polynomial function (Equation "b" in Table 13.3). In this year, 29 active firms had scores greater than 0.6 or probability of bankruptcy at less than 5\%. This low likelihood was consistent in that 27 of these companies remained active through 2009 and 2010. However, 2 of these firms filed for Chapter 11 protection at the onset of recession. In addition, there were 8 companies with scores less than 0.4 or a $6 \%$ chance of bankruptcy. In 2009 and 2010, two of these companies declared bankruptcy; one went private; one changed its name; one emerged from bankruptcy; and three remained active. Also, in 2008, there were 15 companies with scores between 0.4 and 0.6 , or a chance of bankruptcy between 5\% and 6\%. In 2009 and 2010, two-thirds of these companies remained active, while the others were in less stable health as evident by new credit agreements and store closings. 


\subsubsection{Prediction of Health after 2007 based on 1996-2007 Data}

Data for 56 companies were available in 2007, lending to 56 second stage layered scores and corresponding probabilities for 2007 based on a second order polynomial function (Equation "c" in Table 13.3). In this year, 35 firms had scores greater than 0.6 or probability of bankruptcy at less than 5\%. This low chance was consistent with the fact that all but one of these companies remained active through 2008 and 2009. On the other hand, 6 companies had scores less than 0.3 or a $10 \%$ chance of bankruptcy. In 2008 and 2009, 3 of these companies declared bankruptcy; one emerged from bankruptcy; one went private; and one remained active. Furthermore, in 2007, there were 15 companies with scores between 0.3 and 0.6 , or a chance of bankruptcy between 5\% and 6\%. In 2008 and 2009, over two-thirds of these companies remained active, while two firms filed for Chapter 11 protection at the onset of recession.

\subsubsection{Prediction of Health after 2006 based on 1996-2006 Data}

Data for 50 companies were available in 2006 , lending to 56 second stage layered scores and corresponding probabilities for 2006 based on a second order polynomial function (Equation "d" in Table 13.3). In this year, 30 firms had scores greater than 0.6 or probability of bankruptcy at less than 5\%. - all these companies remained active through 2007 and 2008. In contrast, 6 companies had scores less than 0.3 or a $9 \%$ chance of bankruptcy. In 2007 and 2008 , only two of these companies actually declared bankruptcy while the others remained active. Moreover, in 2006, 14 companies had scores between 0.3 and 0.6, or a chance of bankruptcy between 5\% and 9\%. In 2007 and 2008, two firms filed for bankruptcy while the other remained active.

\subsubsection{Prediction of Health after 2005 based on 1996-2005 Data}

Data for 47 companies were available in 2005, lending to 47 second stage layered scores and corresponding probabilities for 2005 based on a second order polynomial function (Equation "e" in Table 13.3). In this year, 26 firms had scores greater than 0.6 or probability of bankruptcy at 4\% - all of which remained active through 2006 and 2007. In contrast, 5 companies had scores less than 0.3 or a $6 \%$ chance of bankruptcy. In 2006 and 2007, only one of these companies actually declared bankruptcy while the others remained active. 
Furthermore, in 2006, 16 companies had scores between 0.3 and 0.6 , or a chance of bankruptcy between 4\% and 6\%. In 2006 and 2007, one firm filed for Chapter 11 protection while the others remained active.

\subsubsection{Prediction of Health after 2004 based on 1996-2004 Data}

Data for 44 companies were available in 2004 , lending to 44 second stage layered scores and corresponding probabilities for 2004 based on a second order polynomial function (Equation "f" in Table 13.3). Because the function does not increase monotonically (Figure F.61), the estimation for the probability of bankruptcy based on data between 1996 and 2004 exclusively, could not be used with reliability. 


\section{Conclusions}

\subsection{Summary of Major Contributions}

In this work, 85 companies in the American retail-apparel industry were studied. These public companies have been traded for some continuous period of time between 1996 and 2009. Two types of information were collected for each company for each year an annual report was available: financial (i.e. numerical variables from balance sheet, income statement and cash flow statement) and managerial decision-making (i.e. categorical variables from Notes, MD\&A and Auditor's Report). Data collection was followed by an extensive survey of bankruptcy and fraud literature, and the profiling of the retail-apparel industry. Next, the exploration of financial and managerial decision-making data involved correlating them with one another as well as with key market and economic factors. Results showed that financial, managerial decision-making, and market and economic data were independent and individually were poor predictors of bankruptcy. It was therefore hypothesized that the inclusion of variables that reflect managerial decision-making, and market and economic factors, enhance the predictive power of current mathematical models that consider financial data exclusively.

With a unique and comprehensive dataset, metrics based on different aspects of the annual report were created then combined with a Data Envelopment Analysis (DEA) model and modified layering technique. This two-stage approach proved to be an effective classification tool, separating companies with a high risk of bankruptcy from those that were healthy, with $80 \%$ accuracy when predicting from one year back. This $22 \%$ improvement over Altman's industry-standard model was attributed to prediction with financial and managerial decision-making data but not with market and economic factors which were shown to be inherent in the values of the former data types.

To summarize, the development of a DEA-based model led to several contributions.

- A rich database for each company was created with managerial decision-making information collected from the Notes, MD\&A and Auditor's Report. The use of this data in a mathematical model was novel and will act as a model for others to follow.

- Novel metrics that reflect different aspects of the annual report were created using normal SBM DEA models. This also offers a new direction for further research. 
- The two-stage model and modified layering technique provided a probability of bankruptcy in addition to a dichotomous prediction. It also offered targets for improvements which can be viewed as profitability strategies and/or preventative measures to help firms out of a high risk of bankruptcy. By providing probabilities, the human decision making process is enhanced when compared to a yes/no answer.

- The methodology was designed to be easily adapted for analyses of other industries (Figure 14.1). For example, if one were to study the manufacturing industry, the same metrics could be created and then combined in a second stage model for an overall measure of company health. The selection of variables for each metric would be at the discretion of the researcher but the philosophy of this thesis was to consider those that have an effect on company state, as determined by correlations and tests of similarly. In the manufacturing industry, a more capital-intensive industry than retailapparel, it would be anticipated that PPE would have a strong influence on the asset metric. There may also be more off-balance sheet liabilities to look for in the Notes such as special purpose entities (SPEs). Moreover, the cash flow statement and trade data may provide valuable information as metrics, if added. Different economic factors that pertain to the manufacturing industry would have to be considered. This industry would likely be more sensitive to the performance of the economy, especially as more US firms invest in off-shore operations.

Finally, the contributions of this thesis have practical applications, with economic and social benefits. For creditors, bankruptcy prediction improves risk assessment while for owners, it would buy extra time to secure more financing or improve current operations to avoid failure altogether. For investors, the model can also be used to identify active and bankrupt companies, helping one to invest in healthy companies or to short unhealthy firms. 


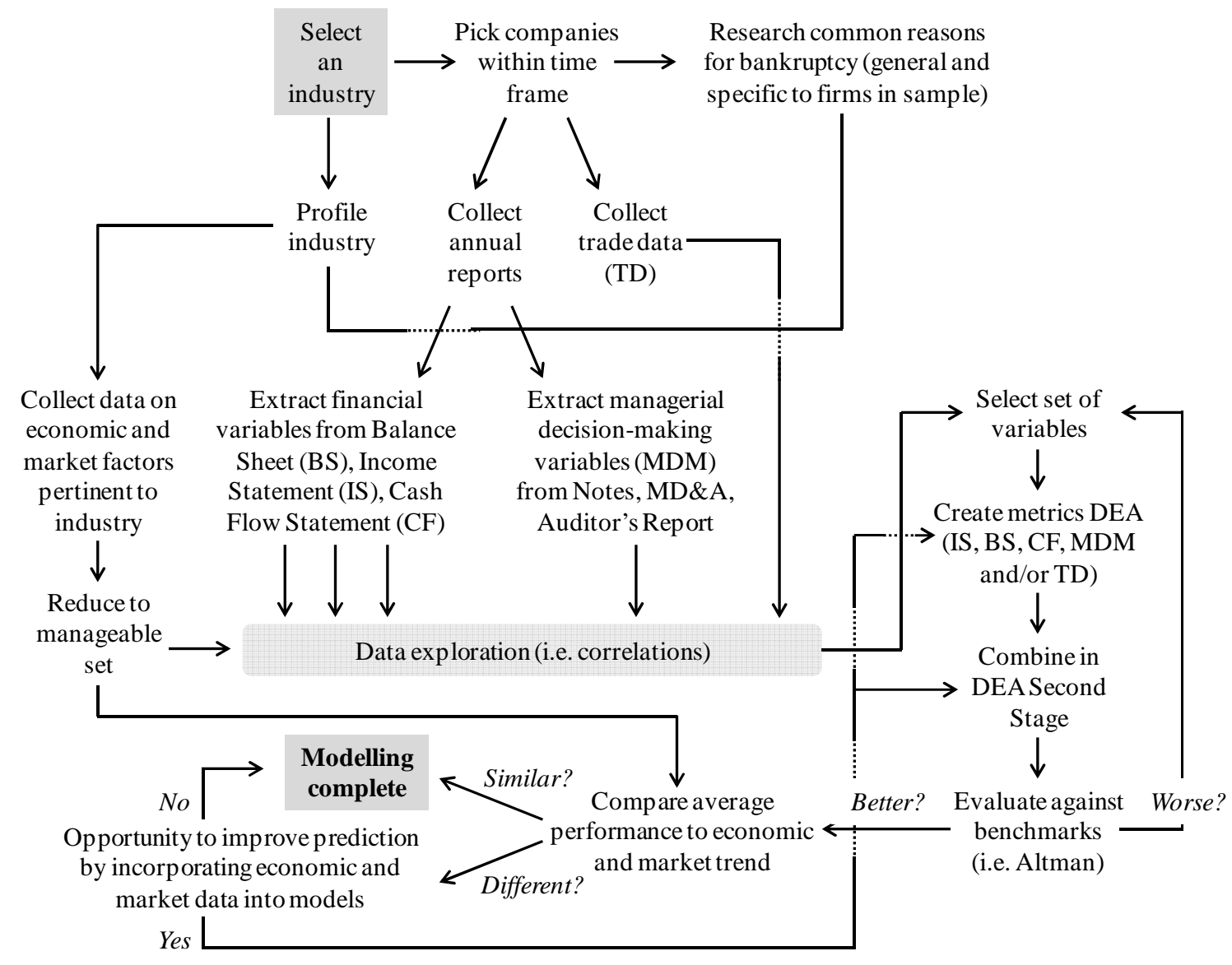

Figure 14.1: Summary of Methodology as Applicable to All Industries

\subsection{Recommendations for Future Work}

Several areas for future research and improvement in both bankruptcy prediction and DEA arise from this work. Opportunities include:

- Adding information that is excluded from the annual reports such as:

- The number of employees and/or layoffs (i.e. turnover) since human capital is pertinent in the services industry;

- The number of new store openings and closings;

- The total retail square footage of retail space, both owned and leased;

- Pension expenses (where applicable);

$\circ$ Executive management salary; and

○ Governance risk indicators (i.e. "GRId" was recently launched as a new measure of governance related risk which identifies and evaluates a 
company's key governance practices across four dimensions: Audit, Board of Directors, Compensation and/or Remuneration, and shareholder rights. It supports investors in their investment decision-making process making by flagging firms with governance-related concerns) (ISS, 2012).

- Using the trend of each variable (i.e. in the form of a slope or derivative for a linear function) as a variable reflecting change over time.

- Analyzing companies by further decomposition by business and geographical segments, and discount or high-end brands.

- Applying this methodology to firms in the private sector or at different stages in their life cycle (i.e. start-up) where the risk of bankruptcy is higher.

- Creating a technique that calibrates for time since data from companies do not overlap entirely over the same period. This would increase the amount of useable data.

- Modelling with quarterly and/or monthly data and adjust for seasonality.

- Examining further the similarities and differences between the layering and nonlayering approaches.

- Conducting a more rigorous sensitivity analysis to test the robustness of the models (i.e. testing the degree to which the overall second stage score is affected by the value of each variable). In this thesis, sensitivity analysis was performed on each variable to determine whether it should be included based on whether prediction improved.

- Considering the cost or percentage loss by bankruptcy as the dependent or target variable, as opposed to the percentage of companies that failed.

- Determining and adjusting the models for the difference in cost of Type I error and Type II error (as it was conservatively assumed equal in this thesis).

- Resolving the limitations of zero and negative numbers for the SBM DEA model.

- Incorporating non-discretionary and/or categorical variables (variables that one has no control over, such as the market and economy) into DEA.

- Investigating the inconsistency between normal and inverse DEA. 


\section{References}

Aigner, D., Lovell, C.A.K., Schmidt, P., 1977. Formulation and estimation of stochastic frontier production function models. Journal of Econometrics 6 (1), 21-37.

Albrecht, C., 2008. The nature of financial statement fraud. Internal Auditing 23 (4), 22-27.

Altman, E.I., 1968. Financial ratios, discriminant analysis and the prediction of corporate bankruptcy. Journal of Finance 23 (4), 589-609.

American Institute of CPAs, 2011. http://www.aicpa.org/Research/Standards/

Apostolou, B., Hassell, J.M., Webber, S.A. October 2001. Fraud risk factors: Rating by forensic experts. CPA Journal, 48-52.

Banker, R.D., Charnes, A., Cooper W.W., 1984. Some models for estimating technical and scale inefficiencies in data envelopment analysis. Management Science 30 (9), 10781092.

Banker, R.D., Morey, R., 1986. Efficiency analysis for exogenously fixed inputs and outputs. Operations Research 34 (4), 513-521.

Banker, R.D., Chang, H., Cooper, W.W., 1996. Simulation studies of efficiency, returns to scale, and misspecification with nonlinear functions in DEA. Annals of Operations Research 66, 233-253.

Barr, R. S., Seiford, L. M., Siems, T.F., 1993. An envelopment-analysis approach to measuring the managerial efficiency of banks. Annals of Operations Research 45, 1 19.

Barr, R. S., Seiford, L.M., Siems, T.F., 1994. Forecasting bank failure: A non-parametric frontier estimation approach. Recherches Economiques de Louvain 60 (4), 417-429.

Bauer, P.W., Berger, A.N., Ferrier, G.D., Humphrey, D.B., 1998. Consistency conditions for regulatory analysis of financial institutions: A comparison of frontier efficiency methods. Journal of Economics and Business 50 (2), 85-114.

Beaver, W., 1966. Financial ratios as predictors of failure. Empirical Research in Accounting: Selected Studies supplement to Journal of Accounting Research 4, 71111.

Bell, T.B., Carello, J.V., 2000. A decision aid for assessing the likelihood of fraudulent financial reporting. Auditing: A Journal of Practice \& Theory 169.

Beneish, M.D., 1999. The detection of earnings manipulation. Financial Analysts Journal 55 (5), 24-36. 
Berger, A.N., 1993. 'Distribution-free' estimates of efficiency in the U.S. banking industry and tests of the standard distributional assumptions. Journal of Productivity Analysis 4 (3), 61-92.

Berger, A.N., Humphrey, D.B., 1997. Efficiency of financial institutions: International survey and directions for future research. European Journal of Operational Research 8 (2), 175-212.

Blum, M., 1974. Failing company discriminant analysis. Journal of Accounting Research.

Bradley, D.B., Cowdery, C., 2004. Small business: Causes of bankruptcy. Internal document of UCA Small Business Advancement National Center, 205-219.

Bureau of Economic Analysis, 2010. http://www.bea.gov/

Bureau of Labour Statistics, 2010. http://www.bls.gov/

Charnes, A., Cooper, W.W., Rhodes, E.L., 1978. Measuring the efficiency of decision making units. European Journal of Operational Research 2 (6), 429-444.

Charnes, A., Cooper, W.W., Lewin, A.Y., Seiford, L.M., (Eds.), 1994. Data Envelopment Analysis: Theory, Methodology and Applications, Kluwer Academic Publishers.

Cielen, A., Peeters, L., Vanhoof, K., 2004. Bankruptcy prediction using a data envelopment analysis. European Journal of Operational Research 154 (2), 526-532.

Cummins, D., Zi, H., 1998. Comparison of frontier efficiency methods: An application to the U.S. life insurance industry. Journal of Productivity Analysis 10.

Cooper, W.W., Seiford, L.M., Tone, K., 2007. Data Envelopment Analysis: A Comprehensive Text with Models, Applications, References and DEA-Solver Software. Springer, New York.

Deakin, E.B., 1972. A discriminant analysis of predictors of business failure. Journal of Accounting Research.

Deloitte, 2008. 2008 Industry Outlook: A look around the corner.

Divine, J.D., 1986. Efficiency analysis and management of not for profit and governmentally regulated organizations. Ph.D. Dissertation, Graduate School of Business, University of Texas, Austin.

Edmister, R.O., 1972. An empirical test of financial ratio analysis for small business failure prediction. Journal of Financial and Quantitative Analysis. 
Elitzur, R., 2008. The accounting art of war: Enron and other cases. Advisor Guide to Risk Management, The Bonham Centre for Finance, Joseph L. Rotman, School of Management, 59-66.

Emrouznejad, A., Amin, G.R., 2007. DEA models for ratio data: Convexity consideration. Applied Mathematical Modelling.

Epstein, B.J., Jermakowicz, E.K., 2007. Interpretation and Application of International Financial Reporting Standards. John Wiley \& Sons.

Farrell, M.J., 1957. The measurement of productive efficiency. Journal of Royal Statistical Society, Series A 120 (3), 253-290.

Forrester Research, 2011. http://www.forrester.com/

Financial Accounting Standards Board, 1976. Accounting for leases. Statement of Financial Accounting Standards No. 13.

Gill, J.O., 1994. Financial Basics of Small Business Success. Crisp Publications.

ISS, 2012. http://issgovernance.com/grid-info.

Hanson, R.O., 2003. A study of Altman's revised four-variable Z"-score bankruptcy prediction model as it applies to the service industry (Edward I. Altman). Dissertation Abstracts International, 63-12A, 4375.

Hall, P., Simar, L., 2002. Estimating a changepoint boundary or frontier in presence of observation error. Journal of the American Statistical Association 97, 523-534.

Hollingsworth, B., Smith, P.C., 2003. The use of ratios in data envelopment analysis. Applied Economics Letters 10, 733-735.

International Council Shopping Centres, 2010. http://www.icsc.org/

Kaminski, K.A., Wetzel, T.S., Guan, L. 2004. Can financial ratios detect fraudulent financial reporting? Managerial Auditing Journal 29 (1), 15-28.

Kao, C., Liu, S.T., 2004. Predicting bank performance with financial forecasts: A case of Taiwan commercial banks. Journal of Banking \& Finance 28, 2353-2368.

Kirkos, E., Charalambos, S., Manolopoulus, Y., 2007. Data mining technique for detection of fraudulent financial statements. Expert Systems with Applications 32, 995-1003.

Land, K.C., Lovell, C.A., Thore, A., 1993. Chance-constrained data envelopment analysis. Managerial and Decision Economics 14, 541-554. 
Lewis, H.F., Sexton, T.R., 2004. Network DEA: efficiency analysis of organization with complex internal structure. Computers \& Operations Research 31, 1365-1410.

Libby, R., 1975. Accounting ratios and the prediction of failure: Some behavioural evidence. Journal of Accounting Research.

Luenberger, D.G., 1998. Investment Science. Oxford University Press, NY.

National Retail Federation, 2010. http://www.nrf.com/

Moyer, R., 1977. Forecasting financial failure: a re-examination. Financial Management.

Ohlson, J.A., 1980. Financial ratios and the probabilistic prediction of bankruptcy. Journal of Accounting Research 18 (1), 109-131.

Özpeynirci, Ö., Köksalan, M., 2007. Performance evaluation using data envelopment analysis in the presence of time lags. Journal of Productivity Analysis 27, 221-229.

Paradi, J.C., Asmild, M., Simak, P.C., 2004. Using DEA and worst practice DEA in credit risk evaluation. Journal of Productivity Analysis 21, 153-165.

Paradi, J.C, Rouatt, S.M., Zhu, H., 2011. Two stage evaluation of bank branch efficiency using data envelopment analysis. Omega 29, 99-109.

Pušnik, K., Tajnikar, M., 2008. Technical and cost efficiencies as determinants of business failures of small firms. Eastern European Economics 46 (1), 43-62.

Premachandra, M., Chen, Y., Watson, J., 2011. DEA as a tool for predicting corporate failure and success: A case of bankruptcy assessment. Omega 39 (6), 620-626.

Ramamoorti, S., Olsen, W., 2007. Fraud: the human factor. Financial Executive, 53-55.

Ravi Kumar, P., Ravi, V., 2006. Bankruptcy prediction in banks and firms via statistical and intelligent techniques - a review. European Journal of Operational Research 180, 1-28.

Schmidt, P., Sickles, R.C., 1984. Production frontiers and panel data. Journal of Business and Economic Statistics 2 (4), 221-250.

Sengupta, J.K., 1996. Dynamic data envelopment analysis. International Journal of Systems Science 27 (3), 277-284.

Seow, J., 2009. Cue usages in financial statement fraud risk assessments: effects of technical knowledge and decision aid uses. Accounting and Finance 49, 183-205.

Smith, M., Baharuddin, I., 2005. Auditors' perception of fraud risk indicators. Managerial Auditing Journal 20 (1), 73-85. 
Shetty, U., Pakkala, T.P.M., Mallikarjunappa, T., 2012. A modified directional distance formulation of DEA to assess bankruptcy: An application to IT/ITES companies in India. Expert Systems with Applications 39, 1988-1997.

Sueyoshi, T., 1998. DEA-discrimant analysis in the view of goal programming. European Journal of Operational Research 22, 349-376.

Sueyoshi., T., Goto, M., 2009. Methodological comparison between DEA (data envelopment analysis) and DEA-DA (discriminant analysis) from the perspective of bankruptcy assessment. European Journal of Operational Research 199, 561-575.

Stickney, C.P., Brown, P., Wahlen, J.M., 2006. Financial Reporting, Financial Statement Analysis, and Valuation: A Strategic Perspective. $6^{\text {th }}$ Edition, South-Western College Pub.

Thanassoulis, E., 1999. Setting achievement targets for school children. Education Economics 7 (2), 101-119.

Thompson, R.G., Singleton, F.D., Thrall, R.M., Smith, B.A., 1986. Comparative site evaluations for locating a high-energy physics lab in Texas. Interfaces 16, 35-49.

Tone, K., 2001. A slacks-based measure of efficiency in data envelopment analysis. European Journal of Operational Research 130 (3), 498-509.

Tran, A., 2007. Two-stage financial risk tolerance assessment using data envelopment analysis. Master's Dissertation, University of Toronto.

U.S. Census Bureau, 2010. http://www.census.gov/econ/industry/current/c448150.htm

U.S. Courts, Bankruptcy Statistics, 2010.

http://www.uscourts.gov/bnkrpctystats/bankruptcystats.htm

U.S. Department of Commerce, 2010. http://www.commerce.gov

U.S. Department of Labour, 2010. http://www.dol.gov

U.S. Municipal Bond Fairness Act, 2008.

Weidman, C.I., 1999. Instructional case: Detecting earnings manipulation. Issues in Accounting Education 14 (1), 145-176.

Wilcox, J.W., 1971. A simple theory of financial ratios as predictors of failure. Journal of Accounting Research 9 (2), 389-395.

Wilks, T.J., Zimbelman, M.F., 2004. Using game theory and strategic reasoning concepts to prevent and detect fraud. Accounting Horizons 18 (3), 173-184. 
Wongphatarakul, V., Friendlander, S.K., Pinto, J.P., 1998. A comparative study of $\mathrm{PM}_{2.5}$ ambient aerosol chemical databases. Environmental Science Technology 32, 39263934.

Xu, X., Wang, Y., 2009. Financial failure prediction using efficiency as a predictor. Expert Systems with Applications 36, 366-373. 


\section{Appendix A Parametric Frontier Methodologies}

There are three major parametric frontier efficiency methodologies: Stochastic Frontier Analysis (SFA), the Thick-Frontier Approach (TFA) and the Distribution-Free Approach (DFA). Unlike DEA, parametric methods must satisfy both technical and allocative efficiency. They require the specification of the shape of the frontier and functional form, limited to single output - multiple input, or single input - multiple output cases. However, they are less likely to misidentify measurement error, transitory differences in cost, or random error as inefficiency (Berger and Humphrey, 1997). SFA, TFA and DFA differ in the distributional assumptions imposed to separate random error from efficiency.

\section{A.1 Stochastic Frontier Analysis (SFA)}

Stochastic Frontier Analysis (SFA) was introduced by Aigner, Lovell and Schmidt (1977). It is a model in which inefficiencies are always bounded and nonnegative, and assumed to follow an asymmetric distribution (i.e. half-normal), while random errors are assumed to follow a symmetric distribution (i.e. standard normal). Inefficiencies $\mu$ and errors $v$ are assumed orthogonal to the input, output and environmental variables specified in the cost function $\varepsilon=\mu+v$. The estimated inefficiency for any DMU is taken as the conditional mean of the distribution of $\mu$ given the estimate of $v$ (Berger and Humphrey, 1997). While SFA is criticized for the somewhat arbitrary distributional assumptions, a positive aspect is that it ranks the efficiencies of the DMUs in the same order as their cost function residuals, no matter what assumptions are imposed (Bauer et al., 1998).

\section{A.2 Thick Frontier Approach (TFA)}

Thick Frontier Approach (TFA) employs the same form for the frontier cost function as SFA but is based on a regression that measures a general level of overall efficiency for all DMUs, rather than point estimates for individual DMUs to reduce the effect of "extreme" points in the sample. This general level of overall efficiency is the estimate of efficiency differences between the best and worst quartile. The thick frontier of efficient DMUs is calculated from data limited to the lowest-cost quartile representing random error only. Like SFA, TFA's rather arbitrary assumptions with respect to the thickness of the frontier are questionable, but still has appeal with rank orderings (Berger and Humphrey, 1997). 


\section{A.3 Distribution-Free Approach (DFA)}

Similar to SFA and TFA, the Distribution-Free Approach (DFA), developed by Schmidt and Sickles (1984) and Berger (1993), specifies a functional form for the cost function but provides an alternative procedure for estimating relative firm inefficiency. In contrast, it does not specify the distribution of efficiency nor impose that deviations within one group are all random errors and deviations between groups are all inefficiencies. Instead, DFA assumes that each DMU has a core efficiency that is constant over time and random error averages out to zero over time. Nonetheless, DFA is criticized for having somewhat arbitrary assumptions, such as inefficiency being the only time-invariant fixed effect (Bauer et al., 1998). 


\section{Appendix B Examples of Data Envelopment Analysis}

For simplicity, these graphical examples consider only one or two inputs and outputs. Unless otherwise stated, CCR efficiency is calculated in these examples.

\section{B.1 One Input, One Output}

Consider 4 DMUs (A, B, C and D), each with one input and one output (Figure B.1). A, B and $\mathbf{C}$ are BCC-efficient but only $\mathbf{B}$ is CCR-efficient.

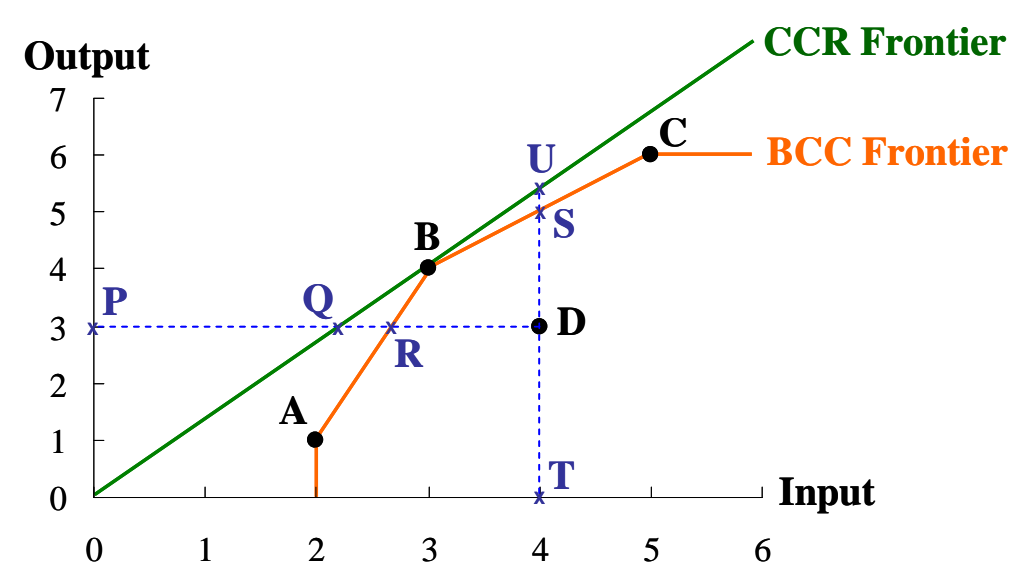

Figure B.1: One Input and One Output Case

If the model is input-oriented, the BCC efficiency of $\mathbf{D}$ is:

$$
\theta_{D, B C C}^{*}=\frac{P R}{P D}=\frac{2.7}{4}=0.667
$$

while its CCR efficiency is:

$$
\theta_{D, C C R}^{*}=\frac{P Q}{P D}=\frac{2.25}{4}=0.5625
$$

Therefore, BBC and CCR efficiency can be achieved by reducing the existing input value (4) by $4 \times(1-0.667)=1.332$ units and $4 \times(1-0.5625)=1.75$ units, respectively.

If the model is output-oriented, the BCC efficiency of $\mathbf{D}$ is:

$$
\eta_{D, B C C}^{*}=\frac{S T}{D T}=1.667
$$

while its CCR efficiency is:

$$
\eta_{D, C C R}^{*}=\frac{U T}{D T}=\frac{5.333}{3}=1.778
$$


In other words, achievement of efficiency requires augmenting D's output from its observed value (3) to the projected value on the frontier (5) by $3 \times(1.667-1)=2$ units. Note that $\eta_{D, C C R}^{*}=\frac{1}{\theta_{D, C C R}^{*}}$, but this simple "reciprocal relation" between input- and output- oriented models is not applicable to the BCC model (Cooper et al., 2005).

\section{B.2 Minimize Two Inputs, Unitized Output}

Suppose there are 7 DMUs (A to $\mathbf{G}$ ) which use two inputs to produce one output (Table B.1, Figure B.2). Note that the output is unitized.

Table B.1: Two Inputs and One Output Case

\begin{tabular}{|l|c|c|c|c|c|c|c|c|}
\cline { 2 - 9 } \multicolumn{1}{c|}{} & DMU & A & B & C & D & E & F & G \\
\hline \multirow{2}{*}{ Input } & $x_{1}$ & 4 & 7 & 8 & 4 & 2 & 10 & 3 \\
& $x_{2}$ & 3 & 3 & 1 & 2 & 4 & 1 & 7 \\
\hline Output & $y$ & 1 & 1 & 1 & 1 & 1 & 1 & 1 \\
\hline
\end{tabular}

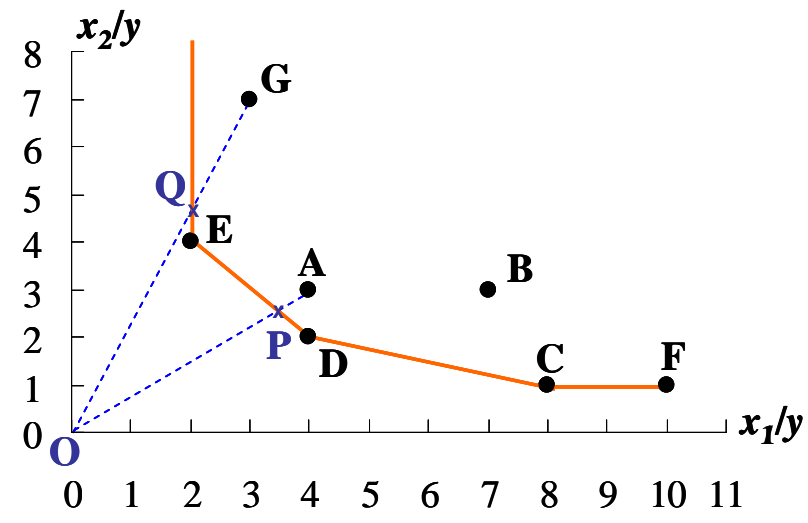

Figure B.2: Two Inputs and One Output Case

CCR efficiency of $\mathbf{A}$ can be calculated by two methods. A line can be projected radially from the origin to $\mathbf{A}$, crossing through the frontier at $\mathbf{P}$ (the projection point). Efficiency is then the ratio of the distance from the origin to $\mathbf{P}$, to the distance from the origin to $\mathbf{A}$ :

$$
\theta_{A}^{*}=\frac{O P}{O A}=0.8571
$$

Therefore, $\mathbf{A}$ can be improved by reducing its inputs to 0.8571 of their existing values; i.e. $\mathbf{P}$ $\left(\hat{x}_{1} \approx 3.4, \hat{x}_{2} \approx 2.6\right)$.

Efficiency can also be determined with the following linear program: 
Phase I : Minimize $\theta_{A}$

Phase II : Minimize $-s_{1}^{-}-s_{2}^{-}-s^{+}$

Subject To

$$
\begin{aligned}
& 4 \theta_{A}-4 \lambda_{A}-7 \lambda_{B}-8 \lambda_{C}-4 \lambda_{D}-2 \lambda_{E}-10 \lambda_{F}-3 \lambda_{G}-s_{1}^{-}=0 \\
& 3 \theta_{A}-3 \lambda_{A}-3 \lambda_{B}-\lambda_{C}-2 \lambda_{D}-4 \lambda_{E}-\lambda_{F}-7 \lambda_{G}-s_{2}^{-}=0 \\
& \lambda_{A}+\lambda_{B}+\lambda_{C}+\lambda_{D}+\lambda_{E}+\lambda_{F}+\lambda_{G}-s^{+}=1
\end{aligned}
$$

which yields an optimal solution of $\theta_{A}^{*}=0.8571$ with $\lambda_{D}^{*}=0.7143, \lambda_{E}^{*}=0.2857$, $\lambda_{A}^{*}=\lambda_{B}^{*}=\lambda_{C}^{*}=\lambda_{F}^{*}=\lambda_{G}^{*}=0$ and $s_{1}^{-*}=s_{2}^{-*}=s^{+^{*}}=0$. The reference set for $\mathbf{A}$ is $E_{A}=$ $\{\mathbf{D}, \mathbf{E}\} . \lambda_{D}^{*}$ and $\lambda_{E}^{*}$ are the proportions contributed by $\mathbf{D}$ and $\mathbf{E}$ to the point on the frontier $\mathbf{P}$ used to evaluate A. P is also a hypothetical DMU which is made from 0.7143 of D's inputs and 0.2857 of E's inputs. Its coordinates $\left(\hat{x}_{1}, \hat{x}_{2}\right)$ can be determined as follows:

$$
\begin{aligned}
& \hat{x}_{1}=0.7143 x_{1 D}+0.2857 x_{1 E}=0.7143 \times 4+0.2857 \times 2 \approx 3.4286 \\
& \hat{x}_{2}=0.7143 x_{2 D}+0.2857 x_{2 E}=0.7143 \times 2+0.2857 \times 4 \approx 2.5714
\end{aligned}
$$

Alternatively, this can be interpreted in terms of CCR projection, which is achieved by a $14.29 \%$ reduction in both inputs.

$$
\begin{aligned}
& \hat{x}_{1} \leftarrow \theta_{A}^{*} x_{1}-s_{1}^{-*}=0.8571 \times 4-0=3.4286 \\
& \hat{x}_{2} \leftarrow \theta_{A}^{*} x_{2}-s_{2}^{-*}=0.8571 \times 4-0=2.5714 \\
& \hat{y} \leftarrow y_{1}+s^{+*}=1
\end{aligned}
$$

For the case where there are slacks (such as $\mathbf{G}$ ), the following LP,

Phase I : Minimize $\theta_{G}$

Phase II : Minimize $-s_{1}^{-}-s_{2}^{-}-s^{+}$

Subject To

$$
\begin{aligned}
& 3 \theta_{A}-4 \lambda_{A}-7 \lambda_{B}-8 \lambda_{C}-4 \lambda_{D}-2 \lambda_{E}-10 \lambda_{F}-3 \lambda_{G}-s_{1}^{-}=0 \\
& 7 \theta_{A}-3 \lambda_{A}-3 \lambda_{B}-\lambda_{C}-2 \lambda_{D}-4 \lambda_{E}-\lambda_{F}-7 \lambda_{G}-s_{2}^{-}=0 \\
& \lambda_{A}+\lambda_{B}+\lambda_{C}+\lambda_{D}+\lambda_{E}+\lambda_{F}+\lambda_{G}-s^{+}=1
\end{aligned}
$$

yields $\theta_{G}^{*}=0.6667$ with $\lambda_{E}^{*}=1, \lambda_{A}^{*}=\lambda_{B}^{*}=\lambda_{C}^{*}=\lambda_{D}^{*}=\lambda_{F}^{*}=\lambda_{G}^{*}=0$ and $s_{1}^{-^{*}}=0$, $s_{2}^{-*}=0.6667, s^{+*}=0$. The reference set for $\mathbf{G}$ is $E_{G}=\{\mathbf{E}\}$. Because of excess in input 2( $\left.s_{2}^{-*}=0.6667\right)$, CCR projection for $\mathbf{G}$ is achieved by a $33.33 \%$ reduction in input 1 and a $42.86 \%$ reduction in input 2 (Cooper et al., 2007). 


$$
\begin{aligned}
& \hat{x}_{1} \leftarrow \theta_{G}^{*} x_{1}-s_{1}^{-*}=0.6667 \times 3-0=2 \\
& \hat{x}_{2} \leftarrow \theta_{G}^{*} x_{2}-s_{2}^{-*}=0.6667 \times 4-0.6667=4 \\
& \hat{y} \leftarrow y_{1}+s^{+*}=1
\end{aligned}
$$

\section{B.3 Maximize Two Outputs, Unitized Input}

Consider 7 DMUs (A to $\mathbf{G}$ ), each consuming one input to produce two outputs (Table B.2, Figure B.3). Note that the input is unitized.

Table B.2: One Input and Two Outputs Case

\begin{tabular}{|l|c|c|c|c|c|c|c|c|}
\cline { 2 - 9 } \multicolumn{1}{c|}{} & DMU & A & B & C & D & E & F & G \\
\hline Input & $x$ & 1 & 1 & 1 & 1 & 1 & 1 & 1 \\
\hline \multirow{2}{*}{ Output } & $y_{1}$ & 1 & 2 & 3 & 4 & 4 & 5 & 6 \\
& $y_{2}$ & 5 & 7 & 4 & 3 & 6 & 5 & 2 \\
\hline
\end{tabular}

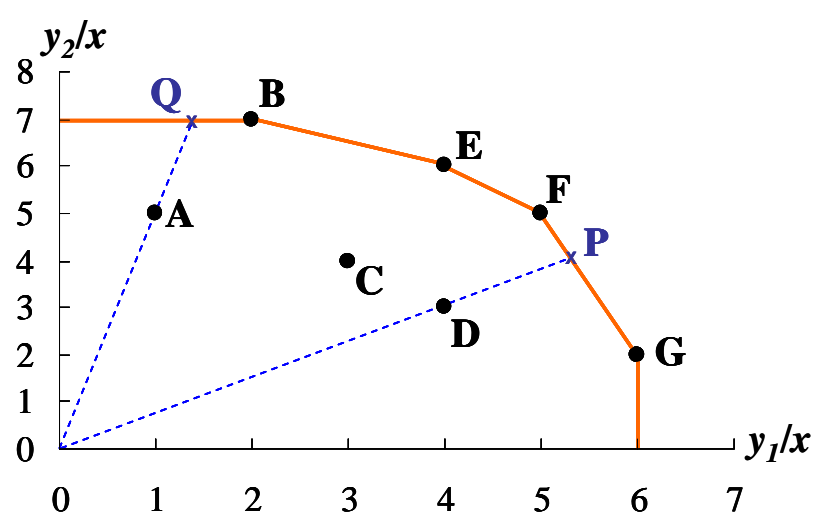

Figure B.3: One Input and Two Outputs Case

CCR efficiency of $\mathbf{D}$ can be calculated by two methods. A line can be projected radially from the origin through $\mathbf{D}$ and onto the frontier at $\mathbf{P}$ (the projection point). Efficiency is then the ratio of the distance from the origin to $\mathbf{D}$, to the distance from the origin to $\mathbf{P}$ - the hypothetical DMU that $\mathbf{D}$ aims to be as efficient as.

$$
\eta_{D}^{*}=\frac{O P}{O D}=1.333
$$

For $\mathbf{D}$ to be efficient, all of its outputs must be increased by 1.333 times their current values $(4,3)$; that is, $\mathbf{D}$ must project to $\mathbf{P}\left(\hat{y}_{1}, \hat{y}_{2}\right)=1.333 \times(4,3)=(5.333,4)$.

Alternatively, the following LP would yield the same results: 
Phase I: Maximize $\eta_{G}$

Phase II : Maximize $s_{1}^{-}+s_{2}^{-}+s^{+}$

Subject To

$$
\begin{aligned}
& 6 \eta_{G}-1 \lambda_{A}-2 \lambda_{B}-3 \lambda_{C}-4 \lambda_{D}-4 \lambda_{E}-5 \lambda_{F}-6 \lambda_{G}+s_{1}^{-}=0 \\
& 2 \eta_{G}-5 \lambda_{A}-7 \lambda_{B}-4 \lambda_{C}-3 \lambda_{D}-6 \lambda_{E}-5 \lambda_{F}-2 \lambda_{G}+s_{2}^{-}=0 \\
& \lambda_{A}+\lambda_{B}+\lambda_{C}+\lambda_{D}+\lambda_{E}+\lambda_{F}+\lambda_{G}+s^{+}=1
\end{aligned}
$$

with the projection:

$$
\begin{aligned}
& \hat{y}_{1} \leftarrow \eta_{B}^{*} y_{1}+t_{1}^{+*} \\
& \hat{y}_{2} \leftarrow \eta_{B}^{*} y_{2}+t_{2}^{+*} \\
& \hat{x} \leftarrow x_{1}-t^{-*}
\end{aligned}
$$

For DMUs with output slacks (such as $\mathbf{A}$ ), efficiency is calculated in two phases: first, a radial projection to $\mathbf{Q}$ on the frontier followed by an expansion to $\mathbf{B}$. For example, $\mathbf{A}$ has a technical efficiency of $\eta_{A}^{*}=\frac{O Q}{O A}=1.41$ but note that after its projection to $\mathbf{Q}$, it is still not as efficient as $\mathbf{B}$. Hence, for $\mathbf{A}$ to be fully efficient, in addition to increasing all its outputs by 1.4 times their current value, output 1 must be increased from 1.4 to 2 (Cooper et al., 2007). 


\section{Appendix C Reasons for Bankruptcy as Cited by Press Releases}

\section{- Filene's Basement Corp (BSMT), Bankruptcy in 1999}

- Chapter 11 filing prompted by low inventory caused by vendors refusing to deliver merchandise, as well as competition (abundance of off-pricers in Northeast)

- Embarked on an ill-advised strategy of expansion in 1988 when acquired by May Department Stores, attempted private label strategy

- High operating losses

- Second filing in 2009: recession and consumers pulling back made debt burden unmanageable

- Christopher \& Banks Corp. (CBK), Bankruptcy in 1996

- Chapter 11 filed after experiencing three-year retail slowdown and consecutive annual losses, as well as debt problems it had been battling since 1986

- Doing well since restructuring and renamed from Brauns Fashion Corporation in July 2000

- Casual Male Corp (CMALQ), Bankruptcy in 2001

- Chapter 11 filing stemmed from a need to restructure its long-term indebtedness

- Delisted by NASDAQ as stock did not closed above the minimum $\$ 5$ per share required

- CML Group (CML), Acquired and Bankruptcy in 1998

- Chapter 11 filing did not surprise industry observers given that the company had not reported an annual profit since 1994

- County Seat Stores, Inc. (CSS), Bankruptcy in 1997

- Severe liquidity problems

- Strategy over last two years produced bloated inventories and labels that did not yield enough profit margin to keep it afloat

- Clothestime, Inc. (CTMEQ), Bankruptcy in 1996

- During the beginning of 1996, sales dropped 36.2\% to $\$ 103.2 \mathrm{M}$ and net losses grew to from $\$ 10 \mathrm{M}$ to $\$ 13.8 \mathrm{M}$.

- Too much owed to landlords, banks and other creditors

- Pummeling stock which traded two years ago at above \$10 to \$1.25 in NASDAQ

- Competition: customers flock to Wal-Mart, Sears and JC Penney that can offer familiar name brands at attractive prices; this is deadly for smaller specialty chains like Clothestime which were profitable by selling their own private-label apparel at low prices

- Eddie Bauer Holdings Inc. (EBHI), Bankruptcy in 2009

- With recession, consumers curtailed spending and the company struggled to pay its debt

- Falloff in sales came as company was trying to pull off a multiyear turnaround that included cost cuts and changes to its management team and merchandise 
- Edison Brothers Stores, Inc. (EDBRW), Bankruptcy in 1996

- Cited severe competition and disappointing operating results (losses) for filing Chapter 11

- Other reasons included a poor specialty retail environment and bleak holiday season outlook

- Just for Feet Inc. (FEETQ), Bankruptcy in 2000

- Collapsed in 1999 amid an accounting fraud: 3 former executives pleaded guilty to crimes related to overstating earnings by $\$ 8 \mathrm{M}$ between 1996 and 1998

- When it filed, company cited lagging sales, excess inventories and high operating costs for losses of more than \$21M in the six months ended July 21, 1999

\section{- Footstar Inc. (FTAR), Bankruptcy in 2002}

- SEC found discrepancies in accounts payable balances, namely an understatement of \$35M in its athletics segment that forced company to restate its financials from 1997 through 2002 which reduced earnings by as much as $\$ 53 \mathrm{M}$ over the five-and-a-halfyear period

- Factory-2-U Stores, Inc (FTUS), Bankruptcy in 2004

- Filed Chapter 11 to restructure $\$ 73.5 \mathrm{M}$ in debt after struggling through a weak holiday shopping season (soft sales) and competition from bigger rivals such as WalMart, Target, Kmart

- Management was in chaos with CEO and CFO resignations

- Gadzooks, Inc. (GADZQ), Bankruptcy in 2005

- Heavy debt load prompted reorganization of core business around 252 stores chosen to strengthen its market position, and develop a plan to boost sales and profit

- Jay Jacobs (JAYJ), Bankruptcy in 1994

- Consequence of financial slide was company losing trade support of its vendors, making it difficult for the stores to get merchandise

- Filed Chapter 11 to get out of leases at unprofitable store sites

- Gantos / Kinder Holding Corp. (KDRH), Bankruptcy in 1993

- Pressed by falling sales, big losses, growing debt, and plummeting stock

- Tailspin caused by slow down in retail apparel market and ill-conceived merchandising rollouts

- Harold's Stores (HRLS), Bankruptcy in 2008

- Ceased operations because of increased competition and weak sales

- Kenwin Shops, Inc. (KNWN), Bankruptcy in 1994

- General economic decline eroded financial position (net losses) and forced several vendors to stop shipping 
- Quality and attractiveness of merchandise did not satisfy consumers' desires causing company to lose customers and sales. Also, overhead and selling expenses were high and company operated numerous stores which were unprofitable

\section{- Lamonts Apparel, Inc. (LAM), Bankruptcy in 1995}

- Filed Chapter 11 to get out of costly store leases and to reduce insolvency (haemorrhage of cash related to its debt service)

- As Lamonts expand, its financial performance deteriorated with general downturn in retail industry and competition from discount retailers like Target and Wal-Mart

- Critics claimed Lamonts failed to keep pace with market changes and was operating with an obsolete strategy, with net losses $\$ 8.5 \mathrm{M}, \$ 11.7 \mathrm{M}, \$ 19.3 \mathrm{M}$ and $\$ 10.8 \mathrm{M}$ from 1990-1993 despite increase in sales

\section{- Loehmann's Inc. (LOEHQ), Bankruptcy in 1999}

- Declining sales and an inability to carry debt load

- More specifically: failure to make a $\$ 5.5 \mathrm{M}$ interest payment to creditors; lost more than $\$ 5 \mathrm{M}$ last year on sales of $\$ 432 \mathrm{M}$; CFO resigned abruptly without explanation; Moody's Investors Service Inc. downgraded its debt to a status lower than junk; many vendors stopped shipping to company; competition from discount chains

\section{- Merry-Go-Round Enterprises Inc. (MGR), Bankruptcy in 1994}

- Filed Chapter 11 after a long but futile effort to placate its creditors (debt)

- Fell into a cash-flow crisis by overestimating the appeal of "hip-hop" clothing which forced the company to take a $\$ 35.1 \mathrm{M}$ charge from having to discount heavily to sell.

- One Price Clothing Stores, Inc. (ONPRQ), Bankruptcy in 2004

- Plagued by liquidity issues

- Paul Harris Stores, Inc. (PHRS), Bankruptcy in 2000

- Plagued by liquidity problems and slow sales

- Problems developed after company cut prices deeply to sell off inventory earlier in the year, hurting results and cash squeeze made it difficult to get new merchandise

- Shoe Pavilion, Inc. (SHOE), Bankruptcy in 2008

- Five straight quarterly losses due to recession

- Today's Man, Inc. (TMAN), Bankruptcy in 1996 and 2002

- Company blamed bad economy, skittish suppliers unwilling to extend credit, a trend among men toward more casual dress, consumers spending more money on computers than clothing, going-out-of-business sales that cut into market share, and merchants so desperate to bring customers into their stores that they practically gave away the goods at extreme discounts (competition)

- Company had too rapid growth, was unprofitable, defaulted on loan and had credit line reduced 


\section{Appendix D Supplementary Background}

\section{D.1 Credit Rating Agencies}

Table D.1: Broad Categories for Economic Indicators

\begin{tabular}{|l|l|l|}
\hline \multicolumn{1}{|c|}{ Category } & \multicolumn{1}{|c|}{ Description } & \multicolumn{1}{c|}{ Examples } \\
\hline $\begin{array}{l}\text { Total Output, Income } \\
\text { and Spending }\end{array}$ & $\begin{array}{l}\text { Broad measures of economic } \\
\text { performance }\end{array}$ & $\begin{array}{l}\text { GDP, National Income, Consumption Expenditure, } \\
\text { Corporate Profits }\end{array}$ \\
\hline $\begin{array}{l}\text { Employment, } \\
\text { Wnemployment and }\end{array}$ & $\begin{array}{l}\text { Measures of the labour } \\
\text { market }\end{array}$ & $\begin{array}{l}\text { Unemployment Rate, Average Weekly Hours and Earnings, } \\
\text { Labour Productivity }\end{array}$ \\
\hline $\begin{array}{l}\text { Production and } \\
\text { Business Activity }\end{array}$ & $\begin{array}{l}\text { Measures of how much } \\
\text { businesses are producing and } \\
\text { the level of new construction }\end{array}$ & $\begin{array}{l}\text { Industrial Production and Capacity Utilization, New } \\
\text { Construction, New Private Housing and Vacancy Rates, } \\
\text { Business Sales and Inventories, Manufacturers' Shipments, } \\
\text { Inventories and Orders }\end{array}$ \\
\hline Prices & $\begin{array}{l}\text { Measures of what consumers } \\
\text { and businesses pay for } \\
\text { commodities }\end{array}$ & $\begin{array}{l}\text { Producer Prices, Consumer Prices, Prices Received and } \\
\text { Paid By Farmers }\end{array}$ \\
\hline $\begin{array}{l}\text { Money, Credit and } \\
\text { Security Markets }\end{array}$ & $\begin{array}{l}\text { Measures of the amount of } \\
\text { money in the economy and } \\
\text { interest rates }\end{array}$ & $\begin{array}{l}\text { Money Stock (M1, M2 and M3), Bank Credit at All } \\
\text { Commercial Banks, Consumer Credit, Interest Rates and } \\
\text { Bond Yields, Stock Prices }\end{array}$ \\
\hline Federal Finance & $\begin{array}{l}\text { Measures of government } \\
\text { spending, deficits and costs }\end{array}$ & $\begin{array}{l}\text { Federal Receipts (Revenue), Federal Outlays (Expenses), } \\
\text { Federal Debt }\end{array}$ \\
\hline International Statistics & $\begin{array}{l}\text { Measures of how much the } \\
\text { country is exporting and } \\
\text { importing }\end{array}$ & $\begin{array}{l}\text { Industrial Production and Consumer Prices of Major } \\
\text { Industrial Countries, U.S. International Trade in Goods and } \\
\text { Services, U.S. International Transactions }\end{array}$ \\
\hline
\end{tabular}

Table D.2: Rating Codes for Each Credit Rating Agencies

\begin{tabular}{|c|c|c|c|}
\hline & Moody's & S\&P & Fitch \\
\hline Prime & Aaa & AAA & AAA \\
\hline \multirow{3}{*}{ High Grade } & Aa1 & $\mathrm{AA}+$ & AA+ \\
\hline & Aa2 & AA & $\mathrm{AA}$ \\
\hline & Aa3 & AA- & AA- \\
\hline \multirow{3}{*}{ Upper Medium Grade } & A1 & $\mathrm{A}+$ & $\mathrm{A}+$ \\
\hline & $\mathrm{A} 2$ & $\mathrm{~A}$ & $\mathrm{~A}$ \\
\hline & A3 & A- & A- \\
\hline \multirow{3}{*}{ Lower Medium Grade } & Baa1 & $\mathrm{BBB}+$ & $\mathrm{BBB}+$ \\
\hline & Baa2 & BBB & BBB \\
\hline & Baa3 & BBB- & BBB- \\
\hline \multirow{3}{*}{ Non-Investment Grade Speculative } & Bal & $\mathrm{BB}+$ & $\mathrm{BB}+$ \\
\hline & $\mathrm{Ba} 2$ & $\mathrm{BB}$ & $\mathrm{BB}$ \\
\hline & $\mathrm{Ba3}$ & BB- & BB- \\
\hline \multirow{3}{*}{ Highly Speculative } & $\mathrm{B} 1$ & $\mathrm{~B}+$ & $\mathrm{B}+$ \\
\hline & $\mathrm{B} 2$ & $\mathrm{~B}$ & $\mathrm{~B}$ \\
\hline & B3 & B- & B- \\
\hline Substantial Risk & Caa1 & $\mathrm{CCC}+$ & \multirow{5}{*}{$\mathrm{CCC}$} \\
\hline Extremely Speculative & Caa2 & $\mathrm{CCC}$ & \\
\hline \multirow{3}{*}{ In default with little prospect for recovery } & Caa3 & $\mathrm{CCC}-$ & \\
\hline & \multirow{2}{*}{$\mathrm{Ca}$} & $\mathrm{CC}$ & \\
\hline & & $\mathrm{C}$ & \\
\hline \multirow[b]{2}{*}{ In default } & $\mathrm{C}$ & \multirow[b]{2}{*}{ D } & DDD \\
\hline & 1 & & $\frac{\mathrm{DD}}{\mathrm{D}}$ \\
\hline
\end{tabular}




\section{Appendix E List of Metrics}

Table E.1: Variables from Principal Component Analysis and Logistic Regression

\begin{tabular}{|c|l|l|}
\hline$\#$ & \multicolumn{1}{|c|}{ Inputs } & \multicolumn{1}{c|}{ Outputs } \\
\hline 1 & $\begin{array}{l}\text { AD, AR,CA, CL, COGS, Inv, Other } \\
\text { NonCA, PPE, SGA, TA, TL }\end{array}$ & Rev, SE \\
\hline 2 & AP, CM, IE, PPE, SGA, TA, TL & Cash, NI, Rev, SE \\
\hline
\end{tabular}

Table E.2: Profitability and Success Metrics (Normal DEA Frontier)

\begin{tabular}{|c|c|c|}
\hline$\#$ & Inputs & Outputs \\
\hline 1 & AR, COGS, IE, Inv, PPE, SGA, TA, TL & NI, Rev \\
\hline 2 & AR, COGS, IE, Inv, PPE, SGA, TA, TL & NI, RE, Rev \\
\hline 3 & AR, COGS, IE, Inv, PPE, SGA, TA, TL & NI, Rev, SE \\
\hline 4 & AR, COGS, IE, Inv, PPE, SGA, TA, TL & Rev \\
\hline 5 & AR, COGS, IE, Inv, PPE, SGA, TA, TL & RE, Rev \\
\hline 6 & AR, COGS, IE, Inv, PPE, SGA, TA, TL & Rev, SE \\
\hline 7 & AR, IE, Inv, PPE, SGA, TA, TL & Rev, SE \\
\hline 8 & COGS, IE, Inv, PPE, SGA, TA, TL & CFO, Rev, SE \\
\hline 9 & COGS, IE, Inv, PPE, SGA, TA, TL & CFO, RE, Rev, SE \\
\hline 10 & COGS, IE, Inv, PPE, SGA, TA, TL & NI, Rev, RE, SE \\
\hline 11 & COGS, IE, Inv, PPE, SGA, TA, TL & RE, Rev, SE \\
\hline 12 & COGS, IE, Inv, PPE, SGA, TA, TL & Rev, SE \\
\hline 13 & COGS, SGA, TA, TL & NI, Rev, SE \\
\hline 14 & COGS, SGA, TA, TL & NI, Rev, SE \\
\hline 15 & COGS, SGA, TA, TL & NI, Rev, RE, SE \\
\hline 16 & IE, TA & CFO, EBIT, RE, WC \\
\hline 17 & IE, TA & CFO, NI, RE, Rev \\
\hline 18 & IE, TA & NI, RE, Rev \\
\hline 19 & IE, TA & NI, RE, Rev, SE \\
\hline 20 & IE, TA, TL & CFO, NI, RE, Rev \\
\hline 21 & IE, TA, TL & NI, RE, Rev \\
\hline 22 & IE, TA, TL & NI, RE, Rev, SE \\
\hline 23 & IE, TA, TL & Rev, SE \\
\hline 24 & SGA, PPE, TA, TL & Rev, SE \\
\hline 25 & TA & CFO, EBIT, RE \\
\hline 26 & TA & CFO, NI, RE \\
\hline 27 & TA & CFO, NI, RE, Rev \\
\hline 28 & TA, TL & CFO, NI, RE, Rev \\
\hline 29 & TA, TL & EBIT, RE, SE,WC \\
\hline 30 & TA, TL & NI, RE, Rev \\
\hline 31 & TA, TL & NI, RE, Rev, SE \\
\hline 32 & $\mathrm{TA}, \mathrm{TL}$ & Rev, SE \\
\hline
\end{tabular}

Table E.3: Profitability and Success Metrics (Inverse DEA Frontier)

\begin{tabular}{|c|l|l|}
\hline$\#$ & \multicolumn{1}{|c|}{ Inputs } & \multicolumn{1}{c|}{ Outputs } \\
\hline 1 & CFO, NI, RE, Rev & TA, TL, IE \\
\hline 2 & NI, RE, Rev & IE, TA \\
\hline 3 & NI, RE, Rev & IE, TA, TL \\
\hline 4 & Rev, SE & AR, COGS, IE, Inv, PPE, SGA, TA, TL \\
\hline 5 & Rev, SE & COGS, IE, Inv, PPE, SGA, TA, TL \\
\hline 6 & Rev, SE & IE, TA, TL \\
\hline 7 & Rev, SE & SGA, PPE, TA, TL \\
\hline
\end{tabular}


Table E.4: Bankruptcy and Failure Metrics (Worst-Practice DEA Frontier)

\begin{tabular}{|c|l|l|}
\hline$\#$ & \multicolumn{1}{|c|}{ Inputs } & \multicolumn{1}{|c|}{ Outputs } \\
\hline 1 & AR, Cash, MS, NR & CL \\
\hline 2 & AR, Cash, Lev, MS, NR & CL \\
\hline 3 & CA, CFO & CL \\
\hline 4 & CA, CFO & CL, NI \\
\hline 5 & CA, CFO, EBIT, RE & CL, IE,TA \\
\hline 6 & CA, CFO, Lev & CL \\
\hline 7 & CFO, EBIT & IE \\
\hline 8 & CFO, EBIT, Lev & IE \\
\hline 9 & CFO, EBIT, Lev, SE, TA & IE, TL \\
\hline 10 & CFO, EBIT, SE, TA & IE, TL \\
\hline 11 & CFO, TA, WC & IE \\
\hline 12 & CFO, WC & IE \\
\hline 13 & Lev, SE, TA & TL \\
\hline 14 & SE, TA & TL \\
\hline
\end{tabular}

Table E.5: Bankruptcy and Failure Metrics (Bad Outputs Model)

\begin{tabular}{|c|l|l|}
\hline$\#$ & \multicolumn{1}{|c|}{ Inputs } & \multicolumn{1}{|c|}{ Outputs } \\
\hline 1 & AR, COGS, IE, Inv, PPE, SGA, TA, TL & Rev, SE \\
\hline 2 & COGS, IE, Inv, PPE, SGA, TA, TL & Rev, SE \\
\hline 3 & COGS, IE, Inv, PPE, SGA, TA, TL & Rev, SE \\
\hline 4 & IE, TA & NI, RE, Rev \\
\hline 5 & IE, TA, TL & CFO, NI, RE, Rev \\
\hline 6 & IE, TA, TL & NI, RE, Rev \\
\hline 7 & IE, TA, TL & Rev, SE \\
\hline 8 & PPE, SGA,TA, TL & Rev, SE \\
\hline
\end{tabular}

Table E.6: Balance Sheet Metrics (Normal DEA Frontier)

\begin{tabular}{|c|l|l|}
\hline$\#$ & \multicolumn{1}{|c|}{ Inputs } & \multicolumn{1}{|c|}{ Outputs } \\
\hline \multirow{2}{*}{1} & $\begin{array}{l}\text { AR, CA, Goodwill, Inv, MS, Net PPE, } \\
\text { LTIS, TA }\end{array}$ & Cash, RE, SE \\
\hline 2 & AP, CL, CM, LTD, NPSTD, TL & RE, SE \\
\hline 3 & $\begin{array}{l}\text { AR, AP, CA, CL, CM, Goodwill, Inv, } \\
\text { MS, Net PPE, NPSTD, LTD, LTIS, TA, } \\
\text { TL }\end{array}$ & Cash, RE, SE \\
\hline
\end{tabular}

Table E.7: Income Statement Metrics (Normal DEA Frontier)

\begin{tabular}{|c|c|c|}
\hline$\#$ & Inputs & Outputs \\
\hline 1 & COGS, ITE, Net IE, SGA & NI, Rev \\
\hline
\end{tabular}

Table E.8: Qualitative Metrics (Normal DEA Frontier)

\begin{tabular}{|c|l|l|}
\hline$\#$ & \multicolumn{1}{|c|}{ Inputs } & \multicolumn{1}{|c|}{ Outputs } \\
\hline \multirow{3}{*}{1} & $\begin{array}{l}\text { Auditors' Opinion, Auditor Turnover, } \\
\text { Legal Proceedings, Management } \\
\text { Turnover, Related Parties, Retirement } \\
\text { Plans }\end{array}$ & Dummy $^{31}$ \\
\hline
\end{tabular}

\footnotetext{
${ }^{31}$ A dummy variable is one where each DMU is given a value of 1 for that variable.
} 
Table E.9: Variables for "Mega" Model

\begin{tabular}{|c|c|c|}
\hline Source & Variable & Orientation \\
\hline \multirow{6}{*}{ Income Statement } & COGS & Input \\
\hline & ITE & Input \\
\hline & Net IE & Input (+) / Output (-) \\
\hline & NI & Output (+) / Input (-) \\
\hline & Rev & Output \\
\hline & SGA & Input \\
\hline \multirow{17}{*}{ Balance Sheet } & $\mathrm{AR}$ & Input \\
\hline & AP & Input \\
\hline & $\mathrm{CA}$ & Input \\
\hline & Cash & Output \\
\hline & $\mathrm{CL}$ & Input \\
\hline & $\mathrm{CM}$ & Input \\
\hline & Goodwill & Input \\
\hline & Inv & Input \\
\hline & LTD & Input \\
\hline & LTIS & Input \\
\hline & MS & Input \\
\hline & Net PPE & Input \\
\hline & NPSTD & Input \\
\hline & RE & Output (+) / Input (-) \\
\hline & SE & Output (+) / Input (-) \\
\hline & TA & Input \\
\hline & TL & Input \\
\hline \multirow{3}{*}{ Cash Flow Statement } & CFO & Output (+) / Input (-) \\
\hline & CFI & Output (+) / Input (-) \\
\hline & $\mathrm{CFF}$ & Input (+) / Output (-) \\
\hline \multirow{6}{*}{ Managerial Decision-Making } & Auditor's Opinion & Input \\
\hline & Auditor Turnover & Input \\
\hline & Legal Proceedings & Input \\
\hline & Management Turnover & Input \\
\hline & Related Parties & Input \\
\hline & Retirement Plans & Input \\
\hline \multirow{3}{*}{ Market Factors } & DJIA & Non-Discretionary Output \\
\hline & S\&P 500 & Non-Discretionary Output \\
\hline & NASDAQ-100 & Non-Discretionary Output \\
\hline \multirow{13}{*}{ Economic Factors } & GDP Growth rate & Non-Discretionary Output \\
\hline & Inflation & Non-Discretionary Output \\
\hline & Interest Rate & Non-Discretionary Output \\
\hline & Unemployment Rate & Non-Discretionary Input \\
\hline & Debt as a Percentage of GDP & Non-Discretionary Input \\
\hline & Personal Consumption Expenditures: Clothing & Non-Discretionary Output \\
\hline & GDP: Clothing & Non-Discretionary Output \\
\hline & Apparel Labour Productivity & Non-Discretionary Output \\
\hline & Apparel Imports & Non-Discretionary Output \\
\hline & Median Months for Sale (Housing) & Non-Discretionary Input \\
\hline & Housing Units Started & Non-Discretionary Output \\
\hline & Cotton Price & Non-Discretionary Input \\
\hline & Oil Price & Non-Discretionary Input \\
\hline
\end{tabular}




\section{Appendix F Modelling Results}

\section{F.1 Logistic Regression (LR) Metric}

Table F.1: Normal Scores Calculated with Variables Derived from LR by State

\begin{tabular}{|c|c|c|c|c|c|}
\hline State & Count & Average & Median & Minimum & Maximum \\
\hline All A & 649 & $0.38 \pm 0.36$ & 0.26 & 0 & 1 \\
\hline All B & 50 & $0.17 \pm 0.30$ & 0.00 & 0 & 1 \\
\hline B & 13 & $0.16 \pm 0.37$ & 0.00 & 0 & 1 \\
\hline B-1 & 12 & $0.06 \pm 0.11$ & 0.00 & 0 & 0.35 \\
\hline B-2 & 13 & $0.23 \pm 0.37$ & 0.03 & 0 & 1 \\
\hline B-3 & 12 & $0.22 \pm 0.28$ & 0.13 & 0 & 1 \\
\hline Total & 699 & $0.37 \pm 0.36$ & 0.24 & 0 & 1 \\
\hline
\end{tabular}

Table F.2: Confusion Matrix for LR Normal Model

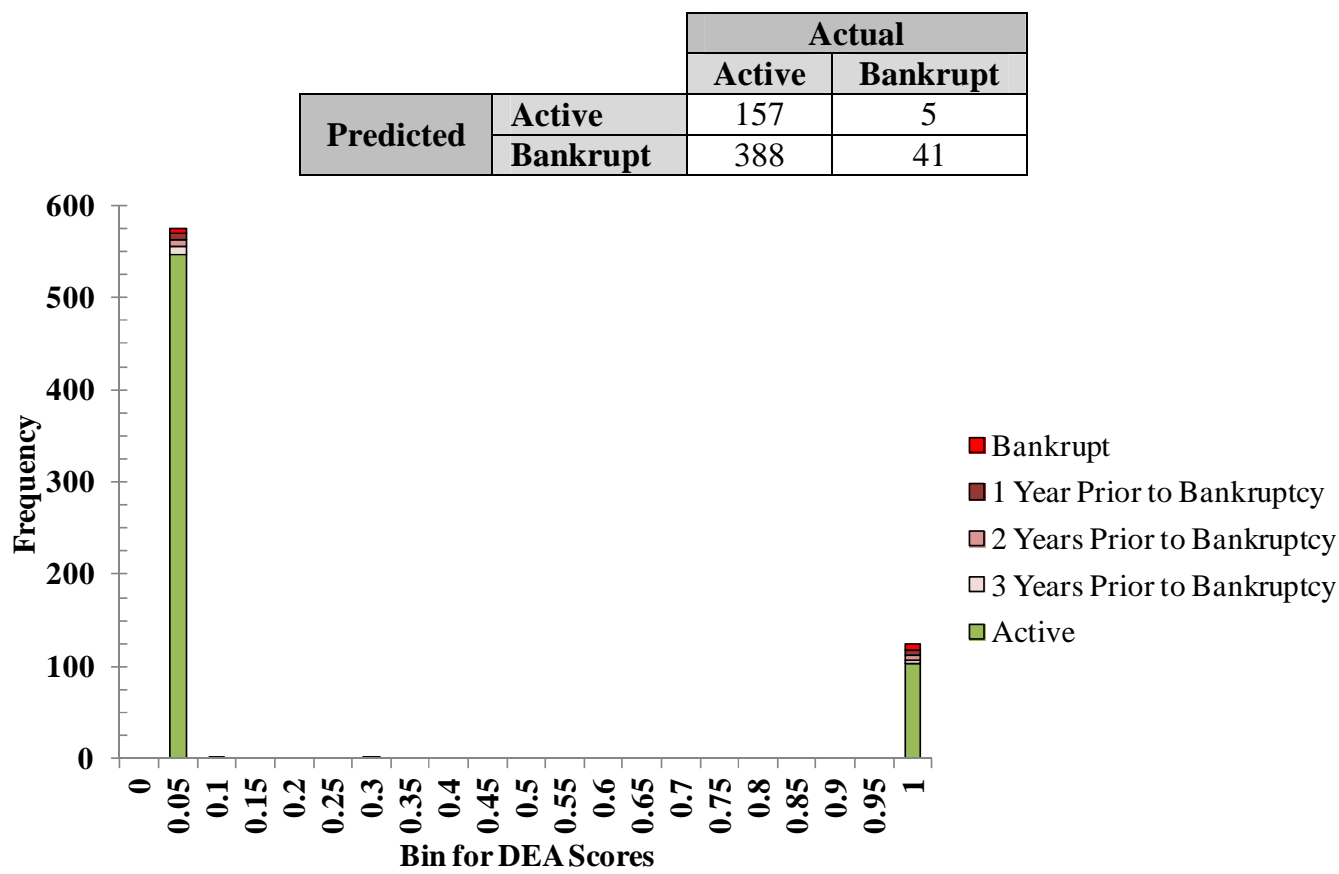

Figure F.1: Distribution of Scores Generated from LR Inverse DEA Model

Table F.3: Inverse Scores Calculated with Variables Derived from LR by State

\begin{tabular}{|c|c|c|c|c|c|}
\hline State & Count & Average & Median & Minimum & Maximum \\
\hline All A & 651 & $0.16 \pm 0.36$ & 0.00 & 0 & 1 \\
\hline All B & 50 & $0.43 \pm 0.49$ & 0.01 & 0 & 1 \\
\hline B & 13 & $0.48 \pm 0.50$ & 0.25 & 0 & 1 \\
\hline B-1 & 12 & $0.50 \pm 0.52$ & 0.51 & 0 & 1 \\
\hline B-2 & 13 & $0.39 \pm 0.51$ & 0.00 & 0 & 1 \\
\hline B-3 & 12 & $0.33 \pm 0.49$ & 0.00 & 0 & 1 \\
\hline Total & 701 & $0.18 \pm 0.38$ & 0.00 & 0 & 1 \\
\hline
\end{tabular}


Table F.4: Confusion Matrix for LR Inverse Model

\begin{tabular}{|c|c|c|c|}
\hline & \multicolumn{2}{|c|}{ Actual } \\
\hline & & Active & Bankrupt \\
\hline \multirow{2}{*}{ Predicted } & Active & 548 & 29 \\
\hline & Bankrupt & 103 & 21 \\
\hline
\end{tabular}

\section{F.2 Income Statement (IS) Metric}

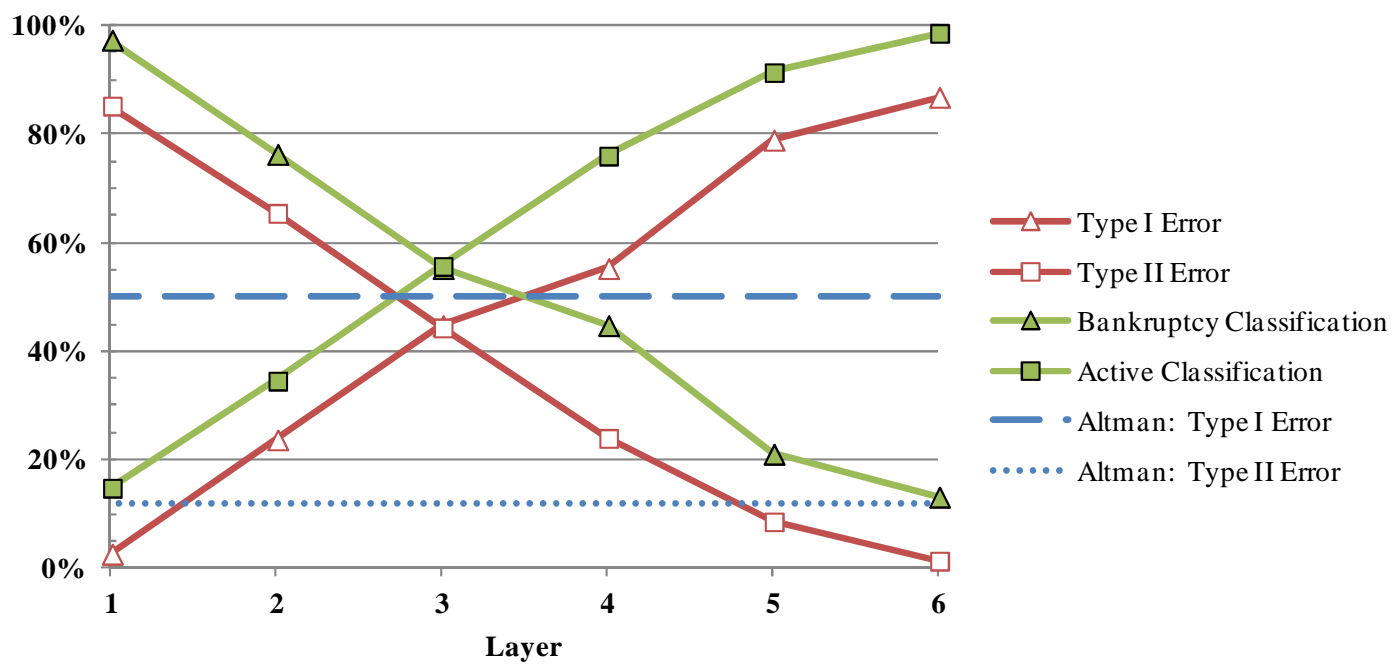

Figure F.2: Prediction by IS Metric from Two Years Back

A DMU was predicted bankrupt up to 2 years prior to filing Chapter 11 .

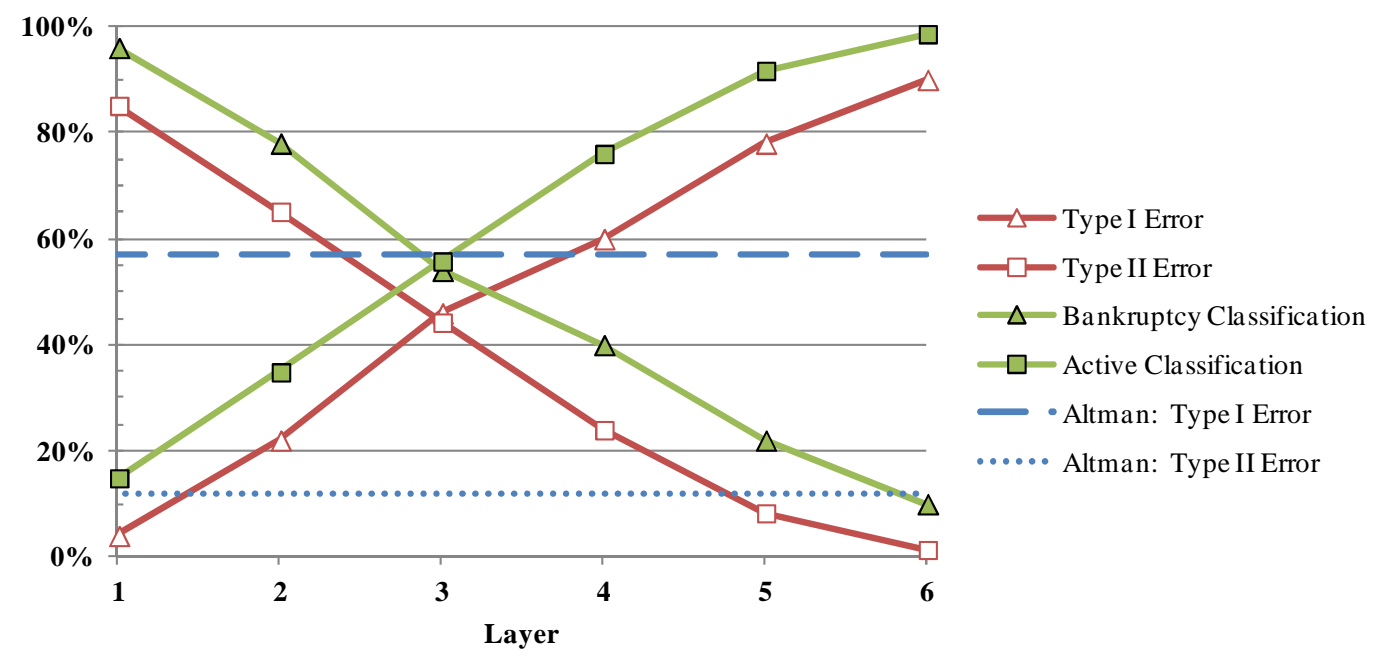

Figure F.3: Prediction by IS Metric from Three Years Back

A DMU was predicted bankrupt up to 3 years prior to filing Chapter 11. 


\section{F.3 Balance Sheet Assets (BSA) Metric}

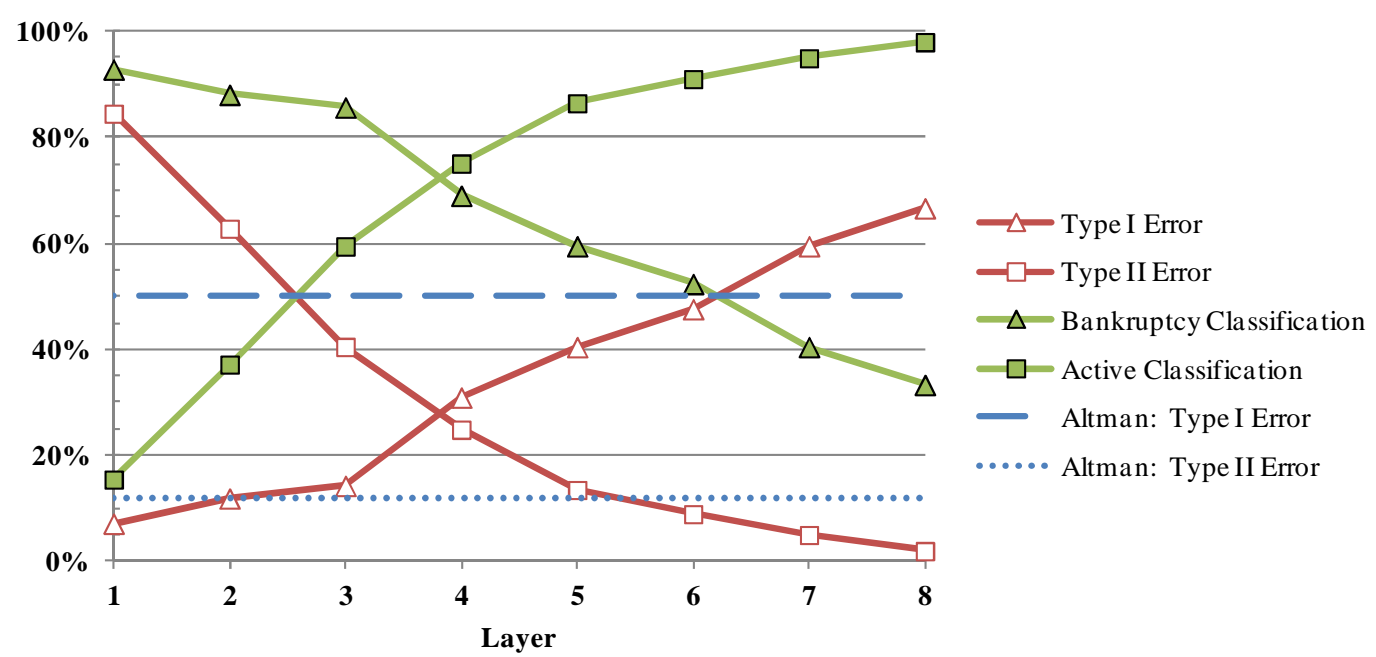

Figure F.4: Prediction by BSA Metric from Two Years Back

A DMU was predicted bankrupt up to 2 years prior to filing Chapter 11.

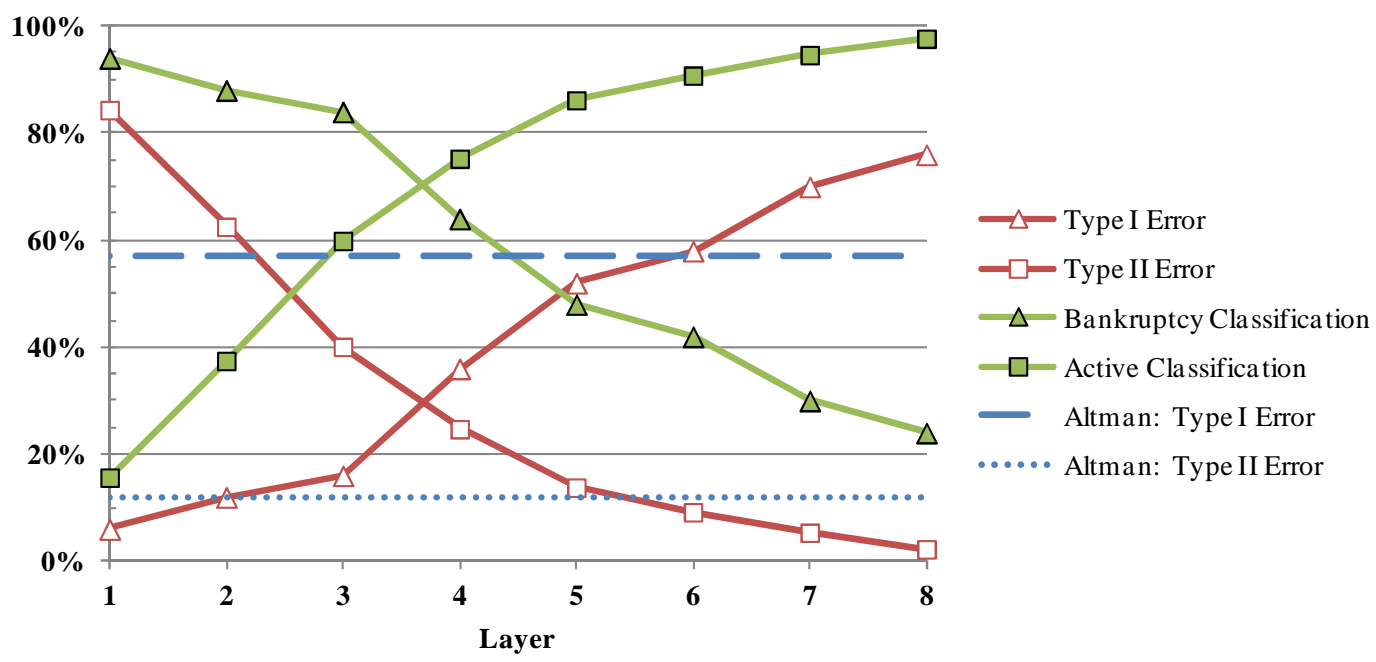

Figure F.5: Prediction by BSA Metric from Three Years Back

A DMU was predicted bankrupt up to 3 years prior to filing Chapter 11. 


\section{F.4 Balance Sheet Liabilities (BSL) Metric}

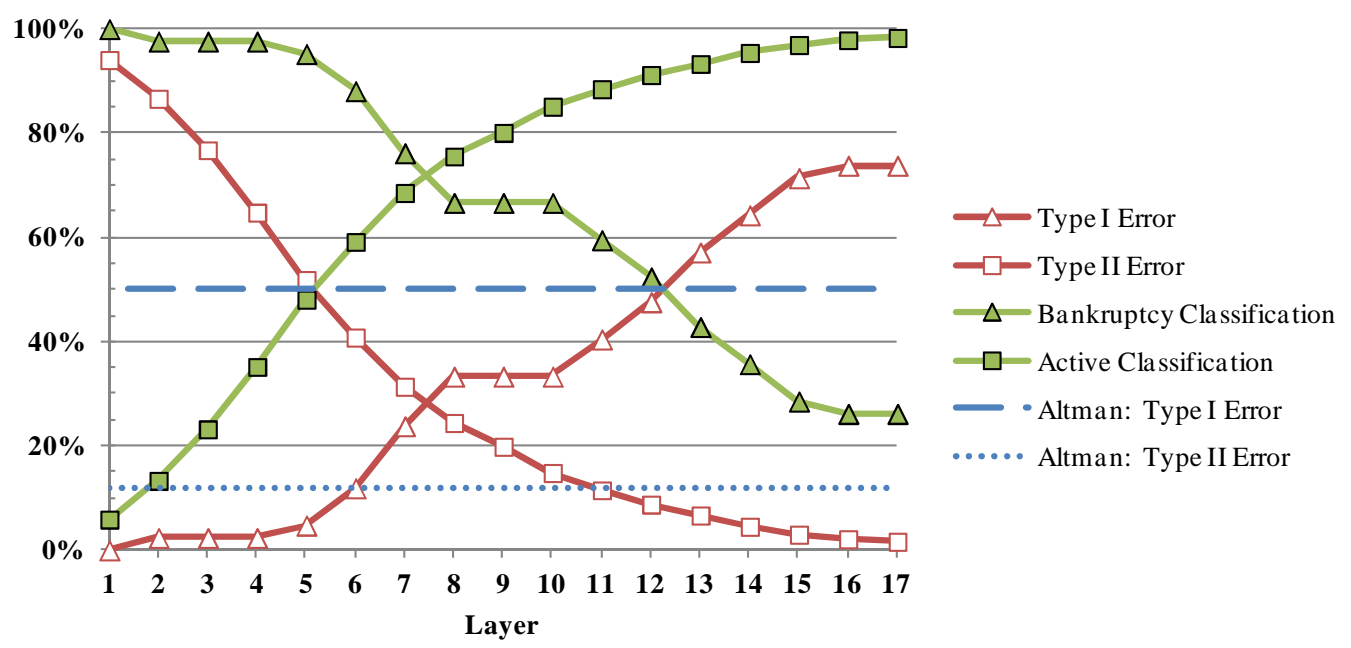

Figure F.6: Prediction by BSL Metric from Two Years Back

A DMU was predicted bankrupt up to 2 years prior to filing Chapter 11.

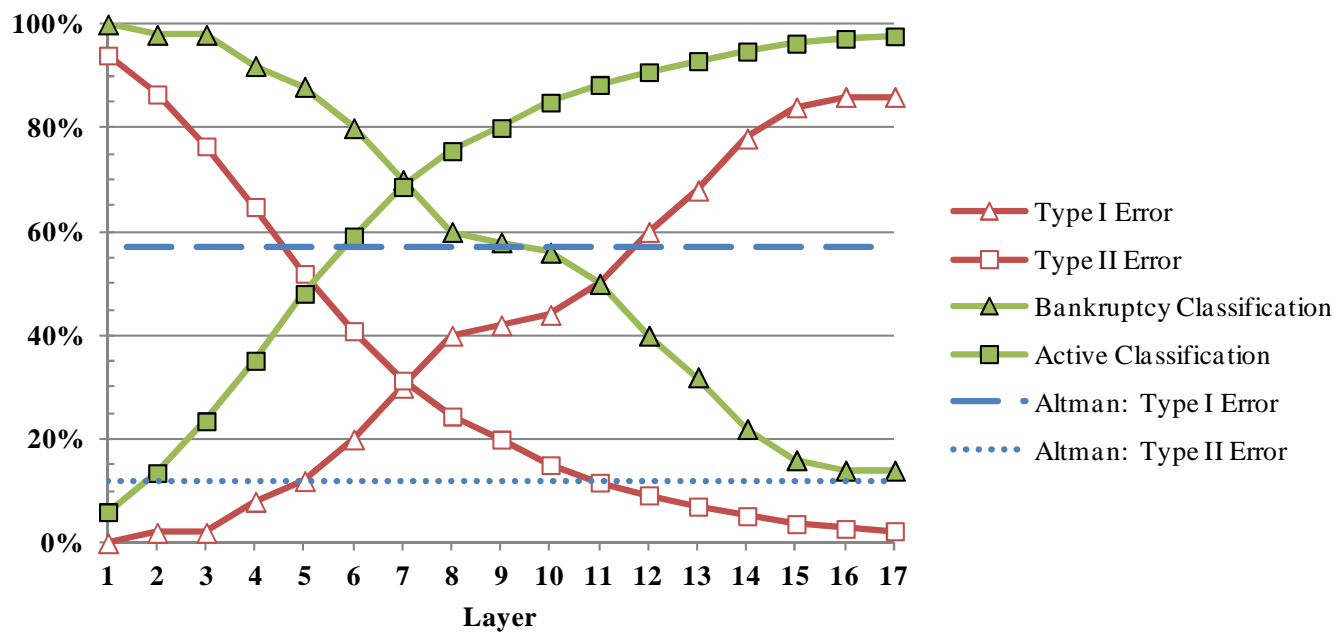

Figure F.7: Prediction by BSL Metric from Three Years Back

A DMU was predicted bankrupt up to 3 years prior to filing Chapter 11. 


\section{F.5 Managerial Decision-Making (MDM) Metric}

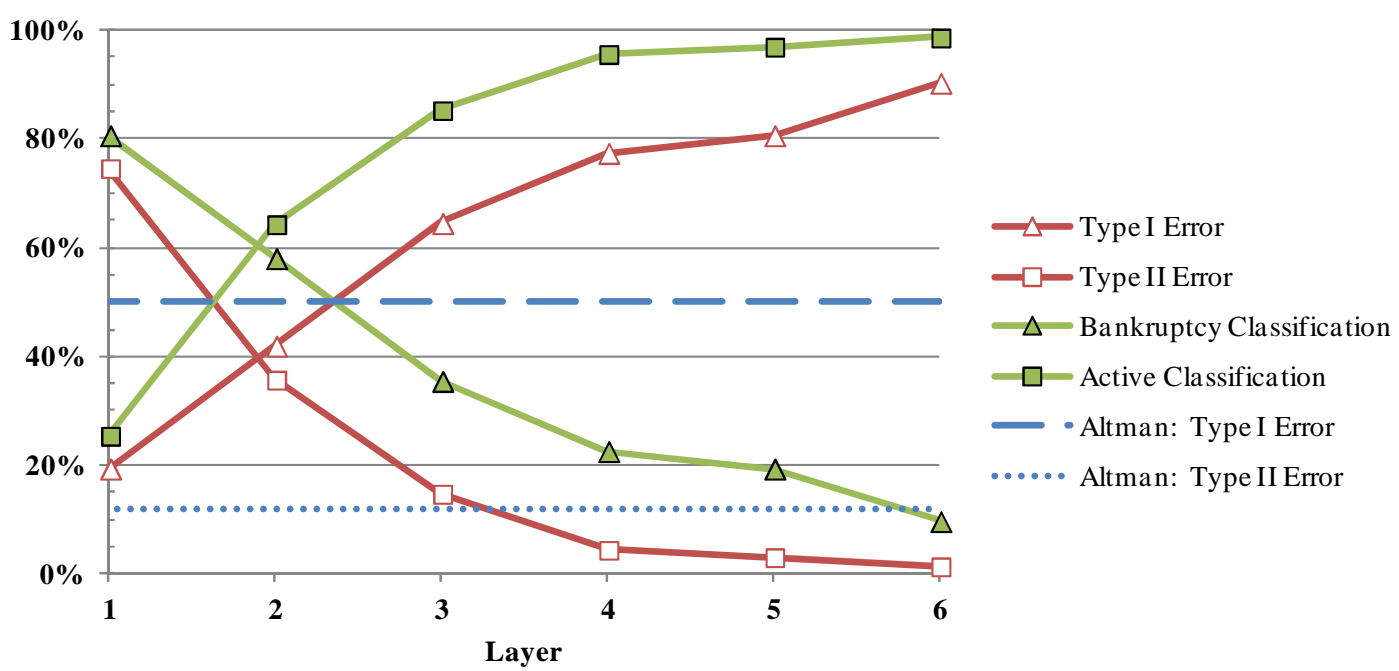

Figure F.8: Prediction by MDM Metric from Two Years Back A DMU was predicted bankrupt up to 2 years prior to filing Chapter 11.

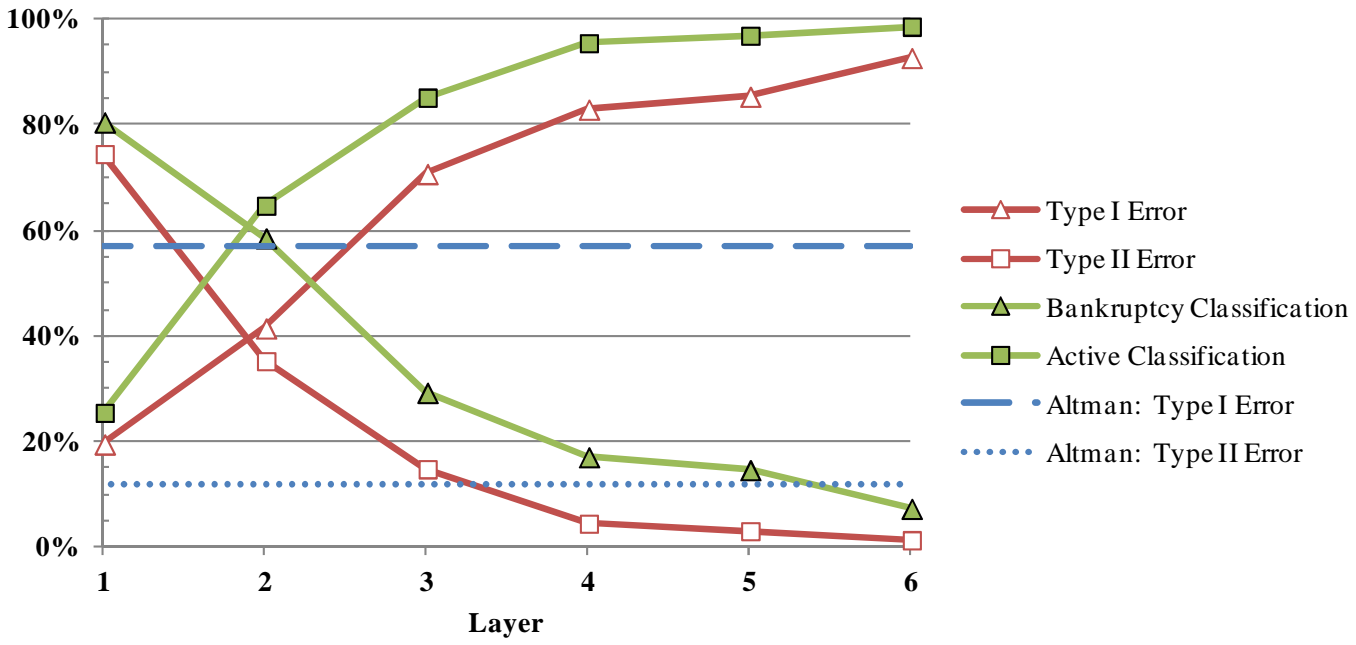

Figure F.9: Prediction by MDM Metric from Three Years Back A DMU was predicted bankrupt up to 3 years prior to filing Chapter 11. 


\section{F.6 Second Stage Models}

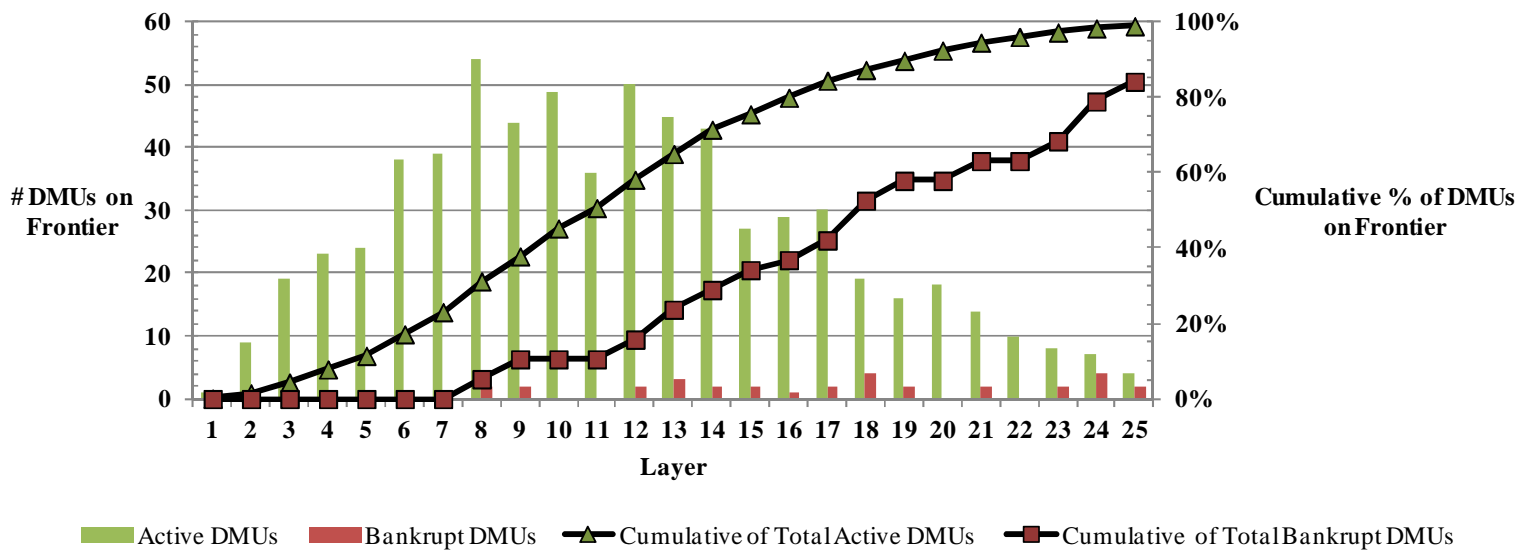

Figure F.10: Classification by Layer in Absolute Numbers from Two Years Back

A DMU was predicted bankrupt up to 2 years prior to filing Chapter 11.

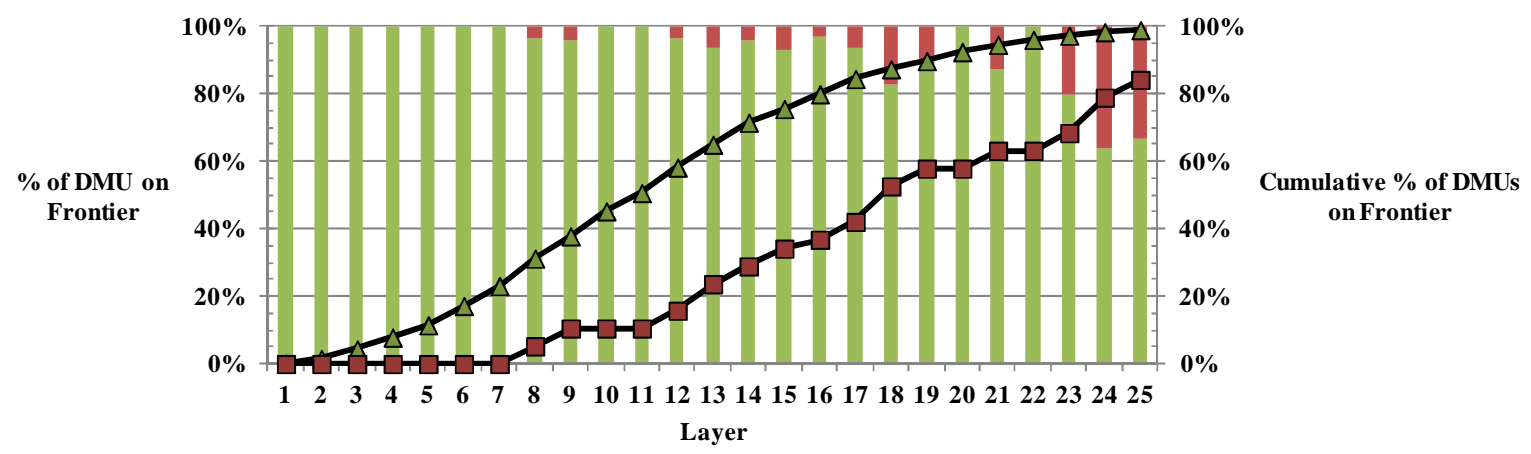

$\%$ Active of Classified This Layer

$\rightarrow$ Cumulative of Total Active DMUs

\% Bankrupt of Classified This Layer

$\neg$-Cumulative of TotalBankrupt DMUs

Figure F.11: Classification by Layer in Percentages from Two Years Back A DMU was predicted bankrupt up to 2 years prior to filing Chapter 11.

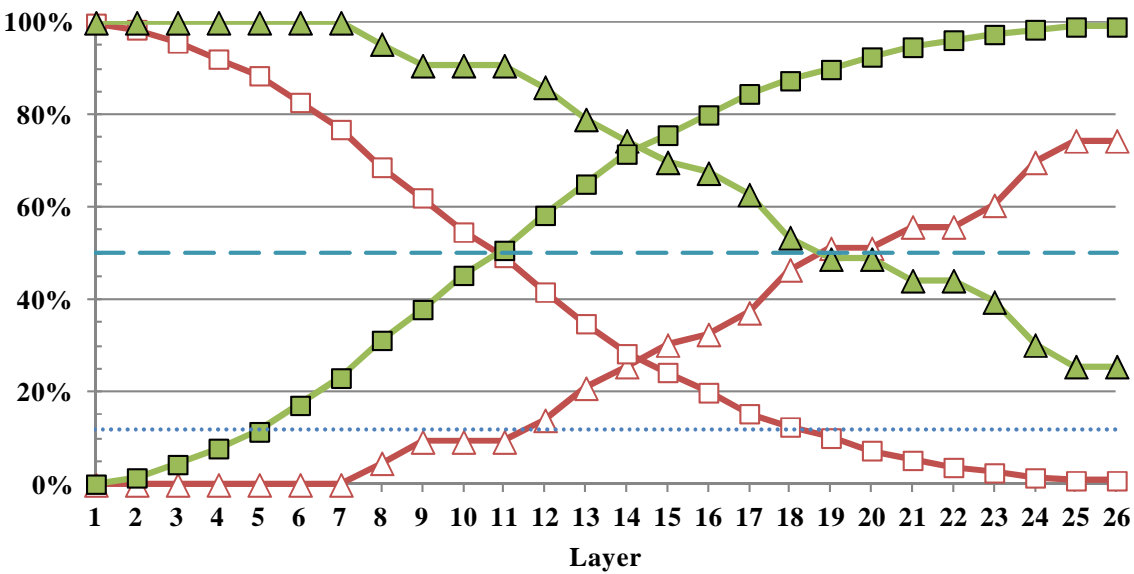

$\triangle$ Type I Error

$-\square$ Type II Error

$\triangle$ Bankruptcy Classification

$-\square-$ Active Classification

- Altman: Type I Error

…..... Altman: Type II Error

Figure F.12: Prediction by Second Stage Model from Two Years Back

A DMU was predicted bankrupt up to 2 years prior to filing Chapter 11. 


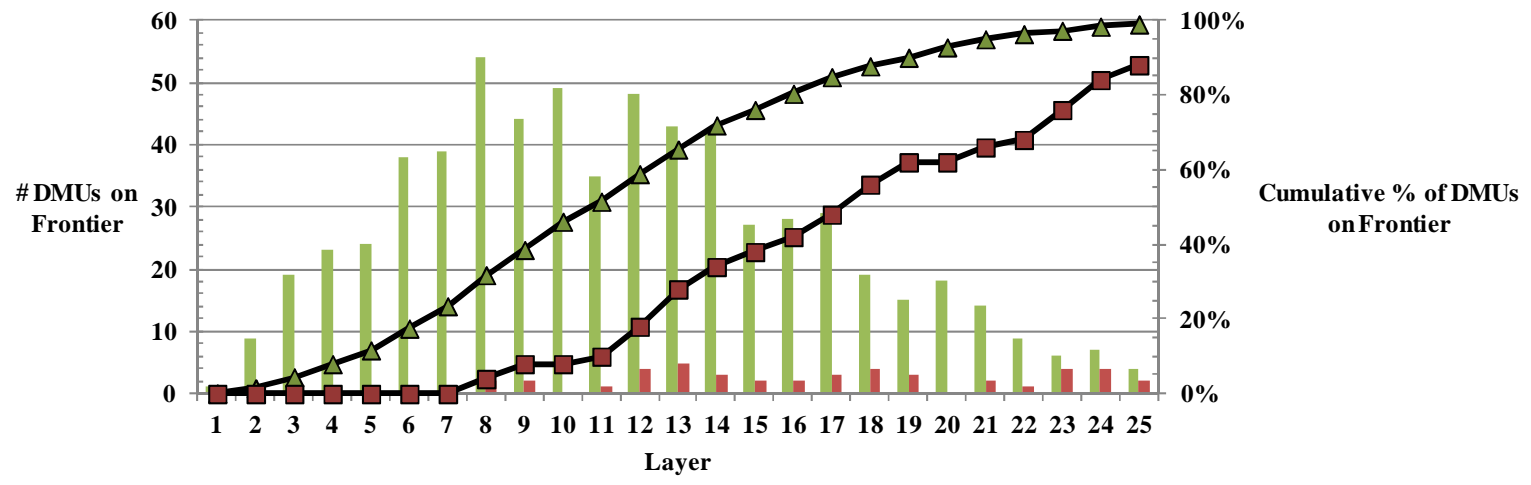

Active DMUs $\quad$ Bankrupt DMUs $\quad-$ Cumulative of Total Active DMUs $\square$ Cumulative of TotalBankrupt DMUs

Figure F.13: Classification by Layer in Absolute Numbers Three Years Back A DMU was predicted bankrupt up to 3 years prior to filing Chapter 11.

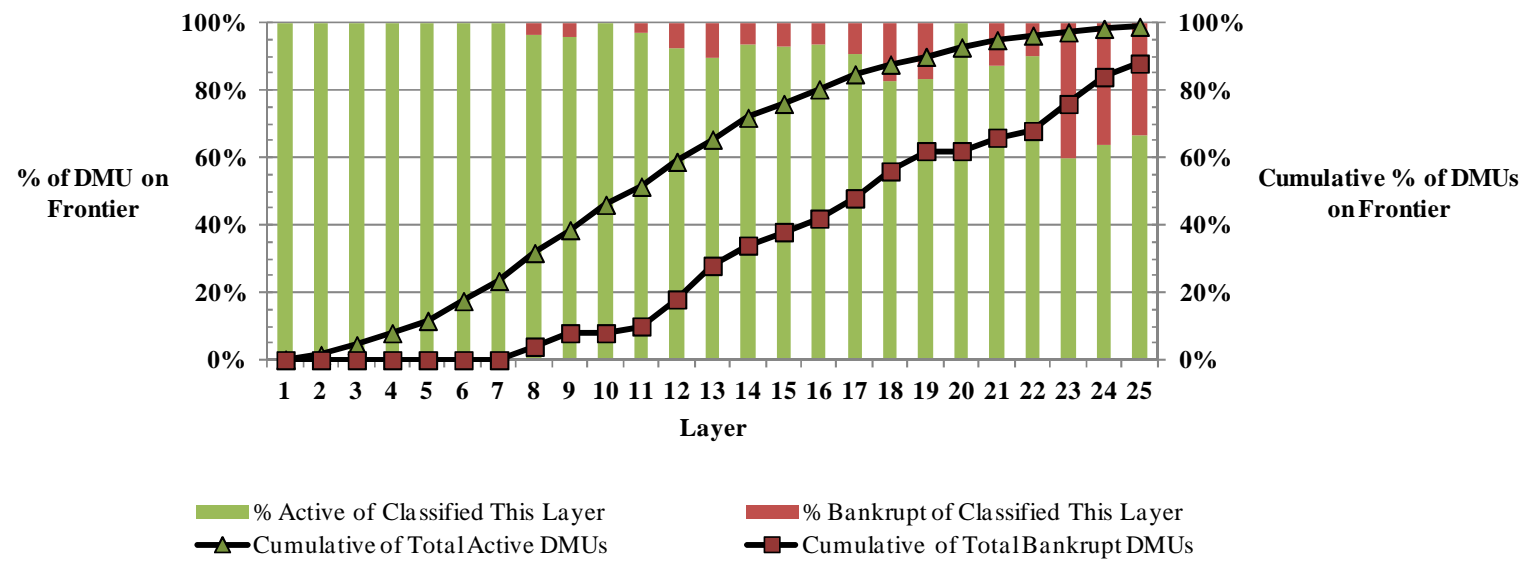

Figure F.14: Classification by Layer in Percentages from Three Years Back A DMU was predicted bankrupt up to 3 years prior to filing Chapter 11 .

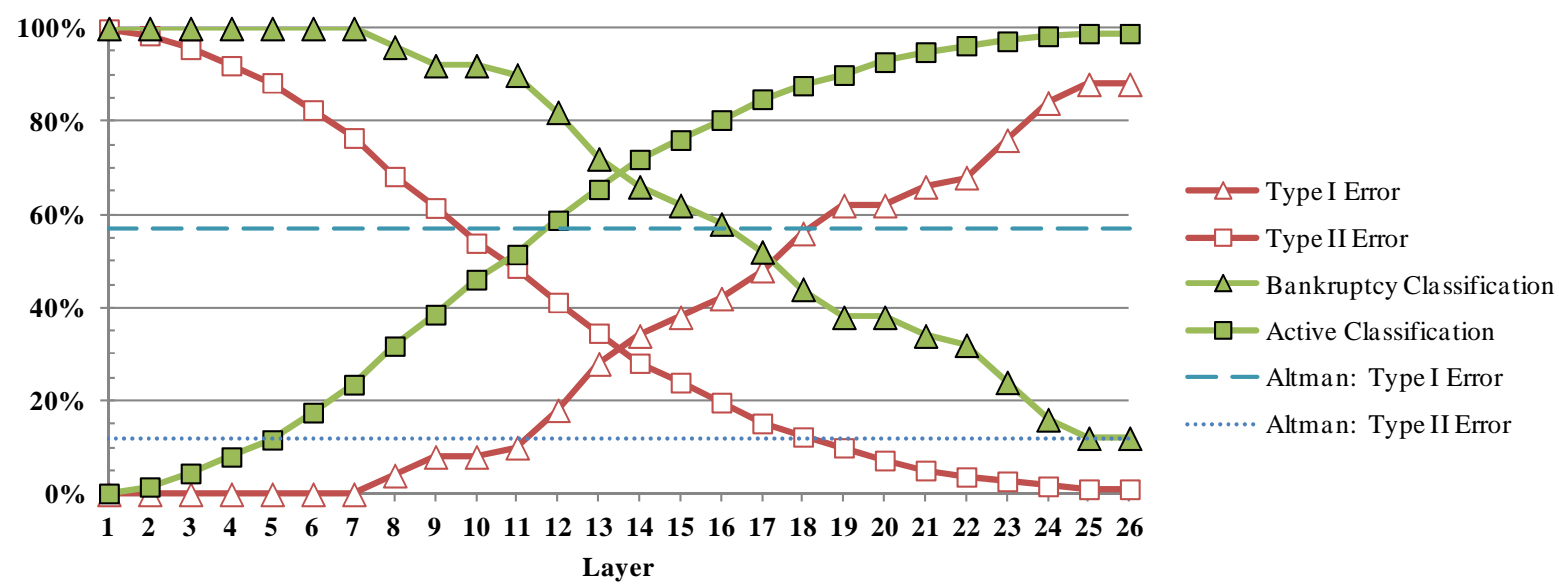

Figure F.15: Prediction by Second Stage Model from Three Years Back A DMU was predicted bankrupt up to 3 years prior to filing Chapter 11. 


\section{F.7 Projections for Active Companies}
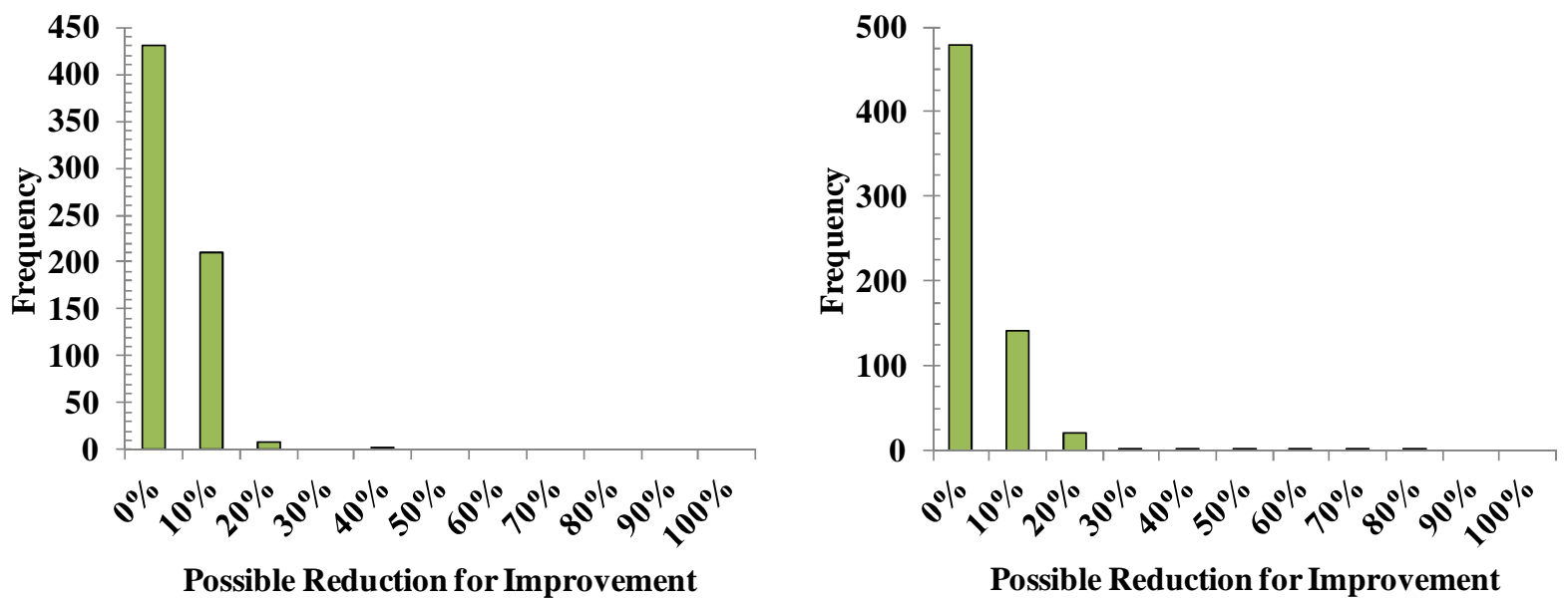

Figure F.16: IS Projections for COGS

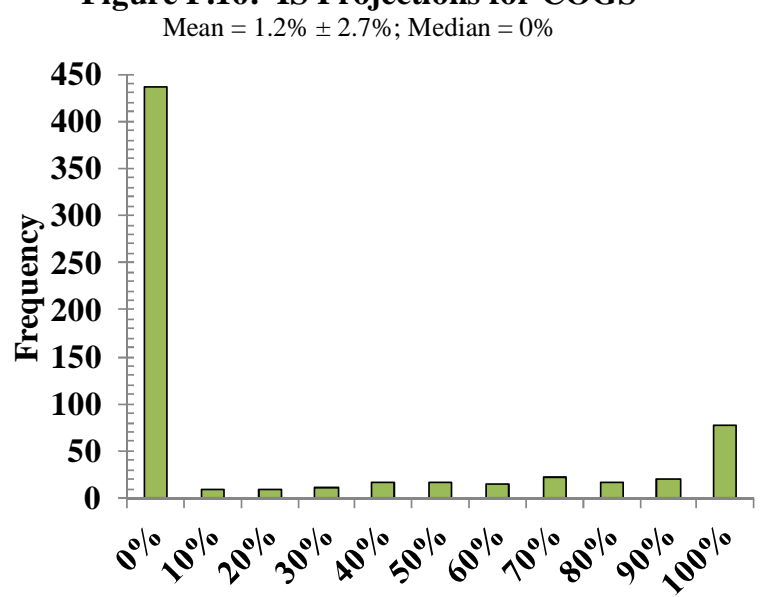

Possible Reduction for Improvement

Figure F.18: IS Projections for Net Interest Expense Mean $=23 \% \pm 36 \%$; Median $=0 \%$

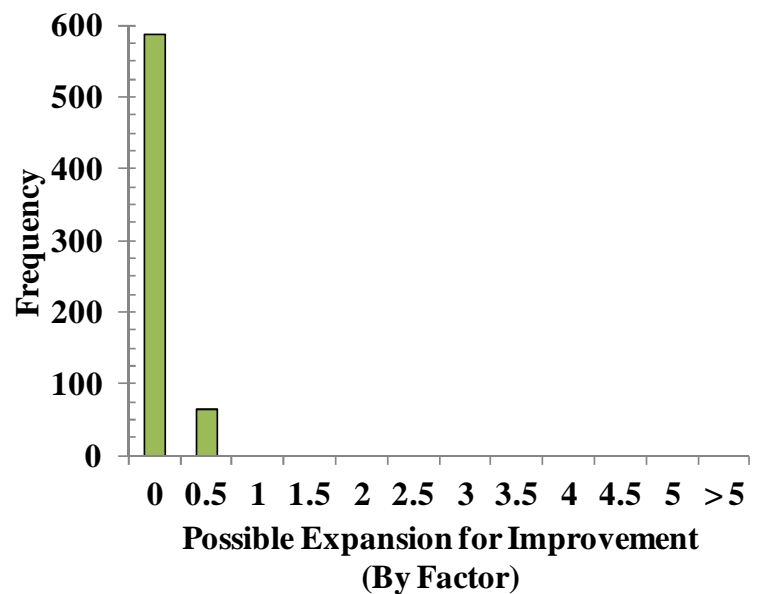

Figure F.20: IS Projections for Revenue Mean $=0.3 \% \pm 0.1 \% ;$ Median $=0 \%$

Figure F.17: IS Projections for SGA

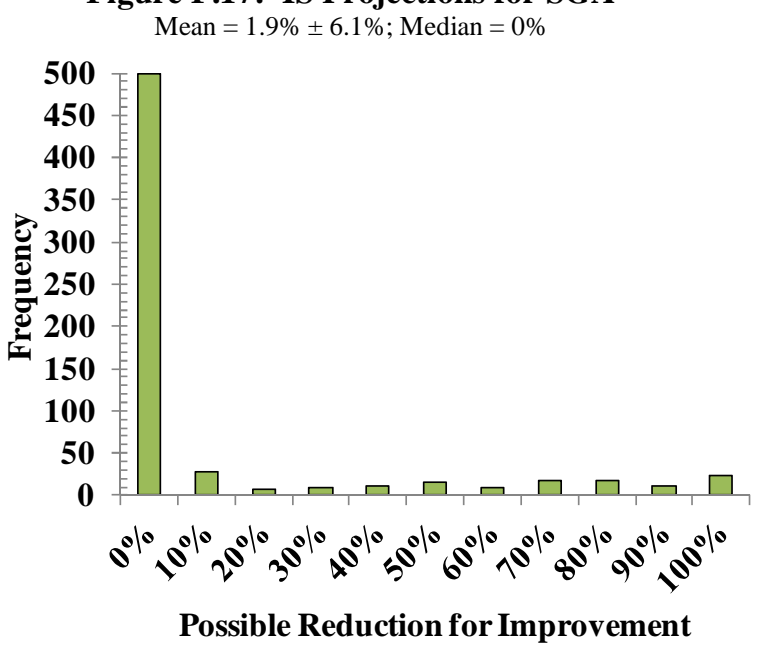

Figure F.19: IS Projections for Income Tax Expense Mean $=12 \% \pm 27 \% ;$ Median $=0 \%$

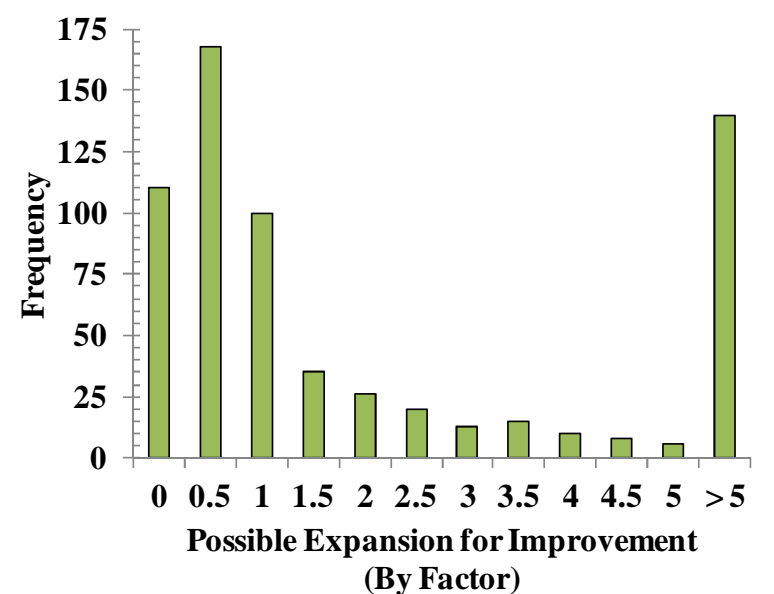

Figure F.21: IS Projections for Net Income Mean $=260 \% \pm 360 \% ;$ Median $=73 \%$ 


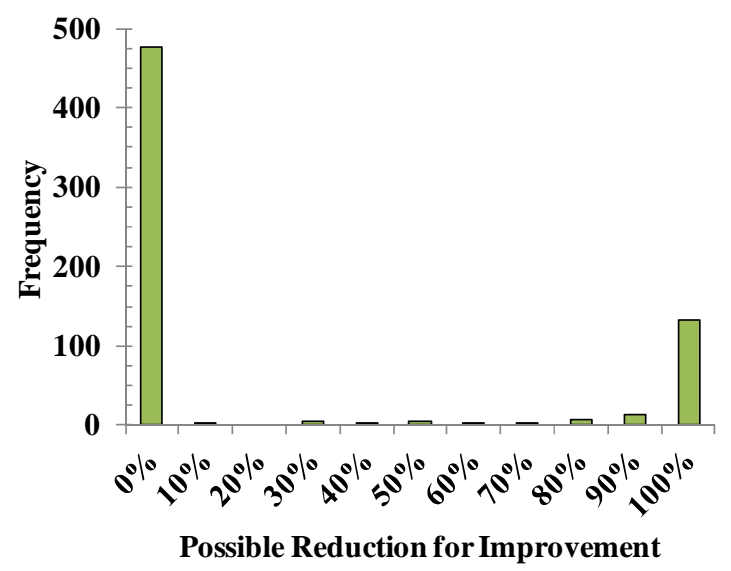

Figure F.22: BSA Projections for Marketable Securities

Mean $=24 \% \pm 41 \% ;$ Median $=0 \%$

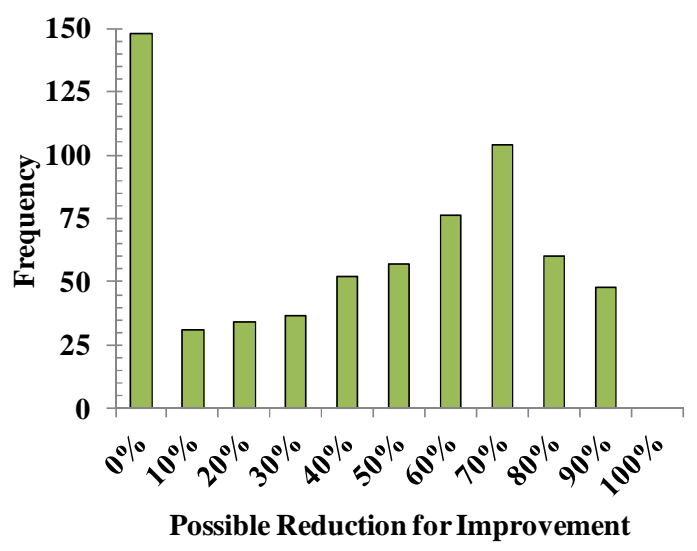

Figure F.24: BSA Projections for Inventories Mean $=39 \% \pm 29 \%$; Median $=44 \%$

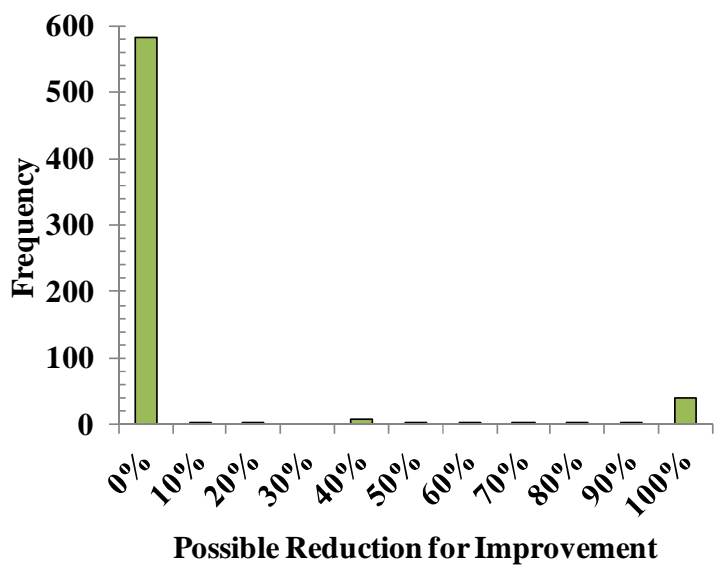

Figure F.26: BSA Projections for Long-Term Investments in Securities Mean $=8 \% \pm 26 \%$; Median $=0 \%$

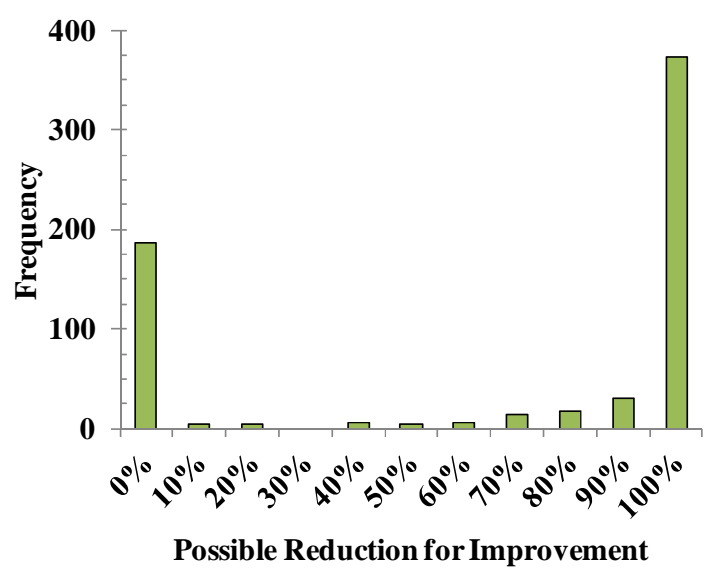

Figure F.23: BSA Projections for Accounts Receivable Mean $=66 \% \pm 44 \% ;$ Median $=98 \%$

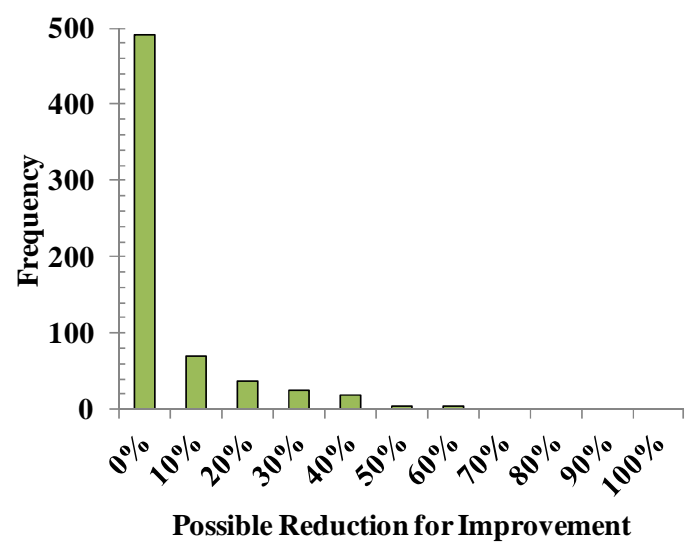

Figure F.25: BSA Projections for Current Assets

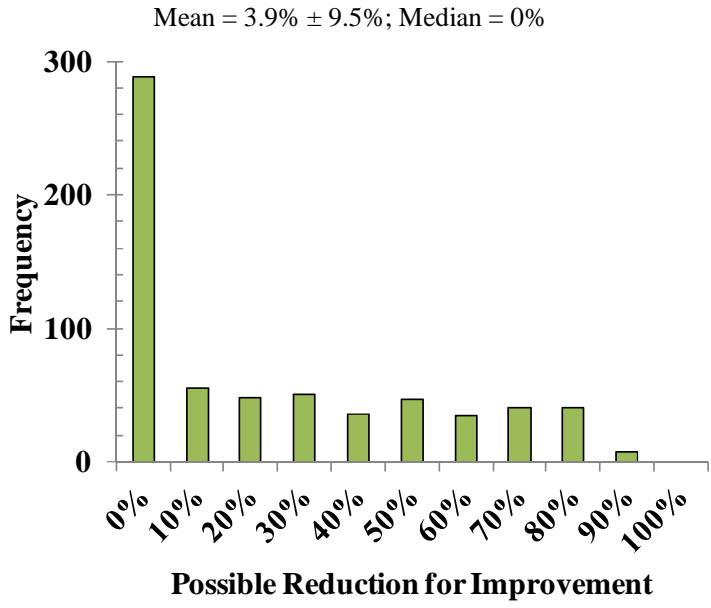

Figure F.27: BSA Projections for Net PPE Mean $=21 \% \pm 26 \% ;$ Median $=5 \%$ 


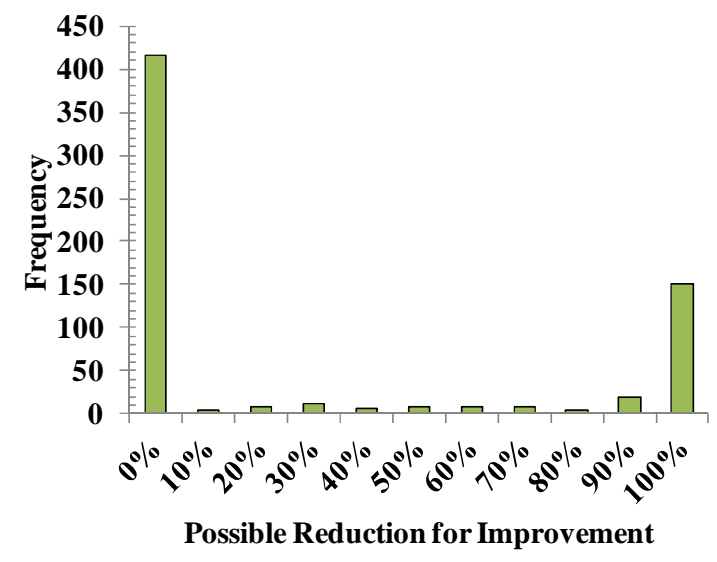

Figure F.28: BSA Projections for Goodwill Mean $=30 \% \pm 43 \% ;$ Median $=0 \%$

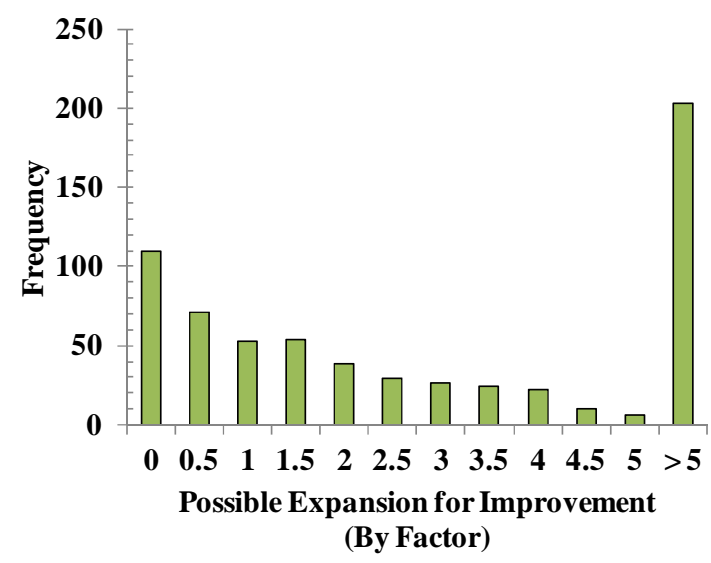

Figure F.30: BSA Projections for Cash Mean $=370 \% \pm 390 \% ;$ Median $=196 \%$

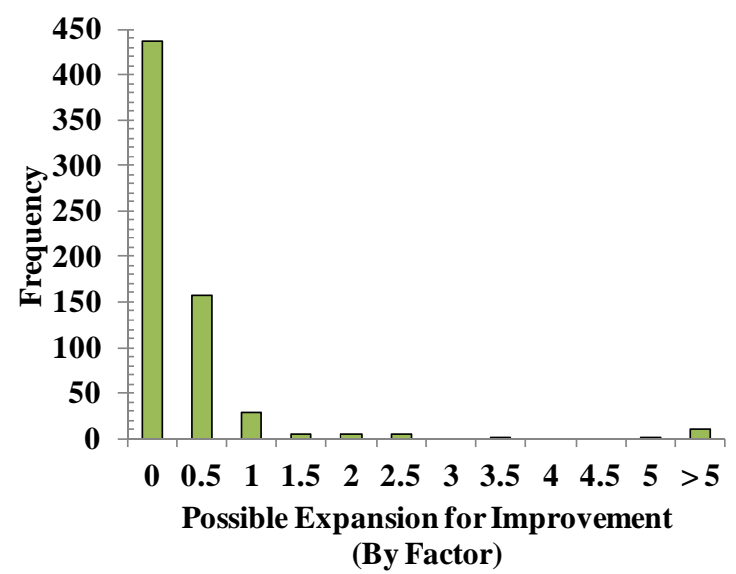

Figure F.32: BSA Projections for Shareholders' Equity Mean $=28 \% \pm 130 \% ;$ Median $=0 \%$

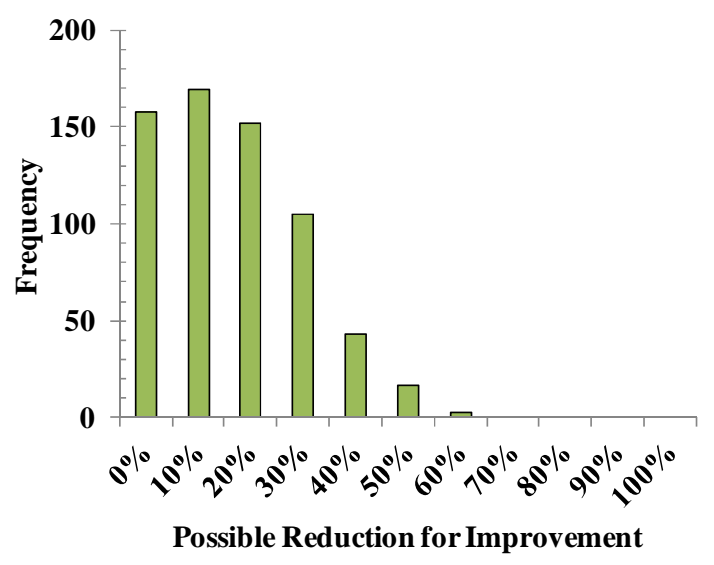

Figure F.29: BSA Projections for Total Assets Mean $=12 \% \pm 12 \% ;$ Median $=10 \%$

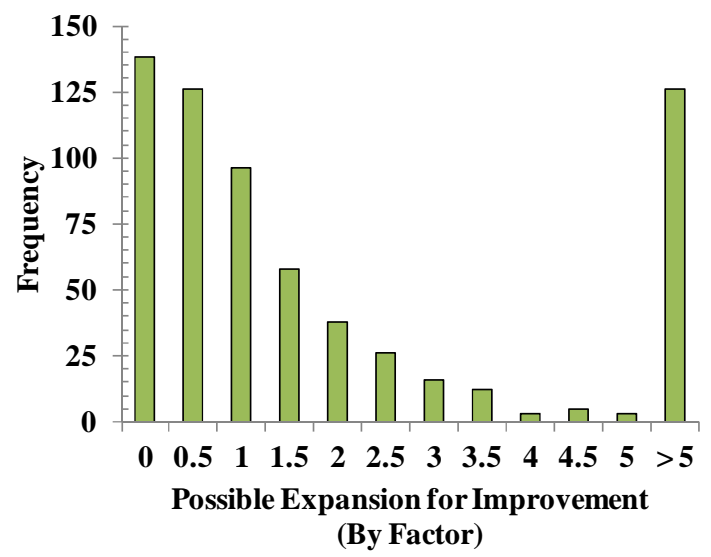

Figure F.31: BSA Projections for Retained Earnings Mean $=247 \% \pm 350 \% ; ;$ Median $=79 \%$

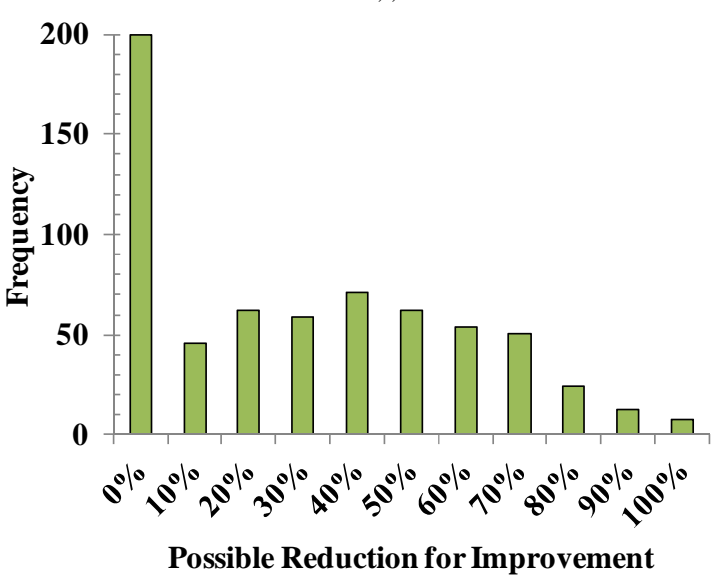

Figure F.33: BSL Projections for Accounts Payable Mean $=28 \% \pm 26 \% ;$ Median $=23 \%$ 


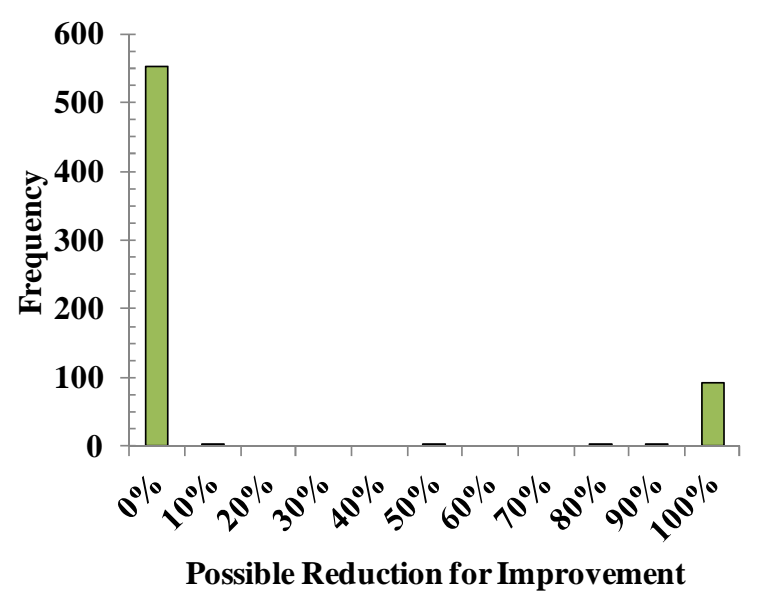

Figure F.34: BSL Projections for Notes Payable and Short-Term Debt Mean $=15 \% \pm 35 \% ;$ Median $=0 \%$

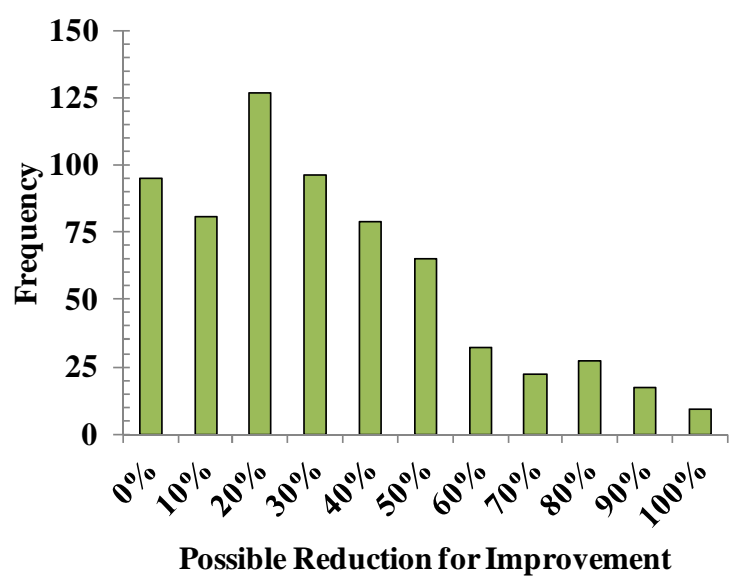

Figure F.36: BSL Projections for Current Liabilities Mean $=28 \% \pm 24 \% ;$ Median $=23 \%$

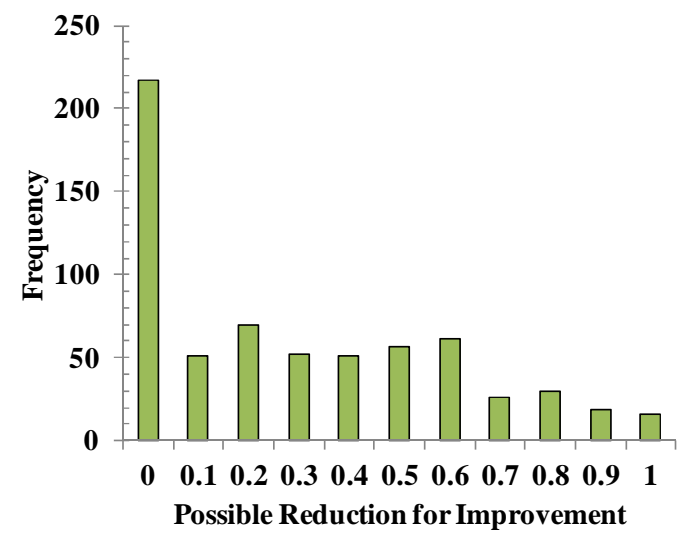

Figure F.38: BSL Projections for Total Liabilities Mean $=27 \% \pm 28 \% ;$ Median $=18 \%$

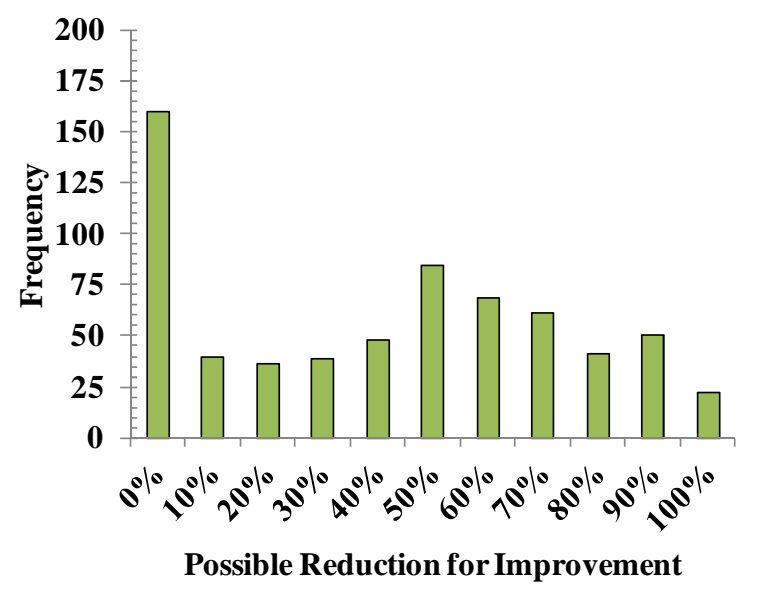

Figure F.35: BSL Projections for Current Maturities of Long-Term Debt Mean $=37 \% \pm 31 \% ;$ Median $=40 \%$

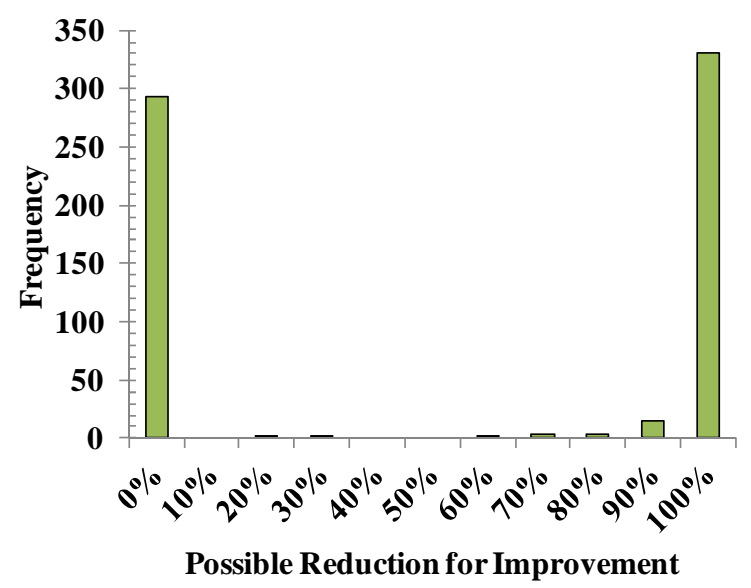

Figure F.37: BSL Projections for Long-Term Debt

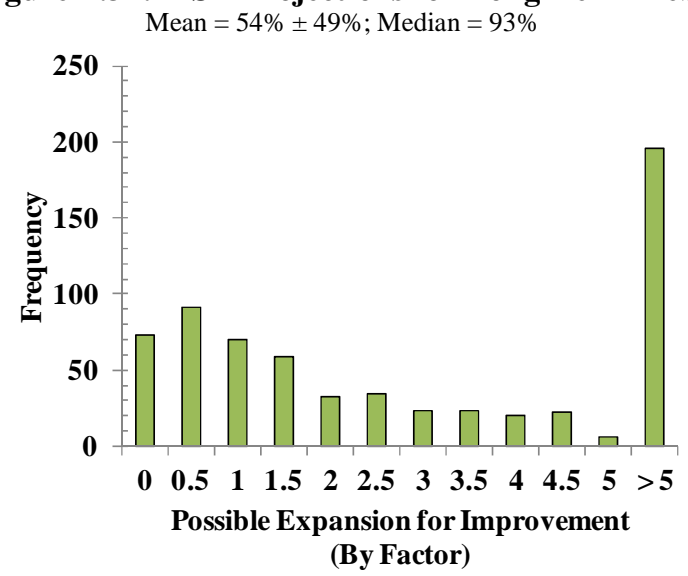

Figure F.39: BSL Projections for Retained Earnings Mean $=370 \% \pm 390 \% ;$ Median $=200 \%$ 


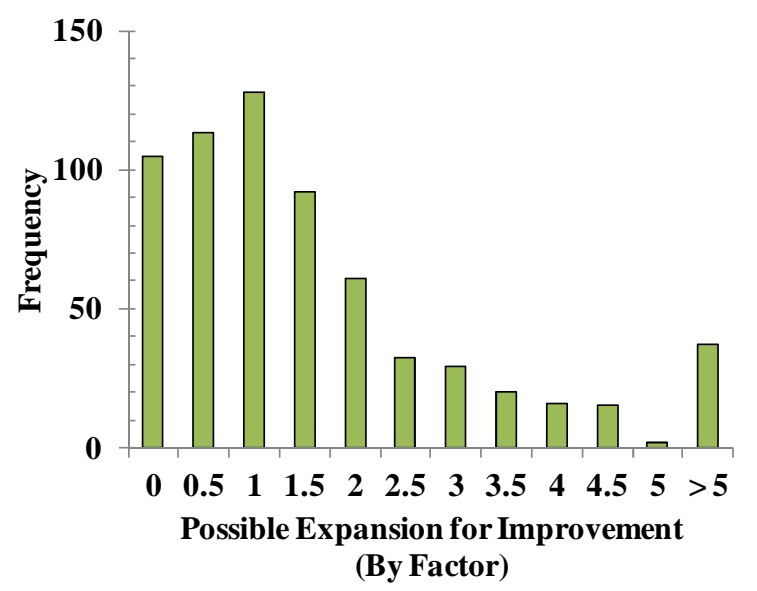

Figure F.40: BSL Projections for Shareholders'

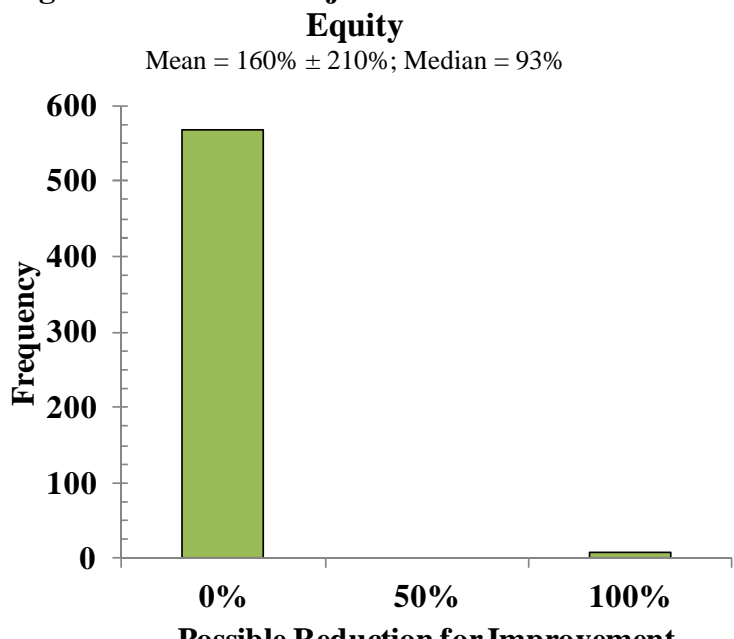

Possible Reduction for Improvement

Figure F.42: MDM Projections for Auditor's Opinion

Mean $=1.2 \% \pm 1.1 \% ;$ Median $=0 \%$

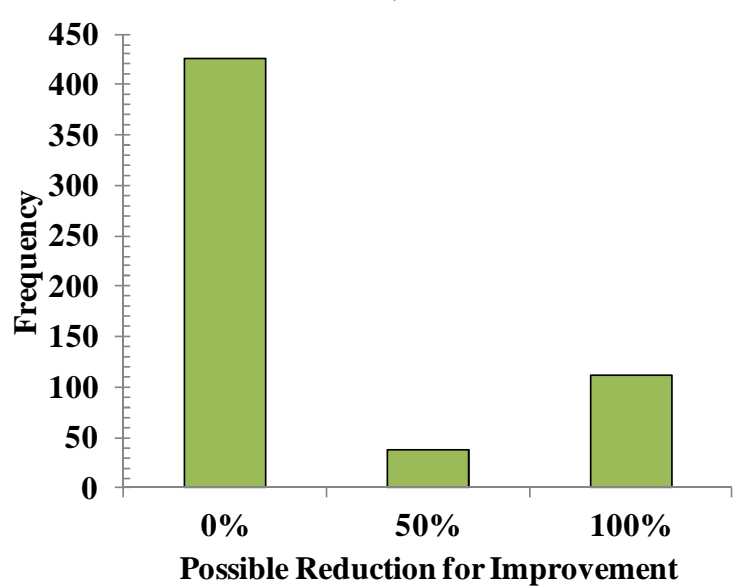

Figure F.44: MDM Projections for Management Turnover

Mean $=22 \% \pm 39 \% ;$ Median $=0 \%$

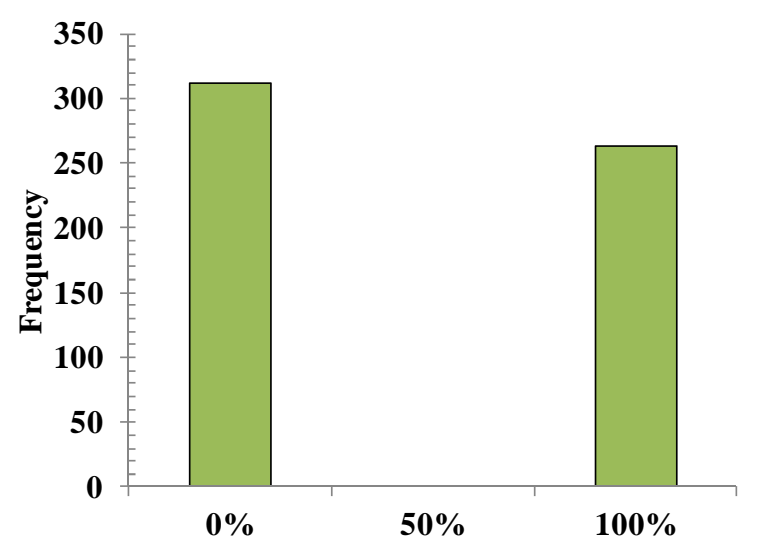

Possible Reduction for Improvement

Figure F.41: MDM Projections for Related Party Translations Mean $=46 \% \pm 50 \%$

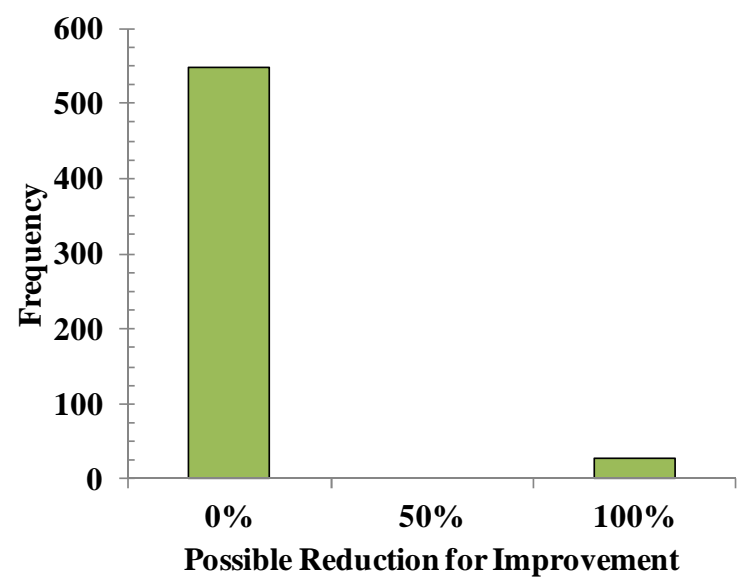

Figure F.43: MDM Projections for Change in Auditors Mean $=5 \% \pm 21 \% ;$ Median $=0 \%$

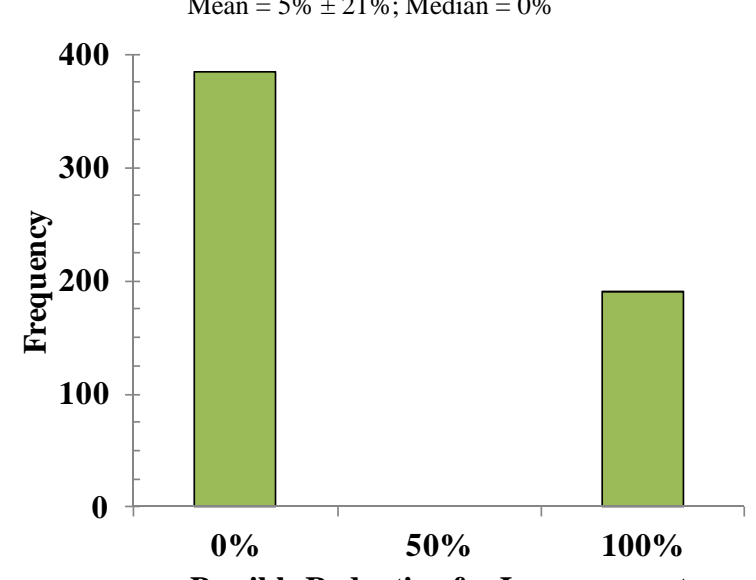

Possible Reduction for Improvement

Figure F.45: MDM Projections for Legal Proceedings Mean $=32 \% \pm 46 \% ;$ Median $=0 \%$ 


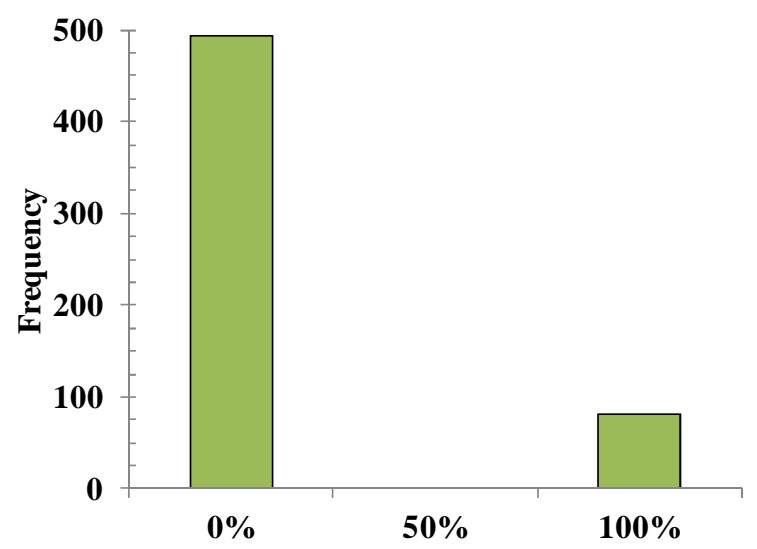

Possible Reduction for Improvement

Figure F.46: MDM Projections for Retirement Plans Mean $=14 \% \pm 39 \% ;$ Median $=0 \%$

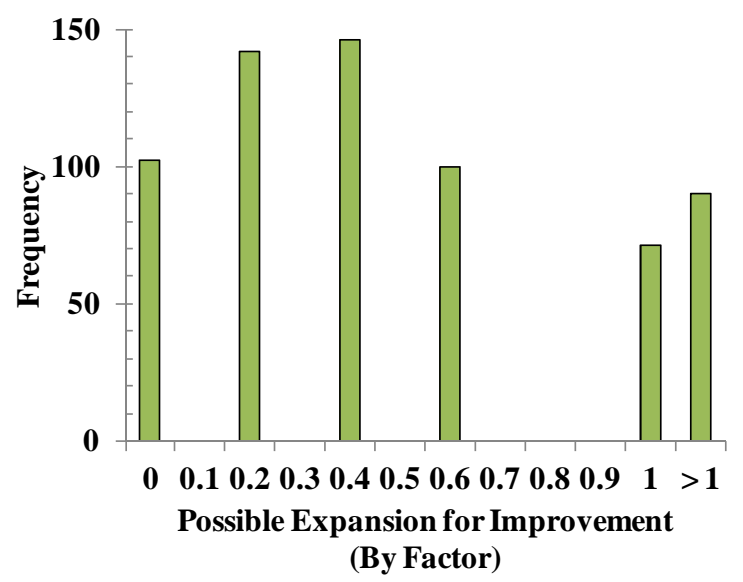

Figure F.48: Second Stage Projections for BSA Metric

Mean $=94 \% \pm 190 \% ;$ Median $=33 \%$

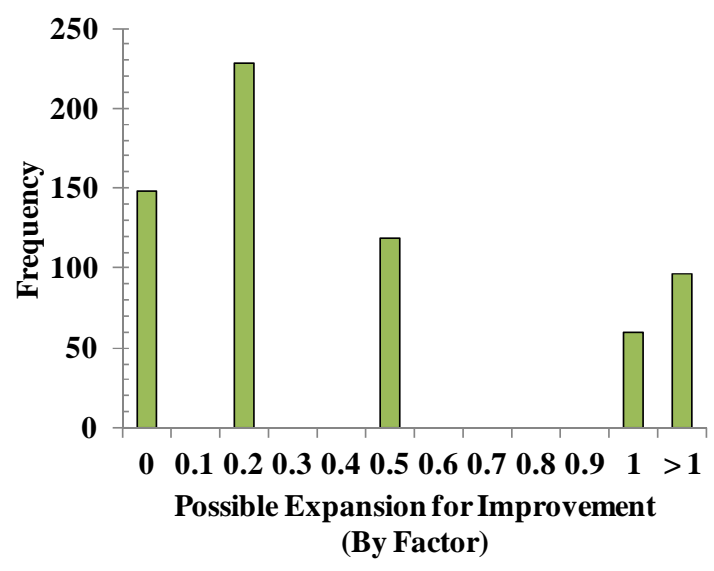

Figure F.50: Second Stage Projections for MDM Metric

Mean $=160 \% \pm 320 \% ;$ Median $=20 \%$

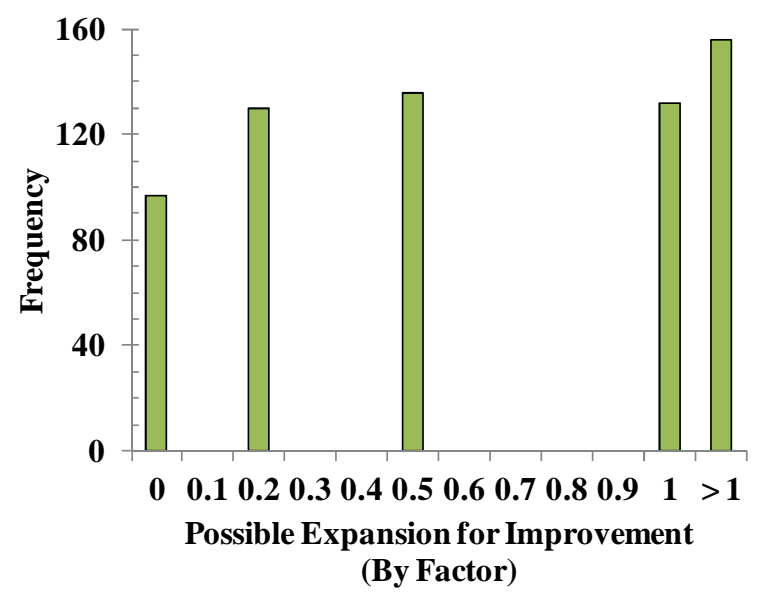

Figure F.47: Second Stage Projections for IS Metric Mean $=120 \% \pm 170 \% ;$ Median $=50 \%$

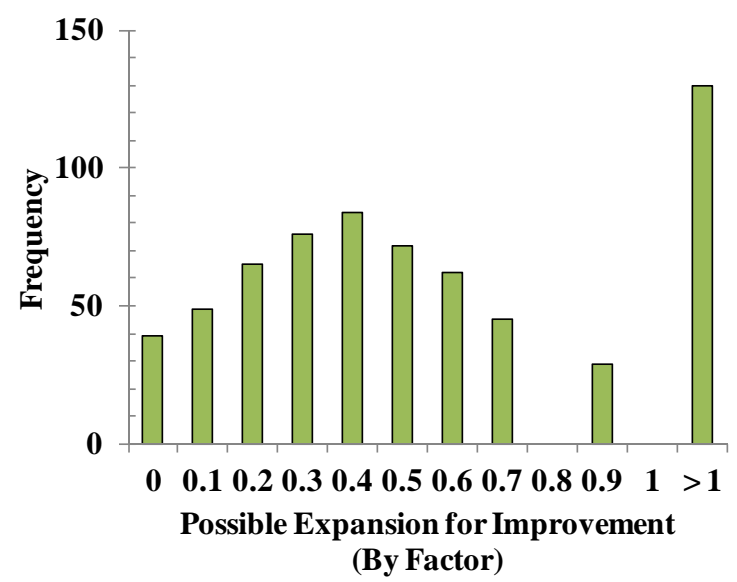

Figure F.49: Second Stage Projections for BSL Metric Mean $=95 \% \pm 190 \%$; Median $=42 \%$ 


\section{F.8 Second Stage Model Results with Different Time Windows}

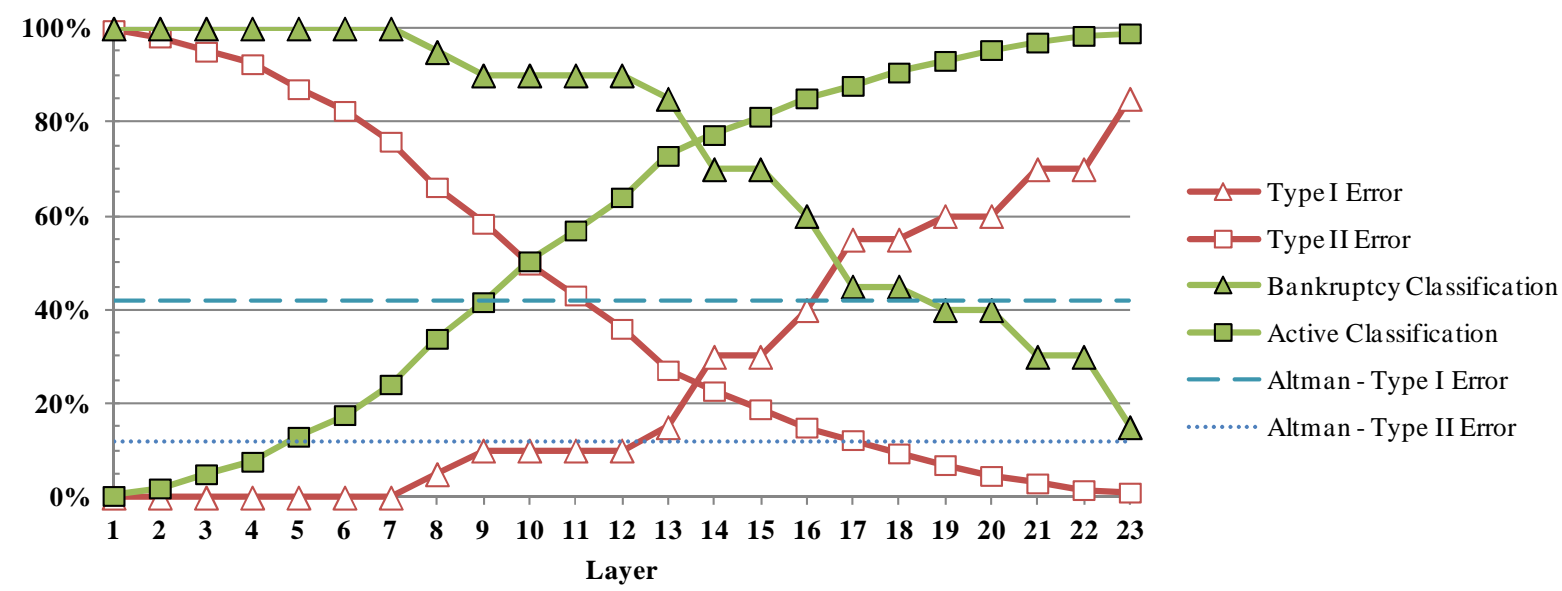

Figure F.51: Prediction by Second Stage Model from One Year Back, 1996-2008

A DMU was predicted bankrupt up to a year prior to filing Chapter 11.

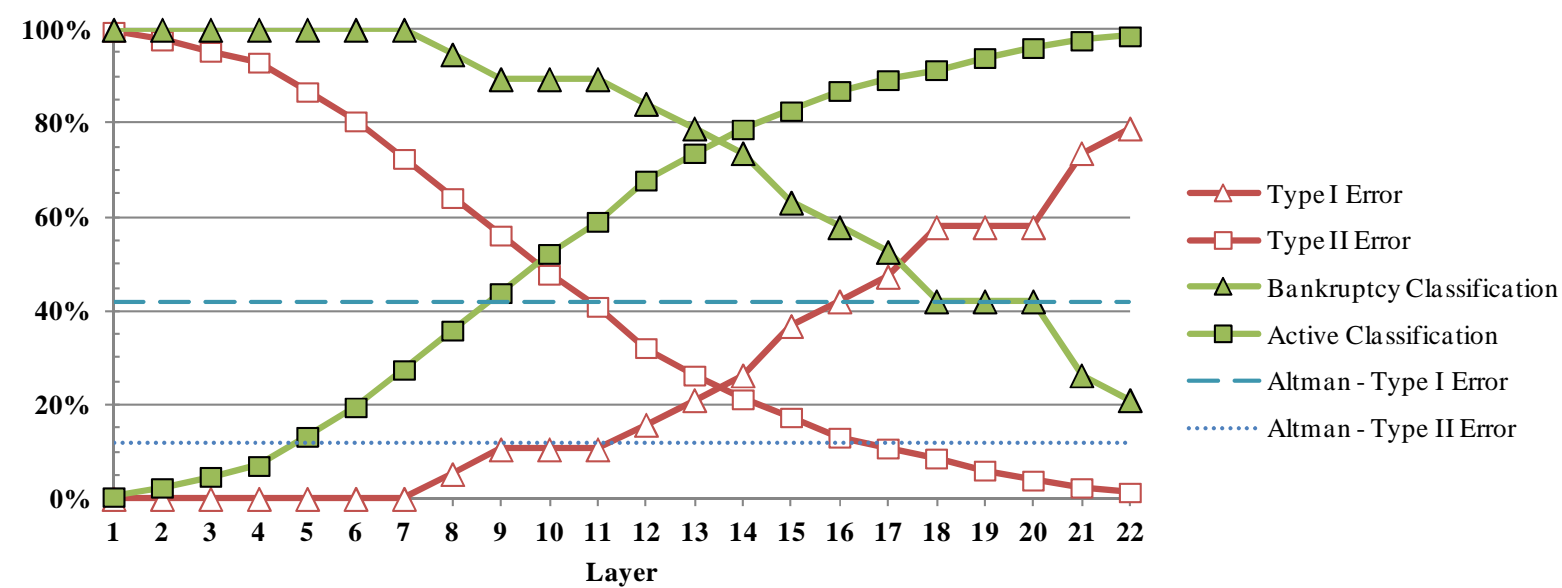

Figure F.52: Prediction by Second Stage Model from One Year Back, 1996-2007

A DMU was predicted bankrupt up to a year prior to filing Chapter 11 .

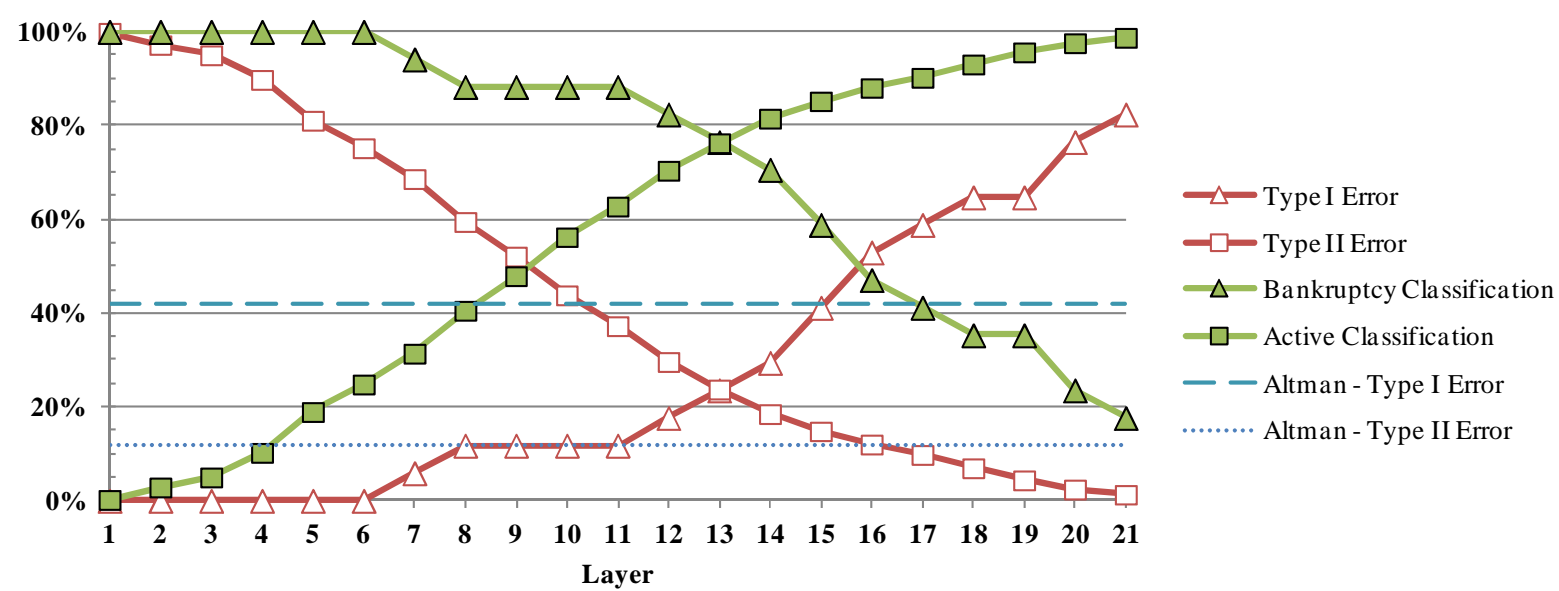

Figure F.53: Prediction by Second Stage Model from One Year Back, 1996-2006

A DMU was predicted bankrupt up to a year prior to filing Chapter 11. 


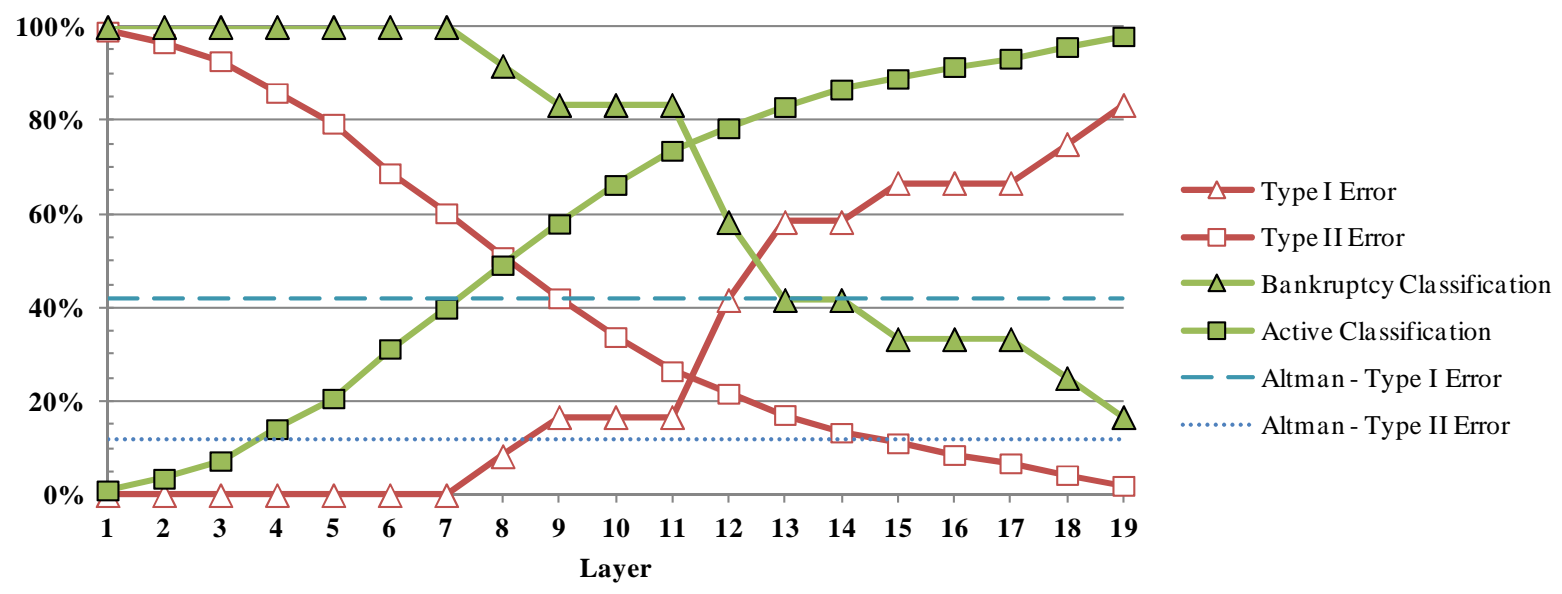

Figure F.54: Prediction by Second Stage Model from One Year Back, 1996-2005

A DMU was predicted bankrupt up to a year prior to filing Chapter 11.

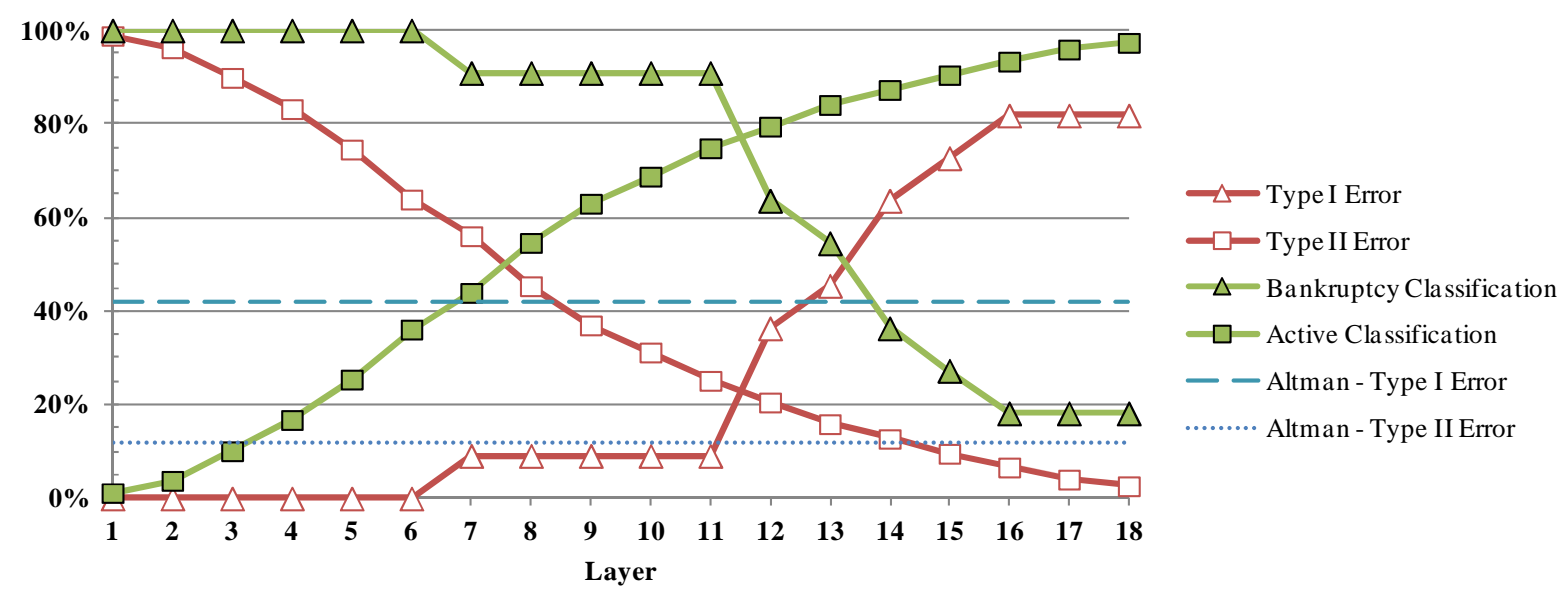

Figure F.55: Prediction by Second Stage Model from One Year Back, 1996-2004

A DMU was predicted bankrupt up to a year prior to filing Chapter 11. 


\section{F.9 Probability Functions for Different Time Windows}

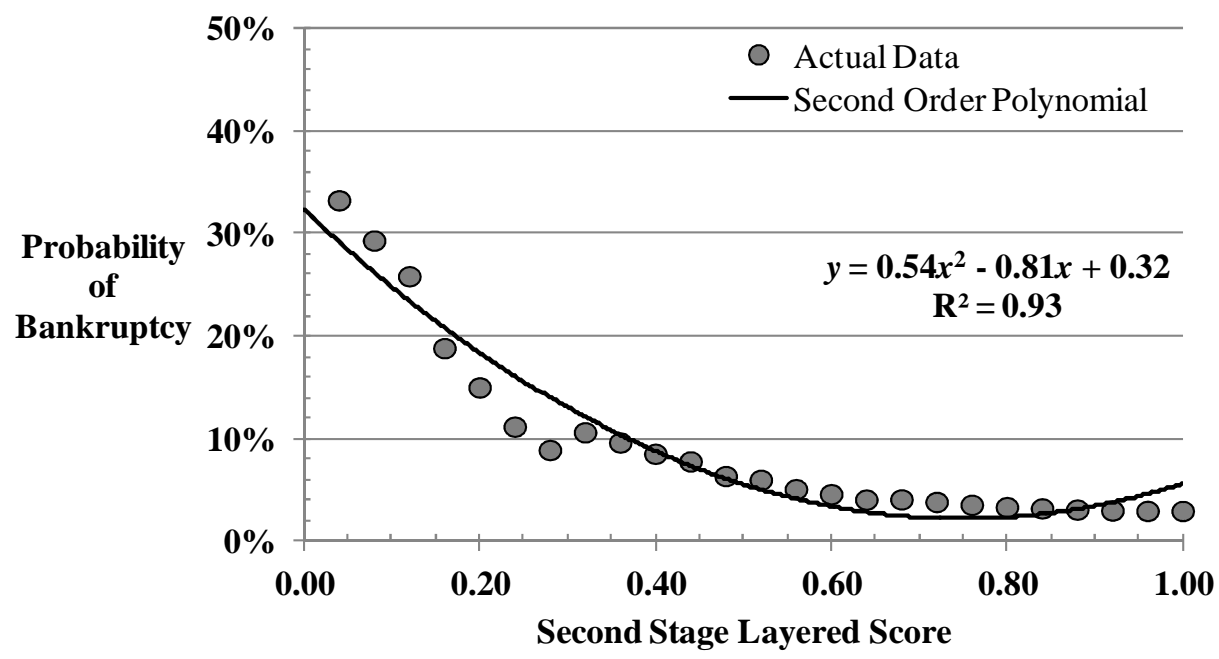

Figure F.56: Probability of Bankruptcy from One Year Back, 1996-2009

A DMU was classified bankrupt up to 3 years prior to filing Chapter 11.

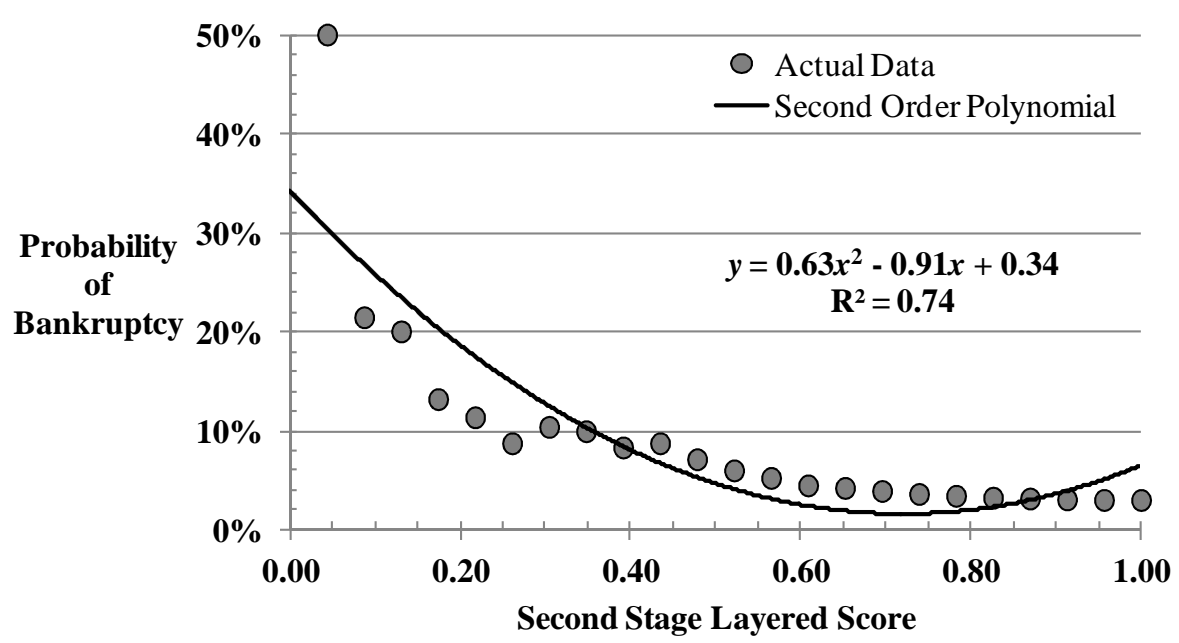

Figure F.57: Probability of Bankruptcy from One Year Back, 1996-2008

A DMU was classified bankrupt up to 3 years prior to filing Chapter 11. 


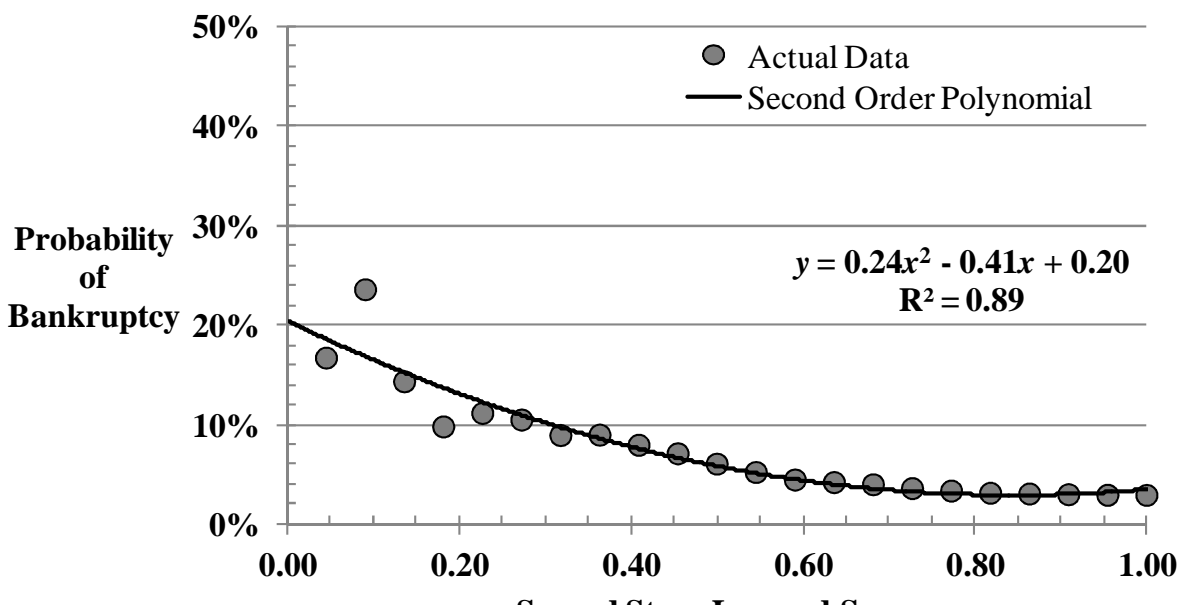

Second Stage Layered Score

Figure F.58: Probability of Bankruptcy from One Year Back, 1996-2007

A DMU was classified bankrupt up to 3 years prior to filing Chapter 11.

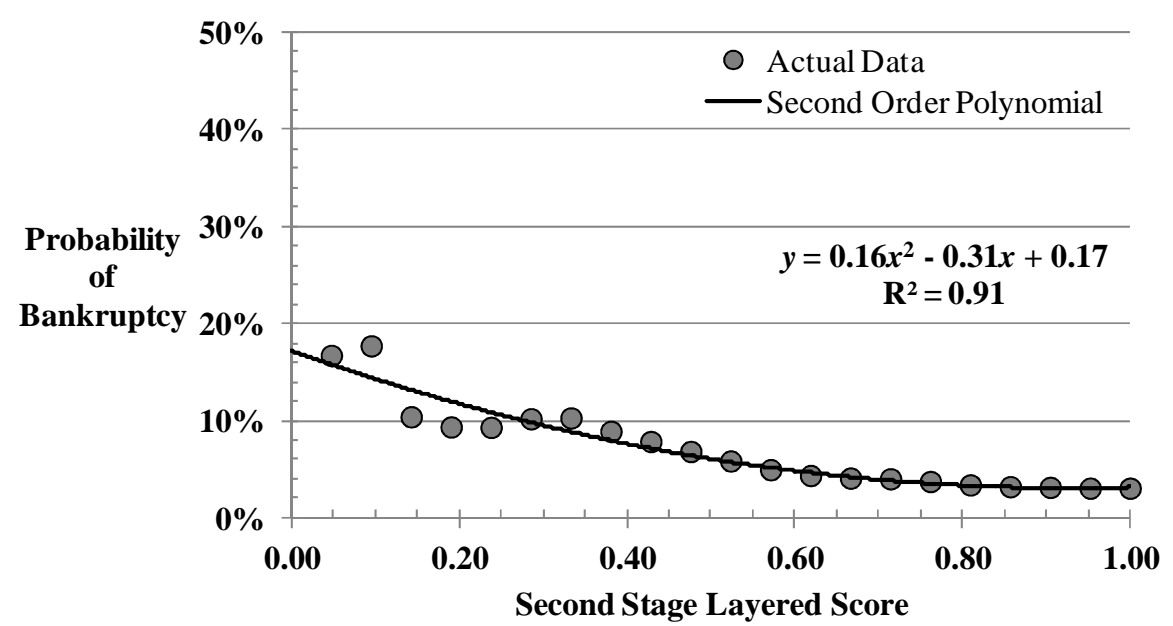

Figure F.59: Probability of Bankruptcy from One Year Back, 1996-2006

A DMU was classified bankrupt up to 3 years prior to filing Chapter 11.

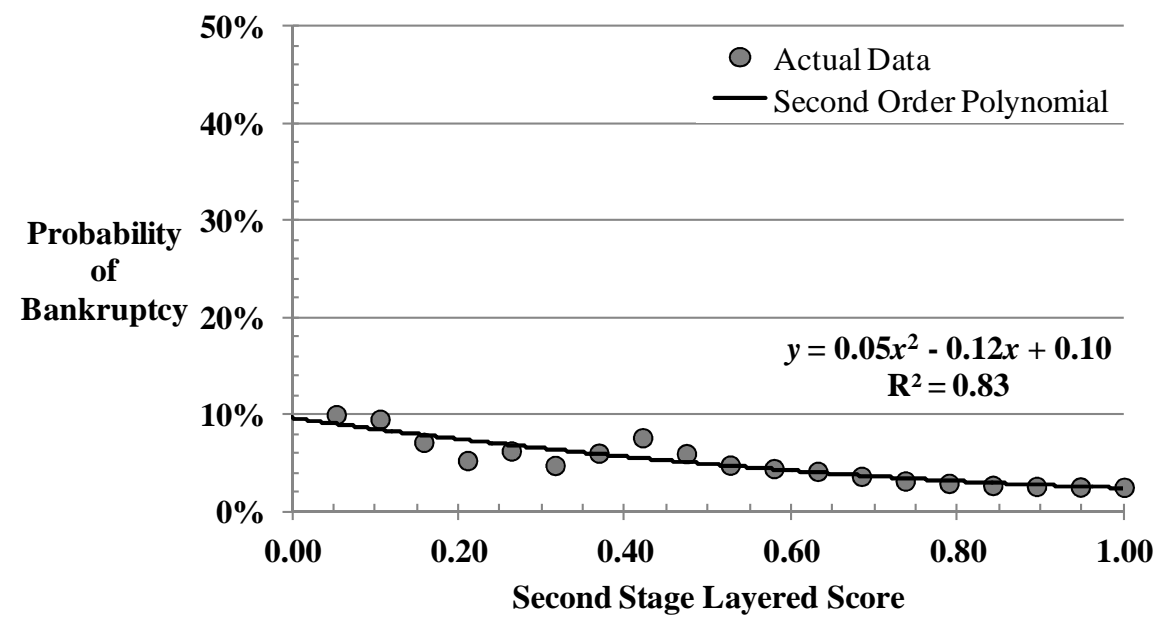

Figure F.60: Probability of Bankruptcy from One Year Back, 1996-2005

A DMU was classified bankrupt up to 3 years prior to filing Chapter 11. 


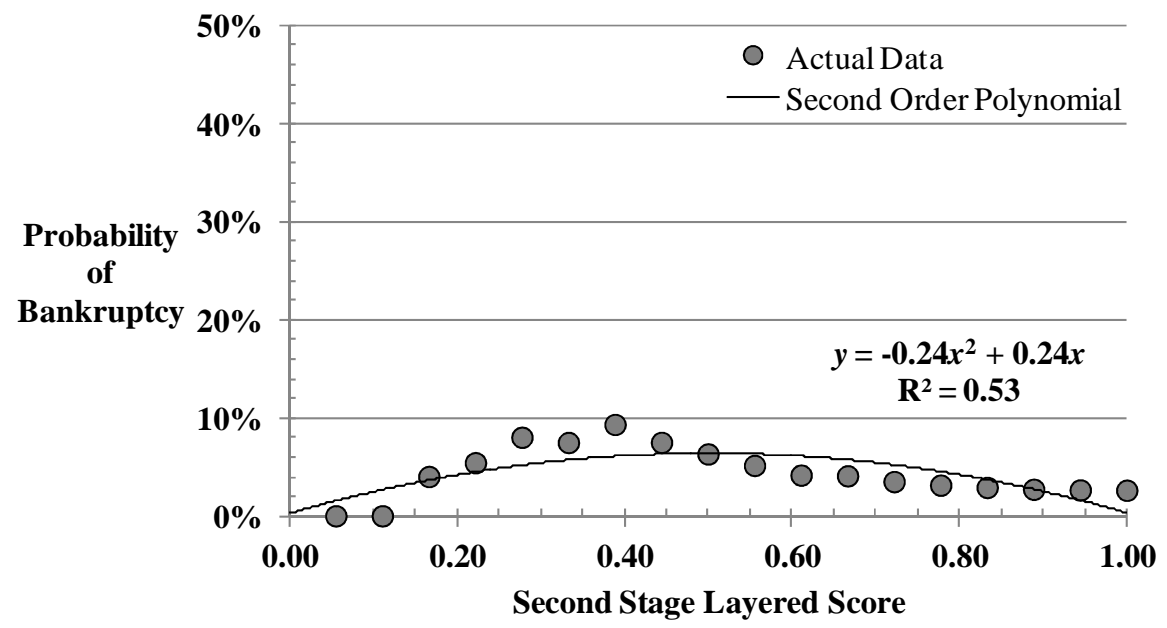

Figure F.61: Probability of Bankruptcy from One Year Back, 1996-2004 A DMU was classified bankrupt up to 3 years prior to filing Chapter 11. 